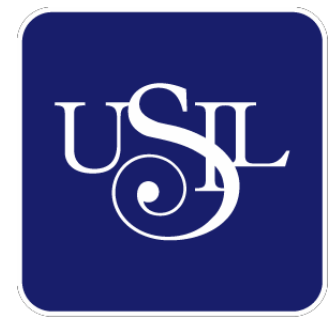

UNIVERSIDAD

SAN IGNACIO

DE LOYOLA

ESCUELA DE POSTGRADO

\title{
PLANEAMIENTO ESTRATÉGICO DE LA EMPRESA NEGOCIOS AGROINDUSTRIALES LOS FERROLES SAC
}

Tesis para optar el grado de:

CARMEN ALICIA JIMÉNEZ PAREDES

Maestro en Ciencias Empresariales con Mención en Gestión Comercial

YOVANA BEATRIZ RÍOS CÁRDENAS

Maestro en Ciencias Empresariales con Mención en Gestión Comercial

DEBBIE ALEXANDRA SOTO SALAZAR

Maestro en Ciencias Empresariales con Mención en Gestión Comercial

\section{YIESMIN ZAAD OPORTO}

Maestro en Ciencias Empresariales con Mención en Gestión Comercial

Asesor:

Horario Barrios Cruz

Lima - Perú

2018 


\section{AGRADECIMIENTO}

Agradecemos a Dios y a nuestras familias por su paciencia, compresión y aliento durante el periodo de realización del presente plan estratégico.

A nuestro ilustre profesor y asesor Dr. Horarios Barrios por su orientación y guía en el desarrollo del proyecto. 
Contenido

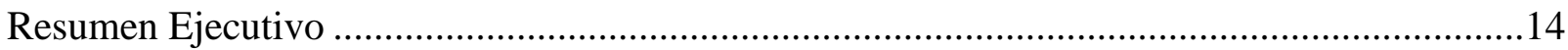

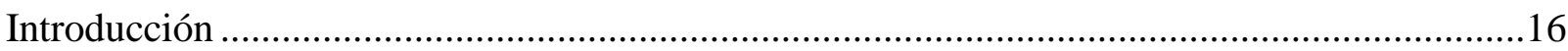

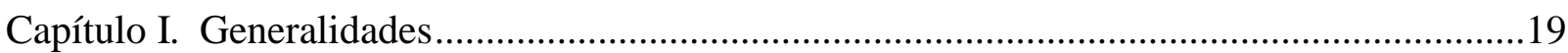

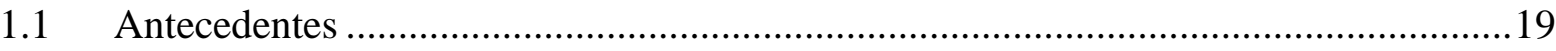

1.2 Determinación del Problema u Oportunidad..............................................................23

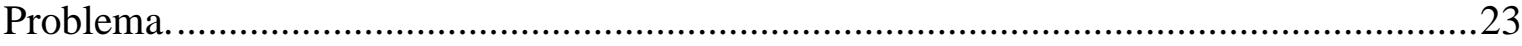

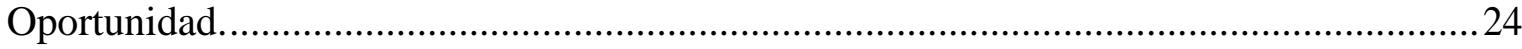

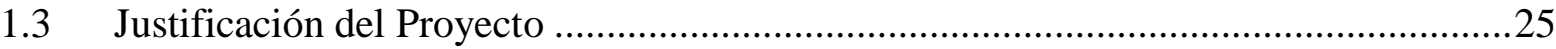

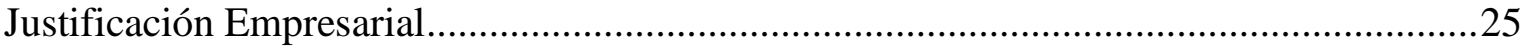

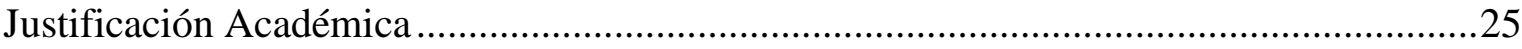

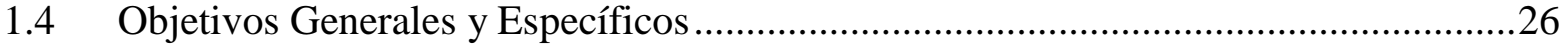

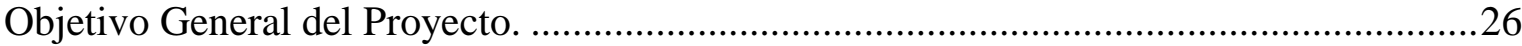

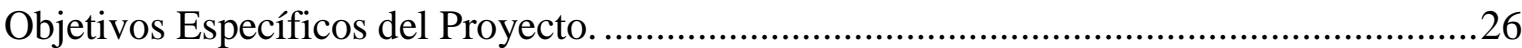

1.5 Alcances y Limitaciones de la Investigación ........................................................26

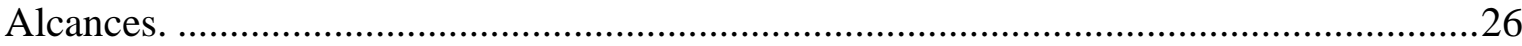

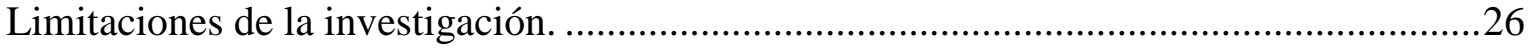

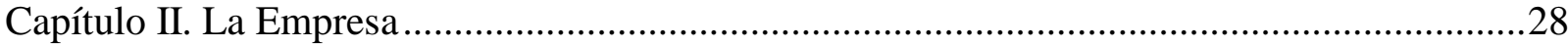

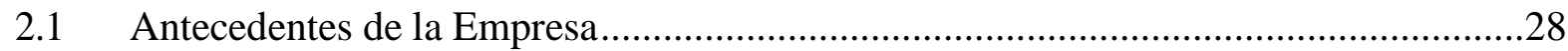

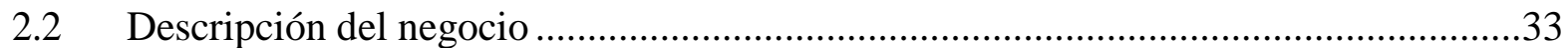

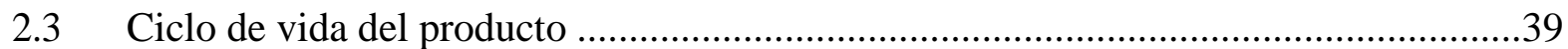

2.4 Estructura organizacional actual de la empresa ......................................................44

2.5 Situación de Mercado y Financiera actual de la Industria...........................................53

Capítulo III. Formulación de Visión, Misión y Valores de la Empresa.........................................58

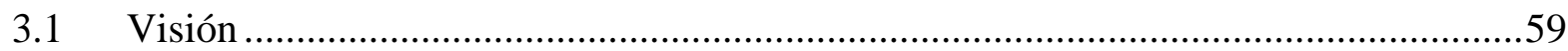

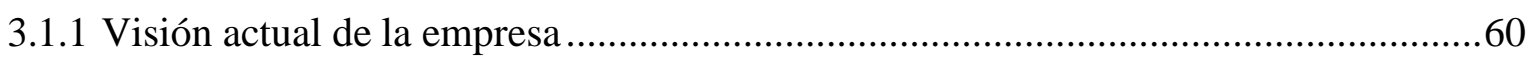

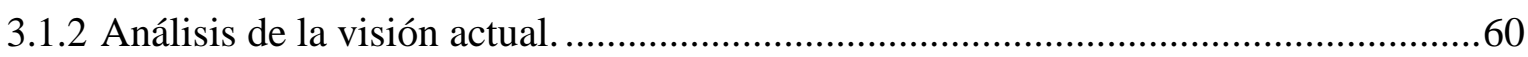

3.1.3 Matriz de la visión propuesta para la empresa ........................................................63

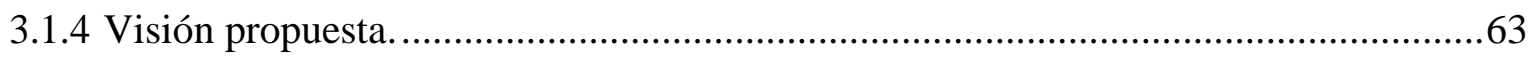

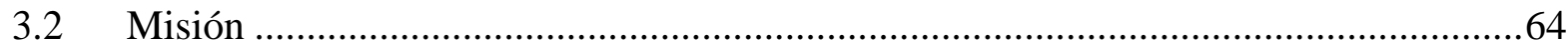

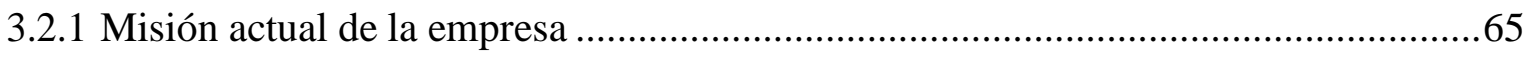

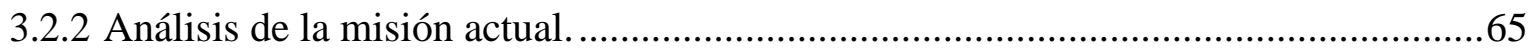

3.2.3 Elementos de la misión propuesta para la empresa .................................................67

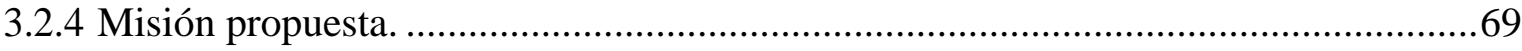


4

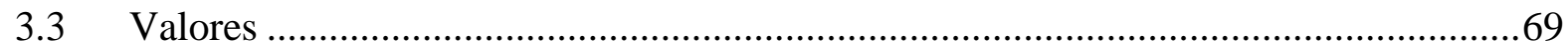

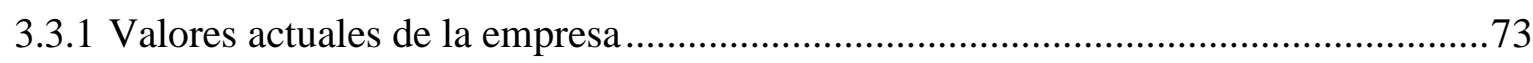

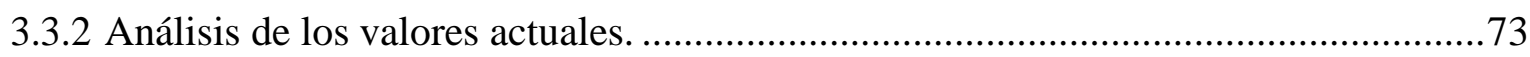

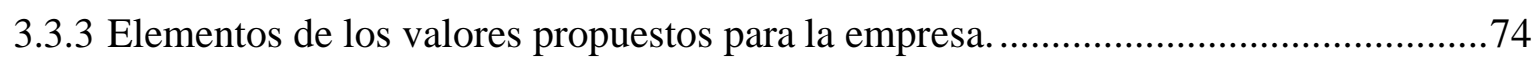

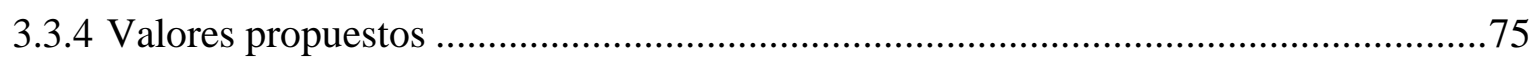

3.4 Alineamiento estratégico de la Visión, Misión y Valores de la empresa......................77

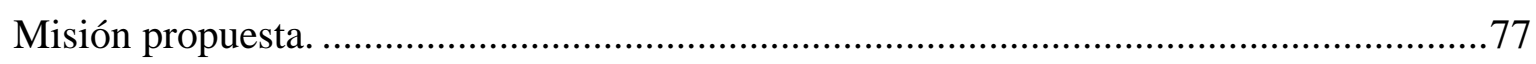

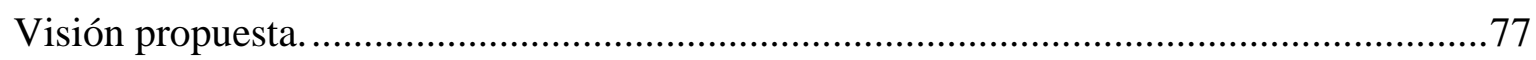

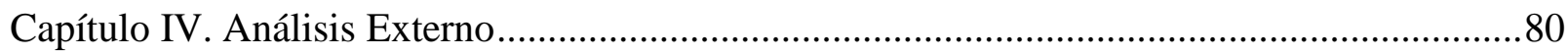

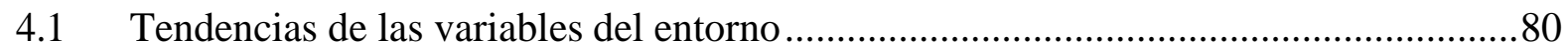

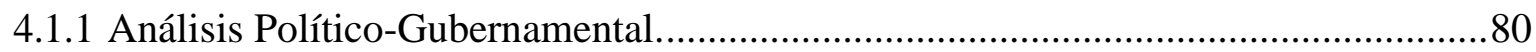

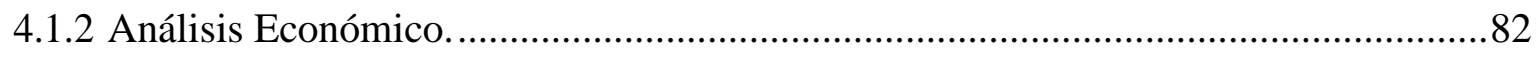

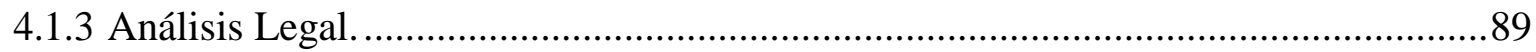

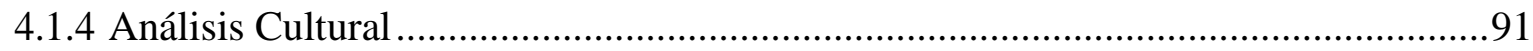

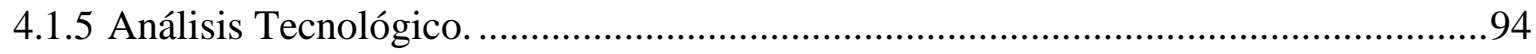

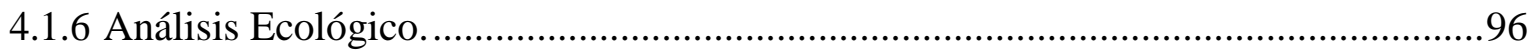

4.2 Impacto en clientes / proveedores de cada una de las variables del entorno. ..............97

4.3 Efecto en la empresa de cada una de las variables del entorno.................................99

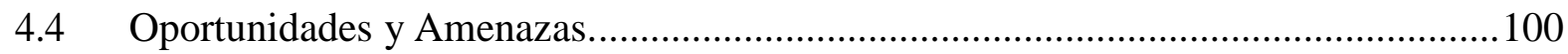

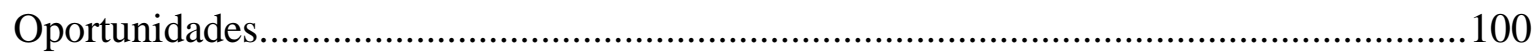

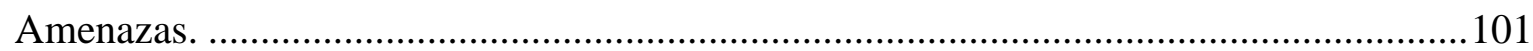

4.5 Matriz de Evaluación de los Factores Externos (EFE) .............................................103

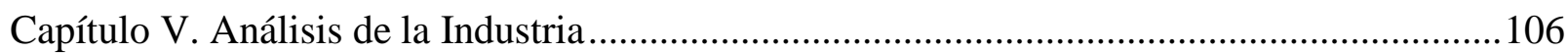

5.1 Descripción del mercado (demanda) e industria (oferta) .........................................106

5.2 Descripción de las cinco fuerzas competitivas de la industria ..................................111

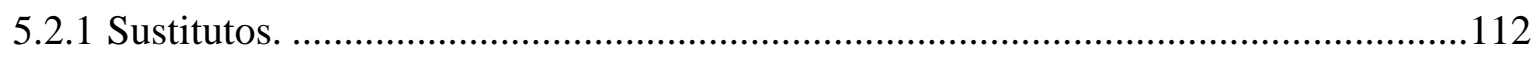

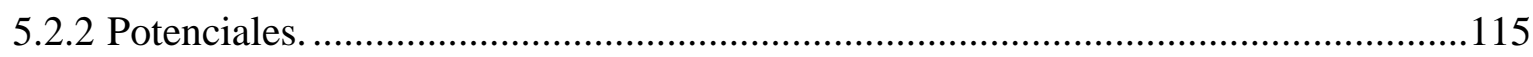

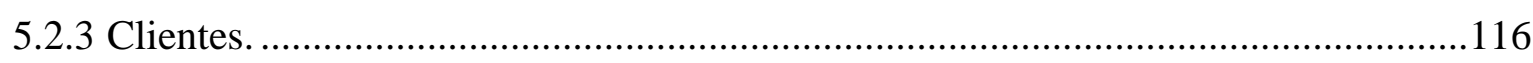

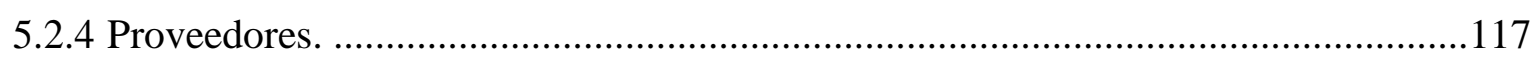

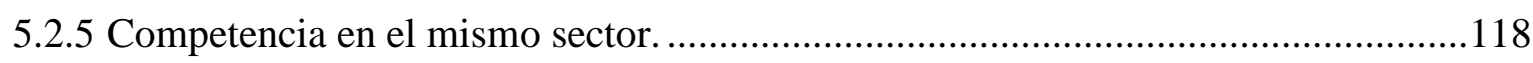

5.3 Matriz de atractividad de cada una de las cinco fuerzas .........................................122

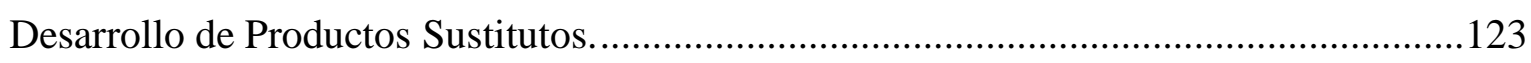

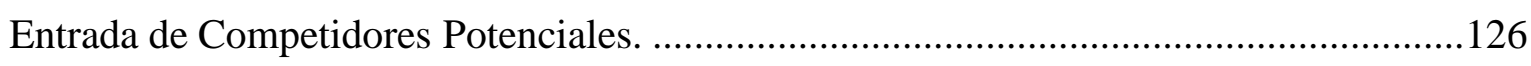

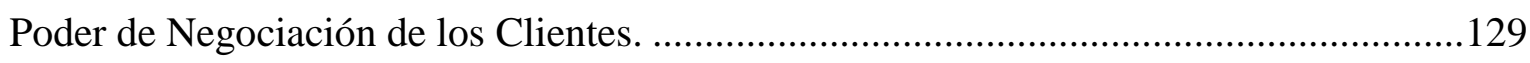

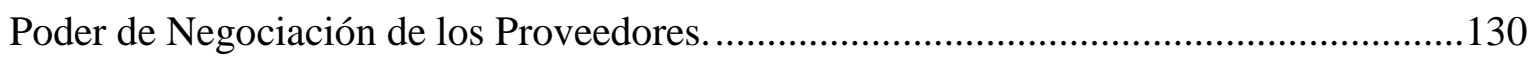


Rivalidad entre Empresas Competidoras.................................................................. 134

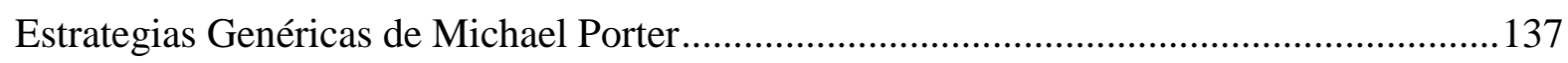

5.4 Análisis del Grado de Atractividad de la Industria ................................................139

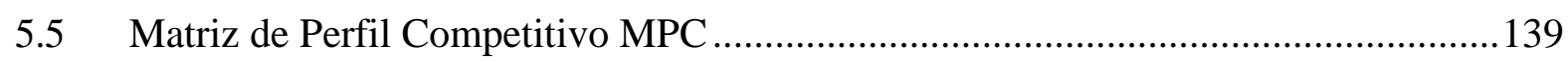

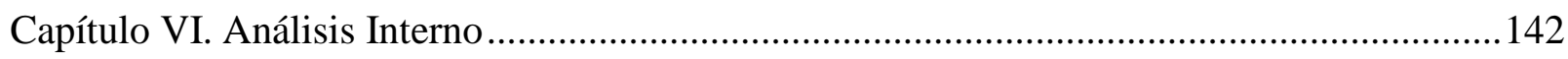

6.1 Descripción de las actividades de la cadena de valor de la empresa Los Ferroles:

Logística interna, Operaciones, Logística externa, Mercadotecnia, Servicios, Adquisiciones,

Recursos Humanos, Tecnología, Infraestructura ..........................................................143

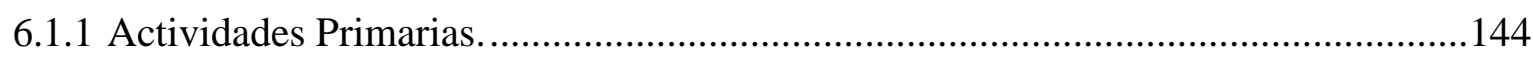

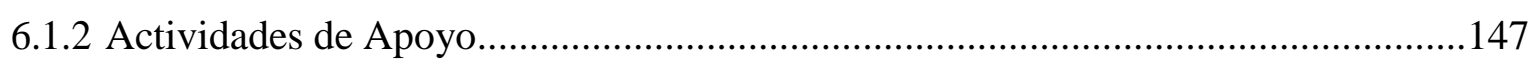

6.2 Indicadores de cada una de las actividades de la cadena de valor..............................151

6.3 Benchmarking y comparación con los líderes de la industria de cada una de las

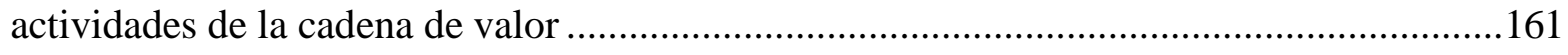

6.4 Determinar las competencias de la empresa........................................................163

6.5 Identificación y determinación de las ventajas competitivas de la empresa ...............165

6.6 Matriz de Evaluación de los Factores Internos EFI .................................................165

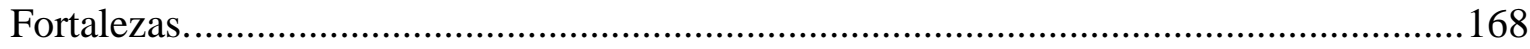

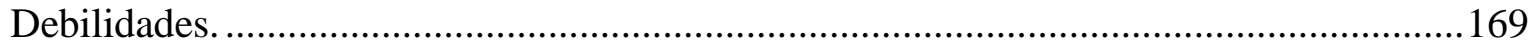

Capítulo VII. Formulación de Objetivos y diseños de las Estrategias ......................................172

7.1 Alcance y planteamiento de los objetivos estratégicos ............................................172

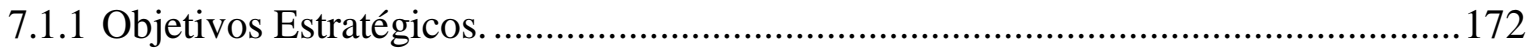

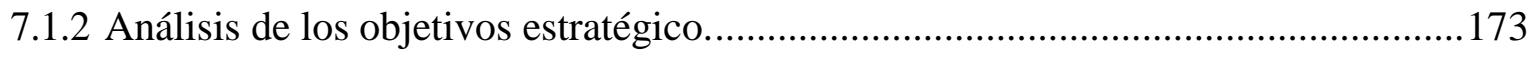

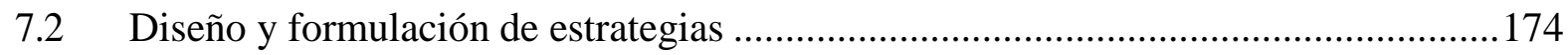

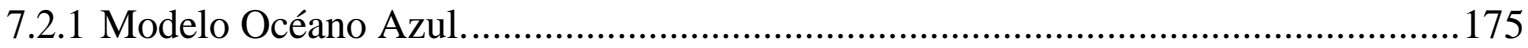

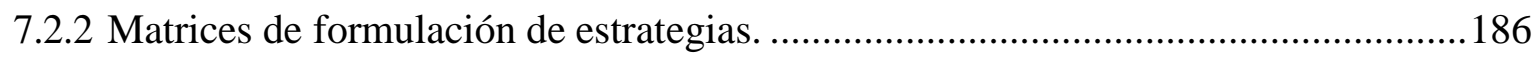

7.3 Resumen de las Estrategias Formuladas ...................................................................204

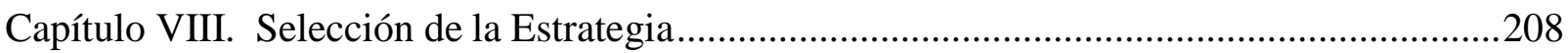

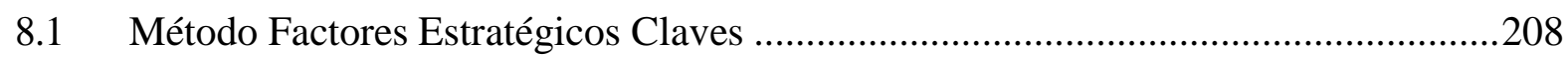

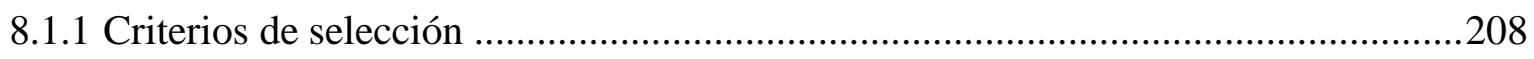

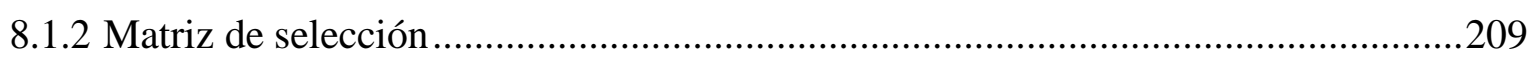

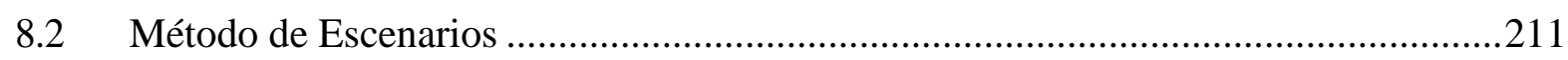

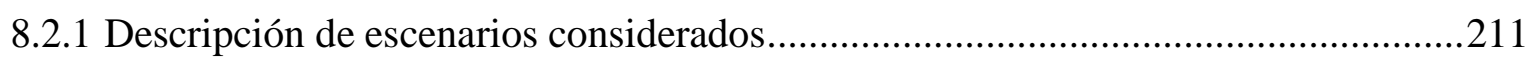

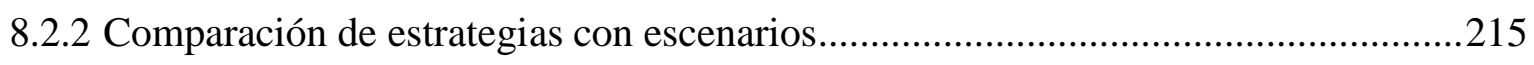

8.3 Matriz de Planeación Estratégica Cuantitativa MPEC.............................................216

8.4 Descripción de estrategia seleccionada ...............................................................223

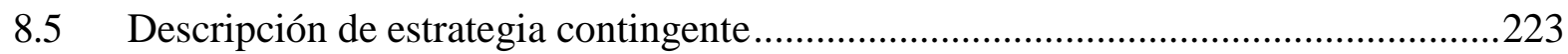




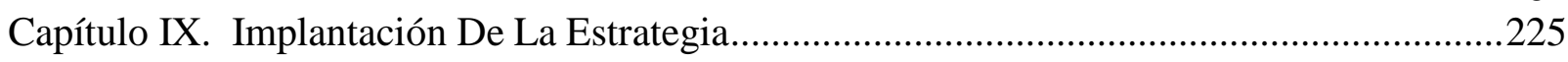

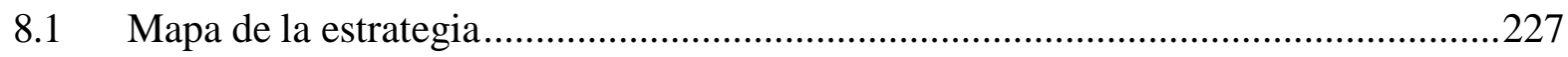

8.2 Objetivos específicos según el mapa estratégico .................................................232

8.3 Indicadores para cada uno de los objetivos específicos ...........................................234

8.4 Metas para cada uno de los objetivos específicos ................................................237

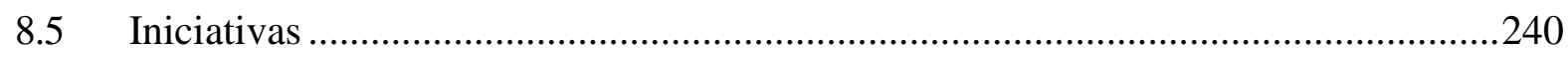

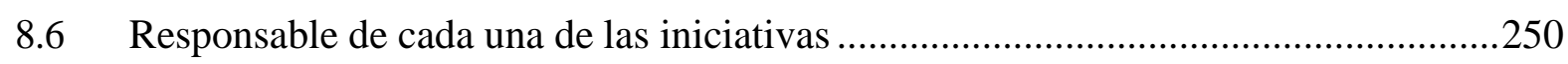

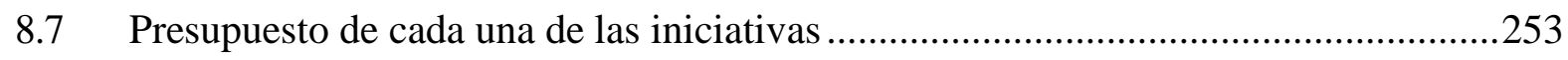

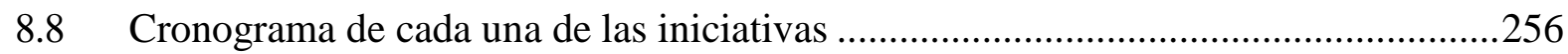

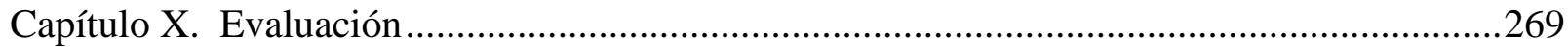

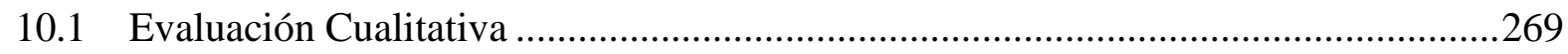

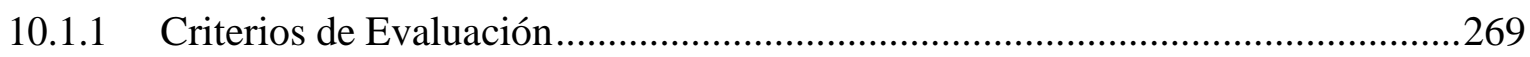

10.1.2 Comparación de la estrategia con los criterios ...................................................271

10.2 Evaluación Financiera de la Estrategia ...................................................................273

10.2.1 Proyección de los estados financieros (situación actual y con la nueva estrategia)

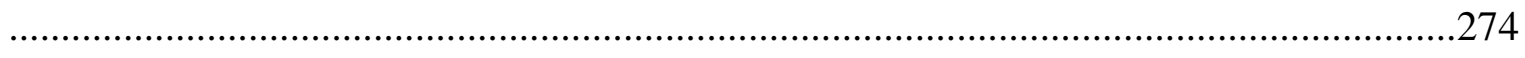

10.2.2 Estado de resultados (situación actual y con la nueva estrategia) .........................276

10.2.3 Balance general (sin estrategia y con la nueva estrategia) .................................281

10.2.4 Flujo de efectivo (situación actual y con la nueva estrategia) ...........................286

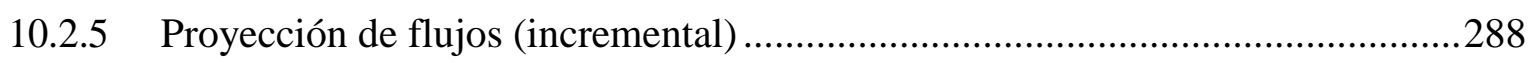

10.2.6 Evaluación financiera (VAN, TIR, ratios financieros) ................................2290

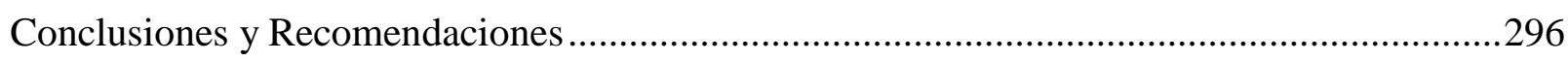

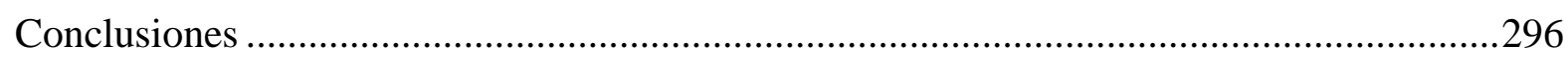

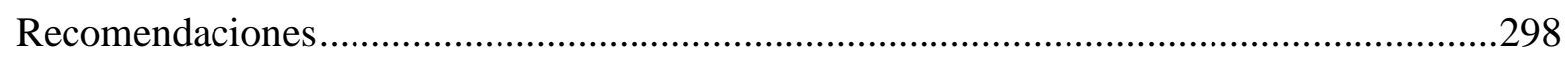

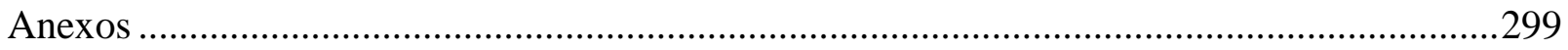

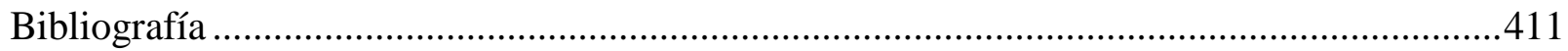

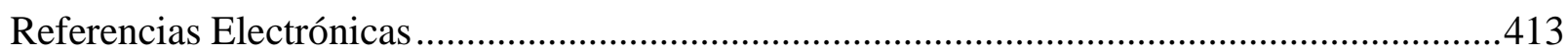




\section{Índice Tablas}

Tabla 1: $\quad$ Especificaciones brasileras para harinas proteicas de origen

Tabla 2: $\quad$ Criterios para la evaluación de la visión actual. $\quad 62$

Tabla 3: $\quad$ Descripción de criterios para la evaluación de la visión propuesta. $\quad 63$

Tabla 4: $\quad$ Criterios para la evaluación de la misión actual. $\quad 67$

$\begin{array}{lll}\text { Tabla 5: } & \text { Componentes para la elaboración de la Misión. } & 68\end{array}$

Tabla 6: Valores dominantes en la fuerza laboral actual. $\quad 72$

Tabla 7: $\quad$ Factores para el desarrollo de valores. $\quad 74$

Tabla 8: $\quad$ Descripción de valores propuestos. 76

Tabla 9: $\quad$ Relación de los Valor Organizacionales con la Misión y Visión. $\quad 78$

Tabla 10: $\quad$ Impacto en clientes / proveedores de cada una de las variables del 98

$\begin{array}{ll}\text { Tabla 11: } & \text { El efecto de cada variable externa y cómo influye en la empresa } \\ \text { Los Ferroles. }\end{array}$

Tabla 12: $\quad$ Matriz de Evaluación de Factores Externos (EFE). 104

Tabla 13: $\quad \begin{aligned} & \text { Parámetros productivos para la transformación de las aves en } \\ & \text { subproductos }\end{aligned}$

Tabla 14: $\quad \begin{array}{ll}\text { Oferta de Harinas Proteicas } 2016 \text { proveniente de Centros de } \\ \text { Acopio }\end{array}$

$\begin{array}{lll}\text { Tabla 15: } & \text { Oferta de Harinas proteicas } 2016 \text { provenientes de Plantas de } & 109\end{array}$

Tabla 16: $\quad$ Oferta Total de Harinas Proteicas $2016 \quad 109$

Tabla 17: Demanda de Harinas Proteicas $\quad 110$

Tabla 18: Matriz de Atractividad de Desarrollo de Productos Sustitutos 125

Tabla 19: $\quad$ Matriz de Atractividad de Entrada de Competidores Potenciales 128

Tabla 20: $\quad$ Matriz de Atractividad del Poder de Negociación de Clientes 131

Tabla 21: $\quad$ Matriz de Atractividad del Poder de Negociación de Proveedores 133

Tabla 22: $\quad \begin{array}{ll}\text { Matriz de Atractividad de Rivalidad entre Empresas } \\ \text { Competidoras }\end{array}$

Tabla 23: Matriz del Perfil Competitivo para la empresa Los Ferroles 141

Tabla 24: Indicadores de Actividades Primarias: Logística Interna 152

$\begin{array}{ll}\text { Tabla 25: } & \text { Indicadores de Actividades Primarias: Producción y } \\ \text { Mantenimiento } & 153\end{array}$

Tabla 26: $\quad$ Indicadores de Actividades Primarias: Logística Externa 154 
Tabla 27: Indicadores de Actividades Primarias: Marketing y Ventas

Tabla 28: Indicadores de Actividades Primarias: Servicio y Post venta

Tabla 29: Indicadores de Actividades de Apoyo: Abastecimiento

Tabla 30: Indicadores de Actividades de Apoyo: Desarrollo de Tecnología

Tabla 31: Indicadores de Actividades de Apoyo: Recursos Humanos

Tabla 32: Indicadores de Actividades de Apoyo: Intraestructura de la

Tabla 33: Benchmarking y comparación con los líderes de la industria

Tabla 34: Competencias de la empresa Los Ferroles

Tabla 35: $\quad$ Matriz de Factores Internos EFI

Tabla 36: Enfoque de los Objetivos Estratégicos

Tabla 37: Factores competitivos y niveles de Los Ferroles y el sector

Tabla 38: Matriz Eliminar, Reducir, Incrementar y Eliminar

Tabla 39: Calificación de las fuerzas para la Matriz Peyea

Tabla 40: Participación de mercado y tasa de crecimiento de Los Ferroles

Tabla 41: Resumen de las estrategias formuladas Los Ferroles

Tabla 42: $\quad$ Matriz de selección Rumelt

Tabla 43: Definición de Contextos

Tabla 44: Definición de Escenarios

Tabla 45: $\quad$ Impactos en principales variables

Tabla 46: Impactos en las estrategias

Tabla 47: Objetivos Específicos

Tabla 48: Indicadores a nivel de Perspectiva Financiera

Tabla 49: Indicadores a nivel de Perspectiva Cliente

Tabla 50: $\quad$ Indicadores a nivel de Perspectiva de Procesos 236

Tabla 51: Indicadores a nivel de Perspectiva Aprendizaje y Crecimiento 236

Tabla 52: $\quad$ Metas Perspectiva Financiera por Objetivos Específicos 238

Tabla 53: $\quad$ Metas Perspectiva Cliente por Objetivos Específicos 238

Tabla 54: $\quad$ Metas Perspectiva Procesos por Objetivos Específicos 239

Tabla 55: $\quad$ Metas Perspectiva Aprendizaje y Crecimiento por Objetivos Específicos 
Tabla 56: Descripción de las Iniciativas - Perspectiva Financiera 246

Tabla 57: $\quad$ Descripción de las Iniciativas - Perspectiva Clientes 247

Tabla 58: $\quad$ Descripción de las Iniciativas - Perspectiva Procesos 248

$\begin{array}{ll}\text { Tabla 59: } & \text { Descripción de las Iniciativas - Perspectiva Aprendizaje y } \\ \text { Crecimiento } & 249\end{array}$

Tabla 60: $\quad$ Responsable de las Iniciativas - Perspectiva Financiera 250

Tabla $61 \quad$ Responsable de las Iniciativas - Perspectiva Clientes 251

Tabla 62: $\quad$ Responsable de las Iniciativas - Perspectiva Procesos 252

$\begin{array}{ll}\text { Tabla 63: } & \text { Responsable de las Iniciativas - Perspectiva Aprendizaje y } \\ \text { Crecimiento } & 253\end{array}$

Tabla 64: Enfoque de Incremento de Ingresos 254

Tabla 65: Enfoque de Optimización de Costos y Gastos 255

Tabla 66: Enfoque de Fortalecimiento Institucional 255

Tabla 67: $\quad$ Cronograma Perspectiva Financiera 2018

Tabla 68: Cronograma Perspectiva Cliente $2018 \quad 258$

Tabla 69: Cronograma Perspectiva Procesos 2018

Tabla 70: $\quad$ Cronograma Perspectiva Aprendizaje y Crecimiento 2018

Tabla 71: Cronograma Perspectiva Financiera $2019 \quad 261$

Tabla 72: $\quad$ Cronograma Perspectiva Cliente 2019

Tabla 73: $\quad$ Cronograma Perspectiva Procesos 2019

Tabla 74: Cronograma Perspectiva Aprendizaje y Crecimiento 2019

Tabla 75: Cronograma Perspectiva Financiera 2020

Tabla 76: Cronograma Perspectiva Cliente $2020 \quad 266$

Tabla 77: $\quad$ Cronograma Perspectiva Procesos 2020

Tabla 78: Cronograma Perspectiva Aprendizaje y Crecimiento 2020

Tabla 79: Matriz de Intereses Organizacionales: Estrategias Seleccionadas 272

Tabla 80: $\quad$ Proyección de volumen y precio - Situación actual 275

Tabla 81: $\begin{aligned} & \text { Supuestos para la proyección de Estados tinancieros - Situación } \\ & \text { actual }\end{aligned}$

Tabla 82: $\quad$ Proyección de volumen y precio - con la nueva estrategia. 276

$\begin{array}{ll}\text { Tabla 83: } & \begin{array}{l}\text { Supuestos para la proyección de Estados financieros, con la nueva } \\ \text { estrategia. }\end{array}\end{array}$ 
Tabla 84: $\quad$ Proyección de los Estados de Resultados, sin estrategia 277

Tabla 85: Costos de operación y de inversión con la nueva estrategia. 279

Tabla 86: $\quad$ Proyección de los Estados de Resultados, con la nueva estrategia. $\quad 280$

Tabla 87: Crecimiento de la utilidad neta, con la nueva estrategia 281

Tabla 88: $\quad$ Proyección del Balance General, sin la estrategia 282

Tabla 89: $\quad$ Proyección del Balance General, con la nueva estrategia 283

Tabla 90: Condiciones de Financiamiento Bancario 284

Tabla 91: Resumen de Financiamiento Bancario 285

Tabla 92: Cronograma de Financiamiento Bancario 285

Tabla 93: $\quad$ Proyección del Flujo de Efectivo, sin la estrategia 286

Tabla 94: $\quad$ Proyección del Flujo de Efectivo, con la nueva estrategia 288

Tabla 95: $\quad$ Proyección del Flujo Incremental 289

Tabla 96: $\quad$ Proyección de los Ratios Financieros situación actual 291

Tabla 97: $\quad$ Proyección de los Ratios Financieros con la estrategia 292

Tabla 98: Cálculos para el Modelo CAPM y WACC $\quad 294$

Tabla 99: Estructura de Fuente de Financiamiento 295

Tabla 100: Cálculos del VAN Y TIR para los flujos de efectivo incremental 295 


\section{Índice Figuras}

Figura 1: Valor bruto de la producción avícola en millones de nuevos soles. 21

Figura 2: Producción de aves en miles de toneladas. $\quad 21$

Figura 3: Aparato digestivo del pollo. $\quad 22$

Figura 4: Relación entre la industria del rendering y la industria avícola. 25

Figura 5: Ubicación geográfica Planta Los Ferroles en el Callao. 30

Figura 6: Ubicación geográfica Planta Oquendo en el Callao. 30

Figura 7: Ciclo Productivo San Fernando - Los Ferroles. 32

Figura 8: Diagrama de flujo del proceso productivo. 34

Figura 9: Cartera de clientes de los Ferroles 2016.

Figura 10: Ventas de harinas de plumas en toneladas $\quad 41$

Figura 11: Ventas de harinas de vísceras en toneladas $\quad 41$

Figura 12: Ciclo de vida de la harina de plumas $\quad 42$

Figura 13: Ciclo de vida de la harina de vísceras 43

Figura 14: Organigrama de la empresa Negocios Agroindustriales Los Ferroles 45

Figura 15: Participación de mercado Industria Rendering. 55

Figura 16: Venta de aves vivas en Centros Acopio por mes, según tipo de ave 57

Figura 17: Las cuatro culturas corporativas. $\quad 71$

Figura 18: Valores básicos y modelo de la organización de las 7 eses. 73

Figura 19: Producto Bruto Interno y Demanda Interna 2008-2016 84

Figura 20: Inversión Privada: 2009 -2018 Variación Porcentual Real 85

Figura 21: Inflación y Meta de Inflación 86

Figura 22: Tasa de interés de referencia nominal y real, en porcentaje 87

Figura 23: Tasa de encaje en moneda nacional y moneda extranjera 87

Figura 24: Tipo de cambio e intervención cambiaria del BCP 88

Figura 25: Diagrama Las 5 Fuerzas de Porter 112

Figura 26: Principales empresas comercializadoras de pollo 117

Figura 27: Las cinco estrategias competitivas genéricas 138

Figura 28: Matriz del grado de atractividad de la industria 139

Figura 29: La Cadena de Valor 144

Figura 30: La Cadena de Valor de la Empresa Los Ferroles 150

Figura 31: Lienzo de la estrategia actual de Los Ferroles 178

Figura 32: Lienzo de la estrategia actual del sector del rendering $\quad 181$

Figura 33: Comparativo entre el lienzo de la estrategia actual de Los Ferroles y 182 
Figura 34: Lienzo de la nueva estrategia océano azul

Figura 35: Matriz Foda Los Ferroles $\quad 190$

Figura 36: Matriz de posición estratégica y evaluación de la acción - PEYEA 193

Figura 37: Matriz Interna y Externa.

Figura 38: Matriz Interna y Externa Los Ferroles 196

Figura 39: Matriz Boston Consulting Group 198

Figura 40: Matriz Boston Consulting Group Los Ferroles 199

Figura 41: Matriz de la Estrategia Principal 201

Figura 42: Matriz de la Estrategia Principal Los Ferroles 204

Figura 43: Modelo analítico para la formulación de estrategias 217

Figura 44: Matriz cuantitativa de la planificación estratégica - MCPE - Estrategia 218

Figura 45: Matriz cuantitativa de la planificación estratégica - MCPE - Estrategia 219

Figura 46: $\begin{aligned} & \text { Matriz cuantitativa de la planificación estratégica - MCPE - } \\ & \text { Estrategias de Integración: Vertical y Horizontal }\end{aligned}$

Figura 47: Matriz cuantitativa de la planificación estratégica - MCPE - Estrategia
Defensiva: Recorte de Gastos.

Figura 48: Trasladar la Estrategia a Términos Operacionales 229

Figura 49: Cuadro de Mando Integral de la empresa Los Ferroles SAC. 230

Figura 50: Matriz Impacto de iniciativas sobre los objetivos - Perspectiva 242

Figura 51: Matriz Impacto de iniciativas sobre los objetivos - Perspectiva Cliente 243

Figura 52: Matriz Impacto de iniciativas sobre los objetivos - Perspectiva
Procesos

Figura 53: Matriz Impacto de iniciativas sobre los objetivos - Perspectiva 245

Figura 54: Teoría tridimensional de la relación entre organizaciones 271 


\section{Índice Anexos}

Anexo 1: Compendio Brasileño de Alimentación Animal 2004

Anexo 2: Fichas de entrevista a Clientes 302

Anexo 3: Fichas de entrevista a la Competencia 320

Anexo 4: $\quad$ Fichas de entrevista a los Directivos de la empresa Los Ferroles 342

Anexo 5: $\quad$ Fichas de entrevista a los Jefe de Área de la empresa Los Ferroles $\quad 363$

Anexo 6: Fichas de entrevista a Expertos del Sector 390

Anexo 7: Fichas de entrevista a No Clientes 400

Anexo 8: Fotos visita Planta Los Ferroles 407 


\section{Resumen Ejecutivo}

El presente Plan Estratégico 2018- 2020 ha sido elaborado para la empresa Negocios Agroindustriales Los Ferroles S.A.C, en adelante Los Ferroles, con el objetivo de incrementar la rentabilidad y asegurar el crecimiento sostenido de la empresa.

Para el desarrollo del proyecto, se ha realizado un exhaustivo análisis de los factores externos e internos, que permitieron elaborar un diagnóstico inicial identificando las principales oportunidades y amenazas de la industria; así como, fortalezas y debilidades de la organización. De esta manera, se pudieron establecer objetivos estratégicos, a fin de alcanzar la visión propuesta.

Producto del análisis se evaluaron una serie de estrategias, quedando como seleccionadas las estrategias intensivas: Penetración de mercado y Desarrollo de productos; y como contingente la estrategia de Integración Vertical hacia Atrás. Adicionalmente, se ha considerado conveniente la implementación de las estrategias internas dado que constituyen un aspecto muy relevante para el negocio y el desarrollo de las demás estrategias.

En el Cuadro de Mando Integral, se definen los objetivos estratégicos y específicos para la empresa, así como metas e indicadores. Se proponen 37 iniciativas las cuales serán gestionadas por responsables asignados y a través de un cronograma establecido.

Las iniciativas a implementar se han agrupado en tres enfoques, los cuales están clasificados de acuerdo a su impacto en la rentabilidad de la empresa: Incremento de Ingresos, Optimización de Costos y Gastos y Fortalecimiento Institucional. Asimismo, se ha asignado un 
presupuesto a cada una de las iniciativas a lo largo de los tres años de duración del proyecto, valorizado en un total de S/ 1'953,000.

Al final del 2020, se espera un incremento en ventas de $14.7 \%$; en cuanto a los indicadores financieros se proyecta obtener una TIRE de 67\% y un VANE de S/. 463 mil, considerando la implementación de las iniciativas propuestas. 


\section{Introducción}

Los Ferroles es una empresa familiar, que desde el año 2004 se dedica al negocio del rendering, a través de la elaboración de harinas proteicas en base a sub productos de origen animal. Los productos que comercializa son harina de pluma y harina de vísceras. Actualmente es líder en el sector, con una participación de mercado de $62 \%$ respecto a sus competidores.

En el presente proyecto se propone un Plan Estratégico para el periodo 2018 - 2020, en donde la empresa asumirá nuevos retos para cambiar su estrategia actual de negocio a una que le permita incrementar su rentabilidad y asegure su crecimiento sostenible en el tiempo.

El proyecto se ha estructurado en diez capítulos los cuales se describen a continuación:

1. Capítulo I - Generalidades, en donde se determinan los problemas y oportunidades que posee la empresa. Así también la justificación del proyecto, objetivos generales y específicos, alcance y limitaciones del presente Plan Estratégico.

2. Capítulo II - La empresa, se describe los antecedentes de la empresa, el giro de negocio, el ciclo de vida del producto, la estructura organizacional. situación de mercado y situación financiera del rendering.

3. Capítulo III - Formulación de la visión, misión y valores de la empresa, se desarrolla una nueva propuesta en base a las entrevistas con los directivos y trabajadores de Los Ferroles. Adicionalmente se platean valores que serán los pilares de la empresa.

4. Capítulo IV - Análisis Externo, se analizan las variables del entorno externo tales como factores: político - gubernamental, económico, legal, cultural, tecnológico y ecológico que podrían tener un impacto en la empresa. 
5. Capítulo V - Análisis de la industria, se desarrollará la descripción del mercado y la industria, las cinco fuerzas competitivas de la industria y su matriz de atractividad, el grado de actractividad de la industria y la matriz del perfil competitivo - MPC.

6. Capítulo VI - Análisis interno, se detalla la cadena de valor de la empresa, se realiza un análisis del benchmarking y comparación con los líderes de la industria. Asimismo, se determinan las competencias, ventajas competitivas de la empresa y se elabora la matriz EFI.

7. Capítulo VII - Formulación de Objetivos y diseño de las Estrategias, se plantean los objetivos estratégicos, se diseñan y formulan las estrategias a través del desarrollo y análisis de matrices. Finalmente se elabora el resumen de las estrategias formuladas.

8. Capítulo VIII - Selección de la Estrategia, se evalúan las estrategias propuestas en base a criterios de selección y métodos de escenarios. Así también, se elabora la matriz MCPE para determinar objetivamente que alternativas estratégicas de las presentadas son las mejores, teniendo en cuenta el impacto de los factores claves internos y externos. Como resultado, se obtiene la estrategia seleccionada y la contingente.

9. Capítulo IX - Implantación de la estrategia, se elabora el mapa de la estrategia, objetivos específicos, indicadores, metas, iniciativas a ejecutarse, responsables, presupuestos y cronogramas de actividades.

10. Capítulo X - Evaluación, se desarrolla una evaluación cualitativa y cuantitativa de las estrategias propuestas. En este capítulo, se analizarán las proyecciones de la situación financiera de Los Ferroles con la implementación de las estrategias seleccionadas para 
contrastarlas con las proyecciones en caso de no realizar los cambios sugeridos en el presente Plan Estratégico. 


\section{Capítulo I. Generalidades}

\subsection{Antecedentes}

La palabra rendering, según el National Renderers Association (2006), se define como el reciclaje de los residuos dejados por la utilización de materia prima cárnica, es decir el procesamiento de los subproductos cárnicos y su conversión en sustancias aptas para la alimentación animal.

La reutilización de los subproductos cárnicos como parte del alimento del ave, hace que el redering sea un concepto estrechamente ligado con la denominación de economía circular. Según la Fundación Ellen MacArthur (2014), este modelo es en un ciclo continuo o ciclo de aprovechamiento que conserva y mejora el capital natural, optimizando de esta manera el uso de los recursos. En otras palabras, procura la reutilización de los elementos reincorporándolos al ciclo de producción

En el Perú, esta industria tiene pocos años y el mercado está concentrado en pocas empresas procesadoras-comercializadoras, siendo las líderes del rubro TechnoFeed SAC, Alimencorp SAC y Negocios Agroindustriales Los Ferroles SAC. Dado que los productos del rendering son una importante fuente proteica para la alimentación animal, el mercado objetivo se centra en la industria ganadera, avícola, acuícola y la industria de alimento para mascotas; siendo la industria avícola la que mayores volúmenes demanda, debido a su desarrollo y crecimiento en el país.

El presidente de la Asociación Peruana de Avicultura (APA), José Vera Vargas, señala que la producción avícola en el Perú se ha incrementado sosteniblemente en los últimos años; asimismo sostiene que entre los años 2009 y 2015 el crecimiento fue de 
$47 \%$, lo que representa un aumento de $8 \%$ por año. Señala también que el sector tiene como reto mejorar el nivel de competitividad, para lo cual el gremio ha firmado un convenio con el Ministerio de Agricultura (MINAGRI) que le permitirá fortalecer el trabajo en conjunto en cuanto a seguridad alimentaria y sostenibilidad. El objetivo de este convenio es concretar los requisitos para poder exportar pollo, del mismo modo en que se logró expandir la exportación de pavo a países de la región. Finalmente, indicó que la tendencia del consumo de aves para el 2020 seguiría en ascenso. (Diario Correo, 2016).

De acuerdo al boletín estadístico mensual de la producción y comercialización avícola - diciembre 2016; la producción del año 2016, muestra un incremento porcentual comparado con el 2015. Las figuras 1 y 2 muestran la evolución mensual desde enero del 2015 hasta diciembre 2016; tanto en miles de toneladas de aves producidas, como en valorización en miles de soles. 


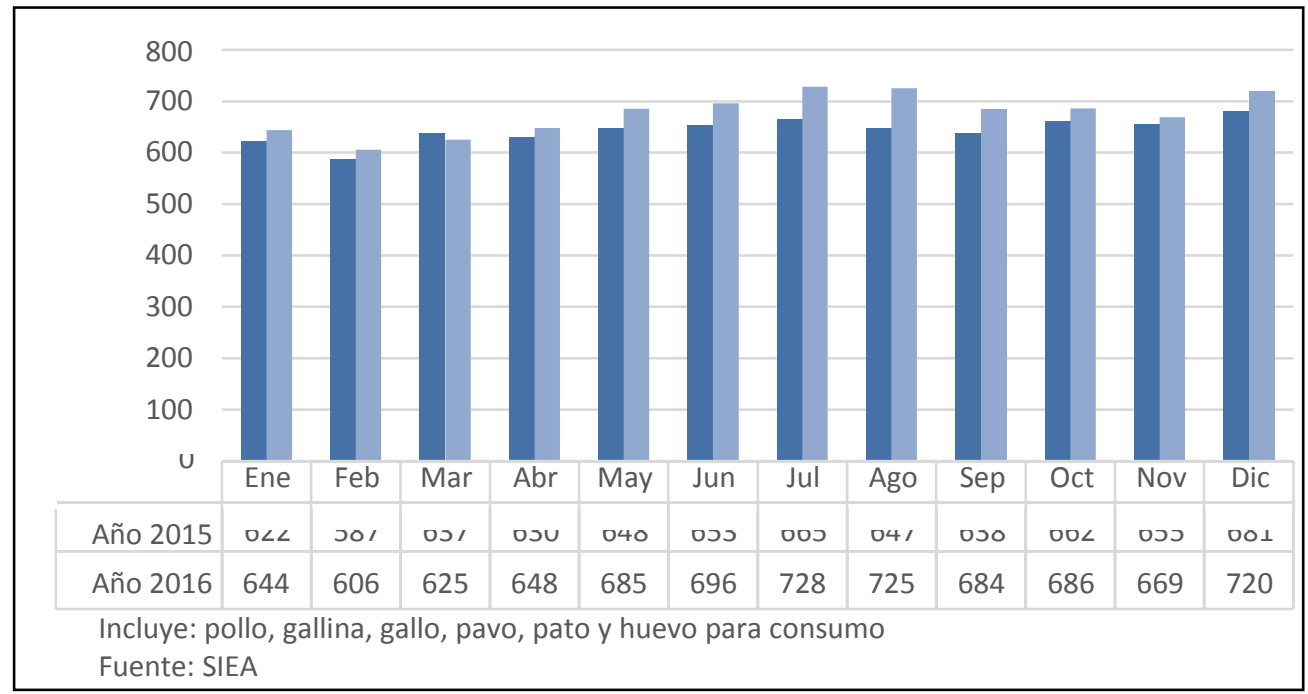

Figura 1. Valor bruto de la producción avícola en millones de nuevos soles. Enero 2015 - diciembre 2016. Tomado de "Boletín estadístico mensual de la producción y comercialización avícola,” por el Ministerio de Agricultura y Riego (MINAGRI), 2016. Recuperado de file:///C:/Users/c4500/Downloads/sector-avicola-diciembre2016.pdf

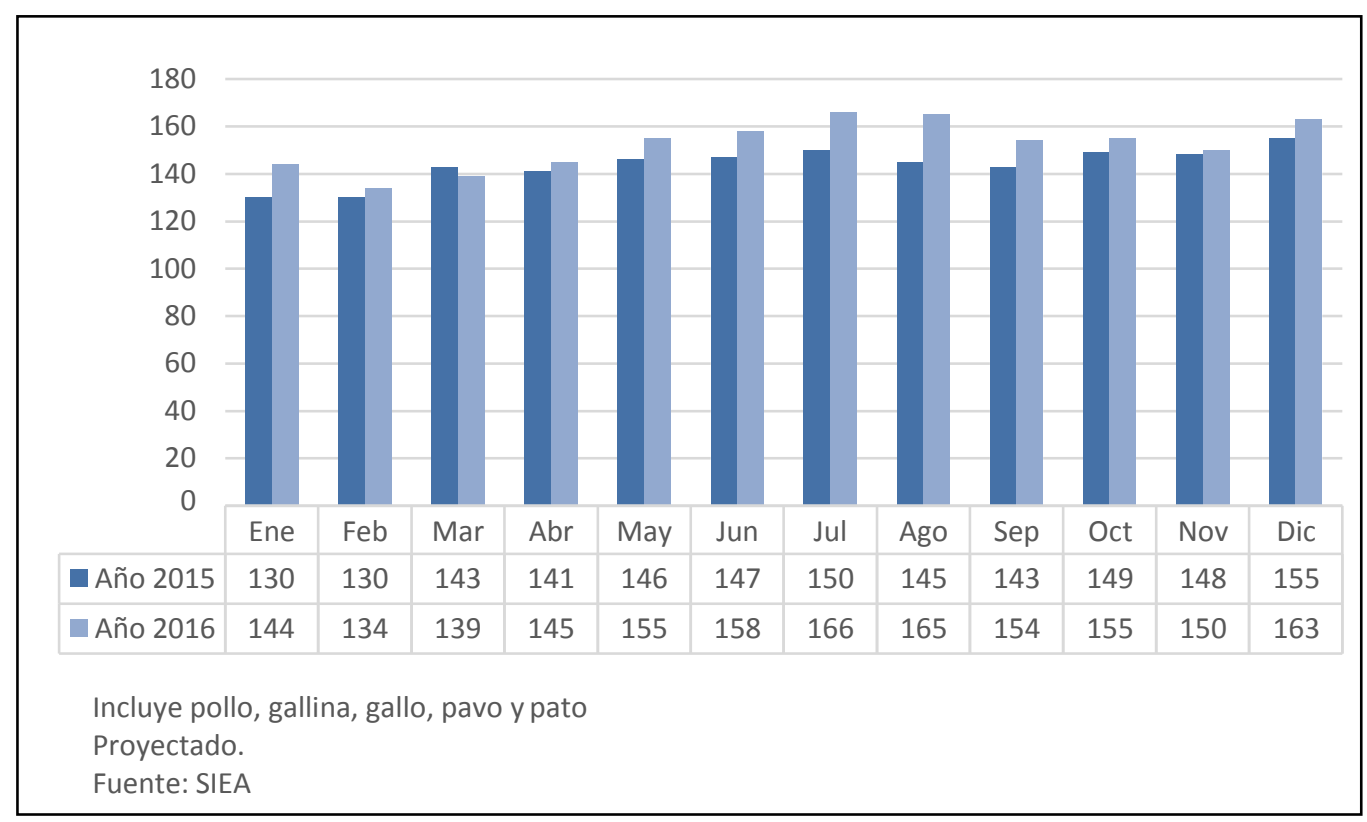

Figura 2. Producción de aves en miles de toneladas. Enero 2015 - diciembre 2016.

Tomado de "Boletín estadístico mensual de la producción y comercialización avícola," por el Ministerio de Agricultura y Riego (MINAGRI), 2016. Recuperado de file:///C:/Users/c4500/Downloads/sector-avicola-diciembre2016.pdf 
Tanto las plantas de beneficio de las empresas formales, como los centros de pelado de aves, de distribuidores y mayoristas pequeños y medianos (PYMES), forman parte del mercado avícola. Estos procesadores son los principales abastecedores de materia prima para la industria del rendering, debido a que más del 10\% de la constitución de un ave, la integran sus subproductos, tales como plumas, vísceras y sangre, los cuales posteriormente se transformarán en harinas proteicas para la fabricación del alimento balanceado.

Esta relación genera beneficios mutuos para ambas industrias; por el lado del procesador avícola reduce los costos del alimento balanceado y brinda una solución para el tratamiento y disposición final de los residuos; por el lado del procesador de rendering, es una oportunidad de negocio donde crea productos de alto valor para sus clientes.

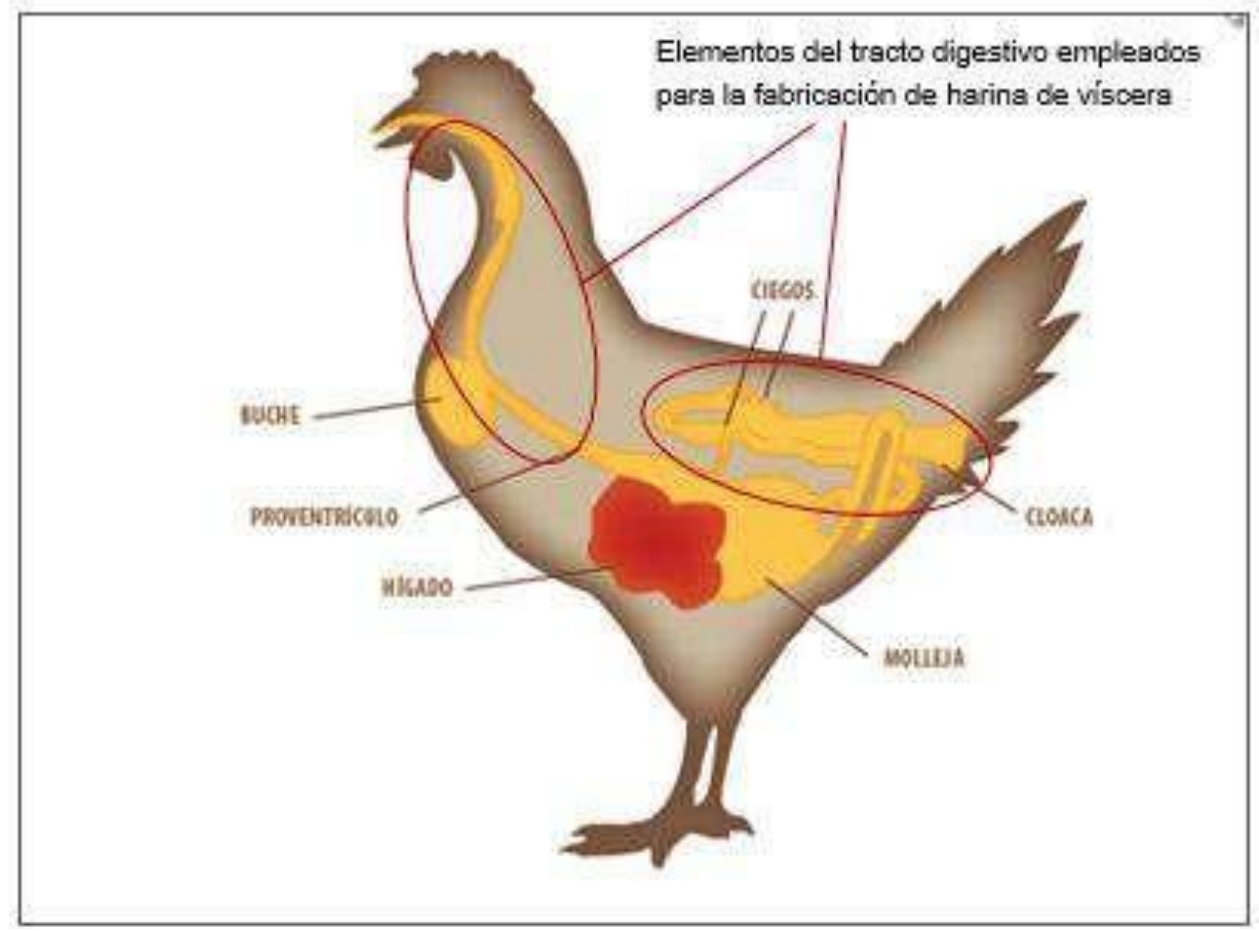

Figura 3. Aparato digestivo del pollo. Tomado de "Dietas Avícolas Groseras // Salud intestinal en pollos y eficiencia," por el AviNews, Avicultura Info 2016. Recuperado de http://avicultura.info/dietas-avicolas-groseras-efectos-sobre-la-eficiencia-del-nitrogenoy-la-salud-intestinal-en-pollos/ 
La empresa para la cual se elaborará el proyecto de planeamiento estratégico es Negocios Agroindustriales Los Ferroles S.A.C, la cual es una empresa de propiedad de la familia Romero Cotera. Actualmente, además de ser dueños, son quienes dirigen y gerencian la empresa.

Los Ferroles se dedican a la producción y comercialización de harinas proteicas de origen animal a nivel de Lima metropolitana y Callao. El mercado al cual está dirigido es el sector avícola, siendo sus principales clientes las empresas avícolas más reconocidas en el sector: San Fernando S.A; Santa Elena S.A; Redondos S.A, entre otros.

\subsection{Determinación del Problema u Oportunidad}

\section{Problema.}

De acuerdo a la entrevista realizada al Director de la empresa Los Ferroles, se pueden considerar los siguientes problemas principales:

- $\quad$ Falta de un Plan Estratégico que alinee las decisiones y acciones de la empresa para el logro de sus objetivos.

- $\quad$ Falta de un plan de sucesión que garantice la continuidad de la empresa en el tiempo.

- $\quad$ Falta de estandarización de procesos productivos y administrativos, ello conlleva a ineficiencias en el uso de recursos y tiempo.

- $\quad$ Falta de gestión comercial. La empresa ha crecido significativamente en los últimos años de una forma desorganizada, sin tener en cuenta estrategias comerciales que encaminen la gestión hacia el logro de objetivos. No han 
desarrollado la marca, ni tienen presencia en medios digitales. No miden el nivel de satisfacción de sus clientes que sirva de retroalimentación para su gestión.

- $\quad$ Problemas en la gestión del recurso humano, dada la falta de organización interna y gestión de áreas funcionales. Esto no les permite crecer organizacionalmente y les genera problemas de clima laboral y rotación de personal.

\section{Oportunidad.}

El sector avícola es el principal proveedor de proteína animal en el país, dado que más del 67\% de ésta proviene de la carne de pollo (El Sitio Avícola, 2016). La Asociación Peruana de Avicultura (APA) señala que el Perú es un país con un nivel de consumo de pollo per cápita creciente; sólo en Lima el consumo es de 75 kilos por habitante al año, mientras que a nivel nacional es de 43 kilos por habitante (Diario Correo, 2016).

El crecimiento y desarrollo que ha tenido este sector en los últimos años, ha generado que la industria del rendering crezca a la par y proyecte un alto potencial de desarrollo.

Existe una estrecha y beneficiosa relación entre la industria avícola y la industria del rendering. El incremento del consumo de pollo trae consigo mayor cantidad de residuos propios del procesamiento, por consiguiente se hace necesaria una solución que cubra las exigencias legales y medio ambientales actuales del país.

En tal sentido, la industria del rendering surge como una solución integral que aprovecha estos residuos y los transforma en productos de alto valor agregado, evitando que la empresa incurra en altos costos para su manejo y disposición final. 


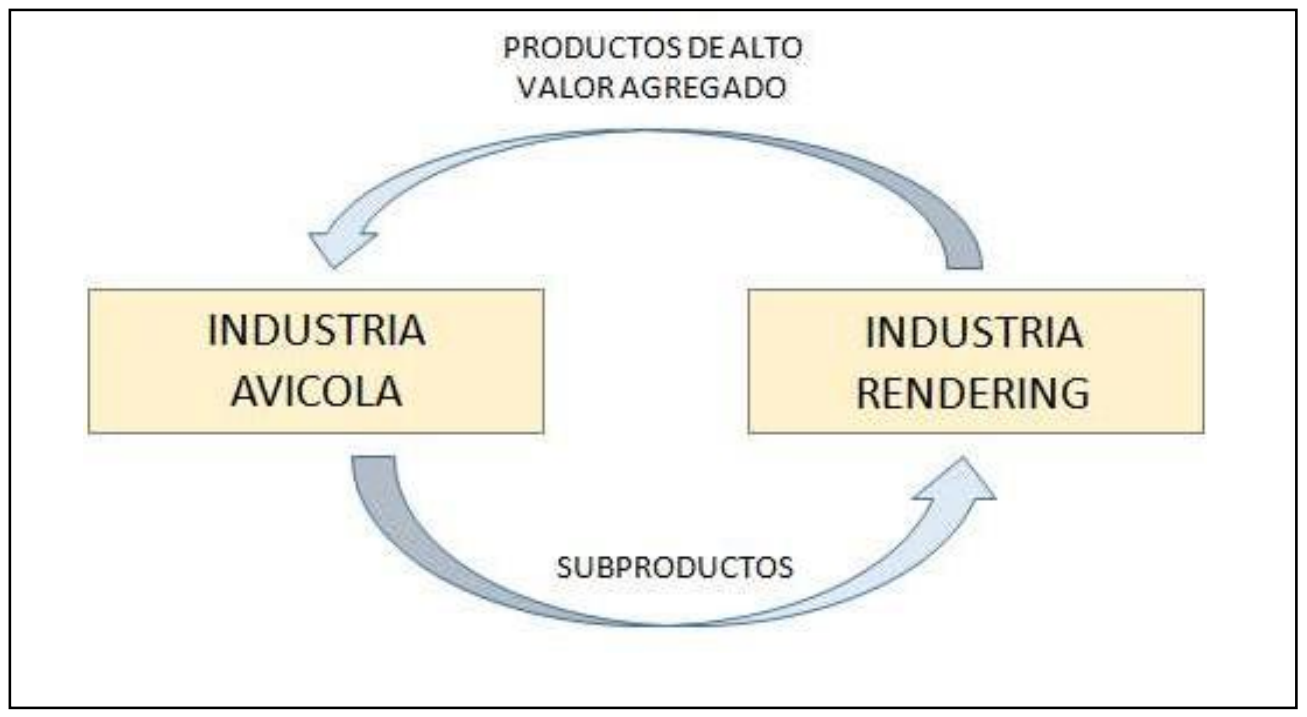

Figura 4. Relación entre la industria del rendering y la industria avícola. Tomado de “Fichas de entrevista a Clientes Entrevista," por la empresa San Fernando, 2016.

\subsection{Justificación del Proyecto}

\section{Justificación Empresarial.}

Desarrollar un Plan Estratégico para el periodo 2017 -2019 para la empresa Negocios Agroindustriales Los Ferroles SAC, con el fin de establecer los lineamientos necesarios para asegurar un crecimiento sostenible, maximizando la rentabilidad de la organización.

\section{Justificación Académica.}

Aplicar los conocimientos adquiridos en los programas de Habilidades Gerenciales, Gestión de Empresas y Gestión Comercial, de la Maestría en Ciencias Empresariales; llevándolos a la práctica en el desarrollo del Plan Estratégico de la empresa Negocios Agroindustriales Los Ferroles SAC. 
1.4 Objetivos Generales y Específicos

Objetivo General del Proyecto.

Desarrollar el Plan Estratégico de la empresa Negocios Agroindustriales Los Ferroles SAC para el período 2018- 2020, con el objetivo de asegurar la sostenibilidad y crecimiento de la empresa.

\section{Objetivos Específicos del Proyecto.}

- Formular visión, misión y valores para la empresa.

- Analizar el entorno interno y externo.

- Formular los objetivos y diseñar las estrategias que se alineen con las necesidades de la empresa.

- Seleccionar la estrategia principal y la estrategia contingente

- Desarrollar la herramienta Balance Score Card (BSC), que permita enlazar las estrategias y los objetivos clave.

- Evaluar la viabilidad financiera de las estrategias seleccionadas a través de indicadores.

\subsection{Alcances y Limitaciones de la Investigación}

Alcances.

Alcance Geográfico: Departamento de Lima y Callao.

Alcance de la Investigación: Elaboración del plan estratégico para la empresa

Negocios Agroindustriales Los Ferroles S.A.C. para el período 2018 - 2020.

\section{Limitaciones de la investigación.}

Entre las principales limitaciones se tienen: 
Falta de información del mercado proveniente de investigaciones cualitativas o cuantitativas.

- $\quad$ Limitado acceso a data estadística gubernamental y del sector actualizada.

- Limitado acceso a la información de la competencia. 


\section{Capítulo II. La Empresa}

\subsection{Antecedentes de la Empresa}

Negocios Agroindustriales Los Ferroles SAC es una empresa familiar que desde hace más de 12 años se dedica al proceso de rendering. El negocio se centra en el tratamiento de dos subproductos de la industria avícola: vísceras y plumas; de los cuales se obtienen harina de vísceras y harina de plumas, insumos de alto valor proteico dentro del alimento balanceado de las aves. El actual modelo comercial que emplea hacia sus clientes es la venta directa, dado que no cuenta con intermediarios.

El fundador y dueño de la empresa, Sr. Rogelio Romero Cotera, tiene a su cargo la dirección. Sus inicios datan del año 2004, fecha en la cual decide asociarse con un empresario del sector avícola (quien tenía un pequeño camal de aves), y emprender el negocio de la recolección y procesamiento de los subproductos de las aves. La sociedad duró pocos años, en el 2007 le compra las acciones al socio, por lo que hoy en día la familia Romero son los accionistas totales de la empresa.

La primera planta de procesamiento se ubicó en el local de Santa Clara, se inició con una tecnología incipiente, constituida principalmente por autoclaves y cocinadores discontinuos; en el año 2006, debido a la presión del crecimiento urbano de la zona, se trasladaron al local ubicado en Av. Prolongación Centenario S/N Urb. Industrial Los Ferroles - Callao, el cual fue comprado con capital propio y exclusivamente para este fin. 
Pocos años después, en el 2008, se incrementa la capacidad de producción y se moderniza la tecnología a digestores y secadores por batch (lote). En el año 2011, cuando se sintieron listos para dar un salto en tecnología, incrementaron su capacidad instalada y modernizaron la maquinaria de la planta adquiriendo equipos de la marca Haarslev (de procedencia danesa) la cual es una de las marcas líderes en el mercado en la industria del rendering. Al inicio, compraron piezas y maquinaria pequeña para ir probando el desempeño de la marca, pocos años después en el 2013, montaron la nueva y moderna Planta Oquendo ubicada en la Av. Playa Oquendo Km. 7, Callao, con una línea continua completa totalmente automatizada para harina de plumas.

Actualmente, la empresa cuenta con dos plantas productoras, la planta Los Ferroles, donde procesan la harina de vísceras, y la planta Oquendo, donde procesa la harina de plumas, ambas ubicadas en la provincia constitucional del Callao a un kilómetro de distancia una de otra. En las figuras 5 y 6 se muestra la ubicación geográfica de las plantas. 


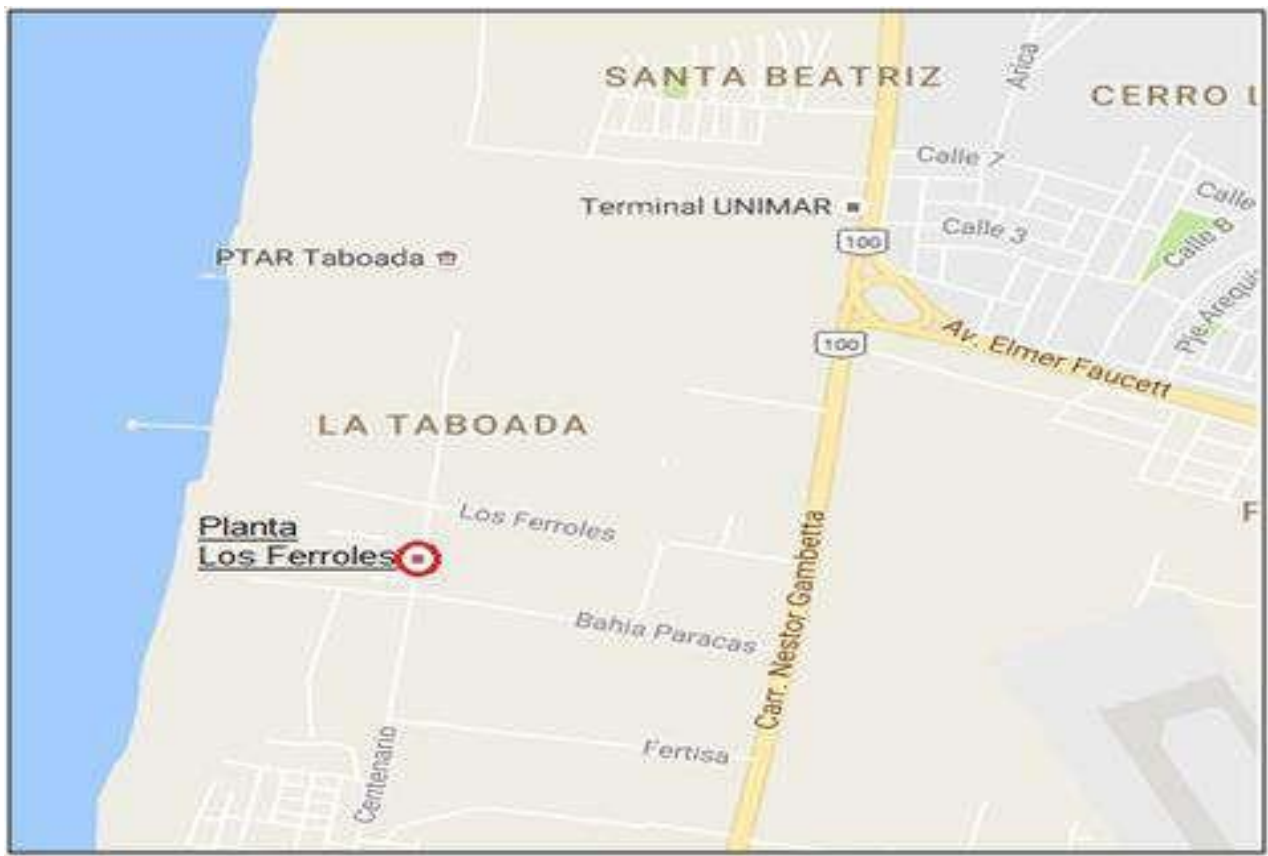

Figura 5. Ubicación geográfica Planta Los Ferroles en el Callao. Tomado de "Google Maps," por Google, 2016. Recuperado de

https://www.google.com.pe/maps/place/Los+Ferroles,+Callao/@-12.002808

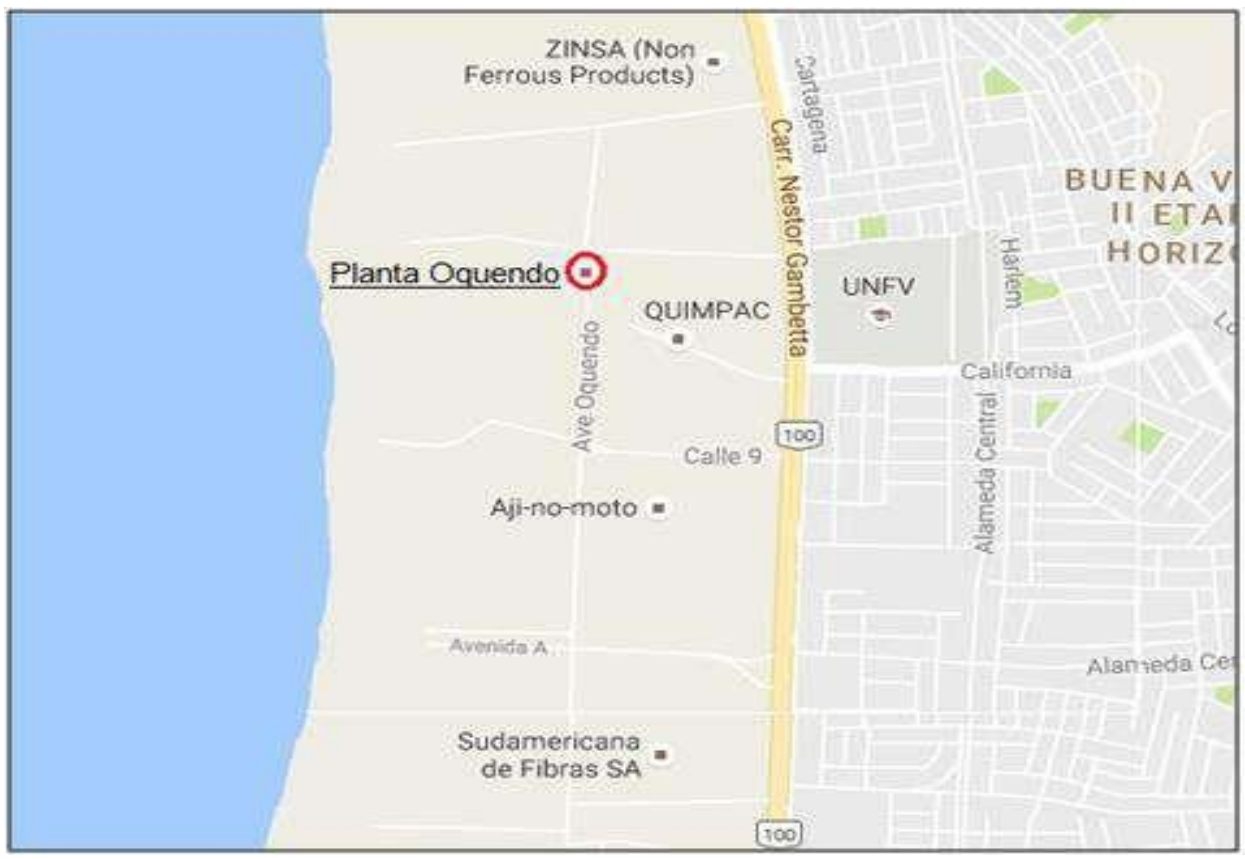

Figura 6. Ubicación geográfica Planta Oquendo en el Callao. Tomado de "Google Maps,” por Google, 2016. Recuperado de https://www.google.com.pe/maps/place/Playa+Oquendo/@-11.9805552 
Durante los primeros años de operación sus principales clientes fueron criadores pequeños e informales de aves, quienes compraban bajo volumen y de manera no continua, debido a que el precio era una variable muy sensible y determinante en la negociación. Este modelo comercial no les permitía crecer sosteniblemente, ni les generaba la rentabilidad esperada; es por ello que desde el año 2008, deciden invertir en tecnología para optimizar los procesos y mejorar la calidad de los productos y de esta manera poder introducirlos en las empresas más grandes y formales del sector, ofreciendo mayor calidad y valor nutricional. Actualmente, Los Ferroles es una empresa con un modelo de comercialización business to business (B2B), y dentro de sus principales clientes se encuentran las empresas líderes del mercado avícola como San Fernando, Santa Elena y Redondos.

Las principales ventajas competitivas que diferencian a Los Ferroles en el mercado son: el uso de tecnología de punta para el proceso productivo (líneas continuas únicas en el país con tecnología europea) lo cual le permite obtener un producto de alta calidad y alto valor proteico; y la especialización de sus productos para la industria avícola, los cuales son fabricados especialmente para esta industria, evitando la contaminación cruzada. (Los Ferroles, 2016).

Una característica importante de Los Ferroles, es el enfoque de Responsabilidad Social que presenta; esto se evidencia a través del compromiso con la comunidad para evitar la contaminación por olores. Para ello, han adquirido tecnología moderna de última generación que capta y controla los olores propios del procesamiento. David (2015) define la Responsabilidad Social como las medidas que la empresa implementa más allá de sus 
obligaciones legales para proteger o mejorar el bienestar de los seres vivos; y es este enfoque el que Los Ferroles viene implementando en sus plantas procesadoras.

Los Ferroles lidera el mercado del procesamiento de subproductos avícolas, debido a que tiene la capacidad de acopiar la mayor cantidad de materia prima del sector; este resultado lo consigue a través de la alianza estratégica que sostiene con la empresa San Fernando. El modelo de negocio que Los Ferroles ha establecido con San Fernando es de servicio de maquila; este modelo consiste en la recepción de materia prima acondicionada (plumas húmedas y limpias, sangre concentrada y vísceras) para su procesamiento y posterior venta como producto terminado; de esta manera, San Fernando asegura la calidad de la harinas proteicas para la crianza de aves. (San Fernando, 2016).

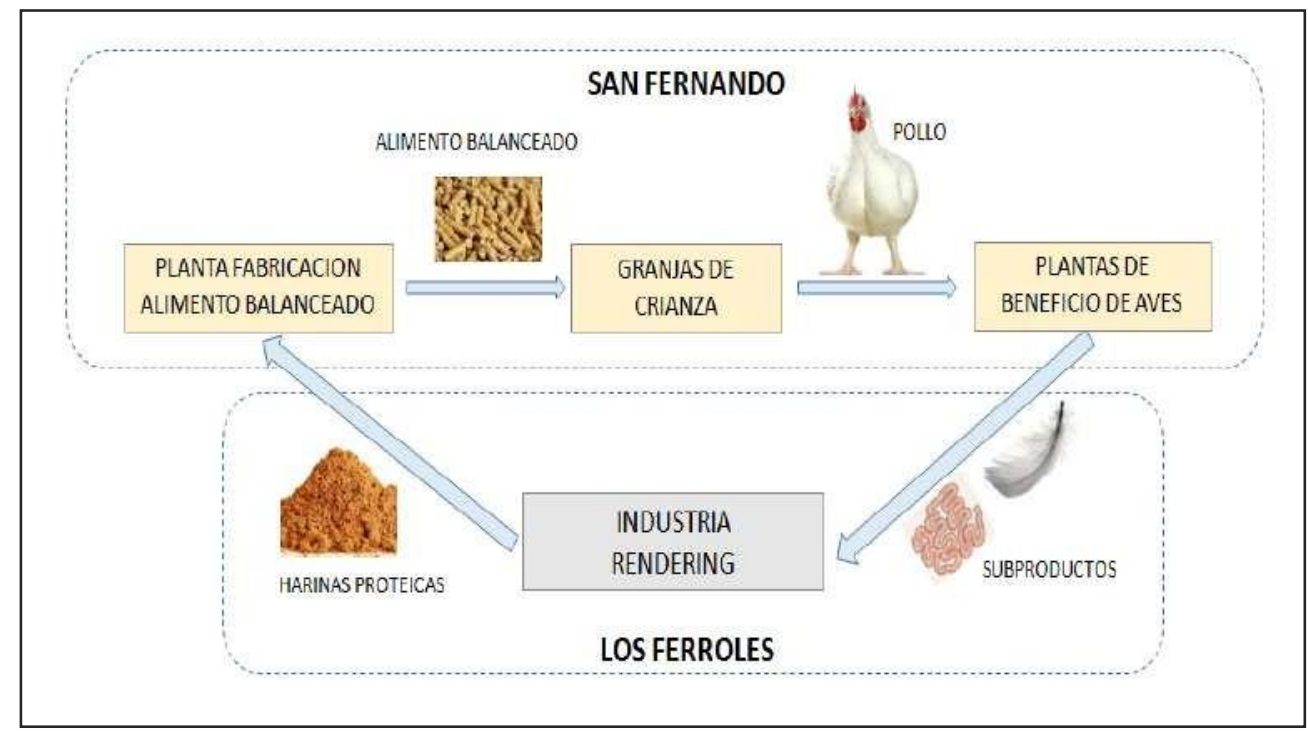

Figura 7. Ciclo Productivo San Fernando - Los Ferroles. Tomado de "Fichas de entrevista a Clientes," por la Empresa San Fernando, 2016. 


\subsection{Descripción del negocio}

La empresa los Ferroles se dedica al procesamiento y comercialización de harinas proteicas elaboradas a base de subproductos de pollo. Estas harinas son de excelente calidad nutricional e insumo clave en la elaboración del alimento balanceado. Actualmente, su nicho de mercado se concentra en el sector avícola.

La oferta de valor de Los Ferroles hacia las empresas avícolas es la garantía de un desarrollo productivo eficiente al menor costo; adicionalmente, desde el punto de vista medio ambiental y legal, brinda una solución integral para el manejo y disposición de los residuos generados durante el procesamiento.

Las operaciones se dividen en tres grandes procesos: (a) la recolección de materia prima, (b) el procesamiento industrial y (c) la distribución a clientes.

La materia prima la reciben de dos grande fuentes: (a) de las plantas de beneficio de aves de la empresa San Fernando, ubicadas en Chincha y Huaral y (b) del acopio de subproductos de los principales mercados de Lima. En ambos casos, la recolección y transporte es tercerizado y está a cargo de empresas autorizadas para el manejo de este tipo de productos (empresas prestadoras de servicios de residuos sólidos -EPS-RS).

La empresa cuenta con dos plantas de producción, una destinada a la línea de plumas y la otra a la de vísceras. En ambos casos, el proceso productivo consta de las siguientes etapas:

1. Recepción de materia prima: proceso a través del cual se reciben los subproductos en planta (entregados por los acopiadores). Esta recepción se realiza en grandes 
tolvas o contenedores, donde los subproductos permanecen almacenados hasta que se dé inicio a la producción.

2. Hidrolización / cocción: proceso a través del cual los subproductos son sometidos a altas temperaturas con el fin de hidrolizar (plumas) o cocinar (vísceras); con ello se logra mayor disponibilidad de los aminoácidos de la proteína.

3. Secado: proceso a través del cual se reduce la humedad de la masa; asimismo por las altas temperaturas alcanzadas, se asegura la inocuidad.

4. Molienda: proceso que reduce y homogeniza el tamaño de partícula de la harina.

5. Envasado: proceso por el cual se ensacan las harinas en sacos por $40 \mathrm{Kg}$.

6. Almacenamiento y despacho: proceso por el cual se estiban los sacos en el almacén, hasta que son programados para su despacho. Aquí se muestrea el producto terminado para los análisis de laboratorio.

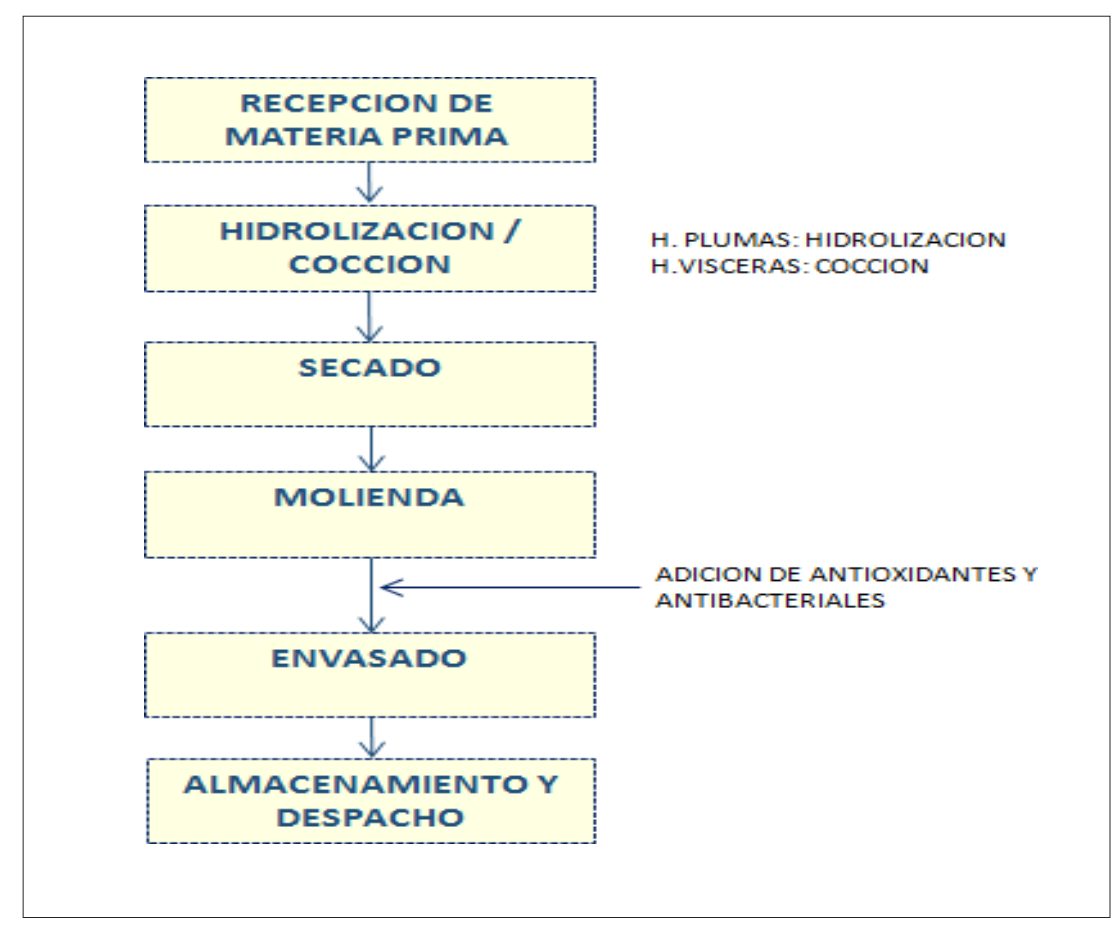

Figura 8. Diagrama de flujo del proceso productivo. Tomado de "Procedimiento del proceso productivo", por la Empresa Los Ferroles, 2016. 
Para la producción de las harinas, Los Ferroles ha establecido sus propios estándares productivos en base al asesoramiento externo recibido y la experiencia de los años en la producción. En el Perú, no existen parámetros técnicos que regulen la producción de estas harinas, por lo que la industria toma las especificaciones brasileras como referencia; dado que Brasil es el país de la región que tiene más desarrollado el rendering y su reglamentación. En la Tabla 1 se muestran las especificaciones técnicas del Compendio Brasilero de Alimentación Animal (2004) para las diferentes harinas proteicas del rendering. El detalle del compendio se encuentra en el anexo 1. 
Tabla 1

Especificaciones brasileras para harinas proteicas de origen animal en alimentos para animales

\begin{tabular}{|c|c|c|c|c|c|c|c|}
\hline Parámetros & Unid. & $\begin{array}{l}\text { H. Pluma y } \\
\text { víscera }\end{array}$ & $\begin{array}{l}\text { H. Pluma } \\
\text { hidroliza. }\end{array}$ & $\begin{array}{c}\text { H. } \\
\text { Vísceras }\end{array}$ & $\begin{array}{l}\text { H. Resid } \\
\text { incubac. }\end{array}$ & $\begin{array}{l}\text { H.Víscera } \\
\text { c/huesos }\end{array}$ & $\begin{array}{l}\text { H. Víscera c/huesos y } \\
\text { resid. incub. }\end{array}$ \\
\hline Unidad (máximo) & $\%$ & 8,00 & 10.00 & 8,00 & 8,00 & 8,00 & 8,00 \\
\hline Extracto Etéreo (mínimo) & $\%$ & 7,00 & 2,00 & 10.00 & 10.00 & 10.00 & 11,00 \\
\hline Materia Mineral (máximo) & $\%$ & 17,00 & 4,00 & 15,00 & 60.00 & 22,00 & 25,00 \\
\hline Fósforo (mínimo) & $\%$ & 1,10 & - & 1,50 & 0.50 & 2,50 & 2,00 \\
\hline $\begin{array}{l}\text { Digestibilidad en Pepsina 1:10.000 a 0.02\% } \\
\text { en HCl } 0.075 \mathrm{~N} \text { (mínimo) }\end{array}$ & $\%$ & 45,00 & 40.00 & 60.00 & - & 60.00 & 60.00 \\
\hline Acidez (máximo) & $\mathrm{mg} \mathrm{NaOH} / \mathrm{g}$ & 3,00 & 2,00 & 3,00 & 3,00 & 3,00 & 3,00 \\
\hline Retención de tamiz 2mm (máximo) & $\%$ & 5,00 & 5,00 & 5,00 & 5,00 & 5,00 & 5,00 \\
\hline Retención de tamiz 1,68mm (máximo) & $\%$ & 10.00 & 10.00 & 10.00 & 10.00 & 10.00 & 10.00 \\
\hline
\end{tabular}

Nota. Adaptado del "Harinas proteicas de origen animal," por Sindiracoes, 2004, Compendio Brasilero de Alimentación Animal, p. 22.

Recuperado de http://sindiracoes.org.br/produtos-e-servicos/compendio-brasileiro-de-alimentacao-animal/ 
La distribución de los productos terminados se realiza según cronograma de entrega, de acuerdo a lo establecido con los clientes. Para ello, emplean servicios de transporte tercerizados, quienes trasladan los productos hasta los almacenes de los clientes.

Los clientes claves del negocio son las empresas líderes del mercado avícola:

(a) San Fernando S.A y (b) Santa Elena S.A. Los volúmenes de compra que mantienen son estables, y se encuentran alineados a sus requerimientos productivos, aunque dependiendo del precio de los sustitutos, podría haber alguna variación. En estos clientes se concentra más del $75 \%$ de la facturación total de la empresa. El resto de clientes está conformado por empresas medianas del sector, cuyos volúmenes de compra son variables y sensibles al precio pues dependen de los productos sustitutos que existan en el mercado en el momento de la compra.

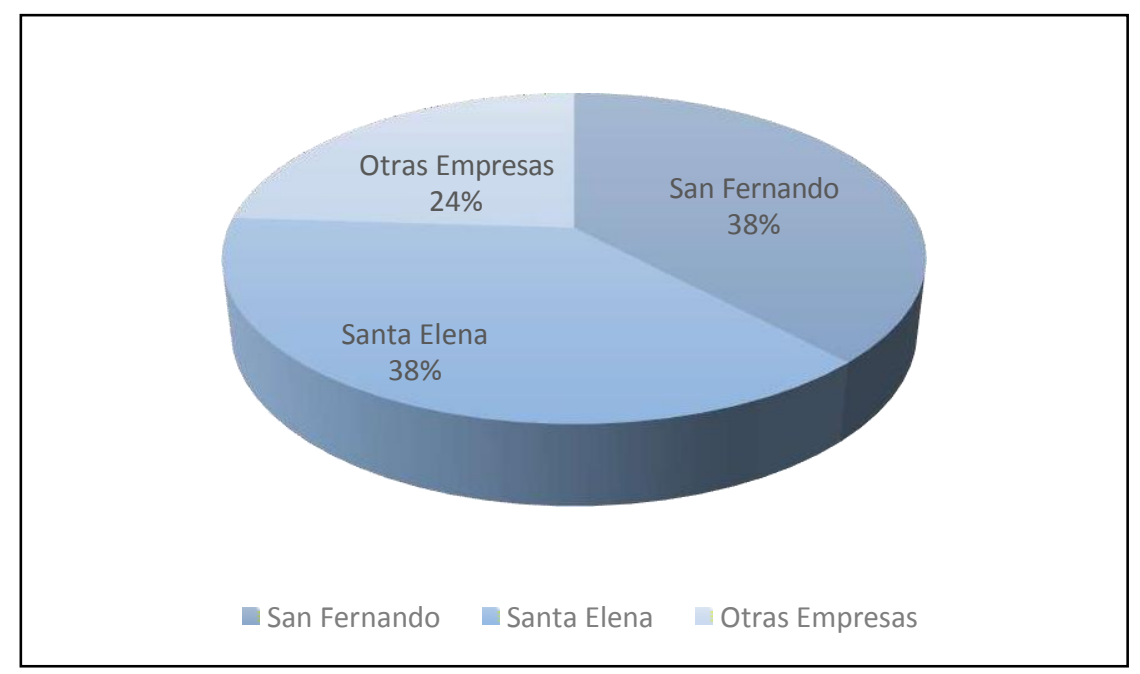

Figura 9. Cartera de clientes de Los Ferroles 2016. Tomado de "Entrevista al Gerente Administración y Finanzas,” por la empresa Los Ferroles, 2016. 
El total de sus actuales clientes son nacionales. Si bien, en años anteriores exportaron productos a Ecuador, actualmente están enfocados en el mercado local dado que la limitante es la materia prima, lo cual les impide pensar en retomar el mercado exterior.

La relación que mantiene con sus clientes claves es directa y personalizada, y es realizada a través del Gerente de Administración y Finanzas. La comunicación es continua, tanto en el aspecto técnico como para la atención de órdenes de compra y facturación. Estos clientes son considerados como socios estratégicos, dado que han desarrollado una relación de mediano plazo, siendo la calidad del producto uno de los principales aspectos valorados. Si bien la relación es cercana con estos clientes, no se mide cuantitativa, ni cualitativamente la satisfacción de sus necesidades y/o expectativas; tampoco se brinda servicio técnico post venta.

En el caso del cliente San Fernando, se les brinda gran apertura para el monitoreo de los procesos operativos e información relacionada. Su personal realiza frecuentes visitas a la planta de producción para evaluar el proceso y la calidad del producto terminado antes de ser despachado. Con el resto de clientes las visitas o comunicación no es tan frecuente, el factor precio es lo que prima en la negociación.

Respecto al uso de tecnología digital para la gestión interna de los procesos, cuentan con un sistema ERP (Planificación de Recursos Empresariales) que los ayuda a integrar la información financiera, contable, logística y de producción. Si bien tienen el sistema informático implementado, aún tienen algunos procesos pendientes por concluir y mejorar. 
En cuanto a marketing digital, no aplican ningún tipo, carecen de página web y presencia en redes sociales. La marca sólo se difunde y fortalece a través del contacto directo que mantiene con sus clientes, y la recomendación boca a boca que éstos puedan hacer de sus productos. (Los Ferroles, 2016).

\subsection{Ciclo de vida del producto}

Kotler (2012) establece lo siguiente: La curva del ciclo del producto se divide en cuatro etapas:

1. Introducción: Periodo de crecimiento lento de las ventas conforme el producto se lanza al mercado. No hay utilidades en esta etapa debido a los elevados gastos en que se incurre con la introducción del producto.

2. Crecimiento: Es un periodo de aceptación rápida en el mercado y de incremento en las utilidades.

3. Madurez: Periodo donde disminuye el crecimiento de las ventas, porque el producto ya ganó la aceptación de la mayoría de los compradores potenciales. El nivel de utilidades se estanca o incluso disminuye a causa de los crecientes gastos de marketing para defender el producto frente a la competencia.

4. Decadencia: Periodo en el que tanto las ventas como las utilidades disminuyen.

En el Perú, la industria del rendering se encuentra en una etapa de progreso tecnológico, teniendo como referente al mercado norteamericano, europeo y algunos países de la región como Brasil, los cuales muestran un avanzado nivel de tecnificación en el sector. 
Actualmente, la industria está concentrada en tres empresas formales, las cuales se encuentran en proceso de crecimiento dado que recién en los últimos años desarrollaron una serie de mejoras como: (a) uso de tecnología moderna, (b) profesionalización de las empresas, (c) generación de productos con alto valor agregado, (d) implementación de sistemas de calidad ISO 9001 y HACCP, (e) compromiso con el medio ambiente. El trabajo realizado en estos aspectos muestra el despegue y crecimiento que el rendering ha tenido de la mano con el crecimiento de la industria avícola.

$\mathrm{Al}$ igual que el sector del rendering, la empresa Los Ferroles se ubica en una etapa de crecimiento; el cual se encuentra soportado por la mayor demanda de harinas en el sector avícola que genera el incremento en la producción y por tanto en las ventas, convirtiéndolos en líderes del mercado para la alimentación avícola.

En las figura 10 y 11 se muestran las ventas de la empresa Los Ferroles expresadas en toneladas correspondiente a los años 2009 al 2016, de las harinas de plumas y de las harinas de vísceras. (Los Ferroles, 2016) 


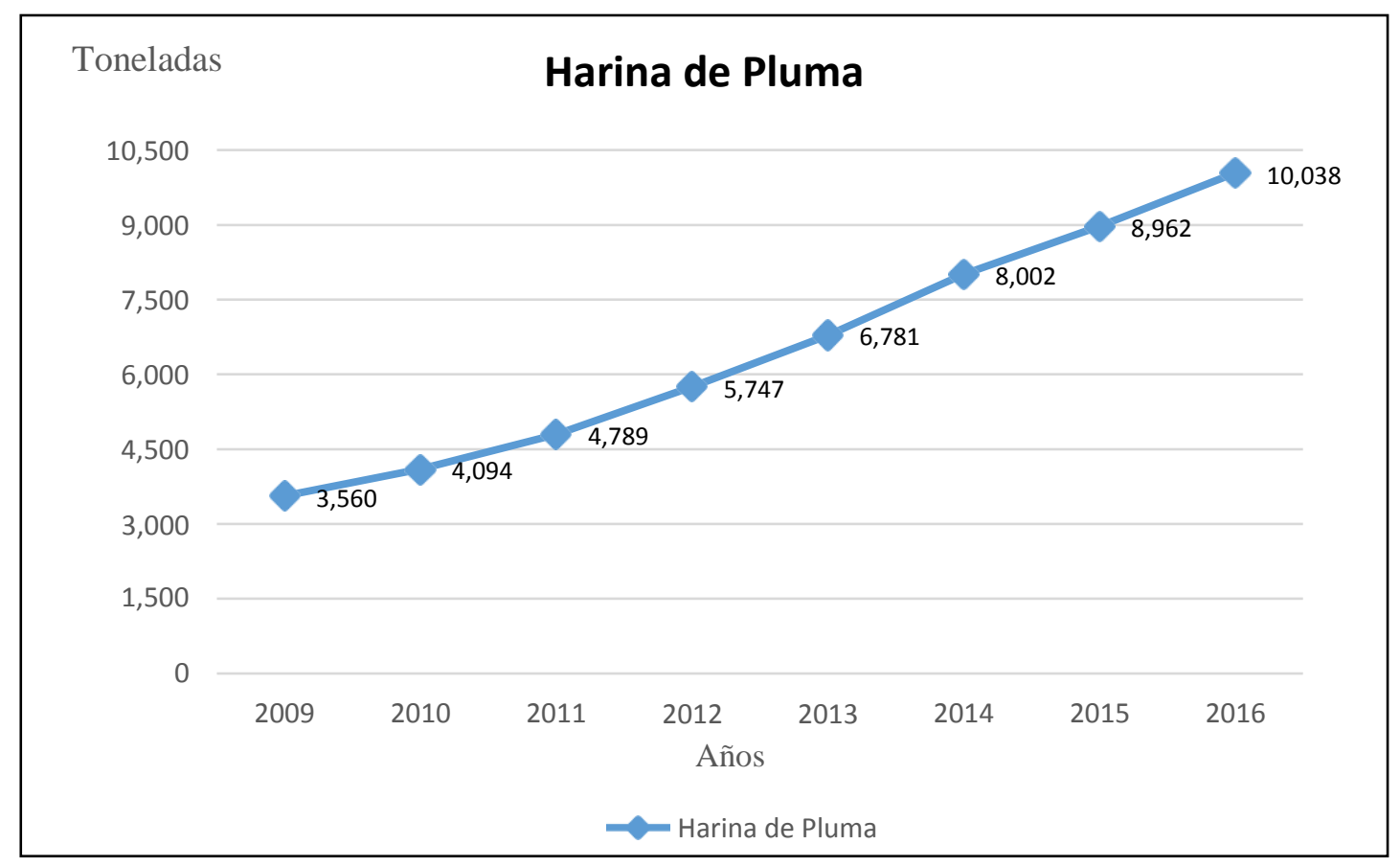

Figura 10. Ventas de harinas de plumas en toneladas. Tomado de "Información de ventas," por la empresa Los Ferroles, 2016.

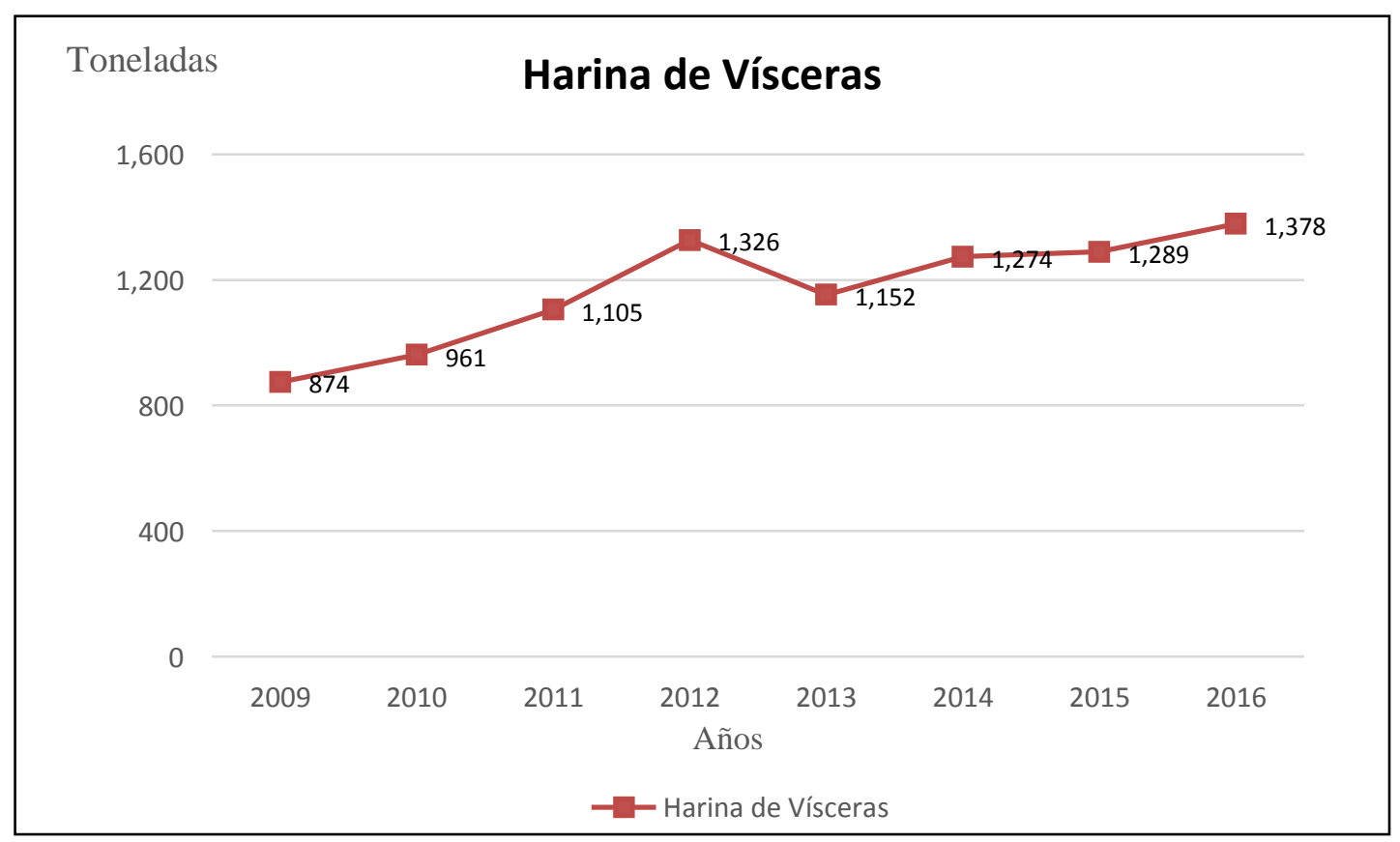

Figura 11. Ventas de harinas de vísceras en toneladas. Tomado de "Información de ventas," por la empresa Los Ferroles, 2016. 
Hoy en día, las plantas de producción trabajan a doble turno y cubren el $70 \%$ de su capacidad instalada, lo que muestra que la empresa puede maximizar aún más la productividad, y por ende optimizar los costos. La limitante más marcada que presenta la empresa para continuar creciendo es el acceso a la materia prima, dada la escasez y el elevado costo que representa su acopio y transporte. (Los Ferroles, 2016).

Las figuras 12 y 13 muestran la etapa del ciclo de vida en que se encuentran las harinas de pluma y vísceras respectivamente, relacionadas a sus volúmenes de producción históricos. Se evidencia que ambas harinas se encuentran en la etapa de crecimiento.

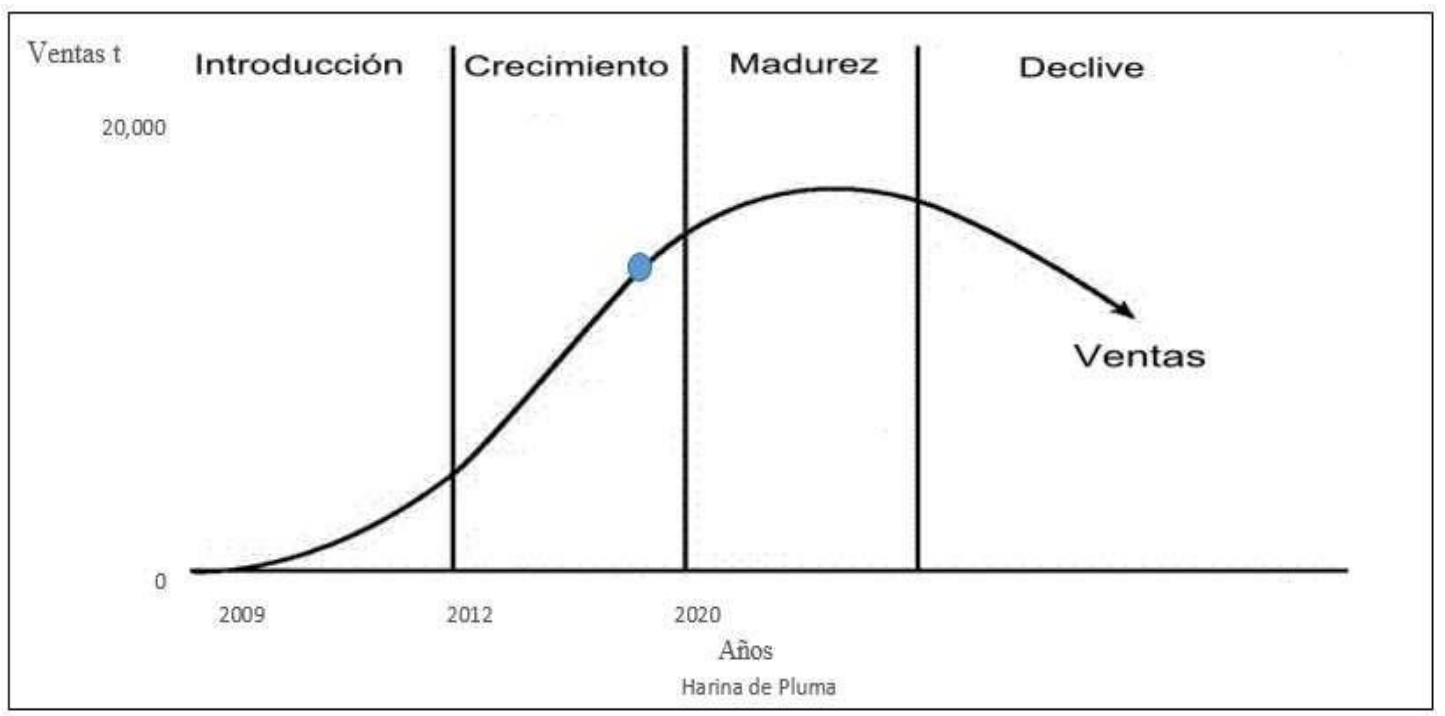

Figura 12. Ciclo de vida de la harina de plumas. Tomado de "Ciclo de vida de un producto," por David Polo, 2015. Recuperado de http://www.emprenderfacil.com/es/ciclo-de-vida-de-un-producto-y-sus-etapas/ 


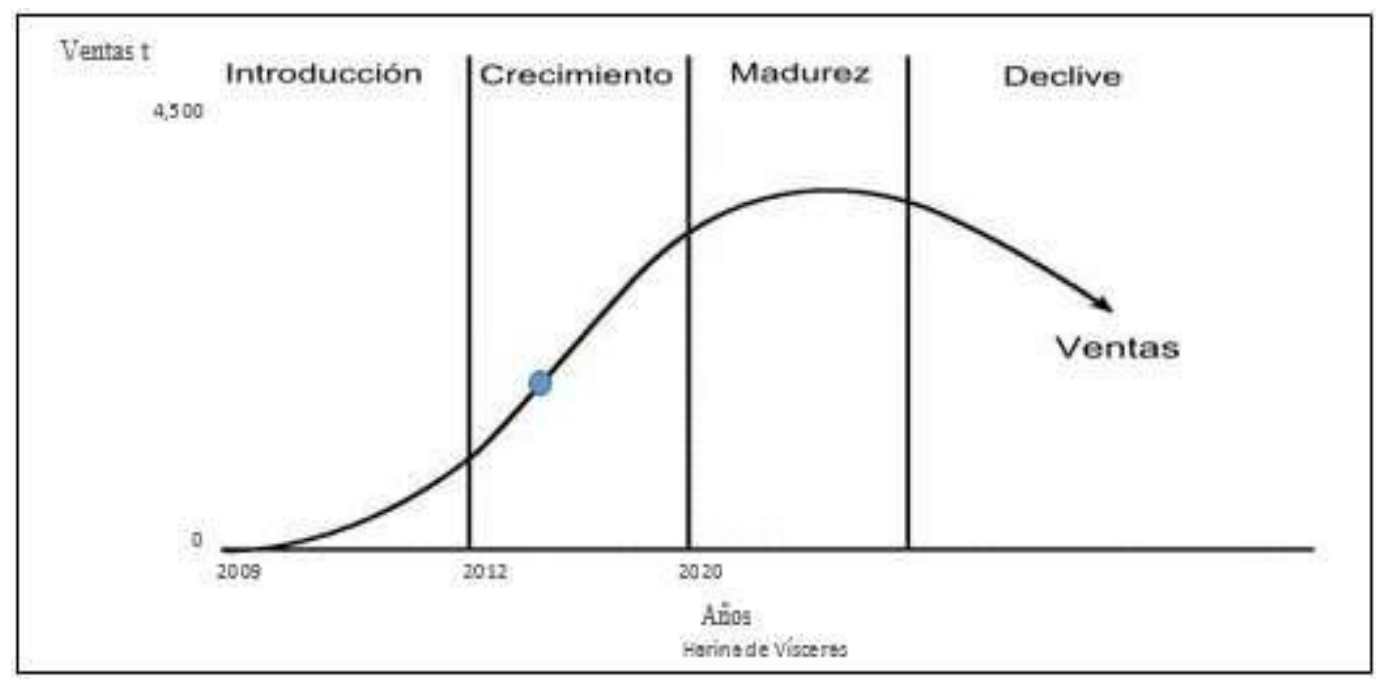

Figura 13. Ciclo de vida de la harina de víscera. Tomado de "Ciclo de vida de un producto," por David Polo, 2015. Recuperado de http://www.emprenderfacil.com/es/ciclo-de-vida-de-un-producto-y-sus-etapas/

Acorde a lo mencionado por Kotler (2012), la empresa está en la etapa de crecimiento, es decir debe decidir entre lograr una alta participación de mercado u obtener utilidades a corto plazo. Si la empresa invierte dinero en mejorar el producto, promoverlo y distribuirlo, podrá captar una posición dominante, renunciará a una parte de utilidades potenciales con la esperanza de obtener utilidades aún más altas en la siguiente etapa.

La fase de crecimiento plantea desafíos a la gerencia comercial y de marketing, dado que en los próximos años deberá incrementar y/o consolidar su posicionamiento en el mercado, así como implementar estrategias de fidelización a sus clientes, y de penetración de mercado. De esta manera, se buscará que los beneficios de la empresa sean mayores gracias a las ganancias derivadas por la venta, por volumen y por la disminución en los costos de fabricación. 
Tanto la harina de plumas como la harina de vísceras, son productos con más de 8 años en el mercado. Si bien, durante estos años han pasado por diferentes tecnologías que les ha permitido mejorar la calidad, recién el cambio de tecnología del año 2015 marcó una diferencia sustancial; asimismo, las pruebas y validaciones realizadas por diversos clientes han contribuido a mejorar el estándar de calidad que se ofrece actualmente al mercado. Siendo la tecnología una de sus principales ventajas competitivas, la empresa deberá emplearla para continuar su crecimiento, focalizando estrategias de penetración de mercado, y desarrollo de nuevos productos.

\subsection{Estructura organizacional actual de la empresa}

Los Ferroles es una empresa familiar, donde los cargos gerenciales están ocupados por los mismos dueños; es decir, el fundador Rogelio Romero ocupa la dirección general, su esposa la gerencia general y el mayor de sus hijos la gerencia de Administración y Finanzas. La estructura organizacional de la empresa es bastante horizontal, no existen más puestos gerenciales que los ocupados por los dueños, y ellos a su vez trabajan de manera directa con los mandos medios. En la Figura 14 se muestra el organigrama de la empresa Los Ferroles.

Si bien la empresa cuenta con un organigrama funcional documentado, éste se encuentra recientemente aprobado, por lo que su despliegue aún no ha sido concluido para todo el personal. Con respecto a la documentación de la estructura organizacional, no cuentan con un manual de organización y funciones, ni una descripción de perfiles de puestos ni competencias; tampoco tienen definidos objetivos laborales individuales ni de área, por lo que no se mide el logro de los resultados ni las brechas existentes. 


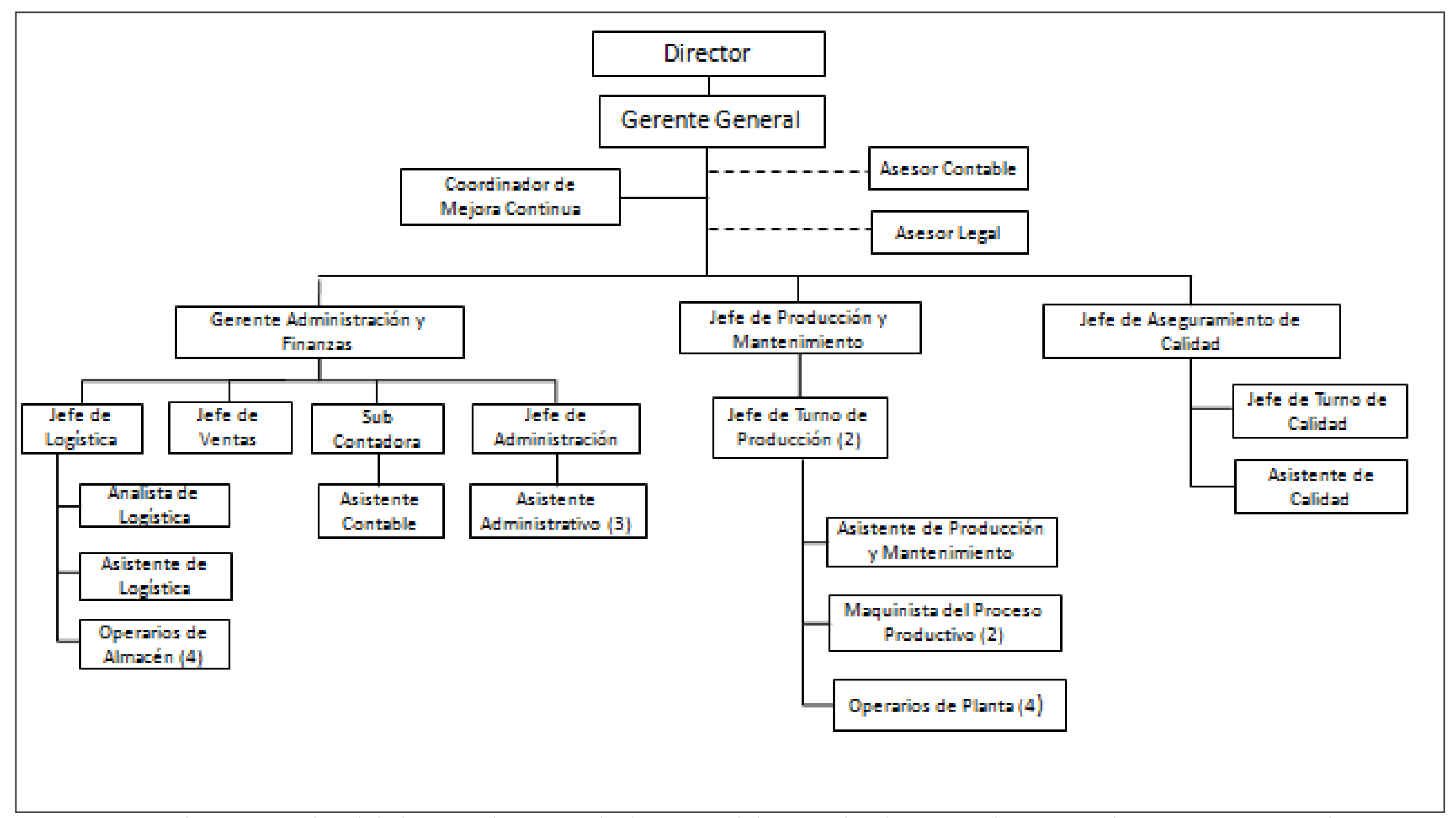

Figura 14. Organigrama Funcional de los Ferroles. Tomado de "Manual de Organización y Funciones," por la empresa Los Ferroles, 2016. 
Considerando la observación realizada a los procesos productivos y la información brindada por los puestos claves de la empresa a través de las entrevistas, podemos describir lo siguiente:

Los Ferroles tienen una estructura organizacional basada en tres actividades principales:

- La gestión de administración y finanzas; que incluye las ventas, administración, finanzas, logística y contabilidad. Esta gestión está a cargo del gerente de Administración y Finanzas (hijo del dueño), quien reporta directamente al Director.

- $\quad$ La gestión de producción y mantenimiento; que abarca todo el proceso productivo. Esta gestión está a cargo del Jefe de producción y mantenimiento, quien reporta directamente al Director. Las operaciones se desarrollan en dos plantas: la planta "Oquendo", donde procesan la harina de plumas, y la planta "Los Ferroles", donde procesan la harina de vísceras; ambas plantas ubicadas en el sector Gambeta en el Callao. El total de personal operativo entre las dos plantas asciende a 40, mientras que el personal de mantenimiento a 10. Este último no pertenece a la planilla de la empresa sino a contrataciones independientes.

- $\quad$ La gestión de aseguramiento de la calidad; que abarca los controles en la producción y análisis de los productos. Esta gestión está a cargo del jefe de aseguramiento de la calidad; quien reporta directamente al gerente general. Este puesto informa de manera directa las incidencias relacionadas a la calidad del producto, y la necesidad de toma de acciones por parte del área de producción. 
Seguidamente, se describen los puestos con sus principales funciones:

1. Director: Es el cargo de mayor nivel jerárquico de la empresa, es el responsable de la toma de decisiones en los temas comerciales y financieros, tiene la responsabilidad de desarrollar y poner en marcha las estrategias operacionales y organizacionales, asimismo es responsable de lograr el crecimiento sostenible y rentable de la empresa.

2. Gerente General: El cargo es ocupado por la esposa de Rogelio Romero. Actualmente no ejerce funciones de gestión dentro de la organización, el rol está limitado a la representación legal.

3. Gerente de Administración y Finanzas: responsable de planear y dirigir las actividades administrativas, logísticas, contables y financieras con el fin de asegurar la rentabilidad de las operaciones para el cumplimiento de las obligaciones de la empresa. Asimismo, es responsable de mantener las relaciones comerciales con los clientes.

4. Coordinador de mejora continua: el puesto ha sido creado recientemente dado que la empresa se encuentra en proceso de implementación del Sistema de Gestión de Calidad ISO 9001, y del Sistema de Seguridad y Salud en el Trabajo. Su principal función es liderar la implementación de los sistemas de gestión, así como mantener vigentes en el tiempo estos sistemas.

5. Jefe de Producción y Mantenimiento: responsable de la elaboración del Plan de Producción considerando los recursos requeridos y los requerimientos del área de 
ventas. Asimismo, es responsable de la ejecución del plan asegurando su cumplimiento en calidad, oportunidad y cantidad; también es responsable de la gestión del personal a su cargo.

6. Jefe de Logística: responsable de las coordinaciones directas con los proveedores para las adquisiciones diversas. Dentro de sus principales funciones está la gestión de compras, atendiendo requerimientos tanto de las áreas administrativas como de la planta de producción, así como el monitoreo y control de los inventarios del almacén. Está fuera de su alcance las negociaciones con los proveedores de materias primas, los cuales son atendidos directamente por los dueños.

7. Jefe de Ventas: responsable del seguimiento y control de las ventas de la empresa; sus principales funciones son la verificación de la correcta facturación de los productos vendidos, así como hacer seguimiento a la cobranza de los mismos, principalmente la venta al crédito. Es el nexo entre los clientes y la empresa, atiende y busca soluciones a las necesidades que se presenten.

8. Jefe de Administración: responsable de elaborar y controlar el presupuesto semanal para la dirección, realiza las operaciones bancarias; también tiene el control y gestión de los documentos administrativos y contables de la empresa. Es uno de los puestos de confianza de los dueños, brindándoles asistencia en temas diversos. 
9. Sub-Contadora: responsable de registrar las operaciones contables de la empresa en el sistema Horizont para la elaboración de los estados financieros, realiza la presentación mensual de los impuestos ante la SUNAT, adicionalmente tiene a su cargo la gestión de recursos humanos en cuanto al pago de planillas y otros pagos.

10. Jefe de Turno de Producción: responsable de supervisar el cumplimiento del programa de producción diario con la finalidad de optimizar los resultados en cantidad, calidad y costo. Toma acciones inmediatas y reporta al jefe de producción cualquier desviación en el proceso productivo.

11. Jefe de Aseguramiento de Calidad: responsable de la coordinación de los análisis de laboratorio externos, y de verificar el cumplimiento de los estándares de la producción; comunicando oportunamente a la alta gerencia cualquier desvío en los procesos. Participa en las reuniones técnicas con clientes para toma de acciones de mejora.

12. Jefe de Turno de Calidad: responsable de verificar que las especificaciones técnicas del proceso y del producto se cumplan de acuerdo a los estándares establecidos. Toma acciones inmediatas y reporta al jefe de aseguramiento de la calidad cualquier desviación en el proceso productivo.

Se detallan brevemente los puestos de asistencia y apoyo: 
13. Asistente de logística: responsable de la coordinación del transporte, tanto de abastecimiento de materia prima como de despacho del producto terminado.

14. Asistente de producción y mantenimiento: responsable de dar seguimiento diario a los programas de producción y de mantenimiento, verificando la conformidad con lo planeado.

15. Analista de logística: responsable de la administración de información logística en la plataforma tecnológica (ERP Horizont).

16. Asistente de Calidad: responsable de ejecutar controles de calidad al proceso y al producto terminado.

17. Asistente Administrativo: responsable del apoyo documentario en la gestión administrativa.

18. Asistente Contable: responsable de elaborar el registro de compras y ventas, así como apoyar en el proceso contable.

19. Maquinista del proceso: responsables del control de la maquinaria, y su mantenimiento básico.

20. Operario de planta: responsable de la realización de actividades operativas dentro de planta, de apoyo a la producción.

21. Operario de almacén: responsable de la realización de actividades operativas dentro del almacén, de apoyo a la recepción y despacho de productos.

Producto de las entrevistas con los jefes de área, se evidenciaron algunas características y formas de trabajo propias de la organización, así como gestiones que deberían ser replanteadas para mejorar la eficiencia y eficacia de los procesos, los cuales se describen a continuación. 
Al ser Los Ferroles una empresa familiar, la toma de decisiones está concentrada en el Director y dueño Rogelio Romero. Ello implica que las jefaturas deban solicitar las aprobaciones directamente al Director, sobre todo para aquellos aspectos que involucran flujo de dinero; sin embargo, esta forma de control no es una traba burocrática para las gestiones, dado que existe una buena y ágil comunicación con él. Por otro lado, podemos señalar que la falta de empoderamiento hacia las jefaturas se debe a que no cuentan con las competencias necesarias para que puedan realizar una gestión más autónoma, y en algunos casos son personal que han crecido con la organización, pero necesitan desarrollar sus competencias.

Con respecto a la gestión de compras, se pudo identificar que las áreas de producción y administración no trabajan con un programa de necesidades establecido para un periodo de tiempo (mensual o anual), por lo que los requerimientos no pueden ser planificados ni evaluados con anticipación. Esto conlleva a realizar compras sin las debidas cotizaciones ni comparaciones de las mejores opciones; tampoco permite negociar con los proveedores programas de compras a varios meses, obteniendo mejores precios. Las compras se gestionan como urgencias, que deben ser atendidas por la presión de no parar el proceso productivo, generando desorden y sobre costos; por ello, es importante que implementen políticas y procesos eficientes, así como mejorar la comunicación y coordinación entre las áreas.

La gestión comercial se encuentra muy poco desarrollada y se limita a los contactos comerciales que los dueños puedan realizar; no trabajan ningún aspecto del marketing, lo cual se evidencia en su falta de presencia en medios digitales y falta de planes promocionales. 
No se gestiona el recurso humano como un proceso integral, no se cuenta con un área estructuralmente organizada ni responsable que maneje estos procesos. El puesto de sub contadora es quien realiza de una manera muy básica las funciones de administración de personal puesto que realiza el pago de la planilla, y es un medio de comunicación adicional entre los trabajadores y sus jefes directos. La falta de gestión del recurso humano se refleja en la falta de organización interna y la carencia de indicadores de gestión que permitan evaluar el desempeño de los procesos.

La empresa Los Ferroles está realizando los esfuerzos por ordenarse internamente, muestra de ello es la incorporación en su organigrama del puesto de Coordinador de mejora continua y el trabajo en la implementación de la norma de Gestión de Calidad ISO 9001 para el proceso de producción de harinas proteicas. Trabajar en base a procesos estandarizados es una buena práctica para toda empresa, pues permite incrementar la satisfacción del cliente al asegurar la calidad de los productos. En el caso de Los Ferroles, lo más conveniente es realizar un proceso de reorganización interna integral, previa a la estandarización.

En cuanto a la gestión de la producción, se evidencias oportunidades de mejora respecto al mantenimiento preventivo para asegurar la continuidad de los procesos y evitar paradas de planta y tiempos muertos en la producción. Asimismo, no existe un adecuado manejo de herramientas estadísticas que permitan el análisis de la data de producción para la toma de decisiones.

Finalmente, el aspecto financiero es gestionado por el director y dueño de la empresa quien posee mucha experiencia en el sector. Sin embargo, dado el actual tamaño 
de la empresa y la competitividad del mercado, es recomendable que se adicionen indicadores de gestión que permitan monitorear los resultados de los procesos para asegurar la rentabilidad deseada.

\subsection{Situación de Mercado y Financiera actual de la Industria}

En los últimos años, el rendering en el Perú ha venido potenciando su desarrollo, el cual se ha visto favorecido gracias al crecimiento de la industria avícola y el aumento de consumo de harinas de rendering. Hoy en día, se reconoce a las harinas de rendering como una de las principales fuentes proteicas para la alimentación animal, y su consumo se ha difundido mucho a nivel nacional. La industria del rendering se relaciona de manera muy directa con la industria avícola, dado que se convierte en un eslabón más de la cadena productiva del pollo al procesar los subproductos y transformarlos en parte de su alimentación.

El sector rendering está conformado por empresas medianas y formales, y por pequeños informales que trabajan a nivel muy artesanal y sin ningún tipo de regulación; se dirigen principalmente a criadores informales. Dentro de las empresas formales, son tres las que captan casi la totalidad del mercado: Alimencorp SAC, Technofeed SAC, y Negocios Agroindustriales Los Ferroles SAC.

A continuación una breve descripción de cada una de ellas:

1. Alimencorp SAC es la empresa pionera en el Perú en la fabricación de harinas proteicas elaboradas en base a subproductos de origen animal para la crianza intensiva. Sus inicios datan del año 2000, año en el cual deciden incorporar al mercado harinas proteicas altamente digestibles. Los principales beneficios de la 
propuesta que ofrece al mercado, son: (a) mejora de los índices de producción en campo, (b) optimización del período de crecimiento, (c) mejora de la conversión alimenticia, (d) incremento de los índices de fertilidad y (e) mayor retribución económica. (Alimencorp, 2015).

2. Technofeed SAC tiene presencia en el mercado desde el año 2006; se dedica a la nutrición animal a través de la elaboración de alimentos balanceados para actividades pecuarias como: ganadería, acuicultura, avicultura, mascotas, entre otros; siendo sus principales líneas de productos: la harina de carne, harina de pollo Premium, harina de plumas con enzimas, harina de plumas estándar y aceite de pollo. La empresa cuenta con el Sistema de Gestión de Calidad ISO 9001, certificado por SGS del Perú; asimismo declaran su compromiso con el medio ambiente y la seguridad y salud en el trabajo de sus colaboradores. (Technofeed, 2013).

3. Negocios Agroindustriales Los Ferroles, inicia sus operaciones en el año 2004. Hoy en día la empresa se encuentra especializada en la fabricación de harinas proteicas exclusivamente para la industria avícola y abarca aproximadamente el $65 \%$ de este mercado; cuentan con tecnología avanzada que permite optimizar sus procesos asegurando la calidad del producto terminado; asimismo, gracias a esta tecnología, logra reducir los impactos negativos al medio ambiente. Las líneas de producción que ofrecen al mercado son: harina de plumas y harina de vísceras.

Si bien el mercado total del rendering está repartido entre estas tres empresas, donde cada una de ellas ha orientado sus productos a un sector pecuario en particular: 
- $\quad$ Alimencorp SAC y Technofeed SAC se orientan principalmente al sector pecuario y de alimento para mascotas, han diversificado sus productos para atender las necesidades de estos sectores y son quienes los lideran actualmente. El sector avícola lo atienden pero la participación no es alta.

- $\quad$ Los Ferroles S.A.C se ha especializado y se concentra íntegramente en el sector avícola, teniendo una participación de mercado en este sector de $62 \%$, las otras dos empresas competidoras comparten el $38 \%$ restante.

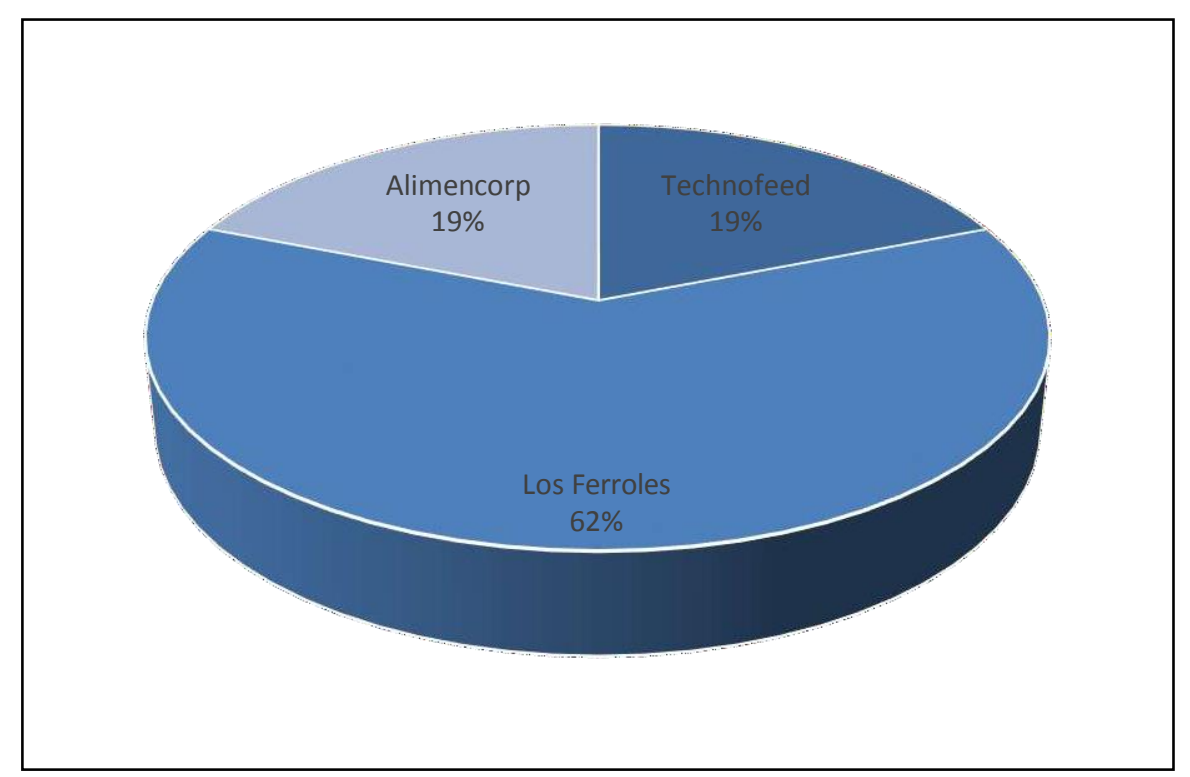

Figura 15. Participación de mercado de la industria del rendering del sector avícola. Tomado de "Entrevista al Gerente de Administración y Finanzas," Los Ferroles, 2016.

En la entrevista realizada al asesor y experto del sector (ver Anexo $\mathrm{N}^{\circ}$ 6), mencionó que si bien uno de los principales clientes demandantes de harinas proteicas de origen animal es el sector avícola, el nicho de mercado más rentable es el alimento para 
mascotas; dada la disposición del precio de parte del comprador final. Aun el Perú no tiene este sector muy desarrollado, por lo que los volúmenes de consumo no son muy altos, pero otros países como México y Colombia son mercados atractivos.

El crecimiento del rendering avícola está determinado por el crecimiento de este sector, dado que depende de la generación de sus subproductos para la producción. Si bien la producción y consumo de pollo ha mostrado un incremento sostenido en los últimos años, el desafío del rendering está en buscar otras fuentes de materias primas que les permita crecer a mayor velocidad y maximizar la producción.

Para que el sector del rendering avícola continúe desarrollando y creciendo a nivel nacional e internacional, es necesario que se diseñen estrategias para superar una serie de limitantes que hoy en día lo restringen. Entre las principales limitantes del sector podemos mencionar:

1. Dependencia del sector avícola y acceso a la materia prima: para la obtención de la materia prima intervienen dos socios estratégicos claves, los centros de beneficio (de las empresas líderes del sector) y los centros acopiadores y peladeros (grandes distribuidores y mayoristas). San Fernando S.A. es de los pocos centros de beneficio que entrega al sector rendering sus subproductos para el procesamiento, la mayoría de empresas avícolas procesa internamente sus harinas para consumo propio. Esto conlleva a que los principales proveedores de materia prima para rendering sean los centros de acopio y peladeros, por lo que en la medida que se establezcan negociaciones con ellos, se podrá tener acceso, caso contrario será muy limitada. 
2. Logística de acopio de la materia prima: Los centros de acopio y peladeros no procesan grandes cantidades de aves porque sus procesos son principalmente manuales y algunos artesanales, son muy pocos los que emplean maquinaria. Al estar atomizados y dispersos a nivel de Lima y Callao, el costo de la logística de acopio y transporte se encarece y se hace compleja, lo cual es determinante en la rentabilidad del producto final. En la figura 16 se muestra la venta de aves en los diversos centros de acopio de Lima Metropolitana.

\begin{tabular}{|c|c|c|c|c|c|c|c|c|c|c|c|c|}
\hline \multirow{3}{*}{$\begin{array}{l}\text { Meses } \\
\text { Ene-Dic }\end{array}$} & \multicolumn{4}{|c|}{ Total } & \multicolumn{3}{|c|}{ Pollo } & \multicolumn{5}{|c|}{ Pavg } \\
\hline & \multicolumn{2}{|c|}{$2015 \mathrm{r}$} & $2016 p$ & Var 8 & $2015 r$ & $2016 p$ & \multicolumn{2}{|c|}{ Var $8 \%$} & $2015 r$ & $2016 p$ & \multicolumn{2}{|c|}{ Var 8} \\
\hline & 260,2 & 256,5 & $-1,4$ & 2,73 & 2,72 & $.0,4$ & 4,0 & 4,6 & 13,7 & 1,91 & 1,93 & 1,1 \\
\hline Ene & 20,9 & 21,7 & 40 & 2,67 & 2,62 & $-1,9$ & 0,3 & 0,3 & 0,0 & 1,93 & 1,94 & 0,5 \\
\hline feb & 19,9 & 21,7 & 9,2 & 2,67 & 2,54 & 4,9 & 0,3 & 0,4 & 24,3 & 1,91 & 1,91 & 0,0 \\
\hline Mar & 21,7 & 21,8 & 0,8 & 2,72 & 2,44 & $-10,3$ & 0,3 & 0,4 & 23,0 & 1,91 & 1,91 & 0,0 \\
\hline Abr & 20,0 & 21,3 & 6,4 & 2,70 & 2,60 & $-3,7$ & 0,3 & 0,4 & 30,3 & 1,90 & 1,94 & 2,1 \\
\hline May & 22,0 & 21,9 & $-0,4$ & 2,67 & 2,69 & 0,7 & 0,3 & 0,4 & 22,6 & 1,91 & 1,92 & 0,5 \\
\hline Jun & 21,2 & 20,4 & $-3,6$ & 2,72 & 2,87 & 5,5 & 0,3 & 0,4 & 26,6 & 1,92 & 1,93 & 0,5 \\
\hline Jul & 22,0 & 21,9 & $-0,4$ & 2,82 & 2,95 & 4,6 & 0,3 & 0,4 & 22,4 & 1,90 & 1,93 & 1,6 \\
\hline Ago & 23,0 & 21,9 & 4,9 & 2,79 & 2,89 & 3,6 & 0,4 & 0,4 & 0,7 & 1,92 & 1,92 & 0,0 \\
\hline Set & 21,1 & 21,1 & $-0,2$ & 2,75 & 2,87 & 4,4 & 0,4 & 0,4 & 10,9 & 1,90 & 1,93 & 1,6 \\
\hline Oct & $n 2,6$ & 21,4 & $-5,0$ & 2,76 & 2,68 & $-2,9$ & 0,3 & 0,4 & 9,5 & 1,88 & 1,96 & 4,3 \\
\hline Nov & 22,2 & 20,1 & $-9,4$ & 2,73 & 2,67 & $-2,2$ & 0,4 & 0,4 & 8,2 & 1,92 & 1,94 & 1,0 \\
\hline Oic & 23,8 & 21,3 & $\cdot 10,5$ & 2,76 & 2,81 & 1,81 & 0,4 & 0,4 & $\cdot 3,6$ & 1,94 & 1,93 & $-0,5$ \\
\hline
\end{tabular}

Figura 16. Lima Metropolitana: Venta de aves vivas en Centros Acopio por mes, según tipo de ave. Enero 2015 - diciembre 2016. Tomado de "Boletín estadístico mensual de la producción y comercialización avícola," por el Ministerio de Agricultura y Riego (MINAGRI), 2016. Recuperado de file:///C:/Users/c4500/Downloads/sector-avicoladiciembre2016.pdf 


\section{Capítulo III. Formulación de Visión, Misión y Valores de la Empresa}

En el presente capítulo se aplicarán las herramientas necesarias para formular, evaluar y desarrollar las declaraciones de visión, misión y valores de la empresa en estudio, siguiendo el modelo de Proceso Estratégico de Fred. R. David.

Este modelo especifica la interacción de los componentes de la organización respecto a sí misma, a través de las tres fases que lo componen: formulación, implantación y evaluación de la estrategia, establece una interacción entre los distintos niveles jerárquicos y reconoce que en la planeación deben intervenir todos: gerentes y empleados. La etapa inicial para David es el desarrollo de las declaraciones de la visión y misión teniendo claro hacia dónde se dirige la empresa. (Patricia Larios, 2016)

En el año 2007, Los Ferroles inició una etapa de fortalecimiento comercial a través de la captación de clientes líderes de la industria avícola. Alineado a este crecimiento, la empresa vio la necesidad de profesionalizarse y tecnificarse, en tal sentido decidió establecer las declaraciones de misión y visión con el objetivo de marcar el rumbo a seguir para los próximos años. Actualmente estas declaraciones se mantienen, sin embargo dada la coyuntura actual interna y externa, es necesaria la revisión y actualización.

En cuanto a sus valores, aún no se encuentran definidos de manera expresa ni formal. Si bien la cultura organizacional de Los Ferroles muestra ciertas características como compromiso, responsabilidad e identificación con la empresa, no están enmarcadas en un contexto organizacional que genere identidad corporativa hacia sus grupos de interés. 
Para el análisis y elaboración de la Visión, Misión y Valores hemos utilizado principalmente el esquema teórico del autor Fred R. David, y los criterios de evaluación del autor Fernando A. D’Alessio.

\subsection{Visión}

“La visión de una organización es la definición deseada de su futuro, que responde a la pregunta: ¿Qué queremos llegar a ser?; es decir, es un enfoque a largo plazo en donde se comunica los objetivos que la organización ha planificado alcanzar, y para el cual se orientan las estrategias". (D'Alessio, 2015, p.59).

Una visión bien definida se compone de dos partes: una ideología central y una visión de futuro; asimismo debe cumplir con características específicas.

1. La ideología central: define el carácter duradero de una organización; es la fuente que sirve de guía e inspiración, perdura y motiva a no cesar en el cambio ni progreso, y complementa la visión de futuro. Está conformada por un propósito central y valores centrales que constituyen las bases fundamentales y duraderas de la organización, cuya determinación es independiente del entorno actual y de los requerimientos competitivos o tendencias de gestión.

2. La visión de futuro: no se crea, sino que se descubre mirando al interior de la organización con sus posibilidades, por lo tanto, debe ser redactada en tiempo futuro.

3. Características de la visión: (a) Simple, clara y comprensible, (b) Ambiciosa, convincente y realista (c) Definida en un horizonte de tiempo que permita los 
cambios, (d) Proyectada a un alcance geográfico, (e) Conocida por todos, (f) Expresada de tal manera que permita crear un sentido de urgencia y (g) Una idea clara desarrollada sobre a donde desea ir la organización. (D’Alessio, 2015, p.61)

\subsubsection{Visión actual de la empresa.}

“Consolidarse como una empresa ecoeficiente en el rubro agroindustrial y proyectarse en un mercado globalizado, empleando tecnología de última generación”. (Los Ferroles, 2007)

\subsubsection{Análisis de la visión actual.}

Tomando como referencia los criterios anteriormente mencionados por el autor D’Alessio, se ha analizado la visión actual, indicando lo siguiente:

1. Sobre la ideología central: la empresa remarca que desea consolidarse como ecoeficiente, es decir desea usar eficientemente los recursos para la producción de bienes y servicios generando el menor impacto ambiental; si bien el objetivo del rendering es brindar soluciones para el manejo de residuos sólidos no se encuentra enfocado el propósito del término ecoeficiente.

2. Sobre el término "rubro agroindustrial" el alcance es bastante amplio pues abarca los sectores agropecuarios, pesca y forestal, no se enfoca directamente en el sector donde se desarrolla el negocio, que es el sector del rendering.

3. Sobre la visión de futuro: la empresa manifiesta que desea proyectarse a un mercado globalizado, pero no señala el alcance geográfico, ni horizonte de tiempo en que se logrará. De acuerdo a las entrevistas realizadas, el Director de la empresa indicó que tiene como objetivo la consolidación en el mercado 
nacional, mas no en el internacional, lo cual evidencia que esta visión futura quedó desfasada en la actualidad. Sobre el término “empleando tecnología de última generación" se considera que en la etapa inicial de la empresa, este concepto era válido, puesto que contar con esta tecnología era un reto a futuro importante. Hoy en día, la empresa ya ha alcanzado un desarrollo tecnológico notable, por lo que ha dejado de ser un objetivo de largo plazo, siendo más bien una meta alcanzada.

4. Sobre las siete características de la visión: se han establecido ponderaciones y calificaciones para evaluar el nivel de cumplimiento de las características citadas por el autor. Del análisis realizado se concluye que la visión actual muestra un nivel de cumplimiento de 1.3 sobre un rango de 1 a 4 ; lo que da como resultado $43 \%$. Las características que muestran la calificación más baja son: (a) horizonte de tiempo, (b) alcance geográfico y (c) el sentido de urgencia; mientras que la que muestra la calificación más alta es: simple, clara y comprensible. Los resultados se detallan en la siguiente tabla. 
Tabla 2

Criterios para la evaluación de la visión actual

\begin{tabular}{|c|c|c|c|}
\hline Características & Ponderación & Calificación & $\begin{array}{l}\text { Calificación } \\
\text { Ponderada }\end{array}$ \\
\hline Simple, clara y comprensible & 0.2 & 2 & 0.4 \\
\hline Ambiciosa, convincente y realista & 0.1 & 2 & 0.2 \\
\hline $\begin{array}{l}\text { Definida en un horizonte de tiempo que } \\
\text { permita los cambios }\end{array}$ & 0.1 & 1 & 0.1 \\
\hline Proyectada en un alcance geográfico & 0.1 & 1 & 0.1 \\
\hline Conocida por todos & 0.2 & 1 & 0.2 \\
\hline $\begin{array}{l}\text { Expresada de tal manera que permita } \\
\text { crear un sentido de urgencia }\end{array}$ & 0.1 & 1 & 0.1 \\
\hline $\begin{array}{l}\text { Una idea clara desarrollada sobre a } \\
\text { donde desea ir la organización }\end{array}$ & 0.2 & 1 & 0.2 \\
\hline TOTAL & 1 & & 1.3 \\
\hline
\end{tabular}

Nota. Adaptado de Planeamiento Estratégico Razonado, Aspectos Conceptuales y Aplicados (p. 24), por F. D’Alessio 2015, Lima, Perú: Copyright 2015 por Pearson Education.

Asimismo el autor David (2013), hace mención al aspecto motivacional que debe contener la declaración de la visión. En este sentido, vemos que la visión genera cierto grado de motivación a sus grupos de interés, dado que menciona que desea consolidarse como una empresa ecoeficiente, proyectarse a un mercado globalizado y emplear tecnología de última generación. 


\subsubsection{Matriz de la visión propuesta para la empresa.}

Tabla 3

Descripción de criterios para la evaluación de la visión propuesta

\begin{tabular}{ll}
\hline Características & \\
\hline Simple, clara y comprensible & Concreta pero con mucho significado. Que sea \\
& entendida por todos los grupos de interés. \\
Ambiciosa, convincente y realista & Que impulsa a seguir adelante en el logro de objetivos. \\
& Que cuenta con argumentos que la respaldan. Que se \\
& pueda visualizar y describir como existente, y sea \\
Definida en un horizonte de tiempo & Con plazos determinados que consideren los cambios \\
que permita los cambios & requeridos. \\
Proyectada en un alcance geográfico & Considerar el alcance geográfico de la empresa \\
Conocida por todos & Que sea replicable y difundida a todos los niveles \\
Expresada de tal manera que permita & Que llame a la toma de acción \\
crear un sentido de urgencia & \\
Una idea clara desarrollada sobre a & Que marque el rumbo \\
donde desea ir la organización &
\end{tabular}

Nota. Adaptado de El Proceso Estratégico (p. 24), por F. D’Alessio 2015, Lima, Perú:

Copyright 2015 por Pearson Education.

\subsubsection{Visión propuesta.}

"Ser reconocidos como líderes en la industria del rendering nacional, ofreciendo insumos proteicos de alta calidad que garanticen el máximo desarrollo cárnico del animal, a través de procesos ecoeficientes, y contando con un equipo humano competente y comprometido." 


\subsection{Misión}

David (2013) define la misión de la siguiente manera:

La declaración de la misión es la expresión perdurable del propósito que distingue a una organización de otras empresas similares; es la declaración de la razón de ser de una organización y la respuesta a la pregunta ¿Cuál es nuestro negocio? Una declaración de misión es esencial para establecer los objetivos y formular estrategias de manera efectiva. (p. 45).

Asimismo, D’Alessio (2015) indica lo siguiente:

La misión estratégica debe especificar los mercados y productos con que la organización desea servirlos, apalancando sus recursos, capacidades y competencias; asimismo, debe contar con áreas de interés, servir de límite entre lo que se debe y no se debe hacer y servir de guía en las decisiones de la gerencia y función administrativa.

Una buena declaración de misión debe poseer las siguientes características:

Amplia en alcance para permitir la creatividad de sus gerentes.

Clara en definir qué es la organización y a qué aspira ser.

Generadora de la impresión que la organización goza de éxito, tiene rumbo, y es merecedora de apoyo e inversión.

Debe ser capaz de excluir iniciativas riesgosas, pero a la vez flexible para permitir un trabajo creativo.

Contundente para distinguir a la organización del resto.

Un marco para evaluar actividades actuales y futuras.

Enunciada en términos suficientemente claros para que pueda ser atendida ampliamente en toda la organización. 
Proveedora de criterios para ayudar a la selección de estrategias.

Reconciliadora de los grupos de interés

Genere emociones y pensamientos positivos.

Motivadora

Relacionada con la gestión operativa de la organización.

Dinámica en orientación.

Transmisora de la responsabilidad social de la organización (p. 63)

\subsubsection{Misión actual de la empresa.}

"Brindar servicios y productos con alto contenido proteínico al sector agropecuario, con filosofía de calidad total.” (Los Ferroles, 2007)

\subsubsection{Análisis de la misión actual.}

Si bien la misión de la empresa posee algunos de los elementos y características indicados por D’Alessio (2015) y David (2013) como por ejemplo, el claro entendimiento de la razón de ser de la empresa y descripción del negocio; no llega a completar todos los aspectos necesarios para definirla como una misión integral. La misión es bastante corta, y no considera elementos importantes como: objetivos y auto concepto de organización, preocupación por imagen pública ni preocupación por los empleados.

En la tabla 4 se han establecido ponderaciones y calificaciones para evaluar el nivel de cumplimiento de las características indicadas por D'alessio. 
Del análisis realizado se concluye que la misión actual muestra un nivel de cumplimiento de 1.76 sobre un rango de 3 (1 a 4); lo que da como resultado 59\%. Los aspectos que muestran la calificación más baja son: (a) mercados, (b) tecnologías, (c) objetivos y auto concepto de organización, (d) preocupación por la imagen de la empresa y (e) preocupación por los empleados; y la calificación más alta es: filosofía de la organización. Los resultados se detallan a continuación: 
Tabla 4

Criterios para la evaluación de la misión actual

\begin{tabular}{|c|c|c|c|}
\hline Características & Ponderación & Calificación & $\begin{array}{l}\text { Calificación } \\
\text { Ponderada }\end{array}$ \\
\hline Clientes - consumidores & 0.14 & 3 & 0.42 \\
\hline Producto o servicio & 0.12 & 2 & 0.24 \\
\hline Mercados & 0.10 & 1 & 0.1 \\
\hline Tecnologías & 0.08 & 1 & 0.08 \\
\hline $\begin{array}{l}\text { Objetivos de la organización: } \\
\text { Supervivencia, crecimiento y rentabilidad. }\end{array}$ & 0.12 & 1 & 0.12 \\
\hline Filosofía de la organización & 0.12 & 4 & 0.48 \\
\hline Auto concepto de la organización & 0.10 & 1 & 0.1 \\
\hline Preocupación por la imagen pública & 0.10 & 1 & 0.1 \\
\hline Preocupación por los empleados & 0.12 & 1 & 0.12 \\
\hline Total & & & 1.76 \\
\hline
\end{tabular}

Nota. Adaptado de El Proceso Estratégico, Un Enfoque de Gerencia (p. 63), por F.

D’Alessio 2015, Lima, Perú: Copyright 2015 por Pearson Education de Perú S.A.

\subsubsection{Elementos de la misión propuesta para la empresa.}

A continuación se describen los componentes de la misión según D’alessio, y su desarrollo al analizarlos al interior de Los Ferroles. 
Tabla 5

Componentes para la elaboración de la Misión

\begin{tabular}{|c|c|c|}
\hline Criterios & Pregunta Clave & Los Ferroles \\
\hline Cliente & $\begin{array}{l}\text { ¿Quiénes son los clientes de la } \\
\text { empresa? }\end{array}$ & $\begin{array}{l}\text { El sector avícola, quienes } \\
\text { fabrican alimentos balanceados. } \\
\text { Los principales son: San } \\
\text { Fernando y Santa Elena. }\end{array}$ \\
\hline Producto o servicio & $\begin{array}{l}\text { ¿Cuáles son los principales } \\
\text { productos o servicios que ofrece la } \\
\text { empresa? }\end{array}$ & $\begin{array}{l}\text { Se ofrecen dos productos: Harina } \\
\text { de plumas y harina de vísceras de } \\
\text { pollo. }\end{array}$ \\
\hline Mercado & $\begin{array}{l}\text { Términos geográficos: ¿En dónde } \\
\text { compite la empresa? }\end{array}$ & $\begin{array}{l}\text { Enfocados en la ciudad de Lima, } \\
\text { con miras a expandirse a otras } \\
\text { ciudades del país. }\end{array}$ \\
\hline Tecnología & $\begin{array}{l}\text { ¿La empresa está al día desde el } \\
\text { punto de vista tecnológico? }\end{array}$ & Tecnología de última generación. \\
\hline $\begin{array}{l}\text { Preocupación por la } \\
\text { supervivencia, el crecimiento y } \\
\text { la rentabilidad }\end{array}$ & $\begin{array}{l}\text { ¿La empresa está comprometida } \\
\text { con el crecimiento y la solidez } \\
\text { financiera? }\end{array}$ & $\begin{array}{l}\text { Comprometidos en la creación de } \\
\text { valor, con el objetivo de generar } \\
\text { utilidades, basados en un trabajo } \\
\text { en equipo, para lograr un } \\
\text { crecimiento prudente y sostenido. }\end{array}$ \\
\hline Filosofía & $\begin{array}{l}\text { ¿Cuáles son las creencias, valores, } \\
\text { aspiraciones y prioridades éticas } \\
\text { básicas en la empresa? }\end{array}$ & La Calidad Total \\
\hline Auto concepto & ¿Cuál es la ventaja competitiva? & $\begin{array}{l}\text { Especialistas y líderes en el } \\
\text { mercado avícola, con productos } \\
\text { de alta calidad. }\end{array}$ \\
\hline Imagen Pública & $\begin{array}{l}\text { ¿La empresa responde a } \\
\text { preocupaciones sociales, } \\
\text { comunitarias y/o } \\
\text { medioambientales? }\end{array}$ & $\begin{array}{l}\text { Respetuosos del medioambiente y } \\
\text { normativa legal. }\end{array}$ \\
\hline $\begin{array}{l}\text { Preocupación por los } \\
\text { empleados }\end{array}$ & $\begin{array}{l}\text { ¿Sus colaboradores son un activo } \\
\text { valioso para la empresa? }\end{array}$ & $\begin{array}{l}\text { Reconoce al capital humano } \\
\text { como valioso y fundamental para } \\
\text { lograr los objetivos. }\end{array}$ \\
\hline
\end{tabular}

Nota. Tomado de Conceptos de Administración Estratégica (p. 24), por F. D’Alessio 2014, Lima, Perú: Copyright 2015 por Pearson Educación. 


\section{Misión propuesta.}

"Somos una empresa de rendering especializada en producir y comercializar insumos de alto valor proteico, garantizando a nuestros clientes una nutrición animal eficiente, a través de procesos innovadores, comprometidos con la calidad total y el cuidado medioambiental".

\subsection{Valores}

D’Alessio (2015) indica que los valores de una organización son políticas y directrices que norman y encaminan el desempeño de sus funcionarios, y establecen el patrón de actuación que guía el proceso de toma de decisiones. Los valores determinan la filosofía de la organización al representar claramente sus creencias, actitudes, tradiciones y su personalidad. Asimismo los valores son indispensables para: (a) moldear los objetivos y propósitos, (b) producir las políticas, (c) definir las intenciones estratégicas.

Para Chiavenato (2009), los valores se transmiten en todos los niveles de las relaciones humanas como el interpersonal, el organizacional, el cultural, el psicológico, el sociológico y el político económico. Asimismo, estos valores son comunicados en las organizaciones a través de diferentes acciones, como:

- $\quad$ Planes de inducción

- Capacitación y desarrollo de personal

- $\quad$ Las recompensas

- Las sanciones

- $\quad$ Lo que se dice al no admitir la responsabilidad de los actos

- $\quad$ Lo que se calla cuando surgen problemas 
- $\quad$ Lo que se hace cuando existe angustia por las críticas

- $\quad$ Lo que no se hace al evitar discutir problemas importantes

- Congruencia o hipocresía, cuando no se hace lo que se dice.

Cuando una organización no tiene claros los valores, se pueden crear conflictos, dilemas o contradicciones; por ello, los valores deben ser expuestos, explicados y reafirmados públicamente. Cuando existe continuidad en los valores de una organización, se puede marcar su rumbo y comportamiento; asimismo, los valores no solo alinean a los colaboradores con los ejecutivos de la organización sino también con el resto de stakeholders.

Las empresas poseen culturas organizacionales particulares, determinadas por ciertas variables como el entorno socioeconómico, político, legal, los códigos de conducta, políticas de trabajo, entre otros. Estas culturas se caracterizan por compartir valores que determinan el comportamiento de la organización. (Chiavenato, 2009).

La matriz de las cuatro culturas corporativas de McDonald y Gandz (como se cita en Chiavenato, 2009) analiza cuatro variables tales como flexibilidad versus estabilidad y enfoque interno versus enfoque externo, donde cada cuadrante especifica un tipo de cultura corporativa y los valores dominantes que la caracterizan, los cuales se muestran en la figura 17. 


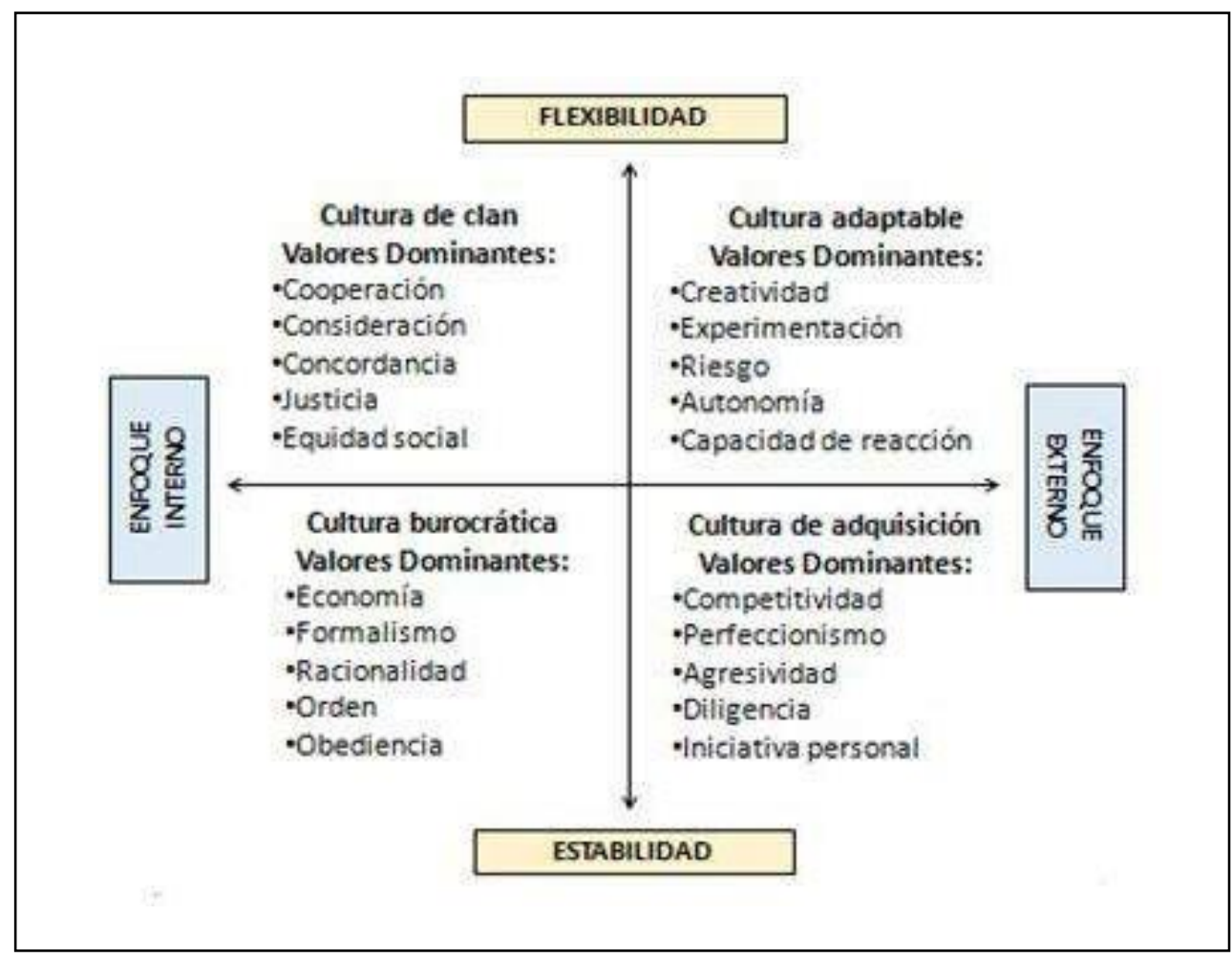

Figura 17. Las cuatro culturas corporativas. Tomado de "Comportamiento

Organizacional” (p.136) por I. Chiavenato, 2009. Copyright 2009 por Mc Graw Hill.

Otra forma de clasificar los valores corporativos, es a través de la generación; en tal sentido Robbins y Judge (2013) muestran una clasificación de valores dominantes según la generación de la fuerza laboral. 
Tabla 6

Valores dominantes en la fuerza laboral actual

\begin{tabular}{|c|c|c|c|}
\hline Generación & $\begin{array}{l}\text { Época de ingreso a } \\
\text { la fuerza laboral }\end{array}$ & $\begin{array}{l}\text { Edad actual } \\
\text { aproximada }\end{array}$ & Valores laborales dominantes \\
\hline Baby boomers & 1965 a 1985 & $\begin{array}{l}\text { Entre } 45 \text { y } \\
65 \text { años }\end{array}$ & $\begin{array}{l}\text { Éxito, logro, ambición, disgusto por la } \\
\text { autoridad, lealtad a la carrera. }\end{array}$ \\
\hline Generación X & 1985 a 2000 & $\begin{array}{l}\text { Entre } 28 \text { y } \\
42 \text { años }\end{array}$ & $\begin{array}{l}\text { Equilibrio entre el trabajo y su vida personal, } \\
\text { orientado a los equipos, no les gustan las } \\
\text { reglas, lealtad en las relaciones }\end{array}$ \\
\hline Milenarios & $\begin{array}{l}\text { De } 2000 \text { a la } \\
\text { actualidad }\end{array}$ & $\begin{array}{l}\text { Menos de } 30 \\
\text { años }\end{array}$ & $\begin{array}{l}\text { Dignos de confianza, éxito financiero, } \\
\text { confianza y lealtad hacia ellos y el equipo. }\end{array}$ \\
\hline
\end{tabular}

Nota. Tomado de Comportamiento Organizacional (p. 146) por Robbins y Judge (2013),

Copyright 2013 por Pearson Educación.

El modelo de las siete "s" de Pascal y Athos (como se cita en Chiavenato, 2009) muestra los elementos de la organización que tienen relación directa y bidireccional con los valores empresariales, y la importancia de su alineamiento. Es así que la identificación de los valores compartidos es el punto inicial si la organización se plantea redefinir alguno de sus elementos, dado que deberá mantener la concordancia. 


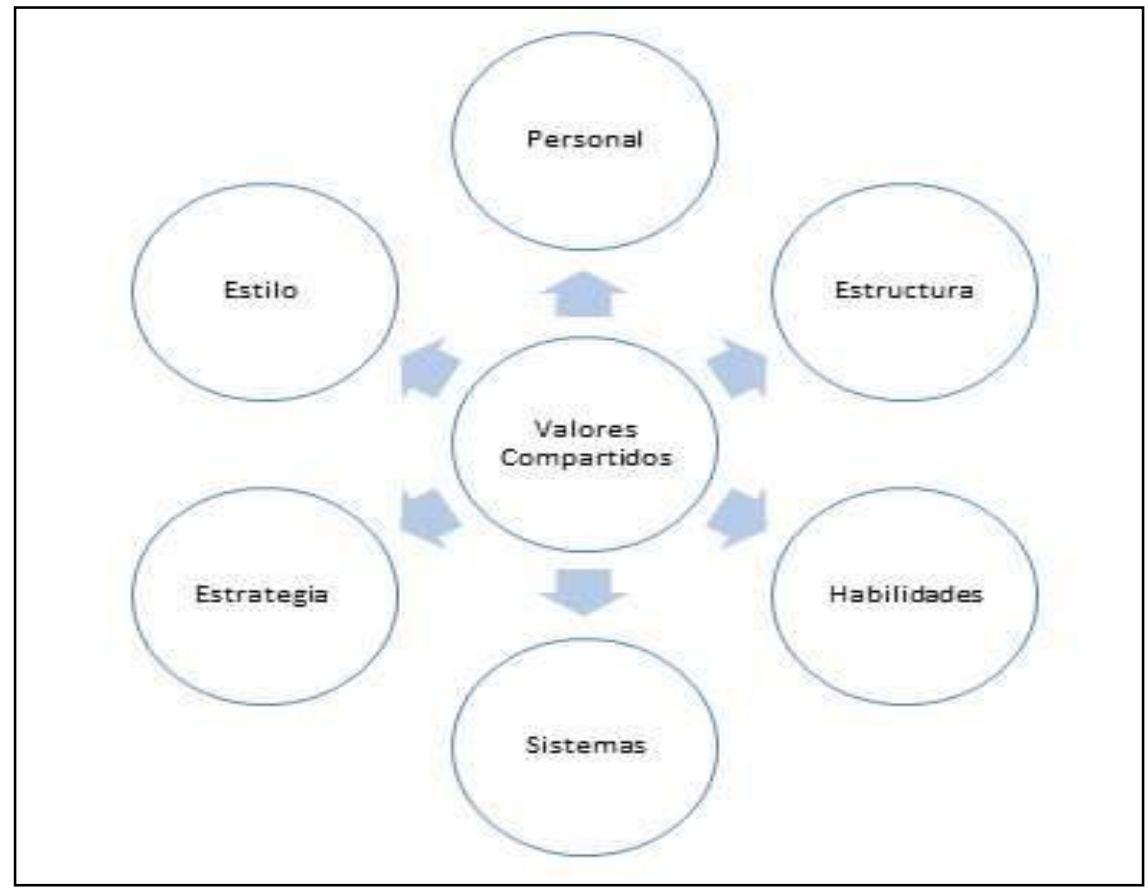

Figura 18. Valores básicos y modelo de la organización de las 7 eses. Adaptado de “Comportamiento Organizacional” (p.135) por I. Chiavenato, 2009. Copyright 2009 por Mc Graw Hill.

\subsubsection{Valores actuales de la empresa.}

Si la bien la empresa Los Ferroles no tiene definida ni formalizada la declaración de sus valores, de las entrevistas realizadas a los directivos y líderes de las diferentes áreas, se evidenciaron ciertas características como compromiso y responsabilidad al describir el desempeño de sus funciones dentro de la organización. Estas características pueden tomarse como referencia para la definición futura de los valores empresariales.

\subsubsection{Análisis de los valores actuales.}

La empresa Los Ferroles no tiene definida ni formalizada la declaración de sus valores. 


\subsubsection{Elementos de los valores propuestos para la empresa.}

La tabla 7 muestra los factores a considerar para reconocer la importancia de los valores de una organización.

Tabla 7

Factores para el desarrollo de valores

\begin{tabular}{ll}
\hline \multicolumn{1}{c}{ Factor } & \multicolumn{1}{c}{ Pregunta clave } \\
\hline Significación & ¿Qué significado tienen los valores? ¿Qué los hace importantes? \\
Universalidad & ¿Qué podría ocurrir si nadie respetara los valores? \\
Liderazgo & ¿Qué podría ocurrir si alguien se apega a determinados valores? \\
Reciprocidad & ¿Qué sentiría una persona si esta norma le fuese aplicada? \\
Publicidad & ¿Cómo se sentiría una persona si su acción o falta de acción se \\
Defensa & conociera públicamente? \\
Responsabilidad & Si una persona asumiese la responsabilidad de una acción o falta de \\
& acción ¿Cuál sería la consecuencia? \\
Intuición & ¿Es posible intuir que una acción o la falta de ella es correcta o \\
& incorrecta?
\end{tabular}

Nota. Tomado de Comportamiento Organizacional (p.134), por I. Chiavenato, 2009, Copyright 2009 por Mc Graw Hill. 
3.3.4 Valores propuestos.

Del análisis de los factores indicados en la tabla 8; alineados a la visión y misión propuesta se determinaron los valores que reflejan de mejor manera la cultura de la empresa; los cuales se describen a continuación:

Responsabilidad

Calidad Total

Aprendizaje y adaptabilidad

Orientación al cliente 


\section{Tabla 8}

Descripción de valores propuestos

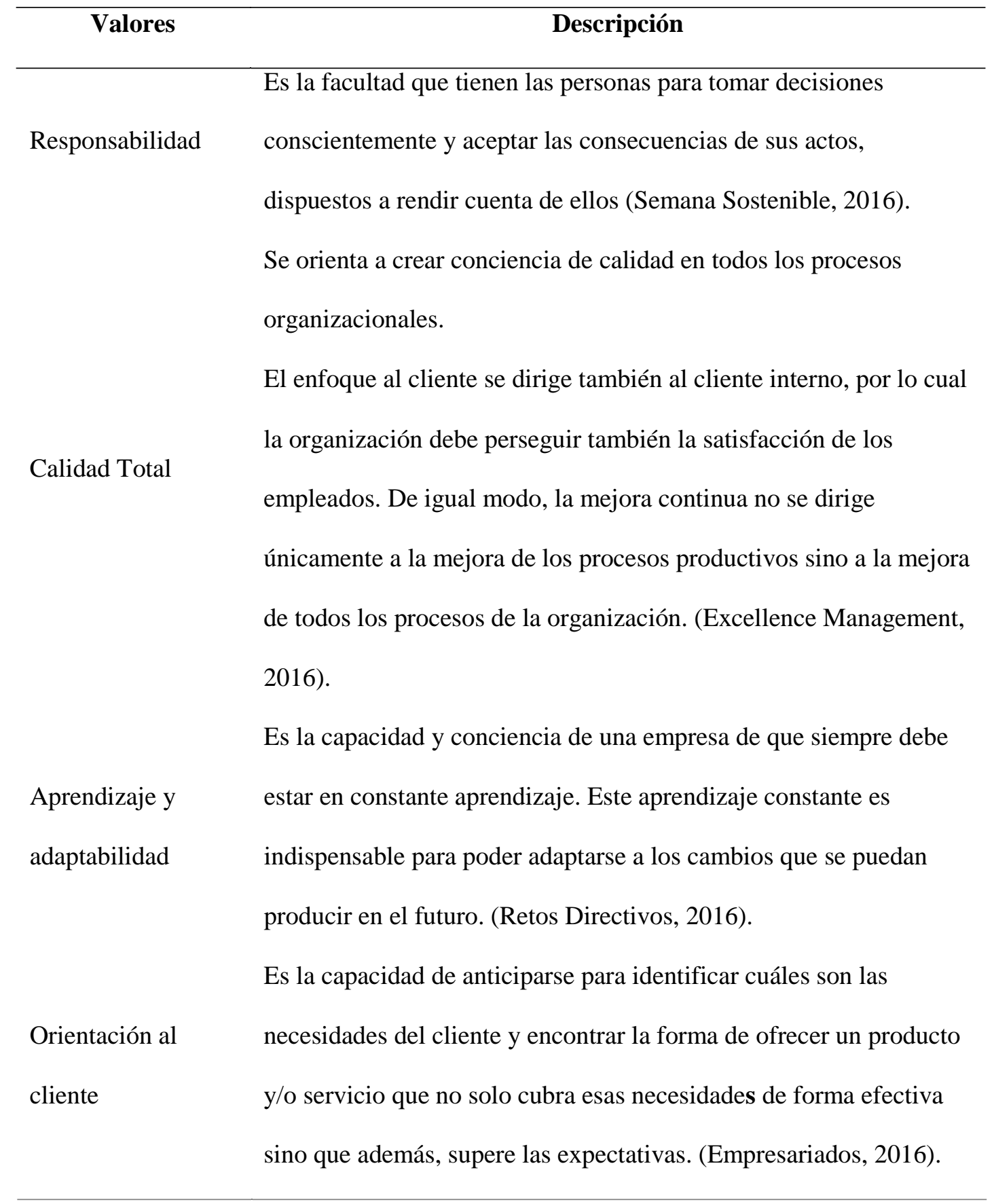




\subsection{Alineamiento estratégico de la Visión, Misión y Valores de la empresa}

Como resultado de la investigación cualitativa realizada a la empresa y tomando como referencia citas bibliográficas de diferentes autores; se ha propuesto formalmente una visión, misión y valores organizacionales alineados entre sí para lograr la máxima sinergia para la empresa. Una cultura organizacional basada en valores, es el motor interno que toda empresa requiere para que la misión se viva y la visión se haga realidad.

En la tabla 9 se describe la relación existente entre los valores, misión y visión.

\section{Misión propuesta.}

“Ser una empresa de rendering especializada en la producción y comercialización de insumos de alto valor proteico, que garantiza a nuestros clientes una nutrición animal eficiente, a través de procesos innovadores, comprometidos con la calidad total y el cuidado medioambiental".

\section{Visión propuesta.}

"Ser reconocidos como líderes en la industria del rendering nacional, ofreciendo insumos proteicos de alta calidad que garanticen el máximo desarrollo cárnico del animal, a través de procesos ecoeficientes, y contando con un equipo humano competente y comprometido" 
Tabla 9

Relación de los Valores Organizacionales con la Misión y Visión.

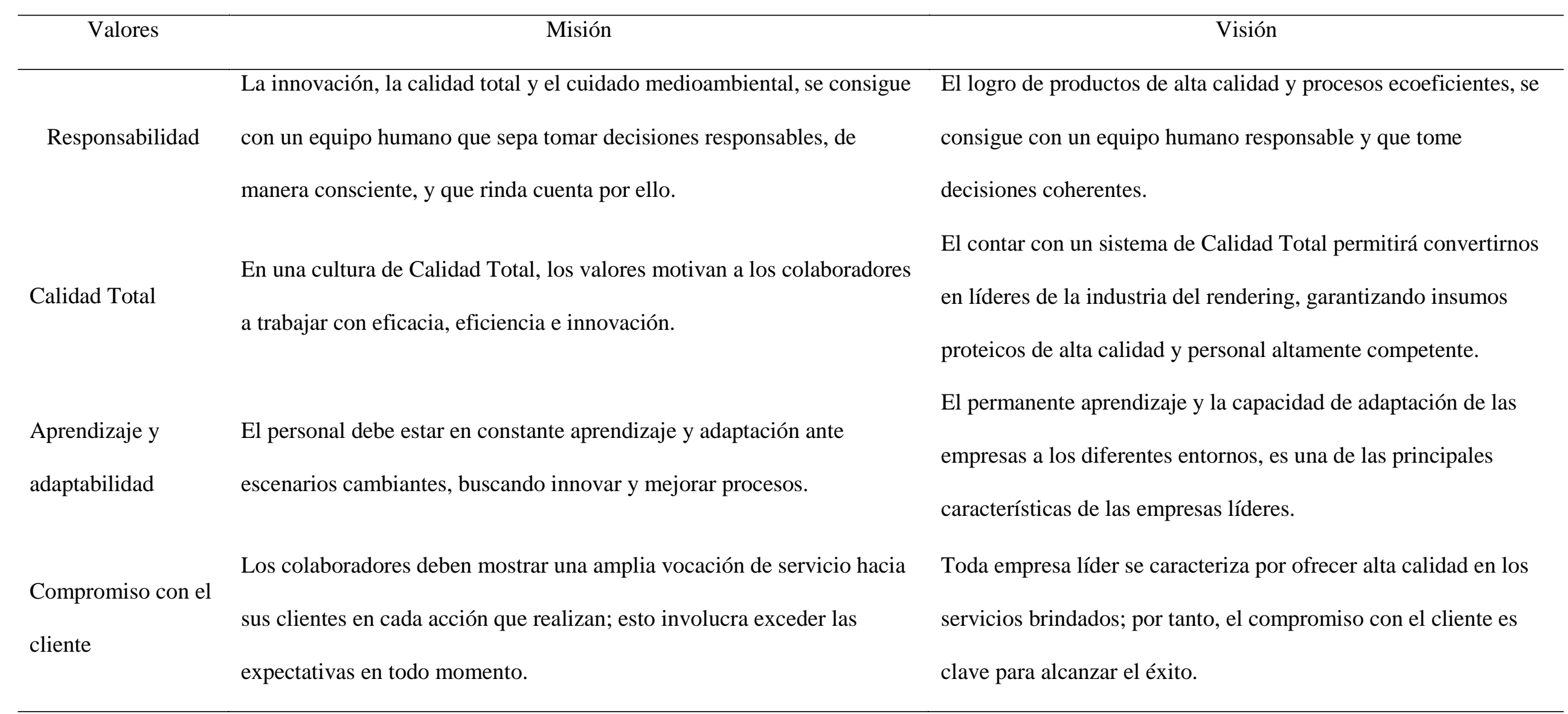


En cuanto al alineamiento de la misión y visión propuesta, podemos indicar lo siguiente:

1. El ser una empresa de rendering especialista en la producción de insumos de alto valor proteico (misión), permitirá que la empresa se convierta en el líder del sector a nivel nacional (visión).

2. La cultura de calidad total y el cuidado medioambiental (misión), permitirá el alineamiento a procesos ecoeficientes y el desarrollo de un equipo humano competente y comprometido (visión). 


\section{Capítulo IV. Análisis Externo}

\subsection{Tendencias de las variables del entorno}

Para describir el entorno en que se desenvuelve Los Ferroles se analizarán seis variables externas: Político gubernamental, económico, legal, cultural, tecnológico y ecológico; que influyen en la toma de decisiones de toda empresa. De esta manera se propondrán acciones estratégicas para hacer frente a las amenazas del entorno, así como aprovechar las oportunidades que representan. (D'Alessio, 2015).

\subsubsection{Análisis Político-Gubernamental.}

Los primeros seis meses de gobierno del Presidente Pedro Pablo Kuczynski han sido difíciles y se proyecta una situación igualmente complicada para el próximo año, por los principales problemas que afronta el actual gobierno que son: Los conflictos sociales al interior del país, la relación entre el oficialismo y el fujimorismo, y por los casos de corrupción de la constructora brasileña Odebrecht, quien admitiera el pago de sobornos a funcionarios peruanos durante los gobiernos de Alejandro Toledo, Alan Garcia y Ollanta Humala. (Diario, El Comercio, 2017)

El escándalo de la empresa Odebrecht está impactando de manera significativa sobre la inversión privada, por ello la agencia calificadora de riesgo Moody’s recorta la proyección de crecimiento de nuestros país de 4.5\% a 3.7\% (Boletín Empresarial Actualidad Empresarial, 2017). 
El Gobierno deberá poner especial énfasis en reformas efectivas que permitan que la economía continúe creciendo, es necesario reducir el déficit de infraestructura y los altos índices de informalidad, son desafíos de mayor relevancia que deberán afrontar el Presidente y su gabinete durante el año que recién empieza. (Diario El Comercio, 2017)

En cuanto a las expectativas de los agentes económicos, reflejan optimismo frente a las políticas de gobierno actuales. En tal sentido, el Ministerio de Economía y Finanzas (MEF) desde el año 2016 viene aplicando una política fiscal moderadamente expansiva, es decir se busca aumentar del gasto público y reducir la recaudación fiscal por medio de bajadas de impuestos. (Semana Económica, 2016)

El Banco Central de Reserva del Perú (BCRP), mantendrá una política expansiva para el año 2017 debido a que la economía del Perú todavía registra tasas por debajo del PBI potencial y se requiere un impulso monetario. (BCRP, 2017)

En los últimos 10 años la industria avícola ha presentado una tasa de crecimiento de 7,8\% anual a nivel nacional en los cinco grandes centros de producción ubicados en La Libertad, Lambayeque, Lima, Ica y Arequipa. Para asegurar y mantener este crecimiento, el Presidente de APA, Sr. José Vera indicó que existe un convenio con el MINAGRI para fortalecer la seguridad alimentaria y sostenibilidad del sector, con la finalidad de cumplir con los requisitos que exige el mercado internacional para la exportación del pollo y estar preparados para lograr la misma expansión que consiguió el pavo, que actualmente se exporta a Ecuador, Panamá, Colombia y Cuba. (Diario El Comercio, 2017) 
Las actividades empresariales en nuestro país se encuentran reguladas y supervisadas por las instituciones gubernamentales. En tal sentido, el Estado puede establecer políticas dirigidas que busquen incentivar la formalidad y/o generar beneficios a las pequeñas y medianas empresas.

\subsubsection{Análisis Económico.}

A continuación se analizarán los principales indicadores macroeconómicos del país:

\section{Producto Bruto Interno (PBI).}

Cifras históricas del comportamiento del PBI desde el año 2008 a la actualidad.

1. Según estadísticas del BCRP, el mayor crecimiento de la producción nacional fue en el segundo trimestre del 2008, el PBI aumentó a 14.13\%, impulsado por los sectores construcción, minería e hidrocarburos, comercio, servicios, electricidad, agua y manufactura.

2. Para el año 2009 el PBI se contrajo debido a la crisis mundial y el decrecimiento del rubro de manufactura.

3. Durante el año 2010 , la economía peruana creció un $8.78 \%$, debido al fuerte dinamismo de su demanda interna y el empuje de sus exportaciones. Este resultado se logró luego de que el PBI avanzó 8.93\% en diciembre, con lo que acumuló 16 meses consecutivos de crecimiento. (Economía Peruana, 2011)

4. En los años 2011 al 2013 el PBI se ha mantenido constante con una ligera tendencia a la baja.

5. En noviembre del 2014 a pesar de las medidas de reactivación económica del Gobierno de Ollanta Humala, el PBI se contrajo aún más debido a la caída en la 
refinación de metales preciosos, la suspensión de la pesca en las zonas norte y centro del país que afectó la producción de harina y conservas de pescado en 87.6\%. (Diario El Comercio, 2015).

6. El INEI, informó que el crecimiento del PBI en el 2015 fue de 3.26\%, el resultado fue impulsado por el aumento de las actividades primarias en $7.37 \%$ y servicios en 4.89\%; mientras que las actividades de transformación disminuyeron en $3.07 \%$. En el crecimiento se debió principalmente por el incremento del consumo privado en $3.4 \%$ y el consumo de Gobierno en $5.8 \%$; en tanto que la inversión disminuyó en 6.6\%. (Perú 21, 2016).

7. En el año 2016 el PBI mostró un crecimiento 3.90\%, un nivel ligeramente superior al 3.8\% que esperaba el mercado. Este crecimiento de la producción nacional se debió al resultado favorable de la mayoría de sectores como Manufactura, Minería e Hidrocarburos, Telecomunicaciones, Pesca y Transporte, Almacenamiento y Mensajería, que en conjunto explicaron alrededor del 70\% de la variación del mes. (Diario Gestión, 2017)

8. La proyecciones del Ministro de Economía, Alfredo Thorne, refiere que el PBI para el año 2017 se desacelerará a 3\% con respecto al 3.9\% de crecimiento registrado el 2016, por el impacto del Nino Costero en el mes de marzo; los casos de corrupción que son materia de investigación y detienen las inversiones en infraestructura: para el año 2018 el PBI crecería en 4.5\% y para el año 2019 lo haría en 5\% dada las políticas de reconstrucción que realizará el Gobierno. (Diario Gestión, 2017) 


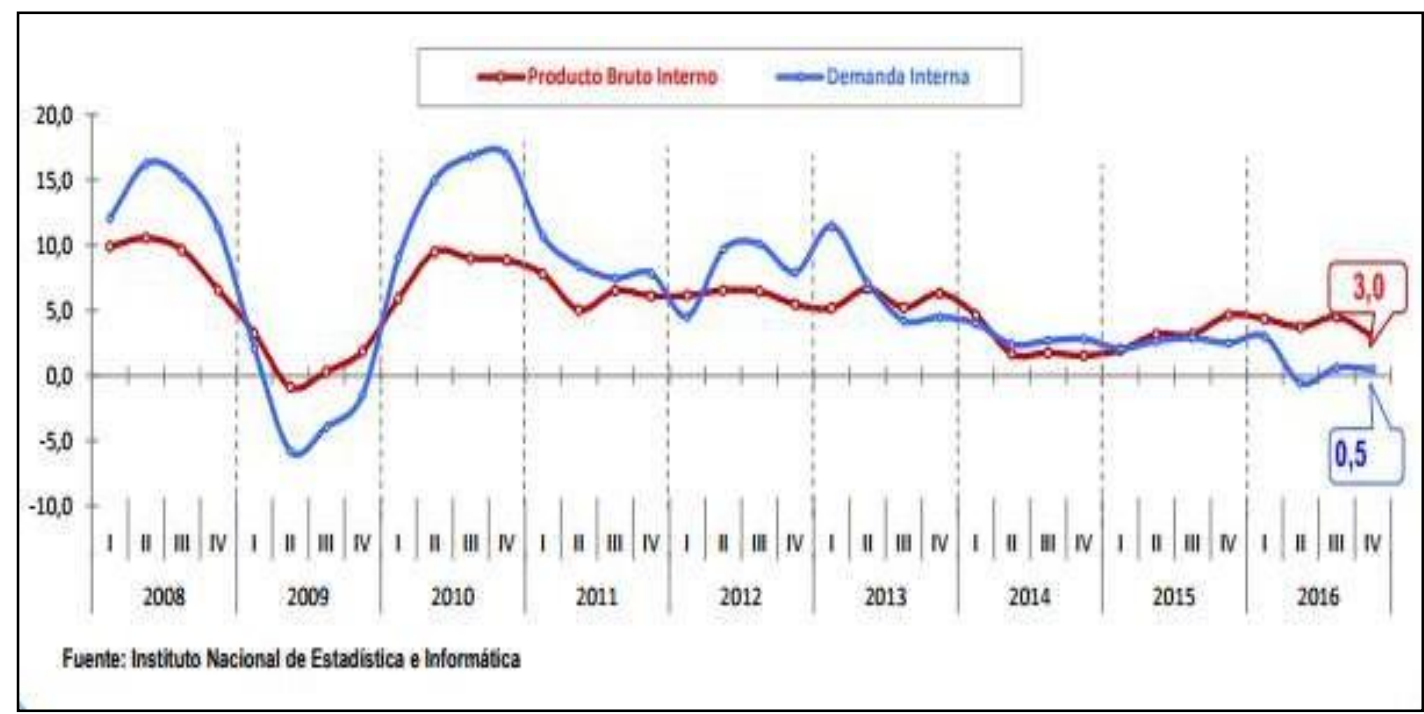

Figura 19. Producto Bruto Interno y Demanda Interna 2008-2016: Variación Porcentual del índice del volumen físico respecto al mismo periodo del año anterior. Tomado de “Informe Técnico N 1, febrero 2017," por el Instituto Nacional de Estadística e Informática (INEI), 2017. Recuperado de http://m.inei.gob.pe/media/MenuRecursivo/boletines/01-informe-tecnico-n01 producto-brutointerno-trimestral-2016iv.PDF

\section{Inversión privada.}

Durante el año 2016 la inversión privada presentó una baja en 4.3 puntos porcentuales, este resultado se genera principalmente por la culminación de los megaproyectos mineros Las Bambas, Cerro Verde y Toromocho. Para el año 2017, la proyección de crecimiento de la inversión del sector privado se estima una baja del $5 \%$ al $2.5 \%$ principalmente por reducción de proyectos de infraestructura tales como Gasoducto Sur Peruano, la Línea 2 del Metro de Lima, Vías Nuevas de Lima y Chavimochic III Etapa. Para el año 2018, se prevé que la inversión privada crecerá 5.3\%, considerando la normalización de las condiciones de inversión reflejadas en la recuperación de la confianza y el avance de los proyectos anunciados y otorgados en concesión. (BCRP, 2017) 


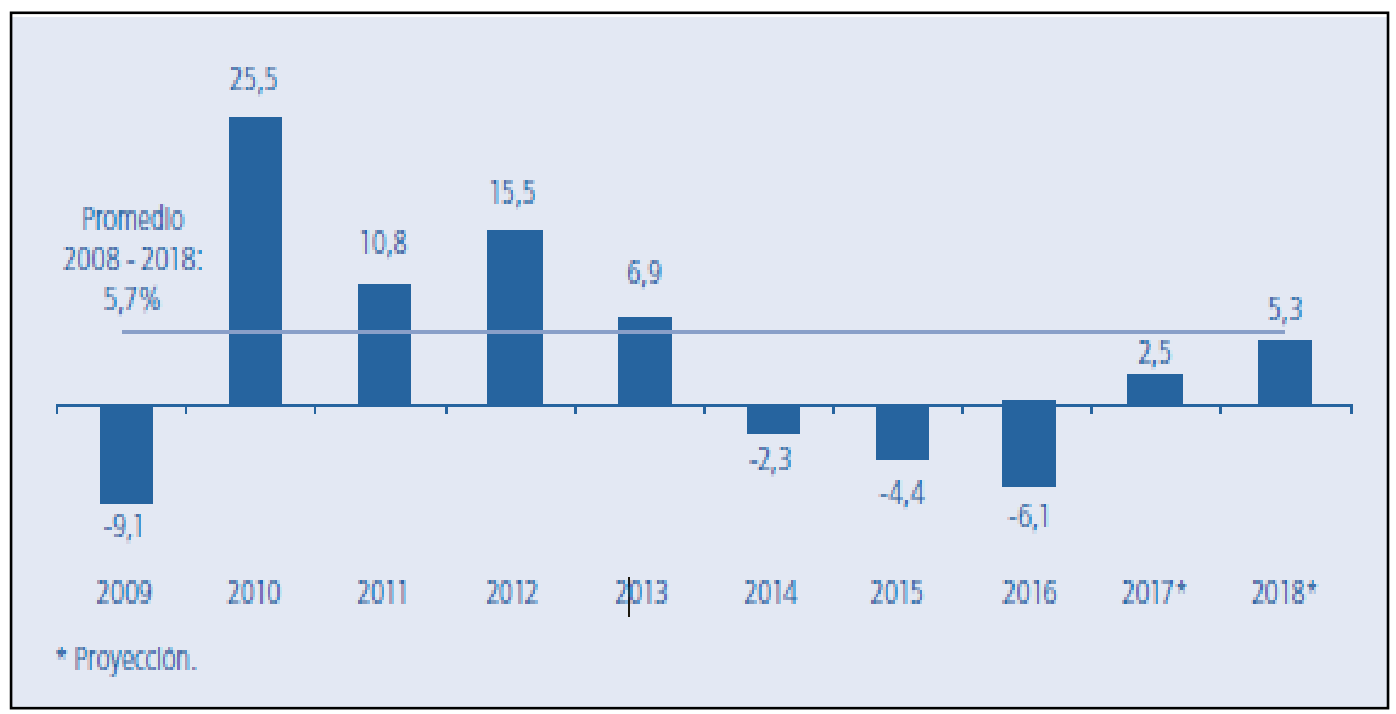

Figura 20. Inversión Privada: 2009 -2018 Variación Porcentual Real. Tomado del “Reporte de Inflación, Marzo 2017,” por el Banco Central de Reserva del Perú (BCRP), 2017. Recuperado de: http://www.bcrp.gob.pe/docs/Publicaciones/ReporteInflacion/2017/marzo/reporte-de-inflacion-marzo-2017.pdf

\section{Inflación.}

Los analistas económicos pronostican que la inflación para el año 2017 cerraría en 2.9\%, manteniéndose dentro del rango meta del BCRP entre $1 \%$ y $3 \%$, proyección que no ha variado en los últimos tres meses, pese a condiciones climáticas adversas que elevaron transitoriamente los precios de algunos alimentos; con respecto al año 2018, se espera que la inflación se desacelere para llegar al 2.6\%. Por lo mencionado, los especialistas concuerdan que la inflación proyectada para el Perú será una de las más bajas de Latinoamérica, (BRCP, 2017) 


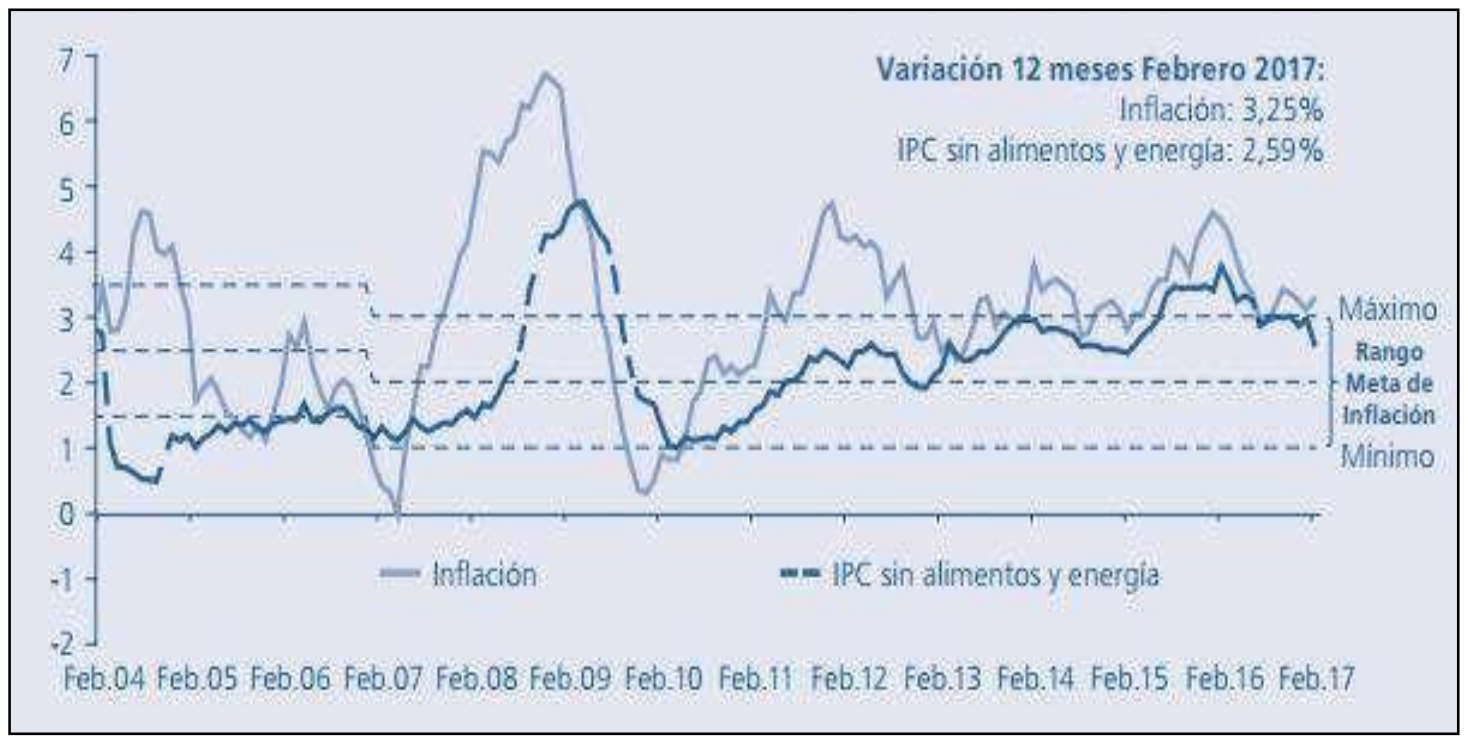

Figura 21. Inflación y Meta de Inflación: Variación Porcentual últimos doce meses.

Tomado del "Reporte de Inflación, Marzo 2017," por el Banco Central de Reserva del Perú (BCRP), 2017. Recuperado de:

http://www.bcrp.gob.pe/docs/Publicaciones/Reporte-Inflacion/2017/marzo/reporte-deinflacion-marzo-2017.pdf

\section{Tasa de Interés.}

El BCRP elevó la tasa de interés de referencia de $3.75 \%$ a $4.25 \%$ entre diciembre 2015 y febrero 2016. En el mes de diciembre se anunció la reducción de la tasa de encaje en moneda nacional de $6.5 \%$ a $6 \%$ y el encaje marginal en moneda extranjera de $70 \%$ a $48 \%$ para hacerse efectivas desde enero de 2017 , dado el contexto de desaceleración del crédito del sector privado consecuente con la menor demanda interna, con el objetivo de flexibilizar las condiciones crediticias domésticas, tomando en cuenta los incrementos esperados en las tasas de interés internacionales. (BCRP, 2017) 


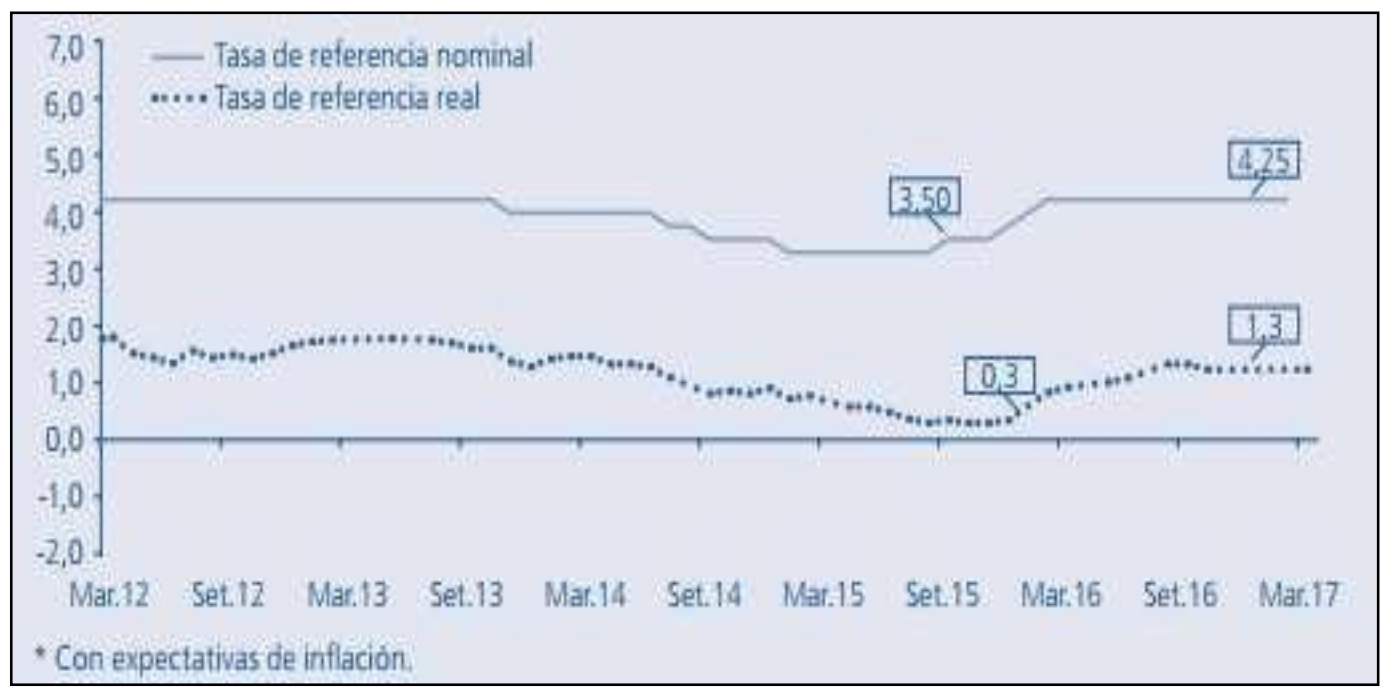

Figura 22. Tasa de interés de referencia nominal y real, en porcentaje. Tomado del “Reporte de Inflación, Marzo 2017," por el Banco Central de Reserva del Perú (BCRP), 2017. Recuperado de: http://www.bcrp.gob.pe/docs/Publicaciones/ReporteInflacion/2017/marzo/reporte-de-inflacion-marzo-2017.pdf

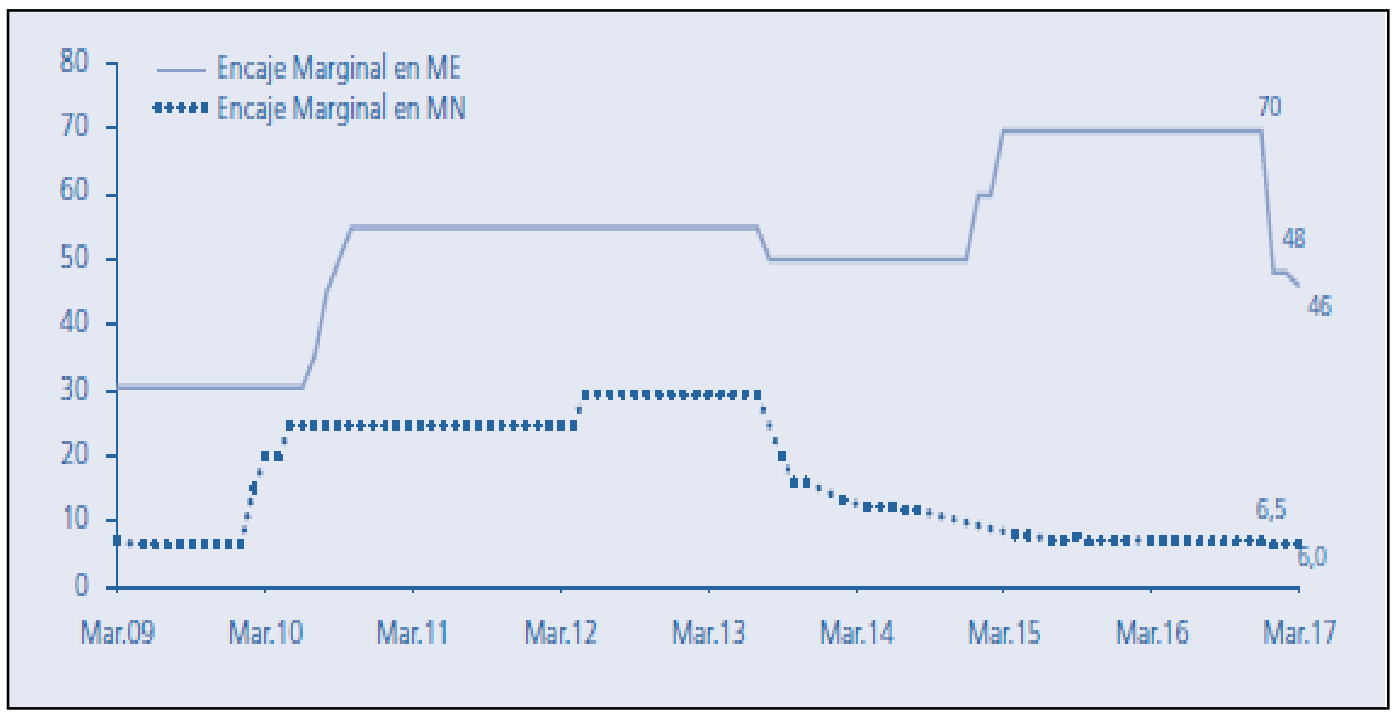

Figura 23. Tasa de encaje en moneda nacional y moneda extranjera. Tomado del

“Reporte de Inflación, Marzo 2017,” por el Banco Central de Reserva del Perú (BCRP), 2017. Recuperado de: http://www.bcrp.gob.pe/docs/Publicaciones/ReporteInflacion/2017/marzo/reporte-de-inflacion-marzo-2017.pdf 


\section{Tipo de cambio.}

Entre diciembre de 2016 y marzo de 2017, el tipo de cambio registró una apreciación de 2, pasando de S/ 3.357 a S/ 3.291 por dólar, influido por mayores precios de los commodities, en particular del cobre, y por la depreciación del dólar a nivel global, dada la incertidumbre en torno a la nueva postura de política de comercial de EUA y las señales en contra de un dólar apreciado. (BCRP, 2017, p. 84).

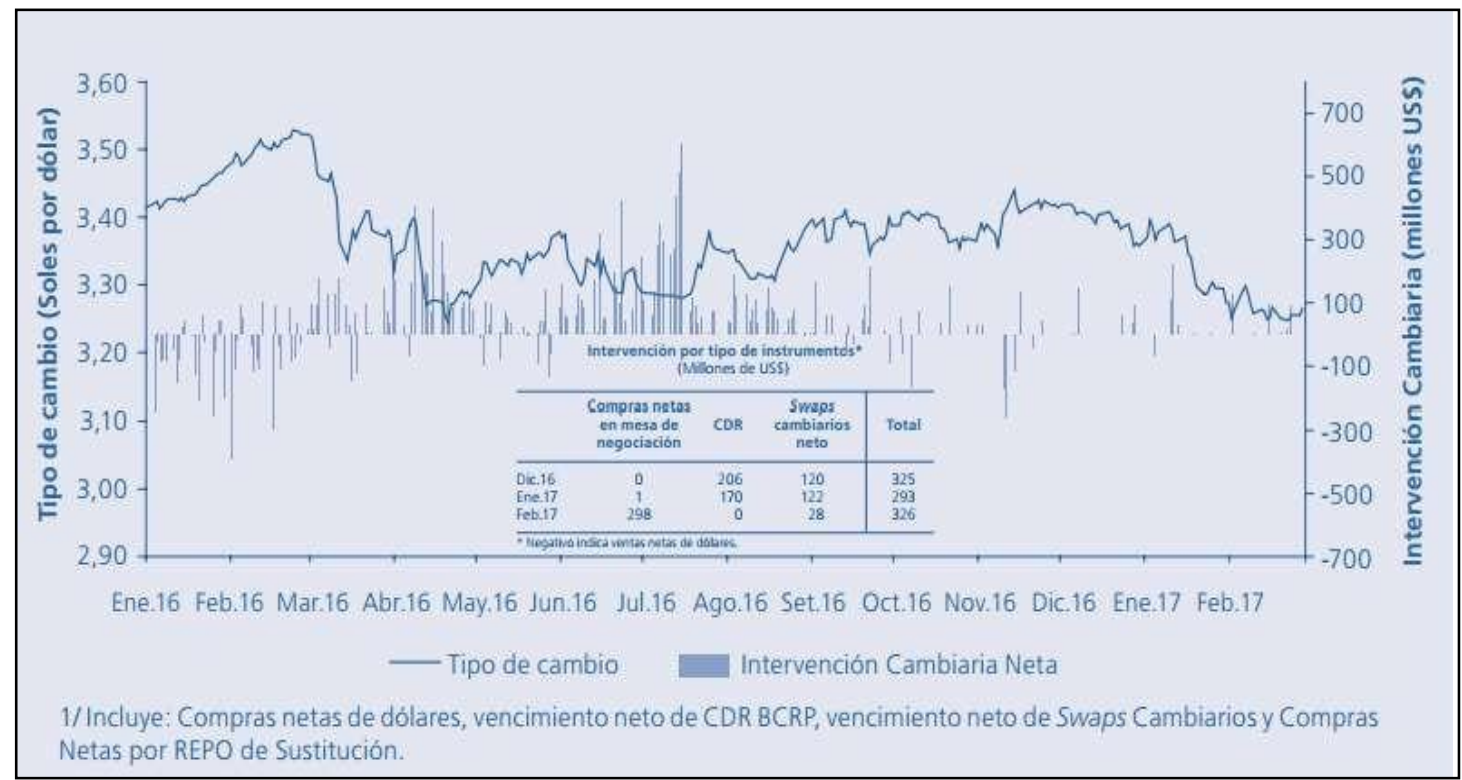

Figura 24. Tipo de cambio e intervención cambiaria del BCP. Tomado del "Reporte de Inflación, Marzo 2017,” por el Banco Central de Reserva del Perú (BCRP), 2017.

Recuperado de: http://www.bcrp.gob.pe/docs/Publicaciones/Reporte-

Inflacion/2017/marzo/reporte-de-inflacion-marzo-2017.pdf

La estabilidad del tipo de cambio que actualmente se está presentando, permite a las empresas controlar sus costos financieros y riesgos de transacción e inversión en el caso de adquirir inmuebles y maquinaria a través de créditos bancarios en moneda extranjera a largo plazo. 
Las referencias previas pronostican un escenario político económico para el año 2017 poco optimista e incierto; mientras que para el próximo año las expectativas macroeconómicas son más favorables. Ante esta situación, se evidencia que las empresas vienen aplicando una política de control de gastos a fin de sobrellevar la coyuntura actual.

\subsubsection{Análisis Legal.}

En sus inicios, la industria del rendering no se encontraba regulada, ni supervisada por una falta de normativas gubernamentales para el tratamiento y disposición de los subproductos cárnicos; en los últimos años, el gobierno peruano ha planteado normativas sanitarias, ambientales, laborales, tributarias entre otras, para ejercer un mayor control en el sector.

La empresa Los Ferroles para el desarrollo de sus actividades se encuentra reguladas por entidades como:

Superintendencia Nacional de Administración Tributaria (SUNAT): Uno de los principales entes reguladores y recaudadores de impuestos por las actividades comerciales. (Superintendencia Nacional de Administración Tributaria [SUNAT], 2017).

- $\quad$ Dirección General de Salud Ambiental (DIGESA): "Es el órgano técnico normativo encargado de formular políticas, regular y fiscalizar las intervenciones en Salud Ambiental, ejerciendo la rectoría a nivel nacional a través de la vigilancia, de la prevención y el control de los factores de riesgos ambientales, que afectan a 
la salud y bienestar de la población.” (Dirección General de Salud Ambiental [DIGESA], 2017).

Servicio Nacional de Sanidad Agraria (SENASA): “Organismo público técnico especializado adscrito al ministerio de agricultura con autoridad oficial en materia de sanidad agraria, calidad de insumos, producción orgánica e inocuidad agroalimentaria y emisor de los certificados de registro sanitario" (Servicio Nacional de Sanidad Agraria [SENASA], 2017).

Superintendencia Nacional de Fiscalización Laboral (SUNAFIL): Supervisa el cumplimiento de las normas laborales establecidas por el Ministerio de Trabajo y Promoción del Empleo. De ésta manera vela por la formalidad, seguridad y salud en el trabajo. (Superintendencia Nacional de Fiscalización Laboral [SUNAFIL], 2017).

- Instituto Nacional de Defensa Civil (INDECI): es un organismo público ejecutor que conforma el SINAGERD. Es el responsable técnico de coordinar, facilitar y supervisar la formulación e implementación de la Política Nacional y el Plan Nacional de Gestión del Riesgo de Desastres, en los procesos de preparación, respuesta y rehabilitación. (Instituto Nacional de Defensa Civil [INDECI], 2017).

- $\quad$ Ministerio de la Producción (PRODUCE), las empresas que realicen actividades manufactureras deberán cumplir con el Reglamento de Protección Ambiental para el Desarrollo de Actividades de la Industria Manufacturera que tiene como objetivo evaluar y supervisar a las empresas con referencia al impacto ambiental y la adecuación ambiental. (Ministerio de la Producción [PRODUCE], 2017). 
- $\quad$ Organismo de Evaluación y Fiscalización Ambiental (OEFA), Organismo público técnico especializado adscrito al Ministerio del Ambiente, encargado de la fiscalización ambiental y de asegurar el adecuado equilibrio entre la inversión privada en actividades económicas y la protección ambiental. (Organismo de Evaluación y Fiscalización Ambiental [OEFA], 2017).

- $\quad$ Autoridad Nacional del Agua (ANA), Ente rector y máxima autoridad técnico normativa del Sistema Nacional de Gestión de los Recursos Hídricos, es cual es parte de Sistema Nacional de Gestión Ambiental. (Autoridad Nacional del Agua [ANA], 2017).

- $\quad$ Ministerio del Ambiente, Ente ministerial cuya función es la de ser rector del sector ambiental, con la finalidad de diseñar establecer, ejecutar y supervisar la política nacional y sectorial ambiental. (Ministerio del Ambiente, 2017).

Si bien el cumplimiento de la normativa legal es de carácter obligatorio, el sector rendering no está tan regulado como lo está en otros países de la región. Este escenario favorece las operaciones de la industria al no existir fuerte presión por parte del gobierno. Adicional a ello, el seguimiento por parte del gobierno no es exhaustivo, dejando vacíos en los procesos de control.

\subsubsection{Análisis Cultural}

Esta fuerza contempla las creencias, actitudes, opiniones, estilos de vida, condiciones sociales, demográficas, étnicas y culturales del entorno de la organización, que permite definir el perfil del consumidor, hábitos de compra, paradigmas de compra que pueden influir en los clientes, por ello se debe considerar la influencia de esta fuerza 
considerando las oportunidades y las amenazas que se puedan identificar. (D’Alessio, 2015)

Una de las limitantes del estudio de la industria del rendering es la poca información documentada sobre su evolución en el Perú. En la entrevista sostenida con el experto del sector (ver en Anexo $\mathrm{N}^{\circ}$ 6), comentó que el rendering es una industria relativamente nueva en el Perú, y que se encuentra en proceso de crecimiento. Si bien rendering se produce desde hace varias décadas, recién en los últimos cinco años es cuando los grandes productores se han formalizado y mejorado la calidad de los productos ofrecidos, esto debido al mayor interés de las empresas avícolas por las harinas proteicas y la oportunidad de negocio rentable que generan.

El bajo desarrollo de la industria del rendering en el Perú es producto del contexto socioeconómico de las décadas pasadas, donde por factores coyunturales no hubo la necesidad de incentivar la producción y utilización de este tipo de subproductos en la crianza animal.

El experto en el sector avícola (ver en Anexo $\mathrm{N}^{\circ}$ 6) menciona que, entre los principales factores que influenciaron en la evolución del rendering en el Perú, se encuentran:

1. Harina de pescado: dada su alta disponibilidad y precio bajo debido al boom de la pesca en el Perú en las décadas de los sesenta y setenta, se convirtió en una de las principales fuentes proteicas para la alimentación animal. A partir de los ochentas 
se hizo más escasa, por lo que se buscó otra harina que pueda reemplazar su valor proteico. Es así que aparece la torta de soya como sustituto.

2. Harina de torta de soya (importada): por su alta disponibilidad y precio bajo, se le ha considerado como la principal fuente de proteína desde hace varias décadas. Entre el 2000 y 2005 se da un boom internacional de este insumo, incrementándose aún más su oferta y disminuyendo el precio. Hoy en día, las cosechas de soya no son tan eficientes como antes, y se ven afectadas por diversos factores (climáticos, económicos, etc), por lo que la disponibilidad en el mercado ha disminuido.

3. Idiosincrasia de los profesionales del sector avícola en las décadas pasadas. Los nutricionistas de las empresas mayormente eran del tipo conservador y no se arriesgaban a probar harinas proteicas procedentes del rendering por considerarlas de alto riesgo sanitario. En este aspecto la avicultura está cambiando, y los nutricionistas de hoy muestran mayor apertura al rendering.

4. Falta de exigencias normativas gubernamentales para el tratamiento y disposición de los subproductos cárnicos. En las décadas pasadas las regulaciones medio ambientales eran muy insipientes, por lo que el sector empresarial no tenían la presión por buscar alternativas de solución para el tratamiento y disposición de subproductos cárnicos; hoy en día las normas relativas al cuidado del medio ambiente son más exigentes, y el gobierno regula de mejor manera su cumplimiento. Esto ha sido un factor determinante para que las industrias vean al rendering como una solución integral al manejo de los residuos cárnicos. 
Actualmente, la globalización ha ejercido fuerte influencia en el entorno avícola, por lo que el rendering ha empezado a introducirse en la alimentación animal como una fuente proteica importante.

\subsubsection{Análisis Tecnológico.}

Las fuerzas tecnológicas tienen la capacidad de crear nuevos mercados, lo que origina nuevos y mejores productos y/o servicios, con menores tiempos y costos de producción, pero también puede volver obsoletos productos y servicios existentes. Ninguna empresa está aislada de los nuevos desarrollos tecnológicos, por ello se debe aprovechar la oportunidad para convertirlas en ventajas competitivas. (David, 2013).

En un entorno globalizado y cada vez más competitivo, las empresas deben estar al día de los últimos avances tecnológicos, así como deben invertir en tecnología de punta para sus procesos internos, lo que les permitirá ser más eficientes y estar un paso más adelante de las empresas de su sector.

La industria del rendering necesita contar con una adecuada tecnología para la producción que maximice la calidad de las harinas, con el mínimo costo energético en la transformación productiva y con el mínimo impacto ambiental, en este sentido la empresa Los Ferroles cuenta con la mejor tecnología del mercado para el procesamiento de residuos sólidos. (Los Ferroles, 2016)

En los últimos años, la tecnología de proceso e ingeniería se centra en la investigación y desarrollo de soluciones personalizadas para la nutrición y crianza de animales para el consumo humano. Las investigaciones han determinado que las harinas 
procedentes del rendering tienen mejor digestibilidad porque genera un mayor desarrollo en el animal y menor cantidad de excretas, optimizando el rendimiento y costos; haciendo más sostenible el negocio de crianza de animales. Se puede observar que, el éxito para las empresas del rendering está en la investigación del mercado para el desarrollo de harinas proteicas de acuerdo a los requerimientos técnicos de los clientes lo que genera alianzas estratégicas; en este sentido la empresa Los Ferroles no ha desarrollado productos como si lo viene haciendo la competencia.

Desde hace varios años las Tecnologías de Información cobran importancia y sirven de apoyo para la alineación de las estrategias del negocio, porque ayudan a mejorar los procesos claves, en este sentido la empresa Los Ferroles cuenta con un sistema ERP Horizont para los procesos administrativos, contables, logísticos y control de inventarios, esta herramienta les proporciona control y centralización de la información para la toma de decisiones de la Dirección.

En cuanto a la utilización de las tecnologías de la información, la empresa no desarrolla estrategias de marketing digital, no cuenta con un sitio web corporativo, ni tiene presencia en redes sociales, perdiendo la oportunidad de un acercamiento e interacción con los clientes actuales y potenciales, pero no todas las redes sociales son viables para las empresas, para ello se debe hacer un estudio previo y contar con una buena gestión de las redes sociales, para evitar un efecto negativo sobre la valoración de la marca. 


\subsubsection{Análisis Ecológico.}

Actualmente, el cuidado medio ambiental ha cobrado gran relevancia y existe una creciente preocupación por el tratamiento que se le debe dar a la generación de residuos sólidos. La producción avícola intensiva es capaz de producir significativos daños ecológicos, en caso no se gestione adecuadamente manejo los subproductos.

Las empresas de rendering tienen un impacto ecológico positivo; porque reducen la cantidad de residuos que se depositan en los vertederos; pero tienen un impacto ecológico negativo por la calidad de aire (los olores y vahos) que generan en el procesamiento de materias primas orgánicas y también por el tratamiento de las aguas residuales. Además, los olores procedentes de plantas de rendering cercanas a zonas residenciales pueden suponer una fuente continua de conflictos en la comunidad y grupos de interés.

En el Perú, la industria del rendering opera bajo leyes y reglamentos ambientales y de salubridad, para controlar el nivel de contaminación en los efluentes y emisiones gaseosas. Es por ello que en el año 2008 el gobierno peruano creó el Ministerio del Ambiente, con la misión de asegurar el uso sostenible, la conservación de los recursos naturales y la calidad ambiental en beneficio de las personas y el entorno, de manera normativa.

La actual ubicación geográfica de la empresa Los Ferroles le permite desarrollar sus operaciones sin afectar zonas urbanas: la tecnología que utilizan está diseñada para reducir el procesamiento de aguas residuales y disminuir la cantidad de olores que se expiden a la atmosfera. 
Otro de los factores a considerar que afectan directamente al sector avícola y por la tanto a la industria del rendering son las enfermedades a las que están propensas las aves, entre ellas la gripe aviar, virus que se presenta principalmente en las aves de corral y puede ser mortal tanto para el ave como para los seres humanos si no se tienen los cuidados necesarios. Por ello, es de suma importancia que las empresas avícolas pongan en práctica sistemas de detección y medidas de prevención en el marco de una estrategia eficaz frente al virus. En caso se detecte la enfermedad el Ministerio de Salud tomará medidas para que las empresas del rubro avícola apliquen la política de "sacrificio sanitario" para erradicarla, por lo que la industria del rendering se vería afectada.

\subsection{Impacto en clientes / proveedores de cada una de las variables del entorno.}

El impacto de las variables externas en los clientes y proveedores, se resume en la siguiente tabla: 
Tabla 10

Impacto en clientes / proveedores de cada una de las variables del entorno

Variable Externa Impacto Clientes (Sector Avícola) Impacto Proveedores (Acopiadores de residuos)

\section{Político Económico}

Entorno político económico incierto.

Industria avícola en crecimiento.

Inversión moderada.

Desarrollo de la industria.

Reducción del precio y aumento de la oferta del principal Mayor utilización de harinas proteicas del rendering. sustituto (harina de pescado).

Mayor accesibilidad al financiamiento crediticio.

\section{Legal}

Mayor exigencia en el cumplimiento de la normativa medio ambiental y sanitaria.

Nuevas políticas regulatorias en el sector rendering.

\section{Tecnológico}

Alto desarrollo de tecnología para el sector.

Mayor inversión, mayor producción.

Mayor control en los procesos.

Mayor calidad y garantía en los productos adquiridos.
Mayor informalidad.

Mayor cantidad de subproductos para el acopio.

Menor demanda de materia prima para el rendering.

Mayor inversión, mayor producción.

Mayor control en los procesos.

Mayor control en los procesos.

\section{Cultural}

Incremento de uso de harinas del rendering en la alimentación animal.

\section{Ecológico}

Mayor conciencia ecológica / medio ambiental empresarial.

Brote de influenza aviar en la industria avícola.
Menor costo y mayor productividad de la materia prima. Integración vertical con proveedores.

Mejora de la comunicación cliente proveedor.

Mejora de la comunicación cliente proveedor.

Mayor calidad nutricional y menor costo en la elaboración del producto balanceado.

Mayor control en el manejo de residuos generados por los procesos.

Sacrificio de aves infectadas.
Incremento de acopio.

Mayor control en el manejo de residuos acopiados.

Falta de materia prima para la producción de harinas en base a subproductos avícolas. 


\subsection{Efecto en la empresa de cada una de las variables del entorno}

Tabla 11

El efecto de cada variable externa y cómo influye en la empresa Los Ferroles.

\begin{tabular}{|c|c|c|}
\hline Variable Externa & Empresa & Oportunidad/Amenaza \\
\hline \multicolumn{3}{|l|}{ 1. Político Económico } \\
\hline Entorno político económico incierto. & Inversión moderada. & Amenaza \\
\hline Industria avícola en crecimiento. & Mayor producción de harinas proteicas & Oportunidad \\
\hline Industria avícola en crecimiento. & Empresas avícolas generen su propio rendering. & Amenaza \\
\hline Industria avícola en crecimiento. & Ingreso de nuevos competidores en la industria. & Amenaza \\
\hline $\begin{array}{l}\text { Reducción del precio y aumento de la oferta del principal } \\
\text { sustituto (harina de pescado). }\end{array}$ & Menor demanda de harinas del rendering. & Amenaza \\
\hline Mayor accesibilidad al financiamiento crediticio. & Incentivo a la inversión. & Oportunidad \\
\hline \multicolumn{3}{|l|}{ 2. Legal } \\
\hline $\begin{array}{l}\text { Mayor exigencia en el cumplimiento de la normativa medio } \\
\text { ambiental y sanitaria. }\end{array}$ & Mayor control y necesidad de adecuación en los procesos. & Amenaza \\
\hline Nuevas políticas regulatorias en el sector rendering. & Mayor control y necesidad de adecuación en los procesos. & Amenaza \\
\hline \multicolumn{3}{|l|}{ 3. Tecnológico } \\
\hline Alto desarrollo de tecnología para el sector. & Incremento de productividad. & Oportunidad \\
\hline Alto desarrollo de marketing a través de medios digitales. & Mejorar el posicionamiento de marca. & Oportunidad \\
\hline \multicolumn{3}{|l|}{ 4. Cultural } \\
\hline $\begin{array}{l}\text { Incremento de uso de harinas del rendering en la alimentación } \\
\text { animal. } \\
\text { 5. Ecológico }\end{array}$ & Mayor producción de harinas proteicas & Oportunidad \\
\hline Mayor conciencia medio ambiental empresarial. & Mejora de procesos con enfoque en el cuidado medioambiental & Oportunidad \\
\hline Brote de influenza aviar en la industria avícola. & Falta de materia prima. & Amenaza \\
\hline
\end{tabular}




\subsection{Oportunidades y Amenazas.}

Luego del análisis desarrollado de los factores del entorno y su impacto en clientes, proveedores y la misma empresa, podemos describir las principales oportunidades y amenazas resultantes:

\section{Oportunidades.}

1. Industria avícola en crecimiento: El sector avícola está evolucionando tanto en el escenario local como en el internacional, asimismo; la producción avícola en el Perú se ha incrementado sosteniblemente; lo cual ha representado un crecimiento de $47 \%$ en los últimos siete años, generando una oportunidad de desarrollo para la industria del rendering. (APA, 2016)

2. Mayor accesibilidad al financiamiento crediticio: De acuerdo a lo mencionado por el BCRP (Banco Central de Reserva del Perú) el fortalecimiento del crédito empresarial permite a las empresas tener una mayor capacidad de desarrollo, realizar nuevas y más eficientes operaciones, ampliar el tamaño de sus operaciones y acceder a créditos en mejores condiciones. El contar con mayor acceso al crédito, favorecerá a la empresa en caso requiera financiamiento para incrementar su capacidad instalada, o realizar algún otro tipo de inversión.

3. Alto desarrollo de tecnología para el sector: La globalización permite el acceso a la tecnología de punta existente en países donde el rendering está altamente tecnificado.

4. Alto desarrollo de marketing a través de medios digitales: El rápido desarrollo del marketing digital obliga a las empresas a establecer nuevas estrategias de 
comunicación usando plataformas o canales digitales, que generen un mayor impacto hacia el mercado. Así mismo, el marketing digital representa menores gastos para la empresa respecto al marketing tradicional.

5. Mayor conciencia medio ambiental empresarial: Actualmente la sociedad tiene un mayor entendimiento del impacto de sus acciones en el medio ambiente. En el caso de Los Ferroles, la empresa viene adecuando sus procesos mediante el uso de tecnología de punta para reducir el impacto que generan sus operaciones.

6. Incremento de uso de harinas del rendering en la alimentación animal: En los últimos años la calidad nutricional de las harinas del rendering se ha visto incrementada; esto gracias a la investigación y el uso de tecnología de punta. Así mismo la tendencia internacional de uso de harinas proteicas en las fórmulas de alimento balanceado ha aumentado.

\section{Amenazas.}

1. Entorno político económico incierto: Dos informes recientes, uno del Banco Interamericano de Desarrollo (BID) y otro del Fondo Monetario Internacional (FMI), ponen énfasis en que la economía mundial está atravesando por una etapa de incertidumbre y turbulencia que se mantendrá al menos por algunos años más y ello obligará al nuevo gobierno a "remar contra la corriente". (Diario Gestión, 2016)

2. Para el 2017, se espera que el PIB se desacelere ligeramente debido a la estabilización en el sector minero y una todavía débil inversión privada (afectada por las condiciones globales adversas y la incertidumbre relacionada con los 
escándalos de corrupción de proyectos firmados en años pasados). (Banco Mundial, 2017)

3. Ingreso de nuevos competidores a la industria: El ingreso de nuevos competidores con tecnología avanzada, inversión en plantas procesadoras y con estrategias de marketing definidas, les resultaría una fuerte amenaza competitiva para las empresas actuales que integran el sector, por lo que tendrían que buscar estrategias de defensa para operar en el mercado.

4. Mayor exigencia en el cumplimiento de la normativa medio ambiental y sanitaria: Obligaría a las empresas del sector a incorporar cambios en sus procesos de producción de manera que aseguren el cumplimiento de las normas establecidas; lo cual generaría incremento en sus costos operativos y hasta limitantes para la producción.

5. Nuevas políticas regulatorias en el sector rendering: El gobierno peruano podría adoptar medidas que regulen en el sector tomando como referencia estándares internacionales, aplicando sanciones ante el incumplimiento.

6. Brote de influencia aviar en industria avícola: Es un factor poco controlable y de altísimo impacto negativo, por lo que la empresa debe plantear estrategias alternas ante la aparición de este escenario crítico.

7. Empresas avícolas generen su propio rendering: Las empresas que integran el sector avícola podrían adoptar esta estrategia comercial lo que generaría menor disponibilidad de materia prima para el sector rendering. 
8. Reducción del precio y aumento de la oferta del principal sustituto (harina de pescado): La disminución del precio y/o aumento de disponibilidad de la harina de pescado desplaza el consumo de las harinas del rendering, dado que se convierte en una alternativa de fuente proteica de bajo costo y de alta calidad nutricional.

\subsection{Matriz de Evaluación de los Factores Externos (EFE)}

Los estrategas deben evaluar el entorno externo en cuanto a las siguientes variables: política, económica, legal, tecnológico, cultural y ecológico, esta información se resume y pondera en la matriz EFE (David, 2013).

1. Identificada las oportunidades y amenazas se debe listar los factores teniendo en consideración cómo afectan a la empresa y la industria en que opera.

2. Se le debe asignar un peso a cada factor, de acuerdo a la importancia para la empresa en la medida que este le genere éxito en el sector que opera, la suma de todos los pesos debe dar como resultado 1.00.

3. Se le debe asignar una calificación del 01 al 04 según con cuánta eficacia responden las estrategias actuales de la empresa en dicho sector, donde " 4 " responde de manera excelente y “1” responde de forma deficiente.

4. El peso ponderado es la suma total que se obtiene de la multiplicación del peso por la calificación, un resultado con valor 4.0 significa que la empresa responde de manera excelente a las oportunidades y amenazas que presenta el sector, el ponderado promedio es 2.5 que significa que las estrategias de la empresa son débiles y el ponderado de 1.0 significa que las estrategias de la empresas no aprovecha las oportunidades que le ofrece el sector ni evita las amenazas que ésta presenta. 
En la tabla 12 se muestran las principales oportunidades y amenazas que enfrenta la empresa Los Ferroles. Las ponderaciones y calificaciones son el resultado de las entrevistas realizadas a los expertos del sector, directivos de la empresa, así mismo de la investigación desarrollada sobre la coyuntura política, social y económica del país.

Tabla 12

Matriz de Evaluación de Factores Externos (EFE)

Factores Determinantes del Éxito

Peso Calificación

Calificación

Ponderada

\section{OPORTUNIDADES:}

1 Mayor accesibilidad al financiamiento crediticio.

$\begin{array}{lll}0.08 & 2 & 0.16\end{array}$

2 Industria avícola en crecimiento.

0.10

3

0.30

3 Alto desarrollo de marketing a través de medios digitales.

0.06

1

0.06

4 Mayor conciencia medio ambiental empresarial

0.08

3

5 Alto desarrollo de tecnología del sector

0.08

4

Incremento de uso de harinas del rendering en la alimentación animal.

0.10

3

AMENAZAS:

1 Incertidumbre en el entorno político -económico

0.10

2

0.20

2 Mayor exigencia en el cumplimiento de la normativa medio ambiental y sanitaria.

$0.07 \quad 2 \quad 0.14$

3 Nuevas políticas regulatorias en el sector rendering.

$0.06 \quad 2 \quad 0.12$

4 Brote de influenza aviar en industria avícola.

$0.05 \quad 1 \quad 0.05$

5 Empresas avícolas generen su propio rendering.

$\begin{array}{lll}0.06 & 1 & 0.06\end{array}$

6 Ingreso de nuevos competidores a la industria.

$0.07 \quad 1$

Reducción del precio y aumento de la oferta del principal

7 sustituto (harina de pescado).

$\begin{array}{lll}0.09 & 3 & 0.27\end{array}$

\section{TOTALES}

1.00

2.29

Tomado de El Proceso Estratégico, Un enfoque de Gerencia (p. 185), por F. D’alessio 2015, Lima, Perú: Copyrigth 2015 por Pearson Educación del Perú SA 
Sobre los resultados obtenidos de la tabla 12, la matriz concluye que la empresa tiene una puntuación ponderada total de 2.29; de acuerdo a lo referido al autor David (2013) una puntuación ponderada total por debajo del promedio (2.5) significa que la empresa no está aprovechando de manera eficaz las oportunidades existentes y tampoco están minimizando las posibles consecuencias adversas de las amenazas externas.

Dado este escenario, la empresa deberá replantear sus estrategias y enfocar sus actividades clave; de tal forma, aprovechar mejor las oportunidades y reducir el impacto de las amenazas. 


\section{Capítulo V. Análisis de la Industria}

El presente capítulo tiene como objetivo realizar el análisis del entorno de la industria del rendering, identificando las cinco fuerzas competitivas y los principales actores que las componen; lo cual sentará las bases para establecer las estrategias que maximicen la rentabilidad de la empresa. Se analizará la rivalidad entre empresas competidoras, la entrada potencial de nuevos competidores, el desarrollo potencial de productos sustitutos, el poder de negociación de los proveedores y el poder de negociación de los consumidores.

Asimismo, es indispensable tener en cuenta que los resultados de la empresa están influenciados por estas fuerzas, las estrategias que se establezcan para afrontar las condiciones cambiantes del entorno externo y las realidades competitivas que se presentan. David (2013).

\subsection{Descripción del mercado (demanda) e industria (oferta)}

Actualmente, el mercado avícola es el principal demandante de harinas proteicas, dado que constituye una excelente fuente para la nutrición animal; mientras que los ofertantes son las empresas de rendering. Ambas industrias tienen una relación de interdependencia, puesto que la industria avícola además de ser cliente del rendering, es también proveedor de la materia prima para la producción de las harinas.

Para el cálculo de la oferta, se ha considerado la materia prima obtenida tanto de centros de acopio como de plantas de beneficio de los principales productores avícolas. Dado que el acopio de residuos no es viable realizarse al 100\%, se ha considerado que solo el $75 \%$ del volumen de plumas y el $40 \%$ de las vísceras es recolectado. 
Para el cálculo de la demanda se ha considerado el requerimiento de harinas proteicas de las empresas avícolas del mercado, tomando como referencia el porcentaje de consumo actual de 5\% (porcentaje de harina proteica con respecto a la fórmula del alimento balanceado). Cabe señalar, que este porcentaje de uso es conservador, considerando que en otros países de la región es mayor, llegando hasta el 10\%.

Los parámetros técnicos considerados para la transformación de las aves en subproductos, y los subproductos en harinas, se establecen en la siguiente tabla:

Tabla 13

Parámetros productivos para la transformación de las aves en subproductos

\begin{tabular}{lc}
\hline Parámetros técnicos & Porcentaje \\
\hline Rendimiento de pluma $(\%)^{*}$ & 12 \\
Rendimiento de vísceras $(\%)^{*}$ & 6 \\
Rendimiento de Harina de plumas $(\%)^{* *}$ & 31 \\
Rendimiento de harina de vísceras $(\%)^{* *}$ & 16 \\
Conversión Alimenticia & 1.80 \\
Uso de Harina de pluma en fórmula (\%) & 3 \\
Uso de Harina de víscera en fórmula $(\%)$ & 2 \\
\hline
\end{tabular}

Nota. *Respecto al pollo vivo; ** Respecto a la materia prima

Tomado de Entrevista a cliente San Fernando (2016). 
Tabla 14

Oferta de Harinas Proteicas 2016 proveniente de Centros de Acopio

\begin{tabular}{|c|c|c|c|c|c|}
\hline \multirow{3}{*}{ Centros de Acopio } & \multirow{3}{*}{$\begin{array}{l}\text { I viu cn } \\
\text { Kilos }\end{array}$} & \multicolumn{2}{|c|}{ Kg Materia Prima } & \multicolumn{2}{|c|}{ Kg Harina Ofertada } \\
\hline & & $12 \%$ & $6 \%$ & $31 \%$ & $16 \%$ \\
\hline & & Kg Pluma & Kg Vísceras & Kg Pluma & $\begin{array}{c}\mathrm{Kg} \\
\text { Vísceras }\end{array}$ \\
\hline Callao & $33,973,818$ & $4,076,858$ & $2,038,429$ & $1,263,826$ & 326,149 \\
\hline Canto Grande & $46,129,455$ & $5,535,535$ & $2,767,767$ & $1,716,016$ & 442,843 \\
\hline Caquetá & $80,664,290$ & $9,679,715$ & $4,839,857$ & $3,000,712$ & 774,377 \\
\hline Chorrillos & $19,594,614$ & $2,351,354$ & $1,175,677$ & 728,920 & 188,108 \\
\hline Comas & $40,110,853$ & $4,813,302$ & $2,406,651$ & $1,492,124$ & 385,064 \\
\hline Independencia & $218,619,412$ & $26,234,329$ & $13,117,165$ & $8,132,642$ & $2,098,746$ \\
\hline La Victoria & $47,969,141$ & $5,756,297$ & $2,878,148$ & $1,784,452$ & 460,504 \\
\hline Puente Piedra & $18,244,683$ & $2,189,362$ & $1,094,681$ & 678,702 & 175,149 \\
\hline Rímac & $7,127,835$ & 855,340 & 427,670 & 265,155 & 68,427 \\
\hline San Luis & $31,758,523$ & $3,811,023$ & $1,905,511$ & $1,181,417$ & 304,882 \\
\hline San Martin de Porres & $27,431,062$ & $3,291,727$ & $1,645,864$ & $1,020,436$ & 263,338 \\
\hline San Miguel & $28,572,645$ & $3,428,717$ & $1,714,359$ & $1,062,902$ & 274,297 \\
\hline Santa Anita & $55,875,994$ & $6,705,119$ & $3,352,560$ & $2,078,587$ & 536,410 \\
\hline Villa El Salvador & $42,197,112$ & $5,063,653$ & $2,531,827$ & $1,569,733$ & 405,092 \\
\hline Total por Centros de Acopio & $698,269,437$ & $83,792,332$ & $41,896,166$ & $25,975,623$ & $6,703,387$ \\
\hline $\begin{array}{l}\text { Materia Prima Acopiada } \\
75 \% \text { : plumas / } 40 \% \text { vísceras }\end{array}$ & $698,269,437$ & $62,844,249$ & $16,758,466$ & $19,481,717$ & $2,681,355$ \\
\hline
\end{tabular}

Nota. Adaptado de "Sistema de abastecimiento y precios," por Minagri, 2016. 
Tabla 15

Oferta de Harinas proteicas 2016 provenientes de Plantas de Beneficio de Aves de San Fernando

\begin{tabular}{lccccc}
\hline & Pollo y & \multicolumn{2}{c}{ Kg Materia Prima } & \multicolumn{2}{c}{ Kg Harina Ofertada } \\
Plantas de beneficio & pavos en & $12 \%$ & $6 \%$ & $31 \%$ & $16 \%$ \\
& Kilos & Kg Pluma & Kg Vísceras & Kg Pluma & Kg Vísceras \\
\hline \multirow{3}{*}{ San Fernando } & & & & & \\
& $98,153,000$ & $11,778,360$ & $5,889,180$ & $3,651,292$ & 942,269 \\
& & & & & \\
\hline
\end{tabular}

Nota. Tomado de Entrevista a Cliente San Fernando (2016)

Tabla 16

Oferta Total de Harinas Proteicas 2016

Kg. Pluma Kg. Vísceras

\begin{tabular}{lcr}
\hline Total por Centros de Acopio & $19,481,717$ & $2,681,355$ \\
Total por Plantas de Beneficio & $3,651,292$ & 942,269 \\
& & $3,623,623$ \\
\hline Sub Total & $23,133,009$ & \\
\hline TOTAL OFERTADO & $26,756,632$ & \\
Nota. Tomado de Entrevista a Cliente San Fernando (2016).
\end{tabular}

Nota. Tomado de Entrevista a Cliente San Fernando (2016). 
Tabla 17

Demanda de Harinas Proteicas

\begin{tabular}{lcccc}
\hline & Producción & $\begin{array}{c}\text { Alimento } \\
\text { Balanceado }\end{array}$ & H. Pluma & H. Vísceras \\
& $(\mathrm{Kg})$ & $(\mathrm{Kg})$ & $(\mathrm{Kg})$ & $(\mathrm{Kg})$ \\
\hline San Fernando pollo & $154,968,148$ & $278,942,666$ & $8,368,280$ & $5,578,853$ \\
San Fernando pavo & $29,956,000$ & $53,920,800$ & $1,617,624$ & $1,078,416$ \\
Redondos pollo & $97,425,836$ & $175,366,506$ & $5,260,995$ & $3,507,330$ \\
Redondos pavo & $8,986,800$ & $16,176,240$ & 485,287 & 323,525 \\
Ganadería Santa Elena & $72,376,824$ & $130,278,282$ & $3,908,348$ & $2,605,566$ \\
Otras Avícolas & $162,640,169$ & $292,752,304$ & $8,782,569$ & $5,855,046$ \\
Total & $526,353,777$ & $947,436,798$ & $28,423,104$ & $18,948,736$ \\
\hline Total Harina Demandada en Kg & & & & $47,371,840$ \\
Total Harina Demandada en Toneladas & & & 47,372 \\
\hline
\end{tabular}

Nota. Tomado de Entrevista a Cliente San Fernando (2016).

Al comparar los resultados de la oferta $(26,757 \mathrm{TM})$ y demanda $(47,372 \mathrm{TM}) \mathrm{de}$ las harinas proteicas en los cuadros anteriores, vemos que la demanda excede la oferta, por lo que existe una demanda insatisfecha. Actualmente, esta demanda insatisfecha viene siendo cubierta por productos sustitutos que ofrecen otras fuentes proteicas como la harina de soya y harina de pescado principalmente.

La demanda de harinas proteicas del rendering tiene potencial para continuar creciendo, ya que los productores avícolas podrían incrementar los porcentajes de uso de estas harinas en las fórmulas del alimento balanceado, llegando hasta un $10 \%$. Actualmente, no exceden del $5 \%$ en la fórmula por restricciones de disponibilidad y políticas sanitarias de los nutricionistas. 


\subsection{Descripción de las cinco fuerzas competitivas de la industria}

Para analizar y comprender el entorno competitivo en que se desenvuelve Los Ferroles, se ha tomado el modelo de las cinco fuerzas de Michael Porter. Esta herramienta nos permitirá analizar el nivel de competencia dentro de la industria para desarrollar estrategias de negocio (David, 2013).

Tal como lo describe David (2013), el modelo de competitividad de la industria está conformada por las siguientes cinco fuerzas:

1. Rivalidad entre competidores: Una de las fuerzas más poderosa del modelo, debido a que constantemente uno o más competidores del sector sienten la presión o ven la necesidad de mejorar su posición dentro del mercado, por lo que las estrategias se orientan en la creación de ventajas competitivas.

2. Entrada potencial de nuevos competidores: Dado que la posibilidad de que nuevas empresas entren a competir a la industria es constante, es indispensable evaluar las barreras de entrada que determinarán si la empresa formará o no parte del mercado.

3. Desarrollo potencial de productos sustitutos: En donde los productos y/o servicios que ofertan diversas empresas satisfacen la misma necesidad al cliente, por lo que en este punto las empresas ofertantes suelen buscar estrategias de diferenciación.

4. Poder de Negociación de los proveedores: Relacionado con las condiciones de compra de un producto. Dependerá de distintas variables como el número de proveedores que existen en el mercado, las condiciones del producto que ofertan, volumen de compra, etc. 
5. Poder de Negociación de los Clientes: En este punto se tiene en cuenta la capacidad de negociación de los clientes frente a la empresa, dado que cuando los clientes son pocos, están más organizados o están más informados, mayores serán sus exigencias en materia de reducción de precios, de mayor calidad y servicios.

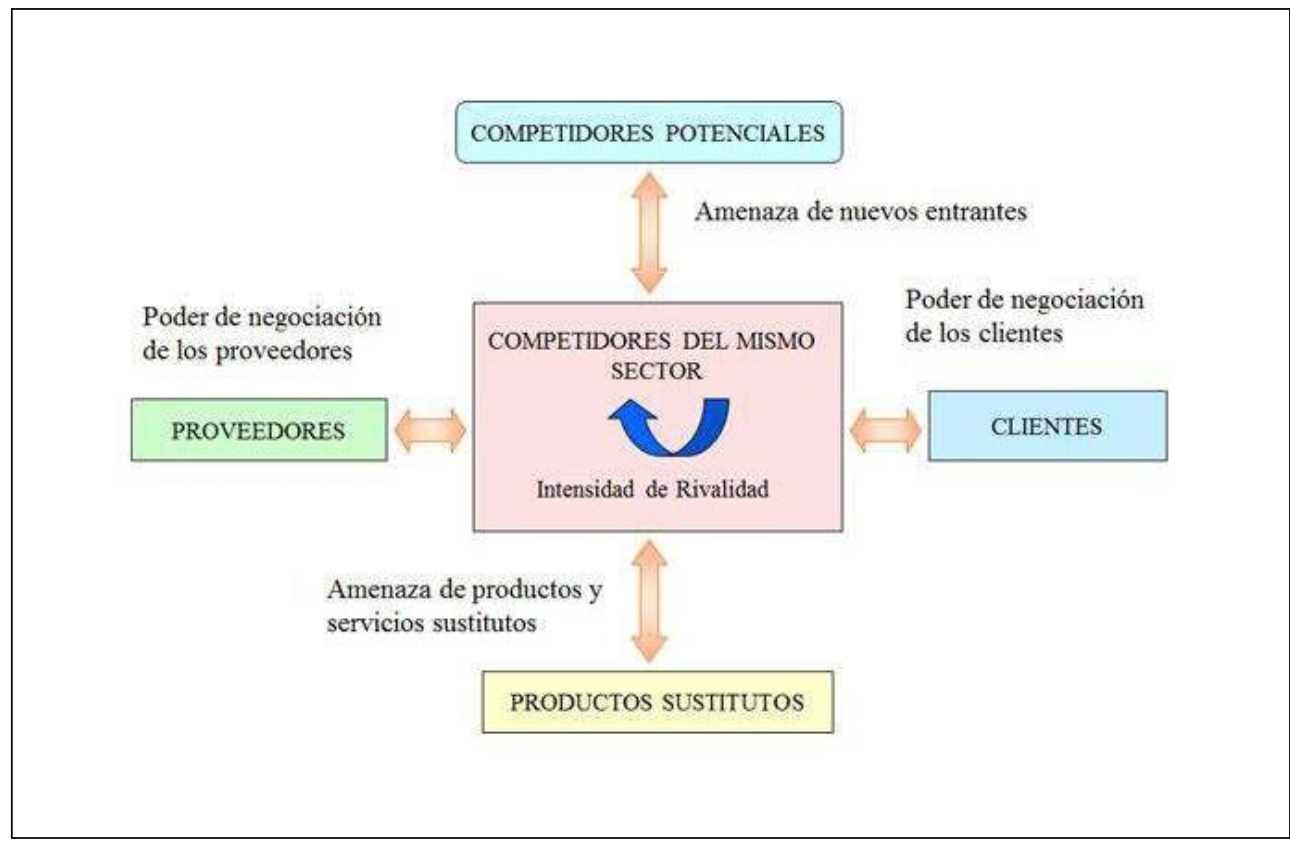

Figura 25. Diagrama Las 5 Fuerzas de Porter. Tomado de "Las 5 Fuerzas de Porter - Clave para el Éxito de la Empresa,” por Matias Riquelme 2015. Recuperado de http://www.5fuerzasdeporter.com/.

\subsubsection{Sustitutos.}

Como David (2013) lo establece, los productos sustitutos establecen un límite máximo al precio que se puede cobrar antes de que los consumidores migren a un producto que cubra la misma necesidad. Estos límites de precio establecen la ganancia máxima y generan un mayor nivel de competencia entre los rivales. La disponibilidad de productos sustitutos genera que el cliente realice una comparación de diversos aspectos tales como la calidad, las especificaciones técnicas, el nivel de desempeño, la practicidad de uso, el precio, entre otros. Es por ello, que las empresas se ven obligadas a 
intensificar esfuerzos para fidelizar a sus clientes y convencerlos que sus productos poseen atributos superiores a los productos sustitutos.

En la industria del rendering, dentro de las principales harinas proteicas que podrían sustituir a las harinas de plumas y vísceras, se tiene: la harina de pescado y la torta de soya. Si bien la calidad nutricional de estos productos es muy alta, su disponibilidad y precio varía en el mercado dependiendo de factores externos. A continuación se detallan ambos sustitutos:

- Harina de pescado: Es un producto obtenido del procesamiento del pescado, eliminando su contenido de agua y aceite. La calidad de la harina dependerá del tipo de pescado que se utilice (pescado rojo o blanco). Este producto es rico en aminoácidos esenciales, especialmente lisina y metionina. (Fis-Net, 2016)

- Torta de soya: Es el subproducto residual del frijol de soya integral, después de extraer el aceite. Posee un contenido alto de proteína y también un buen balance de aminoácidos esenciales. (Agrocolanda, 2016)

Asimismo, como sustitutos secundarios se consideran el corn gluten meal (CGM), los granos secos de destilería (DDGS), el germen de trigo y la torta de girasol. Estos sustitutos no se ofrecen en altos volúmenes al mercado, por lo que su compra se realiza cada vez que están disponibles y con precio competitivo. A continuación se detalla:

- $\quad$ Corn gluten meal (CGM): Es un subproducto del procesamiento de maíz que históricamente se ha utilizado para la alimentación animal. (Todoagro, 2016) 
- Germen de trigo: Proviene de la semilla que se remueve durante el refinamiento del grano de trigo para obtener harina de trigo blanca, el producto es rico en vitaminas, minerales y proteínas.(Botanical online, 2016)

- Torta de girasol: Subproducto de la industria extractora de aceite de girasol, obtenido a partir de las semillas de girasol. Es una fuente de proteína de alta calidad, dado que es libre de compuestos tóxicos. (Aceite de semillas, 2016)

- Granos secos de destilería con solubles (Distillers dried grains with the solubles, DDGS): Coproducto del proceso de producción del bioetanol. Los DDGS poseen una alta concentración de grasa y fibras que lo convierte en un pienso más fácil de digerir para el ganado. Las características y el valor nutricional varía del tipo de cereal del que proceden. (La energía del cambio, 2016)

Si bien la ración proteica en el alimento balanceado no puede cubrirse al 100\% con harinas de rendering, lo más conveniente es hacer un mix de harinas proteicas de origen animal y vegetal. El balance proteico de la mezcla de harinas es lo que genera mejor efecto nutricional en las aves. Según lo señalado por el asesor y experto técnico entrevistado (ver Anexo $\mathrm{N}^{\circ}$ ), el uso exclusivo de torta de soya en la alimentación genera exceso de fibra en los intestinos de las aves, dado que el $47 \%$ de este insumo es proteína, y el resto es mayormente fibra. En los mercados, el principal indicador de la calidad del pollo es el peso de los intestinos, puesto que es merma para el cliente, por lo que cuanto menos cargados estén, mayor será la percepción de calidad para el cliente. Esta particularidad en la torta de soya contrasta con el alto nivel de digestibilidad de las harinas proteicas del rendering, y las hace más atractivas para los nutricionistas avícolas. 


\subsubsection{Potenciales.}

Cuando se conoce que un sector o industria tiene buenos rendimientos de capital, atrae mayor número de inversionistas, lo cual aumenta la competencia e incrementa la capacidad y productividad del sector; sin embargo reduce la rentabilidad. Asimismo, las barreras de entrada que tendría que afrontar un nuevo competidor para introducirse a una industria son: (a) la necesidad de lograr economías de escala, (b) la necesidad de obtener tecnología y conocimientos técnicos especializados, (c) falta de experiencia, (d) lealtad de los clientes, (e) requerimientos de capital, (f) falta de canales de distribución adecuados, (g) políticas gubernamentales, (h) aranceles, (i) dificultad de acceso a la materias primas, (j) posesión de patentes, $(\mathrm{k})$ el contra ataque por parte de empresas bien afianzadas y (l) la potencial saturación del mercado. A pesar de las numerosas barreras de ingreso existentes, algunas empresas logran ingresar al sector, dado que ofrecen productos de alta calidad, precios bajos y una adecuada gestión de marketing. (David, 2013)

Si bien la industria del rendering es una industria atractiva, las barreras de ingreso que presenta son altas, entre ellas podemos destacar las siguientes:

- $\quad$ Escasez de la materia prima: dependencia del sector avícola.

- $\quad$ Alto costo logístico para acopio de la materia prima: básicamente para el traslado de la materia prima desde los centros de faenado y centros de acopio hacia las plantas procesadoras de rendering.

- Conocimiento técnico requerido para los procesos productivos: existen muy pocos profesionales con experiencia en el sector.

- Conocimiento del sector: tanto del rendering como de los canales de comercialización avícola. 


\subsubsection{Clientes.}

“Cuando los clientes están concentrados, son muchos o compran en volumen su poder de negociación representa una importante fuerza que afecta la intensidad de la competencia de la industria". (David, 2013, p.78).

El volumen de venta de Los Ferroles está concentrado en dos clientes claves: San Fernando y Santa Elena, los cuales abarcan más del 75\% de su facturación. El otro 25\% lo conforman clientes menores cuya frecuencia y volumen de compra es fluctuante y sensible al precio. Por lo tanto, los Ferroles tienen una fuerte concentración de sus ventas en sólo dos empresas. Esta concentración de clientes se podría convertir en una desventaja dado que si sus dos grandes clientes dejaran de comprarles, perderían un gran porcentaje de su facturación, asimismo, los hace dependientes de las exigencias de ellos. Por otro lado, limita a la empresa a diversificar en otros nichos de mercado.

Sobre los clientes, tenemos lo siguiente:

- San Fernando S.A.: empresa familiar del Grupo Ikeda. Perteneciente al sector agroindustrial, especializada en producción y comercialización de alimentos de consumos masivo. Líder en el sector avícola con una participación de mercado mayor al $30 \%$.

- Ganadera Santa Elena S.A.: empresa familiar del Grupo Valdez. Productora y comercializadora de pollos y huevos comerciales. Cuenta con una participación de mercado de aproximadamente $14 \%$. 


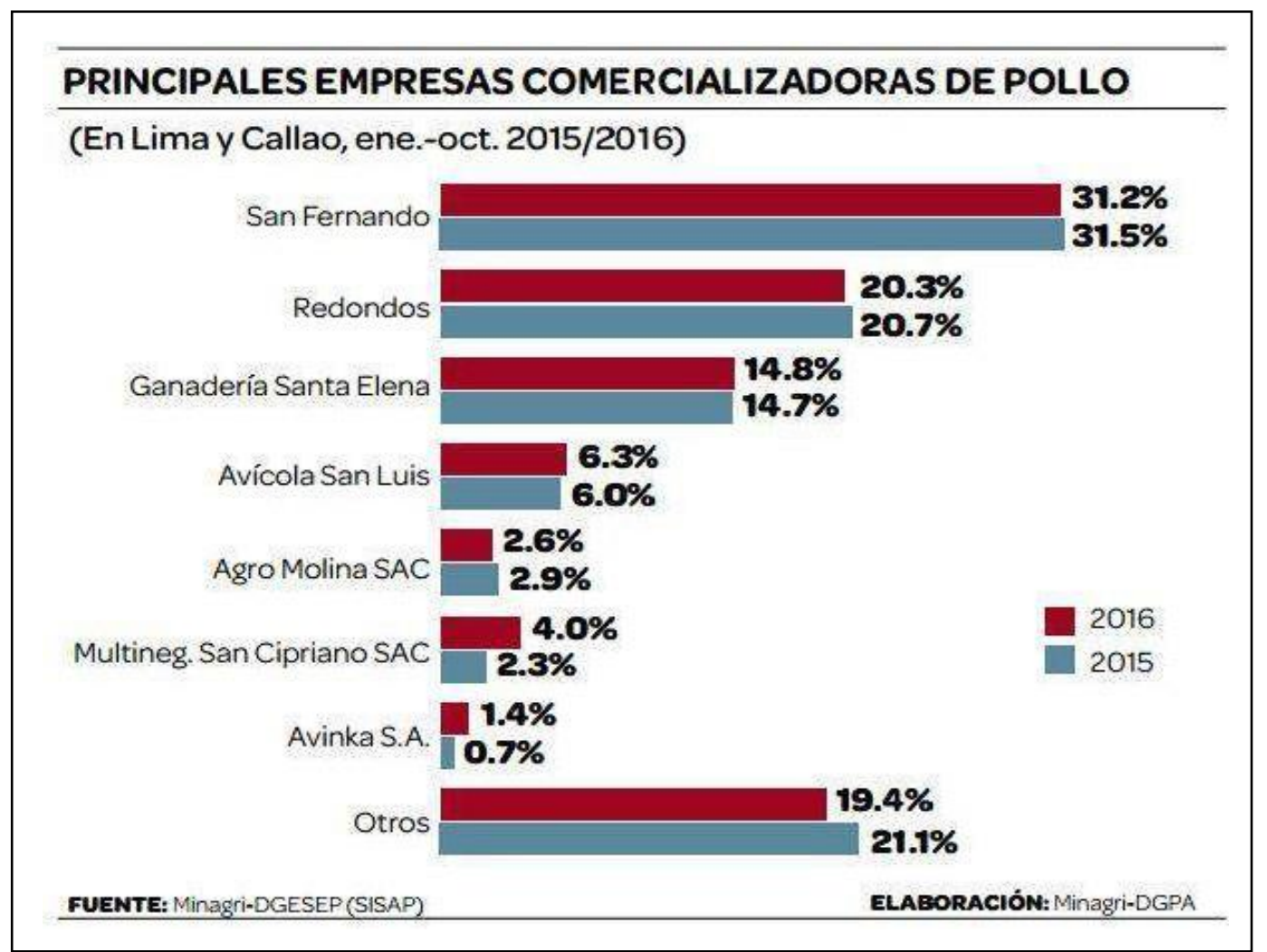

Figura 26. Principales empresas comercializadoras de pollo. Tomado de "Avinka y Ganadera Santa Elena se fusionan”, por El Diario Gestión, 2016. Recuperado de http://gestion.pe/empresas/avinka-y-ganadera-santa-elena-se-fusionan-y-estandetras-san-fernando-2176246

Entre los factores que determinan el impacto del poder de negociación de los clientes tenemos:

- $\quad$ Son proveedores de la materia prima

- Fuerte influencia sobre precio de venta

- Fuerte influencia sobre las condiciones de pago

- Exigencia de estándares de calidad

\subsubsection{Proveedores.}

El poder de negociación de los proveedores afecta en gran medida en los costos de la empresa. Este impacto es alto, cuando en el mercado no se cuenta con un gran número 
de proveedores, o en el caso que la materia prima a utilizar no cuenta con sustitutos cercanos. Es por ello, que dentro de las tácticas utilizadas por las empresas para hacer frente a esta problemática, una alternativa es aplicar la estrategia de integración hacia atrás, obteniéndose de esta manera el control del proveedor. (David, 2013)

Los principales proveedores de Los Ferroles, son las empresas acopiadoras de residuos (vísceras y plumas) procedentes de los centros de distribución y mercado de abastos de Lima. Estos proveedores deben cumplir determinados requisitos sanitarios y medioambientales por lo que deben constituirse como empresas prestadoras de servicios de residuos sólidos (EPS-RS) ante el Ministerio de Salud. Si bien existen varias empresas que prestan el servicio de acopio de residuos a nivel de mercados, son pocas las formales y cumplidoras de los requisitos legales. Estas empresas en su mayoría no cuentan con procesos estandarizados, ni ofrecen garantías de calidad en sus servicios, lo que hace que la negociación con ellos sea más compleja. Ante este escenario, se deben buscar alianzas estratégicas para afianzar los lazos comerciales con estos proveedores.

\subsubsection{Competencia en el mismo sector.}

Como David (2013) lo establece, la intensidad de la rivalidad entre empresas competidoras tiende a aumentar a medida que el número de competidores se incrementa, asimismo, cuando sus características de participación en el mercado tales como tamaño y capacidad, demanda por los productos, reducción de precios se vuelve similares y común entre las empresas competidoras. Otro escenario que se puede presentar cuando aumenta la rivalidad es cuando los consumidores pueden cambiar de marca fácilmente, la demanda del consumidor crece lentamente, los costos fijos son elevados entre otros. 
Una de las estrategias que deben asumir las empresas cuando detectan alguna debilidad entre sus rivales es reforzar sus esfuerzos de gestión comercial y producción para capitalizar la oportunidad.

La industria del rendering en el Perú se concentra en tres empresas:

\section{Alimencorp SAC \\ 2. Technofeed SAC}

3. Negocios Agroindustriales Los Ferroles SAC.

Si bien Alimencorp y Technofeed se dirigen principalmente al mercado pecuario y de alimento para mascotas, también atienden el mercado avícola, lo cual representa una permanente competencia para Los Ferroles, más aún cuando las empresas avícolas no son muchas en el mercado. Adicional a ello, los precios que las tres empresas ofrecen al mercado son similares y competitivos, aunque nunca han llegado a caer en guerra de precios.

A continuación, una breve descripción de cada una de ellas y lo que caracteriza su gestión empresarial:

\section{Alimencorp S.A.C.}

- Se dirige al sector pecuario, alimentos para mascotas (pet food), y avícola.

- Cartera de productos: (a) Harina de subproductos de origen animal: se oferta al mercado con la marca "Proteika", (b) Harina de carne y hueso es de alto valor nutricional: se oferta al mercado con la marca "Haricar", (c) Concentrado nutricional plus: se compone de alto contenido de harina de 
pescado, (d) Harina de plumas hidrolizada, (e) Proteika Plus: harina de subproducto de origen animal premium.

- Dentro de sus principales clientes se encuentran las empresas Purina y Molitalia.

Sus ventajas competitivas se enfocan en:

- Implementación del sistema de calidad HACCP - Sistema de Análisis de Peligros y Control de Puntos Críticos.

- Ofrecen diferentes líneas de productos tanto para el sector pecuario, acuícola y mercado de alimentos para mascotas.

- Cuenta con un área de investigación y desarrollo.

- Su servicio es personalizado y enfocado a las necesidades del cliente.

- Desarrollan servicio de post venta.

\section{Technofeed S.A.C.}

- Se dirige al sector pecuario, acuicultura y alimentos para mascotas (pet food)

- Cartera de productos: (a) Harina de plumas; (b) Harina de pollo (menudencia y vísceras); (c) Aceite de pollo; (d) Harina de carne (equino, vacuno, porcino, ovino) y (e) Harina de hueso.

- Tienen como clientes claves a empresas reconocidas en el mercado peruano: (a) Alicorp (acuicultura), (b) Purina (alimento para mascotas), (c) Vitapro (avicultura), (d) Naltech (acuicultura), (e) Molitalia (alimento para mascotas), (f) Ganadera Santa Elena (avicultura), (g) Caisa aromas (alimento para mascotas). 
Sus ventajas competitivas se enfocan en:

- Es la única empresa de la industria del rendering que cuenta con Certificación ISO 9001.

- Las líneas de productos son de alta calidad, dado que pasan por estrictos controles de calidad.

- Tienen experiencia y conocen el mercado, asimismo, cuentan con equipo multidisciplinario de especialistas en el sector.

\section{Negocios Agroindustriales Los Ferroles SAC}

- Se dirige al sector avícola exclusivamente

- Cartera de productos: (a) Harina de plumas; (b) Harina de vísceras.

- Propuesta de valor: especialistas en la producción y comercialización de

- insumos de alto valor proteico, garantizando a sus clientes una nutrición

- animal de calidad.

- Tiene como clientes claves: (a) San Fernando, (b) Santa Elena, (c) Redondos

Como ventaja competitiva presenta las siguientes características:

- Lidera el mercado de procesamiento de subproductos avícolas

- Alianza estratégica con la empresa San Fernando mediante el servicio de maquila.

- Utiliza tecnología de última generación para el proceso productivo.

- Es especialista en el procesamiento de harinas para el sector avícola. 
Dado que la industria del rendering se concentra en tres grandes empresas y los productos ofrecidos son similares, la rivalidad entre ellas es media; por lo cual la empresa deberá orientar sus estrategias en reducir sus debilidades y repotencias sus fortalezas.

Del análisis de los competidores, se identifican temas a plantear en el planeamiento estratégico para Los Ferroles:

- Certificación de sistema de gestión de calidad e inocuidad ISO 9001 y HACCP respectivamente.

- Mejora de los estándares de calidad

- Posibilidad de diversificar líneas de productos

- Implementación de área de Investigación y Desarrollo.

\subsection{Matriz de atractividad de cada una de las cinco fuerzas}

En las siguientes matrices se muestra el análisis de la atractividad de las cinco fuerzas de Porter, así como el análisis del poder las fuerzas.

Para el análisis se han considerado las variables que generan mayor impacto para cada una de estas fuerzas, dándoles una ponderación según su nivel de importancia, y posteriormente una puntuación de 1 a 5 , donde 1 representa un nivel de intensidad muy bajo, y 5 un nivel de intensidad muy alto. El promedio ponderado de estos resultados es el que determina el nivel de atractividad así como el poder de la fuerza.

Se han establecido los siguientes rangos de puntuación para establecer los niveles de atractividad y de poder de la fuerza: 
- $\quad$ Bajo: 1 a 2.3

- $\quad$ Medio: 2.4 a 3.6

- $\quad$ Alto: 3.7 a 5

\section{Desarrollo de Productos Sustitutos.}

La Matriz de Atractividad de Desarrollo de productos sustitutos, muestra la variable (a) Disponibilidad con mayor puntaje; y la variable (b) grado de bioseguridad con el puntaje más bajo. Esta puntuación se explica a continuación:

- Disponibilidad: Los sustitutos son productos fluctuantes en el mercado, cuya disponibilidad y precio varía. Las harinas proteicas por el contrario, mantienen una oferta y precio más estable.

- Grado de bioseguridad: por la naturaleza de los productos sustitutos (origen vegetal e hidrobiológico), son más seguros sanitariamente. Las harinas proteicas del rendering presentan un riesgo potencial sanitario alto si es que su procesamiento no es controlado, esta condición reduce su nivel de atractividad para la industria. El análisis del Poder de la fuerza muestra las variable (a) bajo costo relativo al cambio con mayor puntaje; y las variables (b) facilidad de pago y (c) marca reconocida, con el puntaje más bajo. Esta puntuación se explica a continuación:

- $\quad$ Bajo costo relativo al cambio: los productos sustitutos presentan características físicas muy similares a las harinas proteicas del rendering, por lo que la tecnología empleada y el flujo del proceso productivo es el mismo, no generando la necesidad 
de incurrir en ningún gasto extra para el cambio. Es muy simple pasar de un producto a otro.

- $\quad$ Facilidad de pago: la ponderación y calificación dada a esta variable es baja, debido a que las negociaciones de pago en grandes volúmenes normalmente son al crédito, tanto para las harinas proteicas del rendering como para los sustitutos; por tanto es una variable que no otorga mayor atractividad a los sustitutos.

- Marca reconocida: a esta variable también se le dio una ponderación y calificación baja. Si bien la marca y el prestigio de las compañías proveedoras suele ser un factor que ejerce influencia en la elección de los sustitutos, las compras normalmente se basan en la calidad de los mismos, es una práctica común de las empresas avícolas realizar análisis de manera que la decisión de compra se sustenta en los análisis físicos químicos y microbiológicos, más que en la marca. 


\section{Tabla 18}

Matriz de Atractividad de Desarrollo de Productos Sustitutos.

\begin{tabular}{|c|c|c|c|c|c|c|c|c|c|c|c|}
\hline \multirow[b]{2}{*}{ Factor Competitivo } & \multirow[b]{2}{*}{ Ponderación } & \multicolumn{2}{|c|}{ Poder de la fuerza } & \multirow[b]{2}{*}{$\begin{array}{l}\text { Criterios nada } \\
\text { atractiva }\end{array}$} & \multicolumn{6}{|c|}{ Atractividad de la Industria } & \multirow[b]{2}{*}{$\begin{array}{c}\text { Calificación } \\
\text { Ponderada }\end{array}$} \\
\hline & & Calificación & $\begin{array}{l}\text { Calificación } \\
\text { Ponderada }\end{array}$ & & $\begin{array}{c}\text { Nada } \\
\text { atractiva } \\
(1) \\
\end{array}$ & $\begin{array}{c}\text { Poco } \\
\text { atractiva } \\
(2) \\
\end{array}$ & $\begin{array}{l}\text { Neutral } \\
\text { (3) }\end{array}$ & $\begin{array}{l}\text { Atractiva } \\
\text { (4) }\end{array}$ & $\begin{array}{c}\text { Muy } \\
\text { Atractiva } \\
(5) \\
\end{array}$ & $\begin{array}{l}\text { Criterio muy } \\
\text { atractiva }\end{array}$ & \\
\hline Precio competitivo & 0.20 & 4 & 0.8 & Precios bajos & & 2 & & & & Precios altos & 0.4 \\
\hline Calidad nutricional & 0.15 & 4 & 0.6 & Alta calidad & & 2 & & & & Baja calidad & 0.3 \\
\hline Disponibilidad & 0.15 & 3 & 0.45 & $\begin{array}{l}\text { Alta disponibilidad } \\
\text { en cantidad y } \\
\text { oportunidad }\end{array}$ & & & 3 & & & $\begin{array}{c}\text { Baja disponibilidad } \\
\text { en cantidad y } \\
\text { oportunidad }\end{array}$ & 0.45 \\
\hline Facilidad de pago & 0.05 & 3 & 0.15 & Grandes facilidades & & & 3 & & & Pocas facilidades & 0.15 \\
\hline $\begin{array}{l}\text { Grado de } \\
\text { bioseguridad }\end{array}$ & 0.10 & 4 & 0.4 & $\begin{array}{l}\text { Alto grado } \\
\text { bioseguridad del } \\
\text { producto }\end{array}$ & 1 & & & & & $\begin{array}{l}\text { Bajo grado } \\
\text { bioseguridad del } \\
\text { producto }\end{array}$ & 0.1 \\
\hline Marca reconocida & 0.05 & 3 & 0.15 & $\begin{array}{c}\text { Alto reconocimiento } \\
\text { de la marca por los } \\
\text { clientes }\end{array}$ & & & 3 & & & $\begin{array}{c}\text { Bajo } \\
\text { reconocimiento de } \\
\text { la marca por los } \\
\text { clientes }\end{array}$ & 0.15 \\
\hline $\begin{array}{l}\text { Bajo costo relativo al } \\
\text { cambio }\end{array}$ & 0.20 & 5 & 1 & $\begin{array}{l}\text { Bajo costo de } \\
\text { cambio }\end{array}$ & 1 & & & & & $\begin{array}{l}\text { Alto costo de } \\
\text { cambio }\end{array}$ & 0.2 \\
\hline Garantía de calidad & 0.10 & 4 & 0.4 & $\begin{array}{l}\text { Alta garantía de } \\
\text { calidad }\end{array}$ & & 2 & & & & $\begin{array}{l}\text { Sin garantía de } \\
\text { calidad }\end{array}$ & 0.2 \\
\hline TOTAL & 1 & ALTO & 3.95 & & & & BAJO & & & & 1.95 \\
\hline
\end{tabular}




\section{Entrada de Competidores Potenciales.}

La Matriz de Atractividad de Entrada de Competidores Potenciales muestra a las variables (a) inversión en tecnología y (b) acceso a materia prima, con mayor puntaje; y la variable (c) fidelidad de los clientes, con el puntaje más bajo. Esta puntuación se explica a continuación:

1. Inversión en tecnología: es una de las mayores barreras de ingreso, lo cual favorece a la industria al restringir el ingreso de nuevos competidores.

2. Acceso a materia prima: es otra de las barreras de ingreso, al ser escasa la materia prima, los nuevos competidores que quieran ingresar deberán evaluar y establecer estrategias para sobrellevar esta limitante.

3. Fidelidad de los clientes: en esta industria si bien la calidad es importante, los clientes no son fieles a las marcas, la oportunidad de compra más que nada está determinada por el precio y la disponibilidad.

El análisis del Poder de la fuerza muestra las variable (a) rentabilidad con el mayor puntaje; y las variables (b) conocimiento técnico requerido, (c) acceso a materias primas (d) expertis en el sector, (e) permisos gubernamentales y (f) fidelidad de los clientes, con el puntaje más bajo. Esta puntuación se explica a continuación:

- $\quad$ Rentabilidad: La rentabilidad es uno de los aspectos que más atrae a los nuevos competidores, dado que es el objetivo primordial de toda empresa, y el rendering es rentable al tener costos de producción bajos. 
- Conocimiento técnico requerido: es necesario conocer la ingeniería del proceso, y en el Perú casi no se encuentran profesionales en esta rama.

- $\quad$ Acceso a materias primas: el acceso es muy limitado, dependerá mucho de las negociaciones que se puedan realizar con los centros de acopio de pollo.

- $\quad$ Expertis en el sector: es necesario conocer cómo se desenvuelve el sector rendering y el sector avícola; este entendimiento es determinante para establecer estrategias de negocio.

- Permisos gubernamentales: tanto en aspectos sanitarios, medioambientales, municipales. Hoy en día la exigencia en este aspecto es mayor.

- $\quad$ Fidelidad de los clientes: en esta industria si bien la calidad es importante, los clientes no son fieles a las marcas, la oportunidad de compra más que nada está determinada por el precio y la disponibilidad. 
Tabla 19

Matriz de Atractividad de Entrada de Competidores Potenciales.

\begin{tabular}{|c|c|c|c|c|c|c|c|c|c|c|c|}
\hline & & PODER DE & A FUERZA & & & ATRA & TIVIDAI & DE LA IN & UUSTRIA & & \\
\hline $\begin{array}{c}\text { FACTOR } \\
\text { COMPETITIVO }\end{array}$ & Ponderación & Calificación & $\begin{array}{c}\text { Calificación } \\
\text { Ponderada }\end{array}$ & $\begin{array}{c}\text { Criterio que la } \\
\text { hace nada } \\
\text { atractiva } \\
(-)\end{array}$ & $\begin{array}{c}\text { Nada } \\
\text { atractiva (1) }\end{array}$ & $\begin{array}{l}\text { Poco } \\
\text { atractiva } \\
(2)\end{array}$ & $\begin{array}{l}\text { Neutral } \\
\text { (3) }\end{array}$ & $\begin{array}{l}\text { Atractiva } \\
\quad(4)\end{array}$ & $\begin{array}{c}\text { Muy } \\
\text { Atractiva } \\
\text { (5) }\end{array}$ & $\begin{array}{c}\text { Criterio que la } \\
\text { hace muy } \\
\text { atractiva } \\
(+)\end{array}$ & $\begin{array}{c}\text { Calificación } \\
\text { Ponderada }\end{array}$ \\
\hline Rentabilidad del negocio & 0.2 & 4 & 0.8 & Baja & & 2 & & & & $\begin{array}{c}\text { Alta } \\
\text { rentabilidad }\end{array}$ & 0.4 \\
\hline Inversión en tecnología & 0.15 & 2 & 0.3 & $\begin{array}{l}\text { rentabilidad } \\
\text { Bajos costos de } \\
\text { inversión }\end{array}$ & & & & & 5 & $\begin{array}{l}\text { Altos costos de } \\
\text { inversión }\end{array}$ & 0.8 \\
\hline $\begin{array}{l}\text { Conocimiento técnico } \\
\text { requerido }\end{array}$ & 0.1 & 2 & 0.2 & $\begin{array}{l}\text { Poco nivel de } \\
\text { conocimiento } \\
\text { requerido }\end{array}$ & & & & 4 & & $\begin{array}{l}\text { Alto nivel de } \\
\text { conocimiento } \\
\text { requerido }\end{array}$ & 0.4 \\
\hline Acceso a materias primas & 0.15 & 1 & 0.2 & $\begin{array}{l}\text { Alta facilidad } \\
\text { para acceder a } \\
\text { las materias } \\
\text { primas }\end{array}$ & & & & & 5 & $\begin{array}{c}\text { Poca facilidad } \\
\text { para acceder a } \\
\text { las materias } \\
\text { primas }\end{array}$ & 0.8 \\
\hline Expertis en el sector & 0.1 & 2 & 0.2 & $\begin{array}{l}\text { Bajo nivel de } \\
\text { experiencia del } \\
\text { sector } \\
\text { requerido }\end{array}$ & & & & & 5 & $\begin{array}{l}\text { Alto nivel de } \\
\text { experiencia del } \\
\text { sector } \\
\text { requerido }\end{array}$ & 0.5 \\
\hline $\begin{array}{l}\text { Permisos } \\
\text { gubernamentales }\end{array}$ & 0.1 & 2 & 0.2 & $\begin{array}{l}\text { Bajo nivel de } \\
\text { exigencia para } \\
\text { permisos }\end{array}$ & & & & 4 & & $\begin{array}{l}\text { Alto nivel } \\
\text { exigencia para } \\
\text { permisos }\end{array}$ & 0.4 \\
\hline Fidelidad de los clientes & 0.05 & 3 & 0.2 & $\begin{array}{l}\text { Alto nivel de } \\
\text { fidelidad de } \\
\text { clientes }\end{array}$ & & & 3 & & & $\begin{array}{l}\text { Bajo nivel de } \\
\text { fidelidad de } \\
\text { clientes }\end{array}$ & 0.2 \\
\hline TOTAL & 1 & BAJO & 2.3 & & & & ALTO & & & & 4 \\
\hline
\end{tabular}




\section{Poder de Negociación de los Clientes.}

La Matriz de Atractividad del Poder de Negociación de los Clientes muestra a la variable (a) necesidad de compra de cliente con el mayor puntaje, y (b) conocimiento sobre la competencia, con el puntaje más bajo. Esta puntuación se explica a continuación:

- $\quad$ Necesidad de compra de los clientes: al ser las harinas de rendering productos de alta calidad nutricional, son insumos muy demandados en la alimentación animal, por lo cual se genera una fuerte necesidad de compra por parte de los clientes.

- Conocimiento sobre la competencia: al ser sólo tres las empresas ofertantes de harinas de rendering, la información sobre sus productos y precios está bastante difundida en el mercado, lo cual favorece a que los clientes puedan pasar de un proveedor a otro según la oferta ofrecida en el momento.

El análisis del Poder de la fuerza muestra la variable (a) número de clientes del sector avícola con el mayor puntaje; y la variable (b) necesidad de compra del cliente con el puntaje más bajo. Esta puntuación se explica a continuación:

- $\quad$ Número de clientes del sector avícola: al ser pocas las empresas en el sector avícola, les genera mayor poder de negociación, dado que pueden presionar por precio y volumen. Si Los Ferroles perdiera como clientes claves a San Fernando o a Santa Elena, perdería más de un tercio de la venta total, lo cual generaría un fuerte impacto; adicional, conseguir nuevos clientes implicaría grandes esfuerzos y probablemente, reducción de rentabilidad. 
- $\quad$ Necesidad de compra del cliente: las harinas proteicas del rendering son un producto muy demandado por los clientes por su alto valor nutricional, y su oferta es restringida en el mercado.

\section{Poder de Negociación de los Proveedores.}

La Matriz de Atractividad del Poder de Negociación de los Proveedores muestra a la variable (a) número de clientes en el mercado, con el mayor puntaje; y la variable (b) abastecimiento directo, con el puntaje más bajo. Esta puntuación se explica a continuación:

- $\quad$ Número de clientes en el mercado: al ser pocas las empresas de rendering, los proveedores (acopiadores de materia prima) no tienen muchas alternativas con quien negociar; lo cual genera más poder para la industria.

- $\quad$ Abastecimiento directo: si bien en la actualidad existen algunas empresas avícolas que producen sus propias harinas de rendering para consumo interno, esta práctica puede extenderse al resto de empresas, lo cual generaría una gran reducción de materia prima al mercado, por lo que la industria del rendering se vería seriamente afectada. 
Tabla 20

Matriz de Atractividad del Poder de Negociación de Clientes

\begin{tabular}{|c|c|c|c|c|c|c|c|c|c|c|c|}
\hline \multirow[b]{2}{*}{$\begin{array}{c}\text { FACTOR } \\
\text { COMPETITIVO }\end{array}$} & \multirow[b]{2}{*}{ Ponderación } & \multicolumn{2}{|c|}{ PODER DE LA FUERZA } & \multicolumn{8}{|c|}{ ATRACTIVIDAD DE LA INDUSTRIA } \\
\hline & & Calificación & $\begin{array}{l}\text { Calificación } \\
\text { Ponderada }\end{array}$ & $\begin{array}{l}\text { Criterio que la } \\
\text { hace nada } \\
\text { atractiva } \\
(-)\end{array}$ & $\begin{array}{c}\text { Nada } \\
\text { atractiva } \\
\text { (1) }\end{array}$ & $\begin{array}{c}\text { Poco } \\
\text { atractiva } \\
\text { (2) }\end{array}$ & $\begin{array}{l}\text { Neutral } \\
\text { (3) }\end{array}$ & $\begin{array}{l}\text { Atractiva } \\
\text { (4) }\end{array}$ & $\begin{array}{c}\text { Muy } \\
\text { Atractiva } \\
\text { (5) }\end{array}$ & $\begin{array}{c}\text { Criterio que la } \\
\text { hace muy } \\
\text { atractiva } \\
(+)\end{array}$ & $\begin{array}{r}\text { Calificación } \\
\text { Ponderada }\end{array}$ \\
\hline $\begin{array}{l}\text { Número de clientes } \\
\text { en sector avícola }\end{array}$ & 0.25 & 5 & 1.3 & $\begin{array}{l}\text { Pocos clientes en } \\
\text { el sector avícola }\end{array}$ & & 2 & & & & $\begin{array}{c}\text { Muchos } \\
\text { clientes en el } \\
\text { sector avícola }\end{array}$ & 0.5 \\
\hline $\begin{array}{l}\text { Concentración en } \\
\text { clientes claves }\end{array}$ & 0.15 & 4 & 0.6 & $\begin{array}{c}\text { Baja } \\
\text { concentración en } \\
\text { clientes claves }\end{array}$ & & 2 & & & & $\begin{array}{c}\text { Alta } \\
\text { concentración } \\
\text { en clientes } \\
\text { claves }\end{array}$ & 0.3 \\
\hline $\begin{array}{l}\text { Necesidad de retener } \\
\text { clientes }\end{array}$ & 0.15 & 4 & 0.6 & $\begin{array}{l}\text { Alta necesidad } \\
\text { de retener } \\
\text { clientes }\end{array}$ & & 2 & & & & $\begin{array}{l}\text { Baja necesidad } \\
\text { de retener } \\
\text { clientes }\end{array}$ & 0.3 \\
\hline $\begin{array}{l}\text { Conocimiento sobre } \\
\text { competencia }\end{array}$ & 0.1 & 4 & 0.4 & $\begin{array}{c}\text { Alto } \\
\text { conocimiento } \\
\text { sobre la } \\
\text { competencia }\end{array}$ & & 2 & & & & $\begin{array}{c}\text { Bajo } \\
\text { conocimiento } \\
\text { sobre la } \\
\text { competencia }\end{array}$ & 0.2 \\
\hline $\begin{array}{l}\text { Necesidad de compra } \\
\text { del cliente }\end{array}$ & 0.15 & 2 & 0.3 & $\begin{array}{l}\text { Baja necesidad } \\
\text { de compra del } \\
\text { cliente }\end{array}$ & & & & & 5 & $\begin{array}{l}\text { Alta necesidad } \\
\text { de compra del } \\
\text { cliente }\end{array}$ & 0.8 \\
\hline $\begin{array}{l}\text { Existencia de } \\
\text { sustitutos }\end{array}$ & 0.2 & 3 & 0.6 & $\begin{array}{l}\text { Existencia de } \\
\text { muchos } \\
\text { sustitutos }\end{array}$ & & & 3 & & & $\begin{array}{c}\text { Existencia de } \\
\text { pocos sustitutos }\end{array}$ & 0.6 \\
\hline TOTAL & 1 & ALTO & 3.8 & & & & MEDIO & & & & 2.7 \\
\hline
\end{tabular}


El análisis del Poder de la fuerza muestra la variable (a) materia prima limitada en mercados con el mayor puntaje; y las variables (b) nivel de especialización y (c) abastecimiento directo, con el puntaje más bajo. Esta puntuación explica a continuación:

- Materia prima limitada: al ser ésta escaza, otorga alto poder a los acopiadores, quienes son los proveedores directos.

- Nivel de especialización: al no ser necesario un alto nivel de especialización en los proveedores, pueden ser reemplazados con facilidad por otros, las barreras de ingreso a este negocio son bajas (baja inversión, baja especialización).

- Abastecimiento directo: la producción de harinas de rendering por las mismas empresas avícolas reduce significativamente la oferta de materia prima en el mercado, lo cual afectaría significativamente no sólo a los proveedores, sino a toda la industria del rendering. 
Tabla 21

Matriz de Atractividad del Poder de Negociación de Proveedores.

\begin{tabular}{|c|c|c|c|c|c|c|c|c|c|c|c|}
\hline \multirow[b]{2}{*}{$\begin{array}{c}\text { FACTOR } \\
\text { COMPETITIVO }\end{array}$} & \multirow[b]{2}{*}{ Ponderación } & \multicolumn{2}{|c|}{$\begin{array}{l}\text { PODER DE LA } \\
\text { FUERZA }\end{array}$} & \multicolumn{8}{|c|}{ ATRACTIVIDAD DE LA INDUSTRIA } \\
\hline & & $\begin{array}{r}\text { FUE } \\
\text { Calificación }\end{array}$ & $\begin{array}{l}\text { RZA } \\
\text { Calificación } \\
\text { Ponderada }\end{array}$ & $\begin{array}{c}\text { Criterio que la hace } \\
\text { nada atractiva (-) }\end{array}$ & $\begin{array}{c}\text { Nada } \\
\text { atractiva } \\
(1) \\
\end{array}$ & $\begin{array}{c}\text { Poco } \\
\text { atractiva } \\
(2) \\
\end{array}$ & $\begin{array}{c}\text { Neutral } \\
\text { (3) }\end{array}$ & $\begin{array}{c}\text { Atractiva } \\
\text { (4) }\end{array}$ & $\begin{array}{c}\text { Muy } \\
\text { Atractiva } \\
(5) \\
\end{array}$ & $\begin{array}{c}\text { Criterio que la } \\
\text { hace muy } \\
\text { atractiva }(+)\end{array}$ & $\begin{array}{c}\text { Calificación } \\
\text { Ponderada }\end{array}$ \\
\hline $\begin{array}{l}\text { Número de } \\
\text { proveedores en el } \\
\text { medio }\end{array}$ & 0.15 & 4 & 0.6 & $\begin{array}{l}\text { Pocos proveedores } \\
\text { an al madin }\end{array}$ & & 2 & & & & $\begin{array}{c}\text { Muchos } \\
\text { proveedores en el } \\
\text { medio }\end{array}$ & 0.3 \\
\hline $\begin{array}{l}\text { Nivel de } \\
\text { Especialización }\end{array}$ & 0.1 & 2 & 0.2 & $\begin{array}{c}\text { Bajo nivel de } \\
\text { especialización }\end{array}$ & & & & 4 & & $\begin{array}{l}\text { Alto nivel de } \\
\text { especialización }\end{array}$ & 0.4 \\
\hline $\begin{array}{l}\text { Requisitos } \\
\text { sanitarios a cumplir } \\
\text { (ser EPS-RS) }\end{array}$ & 0.15 & 5 & 0.8 & $\begin{array}{l}\text { Muchos requisitos } \\
\text { sanitarios a cumplir }\end{array}$ & & 2 & & & & $\begin{array}{l}\text { Pocos requisitos } \\
\text { sanitarios a } \\
\text { cumplir }\end{array}$ & 0.3 \\
\hline $\begin{array}{l}\text { Número de Clientes } \\
\text { en el mercado }\end{array}$ & v.L & 2 & 0.4 & $\begin{array}{l}\text { Muchas empresas } \\
\text { de rendering en el } \\
\text { mercado }\end{array}$ & & & & 4 & & $\begin{array}{l}\text { Pocas empresas } \\
\text { de rendering en el } \\
\text { mercado }\end{array}$ & 0.8 \\
\hline $\begin{array}{l}\text { Materia prima } \\
\text { limitada en el } \\
\text { mercaaos }\end{array}$ & 0.25 & 5 & 1.3 & $\begin{array}{l}\text { Poca materia prima } \\
\text { en el mercado }\end{array}$ & 1 & & & & & $\begin{array}{c}\text { Abundante } \\
\text { materia prima en } \\
\text { eı mercaao }\end{array}$ & 0.3 \\
\hline $\begin{array}{l}\text { Abastecimiento } \\
\text { directo (sin } \\
\text { proveedores) }\end{array}$ & 0.15 & 1 & 0.2 & $\begin{array}{l}\text { Muchas empresas } \\
\text { avícolas realizan su } \\
\text { propio rendendering }\end{array}$ & 1 & & & & & $\begin{array}{l}\text { Pocas empresas } \\
\text { avícolas que no } \\
\text { realızan su propıo } \\
\text { rendendering }\end{array}$ & 0.2 \\
\hline TOTAL & 1 & MEDIO & 3.4 & & & & BAJA & & & & 2.2 \\
\hline
\end{tabular}




\section{Rivalidad entre Empresas Competidoras.}

La Matriz de Atractividad de Rivalidad entre Empresas Competidoras muestra a las variables (a) número de competidores y (b) capacidad instalada del competidor, con el mayor puntaje, y las variables (c) número de clientes y (d) precios competitivos con el puntaje más bajo. Esta puntuación se explica a continuación:

- Número de competidores, cuanto mayor sea el número de empresas competidoras, mayor será la rivalidad generada entre ellas. En la industria del rendering, son 3 las principales empresas, por lo que no es un mercado con gran cantidad de competidores.

- Capacidad instalada, de lo evidenciado entre las empresas competidoras, la mayor parte cuenta con poca capacidad instalada para poder incrementar la producción, y en la su mayoría, la tecnología es muy antigua y no automatizada.

- Número de clientes, en esta industria, así como no son muchos los competidores, tampoco son muchos los clientes; no son más de 5 los clientes grandes (San Fernando, Santa Elena, Redondos, San Cirilo y otros), por los que las empresas deben establecer estrategias que les permita fidelizar a sus clientes. Perder un cliente grande, significará un alto impacto en la facturación de la empresa.

- $\quad$ Precios competitivos; los precios en el mercado son bastante similares, dado que las harinas proteicas en su mayoría no tienen un factor de diferenciación, muchas son vendidas y compradas como comodities. Al ser los precios semejantes, la estrategia de manejo de precios es determinante en las negociaciones. 
El análisis del Poder de la fuerza muestra la variable (a) costo relativo al cambio con el puntaje más alto, y (b) número de competidores, y (c) barreras de ingreso al mercado, con el puntaje más bajo. Esta puntuación se explica a continuación:

- Costo relativo al cambio: el cambiar a un sustituto no involucra para la empresa mayores costos, por lo que dependerá de la atractividad de la oferta de la competencia el continuar usando el producto o pasar a un sustituto. Esto incrementa la competencia entre empresas.

- $\quad$ Número de competidores: al ser pocas empresas las que conforman la industria del rendering, pueden repartirse el mercado sin necesidad de generar guerra de precios o similares.

- $\quad$ Barreras de ingreso al mercado: al ser altas las barreras, difícilmente se arriesgarán nuevas empresas a ingresar, por lo que las empresas de rendering seguirán siendo muy pocas. 
Tabla 22

Matriz de Atractividad de Rivalidad entre Empresas Competidoras.

\begin{tabular}{|c|c|c|c|c|c|c|c|c|c|c|c|}
\hline \multirow[b]{2}{*}{$\begin{array}{c}\text { FACTOR } \\
\text { COMPETITIVO }\end{array}$} & \multirow[b]{2}{*}{ Ponderación } & \multicolumn{2}{|c|}{ PODER DE LA FUERZA } & \multicolumn{8}{|c|}{ ATRACTIVIDAD DE LA INDUSTRIA } \\
\hline & & Calificación & $\begin{array}{l}\text { Calificación } \\
\text { Ponderada }\end{array}$ & $\begin{array}{c}\text { Criterio que la } \\
\text { hace nada atractiva } \\
(-)\end{array}$ & $\begin{array}{l}\text { Nada } \\
\text { atractiva } \\
\quad(1)\end{array}$ & $\begin{array}{c}\text { Poco } \\
\text { atractiva } \\
\text { (2) }\end{array}$ & $\begin{array}{l}\text { Neutral } \\
\text { (3) }\end{array}$ & $\begin{array}{l}\text { Atractiva } \\
\text { (4) }\end{array}$ & $\begin{array}{c}\text { Muy } \\
\text { Atractiva } \\
(5) \\
\end{array}$ & $\begin{array}{c}\text { Criterio que la } \\
\text { hace muy } \\
\text { atractiva }(+)\end{array}$ & $\begin{array}{c}\text { Calificación } \\
\text { Ponderada }\end{array}$ \\
\hline $\begin{array}{l}\text { Número de } \\
\text { competidores }\end{array}$ & 0.15 & 2 & 0.3 & $\begin{array}{l}\text { Alto número de } \\
\text { competidores }\end{array}$ & & & & & 5 & $\begin{array}{l}\text { Bajo número de } \\
\text { competidores }\end{array}$ & 0.8 \\
\hline Número de clientes & 0.15 & 4 & 0.6 & $\begin{array}{l}\text { Bajo número de } \\
\text { clientes }\end{array}$ & & 2 & & & & $\begin{array}{l}\text { Alto número de } \\
\text { clientes }\end{array}$ & 0.3 \\
\hline Precios competitivos & 0.15 & 4 & 0.6 & Precios bajos & & 2 & & & & Precios altos & 0.3 \\
\hline $\begin{array}{l}\text { Capacidad instalada de } \\
\text { competidor }\end{array}$ & 0.2 & 2 & 0.4 & $\begin{array}{l}\text { Alta capacidad } \\
\text { instalada de } \\
\text { competidor }\end{array}$ & & & & 4 & & $\begin{array}{l}\text { Baja capacidad } \\
\text { instalada de } \\
\text { competidor }\end{array}$ & 0.8 \\
\hline $\begin{array}{l}\text { Barreras de ingreso al } \\
\text { mercado }\end{array}$ & 0.15 & 2 & 0.3 & $\begin{array}{l}\text { Bajas barreras de } \\
\text { ingreso al mercado }\end{array}$ & & & & 4 & & $\begin{array}{c}\text { Altas barreras } \\
\text { de ingreso al } \\
\text { mercado. }\end{array}$ & 0.6 \\
\hline $\begin{array}{l}\text { Costo relativo al } \\
\text { cambio de los clientes }\end{array}$ & 0.2 & 5 & 1 & $\begin{array}{l}\text { Bajo costo de } \\
\text { cambio de los } \\
\text { clientes }\end{array}$ & & 2 & & & & $\begin{array}{l}\text { Alto costo de } \\
\text { cambio de los } \\
\text { clientes }\end{array}$ & 0.4 \\
\hline TOTAL & 1 & MEDIO & 3.2 & & & & MEDIO & & & & 3.2 \\
\hline
\end{tabular}




\section{Estrategias Genéricas de Michael Porter}

De acuerdo a David, 2015: Michael Porter indica que las estrategias permiten que las organizaciones obtengan una ventaja competitiva, a partir de tres ejes fundamentales: Liderazgo en costos, Diferenciación y Enfoque. Porter llama a estos ejes estrategias genéricas, las cuales se definen a continuación:

1. Liderazgo en costos, se da énfasis a la producción de bienes estandarizados a un costo unitario muy bajo, enfocándose a consumidores con alta sensibilidad al precio. Se definen dos tipos alternativos. Tipo 1: Es la estrategia de bajo costo, ofrece productos y/o servicios a un amplio rango de clientes y al precio más bajo del mercado. El tipo 2: Es la estrategia del mejor valor, ofrece productos y/o servicios a muchos clientes al mejor valor - precio disponible en el mercado. Tanto las estrategias tipo 1 y tipo 2 se orientan a los grandes mercados.

2. Diferenciación, a esta estrategia se le denomina tipo 3, el objetivo es producir bienes y servicios únicos en toda la industria, y dirigirlos a consumidores que son relativamente insensibles al precio.

3. Enfoque, se refiere a producir bienes y servicios que cubran las necesidades de grupos pequeños de consumidores. Incluye las estrategias tipo 4 y tipo 5 . El tipo 4: Es una estrategia de enfoque de bajo costo, que ofrece el precio más bajo disponible en el mercado a un nicho pequeño de clientes. El tipo 5: Es una estrategia de enfoque en el mejor valor, dado que ofrece productos y servicios a pocos clientes al mejor precio disponible en el mercado. También se le conoce como diferenciación enfocada. Tanto las estrategias tipo 4 y 5 se orientan a mercados 
pequeños (nichos), con la diferencia que las de tipo 5 ofrecen precios más alto, pero con mayores beneficios.

Las cinco estrategias de Porter requieren configuraciones organizacionales y sistemas de control diferentes. El liderazgo en costos o en diferenciación suele ser aplicada por empresas grandes y de mayores recursos, mientras que las empresas más pequeñas suelen seguir la estrategia de enfoque. (David, 2015)

En la figura 27, se muestra las cinco estrategias genéricas de Porter.

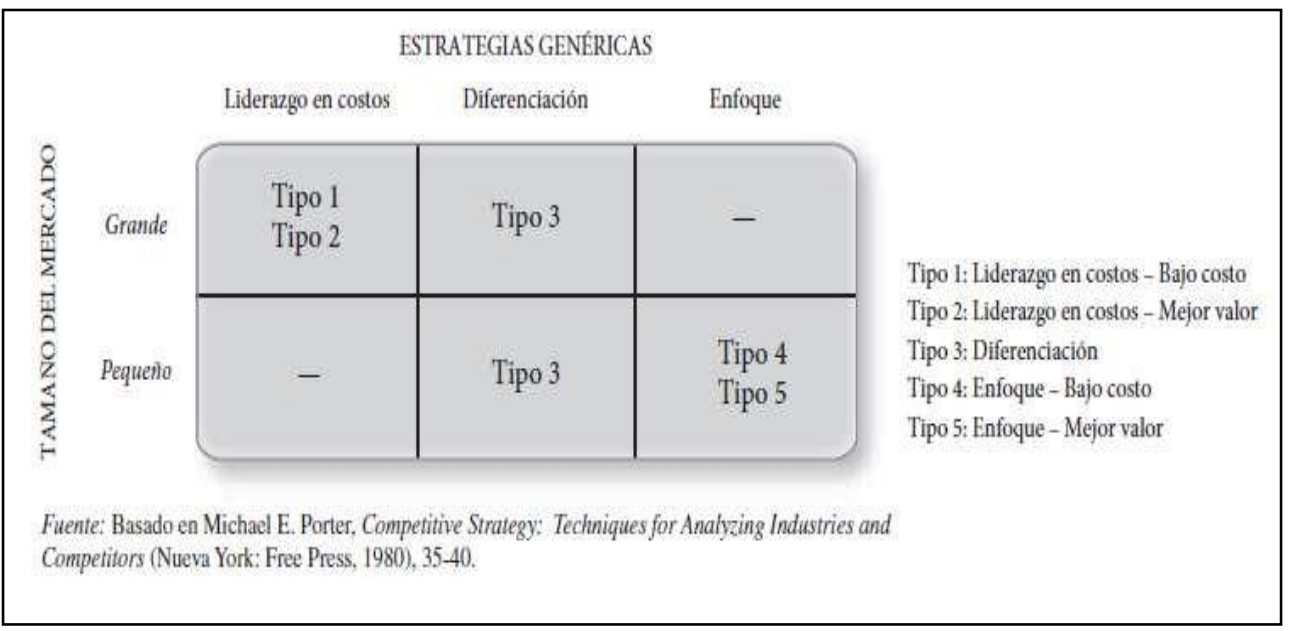

Figura 27: La Cinco Estrategias Genéricas de Porter. Tomado de Conceptos de Administración Estratégica (p. 149), por Fred David, 2013. México. Copyright 2013 por Pearson Educación.

Del análisis de las estrategias mencionadas se evidencia que la situación actual de Los Ferroles se ajusta a la Estrategia de Liderazgo Costo - Mejor Valor, puesto que las harinas ofrecidas a sus clientes son de bajo costo, pero a su vez de alto valor para el cliente. 


\subsection{Análisis del Grado de Atractividad de la Industria}

Luego del análisis independiente de cada una de las fuerzas, se realizó una evaluación global, obteniendo como resultado una puntuación de 2.81. Esta puntuación significa que estas fuerzas ejercen un impacto mediano sobre la industria, es decir, no existen fuerzas que ejerzan marcadas influencias. La fuerza que mayor impacto presentó fue el Entrada potencial de nuevos competidores (4.0); mientras que la que presentó menor impacto fue Desarrollo potencial de productos sustitutos (1.95).

\begin{tabular}{|c|c|c|c|c|c|c|}
\hline \multirow{2}{*}{ Fuerzas Competitivas } & \multirow{2}{*}{ Puntaje } & \multicolumn{5}{|c|}{ GRADO DE ATRACTIVIDAD DE LA INDUSTRIA } \\
\hline & & Muy Alto & Alto (4) & Medio (3) & Bajo (2) & Muy Bajo \\
\hline $\begin{array}{l}\text { Rivalidad entre empresas } \\
\text { competidoras }\end{array}$ & 3.2 & & & & & \\
\hline $\begin{array}{l}\text { Entrada potencial de nuevos } \\
\text { competidores }\end{array}$ & 4.0 & & & & & \\
\hline $\begin{array}{l}\text { Desarrollo potencial de } \\
\text { productos sustitutos }\end{array}$ & 1.95 & & & & & \\
\hline $\begin{array}{l}\text { Poder de negociación de los } \\
\text { proveedores }\end{array}$ & 2.2 & & & & & \\
\hline $\begin{array}{l}\text { Poder de negociación de los } \\
\text { clientes }\end{array}$ & 2.7 & & & & & \\
\hline TOTAL GLOBAL & 2.81 & & & & & \\
\hline
\end{tabular}

Figura 28. Matriz del grado de atractividad de la industria.

\subsection{Matriz de Perfil Competitivo MPC}

La Matriz del Perfil Competitivo identifica los principales competidores que existen en el mercado, así como las fortalezas y debilidades que pueden presentar cada uno de ellos con relación a su posición estratégica. (David 2013).

Para el desarrollo de la matriz se establecieron los factores críticos de éxito más relevantes en la industria del rendering, tanto en los aspectos internos como externos. Estos factores se determinaron luego de las entrevistas realizadas a los directivos de la 
empresa, principales clientes y al experto del sector (ver Anexos $\mathrm{N}^{\circ} 4, \mathrm{~N}^{\circ} 2$ y N $\mathrm{N}^{\circ} 6$ respectivamente). A estos factores se les asignó una ponderación según el nivel de importancia que representan para el logro del éxito, así tenemos que: (a) precio competitivo (b) calidad de producto y (c) costo de producto, fueron los ponderados con mayor peso. Seguidamente a la ponderación se asignó una calificación del 1 al 4, donde 4 es una fortaleza principal, 3 una fortaleza menor, 2 una debilidad menor y 1 una debilidad principal. Finalmente se obtuvo un puntaje total para cada compañía, siendo Los Ferroles la que más puntaje obtuvo (2.75); seguida por muy poco por Technofeed y Alimencorp (2.72 cada una).

Del análisis de la matriz evidenciamos para Los Ferroles los factores claves de éxito que obtuvieron mayor puntuación fueron (a) nivel de tecnología y (b) participación de mercado, por lo que se les considera como fortalezas principales para la compañía. Por otro lado, vemos que los factores que tuvieron menor puntuación fueron (a) reconocimiento de marca y (b) publicidad, por lo que se les considera debilidad menor.

Para el caso de Technofeed y Alimencorp, los factores claves de éxito que obtuvieron mayor puntuación fueron (a) precio competitivo y (b) calidad de producto, por lo que se les considera como fortalezas menores para la compañía. Por otro lado, vemos que los factores que tuvieron menor puntuación fueron (a) personal capacitado y (b) especialización en el sector avícola, por lo que se les considera debilidad menor.

Finalmente, podemos señalar que las principales ventajas competitivas que presenta Los Ferroles son: (a) el alto nivel de tecnología (b) la alta participación de mercado y (c) la especialización en el sector avícola; estas ventajas marcan la diferencia 
con sus principales competidores y le otorgan el liderazgo del mercado. Por otro lado, los aspectos que debe desarrollar son (a) el reconocimiento de la marca y (b) la publicidad, dado que son dos elementos primordiales de la gestión comercial.

Tabla 23

Matriz del Perfil Competitivo para la empresa Los Ferroles

\begin{tabular}{lccccccc}
\hline \multicolumn{1}{c}{$\begin{array}{c}\text { FACTORES CRÍTICOS DE } \\
\text { ExııU }\end{array}$} & \multirow{2}{*}{ Pond. } & \multicolumn{2}{c}{ Los Ferroles } & \multicolumn{2}{c}{ Techofeed } & \multicolumn{2}{c}{ Alimencorp } \\
Calif. & Puntaje & Calif. & Puntaje & Calif. & Puntaje \\
\hline 1. Precios competitivos & 0.16 & 3 & 0.48 & 3 & 0.48 & 3 & 0.48 \\
2. Facilidad de pago & 0.10 & 3 & 0.3 & 3 & 0.3 & 3 & 0.3 \\
3. Variedad de producto & 0.09 & 2 & 0.18 & 3 & 0.27 & 3 & 0.27 \\
4. Calidad de producto & 0.18 & 3 & 0.54 & 3 & 0.54 & 3 & 0.54 \\
5. Reconocimiento de marca & 0.07 & 1 & 0.07 & 2 & 0.14 & 2 & 0.14 \\
6. Disponibilidad de producto & 0.12 & 3 & 0.36 & 2 & 0.24 & 2 & 0.24 \\
7. Nivel de tecnología & 0.08 & 4 & 0.32 & 2 & 0.16 & 2 & 0.16 \\
8. Personal Capacitado & 0.06 & 2 & 0.12 & 2 & 0.12 & 2 & 0.12 \\
9. Especialización en el sector & 0.14 & 4 & 0.56 & 2 & 0.28 & 2 & 0.28 \\
& 1.00 & & 2.93 & & 2.53 & & 2.53 \\
\hline
\end{tabular}

Tomado de El Proceso Estratégico, Un enfoque de Gerencia (p. 185), por F. D'alessio 2015, Lima, Perú: Copyrigth 2015 por Pearson

\section{Educación del Perú SA}




\section{Capítulo VI. Análisis Interno}

En el presente capítulo se describirán las actividades de la cadena de valor de la empresa, de acuerdo a la información que se obtuvo en las entrevistas realizadas a los gerentes y los jefes de las principales áreas claves; con la finalidad de identificar las fortalezas y las debilidades de la compañía.

Según D’Alessio (2015), el análisis interno se enfoca en definir estrategias para capitalizar las fortalezas y neutralizar las debilidades; para ello se debe realizar una auditoría interna de las principales áreas funcionales de la organización (AMOFHIT):

(a) Administración y gerencia (A), (b) Marketing y Ventas (M), (c) Operaciones, Logística e Infraestructura (O), ( d) Finanzas y Contabilidad (F), (e) Recursos Humanos (H), (f) Sistemas de Información y Comunicación (I), (g) Tecnología, Investigación y Desarrollo (T).

Para realizar un adecuado análisis interno se requiere de la honestidad de los responsables de las áreas funcionales al momento de brindar información. La Alta Dirección debe brindar apertura y tolerancia para recibir de la mejor manera información que pueda dejar ver aspectos negativos de la organización, con el fin de determinar la importancia de estos problemas para definir las acciones inmediatas y mejorar la posición interna de la empresa. 
6.1 Descripción de las actividades de la cadena de valor de la empresa Los Ferroles: Logística interna, Operaciones, Logística externa, Mercadotecnia, Servicios, Adquisiciones, Recursos Humanos, Tecnología, Infraestructura.

La cadena de valor son las actividades de la empresa donde se transforma insumos de bajo costo en productos o servicios con un precio superior a sus costos, el excedente obtenido sobre los costos se define como el margen, por lo antes mencionado se dice que una empresa tiene una ventaja competitiva frente a otra cuando es capaz de aumentar el margen ya sea bajando los costos o aumentando las ventas. (David, 2013)

Como se muestra en la figura 29, la cadena de valor clasifica las actividades generadoras de valor en dos actividades, Primarias y de Apoyo.

Las Actividades Primarias, están directamente relacionadas con la producción y comercialización del producto: logística interior (de entrada), operaciones, logística exterior (de salida), marketing y ventas, servicios y post venta.

Las Actividades de Apoyo no agregan valor en forma directa, pero refuerzan la capacidad de las actividades primarias para agregar valor: infraestructura de la empresa, recursos humanos, desarrollo tecnológico y abastecimiento. 


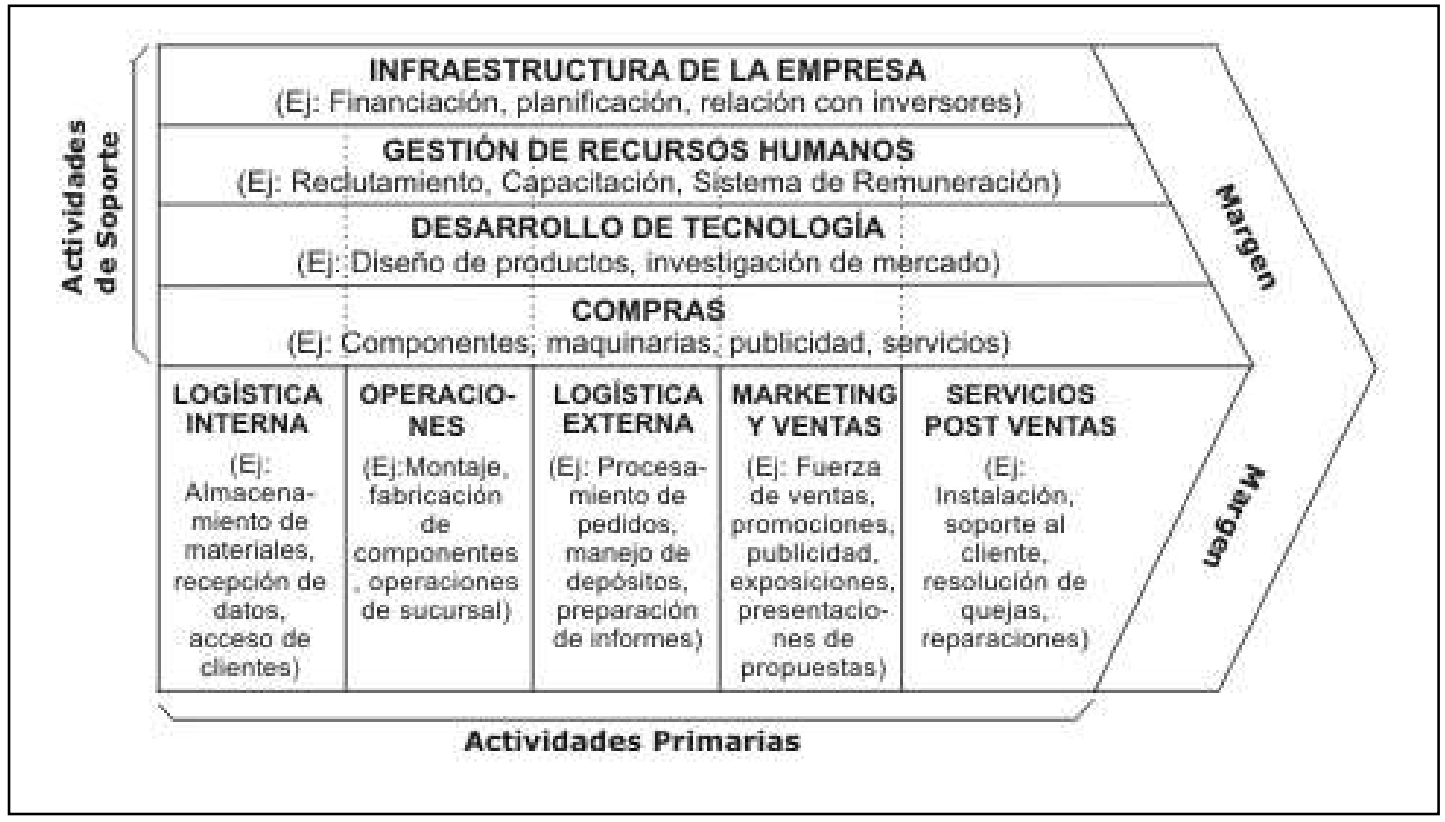

Figura 29: La Cadena de Valor. Tomado de "Administración” por Revista de la Empresa (2016). Recuperado de http://revistadelaempresa.com/la-cadena-de-valor-de-porter/

A continuación se describen las actividades de la cadena de valor de la empresa Los Ferroles.

\subsubsection{Actividades Primarias.}

\section{Logística (Interna).}

La logística interna (almacenes y transportes) está a cargo del Jefe de Logística.

El proceso de transporte para la recolección de materia prima es tercerizada y negociada directamente por el Director de la empresa. Estos proveedores son quienes recolectan y transportan los subproductos ya que cuentan con los permisos sanitarios para realizar dicha actividad (EPS-RS). Las materias primas (plumas y vísceras de ave) son entregadas diariamente en las plantas correspondientes. En cuanto al transporte de 
los demás requerimientos, son abastecidos directamente a las plantas por los proveedores, o en su defecto transportado con la movilidad propia de la empresa.

Respecto al almacenamiento de la materia prima, las plantas cuentan con infraestructura para recepcionar un día de producción (tolva de recepción para plumas y tanque contenedor para vísceras). Si bien el flujo de producción es continuo, no cuentan con infraestuctura ni equipos para almacenar materia prima por más de un día. Cuando se han presentado situaciones que han requerido almacenar dicha materia prima, se ha colocado directamente en el piso, en la zona de ingreso de vehículos, generando desorden y yendo en contra de las normas sanitarias. Con respecto al almacenamiento de los otros suministros, cada planta cuenta con un pequeño almacén para guardar los materiales.

\section{Producción: (Operaciones).}

Está a cargo del Jefe de Producción y Mantenimiento. Se encarga de planear y ejecutar la producción de las dos plantas, así como de asegurar la continuidad de la producción previniendo posibles paralizaciones por falta de mantenimiento a las maquinarias o de mano de obra.

Gran parte del proceso de producción está automatizado, con excepción del proceso de envasado donde interviene mano de obra para el cierre de los contenedores. Se cuentan con dos líneas de producción, pluma y vísceras, cada una de las cuales se produce en una planta diferente. Las plantas trabajan al $70 \%$ de su capacidad, permitiendo incrementar aún más los volúmenes de producción. 
El área presenta problema de rotación de personal dado que por el tipo de actividad es difícil de conseguir mano de obra disponible. La adaptación al puesto es un proceso que requiere de una curva de aprendizaje y tiempo.

Si bien no cuentan con un programa de mantenimiento preventivo, la planta para un día a la semana para realizar los trabajos de limpieza y mantenimiento con el objetivo de asegurar la continuidad de la producción. Se realiza con personal propio y de manera puntual con terceros.

La calidad es uno de los aspectos más valorados por los clientes. La empresa cuenta con un área de control de calidad que se encarga de asegurar el cumplimiento de las especificaciones técnicas de la materia prima y de los productos terminados. Si bien la empresa no cuenta con un laboratorio propio para realizar los análisis, contrata los servicios de un tercero para este fin. Dentro los principales análisis tenemos: porcentaje de proteína, nivel de digestibilidad y análisis microbiológicos para la detección de patógenos.

\section{Almacén (Logística Externa).}

Los almacenes de productos terminados están a cargo del Jefe de Logística. Se cuenta con un almacén por planta, cuya capacidad es de un día de producción. Esta área controla los ingresos, las salidas y la adecuada manipulación y estiba de los productos. Actualmente el control de inventarios no se realiza a través del sistema ERP de la empresa, lo manejan de manera manual en hojas de cálculo, lo cual genera inconvenientes en el control. 
Con respecto al transporte de productos terminados, la empresa terceriza el servicio de entrega.

\section{Marketing y Ventas.}

Respecto al proceso de marketing, la empresa no lo gestiona, por lo que no se han definido ni implementado estrategias en este aspecto. No cuenta con página web ni presencia en redes sociales.

Con referencia a las ventas, se encuentran a cargo del gerente de administración y finanzas, y del jefe de ventas, no cuentan con fuerza de ventas, ellos mismos son quienes gestionan las estrategias de comunicación. Se programan reuniones periódicas con los clientes, lo que les permite estar informados de sus requerimientos y asegurar su fidelización. En estas reuniones se evalúan los aspectos técnicos de los productos y las condiciones de venta. Así mismo, la empresa considera dentro del proceso de ventas la facturación y la cobranza de los productos.

\section{Post Venta.}

Si bien este servicio no se encuentra muy desarrollado en la empresa, es el gerente de administración y finanzas a través de sus reuniones periódicas con los clientes quien brinda este servicio. No cuentan con un área técnico-comercial para este proceso.

\subsubsection{Actividades de Apoyo}

\section{Abastecimiento.}

El proceso de compra y negociación de la materia prima es realizado por el Director de la empresa, la compra de los demás insumos es realizada por la jefatura de 
Compras. Si bien el ERP de la empresa cuenta con un módulo de compras, no todas las solicitudes son ingresadas al sistema, algunas son trabajadas de forma manual. Esta falta de alineamiento no permite que se trabaje de manera integral y planificada la gestión de compras, incurriendo en sobrecostos por compras no planificadas.

El abastecimiento de materia prima es el principal problema que presenta la empresa debido a la escasez, a este factor se le suma la informalidad de los proveedores que recolectan plumas y vísceras de los mercados con los cuales se tiene que negociar precio, cantidad y calidad de los sub productos; todo esto dificulta la realización de alianzas con los proveedores.

\section{Recursos Humanos.}

La empresa no cuenta con un área de Recursos Humanos, actualmente la actividad está a cargo de la Sub Contadora de la empresa quien sólo se limita a cumplir con los cálculos de la carga social.

El reclutamiento de personal es realizado directamente por las áreas operativas o administrativas cuando lo requieren; no se han desarrollado otros procesos como: reclutamiento y selección, desarrollo de personal, planes de retención, etc.

\section{Infraestructura.}

Los Ferroles cuentan con un Director y un gerente de administración y finanzas quienes son los dueños, y que a su vez toman las decisiones estratégicas y financieras de la compañía. La empresa carece de procedimientos definidos y documentados que alinee 
y ordene adecuadamente los procesos internos y lo relacionados con sus grupos de interés.

\section{Desarrollo Tecnológico.}

La empresa cuenta con maquinaria europea de última generación para el desarrollo de los procesos productivos. Asimismo, cuenta con un sistema ERP que le permite integrar la información administrativa, contable y logística para la toma de decisiones.

La compañía no realiza investigación técnica ni desarrollo de productos nuevos, tampoco realiza estudios de mercado. En la figura 30 se muestra la Cadena de Valor de la empresa Los Ferroles. 


\begin{tabular}{|c|c|c|c|c|c|c|}
\hline \multirow{7}{*}{ 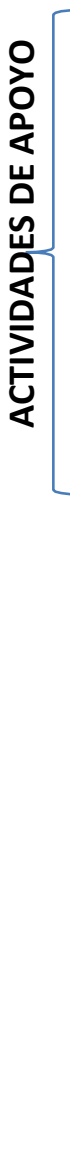 } & \multicolumn{5}{|c|}{$\begin{array}{l}\text { INFRAESTRUCTURA DE LA EMPRESA } \\
\text { La dirección de la empresa está a cargo del Director y Gerente de Adm. y Finanzas, quienes son los dueños. }\end{array}$} & \multirow{7}{*}{$\underset{D}{3}$} \\
\hline & \multicolumn{5}{|c|}{ RECURSOS HUMANOS } & \\
\hline & \multirow{2}{*}{\multicolumn{5}{|c|}{$\begin{array}{l}\text { DESARROLLO DE TECNOLOGIA Y DESARROLLO } \\
\text { Alto nivel de tecnología en proceso productivo. Sistema ERP Horizont para control integral de información }\end{array}$}} & \\
\hline & & & & & & \\
\hline & \multicolumn{5}{|c|}{ ABASTECIMIENTO } & \\
\hline & $\begin{array}{l}\text { LOGISTICA INTERNA } \\
\text { Transporte de la } \\
\text { materia prima (MP) } \\
\text { hasta a cargo de los } \\
\text { proveedores } \\
\text { Almacén recepciona } \\
\text { y controla las MP e } \\
\text { insumos para } \\
\text { atender al Área } \\
\text { Producción. }\end{array}$ & $\begin{array}{l}\text { PRODUCCIÓN } \\
\text { Producción de las } \\
\text { Harinas de Plumas y } \\
\text { Harinas de Vísceras. } \\
\text { Mantenimiento de } \\
\text { planta para } \\
\text { aseguramiento de la } \\
\text { producción. } \\
\text { Controles de calidad } \\
\text { según estándares de } \\
\text { producción. }\end{array}$ & $\begin{array}{l}\text { LOGISTICA EXTERNA } \\
\text { Almacén } \\
\text { Realiza el control de } \\
\text { los inventarios de } \\
\text { productos } \\
\text { terminados. } \\
\\
\text { Transporte } \\
\text { El proceso es } \\
\text { tercerizado. }\end{array}$ & $\begin{array}{l}\text { MARKETING Y VENTAS } \\
\text { No cuentan con Área } \\
\text { Marketing. } \\
\text { El Gerente de Adm y } \\
\text { Finanzas es quien tiene } \\
\text { a cargo la comunicación } \\
\text { constante con los } \\
\text { clientes. } \\
\text { Ventas; dentro del } \\
\text { proceso se incluye la } \\
\text { facturación y cobranzas. }\end{array}$ & $\begin{array}{l}\text { No cuentan con un } \\
\text { Área de Post Venta. } \\
\text { El Gerente de Adm y } \\
\text { Finanzas obtiene } \\
\text { información y brinda } \\
\text { servicio a través sus } \\
\text { visitas a los clientes. }\end{array}$ & \\
\hline & & & TIVIDADES PRIN & IAS & & \\
\hline
\end{tabular}

Figura 30. La Cadena de Valor de la Empresa Los Ferroles. Adaptado de “Administración” por Revista de la Empresa (2016).

Recuperado de http://revistadelaempresa.com/la-cadena-de-valor-de-porter/ 


\subsection{Indicadores de cada una de las actividades de la cadena de valor}

Después de haber realizado un análisis a cada una de las actividades de la cadena de valor de la empresa, se pudo identificar a través de las entrevistas a los puestos claves, que no todos trabajan con indicadores de gestión claramente definidos y establecidos, existiendo una gran carencia de control y seguimiento de los procesos. En la mayoría de procesos no se han establecido metas a futuro de manera estructuradas, se trabaja muy a corto plazo y la toma de decisiones no involucra visión de futuro.

Si bien Producción es el área que más indicadores de gestión ha desarrollado, sólo trabaja los básicos, los que están directamente relacionados con la producción, dejando de lado controles sobre aspectos de gran importancia como mermas, reprocesos, devoluciones, etc, los cuales generan sobre costos y reducen la productividad. También se identificaron áreas que no manejan ningún tipo de indicador de gestión, como las Áreas Administrativas y de Logística.

De acuerdo al análisis realizado, se determinaron cuáles son los indicadores necesarios para cada una de las actividades, tanto primarias como de apoyo. En las siguientes tablas se muestran los indicadores señalando cuales están implementados, y cuales aún no. 
Tabla 24

Indicadores de Actividades Primarias: Logística Interna

\begin{tabular}{|c|c|c|c|c|}
\hline Proceso & Indicador & Objetivo & Unidad de Medida & $\begin{array}{l}\text { Implementado / No } \\
\text { Implementado }\end{array}$ \\
\hline \multirow{5}{*}{$\begin{array}{l}\text { Logística } \\
\text { Interna }\end{array}$} & $\begin{array}{l}\text { Cumplimiento abastecimiento de } \\
\text { materia prima }\end{array}$ & $\begin{array}{l}\text { Medir el cumplimiento de los } \\
\text { proveedores con los } \\
\text { volúmenes negociados }\end{array}$ & $\%$ de cumplimiento & No Implementado \\
\hline & $\begin{array}{l}\text { Puntualidad en la entrega de } \\
\text { materia prima }\end{array}$ & $\begin{array}{l}\text { Medir el cumplimiento de la } \\
\text { ventana horaria en los } \\
\text { abastecimientos }\end{array}$ & $\%$ de cumplimiento & No Implementado \\
\hline & $\begin{array}{l}\text { Costo del transporte de la materia } \\
\text { prima }\end{array}$ & $\begin{array}{l}\text { Medir si los costos del } \\
\text { transporte están alineados a } \\
\text { los costos proyectados. }\end{array}$ & $\begin{array}{l}\text { Soles del transporte / } \mathrm{Kg} \text { de } \\
\text { producto terminado }\end{array}$ & No Implementado \\
\hline & Merma de producto por transporte & $\begin{array}{l}\text { Medir el nivel de pérdidas de } \\
\text { producto por el proceso o } \\
\text { por descontrol }\end{array}$ & $\mathrm{Kg}$ y soles de producto terminado & No Implementado \\
\hline & $\begin{array}{l}\text { Nivel de desempeño de } \\
\text { proveedores de materia prima }\end{array}$ & $\begin{array}{l}\text { Medir el desempeño del } \\
\text { proveedor (calidad de } \\
\text { servicio y producto). }\end{array}$ & $\%$ de cumplimiento sobre requisitos & No Implementado \\
\hline
\end{tabular}


Tabla 25

Indicadores de Actividades Primarias: Producción y Mantenimiento

\begin{tabular}{|c|c|c|c|c|}
\hline Proceso & Indicador & Objetivo & Valor / Unidad de Medida & $\begin{array}{l}\text { Implementado / } \\
\text { No Implementado }\end{array}$ \\
\hline \multirow{9}{*}{ Producción } & $\begin{array}{l}\text { Cumplimiento del plan de } \\
\text { producción }\end{array}$ & $\begin{array}{l}\text { Medir la relación entre lo planeado y lo } \\
\text { ejecutado }\end{array}$ & $98 \%$ de cumplimiento & Implementado \\
\hline & Productividad & Medir la eficiencia de la producción & $\mathrm{Kg} / \mathrm{H}-\mathrm{H}$ & No Implementado \\
\hline & Rendimiento & $\begin{array}{l}\text { Medir el rendimiento de la materia prima } \\
\text { como producto terminado }\end{array}$ & $\begin{array}{l}31 \% \text { rendimiento } \mathrm{H} \text {. Pluma } \\
16 \% \text { rendimiento } \mathrm{H} \text {. Víscera }\end{array}$ & Implementado \\
\hline & Reprocesos & $\begin{array}{l}\text { Medir el nivel de reprocesos por calidad y } \\
\text { otros. }\end{array}$ & $\begin{array}{c}\text { Toneladas y } \\
\text { S/ de productos reprocesados }\end{array}$ & No Implementado \\
\hline & Nivel de mermas de producción & $\begin{array}{l}\text { Medir el nivel de pérdidas de producto en } \\
\text { el proceso productivo }\end{array}$ & $\%$ Mermas & No Implementado \\
\hline & & Medir si los costos del producto & 1680 Soles / TM de H. Pluma & \\
\hline & Costo de producción & $\begin{array}{l}\text { terminado están alineados a los costos } \\
\text { proyectados. }\end{array}$ & 1600 Soles / TM de H. Víscera & Implementado \\
\hline & Costo de materia prima & $\begin{array}{l}\text { Medir si los costos de la MP están } \\
\text { alineados a los costos proyectados. }\end{array}$ & $\begin{array}{l}900 \text { / TM de pluma } \\
820 \text { / TM de víscera }\end{array}$ & Implementado \\
\hline & Costo de servicios & $\begin{array}{l}\text { Medir si los costos de los servicios están } \\
\text { alineados a los costos proyectados. }\end{array}$ & $\begin{array}{l}\text { Soles / KWatt } \\
\text { Soles / galón combustible }\end{array}$ & No Implementado \\
\hline \multirow{4}{*}{ Mantenimiento } & Costo de mantenimiento general & $\begin{array}{l}\text { Medir si los costos del mantenimiento } \\
\text { están alineados a los costos proyectados. }\end{array}$ & \multicolumn{2}{|c|}{ Soles / Kg de producto terminado No Implementado } \\
\hline & $\begin{array}{l}\mathrm{N}^{\circ} \text { de mantenimientos } \\
\text { correctivos }\end{array}$ & $\begin{array}{l}\text { Cuantificar la ejecución de } \\
\text { manteniemientos correctivos }\end{array}$ & $\begin{array}{l}\mathrm{N}^{\circ} \text { de mantenimientos } \\
\text { correctivos }\end{array}$ & No Implementado \\
\hline & Horas de parada de planta & $\begin{array}{l}\text { Medir la cantidad de horas de parada de la } \\
\text { producción }\end{array}$ & Horas de parada & No Implementado \\
\hline & $\begin{array}{l}\text { Programa de mantenimiento } \\
\text { preventivo }\end{array}$ & Medir el cumplimiento del programa & $\%$ de cumplimiento & No Implementado \\
\hline
\end{tabular}


Tabla 26

Indicadores de Actividades Primarias: Logística Externa

\begin{tabular}{|c|c|c|c|c|}
\hline Proceso & Indicador & Objetivo & $\begin{array}{l}\text { Valor / Unidad de } \\
\text { Medida }\end{array}$ & $\begin{array}{l}\text { Implementado / } \\
\text { No Implementado }\end{array}$ \\
\hline \multirow{8}{*}{$\begin{array}{l}\text { Logística } \\
\text { Externa }\end{array}$} & Costo de transporte & $\begin{array}{l}\text { Medir si los costos de transporte están } \\
\text { alineados a los costos proyectados. }\end{array}$ & $\begin{array}{l}45 \text { Soles / TM de } \\
\text { producto terminado } \\
\text { transportadas }\end{array}$ & Implementado \\
\hline & Puntualidad en la entrega & $\begin{array}{l}\text { Medir el cumplimiento de las entregas en } \\
\text { fecha y horarios acordados. }\end{array}$ & $\%$ de cumplimiento & No Implementado \\
\hline & Rotación de inventario & $\begin{array}{l}\text { Medir el número de veces que se han } \\
\text { renovado las existencias durante un período }\end{array}$ & $\begin{array}{l}\text { Costo de venta / } \\
\text { Costo promedio de } \\
\text { existencias }\end{array}$ & No Implementado \\
\hline & Nivel de mermas por transporte & $\begin{array}{l}\text { Medir el nivel de pérdidas de producto por el } \\
\text { proceso o por descontrol }\end{array}$ & $\%$ Merma & No Implementado \\
\hline & Devoluciones de producto & $\begin{array}{l}\text { Medir la cantidad y valor de los productos } \\
\text { devueltos }\end{array}$ & $\begin{array}{l}\% \text { y Soles de } \\
\text { productos devueltos }\end{array}$ & No Implementado \\
\hline & Fill rate & $\begin{array}{l}\text { Medir el nivel de cumplimiento en la } \\
\text { atención del pedido }\end{array}$ & $\begin{array}{l}\% \text { y Soles de Fill } \\
\text { Rate }\end{array}$ & No Implementado \\
\hline & Nivel de stock & Medir el volumen y valorización del stock & Toneladas y Soles & No Implementado \\
\hline & $\begin{array}{l}\text { Productividad en la estiba / } \\
\text { desestiba }\end{array}$ & Medir la eficiencia de la estiba / desestiba & TM estibadas / H-H & No Implementado \\
\hline
\end{tabular}


Tabla 27

Indicadores de Actividades Primarias: Marketing y Ventas

\begin{tabular}{|c|c|c|c|c|}
\hline Proceso & Indicador & Objetivo & Valor / Unidad de Medida & $\begin{array}{c}\text { Implementado / } \\
\text { No } \\
\text { Implementado } \\
\end{array}$ \\
\hline \multirow{5}{*}{$\begin{array}{l}\text { Marketing } \\
\text { y Ventas }\end{array}$} & Venta & $\begin{array}{l}\text { Medir los volúmenes vendidos y su } \\
\text { cuantificación }\end{array}$ & $\begin{array}{c}\text { 16,687 Toneladas (2016) } \\
\text { 30’137,617 soles vendidos } \\
(2016)\end{array}$ & Implementado \\
\hline & $\begin{array}{l}\text { Cumplimiento programa de } \\
\text { ventas }\end{array}$ & $\begin{array}{l}\text { Medir cumplimiento del programa de } \\
\text { venta }\end{array}$ & $\begin{array}{l}\% \text { de cumplimiento del } \\
\text { programa }\end{array}$ & $\begin{array}{c}\text { No } \\
\text { Implementado }\end{array}$ \\
\hline & Participación de mercado & $\begin{array}{l}\text { Medir la participación en el mercado } \\
\text { con los productos }\end{array}$ & $\begin{array}{l}\text { \% de participación en soles y } \\
\text { toneladas. }\end{array}$ & $\begin{array}{l}\text { No } \\
\text { Implementado }\end{array}$ \\
\hline & $\begin{array}{l}\text { Desarrollo de nuevos } \\
\text { productos }\end{array}$ & $\begin{array}{l}\text { Cuantificar los lanzamientos de nuevos } \\
\text { productos }\end{array}$ & $\mathrm{N}^{\circ}$ de nuevos productos & $\begin{array}{c}\text { No } \\
\text { Implementado }\end{array}$ \\
\hline & Rentabilidad por producto & $\begin{array}{l}\text { Medir el margen que aporta cada } \\
\text { producto }\end{array}$ & $\% \mathrm{MB}$ y $\% \mathrm{MN}$ & $\begin{array}{l}\text { No } \\
\text { Implementado }\end{array}$ \\
\hline
\end{tabular}


Tabla 28

Indicadores de Actividades Primarias: Servicio y Post venta

\begin{tabular}{|c|c|c|c|c|}
\hline Proceso & Indicador & Objetivo & Valor / Unidad de Medida & $\begin{array}{l}\text { Implementado } \\
\text { / No } \\
\text { Implementado } \\
\end{array}$ \\
\hline \multirow{4}{*}{$\begin{array}{l}\text { Servicio Post } \\
\text { Venta }\end{array}$} & Reclamos de clientes & $\begin{array}{l}\text { Medir la cantidad de reclamos de } \\
\text { clientes }\end{array}$ & $\mathrm{N}^{\circ}$ de quejas & $\begin{array}{c}\text { No } \\
\text { Implementado }\end{array}$ \\
\hline & $\begin{array}{l}\text { Nivel de satisfacción } \\
\text { de clientes }\end{array}$ & $\begin{array}{l}\text { Medir el grado de satisfacción de } \\
\text { los clientes con respecto a los } \\
\text { productos y servicios }\end{array}$ & \% Satisfacción & $\begin{array}{c}\text { No } \\
\text { Implementado }\end{array}$ \\
\hline & NPS & $\begin{array}{l}\text { Medir el nivel de lealtad de los } \\
\text { clientes a través de la } \\
\text { recomendación de los productos }\end{array}$ & $\%$ NPS & $\begin{array}{c}\text { No } \\
\text { Implementado }\end{array}$ \\
\hline & $\begin{array}{l}\text { Programa de visitas } \\
\text { técnicas }\end{array}$ & $\begin{array}{l}\text { Medir el cumplimiento del } \\
\text { programa de visitas a clientes }\end{array}$ & $\%$ de cumplimiento & $\begin{array}{c}\text { No } \\
\text { Implementado }\end{array}$ \\
\hline
\end{tabular}


Tabla 29

Indicadores de Actividades de Apoyo: Abastecimiento

\begin{tabular}{|c|c|c|c|c|}
\hline Proceso & Indicador & Objetivo & Valor / Unidad de Medida & $\begin{array}{l}\text { Implementado } \\
\quad / \text { No } \\
\text { Implementado } \\
\end{array}$ \\
\hline \multirow{5}{*}{ Abastecimiento } & $\begin{array}{l}\text { Nivel de desempeño de } \\
\text { proveedores }\end{array}$ & $\begin{array}{l}\text { Medir el desempeño del proveedor } \\
\text { (calidad de servicio y producto). }\end{array}$ & $\%$ de cumplimiento sobre requisitos & $\begin{array}{c}\text { No } \\
\text { Implementado }\end{array}$ \\
\hline & $\begin{array}{l}\text { Puntualidad en la } \\
\text { entrega }\end{array}$ & $\begin{array}{l}\text { Medir el cumplimiento de las } \\
\text { entregas en fecha y horario. }\end{array}$ & $\%$ de cumplimiento & $\begin{array}{c}\text { No } \\
\text { Implementado }\end{array}$ \\
\hline & $\begin{array}{l}\text { Cumplimiento en } \\
\text { abastecimiento }\end{array}$ & $\begin{array}{l}\text { Medir el cumplimiento con el } \\
\text { abastecimiento acordado en fecha } \\
\text { y cantidad. }\end{array}$ & $\%$ de cumplimiento & $\begin{array}{c}\text { No } \\
\text { Implementado }\end{array}$ \\
\hline & $\begin{array}{l}\mathrm{N}^{\circ} \text { Reclamos internos } \\
\text { de los productos } \\
\text { adquiridos }\end{array}$ & $\begin{array}{l}\text { Medir el } N^{\circ} \text { de reclamos de los } \\
\text { clientes internos }\end{array}$ & $\mathrm{N}^{\circ}$ de reclamos / clasificación & $\begin{array}{l}\text { No } \\
\text { Implementado }\end{array}$ \\
\hline & $\begin{array}{l}\text { Cumplimiento de } \\
\text { programa de } \\
\text { necesidades }\end{array}$ & $\begin{array}{l}\text { Medir el nivel cumplimiento del } \\
\text { programa y su abastecimiento a los } \\
\text { clientes internos }\end{array}$ & $\%$ de cumplimiento & $\begin{array}{c}\text { No } \\
\text { Implementado }\end{array}$ \\
\hline
\end{tabular}


Tabla 30

Indicadores de Actividades de Apoyo: Desarrollo de Tecnología

\begin{tabular}{|c|c|c|c|c|}
\hline Proceso & Indicador & Objetivo & Valor / Unidad de Medida & $\begin{array}{l}\text { Implementado } \\
\text { / No } \\
\text { Implementado } \\
\end{array}$ \\
\hline \multirow{4}{*}{$\begin{array}{l}\text { Desarrollo de } \\
\text { Tecnología e } \\
\text { Investigación y } \\
\text { Desarrollo }\end{array}$} & $\begin{array}{l}\text { Cumplimiento Pared de } \\
\text { Proyectos }\end{array}$ & $\begin{array}{l}\text { Medir cumplimiento del portafolio } \\
\text { de proyectos }\end{array}$ & $\%$ de cumplimiento de proyectos & $\begin{array}{c}\text { No } \\
\text { Implementado }\end{array}$ \\
\hline & Avance del proyecto & $\begin{array}{l}\text { Medir el grado de avance del } \\
\text { proyecto }\end{array}$ & $\%$ de avance del proyecto & $\begin{array}{c}\text { No } \\
\text { Implementado }\end{array}$ \\
\hline & $\begin{array}{l}\text { Desarrollo de nuevos } \\
\text { productos }\end{array}$ & $\begin{array}{l}\text { Cuantificar los lanzamientos de } \\
\text { nuevos productos }\end{array}$ & $\mathrm{N}^{\circ}$ de nuevos productos & \multirow{2}{*}{$\begin{array}{c}\text { No } \\
\text { Implementado } \\
\text { No } \\
\text { Implementado }\end{array}$} \\
\hline & $\begin{array}{l}\text { Rentabilidad por } \\
\text { producto }\end{array}$ & $\begin{array}{l}\text { Medir el margen que aporta cada } \\
\text { producto }\end{array}$ & $\% \mathrm{MB}$ y $\% \mathrm{MN}$ & \\
\hline
\end{tabular}


Tabla 31

Indicadores de Actividades de Apoyo: Recursos Humanos

\begin{tabular}{|c|c|c|c|c|}
\hline Proceso & Indicador & Objetivo & Valor / Unidad de Medida & $\begin{array}{l}\text { Implementado / } \\
\text { No } \\
\text { Implementado }\end{array}$ \\
\hline \multirow{9}{*}{ Recursos Humanos } & Capacitación & $\begin{array}{l}\text { Cuantificar las horas de capacitación } \\
\text { recibidas por trabajador }\end{array}$ & Horas-hombre de capacitación & $\begin{array}{c}\text { No } \\
\text { Implementado }\end{array}$ \\
\hline & $\begin{array}{l}\text { Cumplimiento Programa } \\
\text { de Capacitación }\end{array}$ & Medir el cumplimiento del programa & $\%$ de cumplimiento & $\begin{array}{c}\text { No } \\
\text { Implementado }\end{array}$ \\
\hline & $\begin{array}{l}\text { Nivel de desempeño } \\
\text { laboral }\end{array}$ & $\begin{array}{l}\text { Medir el logro de objetivos laborales } \\
\text { y competencias }\end{array}$ & $\%$ logro de objetivos & $\begin{array}{c}\text { No } \\
\text { Implementado }\end{array}$ \\
\hline & Clima laboral & Medir la satisfacción laboral & \% satisfacción laboral & No \\
\hline & Contrataciones & Cuantificar el nersonal incornorado & $\mathrm{N}^{\circ}$ de contratados & $\begin{array}{l}\text { Implementado } \\
\text { No }\end{array}$ \\
\hline & & & & Implementado \\
\hline & Ausentismo & $\begin{array}{l}\text { Medir el grado de inasistencias del } \\
\text { personal }\end{array}$ & Índice de ausentismo laboral & $\begin{array}{c}\text { No } \\
\text { Implementado }\end{array}$ \\
\hline & Accidentes laborales & Cuantificar los accidentes ocurridos & $\mathrm{N}^{\circ}$ accidentes & $\begin{array}{c}\text { No } \\
\text { Implementado }\end{array}$ \\
\hline & Rotación de personal & $\begin{array}{l}\text { Cuantificar el } \% \text { de personas que se } \\
\text { vinculan y se desvinculan en la } \\
\text { organización en un periodo de tiempo }\end{array}$ & $\begin{array}{l}\% \text { trabajadores vinculados }+ \text { desvinculados } / \\
\text { total de trabajadores }\end{array}$ & $\begin{array}{c}\text { No } \\
\text { Implementado }\end{array}$ \\
\hline
\end{tabular}


Tabla 32

Indicadores de Actividades de Apoyo: Infraestructura de la Empresa

\begin{tabular}{|c|c|c|c|c|}
\hline Proceso & Indicador & Objetivo & Valor / Unidad de Medida & $\begin{array}{l}\text { Implementado / No } \\
\text { Implementado }\end{array}$ \\
\hline & $\begin{array}{l}\text { Sistemas de gestión } \\
\text { implementados }\end{array}$ & $\begin{array}{l}\text { Cuantificar los sistemas de } \\
\text { gestión implementados }\end{array}$ & $\begin{array}{l}\mathrm{N}^{\circ} \text { de sistemas } \\
\text { implementados }\end{array}$ & No Implementado \\
\hline & $\begin{array}{l}\text { Auditorías realizadas a los } \\
\text { sistemas }\end{array}$ & $\begin{array}{l}\text { Medir el nivel de } \\
\text { cumplimiento de los requisitos } \\
\text { establecidos }\end{array}$ & $\mathrm{N}^{\circ}$ de auditoría realizadas & No Implementado \\
\hline \multirow[t]{3}{*}{$\begin{array}{c}\text { Infraestructura de la } \\
\text { Empresa }\end{array}$} & Certificaciones logradas & $\begin{array}{l}\text { Cuantificar las certificaciones } \\
\text { obtenidas }\end{array}$ & $\mathrm{N}^{\circ}$ de certificaciones & No Implementado \\
\hline & $\begin{array}{l}\text { Políticas, manuales y } \\
\text { procedimientos documentados }\end{array}$ & $\begin{array}{l}\text { Medir el nivel de } \\
\text { estandarización y } \\
\text { documentación de los } \\
\text { procesos }\end{array}$ & $\mathrm{N}^{\circ}$ de documentos aprobados & No Implementado \\
\hline & Estrategias de gestión & $\begin{array}{l}\text { Medir el grado de avance de } \\
\text { las estrategias de negocio }\end{array}$ & $\%$ de cumplimiento & No Implementado \\
\hline
\end{tabular}


6.3 Benchmarking y comparación con los líderes de la industria de cada una de las actividades de la cadena de valor

De acuerdo con F. David (2013), el benckmarking es una herramienta de análisis para evaluar las actividades de la cadena de valor de una empresa con respecto a sus competidores; a fin de identificar y mejorar sus ventajas comparativas en costos, servicios, reputación y operación.

De acuerdo al benchmarking realizado a las empresas de la competencia, se obtuvo información comparativa que se muestra en la tabla 33. 
Tabla 33

Benchmarking y comparación con los líderes de la industria

\begin{tabular}{|c|c|c|c|}
\hline Actividades & Los Ferroles SAC & Technofeed SAC & Alimencorp SAC \\
\hline Inicio Actividades comerciales & 2004 & 2001 & 2001 \\
\hline Plantas de procesamiento & 2 & 1 & 1 \\
\hline Ubicación de planta industrial & Callao (zona industrial) & Callao (zona industrial) & Chilca (zona industrial) \\
\hline Tecnología para la producción & $\begin{array}{l}\text { Planta tecnificada y automatizada } \\
\text { en procesos continuos (tecnología } \\
\text { Danesa) }\end{array}$ & $\begin{array}{l}\text { Tecnología antigua - industria } \\
\text { pesquera (proceso discontinuo) }\end{array}$ & $\begin{array}{l}\text { Tecnología antigua (proceso } \\
\text { discontinuo) }\end{array}$ \\
\hline Certificaciones de calidad & Implementando ISO 9001 & Certificada en ISO:9001 & Certificada en HACCP \\
\hline Portafolio de productos & $\begin{array}{l}\text { Harina de plumas y harinas de } \\
\text { vísceras }\end{array}$ & $\begin{array}{l}\text { Harinas de carne, harinas de pollo } \\
\text { premium, harinas de plumas con } \\
\text { enzimas, harinas de plumas estándar y } \\
\text { aceite de pollo }\end{array}$ & $\begin{array}{l}\text { Haricar (harinas en base a carne y } \\
\text { huesos) y Proteika (harina en base } \\
\text { subproductos de animales), } \\
\text { Concentrado nutricional plus (alto } \\
\text { contenido de harina de pescado), } \\
\text { Harina de plumas hidrolizada, Proteika } \\
\text { Plus (harina de subproducto de origen } \\
\text { animal premium). }\end{array}$ \\
\hline Capacidad instalada & $70 \%$ & $90 \%$ & $90 \%$ \\
\hline Alianzas estratégicas & Maquila con San Fernando & Ninguna & Ninguna \\
\hline Marketing Digital & No desarrollado & Página web & Página web y Facebook \\
\hline Presentación del producto & Sin rotulado en empaque & Sin rotulado en empaque & Producto marcado y rotulado \\
\hline Desarrollo de productos & Sin desarrollo & Sin desarrollo & $\begin{array}{l}\text { Con área de I\&D / Diseño según } \\
\text { necesidad del cliente }\end{array}$ \\
\hline
\end{tabular}




\subsection{Determinar las competencias de la empresa}

Los Ferroles es una empresa familiar que ha basado su desarrollo y crecimiento en función a la gestión de su director y dueño, quien es un emprendedor con visión de negocio.

El director reconoce la necesidad de consolidar y desarrollar las competencias empresariales a fin de mantenerse en el mercado; por ello muestra mucha apertura para realizar cambios organizacionales y tecnológicos.

Dentro del análisis realizado, se identificaron las siguientes competencias de la empresa, las cuales se muestran en la tabla 34. 
Tabla 34

Competencias de la empresa Los Ferroles

Competencia Descripción

Visión de Negocio

Toma de riesgos

Relación con Clientes

\section{Capacidad de} adaptación

Compromiso
El dueño inició el negocio con maquinaria muy básica y a baja escala; posteriormente tuvo la iniciativa de implementar un nuevo modelo de negocio caracterizado por trabajar con tecnología de punta para incrementar significativamente la venta. Este modelo le viene permitiendo liderar el mercado teniendo como clientes a las principales empresas del sector avícola.

La empresa asumió riesgos al apostar por la implementación de una planta de última generación; siendo ésta la primera planta en el país que cuenta con este tipo de tecnología.

La empresa muestra buena comunicación y flexibilidad ante las solicitudes y/o requerimientos. Los clientes son atendidos directamente por el Director y/o Gerente de Administración y Finanzas, lo cual muestra su alto grado de cercanía con ellos.

La empresa ha pasado por un proceso de adaptación tecnológica al comprar maquinaria de última generación para su proceso productivo, así también los procesos administrativos se han automatizado con la adquisición de un ERP para la gestión integral de la información. Durante estos procesos de cambio, el personal se ha mostrado abierto y participativo.

Durante las entrevistas a las jefaturas de área se evidenció no solo compromiso laboral sino además compromiso con el Director, dado que muchos de ellos son trabajadores que vienen trabajando desde los inicios de la empresa. 


\subsection{Identificación y determinación de las ventajas competitivas de la empresa}

La empresa Los Ferroles ha logrado su crecimiento debido al desempeño que ha tenido en el sector que opera, lo que le ha permitido mejorar su posición competitiva en el mercado. Este logro se debe al aprovechamiento de las ventajas competitivas que caracterizan a la empresa, entre las cuales se mencionan:

1. Alto nivel de tecnología, cuentan con tecnología europea de última generación, única en el país, lo cual permite una producción eficiente, de mejor calidad y con un mayor rendimiento que la competencia.

2. Especialización, años dedicados a la producción exclusiva de harinas de plumas y de vísceras los han especializado en el sector avícola. Este enfoque le permite asegurar la calidad sanitaria de las harinas, dado que se evita la contaminación cruzada con insumos de otras especies.

3. Alianza Estratégica, convenio estratégico con la empresa San Fernando líder en el sector avícola, para maquila de su producto. Esta relación genera beneficios no solo económicos (menores costos de producción) sino también es un respaldo financiero y de imagen para la empresa.

\subsection{Matriz de Evaluación de los Factores Internos EFI}

La matriz EFI permite resumir las principales fortalezas y debilidades de las áreas de la empresa, así como el nivel de relaciones que existe en esas áreas.

1. Después de haber realizado el análisis interno se deberá identificar y seleccionar los aspectos internos más importantes que son fortalezas y debilidades de la 
empresa; se recomienda usar entre 10 y 20 factores internos que incluyan tanto fortalezas como debilidades.

2. Asignarle a cada factor un peso relativo; el peso adjudicado a un factor indica el nivel de importancia para la organización, este valor puede ser 0.0 para factores poco importantes, hasta 1.0 para factores muy importantes.

3. Asignarle un valor entre 1 y 4 a cada factor, el cual significa la actual estrategia que emplea la empresa, siendo: 4 = Fortaleza Mayor, 3 Fortaleza Menor, 2 = Debilidad Menor, 1 = Debilidad mayor.

4. Posteriormente se multiplicarán los pesos por los valores, obteniendo su peso ponderado, finalmente se suman estos valores. Los puntajes ponderados totales por debajo de 2.5 significan organizaciones débiles, mientras que los puntajes por encima de 2.5 significan organizaciones con posición interna fuerte. (D’alessio, 2015)

Es importante señalar que las ponderaciones y calificaciones son el resultado de las entrevistas realizadas a los expertos del sector, directivos de la empresa y empresas competidoras. 
Tabla 35

Matriz de Factores Internos EFI

\begin{tabular}{|c|c|c|c|c|}
\hline & Factores Determinantes del Éxito & Peso & Calificación & $\begin{array}{c}\text { Calificación } \\
\text { Ponderada } \\
\end{array}$ \\
\hline & \multicolumn{4}{|l|}{ FORTALEZAS: } \\
\hline 1 & $\begin{array}{l}\text { Tecnología de última generación para el } \\
\text { proceso productivo. }\end{array}$ & 0.08 & 4 & 0.32 \\
\hline 2 & $\begin{array}{l}\text { Líder en la producción y comercialización de } \\
\text { harinas proteicas para el sector avícola. }\end{array}$ & 0.07 & 4 & 0.28 \\
\hline 3 & $\begin{array}{l}\text { Especialistas en el procesamiento de harinas } \\
\text { para el sector avícola. }\end{array}$ & 0.06 & 3 & 0.18 \\
\hline 4 & $\begin{array}{l}\text { Alianza estratégica con San Fernando para } \\
\text { maquila de productos. }\end{array}$ & 0.05 & 3 & 0.15 \\
\hline 5 & $\begin{array}{l}\text { Costos bajos y precios competitivos en el } \\
\text { mercado. }\end{array}$ & 0.08 & 3 & 0.24 \\
\hline 6 & $\begin{array}{l}\text { Cuenta con tecnología orientada a reducir el } \\
\text { impacto ambiental. }\end{array}$ & 0.04 & 3 & 0.12 \\
\hline \multirow[t]{2}{*}{7} & $\begin{array}{l}\text { Cuenta con sistema de información integral } \\
\text { para la gestión de la compañía. }\end{array}$ & 0.04 & 2 & 0.08 \\
\hline & \multicolumn{4}{|l|}{ DEBILIDADES: } \\
\hline 1 & $\begin{array}{l}\text { Falta de control y estandarización de los } \\
\text { procesos. }\end{array}$ & 0.08 & 2 & 0.16 \\
\hline 2 & $\begin{array}{l}\text { Personal operativo poco especializado y } \\
\text { capacitado. }\end{array}$ & 0.04 & 2 & 0.08 \\
\hline 3 & $\begin{array}{l}\text { Falta de planeamiento estratégico y control } \\
\text { presupuestal. }\end{array}$ & 0.07 & 1 & 0.07 \\
\hline 4 & $\begin{array}{l}\text { No cuenta con certificaciones de calidad ni de } \\
\text { inocuidad }\end{array}$ & 0.06 & 2 & 0.12 \\
\hline 5 & Falta de diversificación de productos. & 0.08 & 1 & 0.08 \\
\hline 6 & Falta de indicadores de gestión. & 0.05 & 1 & 0.05 \\
\hline 7 & $\begin{array}{l}\text { No tiene desarrollada la gestión del marketing } \\
\text { digital. }\end{array}$ & 0.06 & 1 & 0.06 \\
\hline 8 & $\begin{array}{l}\text { Cartera de clientes concentrada en líderes del } \\
\text { sector avícola con alto poder de negociación. }\end{array}$ & 0.04 & 2 & 0.08 \\
\hline 9 & No cuenta con plan de sucesión & 0.04 & 2 & 0.08 \\
\hline \multirow[t]{2}{*}{10} & No cuenta con área de Recursos Humanos & 0.06 & 1 & 0.06 \\
\hline & TOTALES & 1.00 & & 2.21 \\
\hline
\end{tabular}

Adaptado de El Proceso Estratégico, Un enfoque de Gerencia (p. 185), por F. D'alessio

2015, Lima, Perú: Copyrigth 2015 por Pearson Educación del Perú SA 
Sobre los resultados obtenidos de la matriz realizada, se concluye que la empresa tiene una puntuación ponderada total de 2.21; de acuerdo a lo referido por el autor D’Alessio (2015), una puntuación ponderada total por debajo del promedio (2.5) significa que la empresa tiene un perfil débil internamente y que no está aprovechando sus fortalezas internas para poder atacar las amenazas externas. Dado este escenario, la empresa deberá replantear sus estrategias y enfocar sus actividades claves para lograr una posición interna más sólida.

A continuación se describen las principales fortalezas y debilidades identificadas para la empresa:

\section{Fortalezas.}

1. Tecnología de última generación para el proceso productivo: La tecnología es una de sus mayores fortalezas y ventajas competitivas en el mercado. La empresa cuenta con tecnología europea para su proceso productivo, lo cual la diferencia de la competencia y le permite obtener un producto de alta calidad y alto valor proteico.

2. Líder en la producción y comercialización de harinas proteicas en el sector avícola: La empresa actualmente lidera el mercado avícola con una participación del 65\%, con sus dos líneas de productos.

3. Especialistas en el procesamiento de harinas para el sector avícola: Es otra fuerte ventaja competitiva que los diferencia en el mercado, debido a los años de experiencia en la producción de harinas proteicas para aves.

4. Alianza estratégica con San Fernando para maquila de productos: El haber establecido la alianza estratégica con la empresa San Fernando le permite tener la 
capacidad de procesar la mayor cantidad de materia prima del sector avícola, los cual reduce los costos de producción, y brinda respaldo financiero y de imagen empresarial.

5. Costos bajos y precios competitivos en el mercado: El contar con tecnología moderna y procesar altos volúmenes de materia prima, permite obtener costos bajos y por tanto, ofrecer al mercado precios competitivos.

6. Cuenta con tecnología orientada a reducir el impacto ambiental: El contar con tecnología de punta les permite desarrollar procesos ecoeficientes, asimismo; contribuye con la comunidad y medio ambiente.

7. Cuenta con un sistema integral para la gestión de la compañía: La empresa tiene implementado un ERP para la gestión de información de sus procesos. Abarca tanto la parte financiera, inventarios y producción.

\section{Debilidades.}

1. Falta de control y estandarización de los procesos: Si bien la empresa se encuentra en proceso de implementación de la norma ISO 9001, aún no cuenta con procedimientos estandarizados, documentados ni desplegados a su personal.

2. Personal operativo poco especializado y capacitado: La empresa al no tener definidos los perfiles de puestos ni de competencias, no puede realizar procesos de selección adecuados, asimismo, no desarrolla planes de capacitación a sus colaboradores.

3. Falta de planeamiento estratégico y control presupuestal: La empresa no cuenta con un plan de sucesión que garantice la continuidad de la empresa en el tiempo, el planeamiento de objetivos es a corto plazo. No se realiza control presupuestal. 
4. No cuenta con certificaciones de calidad ni de inocuidad: la empresa no ha implementado certificaciones de gestión de calidad como el Sistema ISO $9001 \mathrm{ni}$ de inocuidad como el Sistema HACCP, los cuales se enfocan en los clientes, a través del cumplimiento de las especificaciones de los productos y la satisfacción de sus expectativas.

5. Falta de innovación y diversificación de productos: La empresa solo ofrece al mercado dos productos (harina de plumas y harina de vísceras), asimismo no ha implementado un proceso de innovación que permita diversificar su oferta con otras líneas de producción a través de las cuales pueda generar mayor valor agregado. Ello le genera una desventaja en relación a su competencia, la cual si tiene mayor nivel de diversificación de productos.

6. Falta de indicadores de gestión: La empresa no tiene definido objetivos laborales individuales ni de área, por lo que no mide el logro de los resultados ni las brechas existentes. Asimismo, no mide cuantitativa ni cualitativamente la satisfacción, necesidades y/o expectativas de sus clientes.

7. No tiene desarrollada la gestión comercial ni de marketing digital: Actualmente la empresa no cuenta con un área comercial donde gestione las estrategias de marketing, por ende no tiene presencia en medios digitales para desarrollar la marca.

8. Cartera de clientes concentrada en líderes del sector avícola con alto poder de negociación: Sus clientes claves abarcan más del 75\% de la facturación total de la empresa, ello podría generar una amenaza, dado que si los contratos no se renuevan perderían un gran porcentaje de su facturación; asimismo el concentrarse en pocos clientes los hace dependientes de las exigencias de ellos. 
9. No cuenta con plan de sucesión: La empresa no tiene establecido un código familiar de negocio que les permita ordenar su estructura organizacional para asegurar la continuidad del negocio a largo plazo.

10. No cuenta con área de Recursos Humanos: Actualmente, la empresa ha delegado la función de administración del personal a la sub contadora, careciendo de otros procesos de gestión humana necesarios para la adecuada conducción de los procesos. 


\section{Capítulo VII. Formulación de Objetivos y diseños de las Estrategias}

En el presente capítulo se determinarán los objetivos estratégicos de la empresa para los próximos tres años. Los objetivos planteados estarán alineados con la misión y la visión de la empresa, teniendo como base el análisis interno y externo de la organización.

\subsection{Alcance y planteamiento de los objetivos estratégicos}

Los objetivos estratégicos representan los resultados que la organización espera alcanzar después de identificar las estrategias, en un tiempo determinado, lo que conducirá al cumplimiento de la misión y visión. (D’alessio, 2015)

Según David (2013), al plantear los objetivos estratégicos estos deberán ser: cuantitativos, medibles, realistas, comprensibles, desafiantes, jerárquicos, alcanzables y congruentes a través de todas las áreas del negocio. Así mismo, cada objetivo deberá contar con su propia de línea de tiempo para su desarrollo. De esta manera se busca que la empresa alcance los objetivos planteados.

\subsubsection{Objetivos Estratégicos.}

De acuerdo a la misión y visión planteadas para la empresa y sobre el resultado del análisis del entorno externo e interno, se han establecido los siguientes objetivos estratégicos generales enfocados en:

Incrementar Ingresos

Optimizar costos y gastos

Fortalecimiento Institucional 


\subsubsection{Análisis de los objetivos estratégico.}

Para un mejor análisis de los objetivos estratégicos se han agrupado en tres grandes enfoques según el impacto sobre los resultados de la organización, estos son:

1. Incremento de Ingresos: Comprende los objetivos estratégicos cuyas acciones están orientadas a incrementar los ingresos por venta mediante la mejora de la satisfacción y lealtad de clientes, el posicionamiento de la marca y el desarrollo de productos nuevos.

2. Optimización de Costos y Gastos: Comprende los objetivos estratégicos cuyas acciones están orientadas en la optimización de costos de producción y la reducción de gastos, mediante el uso eficiente de los recursos, el control y estandarización de los procesos y el aumento de los volúmenes de producción.

3. Fortalecimiento Institucional: Comprende los objetivos estratégicos cuyas acciones están orientadas a fortalecer la estructura interna de la organización, haciéndola más eficiente y profesional, desarrollando áreas como comercial, recursos humanos e investigación y desarrollo; todo ello con el objetivo de gestionar un clima y desempeño laboral favorable. 
Tabla 36

Enfoque de los Objetivos Estratégicos

\begin{tabular}{ll}
\hline \multicolumn{1}{c}{ Enfoque } & \multicolumn{1}{c}{ Objetivos Estratégico } \\
\hline Incremento de ingresos & Incrementar rentabilidad \\
& Incrementar ingresos \\
& $\begin{array}{l}\text { Incrementar la satisfacción y lealtad de } \\
\text { clientes } \\
\text { Desarrollar productos nuevos }\end{array}$ \\
& Posicionar la marca \\
\hline Optimización de Costos y Gastos & Incrementar rentabilidad \\
& Optimizar gastos \\
& Optimizar costos \\
& Estandarizar procesos \\
& Controlar procesos \\
& Aumentar volumen de producción. \\
\hline Fortalecimiento Institucional & Reestructurar la organización \\
& Gestión de Clima Laboral \\
& Medir y mejorar el desempeño laboral \\
& Contar con personal competente \\
\hline & \\
\hline & \\
& \\
& \\
&
\end{tabular}

\subsection{Diseño y formulación de estrategias}

El proceso estratégico presenta tres etapas: (a) Formulación, (b) Implementación

y (c) Control, el cual se detalla a continuación:

- $\quad$ Fase 1: Etapa de entrada (insumos): se desarrollaron en capítulos previos las siguientes matrices: Matriz de Evaluación de Factores Externos (EFE), La Matriz 
del Perfil Competitivo (MPC) y la Matriz de Evaluación de Factores Internos (EFI).

- $\quad$ Fase 2: Etapa del proceso estratégico: se generan las estrategias ofensivas o defensivas, combinando los recursos y habilidades internas con las oportunidades y amenazas externas, esta fase requiere de mucha intuición. Asimismo, se utilizarán como herramientas las matrices: Matriz de las Fortalezas, Oportunidades, Debilidades y Amenazas (FODA), Matriz de la Posición Estratégica y Evaluación de la Acción (PEYEA), Matriz del Boston Consulting Group (BCG), Matriz Interna - Externa (IE) y la Matriz de la Gran Estrategia (GE).

- $\quad$ Fase 3: Etapa de salida o de la decisión estratégica: en esta etapa se seleccionará las estrategias internas y externas que se consideran más atractivas y relevantes para encaminar a la organización a su visión deseada. Se utilizarán las siguientes matrices: Matriz de Rumelt (MR) y la Matriz Cuantitativa del Planeamiento Estratégico (MCPE). (D’alessio, 2015).

\subsubsection{Modelo Océano Azul.}

En el libro de W. Chan Kim y René Mauborgne (2005): “La Estrategia del Océano Azul” se expone: "La necesidad de dejar a un lado la competencia destructiva entre las empresas (Océano rojo) si se quiere ser un ganador en el futuro, ampliando los horizontes del mercado y generando valor a través de la innovación (Océano azul)”. 
Los autores mencionados se valen de un símil para diferenciar las dos situaciones competitivas más habituales en cualquier tipo de industria. Los océanos rojos representan todas las industrias que existen en la actualidad, mientras que los azules simbolizan las ideas de negocio actualmente desconocidas.

El modelo del Océano Azul contempla cuatro principios básicos para lograr ser exitosos en el futuro, los cuales son:

1. Crear nuevos espacios de consumo.

2. Centrarse en la idea global y no en los números.

3. Ir más allá de la demanda existente.

4. Asegurar la viabilidad comercial del océano azul.

Una vez aplicados estos cuatro principios, las estrategias estarán lista para ser implementadas.

\subsubsection{Lienzo de la estrategia actual de la empresa.}

La empresa en los últimos tres años, ha invertido en reconversión tecnológica con el objetivo de maximizar su producción, mejorar la calidad y reducir sus costos. Gracias a esta estrategia, ha podido captar clientes líderes del sector avícola, los cuales generan el mayor porcentaje de facturación para la empresa. Asimismo, la alianza estratégica que mantiene con la empresa San Fernando para la maquila de plumas, le permite maximizar los volúmenes de producción, aprovechando y optimizando la capacidad instalada de la moderna planta de producción de harinas de plumas. 
Si bien son pocas las actuales empresas que conforman la industria del rendering, las tres principales (Technofeed SAC, Alimencorp SAC y Los Ferroles SAC) son bastante similares en tamaño, productos y precios. Es por ello que Los Ferroles debe trabajar sólidas estrategias para retener su cartera de clientes y captar nuevos, dado que sus competidores ofrecen al mercado productos y servicios muy similares y con precios competitivos. El ser especialistas en la producción de harinas sólo para la industria avícola, marca una relevante diferenciación a favor de Los Ferroles, que si bien es valorada por los clientes, no es determinante cuando los precios de la competencia son menores. Estas características del sector ubican a la empresa en un océano rojo, pues existe rivalidad entre competidores y acciones orientadas a debilitarse entre ellos.

Para la elaboración del lienzo, se han establecido nueve variables que resumen las características más relevantes del sector y de la empresa; las cuales se describen a continuación:

- $\quad$ Alianza estratégica con líderes del sector: Acuerdos sobre compra y venta de materia prima (subproductos) y/o productos terminados (harinas), realizados con empresas líderes del sector avícola.

- $\quad$ Alta tecnología: Uso de maquinaria de última generación para la elaboración de las harinas.

- $\quad$ Producto de alta calidad: Producto con altos estándares de calidad.

- $\quad$ Precio competitivo: Precios atractivos y acorde al mercado.

- $\quad$ Disponibilidad: Cuenta con stock disponible para la venta.

- $\quad$ Servicio postventa: Asistencia técnica pre y post venta.

- $\quad$ Reconocimiento de marca: Posicionamiento de la marca en el mercado. 
- $\quad$ Especialista en el sector avícola: harinas exclusivas para este sector, no abarca materias primas de otras especies de animales.

- $\quad$ Cumplimiento de normativa legal: Nivel de cumplimiento de las normas legales que aplican para el sector.

En la siguiente figura se muestra el lienzo de la estrategia actual de la empresa, caracterizado por las variables anteriormente descritas.

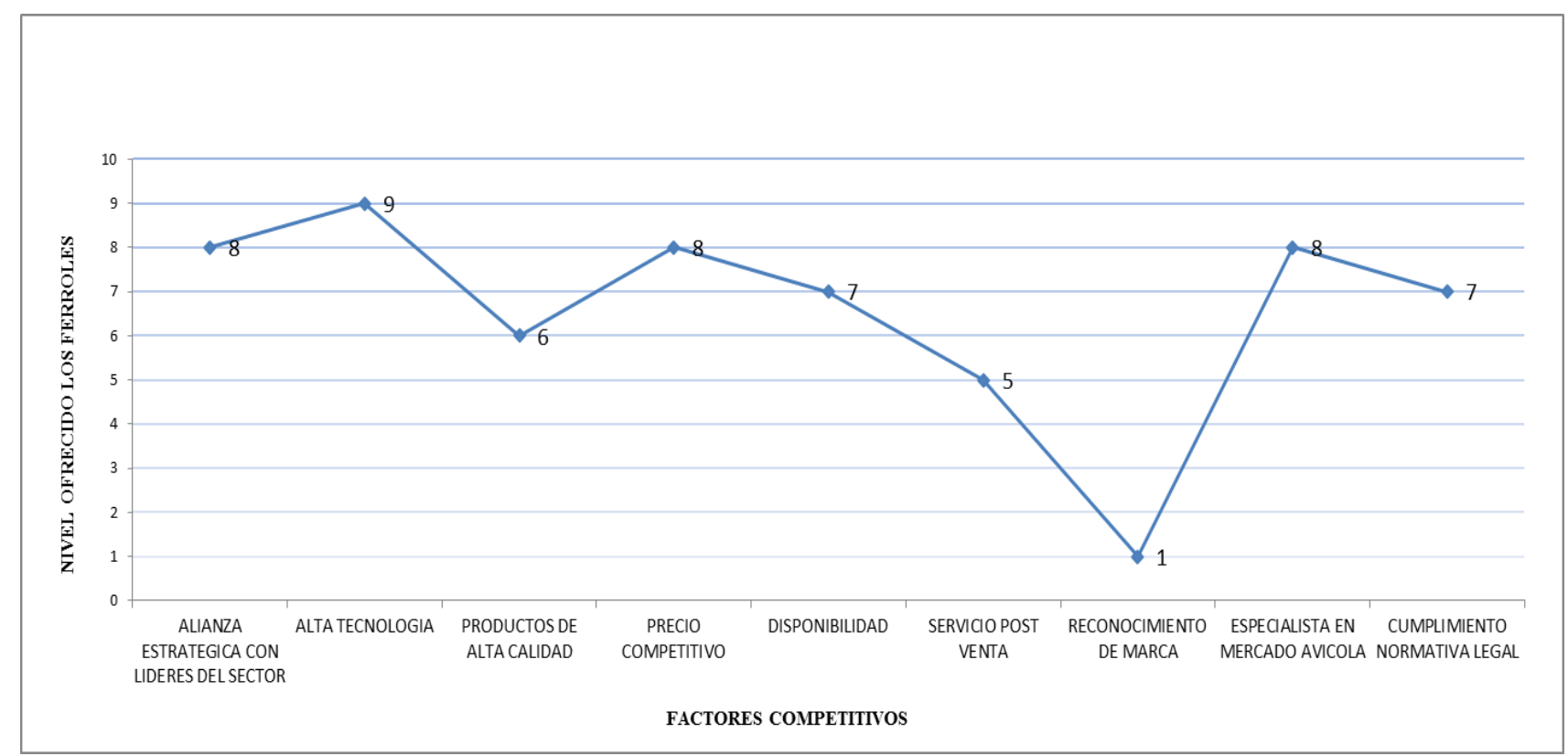

Figura 31. Lienzo de la estrategia actual de Los Ferroles.

\subsubsection{Lienzo de la estrategia de la industria.}

La industria del rendering está conformada principalmente por tres empresas locales que producen harinas proteicas para la elaboración de alimentos balanceados para ganadería, avicultura, peces y mascotas. Las empresas Technofeed y Alimencorp ofrecen variedad de harinas para estas industrias, mientras que Los Ferroles se ha especializado en harinas sólo para la industria avícola, y tiene el liderazgo en este mercado; ellos acopian y procesan la mayor cantidad de plumas generadas. 
Por otro lado, algunas empresas avícolas cuentan con maquinaria para producir sus propias harinas proteicas en base a sus subproductos; si bien su tecnología no es de última generación, les permite procesar sus residuos de plumas y vísceras de manera inmediata evitando costos logísticos y de maquila. Unas de estas empresas es Avinka SA (Chancay).

La tecnología en el sector no es muy avanzada, las empresas en su mayoría utilizan secadores y cocinadores que trabajan por batch (proceso discontinuo), los cuales son de fabricación nacional. Sólo la empresa Los Ferroles cuenta con moderna tecnología europea, lo cual le permite maximizar su productividad.

Sobre el reconocimiento de marca, ninguna de las empresas del sector ha desarrollado una estrategia comercial enfocada en el desarrollo de la marca de manera significativa; sin embargo, se evidencia que algunas realizan gestiones a través de medios digitales para mejorar la comunicación con sus clientes. Una de ellas es Technofeed, la cual cuenta con un portal web a través del cual comunica la historia, visión y valores de la compañía, así como las características de los productos que ofrece. En el portal también vemos que comunica la Certificación ISO 9001 que posee la empresa, y que la convierte en la primera en la industria del rendering en obtener esta certificación. Asimismo, Alimencorp tiene presencia en redes sociales con activa comunicación, difundiendo información sobre sus productos, eventos en los que participa u organiza, visitas a clientes, capacitaciones, entre otros temas. En el caso de Los Ferroles, no tiene desarrollada la gestión de marketing, ni cuenta con presencia en medios digitales. La estrategia que ellos usan es vender las bondades del producto a través del trato y visitas personales a los clientes. 
Si bien los precios ofrecidos por las empresas son semejantes, Technofeed y Alimencorp cuentan con una mayor gama de productos diversificados y categorizados según calidad y el tipo de industria a la cual se orientan. Actualmente, la empresa de estudio no ha categorizado sus productos, sólo cuenta con una calidad estándar tanto para la harina de plumas como para la de vísceras.

De acuerdo a las entrevistas realizadas a los directivos de la empresa, las empresas de la competencia y los expertos del sector (ver Anexos $\mathrm{N}^{\circ} 4, \mathrm{~N}^{\circ} 6$ y $\mathrm{N}^{\circ} 3$ respectivamente), se elaboró la tabla 37 donde se muestra el comparativo de puntuación de factores competitivos entre la industria del rendering y Los Ferroles.

Tabla 37

Factores competitivos y niveles de Los Ferroles y el sector

\begin{tabular}{lcc}
\hline FACTORES COMPETITIVOS & $\begin{array}{c}\text { NIVEL OFRECIDO } \\
\text { LOS FERROLES }\end{array}$ & $\begin{array}{c}\text { NIVEL OFRECIDO } \\
\text { SECTOR }\end{array}$ \\
\hline ALIANZA ESTRATEGICA CON LIDERES DEL SECTOR & 8 & 4 \\
ALTA TECNOLOGIA & 9 & 5 \\
PRODUCTOS DE ALTA CALIDAD & 6 & 7 \\
PRECIO COMPETITIVO & 8 & 8 \\
DISPONIBILIDAD & 7 & 6 \\
SERVICIO POST VENTA & 5 & 6 \\
RECONOCIMIENTO DE MARCA & 1 & 5 \\
ESPECIALISTA EN MERCADO AVICOLA & 8 & 2 \\
CUMPLIMIENTO NORMATIVA LEGAL & 7 & 7 \\
\hline
\end{tabular}

La figura 31 muestra el lienzo de la industria del rendering, donde se observa que

si bien tiene similitudes con el lienzo de Los Ferroles, existen factores que muestran diferencias, tales como:

- $\quad$ Menor nivel en alianzas estratégicas con líderes del sector: sólo Los Ferroles ha establecido alianza con San Fernando para la maquila de sus subproductos). 
- $\quad$ Menor nivel en tecnología: sólo Los Ferroles cuenta con tecnología moderna)

- $\quad$ Menor nivel en disponibilidad: para el sector avícola, Los Ferroles acopia la mayor cantidad de plumas del mercado.

- $\quad$ Mayor nivel en servicio post venta: las otras empresas del sector brindan mayor servicio técnico y capacitaciones a sus clientes.

- $\quad$ Mayor nivel en reconocimiento de marca: el resto de empresas del sector han establecido más canales de comunicación con sus clientes, aprovechando medios digitales.

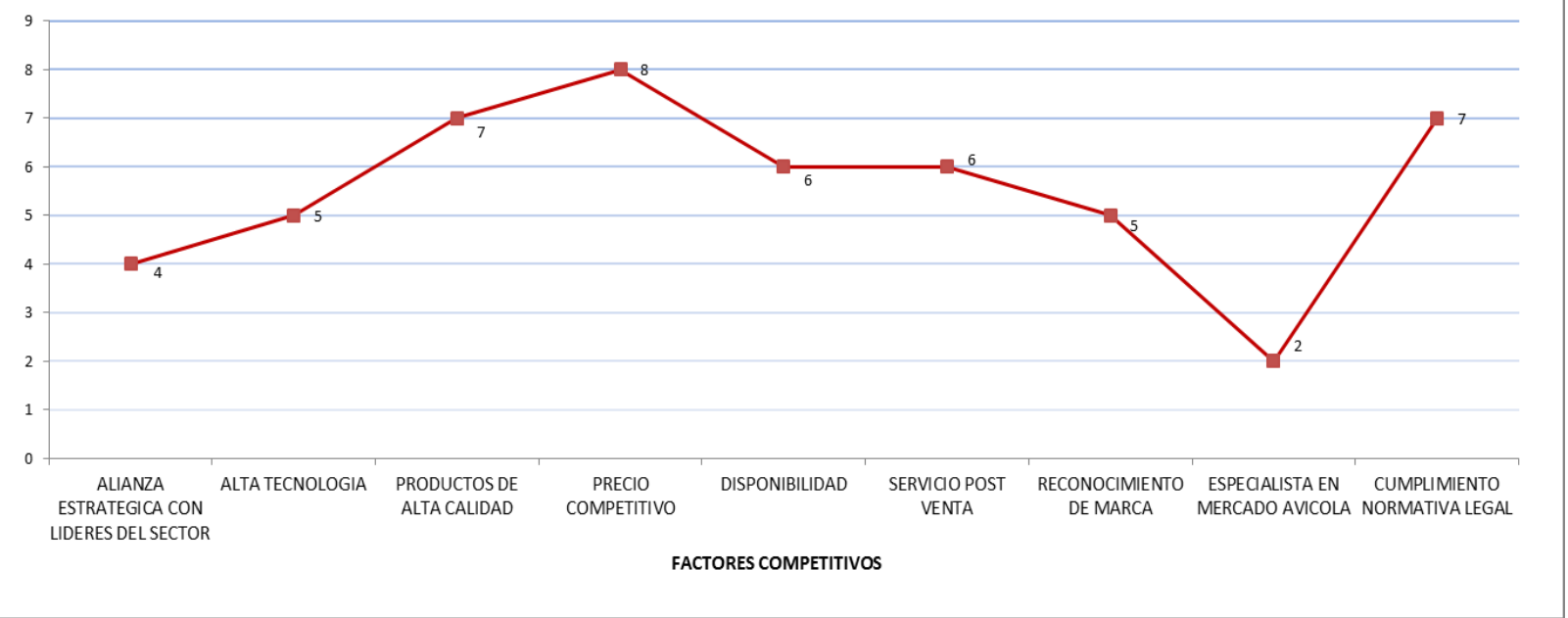

Figura 32. Lienzo de la estrategia actual del sector del rendering

La figura 33 muestra las principales brechas existentes entre el sector rendering y Los Ferroles, siendo las más significativas: (a) alianza estratégica con líderes del sector; (b) alta tecnología; (c) falta de reconocimiento de la marca. 


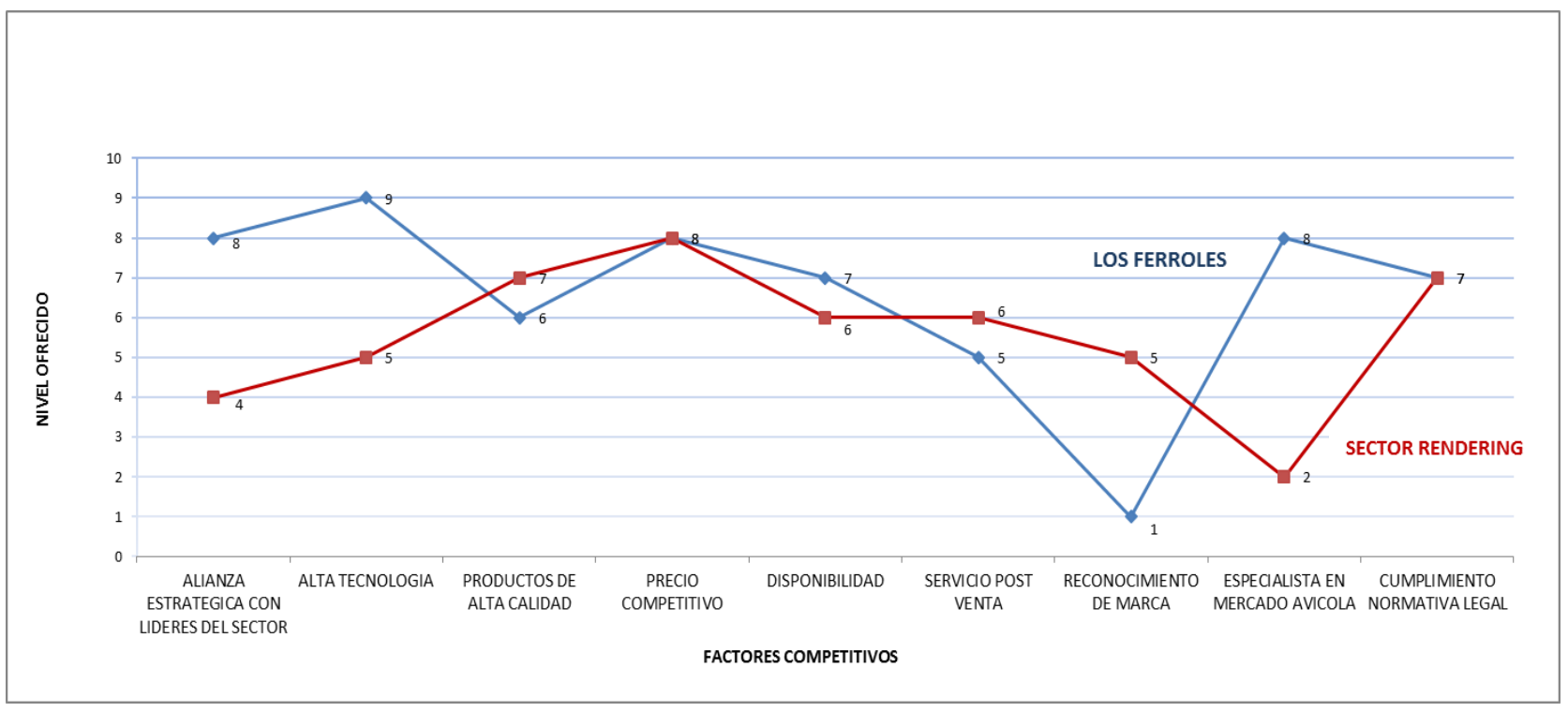

Figura 33. Comparativo entre el lienzo de la estrategia actual de Los Ferroles y del sector.

\subsubsection{Matriz (eliminar, reducir, incrementar, crear).}

Esta matriz permite analizar la estrategia actual para definir qué aspectos se deben eliminar o reducir, incrementar o crear. Estas nuevas características permitirán diseñar la nueva estrategia océano azul que logrará la satisfacción de los clientes, ofreciéndoles un producto de alto valor agregado, diferenciado en calidad y servicio, y al menor costo posible.

Del análisis realizado, concluimos que la nueva estrategia Océano Azul para Los Ferroles, se enfocará en remarcar las características de calidad de los productos, ofreciendo una mayor variedad según los requerimientos y tipos de aves (alimentos según edades, para pollos o pavos); asimismo, se repotenciará la gestión comercial y de marketing, estrechando el vínculo con los clientes.

La estrategia actual de Los Ferroles es parcialmente un océano azul, dado que ellos se han especializado en el sector avícola, dejando de lado los otros sectores como la 
ganadería, peces y mascotas, donde sí se ubican los otros competidores. La tecnología con la que cuentan es exclusiva para este sector, lo que les permite obtener productos de muy buena calidad. El aspecto por reforzar es la diversificación de productos, estandarización de procesos, y la mejora en el servicio post venta.

A continuación, se describe la matriz y los factores que caracterizan cada cuadrante:

Eliminar: no se eliminará ningún factor de los actuales.

- $\quad$ Reducir: no se reducirá ningún factor de los actuales

Incrementar: se incrementarán los factores: Alianza estratégica con líderes del sector, Alta tecnología, Producto de alta calidad, Precio competitivo, Disponibilidad, Servicio postventa, Reconocimiento de marca, Especialista en mercado avícola y Cumplimiento de normativa legal.

Crear: se crearán los factores: Diversificación de productos, Relación con el cliente y Estrategia comercial. 
Tabla 38

Matriz Eliminar, Reducir, Incrementar y Eliminar

ELIMINAR

REDUCIR

\section{INCREMENTAR}

Alianza estratégica con líderes del sector.

Alta tecnología.

Producto de alta calidad.

Precio competitivo.

Disponibilidad.

Servicio postventa.

Reconocimiento de marca.

Especialista en mercado avícola.

Cumplimiento de normativa legal.

\section{CREAR}

Diversificación de productos.

Relación con el cliente.

Estrategia comercial.

\subsubsection{Lienzo de la nueva estrategia considerada.}

La nueva estrategia océano azul, está enfocada en consolidar el liderazgo de la empresa en el sector avícola, a través de la oferta de productos de alta calidad y variedad, y reforzando las relaciones con los clientes actuales. No se eliminarán ni reducirán los factores competitivos actuales, dado que están alineados a la nueva estrategia, por el contrario estos factores se incrementarán, y se crearán tres nuevos. La figura 34 muestra el nuevo lienzo de la estrategia océano azul para Los Ferroles. 


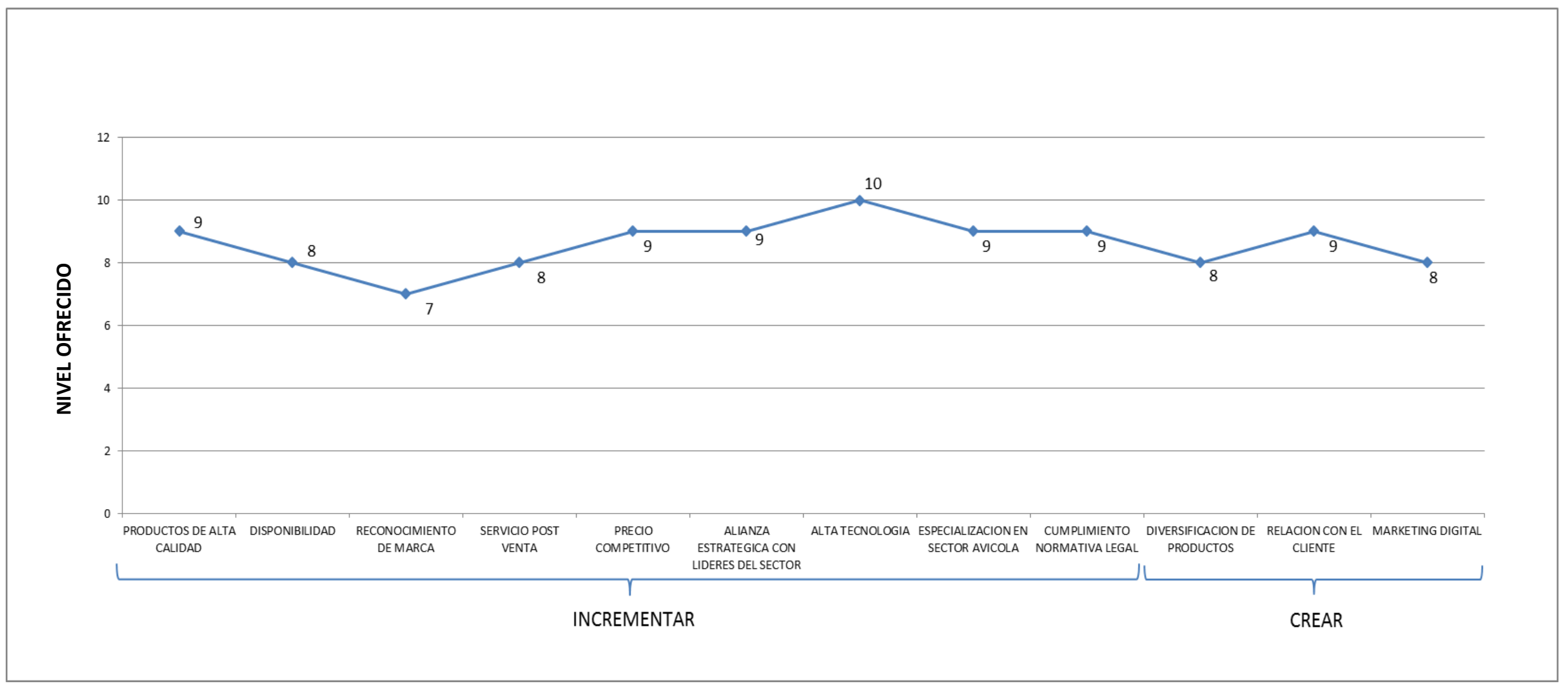

Figura 34. Lienzo de la nueva estrategia océano azul 


\subsubsection{Matrices de formulación de estrategias.}

La etapa de adecuación del modelo de formulación de estrategias consta de cinco técnicas que pueden ser utilizadas en cualquier secuencia; las integran las siguientes matrices: (a) matriz FODA, (b) matriz PEYEA, (c) matriz BCG, (d) matriz IE (Interno, Externa), (e) matriz de la estrategia principal.

La adecuación entre los factores relevantes para el éxito tanto internos como externos, es la clave para el desarrollo de estrategias alternativas factibles. (David, 2013).

\subsubsection{Matriz FODA.}

Uno de los mejores instrumentos para mapear los factores externos e internos claves es la matriz FODA (Fortalezas, Debilidades Oportunidades Amenazas), utilizada para la formulación de las estrategias de negocio basadas en las fortalezas y debilidades de la empresa y las oportunidades y amenazas del entorno. (David, 2013)

Basados en la información de las matrices EFE y EFI de Los Ferroles, se elabora la matriz FODA, dicha herramienta será utilizada para la elaboración de cuatro tipos de estrategias:

Estrategias de fortalezas y oportunidades (FO): utilizan las fortalezas internas de la empresa para aprovechar las oportunidades externas, (b) estrategias de debilidad y oportunidades (DO): buscan superar las debilidades internas, aprovechando las oportunidades externas. (c) estrategias de fortalezas y amenazas (FA): utilizan las fortalezas de la empresa para evitar o reducir el impacto de las amenazas. (d) estrategias 
de debilidades y amenazas (DA): tácticas defensivas cuyo propósito es reducir las debilidades internas y evitar las amenazas externas.

Del análisis obtenido de la matriz FODA, se determinaron las siguientes estrategias:

Estrategias Ofensivas (FO: Fortaleza - Oportunidad).

Captación de materia prima de mercado de provincia de zona norte: negociación con productores avícolas de la zona norte para compra de subproductos. Desarrollo de nuevos productos especializados y de alto valor agregado: diseño y lanzamiento de nuevas variedades de harinas proteicas.

Generar alianzas con proveedores de materias primas para incremento de servicio de maquila: establecer acuerdos comerciales estratégicos con productores avícolas para incrementar el servicio de maquila y así maximizar el uso de la capacidad instalada de planta.

Integración vertical con acopiadores-transportistas de materia prima: integrar el proceso de acopio y transporte de la materia prima, realizándolo sin intermediarios.

Estrategias Defensivas (FA: Fortaleza-Amenaza).

Alineamiento de los procesos de acuerdo a la normativa legal vigente: adecuar los procesos productivos y administrativos de acuerdo a los requisitos legales vigentes. 
Desarrollar rendering para el rubro pecuario, acuícola y alimento para mascotas: desarrollar nuevas categorías de productos para otros sectores, a fin de diversificarse.

Mantener cartera de clientes a través de política de precios: establecer estrategias comerciales que defina precios acordes a las necesidades del mercado.

Estrategias de Reorientación (DO: Debilidad - Oportunidad).

Implementar gestión comercial y de marketing a través de medios digitales: desarrollar estrategias comerciales a través de plataformas digitales. Reestructuración organizacional en toda la compañía: reordenamiento de la estructura interna para fortalecimiento institucional.

- $\quad$ Establecimiento de estrategias y objetivos para proyección de crecimiento a mediano y largo plazo.

Búsqueda de clientes en empresas medianas: no limitar el mercado a empresas líderes del sector, sino también ampliar cartera de cliente a empresas medianas. Certificar sistemas de gestión de calidad e inocuidad: la implementación de los sistemas permitirá potenciar el enfoque al cliente y el cumplimiento de sus expectativas. 
Estrategias de Supervivencia (DA: Debilidad-Amenaza).

Fusión con empresas de la competencia: unirse con otra u otras empresas para asegurar la continuidad del negocio.

- $\quad$ Elaborar un plan de optimización de gastos: recorte de gastos. 


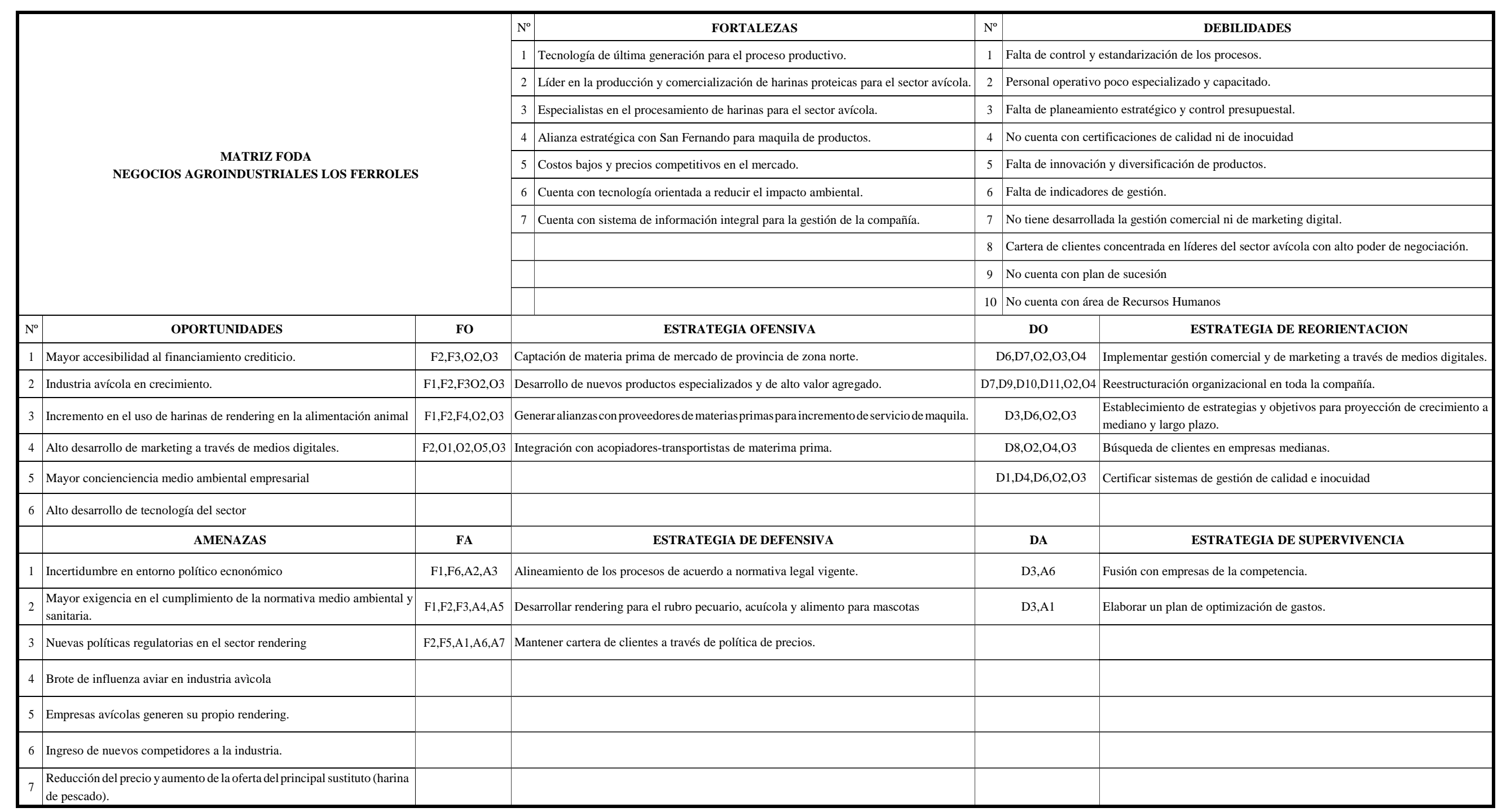

Figura 35. Matriz FODA Tomado de El Proceso Estratégico, Un enfoque de Gerencia (p. 185), por F. D’alessio 2015, Lima, Perú: Copyrigth 2015 por Pearson Educación del Perú SA 


\subsubsection{Matriz PEYEA.}

La matriz PEYEA busca determinar la postura estratégica de la empresa, por lo que la herramienta combina factores relativos de la industria y de la organización. Presenta cuatro cuadrantes: Fortaleza Financiera (FF), Ventaja Competitiva (VC), Estabilidad del Entorno (EE), y Fortaleza de la Industria (FI). La calificación para FF y FI va desde +1 (peor) al +6 (mejor) y desde -1 (mejor) al -6 (peor) para EE y VC. (D’Alessio, 2013).

Para la elaboración de la matriz PEYEA se consideraron las siguientes variables y se asignó la calificación correspondiente de acuerdo al modelo de negocio de la empresa. 
Tabla 39

Calificación de las fuerzas para Matriz PEYEA

Posición Estratégica Interna

\begin{tabular}{lcc}
\hline & Fuerza Financiera (FF) & Calificaciones \\
Retorno de la inversión & 6 \\
Acceso al crédito & 5 \\
Facilidad de salida del mercado & 3 \\
Y & 4 \\
Riesgo involucrado en el negocio & 6 \\
Rotación de inventarios & 5 \\
Uso de economías de escala y experiencia & 29 \\
Total & $\mathbf{4 . 8 3}$ \\
PROMEDIO & Calificaciones \\
& -1 \\
\hline Ventaja Competitiva (VC) & -3 \\
Participación de mercado & -3 \\
Calidad del producto & -1 \\
Ciclo de vida del producto & -6 \\
Especialista en sector avícola & -3 \\
Lealtad del consumidor & -1 \\
Alianzas estratégicas con proveedores & -18 \\
Uso de tecnología & $\mathbf{- 2 . 5 7}$ \\
\hline Total &
\end{tabular}

Posición Estratégica Externa

\begin{tabular}{llc}
\hline & Fuerza de la industria (FI) & Calificaciones \\
& Potencial de Crecimiento & 6 \\
& Estabilidad financiera & 5 \\
& Conocimiento tecnológico & 6 \\
X & Utilización de recursos & 5 \\
& Facilidad de entrada del mercado & 3 \\
& Productividad / utilización de la capacidad & 6 \\
Poder de negociación de los proveedores & 5 \\
Total & 36 \\
PROMEDIO & $\mathbf{5 . 1 4}$ \\
\hline & Calificaciones \\
\hline & -2 \\
Cambiomilidad del Entorno (EE) & -2 \\
Variablidad de la demanda & -5 \\
Rango de precios de los prodcutos competitiv & -2 \\
Barreras de entrada al mercado & -5 \\
Rivalidad / presión competitiva & -5 \\
Presión de los productos sustitutos & -27 \\
Total & $\mathbf{- 3 . 5 0}$ \\
\hline
\end{tabular}


La matriz muestra los siguientes resultados: Posición Estratégica Interna: La fuerza financiera $(\mathrm{FF})$ tiene una calificación de + (4.83) y la ventaja competitiva (VC) tiene una calificación de - (2.57). Respecto a la posición estratégica externa: La fuerza de la industria (FI) tiene una calificación de + (5.14) y la estabilidad del entorno (EE) tiene una calificación - (3.50). Como resultado total el eje X muestra una calificación total de $+(2.57)$ y el eje Y muestra una calificación total de + (1.33). Sobre los resultados obtenidos, la posición estratégica de la empresa se ubica en el cuadrante de estrategia agresiva.

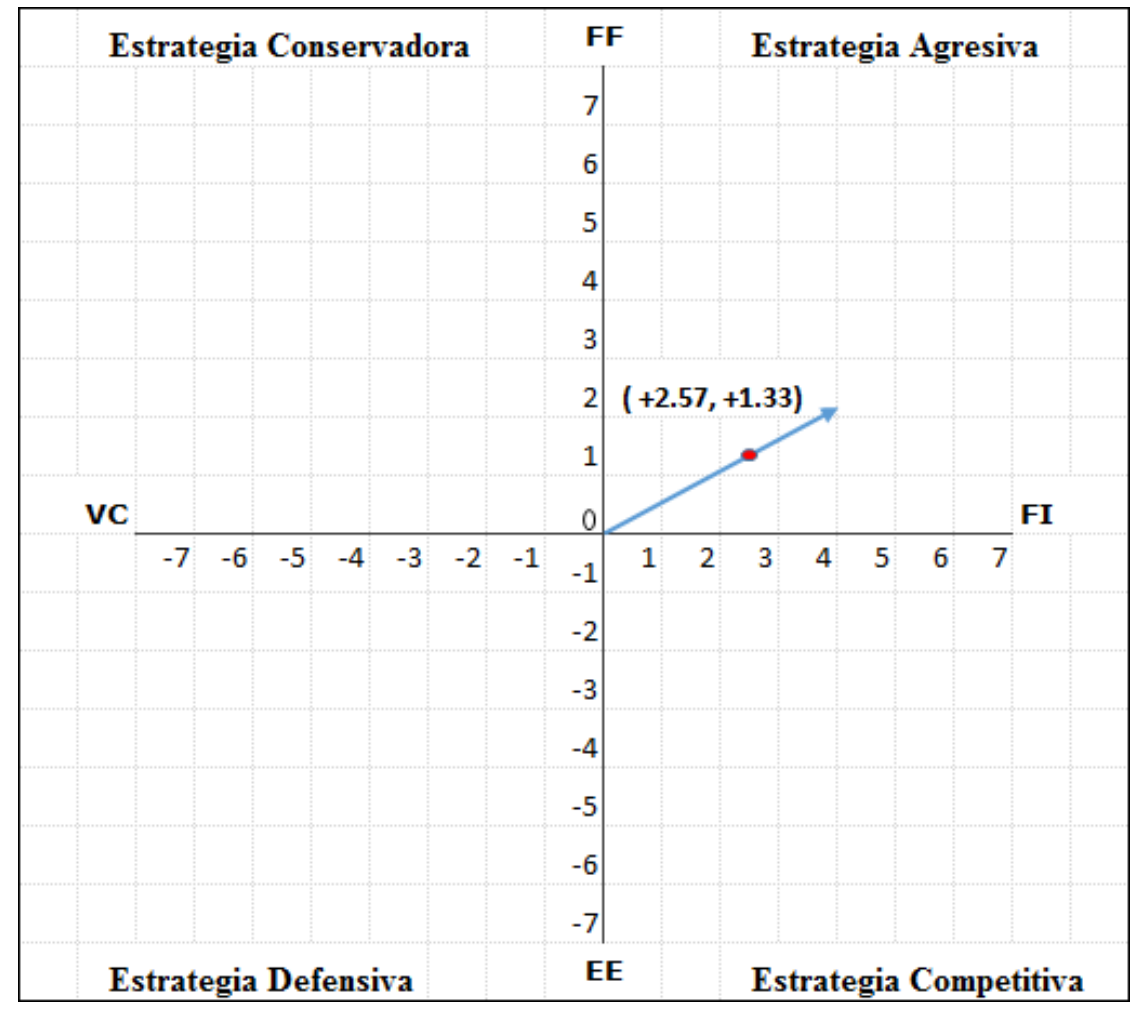

Figura 36. Matriz de posición estratégica y evaluación de la acción - PEYEA. Tomado de "El Proceso Estratégico, Un enfoque de Gerencia" (p. 185), por F. D’alessio 2015, Lima, Perú: Copyrigth 2015 por Pearson Educación del Perú SA 
Según David (2013), la estrategia agresiva significa que la organización está en excelentes condiciones para utilizar sus fortalezas internas con el propósito de (a) aprovechar las oportunidades externas, (b) superar las debilidades internas, y (c) evitar las amenazas externas. Por lo tanto, dependiendo de las circunstancias que enfrenta la empresa, podrían ser factibles, las estrategias de: penetración de mercado, desarrollo de mercado, desarrollo de producto, integración hacia atrás, integración hacia adelante, integración horizontal o diversificación.

\subsubsection{Matriz Interna Externa (IE).}

En la matriz IE se basa en dos dimensione claves: los puntajes totales ponderados de EFI en el eje X y los puntajes totales ponderados de EFE en el eje Y. Estos puntajes permiten la construcción de la matriz IE de la organización. Un puntaje total ponderado de EFI de 1.0 a 1.99 representa una posición interna débil; un puntaje de 2.0 a 2.99 es considerado promedio, y un puntaje de 3.0 a 4.0 se considera como fuerte. De manera similar pero sobre el eje Y, un puntaje total ponderado de EFE de 1.0 a 1.99 se considera bajo; un puntaje de 2.0 a 2.99 se considera medio, y un puntaje de 3.0 a 4.0 se considera alto.

La matriz IE puede dividirse en tres regiones principales, cada uno con diferentes implicaciones estratégicas. La primera región está conformada por las casillas I, II y IV; si una división cae en esa zona se considera que está en posición de crecer y construir. Las estrategias intensivas (penetración de mercado, desarrollo de mercado y desarrollo de producto) o de integración (integración hacia atrás, hacia adelante, horizontal) serían las más apropiadas en estos casos. La segunda región corresponde a 
las casillas III, V y VII; las divisiones que caen en ella se beneficiarán con la implementación de estrategias de conservar y mantener, como las de penetración de mercado y desarrollo de producto. La ultima región está compuesta por las casillas VI, VIII y IX; en este caso se recomienda la cosecha o desinversión. Las organizaciones exitosas son aquellas capaces de lograr una cartera de negocios ubicados en o alrededor de la casilla I de la matriz. (David, 2015).

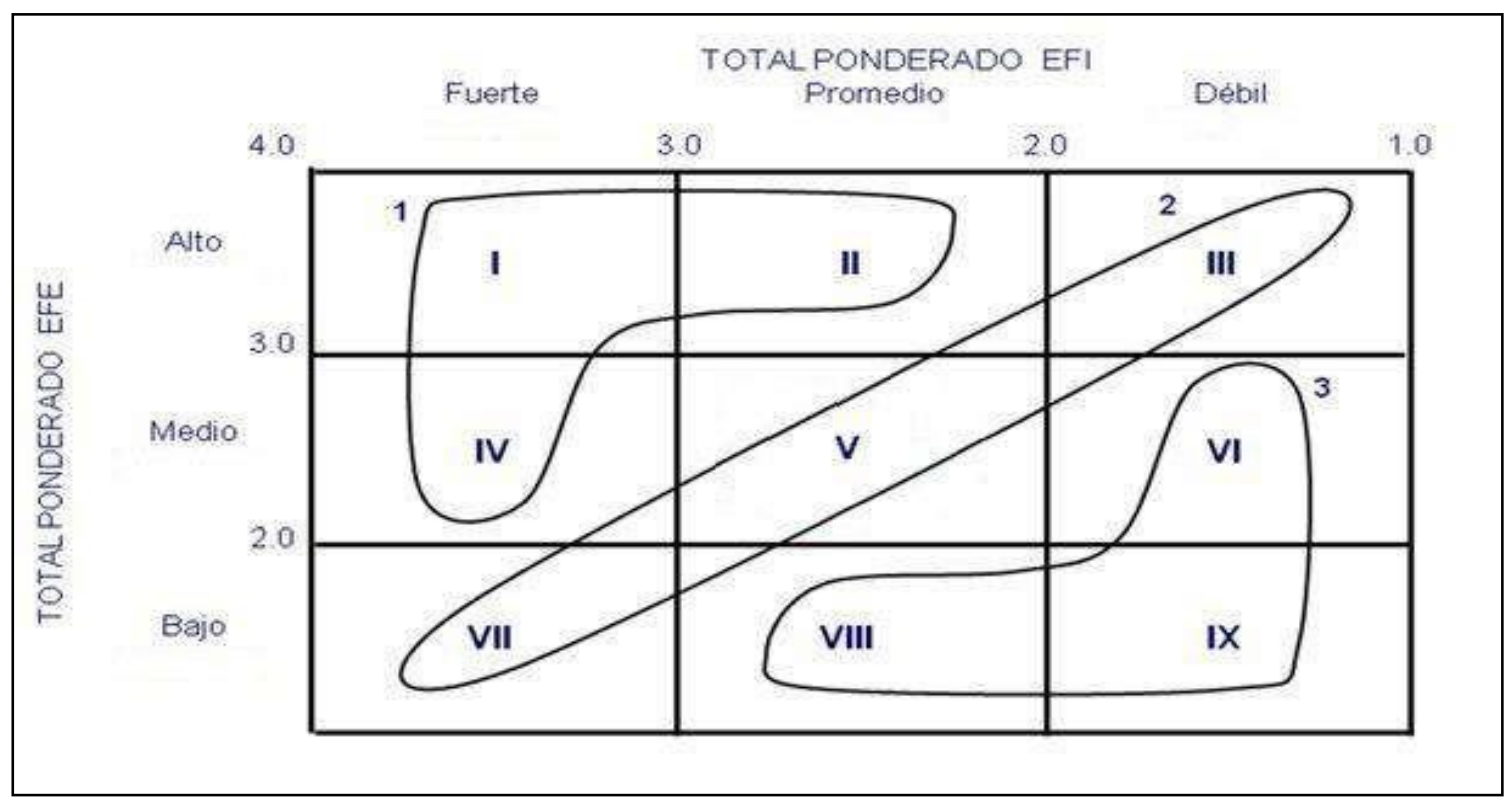

Figura 37. Matriz Interna y Externa. Tomado de Conceptos de Administración Estratégica (p.187), por Fred David, 2013, Mexico. Copyright 2013 por Pearson Educación.

De los resultados obtenidos en la matriz, las puntuaciones EFE (2.29) y EFI (2.21) determinan que la empresa se ubica en el cuadrante $\mathrm{V}$, región dos: conservar y mantener; es decir, las estrategias a emplear deberán estar orientadas en la penetración de mercado y/o en el desarrollo de nuevos productos. 


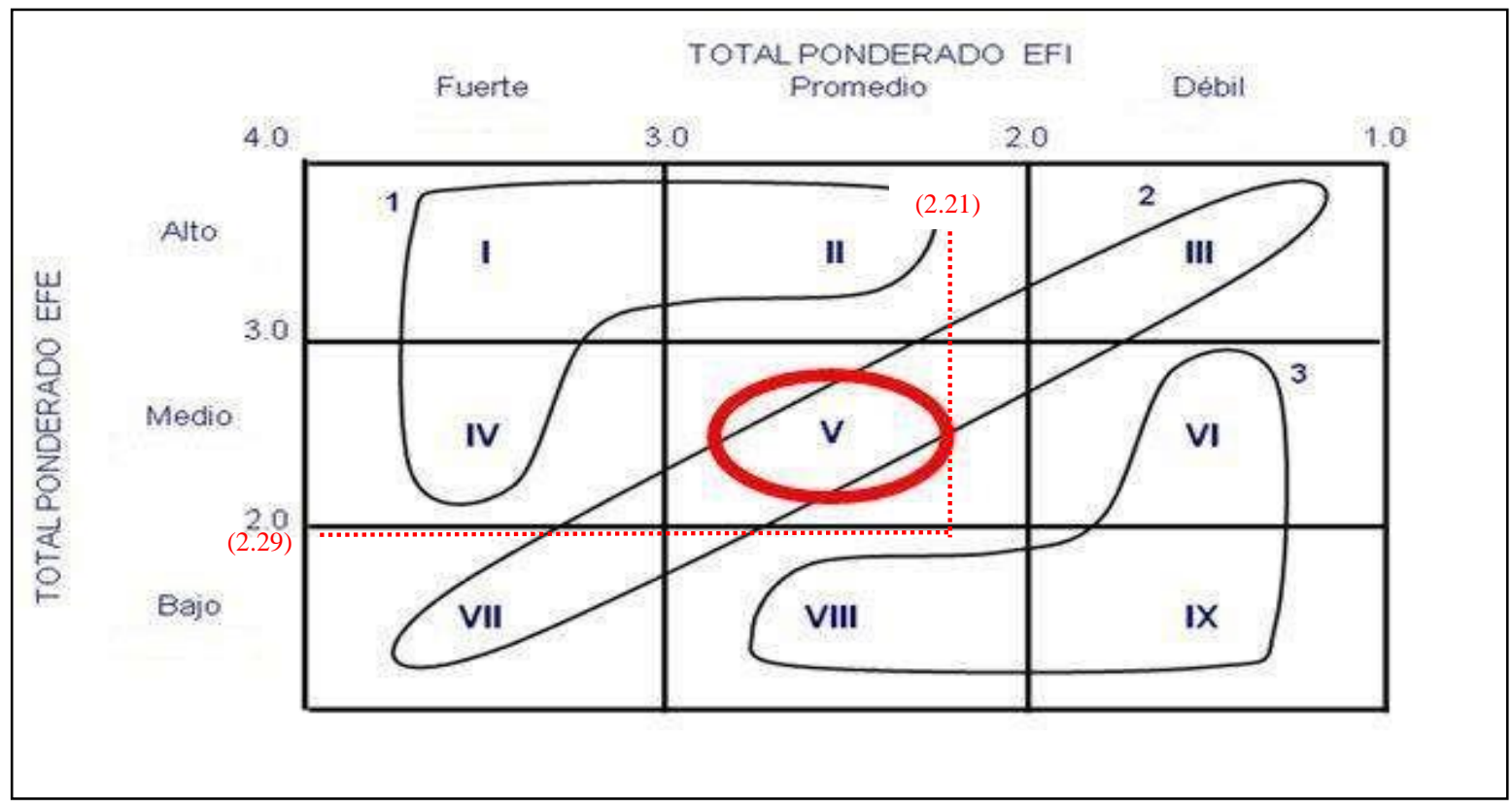

Figura 38. Matriz Interna y Externa Los Ferroles. Adaptado de Conceptos de

Administración Estratégica (p.187), por Fred David, 2013, Mexico. Copyright 2013 por Pearson Educación.

\subsubsection{Matriz Boston Consulting Group.}

La matriz de BCG es un método gráfico que permite desarrollar un análisis estratégico del portafolio de productos de una empresa en base a dos factores: (a) la tasa de crecimiento de mercado; y (b) la participación de mercado. De esta manera, la empresa podrá evaluar si las líneas de negocio que posee ameritan invertir, desinvertir o incluso abandonarlas. (D’Alessio, 2015)

Según David (2013), para agrupar las líneas de negocio que posee una empresa, se trabaja en base a una matriz de 2 x 2, y cada división de negocio se situará en uno de los cuatro cuadrantes de la matriz resultante en función a su valor estratégico. Dichos cuadrantes son: 
- $\quad$ Cuadrante I - Interrogantes: Baja participación relativa del mercado y alto crecimiento en la industria. Demandan inversión y su generación de efectivo (caja) es baja, por lo que se recomienda la implementación de estrategias penetración de mercado, desarrollo de producto, desarrollo de mercado o de desinversión.

- $\quad$ Cuadrante II - Estrellas: Alta participación relativa del mercado y crecimiento en la industria. Requieren de alto grado de inversión para conservar o fortalecer su posición dominante. Se recomienda evaluar estrategias de integración, penetración de mercado, desarrollo de producto y desarrollo de mercado.

- $\quad$ Cuadrante III - Vacas: Alta participación relativa de mercado y bajo crecimiento de la industria. Generan efectivo por encima de sus necesidades. Se recomienda evaluar estrategias de desarrollo de productos, diversificación, recorte de gastos o desinversión.

- $\quad$ Cuadrante IV - Perros: Baja participación relativa del mercado y crecimiento de la industria. Tanto su posición interna como externa es débil, por lo que se recomienda estrategias de desinversión, liquidación o reducción de gastos. 


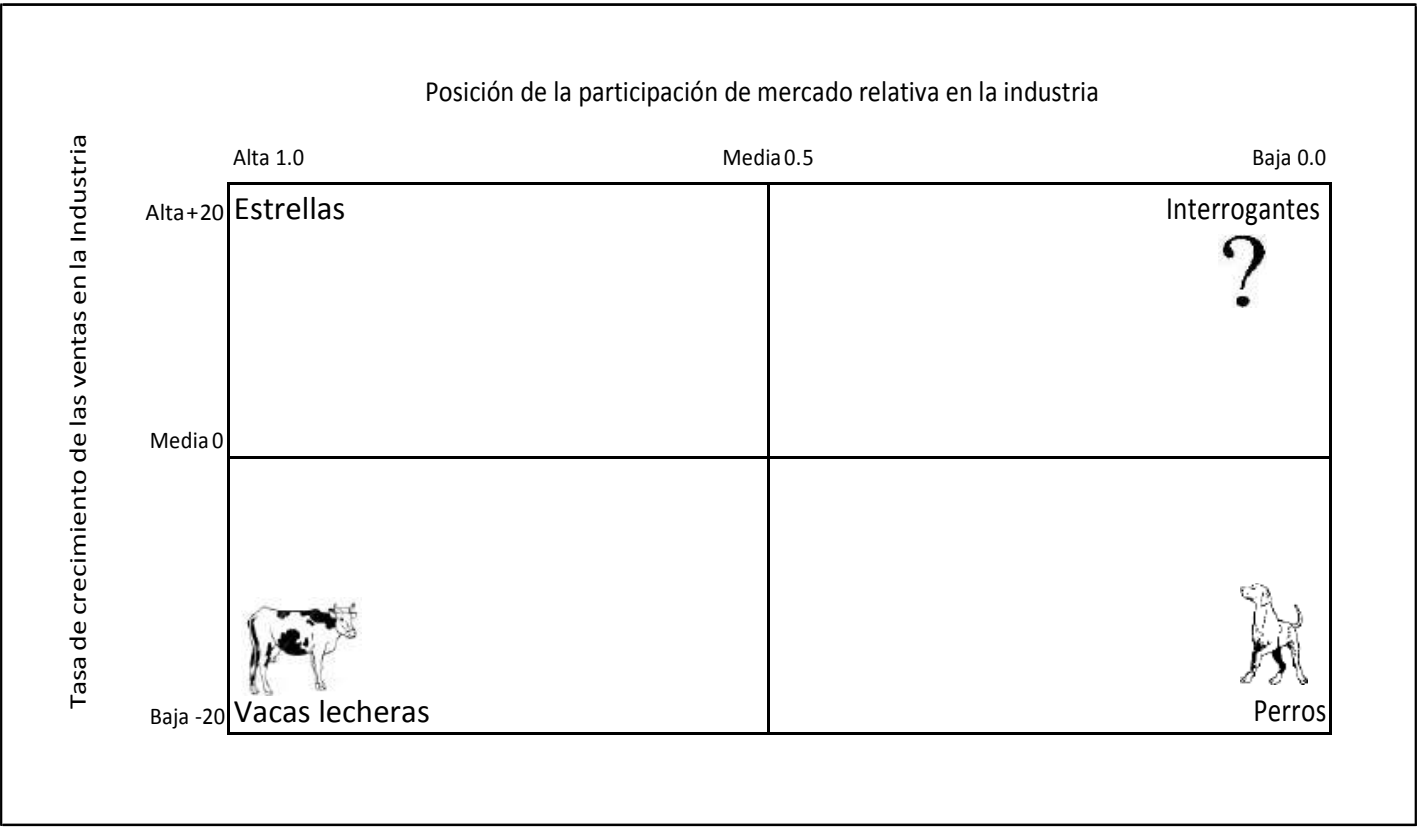

Figura 39. Matriz Boston Consulting Group (MBCG). Tomado de El Proceso Estratégico Un enfoque de gerencia, (p.289) por F. D’Alessio, 2015. Lima, Perú: Copyrigth 2015 por Pearson Educación del Perú SA

De acuerdo a la información brindada por Los Ferroles sobre los niveles de venta, participación de mercado y tasa de crecimiento, se muestra la siguiente tabla:

Tabla 40

Participación de mercado y tasa de crecimiento Los Ferroles

\begin{tabular}{cccc}
\hline Líneas de & Participación de & Tasa de & Ventas \\
Producto & mercado & crecimiento & Totales 2017 \\
\hline Harina de Pluma & 1 & $6 \%$ & $85.9 \%$ \\
Harina de Vísceras & 1 & $6 \%$ & $14.1 \%$ \\
\hline
\end{tabular}


Con el fin de identificar en que cuadrante se posicionan las dos líneas de producción de harinas, se grafica en la figura 40 la posición de la participación de mercado y el crecimiento de las ventas.

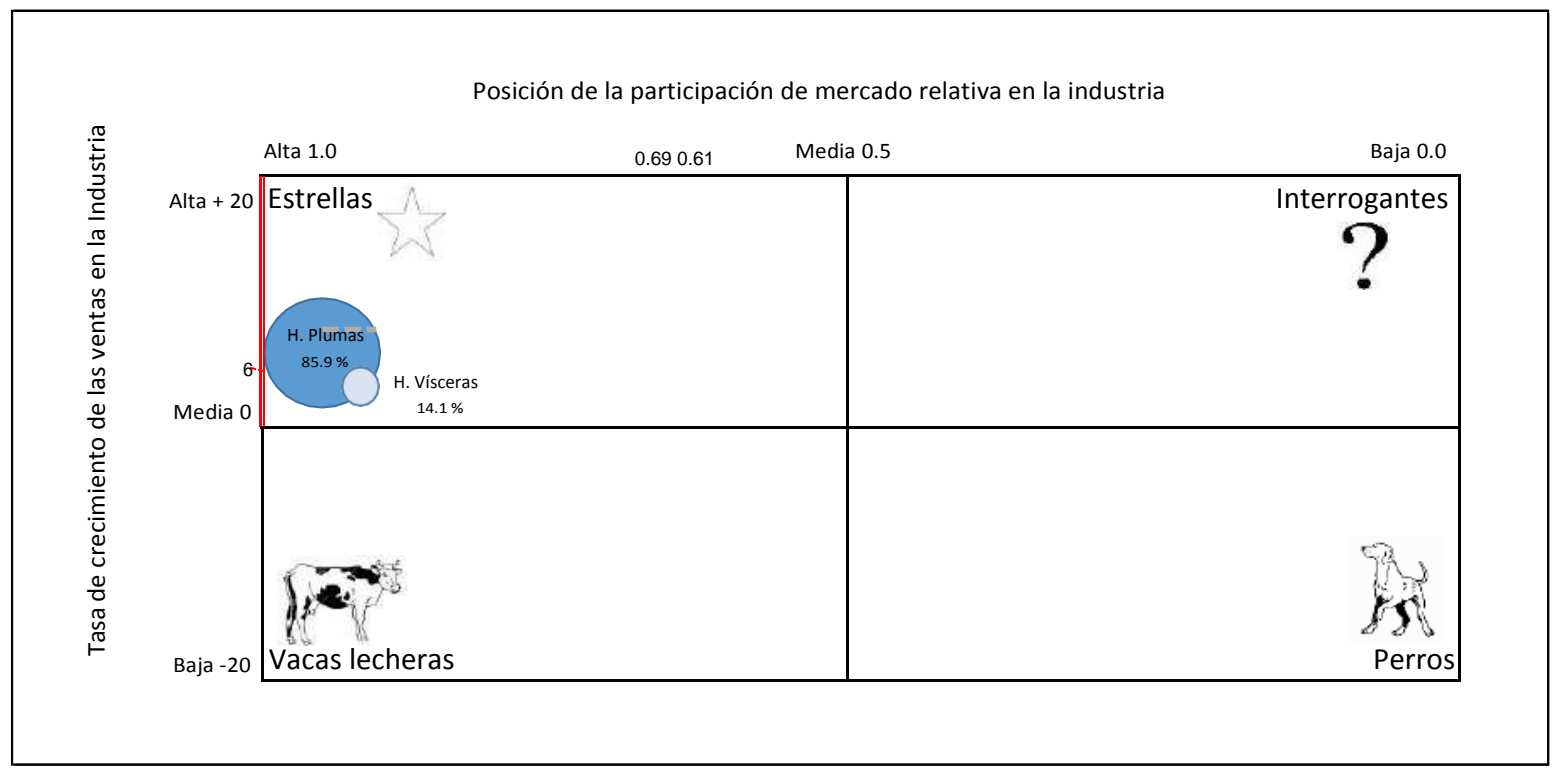

Figura 40. Matriz Boston Consulting Group (MBCG) de Los Ferroles. Adaptado de El Proceso Estratégico, Un enfoque de gerencia, (p. 293) por F. D’Alessio, 2015. Lima, Perú: Copyrigth 2015 por Pearson Educación del Perú SA

De acuerdo al gráfico anterior, la harina de pluma se encuentra ubicada en el cuadrante de productos estrellas dado su liderazgo de participación de mercado (1) y su tasa de crecimiento de la industria (6\%). Para mantener su posición dominante y rentabilidad a largo plazo, la empresa deberá invertir en esta línea de negocio y así consolidar su liderazgo en el mercado. Entre las estrategias que podrán ser aplicadas 
tenemos: las de integración (hacia adelante, hacia atrás u horizontal) y las intensivas (penetración de mercado, desarrollo de mercado o desarrollo de producto).

En cuanto a la harina de vísceras también se encuentra ubicada en el cuadrante estrella, puesto que presenta alta participación en el mercado (1) y una tasa de crecimiento (6\%). Cabe señalar que esta línea de producción presenta como limitante la escasez de materia prima, dado que mayormente es usada para la alimentación de ganado porcino. Esta restricción no permite un mayor crecimiento de este producto en el mercado. Entre las estrategias que podrán ser aplicadas tenemos: las de integración (hacia adelante, hacia atrás u horizontal) y las intensivas (penetración de mercado, desarrollo de mercado o desarrollo de producto).

\subsubsection{Matriz de la Gran Estrategia (MGE).}

La matriz MGE evalúa la elección de la estrategia más apropiada para la empresa. Se determina utilizando el crecimiento del mercado y la posición competitiva de la empresa en el mercado. La evaluación muestra si el crecimiento del mercado es rápido o lento y si la posición competitiva es débil o fuerte. (D’Alessio, 2015) 


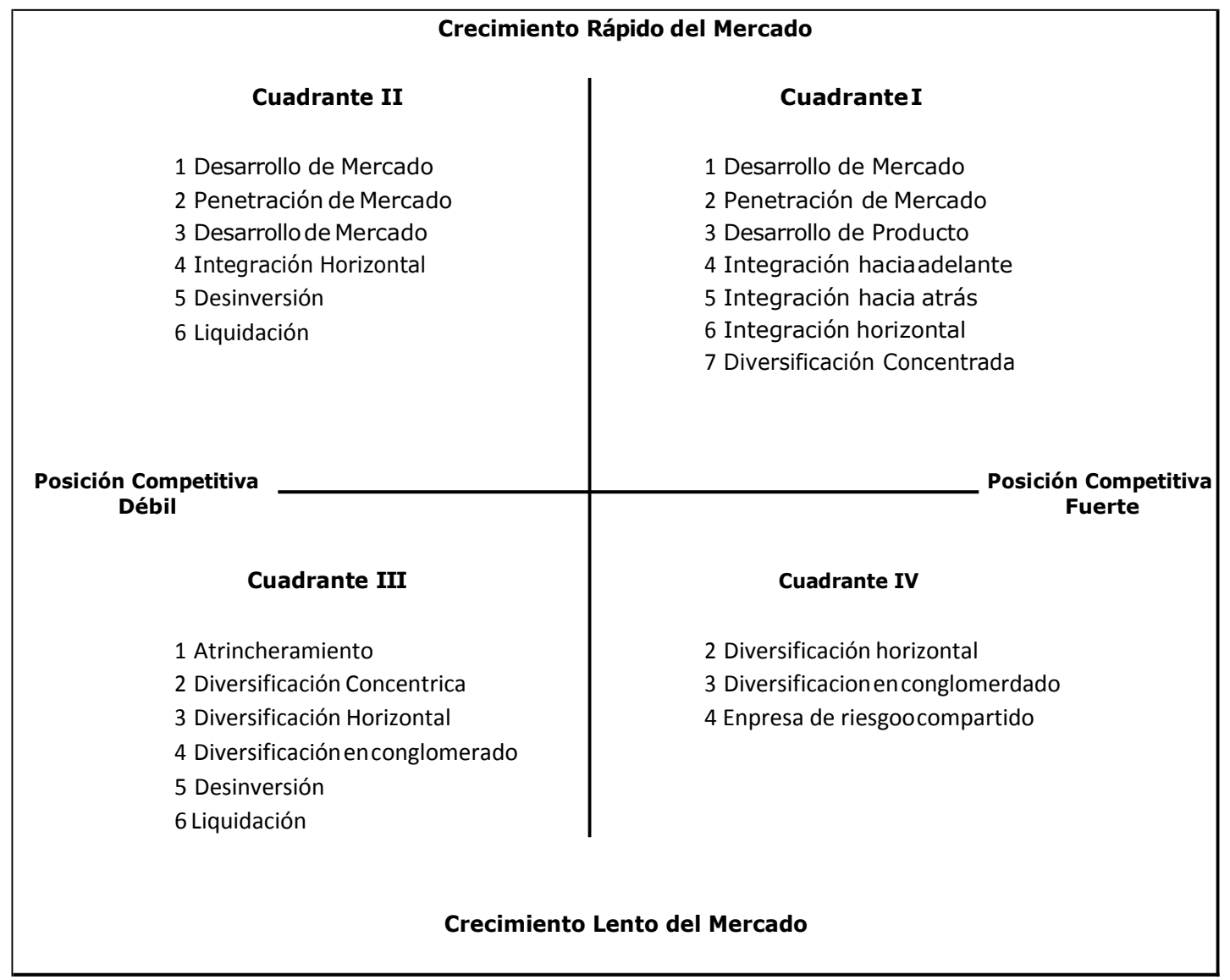

Figura 41. La Matriz de la Estrategia Principal. Tomado de Conceptos de Administración Estratégica (p. 190), por Fred David, 2013. México. Copyright 2013 por Pearson Educación.

Las empresas del cuadrante I de la matriz muestran una excelente posición estratégica. Una estrategia adecuada para ellas es la concentración ininterrumpida en los mercados (penetración de mercado y desarrollo de mercado) y productos actuales (desarrollo de producto). No se recomienda que las empresas ubicadas en el cuadrante I realicen cambios drásticos en sus ventajas competitivas ya consolidadas. Cuando las empresas tienen un exceso de recursos, las estrategias más convenientes son: la integración hacia atrás, integración hacia adelante y la integración horizontal. Cuando las empresas se encuentran muy enfocadas en un solo producto, la diversificación a través 
de la ampliación de líneas de productos es una alternativa para disminuir los riesgos. Este tipo de empresas pueden aprovechar las oportunidades externas e incluso asumir riesgos de ser necesario.

Las empresas ubicadas en el cuadrante II deben evaluar su estrategia de enfoque al mercado. A pesar que su industria se encuentra en crecimiento, no les es factible competir con efectividad y necesitan identificar la manera de cambiar y mejorar su competitividad. Dado que estas empresas se encuentran en rápido crecimiento en el mercado, se suele considerar como primera opción la estrategia intensiva. No obstante, si la empresa no ha logrado una competencia distintiva, usualmente la integración horizontal se convierte en una alternativa adecuada. La desinversión o liquidación se considera como último recurso.

Las empresas del cuadrante III se encuentran en una industria de lento crecimiento y su posición competitiva es débil, por lo que deben aplicar con prontitud cambios drásticos para prevenir mayores daños o posible liquidación. Se recomienda la reducción de costos y gastos, o reasignar los recursos a otras líneas de negocios. En caso las estrategias anteriores no den resultado, se recomienda la desinversión o la liquidación.

Las empresas del cuadrante IV muestran una fuerte posición competitiva pero su industria se encuentra en lento crecimiento. Este tipo de empresas se caracterizan por tener altos niveles de flujos de efectivo y necesidades de crecimiento limitadas, por lo 
que son capaces de implementar estrategias de diversificación relacionada y no relacionada exitosamente. Además, pueden formar alianzas estratégicas. (David, 2013)

De acuerdo al análisis realizado, la empresa presenta una alta posición competitiva puesto que mantiene una participación del 65\% del mercado, con relación a sus dos más grandes competidores (Alimencorp y Technofeed); asimismo, la industria del rendering ha mostrado un crecimiento significativo en los últimos 5 años triplicando sus volúmenes de producción, esto gracias a la reconversión tecnológica realizada, y a la alianza estratégica con la empresa San Fernando para la maquila de productos. Sin embargo, los dos últimos años ha mostrado un menor crecimiento (7\% en el 2015 y $6 \%$ en el año 2016), puesto que viene alcanzando la máxima capacidad de producción. Por lo indicado anteriormente, se concluye que Los Ferroles se ubica en el cuadrante I. 


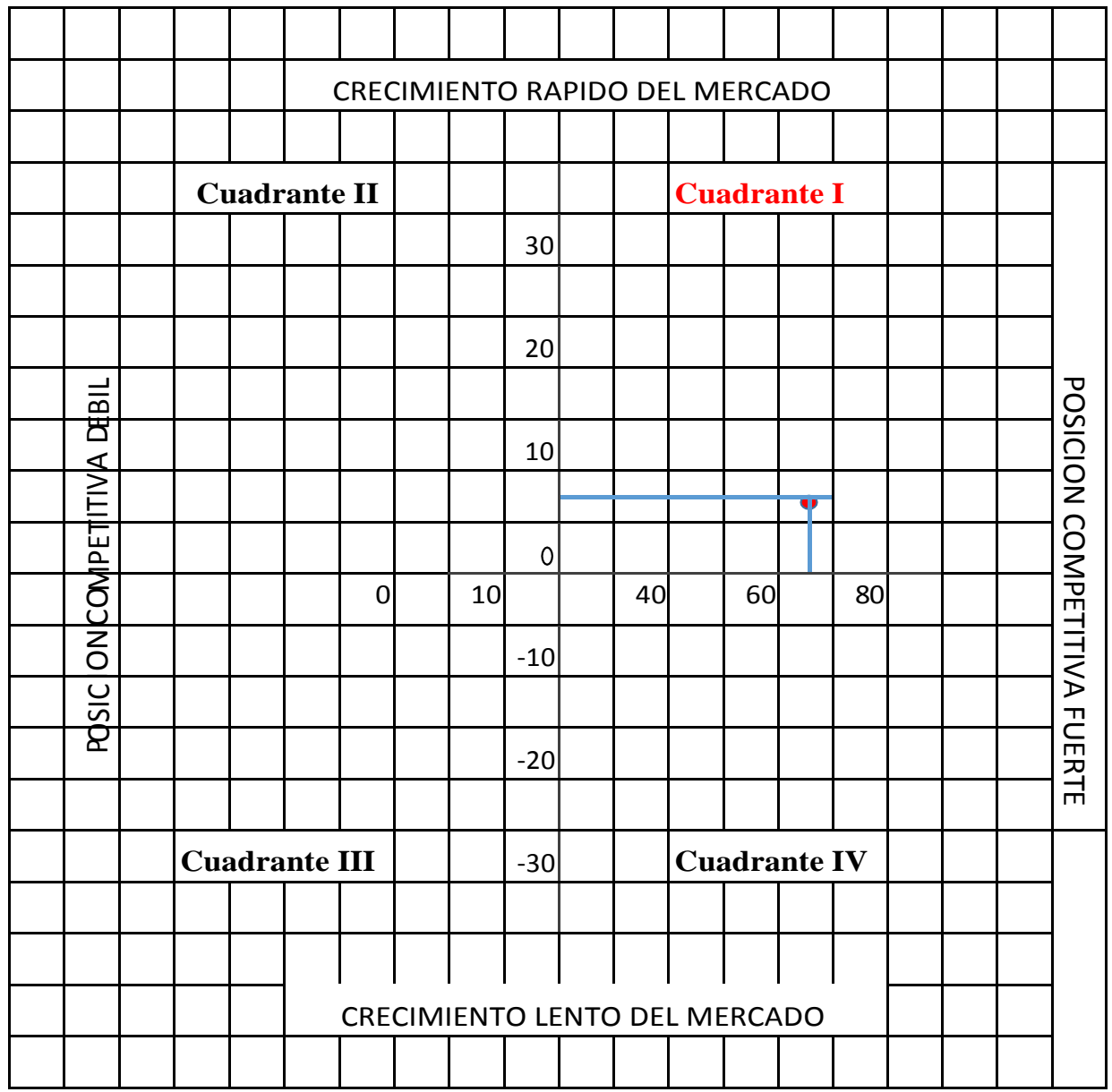

Figura 42. La Matriz de la Estrategia Principal Los Ferroles. Adaptado de Conceptos de Administración Estratégica (p. 190), por Fred David, 2013. México. Copyright 2013 por Pearson Educación.

\subsection{Resumen de las Estrategias Formuladas}

Las matrices desarrolladas para la formulación de estrategias como: Océano Azul, FODA, PEYEA, IE, BCG y La Gran Estrategia, permitieron visualizar las alternativas de estrategias que más se adecuan al modelo de negocio de la empresa, considerando el análisis de los factores internos como externos, y su perfil competitivo. 
En la tabla 41 se presenta el resumen de las estrategias formuladas que destacan por cada matriz, indicando la puntuación obtenida por cada una de ellas.

Las estrategias con mayor puntuación (4 y 5 puntos) son las estrategias intensivas y las de integración:

1. Penetración de mercados (5 puntos): Busca incrementar la participación de mercado con los productos actuales, a través de intensificación de esfuerzos de marketing. (David, 2013). Para Los Ferroles la estrategia de Penetración de Mercado, se enfocará en provincias dado que en Lima son líderes de mercado, con este criterio, las estrategias específicas son:

- Implementar gestión comercial y de marketing a través de medios digitales.

- Búsqueda de clientes en empresas medianas.

- Incrementar participación de mercado a través de política de precios.

- Certificar sistemas de gestión de calidad y de inocuidad.

2. Desarrollo de productos ( 5 puntos): Busca aumentar las ventas a través de la mejora de los productos o servicios actuales, o el desarrollo de nuevos (David, 2013). Para Los Ferroles las estrategias específicas alineadas al desarrollo de productos son:

- Desarrollar nuevos productos especializados y de alto valor agregado.

- Desarrollar rendering para el rubro pecuario, acuícola y alimento para mascotas. 
3. Integración hacia atrás (3 puntos): Busca apropiarse o aumentar el control sobre los proveedores (David, 2013). Para Los Ferroles las estrategias específicas alineadas a la integración vertical hacia atrás son:

- Generar alianzas con proveedores de materias primas para incrementar el servicio de maquila.

- Integración vertical con proveedores que acopien materia prima

4. Integración Horizontal (3 puntos): Busca apropiarse o aumentar el control sobre la competencia. (David, 2013). Para Los Ferroles la estrategia específica alineada a la integración horizontal es:

- Fusión con empresas de la competencia

5. Defensivas (1 punto): Reorganización a través de la reducción de costos y activos con el propósito de revertir la caída de las ventas y las utilidades. (David, 2013).

- Recorte de gastos 
Tabla 41

Resumen de las estrategias formuladas

\begin{tabular}{ccccccc}
\hline Estrategia Alternativa & FODA & PEYEA & BCG & IE & GE & Total \\
\hline Penetración de mercado & $\mathrm{X}$ & $\mathrm{X}$ & $\mathrm{X}$ & $\mathrm{X}$ & $\mathrm{X}$ & 5 \\
Desarrollo de productos & $\mathrm{X}$ & $\mathrm{X}$ & $\mathrm{X}$ & $\mathrm{X}$ & $\mathrm{X}$ & 5 \\
Integración vertical hacia atrás & $\mathrm{X}$ & $\mathrm{X}$ & $\mathrm{X}$ & & & 3 \\
Mejoras Internas & $\mathrm{X}$ & $\mathrm{X}$ & $\mathrm{X}$ & & & 3 \\
Integración horizontal & $\mathrm{X}$ & $\mathrm{X}$ & $\mathrm{X}$ & & & 3 \\
Recorte de gastos & $\mathrm{X}$ & & & & & 1 \\
\hline
\end{tabular}




\section{Capítulo VIII. Selección de la Estrategia}

\subsection{Método Factores Estratégicos Claves}

Planificar estratégicamente implica analizar y formular de manera previsora y sistemática el entorno donde se desenvuelve la empresa, con el fin de determinar los objetivos y estrategias enfocadas al modelo de negocio. En el presente capítulo se analizarán las estrategias seleccionadas, teniendo en cuenta los posibles escenarios relacionados con el entorno externo.

\subsubsection{Criterios de selección}

Para establecer los criterios de selección de las estrategias formuladas se utilizará la matriz de Rumelt, la cual se orienta en cuatro criterios:

1. Consistencia: La estrategia seleccionada no debe presentar objetivos ni políticas inconsistentes.

2. Consonancia: La estrategia seleccionada debe adaptarse al entorno y a los cambios críticos que se puedan presentar.

3. Ventaja: La estrategia debe estar orientada en crear o mantener las ventajas competitivas de la empresa.

4. Factibilidad: La estrategia seleccionada no debe originar sobrecostos en los recursos disponibles, ni generar problemas sin solución.

(D’Alessio, 2015). 
En base al diagnóstico obtenido de las matrices desarrolladas, se propone evaluar las estrategias intensivas y de integración a través de la matriz Rumelt.

Las estrategias a analizar son:

1. Penetración de mercado

2. Desarrollo de productos

3. Integración vertical hacia atrás

4. Integración Horizontal

5. Recorte de gastos

\subsubsection{Matriz de selección}

Las estrategias seleccionadas se analizaron de acuerdo a la Matriz Rumelt, a fin de verificar que cumplen con los criterios de consistencia, consonancia, ventaja y factibilidad.

De acuerdo con el resultado obtenido de la tabla $\mathrm{N}^{\circ} 42$, podemos concluir que todas las estrategias seleccionadas cumplen con los criterios de evaluación; por lo que su implementación es recomendable. 
Tabla 42

Matriz de selección Rumelt.

\begin{tabular}{|c|c|c|c|c|c|}
\hline Estrategias Alternativas y Específicas & Consistencia & Consonancia & Ventaja & Factibilidad & Se acepta \\
\hline \multicolumn{6}{|l|}{ 1. Penetración de mercado } \\
\hline Implementar gestión comercial y de marketing a través de medios digitales & Sí & Sí & Sí & Sí & Sí \\
\hline Búsqueda de clientes en empresas medianas & Sí & Sí & Sí & Sí & Sí \\
\hline Incrementar participación de mercado a través de política de precios & Sí & Sí & Sí & Sí & Sí \\
\hline Certificar sistemas de gestión de calidad y de inocuidad & $\mathrm{Si}$ & Sí & Sí & Sí & Sí \\
\hline \multicolumn{6}{|l|}{ 2. Desarrollo de producto } \\
\hline Desarrollar nuevos productos especializados y de alto valor agregado & Sí & Sí & Sí & Sí & Sí \\
\hline Desarrollar rendering para el rubro pecuario, acuícola y alimento para mascotas. & Sí & Sí & Sí & Sí & Sí \\
\hline \multicolumn{6}{|l|}{ 3.Integración vertical hacia atrás 183} \\
\hline Generar alianzas con proveedores de materias primas para incrementar maquila & Sí & Sí & Sí & Sí & Sí \\
\hline Integración vertical con proveedores que acopien materia prima & Sí & Sí & Sí & Sí & Sí \\
\hline \multicolumn{6}{|l|}{ 4. Integración horizontal } \\
\hline Fusión con empresas de la competencia & Sí & Sí & Sí & Sí & Sí \\
\hline \multicolumn{6}{|l|}{ 5. Recorte de gastos } \\
\hline Elaborar un plan de optimización de gastos & Sí & Sí & Sí & Sí & Sí \\
\hline
\end{tabular}

Nota. Tomado de El Proceso Estratégico, Un enfoque de Gerencia (p. 185), por F. D’alessio 2015, Lima, Perú: Copyrigth 2015 por Pearson Educación del Perú SA. 


\subsection{Método de Escenarios}

Según Godet (1995), el método de escenarios es una técnica en donde se procura definir cómo será el entorno competitivo en el mediano y largo plazo en que se desenvolverá una empresa, a fin de definir acciones y/o decisiones en base a dos escenarios sugeridos.

Los escenarios planteados estarán enfocados en las siguientes variables del entorno externo: (a) Político - Gubernamental, (b) Económico; (c) Legal; (d) Cultural; (e) Tecnológico y (f) Ecológico, que se desarrollaron en el capítulo IV. Dado que la evolución de estas variables no es conocida con exactitud, el autor proponer realizar hipótesis según dos escenarios el probable y menos probable.

\subsubsection{Descripción de escenarios considerados}

En la tabla 43 se describirán tres contextos o situaciones planteadas tomando en cuenta el periodo de estudio de los próximos tres años, basada en el análisis del entorno externo estudiado en el Capítulo IV.

Una vez definidos los contextos, se elabora la tabla 44 de escenarios, formando dos escenarios de estudio: El más probable y el menos probable. 
Tabla 43

\section{Definición de Contextos}

\begin{tabular}{|c|c|c|c|}
\hline $\begin{array}{l}\text { Análisis Político - } \\
\text { Económico }\end{array}$ & 1 (Sin variación) & 2 (Optimista) & 3 (Pesimista) \\
\hline Entorno político económico & Sin cambios & Mayor estabilidad & $\begin{array}{l}\text { Incremento de } \\
\text { incertidumbre }\end{array}$ \\
\hline Nivel de empleo & Se mantiene & Crece empleo & Crece desempleo \\
\hline Conflictos sociales & Se mantiene & Disminuyen & Se acentúan \\
\hline Crecimiento del PBI & Estable $3 \%-4 \%$ & Alto $>4 \%$ & Bajo $<3 \%$ \\
\hline Tendencia del tipo de cambio & Estable $2.8-3.3$ & Alza $>3.3$ & A la baja $<2.8$ \\
\hline $\begin{array}{l}\text { Crecimiento de la industria } \\
\text { avícola }\end{array}$ & $\begin{array}{c}\text { Crecimiento en base } \\
\text { al PBI }\end{array}$ & Alto Crecimiento & Desacelera \\
\hline $\begin{array}{l}\text { Precio de principal sustituto } \\
\text { (harina de pescado) }\end{array}$ & Se mantiene & Se incrementa & Disminuye \\
\hline $\begin{array}{l}\text { Accesibilidad al financiamiento } \\
\text { crediticio }\end{array}$ & Se mantiene & Alto acceso & Acceso limitado \\
\hline \multicolumn{4}{|l|}{ Análisis Legal } \\
\hline $\begin{array}{l}\text { Exigencia en el cumplimiento de } \\
\text { la normativa medio ambiental y } \\
\text { sanitaria }\end{array}$ & Sin variación & Políticas laxas & Políticas restrictivas \\
\hline $\begin{array}{l}\text { Nuevas políticas regulatorias en } \\
\text { el sector rendering }\end{array}$ & Sin nuevas políticas & $\begin{array}{l}\text { Políticas que respalden } \\
\text { crecimiento del sector }\end{array}$ & $\begin{array}{l}\text { Políticas que } \\
\text { restrinjan } \\
\text { crecimiento del } \\
\text { sector }\end{array}$ \\
\hline \multicolumn{4}{|l|}{ Análisis Cultural } \\
\hline $\begin{array}{l}\text { Uso de harinas del rendering en la } \\
\text { alimentación animal }\end{array}$ & Se mantiene $4 \%-6 \%$ & Aumenta $>6 \%$ & Disminuye $<4 \%$ \\
\hline \multicolumn{4}{|l|}{ Análisis Tecnológico } \\
\hline $\begin{array}{l}\text { Desarrollo de tecnología para el } \\
\text { sector }\end{array}$ & Estándar se mantiene & $\begin{array}{l}\text { Tecnología de punta al } \\
\text { alcance }\end{array}$ & $\begin{array}{l}\text { Tecnología } \\
\text { inaccesible }\end{array}$ \\
\hline $\begin{array}{l}\text { Desarrollo de marketing a través } \\
\text { de medios digitales }\end{array}$ & Sin implementación & $\begin{array}{l}\text { Alto grado de } \\
\text { implementación }\end{array}$ & $\begin{array}{l}\text { Bajo uso de medios } \\
\text { digitales }\end{array}$ \\
\hline \multicolumn{4}{|l|}{ Análisis Ecológico } \\
\hline $\begin{array}{l}\text { Brote de influenza aviar en la } \\
\text { industria avícola }\end{array}$ & $\begin{array}{l}\text { Baja probabilidad de } \\
\text { ocurrencia }\end{array}$ & $\begin{array}{l}\text { Muy baja probabilidad } \\
\text { de ocurrencia }\end{array}$ & $\begin{array}{l}\text { Alto probabilidad de } \\
\text { ocurrencia }\end{array}$ \\
\hline $\begin{array}{l}\text { Conciencia ecológica / medio } \\
\text { ambiental empresarial }\end{array}$ & $\begin{array}{c}\text { Incipiente conciencia } \\
\text { empresarial }\end{array}$ & $\begin{array}{l}\text { Alta conciencia } \\
\text { empresarial }\end{array}$ & $\begin{array}{l}\text { Baja conciencia } \\
\text { empresarial }\end{array}$ \\
\hline
\end{tabular}


Tabla 44

\section{Definición de Escenarios}

Escenarios

\section{Análisis Político - Gubernamental}

Entorno político económico

Nivel de empleo

Conflictos sociales

Crecimiento del PBI

Tendencia del tipo de cambio

Crecimiento de la industria avícola

Precio de principal sustituto (harina de pescado)

Accesibilidad al financiamiento crediticio

\section{Análisis Legal}

Exigencia en el cumplimiento de la normativa medio ambiental y sanitaria

Nuevas políticas regulatorias en el sector rendering

\section{Análisis Cultural}

Uso de harinas del rendering en la alimentación animal

\section{Análisis Tecnológico}

Desarrollo de tecnología para el sector

Desarrollo de marketing a través de medios digitales

\section{Análisis Ecológico}

Brote de influenza aviar en la industria avícola

Conciencia ecológica / medio ambiental empresarial
Escenario I (Más Probable)

Mayor estabilidad

Crece empleo

Se mantiene

Alto $>4 \%$

Estable $2.8-3.3$

Alto Crecimiento

Se mantiene

Alto acceso

Políticas laxas

Sin nuevas políticas

Se mantiene $4 \%-6 \%$

Tecnología de punta al alcance

Alto grado de implementación

Baja probabilidad de ocurrencia

Incipiente conciencia empresarial

\section{Escenario II (Menos Probable)}

Incremento de incertidumbre

Crece desempleo

Disminuyen

Estable 3\%-4\%

Alza $>3.3$

Desacelera

Disminuye

Acceso limitado

Políticas restrictivas

Políticas que restrinjan crecimiento del sector

Disminuye $<4 \%$

Tecnología inaccesible

Sin implementación

Alto probabilidad de ocurrencia

Alta conciencia empresarial 
En base a estos tres contextos, se seleccionarán dos escenarios; uno con mayor grado de probabilidad de ocurrencia del otro: (a) Escenario más probable y (b) Escenario menos probable. Estos escenarios deberán ser contrastados con las estrategias seleccionadas, con el fin de determinar cuál es la que brindará los mejores resultados respecto a los criterios de selección determinados.

1. Escenario I (Más Probable): Crecimiento económico, el PBI sea superior a 4\%, una coyuntura política económica con mayor estabilidad pese a los conflictos sociales que podrían aparecer. El escenario presenta una mayor inversión pública como privada en nuestro país y por ende un mayor acceso al crédito para las pequeñas y medianas empresas y un mayor nivel de empleo. El sector avícola en crecimiento, con baja probabilidad de un brote de influenza aviar, así como con una tecnología de punta al alcance de los empresarios del rendering. Alto grado de implementación de estrategias con de medios digitales.

2. Escenario II (Menos Probable): Entorno político económico con incertidumbre, en donde aumenta el desempleo. Desaceleración del crecimiento de la industria avícola, mayor disponibilidad de harinas proteicas sustitutas a bajo precio. Las empresas encuentran restringido el acceso al crédito por la coyuntura del país. El gobierno aplicará normativas sanitarias y medio ambientales más exigentes que podrían generar incremento en los costos. Alta probabilidad de brote de influenza aviar en el Perú, reduciendo la oferta de aves en el país. 


\subsubsection{Comparación de estrategias con escenarios}

En la siguiente tabla, se ha determinado los impactos que generarían los dos escenarios planteados sobre las principales variables de las estrategias alternativas resultantes.

Tabla 45

Impactos en principales variables

\begin{tabular}{|c|c|c|c|c|}
\hline Impacto en el mercado & $\begin{array}{c}\text { Escenario I } \\
\text { (Más Probable) }\end{array}$ & Impacto & $\begin{array}{c}\text { Escenario II } \\
\text { (Menos Probable) }\end{array}$ & Impacto \\
\hline Evolución de mercado avícola & Alto Crecimiento & + & Bajo crecimiento & - \\
\hline $\begin{array}{l}\text { Evolución del consumo de } \\
\text { harinas proteicas }\end{array}$ & $\begin{array}{l}\text { Crecimiento } \\
\text { moderado }\end{array}$ & + & Bajo crecimiento & - \\
\hline Disponibilidad de materia prima & $\begin{array}{l}\text { Disponibilidad } \\
\text { moderada }\end{array}$ & o & Baja disponibilidad & - \\
\hline \multicolumn{5}{|l|}{ Impacto en la competencia } \\
\hline $\begin{array}{l}\text { Precio de los productos } \\
\text { sustitutos }\end{array}$ & Se mantiene & o & Disminuye & - \\
\hline $\begin{array}{l}\text { Ingreso de nuevas empresas de } \\
\text { rendering }\end{array}$ & Poco probable & + & Muy probable & - \\
\hline $\begin{array}{l}\text { Evolución de las empresas de la } \\
\text { competencia }\end{array}$ & $\begin{array}{l}\text { Crecimiento } \\
\text { moderado }\end{array}$ & - & Bajo crecimiento & + \\
\hline
\end{tabular}

Posteriormente, en función a estos impactos se ha determinado en qué grado favorecen o no a cada una de las estrategias alternativas analizadas. 
Tabla 46

Impactos en las estrategias

\begin{tabular}{ccc}
\hline Estrategias & $\begin{array}{c}\text { Escenario I (Más } \\
\text { Probable) }\end{array}$ & $\begin{array}{c}\text { Escenario II (Menos } \\
\text { Probable) }\end{array}$ \\
\hline Penetración de mercado & Favorable & Poco favorable \\
Desarrollo de productos & Altamente favorable & Poco favorable \\
Integración vertical hacia atrás & Favorable & Poco favorable \\
Integración Horizontal & Poco favorable & Favorable \\
Recorte de gastos & Poco favorable & Favorable \\
\hline
\end{tabular}

Los resultados obtenidos muestran que en el escenario I (más probable) la aplicación de las estrategias: (a) Penetración de mercado; (b) Desarrollo de productos y (c) Integración vertical hacia atrás, tendrían un impacto favorable para el logro de los objetivos estratégicos de la empresa, mientras que para la (d) integración horizontal y el (e) recorte de gastos resulta poco favorable.

\subsection{Matriz de Planeación Estratégica Cuantitativa MPEC}

De acuerdo con David (2013), el modelo analítico de formulación de estrategias comprende 3 etapas: (a) Etapa de los insumos (b) Etapa de adecuación y (c) Etapa de decisión. La matriz de Planeación Estratégica- MCPE está ubicada en la etapa 3.

La matriz MCPE utiliza el análisis de los insumos realizado en la etapa 1 (EFI, EFE y de Perfil Competitivo - MPC-) y los resultados obtenidos de las matrices de la etapa 2 (FODA, PEYEA, BCG, IE y la Estrategia Principal), para efectuar una elección objetiva entre las estrategias alternativas. 
La matriz MCPE determina objetivamente que alternativas estratégicas de las presentadas son las mejores, considerando el impacto de los factores claves internos y externos. Como resultado, se obtiene la estrategia seleccionada y la contingente.

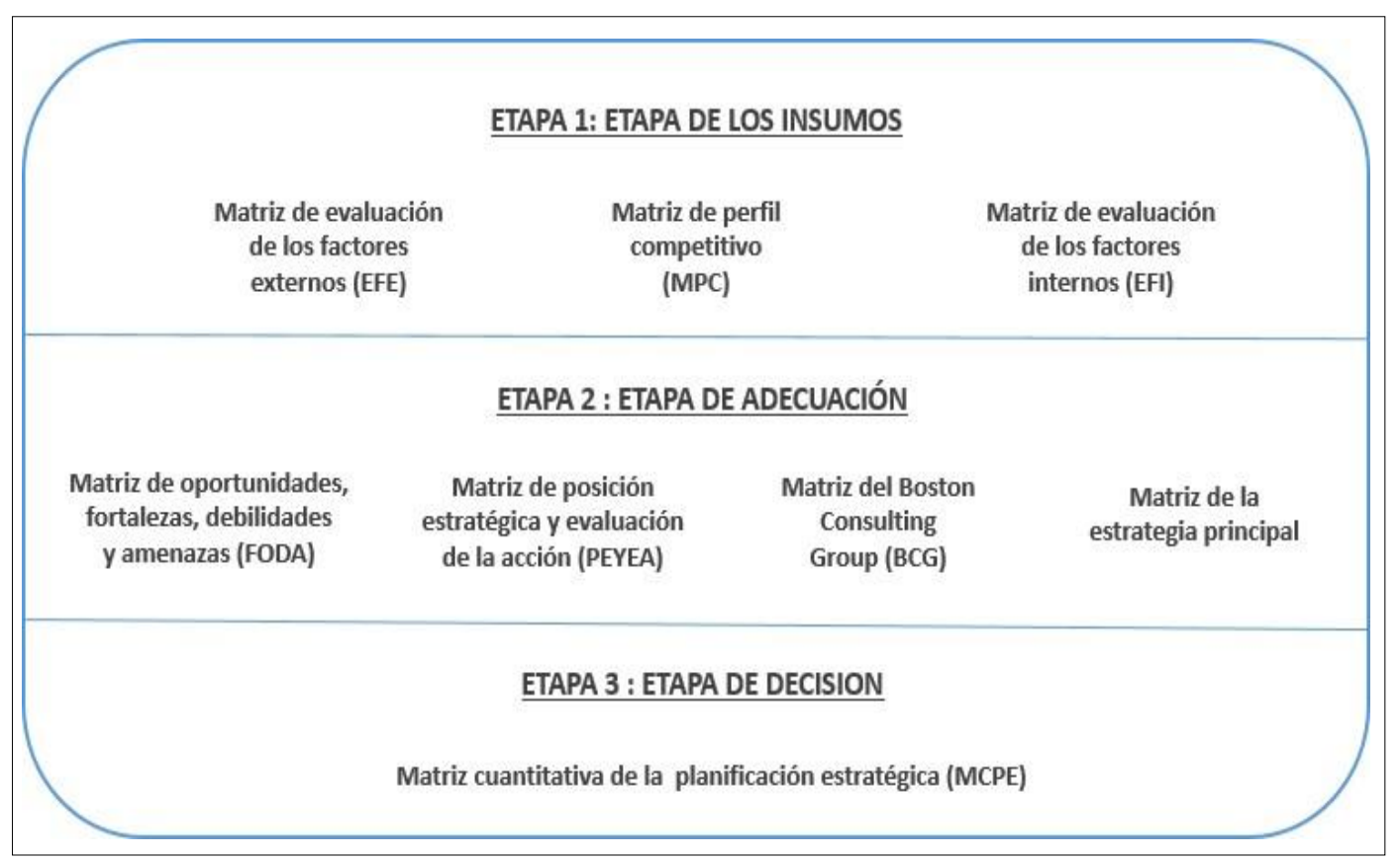

Figura 43. Modelo analítico para la formulación de estrategias. Tomado de “Concepto de Administración Estratégica” (p. 137) por Fred David (2013) (14ava ed.). México: Pearson Educación.

A continuación en las figuras 45, 45 y 46, se presenta la Matriz de planificación estratégica cuantitativa (MCPE), donde se muestra la evaluación de las estrategias alternativas intensivas y de integración, detallando las estrategias específicas correspondientes. 


\begin{tabular}{|c|c|c|c|c|c|c|c|c|c|}
\hline \multicolumn{2}{|l|}{ Estrategia Alternativa Intensiva } & \multicolumn{8}{|c|}{ Penetración de Mercado } \\
\hline \multicolumn{2}{|l|}{ Estrategias Especificas } & \multicolumn{2}{|c|}{$\begin{array}{l}\text { Implementar gestión } \\
\text { comercial y de marketing } \\
\text { a través de medios } \\
\text { digitales }\end{array}$} & \multicolumn{2}{|c|}{$\begin{array}{l}\text { Búsqueda de clientes en } \\
\text { empresas medianas }\end{array}$} & \multicolumn{2}{|c|}{$\begin{array}{l}\text { Incrementar participación } \\
\text { de mercados a través de } \\
\text { politica de precios }\end{array}$} & \multicolumn{2}{|c|}{$\begin{array}{c}\text { Certificar sistemas de } \\
\text { gestión de calidad y de } \\
\text { inocuidad }\end{array}$} \\
\hline Oportunidades & PESO & PA & $\mathrm{CA}$ & $\mathrm{PA}$ & $\mathrm{CA}$ & PA & $\mathrm{CA}$ & PA & $\mathrm{CA}$ \\
\hline 1 Mayor accesibilidad al financiamiento crediticio & 0.08 & 3 & 0.24 & 3 & 0.24 & 3 & 0.24 & 4 & 0.32 \\
\hline 2 Industria avícola en crecimiento & 0.10 & 4 & 0.4 & 4 & 0.40 & 4 & 0.40 & 4 & 0.40 \\
\hline 3 Alto desarrollo de marketing a través de medios digitales & 0.06 & 4 & 0.24 & 3 & 0.18 & 3 & 0.18 & 2 & 0.12 \\
\hline 4 Mayor conciencia ambiental empresarial & 0.08 & 2 & 0.16 & 3 & 0.24 & 0 & 0.00 & 3 & 0.24 \\
\hline 5 Alto desarrollo de tecnologias del sector & 0.08 & 0 & 0.00 & 3 & 0.24 & 3 & 0.24 & 4 & 0.32 \\
\hline 6 Incremento de uso de harinas del rendering en la alimentación animal & 0.10 & 3 & 0.30 & 4 & 0.40 & 3 & 0.30 & 3 & 0.30 \\
\hline \multicolumn{10}{|l|}{ Amenazas } \\
\hline 1 Incertidumbre en el entorno político económico & 0.10 & 1 & 0.10 & 1 & 0.10 & 1 & 0.10 & 1 & 0.10 \\
\hline 2 Mayor exigencia en el cumplimiento de la normativa medio ambiental y sanitaria & 0.07 & 0 & 0.00 & 3 & 0.21 & 0 & 0.00 & 2 & 0.14 \\
\hline 3 Nuevas politicas regulatorias en el sector rendering & 0.06 & 1 & 0.06 & 1 & 0.06 & 1 & 0.06 & 2 & 0.12 \\
\hline 4 Brote de influenza aviar en industria avicola & 0.05 & 1 & 0.05 & 1 & 0.05 & 1 & 0.05 & 2 & 0.10 \\
\hline 5 Empresas avícolas generen su propio rendering & 0.06 & 1 & 0.06 & 1 & 0.06 & 1 & 0.06 & 1 & 0.06 \\
\hline 6 Ingreso de nuevos competidores a la industria & 0.07 & 1 & 0.07 & 1 & 0.07 & 1 & 0.07 & 1 & 0.07 \\
\hline \multirow{2}{*}{$\begin{array}{l}7 \text { Reducción del precio y aumento de la oferta del principal sustituto (harina de pescado) } \\
\text { SUB TOTAL }\end{array}$} & 0.09 & 2 & 0.18 & 0 & 0 & 4 & 0.36 & 1 & 0.09 \\
\hline & 1.00 & & 1.86 & & 2.25 & & 2.06 & & 2.38 \\
\hline Fortalezas & PESO & PA & $\mathrm{CA}$ & PA & $\mathrm{CA}$ & $\mathrm{PA}$ & $\mathrm{CA}$ & PA & $\mathrm{CA}$ \\
\hline 1 Tecnología de última generación para el proceso productivo. & 0.08 & 2 & 0.16 & 4 & 0.32 & 4 & 0.32 & 4 & 0.32 \\
\hline 2 Líder en la producción y comercialización de harinas proteicas para sector avícola. & 0.07 & 4 & 0.28 & 4 & 0.28 & 4 & 0.28 & 4 & 0.28 \\
\hline 3 Especialistas en el procesamiento de harinas para el sector avicola. & 0.06 & 4 & 0.24 & 4 & 0.24 & 4 & 0.24 & 3 & 0.18 \\
\hline 4 Alianza estratégica con San Femando para maquila de productos. & 0.05 & 4 & 0.20 & 4 & 0.20 & 4 & 0.20 & 4 & 0.2 \\
\hline 5 Costos bajos y precios competitivos en el mercado. & 0.08 & 4 & 0.32 & 4 & 0.32 & 4 & 0.32 & 0 & 0 \\
\hline 6 Cuenta con tecnología orientada a reducir el impacto ambiental. & 0.04 & 3 & 0.12 & 3 & 0.12 & 2 & 0.08 & 4 & 0.16 \\
\hline $\begin{array}{l}7 \text { Cuenta con sistema de información integral para la gestión de la compañía. } \\
\text { Debilidades }\end{array}$ & 0.04 & 2 & 0.08 & 2 & 0.08 & 2 & 0.08 & 4 & 0.16 \\
\hline 1 Falta de control y estandarización de los procesos. & 0.08 & 1 & 0.08 & 1 & 0.08 & 1 & 0.08 & 1 & 0.08 \\
\hline 2 Personal operativo poco especializado y capacitado. & 0.04 & 1 & 0.04 & 1 & 0.04 & 1 & 0.04 & 1 & 0.04 \\
\hline 3 Falta de planeamiento estratégico y control presupuestal & 0.07 & 1 & 0.07 & 2 & 0.14 & 1 & 0.07 & 1 & 0.07 \\
\hline 4 No cuenta con certificaciones de calidad ni de inocuidad & 0.06 & 2 & 0.12 & 3 & 0.18 & 0 & 0 & 1 & 0.06 \\
\hline 5 Falta de diversificación de productos. & 0.08 & 2 & 0.16 & 2 & 0.16 & 2 & 0.16 & 0 & 0.00 \\
\hline 6 Falta de indicadores de gestión. & 0.05 & 1 & 0.05 & 1 & 0.05 & 1 & 0.05 & 1 & 0.05 \\
\hline 7 No tiene desarrollada la gestión comercial ni de marketing digital. & 0.06 & 1 & 0.06 & 1 & 0.06 & 0 & 0.00 & 0 & 0.00 \\
\hline 8 Clientes concentrados en líderes del sector avicola con alto poder de negociación. & 0.04 & 1 & 0.04 & 2 & 0.08 & 2 & 0.08 & 0 & 0.00 \\
\hline 9 No cuenta con plan de sucesión & 0.04 & 1 & 0.04 & 0 & 0.00 & 0 & 0.00 & 0 & 0.00 \\
\hline \multirow{2}{*}{$\begin{array}{l}10 \text { No cuenta con área de recursos humanos } \\
\text { SUB TOTAL }\end{array}$} & 0.06 & 1 & 0.06 & 1 & 0.06 & 0 & 0.00 & 1 & 0.06 \\
\hline & 1 & & 2.12 & & 2.41 & & 2 & & 1.66 \\
\hline GRAN TOTAL & & & 3.98 & & 4.66 & & 4.06 & & 3.95 \\
\hline
\end{tabular}

Figura 44. Matriz cuantitativa de la planificación estratégica - MCPE - Estrategia Intensiva: Penetración de Mercado 


\begin{tabular}{|c|c|c|c|c|c|}
\hline \multirow[t]{2}{*}{ Estrategia Alternativa Intensiva } & & \multicolumn{4}{|c|}{ Desarrollo de productos } \\
\hline & & \multicolumn{2}{|c|}{$\begin{array}{l}\text { Desarrollo de nuevos } \\
\text { productos especializados y } \\
\text { de alto valor agregado }\end{array}$} & \multicolumn{2}{|c|}{$\begin{array}{c}\text { Desarrollar rendering para } \\
\text { el rubro pecuario, } \\
\text { acuicola y de alimento } \\
\text { para mascotas }\end{array}$} \\
\hline Oportunidades & PESO & PA & $\mathrm{CA}$ & PA & $\mathrm{CA}$ \\
\hline 1 Mayor accesibilidad al financiamiento crediticio & 0.08 & 4 & 0.32 & 4 & 0.32 \\
\hline 2 Industria avícola en crecimiento & 0.10 & 4 & 0.40 & o & 0.00 \\
\hline 3 Alto desarrollo de marketing a través de medios digitales & 0.06 & 3 & 0.18 & 3 & 0.18 \\
\hline 4 Mayor conciencia ambiental empresarial & 0.08 & 2 & 0.16 & 3 & 0.24 \\
\hline 5 Alto desarrollo de tecnologías del sector & 0.08 & 4 & 0.32 & 3 & 0.24 \\
\hline 6 Incremento de uso de harinas del rendering en la alimentación animal & 0.10 & 4 & 0.40 & 3 & 0.30 \\
\hline \multicolumn{6}{|l|}{ Amenazas } \\
\hline 1 Incertidumbre en el entorno político económico & 0.10 & 1 & 0.10 & 1 & 0.10 \\
\hline 2 Mayor exigencia en el cumplimiento de la normativa medio ambiental y sanitaria & 0.07 & 3 & 0.21 & 2 & 0.14 \\
\hline 3 Nuevas políticas regulatorias en el sector rendering & 0.06 & 1 & 0.06 & 1 & 0.06 \\
\hline 4 Brote de influenza aviar en industria avícola & 0.05 & 1 & 0.05 & o & 0.00 \\
\hline 5 Empresas avícolas generen su propio rendering & 0.06 & 1 & 0.06 & o & 0.00 \\
\hline 6 Ingreso de nuevos competidores a la industria & 0.07 & 1 & 0.07 & o & 0.00 \\
\hline 7 Reducción del precio y aumento de la oferta del principal sustituto (harina de pescado) & 0.09 & 2 & 0.18 & 3 & 0.27 \\
\hline SUB TOTAL & 1.00 & & 2.51 & & 1.85 \\
\hline Fortalezas & PESO & PA & $\mathrm{CA}$ & PA & $\mathrm{CA}$ \\
\hline 1 Tecnología de última generación para el proceso productivo. & 0.08 & 4 & 0.32 & 4 & 0.32 \\
\hline 2 Líder en la producción y comercialización de harinas proteicas para sector avícola. & 0.07 & 4 & 0.28 & 4 & 0.28 \\
\hline 3 Especialistas en el procesamiento de harinas para el sector avícola. & 0.06 & 4 & 0.24 & 2 & 0.12 \\
\hline 4 Alianza estratégica con San Fernando para maquila de productos. & 0.05 & 3 & 0.15 & 3 & 0.15 \\
\hline 5 Costos bajos y precios competitivos en el mercado. & 0.08 & 4 & 0.32 & 4 & 0.32 \\
\hline 6 Cuenta con tecnología orientada a reducir el impacto ambiental. & 0.04 & 3 & 0.12 & 3 & 0.12 \\
\hline 7 Cuenta con sistema de información integral para la gestión de la compañía. & 0.04 & 1 & 0.04 & 2 & 0.08 \\
\hline \multicolumn{6}{|l|}{ Debilidades } \\
\hline 1 Falta de control y estandarización de los procesos. & 0.08 & 1 & 0.08 & 1 & 0.08 \\
\hline 2 Personal operativo poco especializado y capacitado. & 0.04 & 1 & 0.04 & 1 & 0.04 \\
\hline 3 Falta de planeamiento estratégico y control presupuestal & 0.07 & 1 & 0.07 & 1 & 0.07 \\
\hline 4 No cuenta con certificaciones de calidad ni de inocuidad & 0.06 & 2 & 0.12 & 2 & 0.12 \\
\hline 5 Falta de diversificación de productos. & 0.08 & 1 & 0.08 & 1 & 0.08 \\
\hline 6 Falta de indicadores de gestión. & 0.05 & 1 & 0.05 & 1 & 0.05 \\
\hline 7 No tiene desarrollada la gestión comercial ni de marketing digital. & 0.06 & 2 & 0.12 & o & 0.00 \\
\hline 8 Clientes concentrados en líderes del sector avícola con alto poder de negociación. & 0.04 & o & 0.00 & o & 0.00 \\
\hline 9 No cuenta con plan de sucesión & 0.04 & o & 0.00 & o & 0.00 \\
\hline 10 No cuenta con área de recursos humanos & 0.06 & 1 & 0.06 & o & 0.00 \\
\hline SUB TOTAL & 1 & & 2.03 & & 1.83 \\
\hline GRAN TOTAL & & & 4.54 & & 3.68 \\
\hline
\end{tabular}

Figura 45. Matriz cuantitativa de la planificación estratégica - MCPE - Estrategia Intensiva: Desarrollo de Productos 


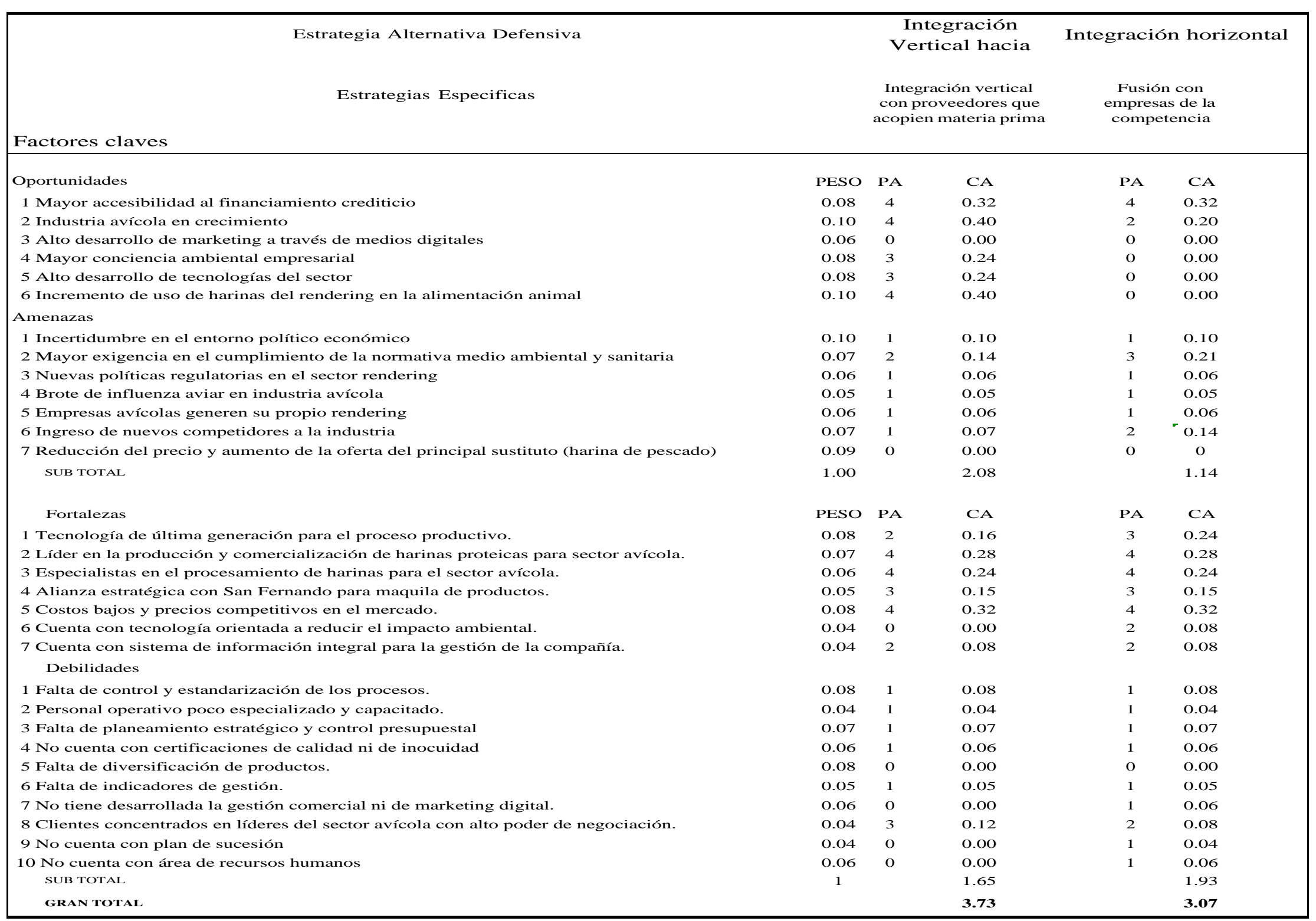

Figura 46. Matriz cuantitativa de la planificación estratégica - MCPE - Estrategias de Integración: Vertical y Horizontal. 


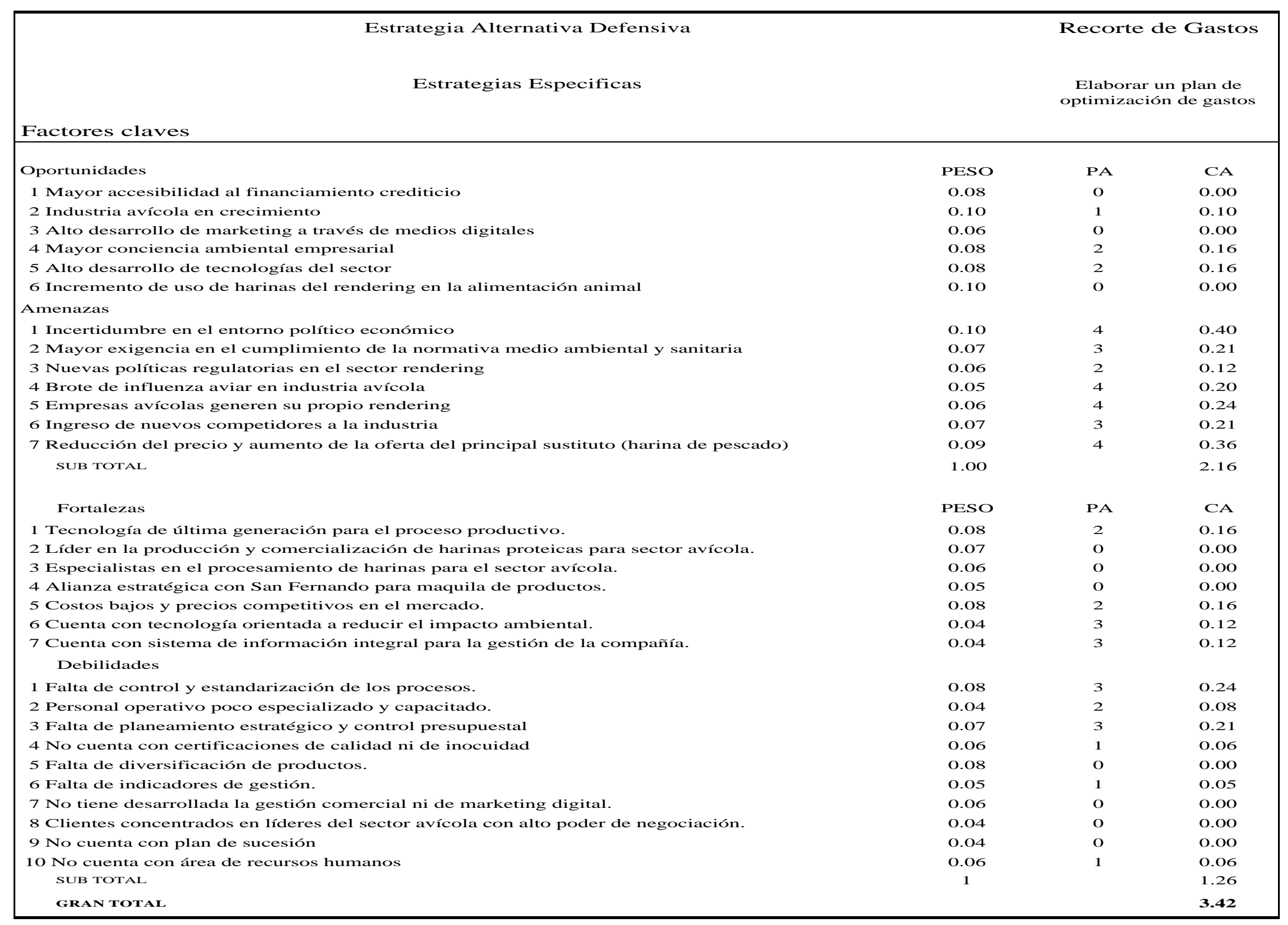

Figura 47. Matriz cuantitativa de la planificación estratégica - MCPE - Estrategia Defensiva: Recorte de Gastos. 
De las puntuaciones obtenidas de las matrices MCPE se evidencia que las estrategias con mayor puntuación de acuerdo al atractivo con los factores claves son:

1. Estrategias Intensivas:

Penetración de mercado (Provincias)

- Búsqueda de clientes en empresas medianas (4.66)

- Incrementar participación de mercados a través de política de precios (4.06)

- Implementar gestión comercial y de marketing a través de medios digitales (3.98)

- Certificar sistemas de gestión de calidad y de inocuidad (3.95)

Desarrollo de productos (Lima y Provincias)

- Desarrollo de nuevos productos especializados y de alto valor agregado (4.54)

- Desarrollar rendering para el rubro pecuario, acuícola y alim. para mascotas (3.68)

2. Estrategias de Integración:

Estrategias de Integración vertical hacia atrás

- Integración vertical con proveedores que acopien materia prima (3.73).

Por otro lado, las estrategias con menores puntuaciones son:

3. Estrategias de Integración

Integración Horizontal: Fusión con empresas de la competencia (3.07). 


\section{Estrategias Defensivas}

Recorte de gastos: Elaborar un plan de optimización de gastos (3.42)

\subsection{Descripción de estrategia seleccionada}

De las puntuaciones obtenidas anteriormente, concluimos que se considera como estrategia seleccionada la estrategia intensiva de Penetración Mercado en todo el país, con enfoque en provincias, dado que a nivel de Lima son líderes de mercado.

La estrategia de penetración de mercado tiene como objetivo incrementar la participación de mercado de los productos presentes en los mercados actuales, con el propósito de incrementar la rentabilidad. David (2013). Como parte de las estrategias planteadas se propone implementar políticas comerciales y de marketing orientadas al cliente, fortalecer la penetración de mercado en el sector avícola en todo el Perú enfocándose en clientes medianos, gestionar una política de precios flexible y certificar en normas internacionales como el Sistema de Gestión de la Calidad ISO 9001 y el Sistema HACCP.

\subsection{Descripción de estrategia contingente}

Como estrategia contingente resultante se considera la estrategia de Desarrollo de Producto, la cual se enfoca en aumentar las ventas a través de la mejora de los productos presentes o el desarrollo de nuevos. (David, 2013). 
Dentro de esta estrategia se considera el desarrollo de nuevos productos especializados para el sector avícola, que permita satisfacer y adaptarse a las nuevas necesidades del mercado, permitiendo así captar nuevos clientes y aumentar el nivel de ventas. Así también, el desarrollo de rendering para el rubro pecuario, acuícola y alimento para mascotas, lo que permitirá captar nuevos clientes en estos sectores.

Por otro lado, las estrategias internas se han considerado necesarias para poder alcanzar los objetivos de la empresa y contribuir a la realización de las estrategias seleccionadas las cuales son:

- Integración vertical con proveedores de materia prima.

- Reestructuración organizacional en toda la compañía

- Establecimiento de estrategias y objetivos para proyección de crecimiento a mediano y largo plazo.

- $\quad$ Alineamiento de los procesos de acuerdo a normativa legal vigente.

Finalmente, las estrategias de Integración Horizontal y de Recorte de Gastos no serán consideradas para el desarrollo del plan estratégico de la empresa, dado que no se ajustan a las expectativas de los directores, ni tampoco a lo analizado en el entorno interno / externo de la empresa ni del sector. Adicional, obtuvieron las menores puntuaciones en la Matriz Cuantitativa de la Planificación Estratégica (MCPE). 


\section{Capítulo IX. Implantación De La Estrategia}

En este capítulo se describen los objetivos estratégicos definidos a partir de la estrategia previamente seleccionada. La herramienta empleada para la descripción de la implantación de las estrategias es el Cuadro de Mando Integral, en inglés, Balanced Scorecard (BSC).

El Cuadro de Mando Integral permite ejercer una visión integral y holística de la organización. Al ser una herramienta de control, permite ver hacia donde se dirige la organización y corregir de ser necesario. Cierra el vacío entre lo que la organización desea hacer y lo que hace, es decir permite el alineamiento estratégico, el cual lleva a lograr los siguientes resultados:

- Accionistas satisfechos: incremento de patrimonio.

- $\quad$ Clientes contentos: satisfacción de necesidades.

- Procesos productivos: al producir y vender productos de calidad a un costo adecuado.

- $\quad$ Empleados motivados y preparados: mueven a la organización. (D’Alessio, 2015).

El propósito general del Cuadro de Mando Integral es equilibrar los objetivos de los accionistas con los objetivos operacionales y los objetivos del cliente (David, 2013). 
Las empresas deben establecer objetivos y evaluar estrategias a partir criterios adicionales a los financieros. Si bien, las medidas y razones financieras son de gran importancia en la planificación estratégica, igual relevancia tienen otros factores, como el servicio al cliente, la gestión y moral de los empleados, la calidad del producto, la prevención y reducción de la contaminación, la ética en las negociaciones, la responsabilidad social y la participación comunitaria. Conjuntamente con las medidas financieras, estos otros factores son parte integral del proceso de establecimiento de objetivos y de evaluación de estrategias. El cuadro de Mando Integral resume los objetivos claves que persigue la empresa, juntamente con su programa de cumplimiento y responsables por área (David, 2013).

Para el desarrollo del Cuadro de Mando Integral de Los Ferroles, adicional a la estrategia seleccionada y el aspecto financiero, se ha considerado la inclusión de otros aspectos relevantes para la compañía, como lo son la necesidad del desarrollo de procesos de gestión humana y de procesos comerciales; dado que son considerados procesos críticos para el crecimiento.

El contar con procesos de gestión humana permitirá fortalecer la cultura empresarial, y desarrollar el capital humano, pues son piezas claves para la implantación de cualquier estrategia; el compromiso que los colaboradores muestren hacia el logro de los objetivos es determinante para el éxito o fracaso de cualquier proyecto. Los colaboradores deben sentir el plan como parte de ellos, y entender los beneficios que éste les genera. En tal sentido, el fortalecimiento de los procesos orientados al capital humano, es indispensable para el logro de los objetivos. 
Por otro lado, el desarrollo de la gestión comercial es de vital importancia para todas las compañías, pues es donde nacen las estrategias y objetivos con enfoque en los clientes, y la encargada de llevar la voz del cliente al interior de la empresa a fin de mantener sus necesidades siempre satisfechas. En el caso de Los Ferroles, requiere potenciar esta área para poder llevar a cabo los objetivos e iniciativas planteadas, de otra forma, sin un equipo de trabajo focalizado en este aspecto, será muy difícil el logro del plan.

\subsection{Mapa de la estrategia}

Cada empresa adapta el mapa estratégico a su conjunto de objetivos y estrategias, con el fin de describirlas de forma gráfica y coherente, y alineadas según las 4 perspectivas del Balaced Scorecard:

- $\quad$ Financiera: Describe los resultados tangibles de la estrategia en términos financieros tradicionales. Se enfoca en el manejo y procesamiento de los datos financieros.

- $\quad$ Clientes: Define la propuesta de valor para los clientes. La propuesta de valor funciona como contexto para que los activos intangibles puedan generar valor.

- $\quad$ Procesos internos: Describe los procesos internos que tienen el mayor impacto en la estrategia.

- $\quad$ Aprendizaje y crecimiento: Se enfoca en el personal de la organización que es considerado como un activo intangible que la distingue de otras organizaciones.

El mapa estratégico ayuda a entender como el trabajo de una persona impacta a la estrategia de la empresa, dado que traduce la estrategia en acciones concretas que tienen 
resultados tangibles, lo cual permite comunicar y delegar responsabilidades de manera clara y efectiva.

Así mismo, el mapa estratégico despliega la relación lógica de causa-efecto entre los objetivos establecidos y los temas estratégicos. Estas relaciones causa- efecto son expresadas a través de flechas que interrelacionan los objetivos con las perspectivas.

Los objetivos definidos deben reflejar tanto la perspectiva en la que se encuentran como el tema estratégico al que pertenecen; asimismo, deben ser redactados de manera muy clara para que cualquier persona de la empresa pueda verlos y comprender cómo se planea lograr la estrategia.

Tras determinar los objetivos estratégicos de la organización, se establecen dos tipos de relaciones causa-efecto: relaciones horizontales y verticales. Las relaciones horizontales describen la relación entre las áreas y funciones de cada perspectiva y las relaciones verticales describen la relación causa y efecto entre los objetivos de la organización. (Trissa Strategy Consulting, 2016).

La figura 48 muestra la interrelación de la visión y la estrategia con las cuatro perspectivas. La elaboración del Cuadro de Mando Integral empieza con el análisis de la perspectiva del Aprendizaje y Crecimiento y la definición de los objetivos, hasta llegar a la perspectiva Financiera. La medición y comparación de los resultados se realiza desde la perspectiva Financiera hacia la perspectiva del Aprendizaje y Crecimiento. 


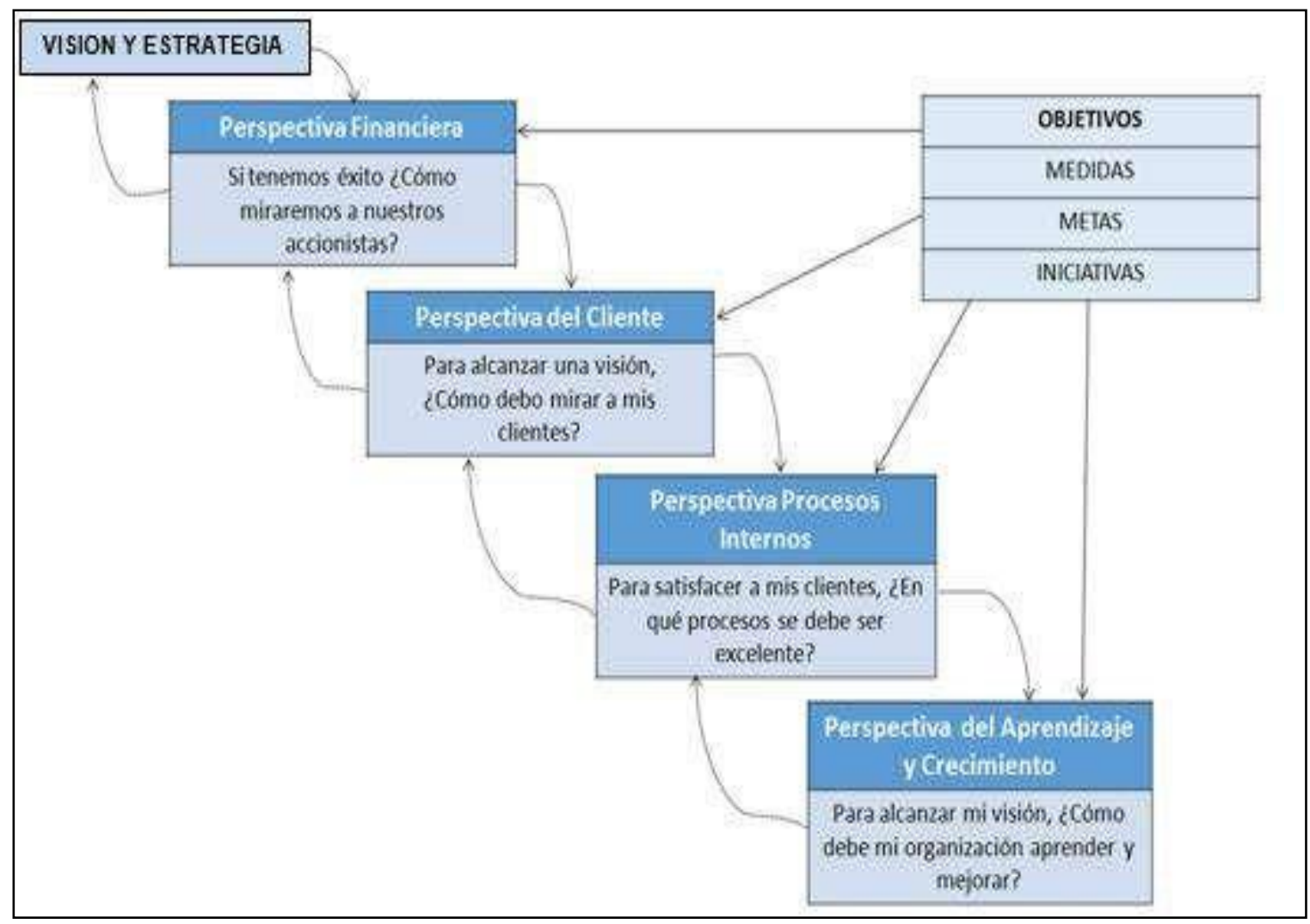

Figura 48. Trasladar la Estrategia a Términos Operacionales. Tomado de El Proceso Estratégico, Un enfoque de Gerencia (p. 185), por F. D’alessio 2015, Lima, Perú: Copyrigth 2015 por Pearson Educación del Perú SA

Para la elaboración del mapa estratégico de Los Ferroles, se analizaron y consideraron los siguientes temas estratégicos por ser los que influyen de manera más directa en el logro de la estrategia corporativa:

- $\quad$ La innovación y desarrollo de productos.

- Gestión Comercial

- $\quad$ Excelencia operativa.

- $\quad$ Gestión Humana 


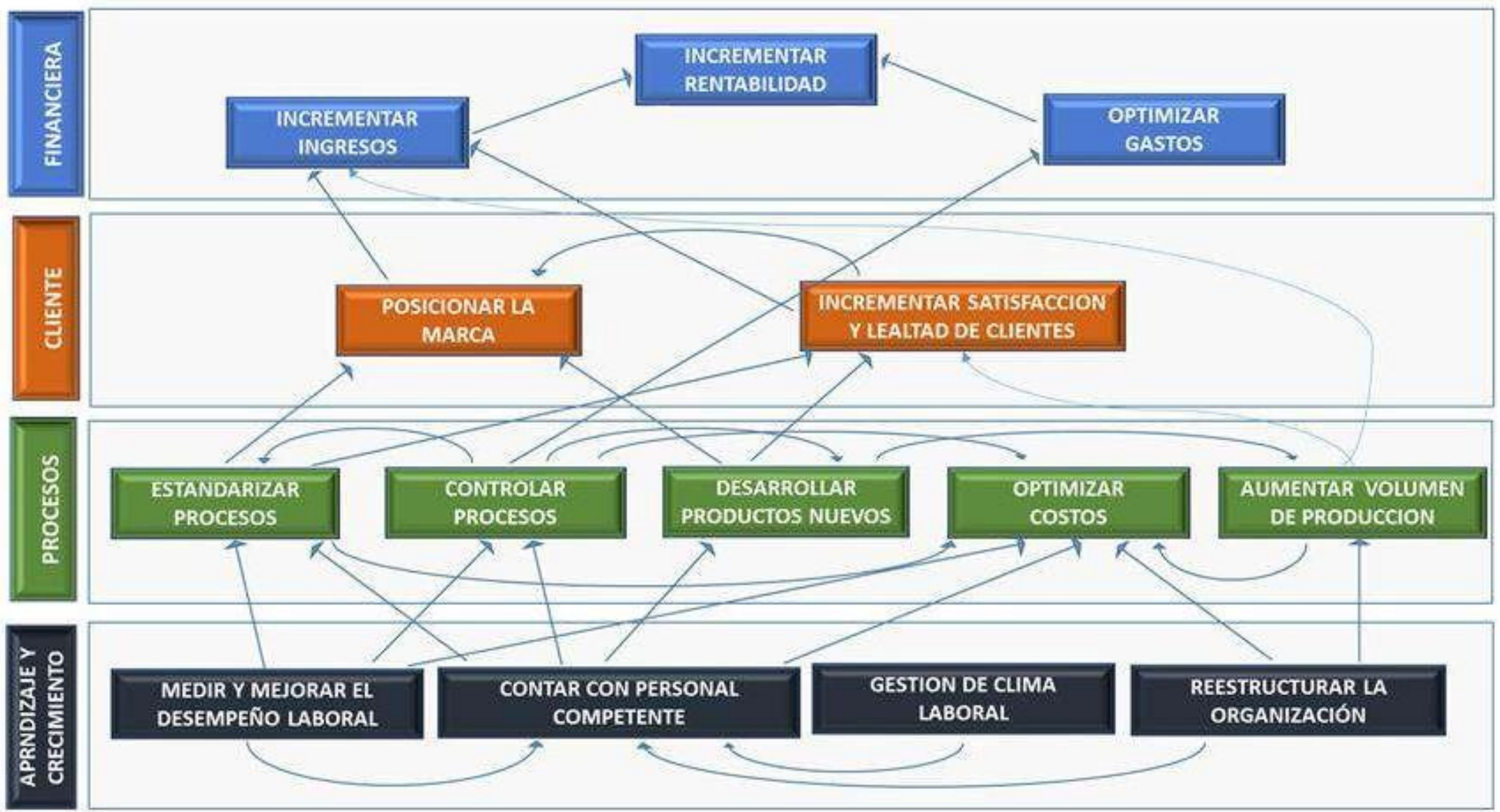

Figura 49. Cuadro de Mando Integral de la empresa Los Ferroles SAC. 
La figura 49 muestra los Objetivos Estratégicos definidos para la empresa, de acuerdo a las perspectivas del Cuadro de Mando Integral.

Para interpretar el mapa estratégico se deben leer de abajo hacia arriba los objetivos de cada perspectiva, analizando las relaciones causa - efecto de manera horizontal y vertical:

1. Aprendizaje y crecimiento: Se sitúa el capital humano de la empresa y los procesos que requieren ser trabajados para su desarrollo. Se ha priorizado objetivos como la medición del clima y desempeño laboral, la reestructuración organización y la capacitación.

2. Procesos: Se indican objetivos de control y estandarización de los procesos productivos y administrativos como requerimientos básicos para poder trabajar los objetivos alineados a los clientes. Asimismo se señala el desarrollo de nuevos productos como un nuevo proceso por implementar que permitirá un mayor crecimiento.

3. Clientes: Se indican objetivos enfocados a la mejora de la satisfacción y lealtad de los clientes, así como al fortalecimiento de la marca; la mejora en estos aspectos debe verse reflejado en el incremento de las ventas y la mayor participación de mercado.

4. Financiera: Estos objetivos son el resumen y consecuencia del logro de los objetivos de las perspectivas anteriores. El principal es el incremento de la 
rentabilidad, soportado por la optimización de los costos y el incremento de los ingresos.

\subsection{Objetivos específicos según el mapa estratégico}

Siguiendo las perspectivas del Cuadro de Mando Integral y los objetivos estratégicos planteados, se definen los objetivos específicos, los cuales señalan de manera más concreta y cuantificada, el cómo lograr los objetivos estratégicos.

D’Alessio (2015) señala que los objetivos deben mantener una jerarquía y compatibilidad entre ellos, así como un ordenamiento que va desde los globales hasta los más específicos, evitando la generación de conflicto entre ellos, con lo cual se asegura el desempeño de la organización en el corto y largo plazo.

Otra característica importante de los objetivos específicos, es que deben cumplir con la metodología S.M.A.R.T (metodología inteligente). Los objetivos S.M.A.R.T ponen un fuerte énfasis en el resultado final de una situación, en lugar de las actividades que se realizan a lo largo del camino.

Los objetivos S.M.A.R.T. son descritos de acuerdo a los siguientes lineamientos:

1. Specific (Específico): ¿se define exactamente qué es lo que está siendo perseguido?

2. Measurable (Medible): ¿existe un número que describa el objetivo completo?

3. Attainable (Alcanzable): ¿puede ser el objetivo logrado?

4. Realistic (Realista): ¿puede ser el objetivo realizado desde una perspectiva empresarial? 
5. Timely (Fecha límite de ejecución): ¿puede ser el objetivo completado en una cantidad de tiempo razonable? (Web y empresas, 2016)

Tabla 47

Objetivos Específicos

\begin{tabular}{|c|c|c|}
\hline Perspectiva & Objetivos Estratégico & Objetivo Específico \\
\hline \multirow{6}{*}{ Financiera } & \multirow{2}{*}{ Incrementar rentabilidad } & Incrementar el ROE \\
\hline & & Incrementar el ROA \\
\hline & Optimizar gastos & Incrementar la utilidad neta \\
\hline & \multirow{3}{*}{ Incrementar ingresos } & Incrementar uso de capacidad instalada \\
\hline & & Incrementar ingresos por venta \\
\hline & & Incrementar participación de mercado \\
\hline \multirow[t]{2}{*}{ Cliente } & $\begin{array}{l}\text { Incrementar la satisfacción y } \\
\text { lealtad de clientes }\end{array}$ & $\begin{array}{l}\text { Mejorar la calidad del servicio pre y post venta } \\
\text { Mejorar el nivel de lealtad de los clientes } \\
\text { Mejorar el cumplimiento en la entrega de } \\
\text { pedidos }\end{array}$ \\
\hline & Posicionar la marca & Dar a conocer la marca en el sector avícola \\
\hline \multirow{8}{*}{ Procesos } & Desarrollar productos nuevos & Implementar área de I\&D \\
\hline & \multirow[b]{2}{*}{ Optimizar costos } & Reducir el costo de producción \\
\hline & & Reducir el costo de la materia prima \\
\hline & \multirow{2}{*}{ Estandarizar procesos } & $\begin{array}{l}\text { Implementación de Sistema de Inocuidad } \\
\text { Alimentaria: HACCP. }\end{array}$ \\
\hline & & $\begin{array}{l}\text { Implementación de Sistema de Gestión de } \\
\text { Calidad: ISO } 9001 .\end{array}$ \\
\hline & \multirow[t]{2}{*}{ Controlar procesos } & $\begin{array}{l}\text { Implementar control estadístico de procesos en } \\
\text { plantas de producción (CEP). }\end{array}$ \\
\hline & & Implementar sistema de gestión por resultados \\
\hline & $\begin{array}{l}\text { Aumentar volumen de } \\
\text { producción. }\end{array}$ & Acopiar mayor volumen de materia prima. \\
\hline \multirow{7}{*}{$\begin{array}{l}\text { Aprendizaje y } \\
\text { Crecimiento }\end{array}$} & \multirow{3}{*}{ Reestructurar la organización } & $\begin{array}{l}\text { Definir e implementar estructura organizacional } \\
\text { y perfiles requeridos. }\end{array}$ \\
\hline & & Homologar escalas salariales \\
\hline & & Implementar Cultura de la Calidad Total \\
\hline & Gestión de Clima Laboral & Medir y mejorar el clima laboral. \\
\hline & $\begin{array}{l}\text { Medir y mejorar el desempeño } \\
\text { laboral }\end{array}$ & $\begin{array}{l}\text { Implementar sistema de evaluación del } \\
\text { desempeño }\end{array}$ \\
\hline & \multirow{2}{*}{$\begin{array}{l}\text { Contar con personal } \\
\text { competente }\end{array}$} & $\begin{array}{l}\text { Implementar sistema de reclutamiento y } \\
\text { selección }\end{array}$ \\
\hline & & Desarrollar plan de inducción y capacitación \\
\hline
\end{tabular}




\subsection{Indicadores para cada uno de los objetivos específicos}

Los indicadores permiten hacer seguimiento a los resultados obtenidos y relacionar los objetivos de la empresa con planes de acción concretos.

Los indicadores van más allá de los aspectos exclusivamente cuantitativos o tangibles, (ventas o la rentabilidad), dado que también valoran aspectos intangibles que son muy relevantes en el mediano y largo plazo como: la satisfacción de los clientes, la gestión ambiental o el bienestar de los empleados. Es importante que los indicadores no controlen la actividad pasada solamente, si bien deben reflejar los resultados de los objetivos, también deben informar sobre el avance para alcanzar esos objetivos. Es decir, la mezcla balanceada entre indicadores de resultados e indicadores de actuación es lo que permitirá comunicar la forma de conseguir los resultados y, al mismo tiempo, el camino para lograrlo. (Issotools, 2015)

A continuación se muestran los objetivos estratégicos y específicos con sus respectivos indicadores, según las perspectivas del Cuadro de Mando Integral. 
Tabla 48

Indicadores a nivel de Perspectiva Financiera

\begin{tabular}{lclc}
\hline Perspectiva & $\begin{array}{c}\text { Objetivos } \\
\text { Estratégico }\end{array}$ & \multicolumn{1}{c}{ Objetivo Específico } & Indicadores \\
\hline \multirow{2}{*}{$\begin{array}{l}\text { Incrementar } \\
\text { rentabilidad }\end{array}$} & $\begin{array}{l}\text { Incrementar el ROE (Rentabilidad del } \\
\text { patrimonio) } \\
\text { Incrementar el ROA (Rentabilidad de los } \\
\text { activos) } \\
\text { Financiera }\end{array}$ & $\begin{array}{l}\text { Optimizar gastos } \\
\text { Incrementar el Margen Neto }\end{array}$ & ROA \\
& $\begin{array}{l}\text { Incrementar uso de capacidad instalada } \\
\text { ingresos }\end{array}$ & Incrementar ingresos por venta & $\begin{array}{c}\text { Margen Neto (\%) capacidad } \\
\text { Incremento de } \\
\text { venta }\end{array}$ \\
& & $\begin{array}{c}\text { Incrementar participación de mercado } \\
\text { participación }\end{array}$ \\
\hline
\end{tabular}

Tabla 49

Indicadores a nivel de Perspectiva Cliente

\begin{tabular}{|c|c|c|c|}
\hline Perspectiva & Objetivos Estratégico & Objetivo Específico & Indicadores \\
\hline \multirow{4}{*}{ Cliente } & \multirow{3}{*}{$\begin{array}{l}\text { Incrementar la } \\
\text { satisfacción y lealtad } \\
\text { de clientes }\end{array}$} & $\begin{array}{l}\text { Mejorar la calidad del servicio pre y post } \\
\text { venta }\end{array}$ & $\begin{array}{l}\text { Incremento en \% } \\
\text { satisfacción }\end{array}$ \\
\hline & & Mejorar el nivel de lealtad de los clientes & $\%$ NPS \\
\hline & & $\begin{array}{l}\text { Mejorar el cumplimiento en la entrega de } \\
\text { pedidos }\end{array}$ & $\%$ Fill rate \\
\hline & Posicionar la marca & $\begin{array}{l}\text { Dar a conocer la marca en el sector } \\
\text { avícola }\end{array}$ & $\begin{array}{l}\mathrm{N}^{\circ} \text { de eventos } \\
\text { asistidos } \\
\text { Nivel de } \\
\text { posicionamiento }\end{array}$ \\
\hline
\end{tabular}


Tabla 50

Indicadores a nivel de Perspectiva de Procesos

\begin{tabular}{|c|c|c|c|}
\hline Perspectiva & $\begin{array}{c}\text { Objetivos } \\
\text { Estratégico }\end{array}$ & Objetivo Específico & Indicadores \\
\hline \multirow{9}{*}{ Procesos } & $\begin{array}{l}\text { Desarrollar productos } \\
\text { nuevos }\end{array}$ & Implementar área de I\&D & $\begin{array}{l}\mathrm{N}^{\circ} \text { de productos nuevos } \\
\text { desarrollados }\end{array}$ \\
\hline & \multirow{3}{*}{ Optimizar costos } & Reducir el costo de producción & $\begin{array}{l}\text { \% disminución del } \\
\text { costo }\end{array}$ \\
\hline & & & \% disminución del \\
\hline & & Reducir el costo de la materia prima & $\begin{array}{l}\text { costo de la materia } \\
\text { prima }\end{array}$ \\
\hline & \multirow{2}{*}{ Estandarizar procesos } & $\begin{array}{l}\text { Implementación de Sistema de Inocuidad } \\
\text { Alimentaria: HACCP. }\end{array}$ & $\%$ avance \\
\hline & & $\begin{array}{l}\text { Implementación de Sistema de Gestión } \\
\text { de Calidad: ISO } 9001 .\end{array}$ & $\%$ avance \\
\hline & \multirow{2}{*}{ Controlar procesos } & $\begin{array}{l}\text { Implementar control estadístico de } \\
\text { procesos en plantas de producción (CEP). }\end{array}$ & $\%$ avance \\
\hline & & $\begin{array}{l}\text { Implementar sistema de gestión por } \\
\text { resultados }\end{array}$ & $\%$ de avance \\
\hline & $\begin{array}{l}\text { Aumentar volumen de } \\
\text { producción. }\end{array}$ & $\begin{array}{l}\text { Acopiar mayor volumen de materia } \\
\text { prima. }\end{array}$ & TM de materia prima \\
\hline
\end{tabular}

Tabla 51

Indicadores a nivel de Perspectiva Aprendizaje y Crecimiento

\begin{tabular}{|c|c|c|c|}
\hline Perspectiva & Objetivos Estratégico & Objetivo Específico & Indicadores \\
\hline \multirow{6}{*}{$\begin{array}{l}\text { Aprendizaje } \\
\underset{y}{\text { Crecimiento }}\end{array}$} & \multirow{3}{*}{$\begin{array}{l}\text { Reestructurar la } \\
\text { organización }\end{array}$} & $\begin{array}{l}\text { Definir e implementar estructura organizacional } \\
\text { y perfiles requeridos. }\end{array}$ & $\%$ de avance \\
\hline & & Homologar escalas salariales & $\%$ de avance \\
\hline & & Implementar Cultura de la Calidad Total & $\%$ de avance \\
\hline & $\begin{array}{l}\text { Gestión de Clima } \\
\text { Laboral }\end{array}$ & Medir y mejorar el clima laboral. & $\%$ de incremento \\
\hline & $\begin{array}{l}\text { Medir y mejorar el } \\
\text { desempeño laboral }\end{array}$ & $\begin{array}{l}\text { Implementar sistema de evaluación del } \\
\text { desempeño }\end{array}$ & $\%$ de avance \\
\hline & $\begin{array}{l}\text { Contar con personal } \\
\text { competente }\end{array}$ & $\begin{array}{l}\text { Implementar sistema de reclutamiento y } \\
\text { selección } \\
\text { Desarrollar plan de inducción y capacitación }\end{array}$ & $\begin{array}{l}\% \text { avance } \\
\text { Horas-hombre de } \\
\text { capacitación }\end{array}$ \\
\hline
\end{tabular}




\subsection{Metas para cada uno de los objetivos específicos}

Establecer metas es crucial para lograr objetivos de crecimiento y medir los avances y resultados que se han obtenido. "Las metas son sueños con fecha" y éstas deben ser una de las bases en la mentalidad de cualquier emprendedor. (Entrepeneur, 2016)

Una vez definidos los indicadores, se establecieron las metas para un horizonte de tres años, en la tabla 54 se muestra los objetivos específicos asociados con sus respectivos indicadores y metas para el periodo 2018-2020. 


\section{Tabla 52}

Metas Perspectiva Financiera por Objetivos Específicos

\begin{tabular}{|c|c|c|c|c|c|c|}
\hline $\begin{array}{l}\text { Objetivos } \\
\text { Estratégico }\end{array}$ & $\begin{array}{l}\text { Objetivo } \\
\text { Específico }\end{array}$ & Indicador & Año Base & $\begin{array}{r}\text { Meta } \\
2018\end{array}$ & $\begin{array}{r}\text { Meta } \\
2019\end{array}$ & $\begin{array}{r}\text { Meta } \\
2020\end{array}$ \\
\hline \multirow{2}{*}{$\begin{array}{l}\text { Incrementar } \\
\text { rentabilidad }\end{array}$} & $\begin{array}{l}\text { Incrementar el } \\
\text { ROE }\end{array}$ & $\operatorname{ROE}(\%)$ & $15.9 \%$ & $12.5 \%$ & $16.6 \%$ & $20.4 \%$ \\
\hline & $\begin{array}{c}\text { Incrementar el } \\
\text { ROA }\end{array}$ & ROA $(\%)$ & $5.3 \%$ & $4.0 \%$ & $5.2 \%$ & $6.2 \%$ \\
\hline \multirow[t]{2}{*}{ Optimizar gastos } & $\begin{array}{l}\text { Incrementar la } \\
\text { utilidad neta }\end{array}$ & Utilidad neta $(\%)$ & $5.4 \%$ & $3.8 \%$ & $4.5 \%$ & $4.9 \%$ \\
\hline & $\begin{array}{c}\text { Incrementar uso } \\
\text { de capacidad } \\
\text { instalada }\end{array}$ & $\%$ uso capacidad & $65 \%$ & $72 \%$ & $78 \%$ & $82 \%$ \\
\hline \multirow[t]{2}{*}{$\begin{array}{c}\text { Incrementar } \\
\text { ingresos }\end{array}$} & $\begin{array}{c}\text { Incrementar } \\
\text { ingresos por venta }\end{array}$ & $\begin{array}{c}\% \text { incremento de } \\
\text { venta }\end{array}$ & $9 \%$ & $14.7 \%$ & $14.7 \%$ & $14.7 \%$ \\
\hline & $\begin{array}{c}\text { Incrementar } \\
\text { participación de } \\
\text { mercado }\end{array}$ & \% participación & $62 \%$ & $65 \%$ & $68 \%$ & $70 \%$ \\
\hline
\end{tabular}

Tabla 53

Metas Perspectiva Cliente por Objetivos Específicos

\begin{tabular}{|c|c|c|c|c|c|c|}
\hline $\begin{array}{l}\text { Objetivos } \\
\text { Estratégico }\end{array}$ & Objetivo Específico & Indicador & Año Base & $\begin{array}{l}\text { Meta } \\
2018\end{array}$ & $\begin{array}{l}\text { Meta } \\
2019\end{array}$ & $\begin{array}{l}\text { Meta } \\
2020\end{array}$ \\
\hline \multirow{3}{*}{$\begin{array}{l}\text { Incrementar la } \\
\text { satisfacción y } \\
\text { lealtad de } \\
\text { clientes }\end{array}$} & $\begin{array}{l}\text { Mejorar la calidad } \\
\text { del servicio pre y } \\
\text { post venta }\end{array}$ & $\begin{array}{l}\text { Incremento en } \% \\
\text { satisfacción }\end{array}$ & $\begin{array}{c}\text { No } \\
\text { implementado }\end{array}$ & - & \multicolumn{2}{|c|}{ Mín: 5\% Mín: 5\% } \\
\hline & $\begin{array}{c}\text { Mejorar el nivel de } \\
\text { lealtad de los } \\
\text { clientes }\end{array}$ & $\%$ NPS & $\begin{array}{c}\text { No } \\
\text { implementado }\end{array}$ & - & $\begin{array}{l}\text { Mín: } \\
30 \%\end{array}$ & $\begin{array}{l}\text { Mín: } \\
50 \%\end{array}$ \\
\hline & $\begin{array}{c}\text { Mejorar el } \\
\text { cumplimiento en la } \\
\text { entrega de pedidos }\end{array}$ & $\%$ Fill rate & $\begin{array}{c}\text { No } \\
\text { implementado }\end{array}$ & - & $80 \%$ & $85 \%$ \\
\hline \multirow{2}{*}{$\begin{array}{c}\text { Posicionar la } \\
\text { marca }\end{array}$} & \multirow{2}{*}{$\begin{array}{l}\text { Dar a conocer la } \\
\text { marca en el sector } \\
\text { avícola }\end{array}$} & $\begin{array}{l}\mathrm{N}^{\circ} \text { de eventos } \\
\text { asistidos }\end{array}$ & $\begin{array}{c}\text { No } \\
\text { implementado }\end{array}$ & - & 2 & 3 \\
\hline & & $\begin{array}{c}\text { Nivel de } \\
\text { posicionamiento }\end{array}$ & $\begin{array}{c}\text { No } \\
\text { implementado }\end{array}$ & - & $\begin{array}{l}\text { Top of } \\
\text { mind }\end{array}$ & $\begin{array}{l}\text { Top of } \\
\text { mind }\end{array}$ \\
\hline
\end{tabular}




\section{Tabla 54}

Metas Perspectiva Procesos por Objetivos Específicos

\begin{tabular}{|c|c|c|c|c|c|c|}
\hline $\begin{array}{l}\text { Objetivos } \\
\text { Estratégico }\end{array}$ & Objetivo Específico & Indicador & Año Base & Meta 2018 & Meta $2019 \mathrm{~N}$ & eta 2020 \\
\hline $\begin{array}{l}\text { Desarrollar } \\
\text { productos nuevos }\end{array}$ & $\begin{array}{l}\text { Implementar área de } \\
\text { I\&D }\end{array}$ & $\begin{array}{c}\mathrm{N}^{\circ} \text { de } \\
\text { productos } \\
\text { nuevos } \\
\text { desarrollados }\end{array}$ & $\begin{array}{l}\text { Sin productos } \\
\text { nuevos }\end{array}$ & Mín. 2 & Mín. 4 & Mín. 4 \\
\hline \multirow[b]{2}{*}{ Optimizar costos } & $\begin{array}{l}\text { Reducir el costo de } \\
\text { producción }\end{array}$ & $\begin{array}{c}\% \\
\text { disminución } \\
\text { del costo }\end{array}$ & $0 \%$ & $4 \%$ & $4 \%$ & $2 \%$ \\
\hline & $\begin{array}{l}\text { Reducir el costo de la } \\
\text { materia prima }\end{array}$ & $\begin{array}{c}\% \\
\text { disminución } \\
\text { del costo de } \\
\text { la materia } \\
\text { prima }\end{array}$ & $0 \%$ & $10 \%$ & $5 \%$ & $2 \%$ \\
\hline \multirow{2}{*}{$\begin{array}{l}\text { Estandarizar } \\
\text { procesos }\end{array}$} & $\begin{array}{l}\text { Implementación de } \\
\text { Sistema de Inocuidad } \\
\text { Alimentaria: HACCP. }\end{array}$ & $\%$ avance & $0 \%$ & $\begin{array}{c}\text { Implemen } \\
\text { ta: } 2 \\
\text { plantas }\end{array}$ & $\begin{array}{l}\text { Certificaci } \\
\text { ón: } 2 \\
\text { plantas }\end{array}$ & - \\
\hline & $\begin{array}{l}\text { Implementación de } \\
\text { Sistema de Gestión de } \\
\text { Calidad: ISO } 9001 .\end{array}$ & $\%$ avance & $0 \%$ & $\begin{array}{c}\text { Implemen } \\
\text { ta: } 2 \\
\text { plantas }\end{array}$ & $\begin{array}{l}\text { Certificaci } \\
\text { ón } 2 \\
\text { plantas }\end{array}$ & - \\
\hline \multirow{2}{*}{$\begin{array}{l}\text { Controlar } \\
\text { procesos }\end{array}$} & $\begin{array}{l}\text { Implementar control } \\
\text { estadístico de procesos } \\
\text { en plantas de } \\
\text { producción (CEP). }\end{array}$ & $\%$ avance & $0 \%$ & - & $\begin{array}{l}100 \% \\
\text { planta de } \\
\text { plumas }\end{array}$ & $\begin{array}{c}100 \% \\
\text { planta de } \\
\text { víscera }\end{array}$ \\
\hline & $\begin{array}{l}\text { Implementar sistema de } \\
\text { gestión por resultados }\end{array}$ & $\%$ de avance & $0 \%$ & $100 \%$ & & \\
\hline $\begin{array}{l}\text { Aumentar } \\
\text { volumen de } \\
\text { producción. }\end{array}$ & $\begin{array}{c}\text { Acopiar mayor } \\
\text { volumen de materia } \\
\text { prima. }\end{array}$ & $\begin{array}{c}\text { TM de } \\
\text { materia prima }\end{array}$ & $16,000 \mathrm{TM}$ & $\begin{array}{c}17,000 \\
\mathrm{TM}\end{array}$ & $\begin{array}{c}19,000 \\
\text { TM }\end{array}$ & $\begin{array}{c}21,500 \\
\text { TM }\end{array}$ \\
\hline
\end{tabular}




\section{Tabla 55}

Metas Perspectiva Aprendizaje y Crecimiento por Objetivos Específicos

\begin{tabular}{|c|c|c|c|c|c|c|}
\hline Estratégico & Objetivo Específico & Indicador & Año Base & $\begin{array}{l}\text { IVIeta } \\
2018\end{array}$ & $\begin{array}{l}\text { Meta } \\
2019\end{array}$ & $\begin{array}{l}\text { Meta } \\
2020\end{array}$ \\
\hline \multirow{3}{*}{$\begin{array}{l}\text { Reestructurar la } \\
\text { organización }\end{array}$} & $\begin{array}{c}\text { Definir e implementar } \\
\text { estructura organizacional y } \\
\text { perfiles requeridos. }\end{array}$ & $\%$ de avance & $0 \%$ & $100 \%$ & - & - \\
\hline & $\begin{array}{c}\text { Homologar escalas } \\
\text { salariales }\end{array}$ & $\%$ de avance & $0 \%$ & & $100 \%$ & - \\
\hline & $\begin{array}{l}\text { Implementar Cultura de la } \\
\text { Calidad Total }\end{array}$ & $\%$ de avance & $0 \%$ & $100 \%$ & - & - \\
\hline $\begin{array}{l}\text { Gestión de Clima } \\
\text { Laboral }\end{array}$ & $\begin{array}{c}\text { Medir y mejorar el clima } \\
\text { laboral. }\end{array}$ & $\begin{array}{c}\% \text { de } \\
\text { incremento }\end{array}$ & $0 \%$ & - & - & $5 \%$ \\
\hline $\begin{array}{l}\text { Medir y mejorar } \\
\text { el desempeño } \\
\text { laboral }\end{array}$ & $\begin{array}{l}\text { Implementar sistema de } \\
\text { evaluación del desempeño }\end{array}$ & $\%$ de avance & $0 \%$ & $80 \%$ & $100 \%$ & - \\
\hline \multirow{2}{*}{$\begin{array}{l}\text { Contar con } \\
\text { personal } \\
\text { competente }\end{array}$} & $\begin{array}{l}\text { Implementar sistema de } \\
\text { reclutamiento y selección }\end{array}$ & $\%$ avance & $0 \%$ & $100 \%$ & - & - \\
\hline & $\begin{array}{l}\text { Desarrollar plan de } \\
\text { inducción y capacitación }\end{array}$ & $\begin{array}{c}\text { Horas- } \\
\text { hombre de } \\
\text { capacitación }\end{array}$ & $2 \mathrm{H}-\mathrm{H}$ & $\begin{array}{c}\text { Mín } 6 \\
\text { H-H }\end{array}$ & $\begin{array}{l}\text { Mín: } 12 \\
\text { H-H }\end{array}$ & $\begin{array}{l}\text { Mín: } 18 \\
\text { H-H }\end{array}$ \\
\hline
\end{tabular}

\subsection{Iniciativas}

Las iniciativas son proyectos de duración acotada que no se incluyen dentro del trabajo rutinario de la compañía. Estos proyectos están diseñados para ayudar a lograr el desempeño propuesto en la estrategia. (Issotools, 2015)

Las iniciativas presentadas en el Cuadro de Mando Integral van a generar un alto impacto en la dirección de la empresa, dado que parten con la reestructuración organizacional de la compañía para una mejor alineación de los procesos productivos y comerciales. La resistencia al cambio que probablemente aparezca en algunos de los 
trabajadores, será un tema por trabajar y superar, de manera que los nuevos sistemas y formas de trabajo abran paso a la nueva cultura organizacional deseada, alineada a su visión, misión y valores corporativos.

Con el objetivo de poder priorizar las iniciativas, se elaboró una matriz para definir el impacto de éstas sobre los objetivos estratégicos y específicos. A cada iniciativa se le asignó una calificación de acuerdo a su relevancia sobre el logro del objetivo, esta calificación es la siguiente:

- $\quad 0$ : Ningún impacto

- $\quad 1$ : Poco impacto

- $\quad 2$ : Mediano impacto

- $\quad 3:$ Alto impacto

Una vez realizada la calificación se ponderó según pesos asignados (1, 2 y 3) para totalizar el puntaje por cada iniciativa, obteniendo los siguientes 3 niveles de impacto:

- $\quad$ Bajo : de 0 a 28 puntos

- Medio : de 29 a 57 puntos

- $\quad$ Alto de 58 a más puntos 


\begin{tabular}{|c|c|c|c|c|c|c|c|c|}
\hline \multicolumn{9}{|c|}{ 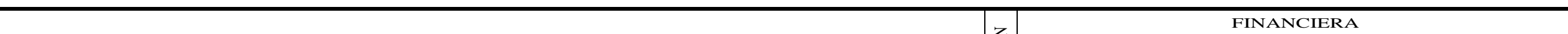 } \\
\hline \multicolumn{3}{|c|}{ MATRIZ DE IMPACTO DE INICITIVAS SOBRE OBJETIVOS } & \multirow{2}{*}{ 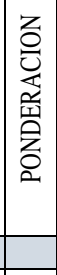 } & \multirow[t]{3}{*}{ 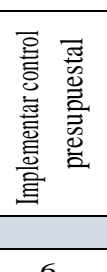 } & \multirow{2}{*}{ 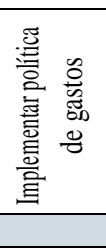 } & \multirow{2}{*}{ 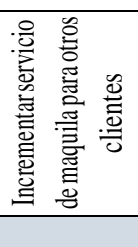 } & \multirow{2}{*}{ 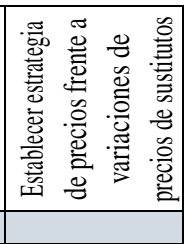 } & \multirow{2}{*}{ 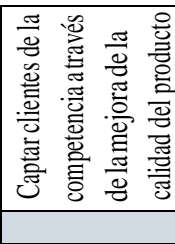 } \\
\hline & Objetivos Estratégico & Objetivo Específico & & & & & & \\
\hline \multirow{5}{*}{ 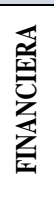 } & Incrementar rentabilidad & Incrementar el ROE & 3 & & 6 & 6 & 6 & 6 \\
\hline & Optimizar gastos & Incrementar la utilidad neta & 3 & 6 & 6 & 6 & 6 & 6 \\
\hline & Incrementar ingresos & Incrementar ingresos por venta & 3 & o & o & 6 & 6 & 6 \\
\hline & Incrementar ingresos & Incrementar participación de mercado & 3 & o & o & 6 & 6 & 6 \\
\hline & Incrementar ingresos & Incrementar uso de capacidad instalada & 3 & 0 & 0 & 6 & 0 & 6 \\
\hline \multirow{5}{*}{ 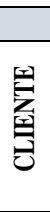 } & Objetivos Estratégico & Objetivo Específico & & & & & & \\
\hline & Incrementar la satisfacción y lealtad de clientes & Mejorar la calidad del servicio pre y post venta & 2 & o & o & 2 & 1 & 3 \\
\hline & Incrementar la satisfacción y lealtad de clientes & Mejorar el nivel de lealtad de los clientes & 2 & o & o & 2 & 3 & 2 \\
\hline & Incrementar la satisfacción y lealtad de clientes & Mejorar el cumplimiento en la entrega de pedidos & 2 & o & o & o & o & o \\
\hline & Posicionar la marca & Dar a conocer la marca en el sector avícola & 2 & o & 0 & 3 & 1 & 2 \\
\hline & Objetivos Estratégico & Objetivo Específico & & & & & & \\
\hline \multirow{8}{*}{ 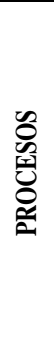 } & Desarrollar productos nuevos & Implementar área de I\&D & 2 & 1 & 0 & 1 & 0 & 1 \\
\hline & Optimizar costos & Reducir el costo de producción & 2 & 3 & 2 & 3 & o & 3 \\
\hline & Optimizar costos & Reducir el costo de la materia prima & 2 & 2 & 2 & 0 & o & 0 \\
\hline & Estandarizar procesos & Implementación de Sistema de Inocuidad : HACCP. & 2 & o & o & o & o & o \\
\hline & Estandarizar procesos & Implementación de Sistema de Gestión : ISO 9001. & 2 & o & o & o & o & o \\
\hline & Controlar procesos & Implementar control estadístico de procesos (CEP). & 2 & o & o & o & o & o \\
\hline & Controlar procesos & Implementar sistema de gestión por resultados & 2 & 2 & 1 & o & o & o \\
\hline & Aumentar volumen de producción & Acopiar mayor volumen de materia prima & 2 & 1 & 1 & o & 1 & o \\
\hline \multirow{8}{*}{ 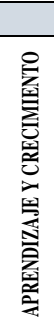 } & Objetivos Estratégico & Objetivo Específico & & & & & & \\
\hline & Reestructurar la organización & Definir e implementar estructura organiz. y perfiles. & 1 & o & 2 & o & o & o \\
\hline & Reestructurar la organización & Homologar escalas salariales & 1 & 1 & 2 & o & o & o \\
\hline & Reestructurar la organización & Implementar Cultura de la Calidad Total & 1 & 1 & 1 & o & o & 1 \\
\hline & Gestión de Clima Laboral & Medir y mejorar el clima laboral. & 1 & o & 1 & o & $\mathrm{O}$ & o \\
\hline & Medir y mejorar el desempeño laboral & Implementar sistema de evaluación del desempeño & 1 & o & o & o & o & o \\
\hline & Contar con personal competente & Implementar sistema de reclutamiento y selección & 1 & o & o & o & o & o \\
\hline & Contar con personal competente & Desarrollar plan de inducción y capacitación & 1 & o & 1 & o & o & o \\
\hline & & & & 23 & 25 & 41 & 30 & 42 \\
\hline & & & & Bajo & Bajo & Medio & Medio & Medio \\
\hline
\end{tabular}

Figura 50. Matriz Impacto de iniciativas sobre los objetivos - Perspectiva Financiera 


\begin{tabular}{|c|c|c|c|c|c|c|c|c|c|c|c|c|}
\hline & & & & & & & & LIENTE & & & & \\
\hline & MATRIZ DE IMPACTO DE & ICITIVAS SOBRE OBJETIVOS & 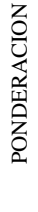 & 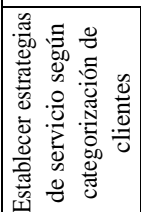 & 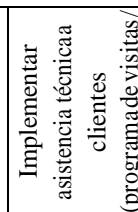 & 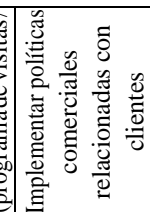 & 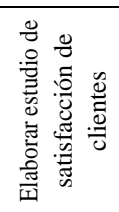 & 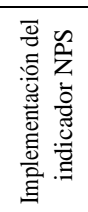 & 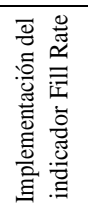 & 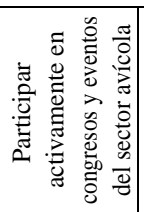 & 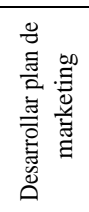 & 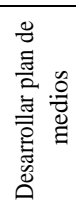 \\
\hline & Objetivos Estratégico & Objetivo Específico & & & & & & & & & & \\
\hline & Incrementar rentabilidad & Incrementar el ROE & 3 & 4 & 4 & 4 & 2 & 2 & 2 & 2 & 4 & 4 \\
\hline$\frac{4}{x}$ & Optimizar gastos & Incrementar la utilidad neta & 3 & 4 & 4 & 4 & 2 & 2 & 2 & 2 & 4 & 4 \\
\hline$\underline{z}$ & Incrementar ingresos & Incrementar ingresos por venta & 3 & 4 & 4 & 6 & 2 & 2 & 2 & 4 & 4 & 4 \\
\hline 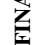 & Incrementar ingresos & Incrementar participación de mercado & 3 & 4 & 4 & 4 & 2 & 2 & 2 & 4 & 4 & 4 \\
\hline & Incrementar ingresos & Incrementar uso de capacidad instalada & 3 & 0 & 0 & 0 & 0 & 0 & 0 & 0 & 0 & 0 \\
\hline & Objetivos Estratégico & Objetivo Específico & & & & & & & & & & \\
\hline & Incrementar la satisfacción y lealtad de clientes & Mejorar la calidad del servicio pre y post venta & 2 & 3 & 3 & 3 & 3 & 3 & 3 & 3 & 2 & 1 \\
\hline $\bar{z}$ & Incrementar la satisfacción y lealtad de clientes & Mejorar el nivel de lealtad de los clientes & 2 & 3 & 3 & 3 & 3 & 3 & 3 & 3 & 3 & 1 \\
\hline $\bar{J}$ & Incrementar la satisfacción y lealtad de clientes & Mejorar el cumplimiento en la entrega de pedidos & 2 & 0 & 0 & 0 & 0 & 3 & 3 & 0 & 0 & 0 \\
\hline & Posicionar la marca & Dar a conocer la marca en el sector avícola & 2 & 2 & 3 & 1 & 0 & 0 & 0 & 3 & 3 & 3 \\
\hline & Objetivos Estratégico & Objetivo Específico & & & & & & & & & & \\
\hline & Desarrollar productos nuevos & Implementar área de I\&D & 2 & 0 & 2 & 0 & 0 & 0 & 0 & 0 & 0 & 0 \\
\hline & Optimizar costos & Reducir el costo de producción & 2 & 0 & 0 & 0 & 0 & 0 & 0 & 0 & 0 & 0 \\
\hline & Optimizar costos & Reducir el costo de la materia prima & 2 & 0 & 0 & 0 & 0 & 0 & 0 & 0 & 0 & 0 \\
\hline 总 & Estandarizar procesos & Implementación de Sistema de Inocuidad : HACCP. & 2 & 0 & 0 & 0 & 0 & 0 & 0 & 0 & 0 & 0 \\
\hline 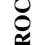 & Estandarizar procesos & Implementación de Sistema de Gestión : ISO 9001. & 2 & 0 & 0 & 1 & 3 & 2 & 1 & 0 & 0 & 0 \\
\hline & Controlar procesos & Implementar control estadístico de procesos (CEP). & 2 & 0 & 0 & 0 & 0 & 0 & 0 & 0 & 0 & 0 \\
\hline & Controlar procesos & Implementar sistema de gestión por resultados & 2 & 0 & 1 & 1 & 1 & 2 & 3 & 0 & 0 & 0 \\
\hline & Aumentar volumen de producción & Acopiar mayor volumen de materia prima & 2 & 0 & 0 & 0 & 0 & 0 & 0 & 0 & 0 & 0 \\
\hline & Objetivos Estratégico & Objetivo Específico & & & & & & & & & & \\
\hline$\stackrel{\circ}{\xi}$ & Reestructurar la organización & Definir e implementar estructura organiz. y perfiles. & 1 & 0 & 0 & 0 & 0 & 0 & 0 & 0 & 0 & 0 \\
\hline 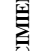 & Reestructurar la organización & Homologar escalas salariales & 1 & 0 & 0 & 0 & 0 & 0 & 0 & 0 & 0 & 0 \\
\hline 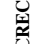 & Reestructurar la organización & Implementar Cultura de la Calidad Total & 1 & 1 & 1 & 1 & 3 & 2 & 2 & 0 & 0 & 0 \\
\hline 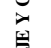 & Gestión de Clima Laboral & Medir y mejorar el clima laboral. & 1 & 0 & 0 & 0 & 0 & 0 & 0 & 0 & 0 & 0 \\
\hline 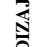 & Medir y mejorar el desempeño laboral & Implementar sistema de evaluación del desempeño & 1 & 0 & 0 & 0 & 0 & 0 & 0 & 0 & 0 & 0 \\
\hline 产 & Contar con personal competente & Implementar sistema de reclutamiento y selección & 1 & 0 & 0 & 0 & 0 & 0 & 0 & 0 & 0 & 0 \\
\hline & Contar con personal competente & Desarrollar plan de inducción y capacitación & 1 & 0 & 0 & 0 & 0 & 0 & 0 & 0 & 0 & 0 \\
\hline & & & & 25 & 29 & 28 & 21 & 23 & 23 & 21 & 24 & 21 \\
\hline & & & & Bajo & Medio & Medio & Bajo & Bajo & Bajo & Bajo & Bajo & Bajo \\
\hline
\end{tabular}

Figura 51. Matriz Impacto de iniciativas sobre los objetivos - Perspectiva Cliente 


\begin{tabular}{|c|c|c|c|c|c|c|c|c|c|c|c|c|c|c|c|c|}
\hline \multirow{2}{*}{ 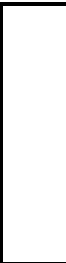 } & \multirow{2}{*}{\multicolumn{2}{|c|}{ MATRIZ DE IMPACTO DE INICITIVAS SOBRE OBJETIVOS }} & \multirow[b]{2}{*}{$\mid \begin{array}{c}z \\
0 \\
0 \\
z \\
\tilde{u} \\
\hat{u} \\
0 \\
2\end{array}$} & \multicolumn{13}{|c|}{ PROCESOS } \\
\hline & & & & 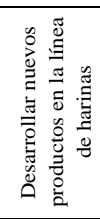 & 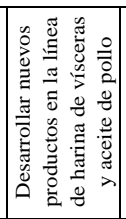 & 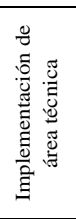 & 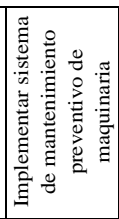 & 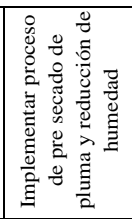 & 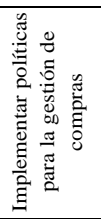 & 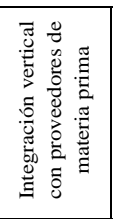 & 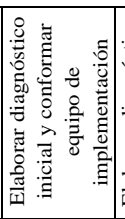 & 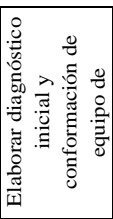 & 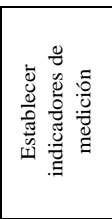 & 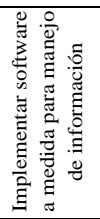 & 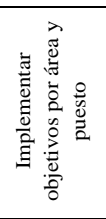 & 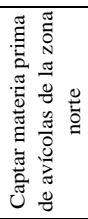 \\
\hline & Objetivos Estratégico & Objetivo Específico & & & & & & & & & & & & & & \\
\hline \multirow{5}{*}{ 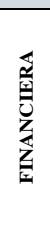 } & Incrementar rentabilidad & Incrementar el ROE & 3 & 4 & 4 & 2 & 4 & 6 & 4 & 6 & 2 & 2 & 4 & 2 & 4 & 6 \\
\hline & Optimizar gastos & Incrementar la utilidad neta & 3 & 4 & 4 & 2 & 4 & 6 & 4 & 6 & 2 & 2 & 4 & 2 & 4 & 6 \\
\hline & Incrementar ingresos & Incrementar ingresos por venta & 3 & 6 & 6 & 2 & 0 & 0 & 0 & 0 & 0 & 0 & 0 & 0 & 4 & 6 \\
\hline & Incrementar ingresos & Incrementar participación de mercado & 3 & 6 & 6 & 2 & 0 & 0 & 0 & 0 & 0 & 0 & 0 & 0 & 4 & 6 \\
\hline & Incrementar ingresos & Incrementar uso de capacidad instalada & 3 & 2 & 2 & 0 & 0 & 6 & 0 & 2 & 0 & 0 & 0 & 0 & 0 & 6 \\
\hline \multirow{5}{*}{ 齐 } & Objetivos Estratégico & Objetivo Específico & & & & & & & & & & & & & & \\
\hline & Incrementar la satisfacción y lealtad de clientes & Mejorar la calidad del servicio pre y post venta & 2 & 1 & 1 & 3 & 1 & 0 & 0 & 2 & 0 & 2 & 2 & 0 & 3 & 1 \\
\hline & Incrementar la satisfacción y lealtad de clientes & Mejorar el nivel de lealtad de los clientes & 2 & 1 & 1 & 3 & 0 & 0 & 0 & 1 & 0 & 2 & 1 & 0 & 2 & 0 \\
\hline & Incrementar la satisfacción y lealtad de clientes & Mejorar el cumplimiento en la entrega de pedidos & 2 & 0 & 0 & 0 & 2 & 0 & 1 & 2 & 1 & 2 & 3 & 2 & 2 & 2 \\
\hline & Posicionar la marca & Dar a conocer la marca en el sector avícola & 2 & 2 & 2 & 2 & 0 & 1 & 0 & 0 & 2 & 2 & 0 & 0 & 1 & 2 \\
\hline & Objetivos Estratégico & Objetivo Específico & & & & & & & & & & & & & & \\
\hline \multirow{8}{*}{ 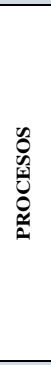 } & Desarrollar productos nuevos & Implementar área de I\&D & 2 & 3 & 3 & 3 & 0 & 0 & 0 & 0 & 0 & 0 & 2 & 0 & 2 & 0 \\
\hline & Optimizar costos & Reducir el costo de producción & 2 & 0 & 0 & 0 & 3 & 3 & 3 & 3 & 1 & 1 & 2 & 1 & 3 & 0 \\
\hline & Optimizar costos & Reducir el costo de la materia prima & 2 & 0 & 0 & 0 & 0 & 3 & 2 & 3 & 1 & 1 & 2 & 1 & 3 & 0 \\
\hline & Estandarizar procesos & Implementación de Sistema de Inocuidad : HACCP. & 2 & 0 & 0 & 0 & 0 & 0 & 0 & 1 & 3 & 3 & 3 & 3 & 3 & 0 \\
\hline & Estandarizar procesos & Implementación de Sistema de Gestión : ISO 9001. & 2 & 0 & 0 & 0 & 1 & 0 & 2 & 0 & 3 & 3 & 3 & 3 & 3 & 0 \\
\hline & Controlar procesos & Implementar control estadístico de procesos (CEP). & 2 & 0 & 0 & 0 & 3 & 0 & 0 & 0 & 3 & 3 & 3 & 3 & 3 & 0 \\
\hline & Controlar procesos & Implementar sistema de gestión por resultados & 2 & 0 & 0 & 0 & 2 & 0 & 0 & 0 & 3 & 3 & 3 & 3 & 3 & 0 \\
\hline & Aumentar volumen de producción & Acopiar mayor volumen de materia prima & 2 & 0 & 0 & 0 & 0 & 3 & 0 & 3 & 0 & 0 & 0 & 0 & 0 & 3 \\
\hline & Objetivos Estratégico & Objetivo Específico & & & & & & & & & & & & & & \\
\hline \multirow{9}{*}{ 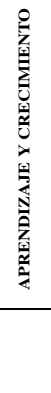 } & Reestructurar la organización & Definir e implementar estructura organiz. y perfiles. & 1 & 0 & 0 & 3 & 0 & 0 & 0 & 2 & 0 & 3 & 0 & 0 & 3 & 0 \\
\hline & Reestructurar la organización & Homologar escalas salariales & 1 & 0 & 0 & 0 & 0 & 0 & 0 & 0 & 0 & 0 & 0 & 0 & 2 & 0 \\
\hline & Reestructurar la organización & Implementar Cultura de la Calidad Total & 1 & 0 & 0 & 2 & 1 & 0 & 2 & 1 & 3 & 3 & 3 & 2 & 3 & 0 \\
\hline & Gestión de Clima Laboral & Medir y mejorar el clima laboral. & 1 & 0 & 0 & 1 & 0 & 0 & 0 & 0 & 0 & 0 & 1 & 0 & 2 & 0 \\
\hline & Medir y mejorar el desempeño laboral & Implementar sistema de evaluación del desempeño & 1 & 0 & 0 & 0 & 0 & 0 & 0 & 0 & 0 & 0 & 3 & 3 & 3 & 0 \\
\hline & Contar con personal competente & Implementar sistema de reclutamiento y selección & 1 & 0 & 0 & 0 & 0 & 0 & 0 & 0 & 0 & 0 & 0 & 0 & 0 & 0 \\
\hline & Contar con personal competente & Desarrollar plan de inducción y capacitación & 1 & 0 & 0 & 0 & 0 & 0 & 0 & 0 & 0 & 0 & 1 & 0 & 2 & 0 \\
\hline & & & & 29 & 29 & 25 & 21 & 28 & 18 & 32 & 24 & 32 & 40 & 25 & 59 & 38 \\
\hline & & & & Medio & Medio & Bajo & Bajo & Medio & Bajo & Medio & Bajo & Medio & Medio & Bajo & Alto & Medio \\
\hline
\end{tabular}

Figura 52. Matriz Impacto de iniciativas sobre los objetivos - Perspectiva Procesos 


\begin{tabular}{|c|c|c|c|c|c|c|c|c|c|c|c|c|c|}
\hline & & & & & & & APRE & NDIZAJE & CRECIMII & ENTO & & & \\
\hline & MATRIZ DE IMPACTO DE I & ICITIVAS SOBRE OBJETIVOS & 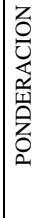 & 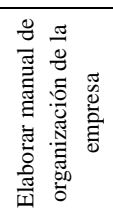 & 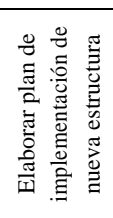 & 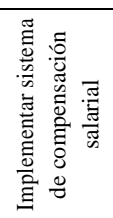 & 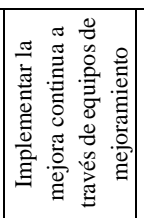 & 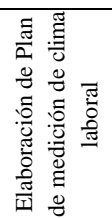 & 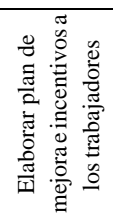 & 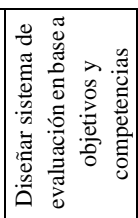 & 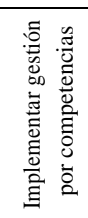 & 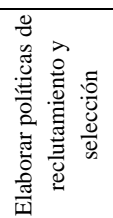 & 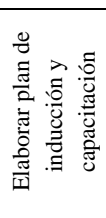 \\
\hline & Objetivos Estratégico & Objetivo Específico & & & & & & & & & & & \\
\hline & Incrementar rentabilidad & Incrementar el ROE & 3 & 2 & 2 & 2 & 2 & 2 & 2 & 2 & 2 & 2 & 2 \\
\hline 啚 & Optimizar gastos & Incrementar la utilidad neta & 3 & 2 & 2 & 2 & 2 & 2 & 2 & 2 & 2 & 2 & 2 \\
\hline $\bar{z}$ & Incrementar ingresos & Incrementar ingresos por venta & 3 & 2 & 2 & 2 & 2 & 2 & 2 & 2 & 2 & 2 & 2 \\
\hline & Incrementar ingresos & Incrementar participación de mercado & 3 & 0 & 0 & 0 & 0 & 0 & 0 & 0 & 2 & 0 & 0 \\
\hline & Incrementar ingresos & Incrementar uso de capacidad instalada & 3 & 0 & 0 & 0 & 0 & 0 & 0 & 0 & 0 & 0 & 0 \\
\hline & Objetivos Estratégico & Objetivo Específico & & & & & & & & & & & \\
\hline & Incrementar la satisfacción y lealtad de clientes & Mejorar la calidad del servicio pre y post venta & 2 & 2 & 2 & 1 & 3 & 2 & 2 & 1 & 2 & 2 & 2 \\
\hline$\sum_{x=1}^{n}$ & Incrementar la satisfacción y lealtad de clientes & Mejorar el nivel de lealtad de los clientes & 2 & 1 & 1 & 1 & 2 & 2 & 2 & 1 & 2 & 2 & 2 \\
\hline 氠 & Incrementar la satisfacción y lealtad de clientes & Mejorar el cumplimiento en la entrega de pedidos & 2 & 1 & 1 & 0 & 2 & 1 & 1 & 1 & 2 & 1 & 1 \\
\hline & Posicionar la marca & Dar a conocer la marca en el sector avícola & 2 & 0 & 0 & 0 & 1 & 0 & 0 & 0 & 2 & 1 & 1 \\
\hline & Objetivos Estratégico & Objetivo Específico & & & & & & & & & & & \\
\hline & Desarrollar productos nuevos & Implementar área de I\&D & 2 & 3 & 3 & 0 & 0 & 0 & 0 & 1 & 2 & 2 & 2 \\
\hline & Optimizar costos & Reducir el costo de producción & 2 & 1 & 1 & 1 & 2 & 1 & 1 & 1 & 2 & 1 & 1 \\
\hline & Optimizar costos & Reducir el costo de la materia prima & 2 & 0 & 0 & 0 & 2 & 0 & 0 & 0 & 2 & 0 & 0 \\
\hline O & Estandarizar procesos & Implementación de Sistema de Inocuidad : HACCP. & 2 & 0 & 0 & 0 & 3 & 0 & 0 & 2 & 2 & 2 & 3 \\
\hline 8 & Estandarizar procesos & Implementación de Sistema de Gestión : ISO 9001. & 2 & 3 & 3 & 2 & 3 & 3 & 3 & 3 & 3 & 3 & 3 \\
\hline & Controlar procesos & Implementar control estadístico de procesos (CEP). & 2 & 1 & 1 & 0 & 3 & 0 & 0 & 3 & 2 & 1 & 3 \\
\hline & Controlar procesos & Implementar sistema de gestión por resultados & 2 & 2 & 2 & 3 & 3 & 2 & 3 & 3 & 3 & 1 & 3 \\
\hline & Aumentar volumen de producción & Acopiar mayor volumen de materia prima & 2 & 0 & 0 & 0 & 0 & 0 & 0 & 0 & 0 & 0 & 0 \\
\hline & Objetivos Estratégico & Objetivo Específico & & & & & & & & & & & \\
\hline \& & Reestructurar la organización & Definir e implementar estructura organiz. y perfiles. & 1 & 3 & 3 & 0 & 1 & 2 & 2 & 2 & 3 & 3 & 3 \\
\hline 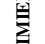 & Reestructurar la organización & Homologar escalas salariales & 1 & 3 & 3 & 3 & 1 & 1 & 1 & 3 & 1 & 1 & 0 \\
\hline 惫 & Reestructurar la organización & Implementar Cultura de la Calidad Total & 1 & 3 & 3 & 1 & 3 & 3 & 3 & 3 & 3 & 3 & 3 \\
\hline 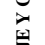 & Gestión de Clima Laboral & Medir y mejorar el clima laboral. & 1 & 2 & 2 & 3 & 3 & 3 & 3 & 3 & 3 & 3 & 3 \\
\hline ] & Medir y mejorar el desempeño laboral & Implementar sistema de evaluación del desempeño & 1 & 3 & 3 & 3 & 3 & 3 & 2 & 3 & 3 & 2 & 1 \\
\hline$\underset{\mathbf{n}}{\stackrel{\bar{n}}{\underline{n}}}$ & Contar con personal competente & Implementar sistema de reclutamiento y selección & 1 & 3 & 3 & 1 & 2 & 2 & 2 & 1 & 3 & 3 & 1 \\
\hline & Contar con personal competente & Desarrollar plan de inducción y capacitación & 1 & 2 & 2 & 0 & 1 & 2 & 2 & 1 & 2 & 2 & 3 \\
\hline & & & & 39 & 39 & 25 & 44 & 33 & 33 & 38 & 50 & 39 & 41 \\
\hline & & & & Medio & Medio & Bajo & Medio & Medio & Medio & Medio & Medio & Medio & Medio \\
\hline
\end{tabular}

Figura 53. Matriz Impacto de iniciativas sobre los objetivos - Perspectiva Aprendizaje 
En las siguientes tablas, se muestran la descripción de las iniciativas y su nivel de impacto sobre los objetivos. Este nivel de impacto indicará la prioridad de ejecución de las iniciativas planteadas.

Tabla 56

Descripción de las Iniciativas - Perspectiva Financiera

\begin{tabular}{|c|c|c|c|}
\hline $\mathbf{N}^{\circ}$ & Iniciativa & Descripción de Iniciativa & $\begin{array}{l}\text { Impacto } \\
\text { sobre } \\
\text { objetivos }\end{array}$ \\
\hline 1 & Implementar control presupuestal & $\begin{array}{l}\text { Planificar y controlar el presupuesto anual } \\
\text { por área. }\end{array}$ & Bajo \\
\hline 2 & Implementar política de gastos & $\begin{array}{l}\text { Identificar en los procesos de la empresa } \\
\text { las actividades que no son eficientes y/o no } \\
\text { generan valor, y eliminarlas. }\end{array}$ & Bajo \\
\hline 3 & $\begin{array}{l}\text { Incrementar servicio de maquila para } \\
\text { otros clientes }\end{array}$ & $\begin{array}{l}\text { Desarrollar plan de captación de nuevos } \\
\text { clientes para servicio de maquila. }\end{array}$ & Medio \\
\hline 4 & $\begin{array}{l}\text { Establecer estrategia de precios frente a } \\
\text { variaciones de precios de sustitutos }\end{array}$ & $\begin{array}{l}\text { Determinar estrategias sobre la volatilidad } \\
\text { de precios de productos sustitutos. }\end{array}$ & Medio \\
\hline 5 & $\begin{array}{l}\text { Captar clientes de la competencia a } \\
\text { través de la mejora de la calidad del } \\
\text { producto y del servicio }\end{array}$ & $\begin{array}{l}\text { Desarrollar plan de benchmarking para } \\
\text { analizar a la competencia y establecer } \\
\text { estrategias para la mejora del producto y } \\
\text { servicio. }\end{array}$ & Medio \\
\hline
\end{tabular}




\section{Tabla 57}

Descripción de las Iniciativas - Perspectiva Clientes

\begin{tabular}{|c|c|c|c|}
\hline $\mathbf{N}^{\circ}$ & Iniciativa & Descripción de Iniciativa & $\begin{array}{c}\text { Impacto sobre } \\
\text { objetivos }\end{array}$ \\
\hline 6 & $\begin{array}{l}\text { Establecer estrategias de servicio según } \\
\text { categorización de clientes }\end{array}$ & $\begin{array}{l}\text { Categorizar los clientes y determinar } \\
\text { estrategias de servicio de acuerdo al tipo } \\
\text { de cliente. }\end{array}$ & Bajo \\
\hline 7 & $\begin{array}{l}\text { Implementar asistencia técnica a } \\
\text { clientes } \\
\text { (programa de visitas / asesorías en } \\
\text { nutrición) }\end{array}$ & $\begin{array}{l}\text { Brindar orientación y asesoría técnica a los } \\
\text { clientes a través de especialista en el rubro. }\end{array}$ & Medio \\
\hline 8 & $\begin{array}{l}\text { Implementar políticas comerciales } \\
\text { relacionadas con clientes }\end{array}$ & $\begin{array}{l}\text { Determinar lineamientos y procedimientos } \\
\text { para la gestión de reclamos. }\end{array}$ & Medio \\
\hline 9 & $\begin{array}{l}\text { Elaborar estudio de satisfacción de } \\
\text { clientes }\end{array}$ & $\begin{array}{l}\text { Encuestar a clientes para conocer su nivel } \\
\text { de satisfacción respecto a los servicios y } \\
\text { productos brindados. }\end{array}$ & Bajo \\
\hline 10 & Implementación del indicador NPS & $\begin{array}{l}\text { Desarrollo de la metodología NPS para la } \\
\text { medición de la satisfacción de clientes. }\end{array}$ & Bajo \\
\hline 11 & Implementación del indicador Fill Rate & $\begin{array}{l}\text { Desarrollo de indicador para medir entrega } \\
\text { de pedidos sobre lo solicitado por el } \\
\text { cliente. }\end{array}$ & Bajo \\
\hline 12 & $\begin{array}{l}\text { Participar activamente en congresos y } \\
\text { eventos del sector avícola }\end{array}$ & $\begin{array}{l}\text { Diseñar plan para lograr presencia en las } \\
\text { principales ferias y eventos del país del } \\
\text { sector avícola. }\end{array}$ & Bajo \\
\hline 13 & Desarrollar plan de marketing & $\begin{array}{l}\text { Desarrollar plan de marketing integral. } \\
\text { Definición de canales en donde se dará a }\end{array}$ & Bajo \\
\hline 14 & Desarrollar plan de medios & conocer los productos. & Bajo \\
\hline
\end{tabular}


Tabla 58

Descripción de las Iniciativas - Perspectiva Procesos

\begin{tabular}{|c|c|c|c|}
\hline $\mathbf{N}^{\circ}$ & Iniciativa & Descripción de Iniciativa & $\begin{array}{c}\text { Impacto sobre } \\
\text { objetivos }\end{array}$ \\
\hline 15 & $\begin{array}{l}\text { Desarrollar nuevos productos en la } \\
\text { línea de harinas }\end{array}$ & $\begin{array}{l}\text { Diseñar y producir nueva gama de } \\
\text { productos para la línea de harinas, } \\
\text { ofreciendo mayor variedad a los clientes } \\
\text { según necesidades. }\end{array}$ & Medio \\
\hline 16 & $\begin{array}{l}\text { Desarrollar nuevos productos en la } \\
\text { línea de harina de vísceras y aceite de } \\
\text { pollo }\end{array}$ & $\begin{array}{l}\text { Diseñar y producir nueva línea de aceite de } \\
\text { pollo, utilizando el residuo de la } \\
\text { producción de harina de vísceras. }\end{array}$ & Medio \\
\hline 17 & Implementar de área técnica & $\begin{array}{l}\text { Implementar área de investigación y } \\
\text { desarrollo de nuevos productos, y brindar } \\
\text { soporte técnico post venta. }\end{array}$ & Bajo \\
\hline 18 & $\begin{array}{l}\text { Implementar sistema de mantenimiento } \\
\text { preventivo de maquinaria }\end{array}$ & $\begin{array}{l}\text { Diseñar el flujo del proceso de } \\
\text { mantenimiento preventivo, que permita } \\
\text { controlar y costear el sistema. }\end{array}$ & Bajo \\
\hline 19 & $\begin{array}{l}\text { Implementar proceso de pre secado de } \\
\text { pluma y reducción de humedad }\end{array}$ & $\begin{array}{l}\text { Diseñar sistema para reducir el porcentaje } \\
\text { de humedad en las plumas al momento de } \\
\text { su recojo en las plantas de beneficio, y en } \\
\text { los proveedores de las provincias de la } \\
\text { zona norte. }\end{array}$ & Medio \\
\hline 21 & compras & $\begin{array}{l}\text { Establecer lineamientos relacionados al } \\
\text { control de proveedores y políticas que } \\
\text { optimicen la gestión de compras. }\end{array}$ & Bajo \\
\hline 22 & $\begin{array}{l}\text { Elaborar diagnóstico inicial y } \\
\text { conformar equipo de implementación }\end{array}$ & $\begin{array}{l}\text { Formulación y evaluación de proyecto de } \\
\text { inversión para la adquisición de camiones } \\
\text { propios para recolección y transporte de la } \\
\text { materia prima. }\end{array}$ & Medio \\
\hline 23 & $\begin{array}{l}\text { HACCP } \\
\text { Elaborar diagnóstico inicial y } \\
\text { conformación de equipo de }\end{array}$ & $\begin{array}{l}\text { Medir la situación actual de la empresa y } \\
\text { conformar equipos de trabajo para la } \\
\text { implementación del Sistema HACCP. }\end{array}$ & Bajo \\
\hline 24 & Establecer indicadores de medición & $\begin{array}{l}\text { Medir la situación actual de la empresa y } \\
\text { conformar equipos de trabajo para la } \\
\text { implementación del Sistema de Calidad } \\
\text { ISO. }\end{array}$ & Medio \\
\hline 25 & $\begin{array}{l}\text { Implementar software a medida para } \\
\text { manejo de información }\end{array}$ & $\begin{array}{l}\text { Desarrollar indicadores de gestión como } \\
\text { instrumento de medición para evaluar el } \\
\text { desempeño de las áreas. }\end{array}$ & Medio \\
\hline 26 & $\begin{array}{l}\text { Implementar objetivos por área y } \\
\text { puesto } \\
\text { Captar materia prima de avícolas de la }\end{array}$ & $\begin{array}{l}\text { Desarrollar un software a medida para } \\
\text { control de parámetros de procesos de } \\
\text { producción. }\end{array}$ & Bajo \\
\hline & zona norte & $\begin{array}{l}\text { Establecer objetivos de acuerdo al área y } \\
\text { perfil de puestos. }\end{array}$ & Alto \\
\hline & & $\begin{array}{l}\text { Negociar con los productores que cuentan } \\
\text { con planta de beneficio para compra de } \\
\text { plumas y traslado a Lima. }\end{array}$ & Medio \\
\hline
\end{tabular}




\section{Tabla 59}

Descripción de las Iniciativas - Perspectiva Aprendizaje y Crecimiento

\begin{tabular}{ll}
\hline $\mathbf{N}^{\circ}$ & Iniciativa \\
\hline 28 & $\begin{array}{l}\text { Elaborar manual de organización de la } \\
\text { empresa }\end{array}$
\end{tabular}

Definir organigrama interno de la empresa, perfiles y competencias. Diseñar un MOF en

Impacto

sobre

objetivos

29 Elaborar plan de implementación de nueva estructura base al análisis de las áreas, puestos,

objetivos y funciones.

Elaborar manual de organización de la
empresa

Detallar las actividades, recursos y plazos necesarios para el éxito de la implementación y despliegue de la nueva estructura organizacional.

Medio

Establecer bandas salariales que incluyan un sistema de compensación monetario.

Valorización de puestos.

Bajo

Crear equipos de trabajos funcionales o multifuncionales que lideren y fomenten la mejora continua de los procesos.

Medio

Elaborar encuesta de Clima Laboral y plan de actividades para su realización.

Presentación de resultados a director.

Medio

Realizar planes de acción y medición para mejorar el clima laboral enfocado en lograr un mejor desempeño.

Medio

Diseñar sistema de evaluación que permita evaluar al trabajador en base a cumplimiento de metas, así como al desarrollo de sus competencias.

Medio

Definir las competencias y los niveles requeridos para cada puesto de la organización. Documentarlo y desplegarlo al interior de la compañía.

Medio

Definir las políticas y procedimientos de reclutamientos y selección de personal.

Medio

Elaborar plan de inducción para nuevos trabajadores que comprenda inducción a la empresa y al puesto. 


\subsection{Responsable de cada una de las iniciativas}

Las iniciativas son proyectos de duración acotada que no se incluyen dentro del trabajo rutinario de la compañía. Estos proyectos están diseñados para ayudar a lograr el desempeño propuesto en la estrategia. (Issotools, 2015)

Tabla 60

Responsable de las Iniciativas - Perspectiva Financiera

\begin{tabular}{cclc}
\hline Perspectiva & $\mathbf{N}^{\circ}$ & \multicolumn{1}{c}{ Iniciativa } & Responsable \\
\hline & 1 & Implementar control presupuestal & Director \\
& 2 & Implementar política de gastos & Director \\
FINANCIERA & 3 & $\begin{array}{l}\text { Incrementar servicio de maquila para otros } \\
\text { clientes }\end{array}$ & Director \\
& 4 & $\begin{array}{l}\text { Establecer estrategia de precios frente a } \\
\text { variaciones de precios de sustitutos } \\
\text { Captar clientes de la competencia a través de }\end{array}$ & Director \\
& 5 & $\begin{array}{l}\text { la mejora de la calidad del producto y del } \\
\text { servicio }\end{array}$ & Director \\
\hline
\end{tabular}


Tabla 61

Responsable de las Iniciativas - Perspectiva Clientes

\begin{tabular}{|c|c|c|c|}
\hline Perspectiva & $\mathbf{N}^{\circ}$ & Iniciativa & Responsable \\
\hline \multirow{10}{*}{ CLIENTE } & 6 & $\begin{array}{l}\text { Establecer estrategias de servicio según } \\
\text { categorización de clientes }\end{array}$ & Gerente de Administración y \\
\hline & 7 & $\begin{array}{l}\text { Implementar asistencia técnica a } \\
\text { clientes } \\
\text { (programa de visitas / asesorías en } \\
\text { nutrición) }\end{array}$ & $\begin{array}{c}\text { Gerente de Administración y } \\
\text { Finanzas }\end{array}$ \\
\hline & 8 & $\begin{array}{l}\text { Implementar políticas comerciales } \\
\text { relacionadas con clientes }\end{array}$ & $\begin{array}{c}\text { Gerente de Administración y } \\
\text { Finanzas }\end{array}$ \\
\hline & 9 & $\begin{array}{l}\text { Elaborar estudio de satisfacción de } \\
\text { clientes }\end{array}$ & $\begin{array}{c}\text { Gerente de Administración y } \\
\text { Finanzas }\end{array}$ \\
\hline & & Implementación del indicador NPS & Gerente de Administración y \\
\hline & 10 & & Finanzas \\
\hline & 11 & Implementación del indicador Fill Rate & $\begin{array}{c}\text { Gerente de Administración y } \\
\text { Finanzas }\end{array}$ \\
\hline & 12 & $\begin{array}{l}\text { Participar activamente en congresos y } \\
\text { eventos del sector avícola }\end{array}$ & $\begin{array}{c}\text { Gerente de Administración y } \\
\text { Finanzas }\end{array}$ \\
\hline & 13 & Desarrollar plan de marketing & $\begin{array}{c}\text { Gerente de Administración y } \\
\text { Finanzas }\end{array}$ \\
\hline & 14 & Desarrollar plan de medios & $\begin{array}{c}\text { Gerente de Administración y } \\
\text { Finanzas }\end{array}$ \\
\hline
\end{tabular}


Tabla 62

Responsable de las Iniciativas - Perspectiva Procesos

\begin{tabular}{|c|c|c|c|}
\hline Perspectiva & $\mathbf{N}^{\circ}$ & Iniciativa & Responsable \\
\hline \multirow{14}{*}{ PROCESOS } & 15 & $\begin{array}{l}\text { Desarrollar nuevos productos en la línea } \\
\text { de harinas }\end{array}$ & Jefe de producción y \\
\hline & 16 & $\begin{array}{l}\text { Desarrollar nuevos productos en la línea } \\
\text { de harina de vísceras y aceite de pollo }\end{array}$ & $\begin{array}{l}\text { Jefe de producción y } \\
\text { mantenimiento }\end{array}$ \\
\hline & 17 & Implementar de área técnica & $\begin{array}{l}\text { Jefe de producción y } \\
\text { mantenimiento }\end{array}$ \\
\hline & 18 & $\begin{array}{l}\text { Implementar sistema de mantenimiento } \\
\text { preventivo de maquinaria }\end{array}$ & Jefe de producción y \\
\hline & 19 & $\begin{array}{l}\text { Implementar proceso de pre secado de } \\
\text { pluma y reducción de humedad }\end{array}$ & \multirow[b]{2}{*}{ Director } \\
\hline & 20 & $\begin{array}{l}\text { Implementar políticas para la gestión de } \\
\text { compras }\end{array}$ & \\
\hline & 21 & $\begin{array}{l}\text { Integración vertical con proveedores de } \\
\text { materia prima }\end{array}$ & Director \\
\hline & \multirow[t]{2}{*}{22} & $\begin{array}{l}\text { Elaborar diagnóstico inicial y conformar } \\
\text { equipo de implementación HACCP }\end{array}$ & Director \\
\hline & & Elaborar diagnóstico inicial y & Director \\
\hline & 23 & $\begin{array}{l}\text { conformación de equipo de } \\
\text { implementación ISO }\end{array}$ & Director \\
\hline & 24 & Establecer indicadores de medición & Director \\
\hline & 25 & $\begin{array}{l}\text { Implementar software a medida para } \\
\text { manejo de información }\end{array}$ & Director \\
\hline & 26 & Implementar objetivos por área y puesto & Director \\
\hline & 27 & $\begin{array}{l}\text { Captar materia prima de avícolas de la } \\
\text { zona norte }\end{array}$ & Director \\
\hline
\end{tabular}


Tabla 63

Responsable de las Iniciativas - Perspectiva Aprendizaje y Crecimiento

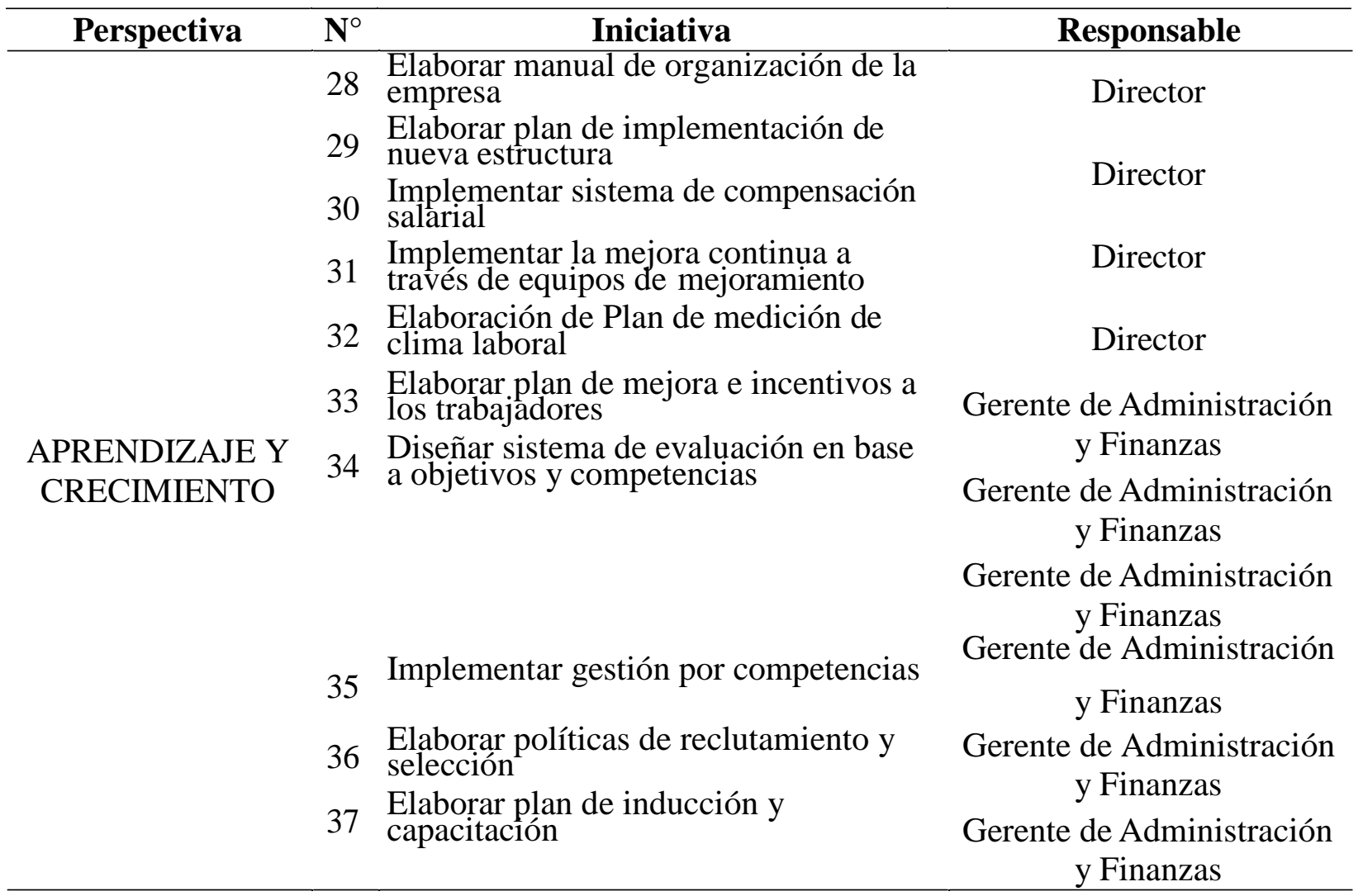

\subsection{Presupuesto de cada una de las iniciativas}

Las iniciativas son proyectos de duración acotada que no se incluyen dentro del trabajo rutinario de la compañía. Estos proyectos están diseñados para ayudar a lograr el desempeño propuesto en la estrategia. (Issotools, 2015)

Las iniciativas planteadas para Los Ferroles se han clasificado según el enfoque en que contribuyen al cumplimiento de los objetivos estratégicos, en tal sentido se tienen 3 grandes grupos:

- Enfoque incremento de ingresos.

- Enfoque optimización de costos y gastos.

- Enfoque fortalecimiento institucional. 
Estos enfoques se presupuestaron de acuerdo a las iniciativas y recursos asociados, para los siguientes tres años de estudio.

Tabla 64

Enfoque de Incremento de Ingresos

\begin{tabular}{|c|c|c|c|c|c|}
\hline Enfoque & $\begin{array}{l}\mathbf{N}^{\circ} \text { de Iniciativa } \\
\text { Asociada }\end{array}$ & Recursos necesarios & $\begin{array}{c}2018 \\
\text { S/ }\end{array}$ & $\begin{array}{c}2019 \\
\text { S/ }\end{array}$ & $\begin{array}{c}2020 \\
\mathrm{~S} /\end{array}$ \\
\hline & $\begin{array}{c}4,6,8,9,10,11,13 \\
14\end{array}$ & $\begin{array}{l}\text { Contratación de consultora para monitoreo de la } \\
\text { implementación de las iniciativas comerciales y } \\
\text { financieras }\end{array}$ & 30,000 & & \\
\hline & 12,14 & $\begin{array}{l}\text { Alquiler de stands en ferias y congresos avícolas } \\
\text { (2) }\end{array}$ & 10,000 & 10,000 & 10,000 \\
\hline & 12,14 & Participación en Seminarios Avícolas & 4,000 & 4,000 & 4,000 \\
\hline & $\begin{array}{c}3,4,5,6,7,8,9,10,1 \\
1,12,13,14\end{array}$ & Contratación de Jefe de Marketing & 80,000 & 80,000 & 80,000 \\
\hline & 12 & Material Publicitario & 5,000 & 5,000 & 5,000 \\
\hline \multirow[t]{7}{*}{$\begin{array}{l}\text { INCREMENTO } \\
\text { DE INGRESOS }\end{array}$} & 12 & Brochures & 5,000 & 5,000 & 5,000 \\
\hline & 14 & Desarrollo página web y redes sociales & 10,000 & & \\
\hline & 14 & Revista técnica & 5,000 & 5,000 & 5,000 \\
\hline & $7,15,16,17$ & Contratación de Ingeniero de desarrollo & 80,000 & 80,000 & 80,000 \\
\hline & $15,16,17$ & Análisis y pruebas de investigación & 25,000 & 25,000 & 25,000 \\
\hline & 10,11 & $\begin{array}{l}\text { Contratación de proveedor para desarrollo de } \\
\text { indicadores comerciales }\end{array}$ & 5,000 & & \\
\hline & & Totales & 259,000 & 14,0002 & 4,000 \\
\hline
\end{tabular}




\section{Tabla 65}

Enfoque de Optimización de Costos y Gastos

\begin{tabular}{|c|c|c|c|c|c|}
\hline Enfoque & $\begin{array}{c}\mathbf{N}^{\circ} \text { de Iniciativa } \\
\text { Asociada }\end{array}$ & Recursos necesarios & $\begin{array}{c}2018 \\
\text { S/ }\end{array}$ & $\begin{array}{c}2019 \\
\mathrm{~S} /\end{array}$ & $\begin{array}{c}2020 \\
\mathrm{~S} /\end{array}$ \\
\hline \multirow{8}{*}{$\begin{array}{c}\text { OPTIMIZACIÓN } \\
\text { DE COSTOS Y } \\
\text { GASTOS }\end{array}$} & $2,18,20,22,24$ & $\begin{array}{l}\text { Contratación de consultora para } \\
\text { monitoreo de la implementación } \\
\text { de las iniciativas de operaciones }\end{array}$ & 30,000 & & \\
\hline & 21 & $\begin{array}{l}\text { Adquisición de camiones para } \\
\text { acopio de materia prima ( } 3 \text { ) }\end{array}$ & 400,000 & & \\
\hline & 21 & Mantenimiento de vehículos (3) & 30,000 & 30,000 & 30,000 \\
\hline & $\angle 1$ & $\begin{array}{c}\text { Contratación de choferes y viáticos } \\
\text { (3) }\end{array}$ & 65,000 & 65,000 & 65,000 \\
\hline & 18 & $\begin{array}{l}\text { Adquisición de software para } \\
\text { mantenimiento preventivo }\end{array}$ & 10,000 & & \\
\hline & 24,25 & $\begin{array}{l}\text { Adquisición de software para } \\
\text { control estadístico de procesos }\end{array}$ & 10,000 & & \\
\hline & 19 & $\begin{array}{l}\text { Instalación de sistema para pre } \\
\text { secado de plumas y reducción de } \\
\text { humedad }\end{array}$ & 150,000 & 75,000 & \\
\hline & \multicolumn{2}{|c|}{ Totales } & 695,000 & 170,000 & 95,000 \\
\hline
\end{tabular}

Tabla 66

Enfoque de Fortalecimiento Institucional

\begin{tabular}{|c|c|c|c|c|c|}
\hline Enfoque & $\mathbf{N}^{\circ}$ de Iniciativa Asociada & Recursos necesarios & $\begin{array}{l}2018 \\
\text { S/ }\end{array}$ & $\begin{array}{l}2019 \\
\text { S/ }\end{array}$ & $\begin{array}{l}2020 \\
\mathrm{~S} /\end{array}$ \\
\hline \multirow{3}{*}{$\begin{array}{l}\text { Fortalecimient } \\
\text { Institucional }\end{array}$} & $\begin{array}{c}23,26,28,29,30,31,32,33,34 \\
35.36,37\end{array}$ & $\begin{array}{l}\text { Contratación de consultora para } \\
\text { monitoreo de la implementación } \\
\text { de las iniciativas de gestión } \\
\text { humana y de calidad }\end{array}$ & 30,000 & & \\
\hline & 23,37 & Talleres de capacitación (4) & 12,000 & 12,000 & 12,000 \\
\hline & $\begin{array}{c}26,28,29,30,32,33,34,35,36 \\
37\end{array}$ & $\begin{array}{l}\text { Contratación Jefe de Gestión } \\
\text { Humana }\end{array}$ & 80,000 & 80,000 & 80,000 \\
\hline \multicolumn{3}{|c|}{ Totales } & 122,000 & 92,000 & 92,000 \\
\hline
\end{tabular}




\subsection{Cronograma de cada una de las iniciativas}

De acuerdo a la priorización realizada a las iniciativas, se planteó el siguiente cronograma de trabajo para los siguientes tres años; donde se consideró para el primer año las estrategias seleccionadas, y del segundo año en adelante, las estrategias contingentes.

El cronograma detalla las actividades mes a mes y los respectivos responsables de la ejecución. 
Tabla 67

Cronograma Perspectiva Financiera 2018

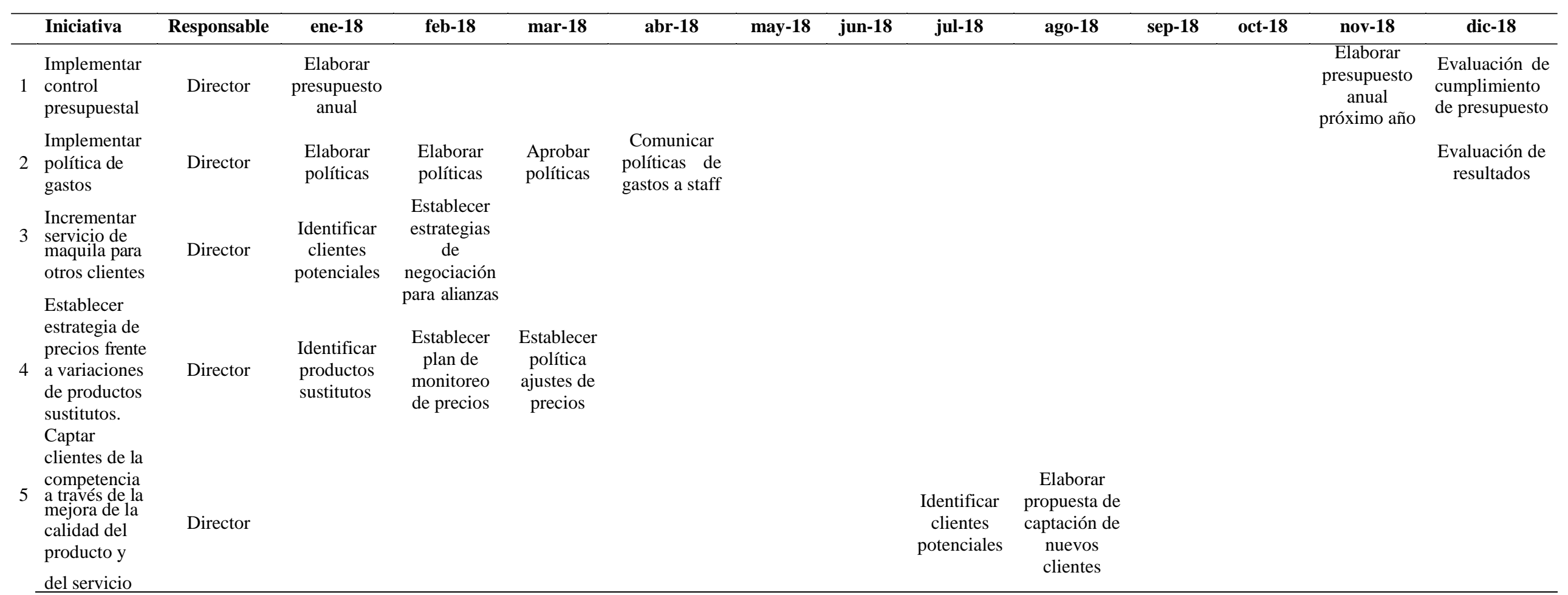




\section{Tabla 68}

Cronograma Perspectiva Cliente 2018

\begin{tabular}{|c|c|c|c|c|c|c|c|c|c|c|c|c|c|c|}
\hline & Iniciativa & Responsable & ene-18 & feb-18 & mar-18 & abr-18 & may-18 & jun-18 & jul-18 & ago-18 & sep-18 & oct-18 & nov-18 & dic-18 \\
\hline 6 & $\begin{array}{l}\text { Establecer estrategias de } \\
\text { servicio según categorización de }\end{array}$ & $\begin{array}{c}\text { Gerente de } \\
\text { Administración }\end{array}$ & & & & $\begin{array}{l}\text { Categorizac } \\
\text { ión de }\end{array}$ & $\begin{array}{l}\text { Definición } \\
\text { de }\end{array}$ & & & & & & & \\
\hline 7 & $\begin{array}{l}\text { Implementar asistencia técnica a } \\
\text { clientes } \\
\text { (programa de visitas / asesorías } \\
\text { en nutrición) }\end{array}$ & $\begin{array}{l}\text { Gerente de } \\
\text { Administración } \\
\text { y Finanzas }\end{array}$ & & & & CHCTILs & & $\begin{array}{l}\text { Definir } \\
\text { Plan de } \\
\text { asistencia } \\
\text { técnica }\end{array}$ & & & & & & \\
\hline 8 & $\begin{array}{l}\text { Implementar politicas } \\
\text { comerciales relacionadas con } \\
\text { clientes. }\end{array}$ & $\begin{array}{l}\text { Gerente de } \\
\text { Administración } \\
\text { y Finanzas }\end{array}$ & & & & & & $\begin{array}{l}\text { Elaborar } \\
\text { políticas }\end{array}$ & $\begin{array}{l}\text { Elaborar } \\
\text { políticas }\end{array}$ & $\begin{array}{l}\text { Aprobar } \\
\text { políticas }\end{array}$ & $\begin{array}{l}\text { Difundir } \\
\text { políticas }\end{array}$ & & & \\
\hline 10 & $\begin{array}{l}\text { Elaborar estudio de satisfacción } \\
\text { de clientes } \\
\text { Implementación del indicador } \\
\text { NPS }\end{array}$ & $\begin{array}{l}\text { Gerente de } \\
\text { Administración } \\
\text { y Finanzas } \\
\text { Gerente de } \\
\text { Administración }\end{array}$ & & $\begin{array}{l}\text { Diseñar } \\
\text { encuesta }\end{array}$ & $\begin{array}{l}\text { Realizar } \\
\text { entrevistas } \\
\text { a clientes }\end{array}$ & $\begin{array}{l}\text { Evaluación } \\
\text { de } \\
\text { resultados }\end{array}$ & & & & & & & & \\
\hline 11 & $\begin{array}{l}\text { Implementación del indicador } \\
\text { Fill Rate }\end{array}$ & $\begin{array}{l}\text { y Finanzas } \\
\text { Gerente de }\end{array}$ & & & & & & & & & & & & \\
\hline 12 & $\begin{array}{l}\text { Participar activamente en } \\
\text { congresos y eventos del sector } \\
\text { avícola. }\end{array}$ & $\begin{array}{l}\text { Administración } \\
\text { y Finanzas } \\
\text { Gerente de } \\
\text { Administración } \\
\text { y Finanzas }\end{array}$ & & & & & & & & & & & & \\
\hline 13 & Desarrollar plan de marketing & $\begin{array}{l}\text { Gerente de } \\
\text { Administración } \\
\text { y Finanzas } \\
\text { Gerente de }\end{array}$ & & & & & & & & & & & & \\
\hline 14 & Desarrollar plan de medios & $\begin{array}{l}\text { Administración } \\
\text { y Finanzas }\end{array}$ & & & & & & & & & & & & \\
\hline
\end{tabular}


Tabla 69

Cronograma Perspectiva Procesos 2018

\begin{tabular}{|c|c|c|c|c|c|c|c|c|c|c|c|c|c|c|}
\hline & Iniciativa & Responsable & ene-18 & feb-18 & mar-18 & abr-18 & may-18 & jun-18 & jul-18 & $\begin{array}{c}\text { ago- } \\
18 \\
\end{array}$ & sep-18 & oct-18 & nov-18 & dic-18 \\
\hline 15 & $\begin{array}{l}\text { Desarrollar nuevos } \\
\text { productos en línea de } \\
\text { harinas de plumas }\end{array}$ & $\begin{array}{c}\text { Jefe de } \\
\text { producción y } \\
\text { mantenimiento }\end{array}$ & & & & $\begin{array}{l}\text { Elaboración de } \\
\text { Prototipo }\end{array}$ & Pruebas & Pruebas & $\begin{array}{l}\text { Lanzamiento de } \\
\text { producto }\end{array}$ & & & & & \\
\hline 16 & $\begin{array}{l}\text { Desarrollar nuevos } \\
\text { productos en la línea } \\
\text { de harina de vísceras y } \\
\text { aceites de pollo }\end{array}$ & $\begin{array}{l}\text { Jefe de } \\
\text { producción y } \\
\text { mantenimiento }\end{array}$ & & & & & & & & & & & & \\
\hline 17 & $\begin{array}{l}\text { Implementación de } \\
\text { área técnica }\end{array}$ & $\begin{array}{c}\text { Jefe de } \\
\text { producción y } \\
\text { mantenimiento }\end{array}$ & & $\begin{array}{l}\text { Contratar } \\
\text { Ingeniero de } \\
\text { desarrollo }\end{array}$ & $\begin{array}{l}\text { Elaborar plan de } \\
\text { trabajo y } \\
\text { objetivos }\end{array}$ & & & & & & & & & \\
\hline 18 & $\begin{array}{l}\text { Implementar sistema } \\
\text { de mantenimiento } \\
\text { preventivo de } \\
\text { maquinaria }\end{array}$ & $\begin{array}{c}\text { Jefe de } \\
\text { producción y } \\
\text { mantenimiento }\end{array}$ & $\begin{array}{l}\text { Diseño de } \\
\text { proceso de } \\
\text { mantenimiento } \\
\text { preventivo }\end{array}$ & $\begin{array}{l}\text { Diseño de } \\
\text { reportes }\end{array}$ & $\begin{array}{c}\text { Sistematización } \\
\text { del } \\
\text { mantenimiento } \\
\text { preventivo }\end{array}$ & & & & & & & & & \\
\hline 19 & $\begin{array}{l}\text { Implementar proceso } \\
\text { de pre secado de pluma } \\
\text { y reducción de } \\
\text { humedad }\end{array}$ & Director & & & & Estudio técnico & $\begin{array}{l}\text { Implementación y } \\
\text { puesta en marcha ( } \\
\text { Lima, Ica) }\end{array}$ & & & & & & & \\
\hline 20 & $\begin{array}{l}\text { Implementar políticas } \\
\text { para la gestión de } \\
\text { compras. }\end{array}$ & Director & & & & $\begin{array}{l}\text { Evaluar sistema de } \\
\text { compras actual }\end{array}$ & $\begin{array}{l}\text { Establecer políticas de } \\
\text { gestión compras }\end{array}$ & $\begin{array}{l}\text { Implementar } \\
\text { sistema de } \\
\text { gestión de } \\
\text { compras }\end{array}$ & & & & & & \\
\hline 21 & $\begin{array}{l}\text { Integración vertical } \\
\text { con proveedores de } \\
\text { materia prima }\end{array}$ & Director & $\begin{array}{l}\text { Reconocimiento } \\
\text { de proveedores } \\
\text { de materia prima }\end{array}$ & $\begin{array}{l}\text { Establecer } \\
\text { estrategias de } \\
\text { negociación } \\
\text { para alianzas }\end{array}$ & $\begin{array}{l}\text { Adquisición de } \\
\text { flota }\end{array}$ & & & & & & & & & \\
\hline 22 & $\begin{array}{l}\text { Elaborar diagnóstico } \\
\text { inicial y conformar } \\
\text { equipo de } \\
\text { implementación } \\
\text { HACCP }\end{array}$ & Director & $\begin{array}{c}\text { Diagnóstico } \\
\text { inicial }\end{array}$ & $\begin{array}{l}\text { Conformación } \\
\text { de equipo } \\
\text { HACCP }\end{array}$ & $\begin{array}{l}\text { Implementación } \\
\text { del sistema }\end{array}$ & $\begin{array}{l}\text { Implementación } \\
\text { del sistema }\end{array}$ & $\begin{array}{l}\text { Implementación del } \\
\text { sistema }\end{array}$ & $\begin{array}{l}\text { Implementación } \\
\text { del sistema }\end{array}$ & & & & & & \\
\hline 23 & $\begin{array}{l}\text { Elaborar diagnóstico } \\
\text { inicial y conformación } \\
\text { de equipo de } \\
\text { implementación ISO }\end{array}$ & Director & $\begin{array}{l}\text { Diagnóstico } \\
\text { inicial }\end{array}$ & $\begin{array}{l}\text { Conformación } \\
\text { de equipo ISO }\end{array}$ & $\begin{array}{l}\text { Implementación } \\
\text { del sistema }\end{array}$ & $\begin{array}{l}\text { Implementación } \\
\text { del sistema }\end{array}$ & $\begin{array}{l}\text { Implementación del } \\
\text { sistema }\end{array}$ & $\begin{array}{l}\text { Implementación } \\
\text { del sistema }\end{array}$ & & & & & & \\
\hline 24 & $\begin{array}{l}\text { Establecer indicadores } \\
\text { de medición } \\
\text { Implementar software }\end{array}$ & Director & & & & & & & & & & & & \\
\hline 25 & $\begin{array}{l}\text { a medida para manejo } \\
\text { de información }\end{array}$ & Director & & & & & & & & & & & & \\
\hline 26 & $\begin{array}{l}\text { Implementar objetivos } \\
\text { por área y puesto }\end{array}$ & Director & & $\begin{array}{l}\text { Alineación de } \\
\text { los obj. } \\
\text { estratégicos de } \\
\text { la empresa con } \\
\text { las áreas }\end{array}$ & $\begin{array}{l}\text { Asignar los } \\
\text { objetivos a las } \\
\text { Jefaturas }\end{array}$ & & & & & & & & & $\begin{array}{l}\text { Medición } \\
\text { de } \\
\text { objetivos }\end{array}$ \\
\hline 27 & $\begin{array}{l}\text { Captar materia prima } \\
\text { de avícolas de la zona } \\
\text { norte }\end{array}$ & Director & & & & & & & & & & & & \\
\hline
\end{tabular}


Tabla 70

Cronograma Perspectiva Aprendizaje y Crecimiento 2018

\begin{tabular}{|c|c|c|c|c|c|c|c|c|c|c|c|c|c|c|}
\hline & Iniciativa & Responsable & ene-18 & feb-18 & mar-18 & abr-18 & may-18 & jun-18 & jul-18 & ago-18 & sep-18 & oct-18 & nov-18 & dic-18 \\
\hline 28 & $\begin{array}{l}\text { Elaborar manual de } \\
\text { organización de la } \\
\text { empresa. }\end{array}$ & Director & & & $\begin{array}{l}\text { Realizar diagnóstico } \\
\text { inicial de la empresa }\end{array}$ & $\begin{array}{c}\text { Definir estructura } \\
\text { organizacional }\end{array}$ & $\begin{array}{c}\text { Definir perfiles } \\
\text { de puestos }\end{array}$ & $\begin{array}{c}\text { Documentar } \\
\text { estructura }\end{array}$ & & & & & & \\
\hline 29 & $\begin{array}{l}\text { Elaborar plan de } \\
\text { implementación de } \\
\text { nueva estructura }\end{array}$ & Director & $\begin{array}{l}\text { Contratar } \\
\text { Jefe de } \\
\text { RRHH }\end{array}$ & $\begin{array}{c}\text { Elaborar plan } \\
\text { de trabajo y } \\
\text { objetivos }\end{array}$ & & & $\begin{array}{l}\text { Contratar } \\
\text { personal } \\
\text { requerido }\end{array}$ & & & & & & & \\
\hline 30 & $\begin{array}{l}\text { Implementar } \\
\text { sistema de } \\
\text { compensación } \\
\text { salarial }\end{array}$ & Director & & & & & & & & & & & & \\
\hline 31 & $\begin{array}{l}\text { Implementar la } \\
\text { mejora continua a } \\
\text { través de equipos de } \\
\text { mejoramiento. }\end{array}$ & Director & & $\begin{array}{l}\text { Conformar } \\
\text { comité de } \\
\text { calidad }\end{array}$ & $\begin{array}{l}\text { Capacitación y } \\
\text { sensibilización de la } \\
\text { cultura de calidad }\end{array}$ & $\begin{array}{l}\text { Conformación de } \\
\text { equipos de } \\
\text { mejoramiento }\end{array}$ & & & & & & & & $\begin{array}{l}\text { Evaluación } \\
\text { de } \\
\text { resultados }\end{array}$ \\
\hline 32 & $\begin{array}{l}\text { Elaboración de Plan } \\
\text { de medición de } \\
\text { clima laboral }\end{array}$ & $\begin{array}{c}\text { Gerente de } \\
\text { Administración y } \\
\text { Finanzas }\end{array}$ & & & & & & & & & & & & \\
\hline 33 & $\begin{array}{l}\text { Elaborar plan de } \\
\text { mejora e incentivos } \\
\text { a los trabajadores }\end{array}$ & $\begin{array}{c}\text { Gerente de } \\
\text { Administración y } \\
\text { Finanzas }\end{array}$ & & & & & & & & & & & & \\
\hline 34 & $\begin{array}{l}\text { Diseñar sistema de } \\
\text { evaluación en base } \\
\text { a objetivos y } \\
\text { competencias }\end{array}$ & $\begin{array}{c}\text { Gerente de } \\
\text { Administración y } \\
\text { Finanzas }\end{array}$ & $\begin{array}{c}\text { Determinar } \\
\text { indicadores } \\
\text { de } \\
\text { desempeño }\end{array}$ & $\begin{array}{l}\text { Establecer } \\
\text { método de } \\
\text { evaluación }\end{array}$ & & & & & & & & & & \\
\hline 35 & $\begin{array}{l}\text { Implementar } \\
\text { gestión por } \\
\text { competencias }\end{array}$ & $\begin{array}{c}\text { Gerente de } \\
\text { Administración y } \\
\text { Finanzas }\end{array}$ & & & & & & & & & & & & \\
\hline \multirow[t]{2}{*}{36} & $\begin{array}{l}\text { Elaborar políticas } \\
\text { de reclutamiento y } \\
\text { selección }\end{array}$ & $\begin{array}{c}\text { Gerente de } \\
\text { Administración y } \\
\text { Finanzas }\end{array}$ & $\begin{array}{c}\text { Definir } \\
\text { políticas }\end{array}$ & $\begin{array}{l}\text { Aprobar } \\
\text { políticas }\end{array}$ & Desplegar políticas & & & & & & & & & \\
\hline & $\begin{array}{l}\text { Elaborar plan de } \\
\text { inducción y } \\
\text { capacitación }\end{array}$ & $\begin{array}{c}\text { Gerente de } \\
\text { Administración y } \\
\text { Finanzas }\end{array}$ & & $\begin{array}{l}\text { Identificación } \\
\text { de Necesidades }\end{array}$ & $\begin{array}{l}\text { Elaboración de Plan } \\
\text { Anual de } \\
\text { Capacitación }\end{array}$ & & & & & & & & & \\
\hline
\end{tabular}


Tabla 71

Cronograma Perspectiva Financiera 2019

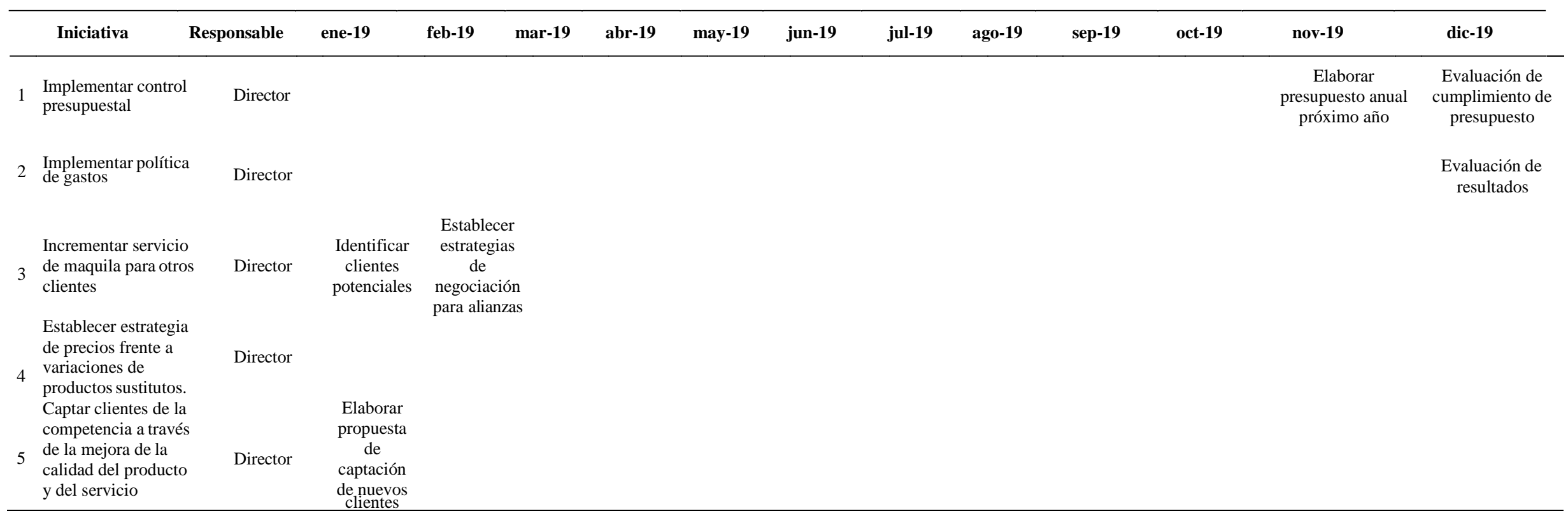


Tabla 72

Cronograma Perspectiva Cliente 2019

\begin{tabular}{|c|c|c|c|c|c|c|c|c|c|c|c|c|c|c|}
\hline & Iniciativa & Responsable & ene-19 & feb-19 & mar-19 & abr-19 & may-19 & jun-19 & jul-19 & ago-19 & sep-19 & oct-19 & nov-19 & dic-19 \\
\hline 6 & $\begin{array}{l}\text { Establecer estrategias de } \\
\text { servicio según } \\
\text { categorización de clientes }\end{array}$ & $\begin{array}{c}\text { Gerente de } \\
\text { Administración } \\
\text { y Finanzas }\end{array}$ & & & & & & & & & & & & \\
\hline 7 & $\begin{array}{l}\text { Implementar asistencia } \\
\text { técnica a clientes } \\
\text { (programa de visitas / } \\
\text { asesorías en nutrición) }\end{array}$ & $\begin{array}{c}\text { Gerente de } \\
\text { Administración } \\
\text { y Finanzas }\end{array}$ & & & & & & & & & & & & \\
\hline 8 & $\begin{array}{l}\text { Implementar políticas } \\
\text { comerciales relacionadas } \\
\text { con clientes. }\end{array}$ & $\begin{array}{c}\text { Gerente de } \\
\text { Administración } \\
\text { y Finanzas }\end{array}$ & & & & & & & & & & & & \\
\hline 9 & $\begin{array}{l}\text { Elaborar estudio de } \\
\text { satisfacción de clientes }\end{array}$ & $\begin{array}{c}\text { Gerente de } \\
\text { Administración } \\
\text { y Finanzas }\end{array}$ & & & & & & & & & & & & \\
\hline 10 & $\begin{array}{l}\text { Implementación del } \\
\text { indicador NPS }\end{array}$ & $\begin{array}{c}\text { Gerente de } \\
\text { Administración } \\
\text { y Finanzas }\end{array}$ & & $\begin{array}{l}\text { Elaboración } \\
\text { de encuesta }\end{array}$ & $\begin{array}{l}\text { Medición de } \\
\text { indicador }\end{array}$ & & & & & & & & & \\
\hline 11 & $\begin{array}{l}\text { Implementación del } \\
\text { indicador Fill Rate }\end{array}$ & $\begin{array}{c}\text { Gerente de } \\
\text { Administración } \\
\text { y Finanzas }\end{array}$ & & $\begin{array}{l}\text { Definir } \\
\text { variables de } \\
\text { proceso de } \\
\text { entrega de }\end{array}$ & $\begin{array}{l}\text { Alineamiento } \\
\text { de procesos }\end{array}$ & & $\begin{array}{l}\text { Medición de } \\
\text { indicador }\end{array}$ & & & & & & & \\
\hline 12 & $\begin{array}{l}\text { Participar activamente en } \\
\text { congresos y eventos del } \\
\text { sector avícola. }\end{array}$ & $\begin{array}{c}\text { Gerente de } \\
\text { Administración } \\
\text { y Finanzas }\end{array}$ & $\begin{array}{l}\text { Cronograma } \\
\text { de } \\
\text { participación } \\
\text { en eventos }\end{array}$ & pedidos & & & & & & & & & & \\
\hline 13 & marke & $\begin{array}{c}\text { Gerente de } \\
\text { Administración } \\
\text { y Finanzas }\end{array}$ & $\begin{array}{l}\text { Definición de } \\
\text { objetivos y } \\
\text { estrategias }\end{array}$ & $\begin{array}{l}\text { Establecer } \\
\text { presupuesto }\end{array}$ & & & & & & & & & & \\
\hline 14 & Desarrollar plan de medios & $\begin{array}{l}\text { Gerente de } \\
\text { Administración } \\
\text { y Finanzas }\end{array}$ & & & $\begin{array}{c}\text { Evaluación y } \\
\text { definición de } \\
\text { medios a } \\
\text { utilizar }\end{array}$ & $\begin{array}{l}\text { Establecer } \\
\text { presupuesto }\end{array}$ & & & & & & & & \\
\hline
\end{tabular}


Tabla 73

Cronograma Perspectiva Procesos 2019

\begin{tabular}{|c|c|c|c|c|c|c|c|c|c|c|c|c|c|c|}
\hline & Iniciativa & Responsable & ene-19 & feb-19 & mar-19 & abr-19 & may-19 & jun-19 & jul-19 & ago-19 & sep-19 & oct-19 & nov-19 & dic-19 \\
\hline 15 & $\begin{array}{l}\text { Desarrollar nuevos } \\
\text { productos en línea de } \\
\text { harinas de plumas }\end{array}$ & $\begin{array}{l}\text { Jefe de producción y } \\
\text { mantenimiento }\end{array}$ & $\begin{array}{l}\text { Elaboración de } \\
\text { Prototipo }\end{array}$ & Pruebas & Pruebas & $\begin{array}{l}\text { Lanzamiento } \\
\text { de producto }\end{array}$ & & & & & & & & \\
\hline 16 & $\begin{array}{l}\text { Desarrollar nuevos } \\
\text { productos en la línea de } \\
\text { harina de vísceras y aceites } \\
\text { de pollo }\end{array}$ & $\begin{array}{l}\text { Jefe de producción y } \\
\text { mantenimiento }\end{array}$ & $\begin{array}{l}\text { Elaboración de } \\
\text { Prototipo }\end{array}$ & Pruebas & Pruebas & $\begin{array}{l}\text { Lanzamiento } \\
\text { de producto }\end{array}$ & & & & & & & & \\
\hline 17 & $\begin{array}{l}\text { Implementación de área } \\
\text { técnica } \\
\text { Implementar sistema de }\end{array}$ & $\begin{array}{l}\text { Jefe de producción y } \\
\text { mantenimiento }\end{array}$ & & & & & & & & & & & & \\
\hline 18 & $\begin{array}{l}\text { mantenimiento preventivo } \\
\text { de maquinaria }\end{array}$ & $\begin{array}{l}\text { Jefe de producción y } \\
\text { mantenimiento }\end{array}$ & & & & & & & & & & & & \\
\hline 19 & $\begin{array}{l}\text { Implementar proceso de } \\
\text { pre secado de pluma y } \\
\text { reducción de humedad }\end{array}$ & Director & & & & $\begin{array}{l}\text { Estudio } \\
\text { técnico }\end{array}$ & $\begin{array}{l}\text { Implementación } \\
\text { y puesta en } \\
\text { marcha } \\
\text { (Provincia } \\
\text { Norte) }\end{array}$ & & & & & & & \\
\hline 20 & $\begin{array}{l}\text { Implementar políicicas para } \\
\text { la gestión de compras. } \\
\text { Integración vertical con }\end{array}$ & Director & & & & & & & & & & & & \\
\hline 21 & $\begin{array}{l}\text { proveedores de materia } \\
\text { prima }\end{array}$ & Director & & & & & & & & & & & & \\
\hline 22 & $\begin{array}{l}\text { Elaborar diagnóstico } \\
\text { inicial y yonformar equipo } \\
\text { de implementación } \\
\text { HACCP } \\
\text { Elaborar diagnóstico }\end{array}$ & Director & & $\begin{array}{l}\text { Auditoria } \\
\text { externa y } \\
\text { certificación }\end{array}$ & & & & & & & & & & \\
\hline 23 & $\begin{array}{l}\text { inicial y conformación de } \\
\text { equipo de implementación } \\
\text { ISO }\end{array}$ & Director & & $\begin{array}{l}\text { Auditoria } \\
\text { externa y } \\
\text { certificación }\end{array}$ & & & & & & & & & & \\
\hline 24 & $\begin{array}{l}\text { Establecer indicadores de } \\
\text { medición } \\
\text { Implementar software a } \\
\text { medida para maneio de }\end{array}$ & Director & & & & & & $\begin{array}{l}\text { Establecer } \\
\quad \text { los } \\
\text { indicadores } \\
\text { de gestión }\end{array}$ & $\begin{array}{l}\text { Establecer } \\
\text { parámetros de } \\
\text { control }\end{array}$ & & & & & \\
\hline 25 & $\begin{array}{l}\text { información } \\
\text { Implementar objetivos por }\end{array}$ & Director & & & & & & & & & $\begin{array}{l}\text { Diseño de la } \\
\text { herramienta } \\
\text { a medida }\end{array}$ & $\begin{array}{l}\text { Piloto de la } \\
\text { herramienta }\end{array}$ & $\begin{array}{c}\text { Pase a } \\
\text { producción } \\
\text { del Sistema }\end{array}$ & \\
\hline 26 & área y puesto & Director & & & & & & & & & & & & $\begin{array}{l}\text { Medición } \\
\text { de } \\
\text { objetivos }\end{array}$ \\
\hline 27 & $\begin{array}{l}\text { Captar materia prima de } \\
\text { avícolas de la zona norte }\end{array}$ & Director & $\begin{array}{l}\text { Negociación } \\
\text { con avícolas de } \\
\text { zona norte }\end{array}$ & $\begin{array}{l}\text { Negociación } \\
\text { con avícolas de } \\
\text { zona norte }\end{array}$ & $\begin{array}{c}\text { Acopio de } \\
\text { materia prima }\end{array}$ & & & & & & & & & \\
\hline
\end{tabular}


Tabla 74

Cronograma Perspectiva Aprendizaje y Crecimiento 2019

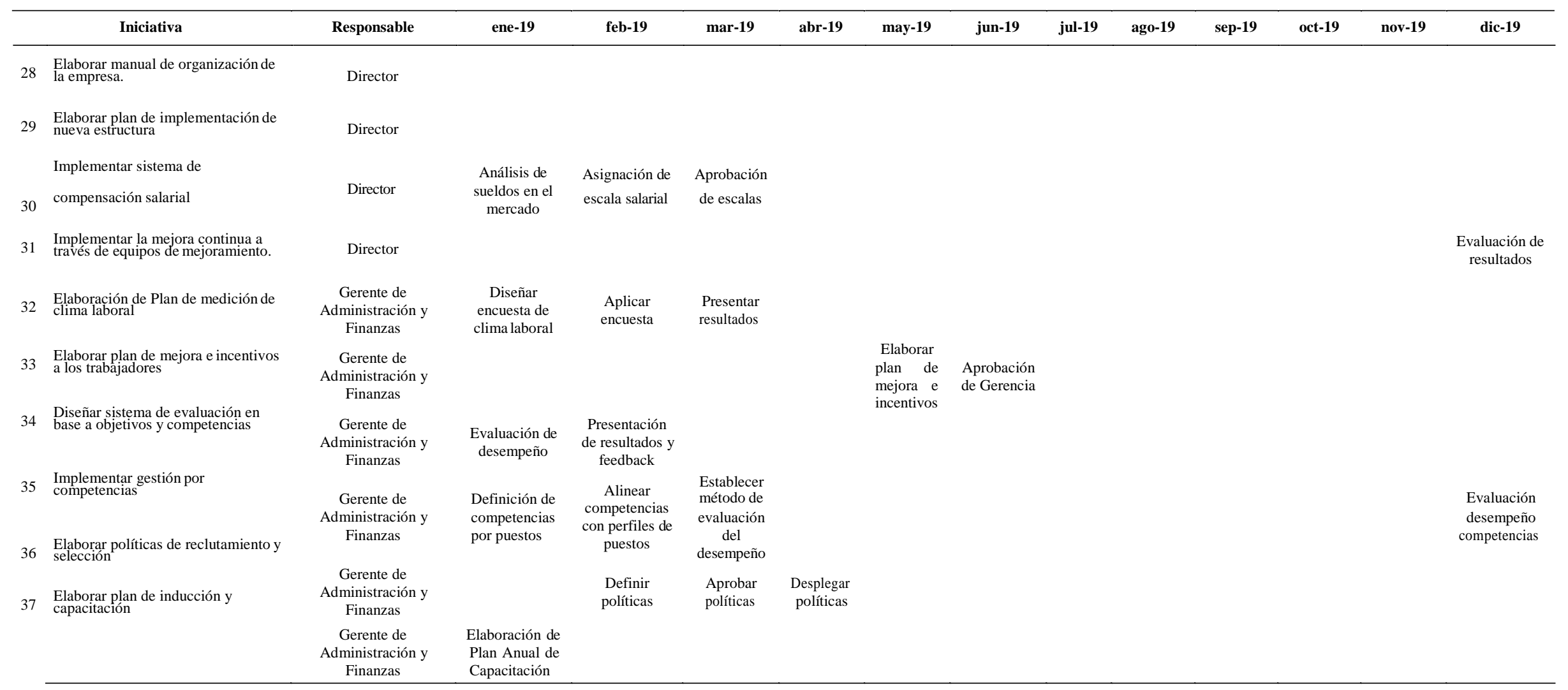


Tabla 75

Cronograma Perspectiva Financiera 2020

\begin{tabular}{|c|c|c|c|c|c|c|c|c|c|c|c|c|c|c|}
\hline & Iniciativa & Responsable & ene-20 & feb-20 & mar-20 & abr-20 & may-20 & jun-20 & jul-20 & ago-20 & sep-20 & oct-20 & nov-20 & dic-20 \\
\hline 1 & $\begin{array}{l}\text { Implementar control } \\
\text { presupuestal }\end{array}$ & Director & & & & & & & & & & & $\begin{array}{c}\text { Elaborar } \\
\text { presupuesto } \\
\text { anual próximo } \\
\text { año }\end{array}$ & $\begin{array}{l}\text { Evaluación de } \\
\text { cumplimiento } \\
\text { de presupuesto }\end{array}$ \\
\hline 2 & $\begin{array}{l}\text { Implementar política de } \\
\text { gastos }\end{array}$ & Director & & & & & & & & & & & & $\begin{array}{l}\text { Evaluación de } \\
\text { resultados }\end{array}$ \\
\hline 3 & $\begin{array}{l}\text { Incrementar servicio de } \\
\text { maquila para otros clientes }\end{array}$ & Director & $\begin{array}{l}\text { Identificar } \\
\text { clientes } \\
\text { potenciales }\end{array}$ & $\begin{array}{c}\text { Establecer } \\
\text { estrategias } \\
\text { de } \\
\text { negociación } \\
\text { para } \\
\text { alianzas }\end{array}$ & & & & & & & & & & \\
\hline 4 & $\begin{array}{l}\text { Establecer estrategia de } \\
\text { precios frente a variaciones } \\
\text { de productos sustitutos. }\end{array}$ & Director & & & & & & & & & & & & \\
\hline 5 & $\begin{array}{l}\text { Captar clientes de la } \\
\text { competencia a través de la } \\
\text { mejora de la calidad del } \\
\text { producto y del servicio }\end{array}$ & Director & $\begin{array}{c}\text { Elaborar } \\
\text { propuesta } \\
\text { de } \\
\text { captación } \\
\text { de nuevos } \\
\text { clientes }\end{array}$ & & & & & & & & & & & \\
\hline
\end{tabular}


Tabla 76

Cronograma Perspectiva Cliente 2020

\begin{tabular}{|c|c|c|c|c|c|c|c|c|c|c|c|c|c|c|}
\hline & Iniciativa & Responsable & ene-20 & feb-20 & mar-20 & abr-20 & may-20 & jun-20 & jul-20 & ago-20 & sep-20 & oct-20 & nov-20 & dic-20 \\
\hline 6 & $\begin{array}{l}\text { Establecer estrategias de servicio según } \\
\text { categorización de clientes }\end{array}$ & $\begin{array}{c}\text { Gerente de } \\
\text { Administración y } \\
\text { Finanzas }\end{array}$ & & & & & & & & & & & & \\
\hline 7 & $\begin{array}{l}\text { Implementar asistencia técnica a clientes } \\
\text { (programa de visitas / asesorías en nutrición) }\end{array}$ & $\begin{array}{c}\text { Gerente de } \\
\text { Administración y } \\
\text { Finanzas }\end{array}$ & & & & & & & & & & & & \\
\hline 8 & $\begin{array}{l}\text { Implementar políticas comerciales relacionadas } \\
\text { con clientes. }\end{array}$ & $\begin{array}{c}\text { Gerente de } \\
\text { Administración y } \\
\text { Finanzas }\end{array}$ & & & & & & & & & & & & \\
\hline 9 & Elaborar estudio de satisfacción de clientes & $\begin{array}{c}\text { Gerente de } \\
\text { Administración y } \\
\text { Finanzas }\end{array}$ & & & & & & & & & & & & \\
\hline 10 & Implementación del indicador NPS & $\begin{array}{c}\text { Gerente de } \\
\text { Administración y } \\
\text { Finanzas }\end{array}$ & & & & & & & & & & & & \\
\hline 11 & Implementación del indicador Fill Rate & $\begin{array}{c}\text { Gerente de } \\
\text { Administración y } \\
\text { Finanzas }\end{array}$ & & & & & & & & & & & & \\
\hline 12 & $\begin{array}{l}\text { Participar activamente en congresos y eventos } \\
\text { del sector avícola. }\end{array}$ & $\begin{array}{c}\text { Gerente de } \\
\text { Administración y } \\
\text { Finanzas }\end{array}$ & $\begin{array}{c}\text { Cronograma } \\
\text { de } \\
\text { participación } \\
\text { en eventos }\end{array}$ & & & & & & & & & & & \\
\hline 13 & Desarrollar plan de marketing & $\begin{array}{c}\text { Gerente de } \\
\text { Administración y } \\
\text { Finanzas }\end{array}$ & $\begin{array}{l}\text { Actualización } \\
\text { de Plan de } \\
\text { Marketing }\end{array}$ & & & & & & & & & & & \\
\hline 14 & Desarrollar plan de medios & $\begin{array}{c}\text { Gerente de } \\
\text { Administración y } \\
\text { Finanzas }\end{array}$ & $\begin{array}{l}\text { Actualización } \\
\text { de Plan de } \\
\text { Medios }\end{array}$ & & & & & & & & & & & \\
\hline
\end{tabular}


Tabla 77

Cronograma Perspectiva Procesos 2020

\begin{tabular}{|c|c|c|c|c|c|c|c|c|c|c|c|c|c|c|}
\hline & Iniciativa & Responsable & ene-20 & feb-20 & mar-20 & abr-20 & may-20 & jun-20 & jul-20 & ago-20 & sep-20 & oct-20 & nov-20 & dic-20 \\
\hline 15 & $\begin{array}{l}\text { Desarrollar nuevos productos en } \\
\text { linea de harinas de plumas }\end{array}$ & $\begin{array}{c}\text { Jefe de } \\
\text { producción y } \\
\text { mantenimiento }\end{array}$ & $\begin{array}{l}\text { Elaboración } \\
\text { de Prototipo }\end{array}$ & Pruebas & Pruebas & $\begin{array}{l}\text { Lanzamiento } \\
\text { de producto }\end{array}$ & & & & & & & & \\
\hline 16 & $\begin{array}{l}\text { Desarrollar nuevos productos en la } \\
\text { línea de harina de vísceras y aceites } \\
\text { de pollo }\end{array}$ & $\begin{array}{l}\text { mantenimiento } \\
\text { Jefe de } \\
\text { producción y } \\
\text { mantenimiento }\end{array}$ & $\begin{array}{l}\text { Elaboración } \\
\text { de Prototipo }\end{array}$ & Pruebas & Pruebas & $\begin{array}{l}\text { Lanzamiento } \\
\text { de producto }\end{array}$ & & & & & & & & \\
\hline 17 & Implementación de área técnica & $\begin{array}{l}\text { Jefe de } \\
\text { producción y } \\
\text { mantenimiento }\end{array}$ & & & & & & & & & & & & \\
\hline 18 & $\begin{array}{l}\text { Implementar sistema de } \\
\text { mantenimiento preventivo de } \\
\text { maquinaria }\end{array}$ & $\begin{array}{c}\text { Jefe de } \\
\text { producción y } \\
\text { mantenimiento }\end{array}$ & & & & & & & & & & & & \\
\hline 19 & $\begin{array}{l}\text { Implementar proceso de pre secado } \\
\text { de pluma y reducción de humedad }\end{array}$ & Director & & & & & & & & & & & & \\
\hline 20 & $\begin{array}{l}\text { Implementar políticas para la } \\
\text { gestión de compras. }\end{array}$ & Director & & & & & & & & & & & & \\
\hline 21 & $\begin{array}{l}\text { Integración vertical con proveedores } \\
\text { de materia prima }\end{array}$ & & & & & & & & & & & & & \\
\hline & Elaborar diagnóstico inicial y & Director & & & & & & & & & & & & \\
\hline 22 & $\begin{array}{l}\text { conformar equipo de } \\
\text { implementación HACCP }\end{array}$ & Director & & & & & & & & & & & & \\
\hline 23 & $\begin{array}{l}\text { Elaborar diagnóstico inicial y } \\
\text { conformación de equipo de } \\
\text { implementación ISO }\end{array}$ & Director & & & & & & & & & & & & \\
\hline 24 & Establecer indicadores de medición & Director & $\begin{array}{l}\text { Establecer } \\
\text { los } \\
\text { indicadores } \\
\text { de gestión }\end{array}$ & $\begin{array}{l}\text { Establecer } \\
\text { parámetros } \\
\text { de control }\end{array}$ & & & & & & & & & & \\
\hline 25 & $\begin{array}{l}\text { Implementar software a medida para } \\
\text { manejo de información }\end{array}$ & Director & & & & $\begin{array}{l}\text { Diseño de la } \\
\text { herramienta a } \\
\text { medida }\end{array}$ & $\begin{array}{l}\text { Piloto de la } \\
\text { herramienta }\end{array}$ & $\begin{array}{c}\text { Pase a } \\
\text { producción del } \\
\text { Sistema }\end{array}$ & & & & & & \\
\hline 26 & $\begin{array}{l}\text { Implementar objetivos por área y } \\
\text { puesto }\end{array}$ & Director & & & & & & & & & & & & $\begin{array}{l}\text { Medición } \\
\text { de } \\
\text { objetivos }\end{array}$ \\
\hline 27 & $\begin{array}{l}\text { Captar materia prima de avícolas de } \\
\text { la zona norte }\end{array}$ & Director & & & & & & & & & & & & \\
\hline
\end{tabular}


Tabla 78

Cronograma Perspectiva Aprendizaje y Crecimiento 2020

\begin{tabular}{|c|c|c|c|c|c|c|c|c|c|c|c|c|c|c|}
\hline & Iniciativa & Responsable & ene-20 & feb-20 & mar-20 & abr-20 & may-20 & jun-20 & jul-20 & ago-20 & sep-20 & oct-20 & nov-20 & dic-20 \\
\hline 28 & $\begin{array}{l}\text { Elaborar manual de } \\
\text { organización de la } \\
\text { empresa. }\end{array}$ & Director & & & & & & & & & & & & \\
\hline 29 & $\begin{array}{l}\text { Elaborar plan de } \\
\text { implementación de nueva } \\
\text { estructura }\end{array}$ & Director & & & & & & & & & & & & \\
\hline 30 & $\begin{array}{l}\text { Implementar sistema de } \\
\text { compensación salarial }\end{array}$ & Director & & & & & & & & & & & & \\
\hline 31 & $\begin{array}{l}\text { Implementar la mejora } \\
\text { continua a través de } \\
\text { equipos de mejoramiento. }\end{array}$ & Director & & & & & & & & & & & & $\begin{array}{l}\text { Evaluación } \\
\quad \text { de } \\
\text { resultados }\end{array}$ \\
\hline 32 & $\begin{array}{l}\text { Elaboración de Plan de } \\
\text { medición de clima laboral }\end{array}$ & $\begin{array}{c}\text { Gerente de } \\
\text { Administración } \\
\text { y Finanzas }\end{array}$ & & $\begin{array}{l}\text { Aplicar } \\
\text { encuesta }\end{array}$ & $\begin{array}{l}\text { Presentar } \\
\text { resultados }\end{array}$ & & & & & & & & & \\
\hline 33 & $\begin{array}{l}\text { Elaborar plan de mejora e } \\
\text { incentivos a los } \\
\text { trabajadores }\end{array}$ & $\begin{array}{l}\text { Gerente de } \\
\text { Administración } \\
\text { y Finanzas }\end{array}$ & & & & & & & & & & & & \\
\hline 34 & $\begin{array}{l}\text { Diseñar sistema de } \\
\text { evaluación en base a } \\
\text { objetivos y competencias }\end{array}$ & $\begin{array}{l}\text { Gerente de } \\
\text { Administración } \\
\text { y Finanzas }\end{array}$ & $\begin{array}{l}\text { Evaluación } \\
\text { de } \\
\text { desempeño }\end{array}$ & $\begin{array}{l}\text { Presentación } \\
\text { de } \\
\text { resultados y } \\
\text { feedback }\end{array}$ & & & & & & & & & & \\
\hline 35 & $\begin{array}{l}\text { Implementar gestión por } \\
\text { competencias }\end{array}$ & $\begin{array}{l}\text { Gerente de } \\
\text { Administración } \\
\text { y Finanzas }\end{array}$ & $\begin{array}{l}\text { Presentación } \\
\text { de } \\
\text { resultados y } \\
\text { feedback }\end{array}$ & & & & & & & & & & & \\
\hline 36 & $\begin{array}{l}\text { Elaborar políticas de } \\
\text { reclutamiento y selección }\end{array}$ & $\begin{array}{l}\text { Gerente de } \\
\text { Administración } \\
\text { y Finanzas }\end{array}$ & & & & & & & & & & & & \\
\hline 37 & $\begin{array}{l}\text { Elaborar plan de inducción } \\
\text { y capacitación }\end{array}$ & $\begin{array}{l}\text { Gerente de } \\
\text { Administración } \\
\text { y Finanzas }\end{array}$ & $\begin{array}{l}\text { Elaboración } \\
\text { de Plan } \\
\text { Anual de } \\
\text { Capacitación }\end{array}$ & & & & & & & & & & & \\
\hline
\end{tabular}




\section{Capítulo X. Evaluación}

\subsection{Evaluación Cualitativa}

Durante el desarrollo de los anteriores capítulos, se han analizado datos y elaborado matrices con el fin de cuantificar, comparar y priorizar estrategias. Adicional a este análisis, también se han trabajado técnicas cualitativas como entrevistas con los diferentes grupos de interés, y observación de los procesos productivos y administrativos. Tanto la información cuantitativa como la cualitativa, ha permitido realizar la selección de las estrategias que más se alinean a la misión y visión de la empresa para el desarrollo del plan estratégico.

\subsubsection{Criterios de Evaluación}

Como criterios de evaluación se ha considerado la Matriz de Intereses Organizacionales (MIO). Los intereses organizacionales son fines que se intentan alcanzar para tener éxito en la industria y en los mercados donde compite la empresa; son fines supremos basados en la organización en marcha y para el largo plazo. Esta matriz prioriza la intensidad de los intereses de la organización clasificándolos como:

1. Vitales: si los intereses son relevantes para la organización, y el hecho de no alcanzarlos genera daños peligrosos.

2. Importantes: si los intereses se ven afectados adversamente.

3. Periféricos: si los intereses generan consecuencias marginales no importantes. 
Para el caso de Los Ferroles, se han considerado las estrategias seleccionadas como los intereses organizacionales a evaluar, los cuales se clasificarán según el interés que la empresa tiene sobre cada una de ellas. Para analizar a profundidad la relevancia de las estrategias, se ha considerado el impacto de los cuatro Principios Cardinales Organizacionales, los cuales se describen a continuación:

- Influencia de terceras partes: Ninguna interacción es únicamente bilateral, siempre hay terceras o más partes que evalúan la conveniencia de los acuerdos, o evitan que se concreten.

- Lazos pasados-presentes: Se analiza cómo han rivalizado históricamente los competidores y si esta competencia ha sido leal o desleal.

- Contra balance de intereses: Evalúa los intereses de los competidores para decidir si éstos afectarán los planes de la organización.

- Conservación de los enemigos (competidores): Contar con un número adecuado de competidores es prudente porque obliga a estar preparado para enfrentarlos por lo que hace más productiva y competitiva a la organización. (D’Alessio, 2015). 


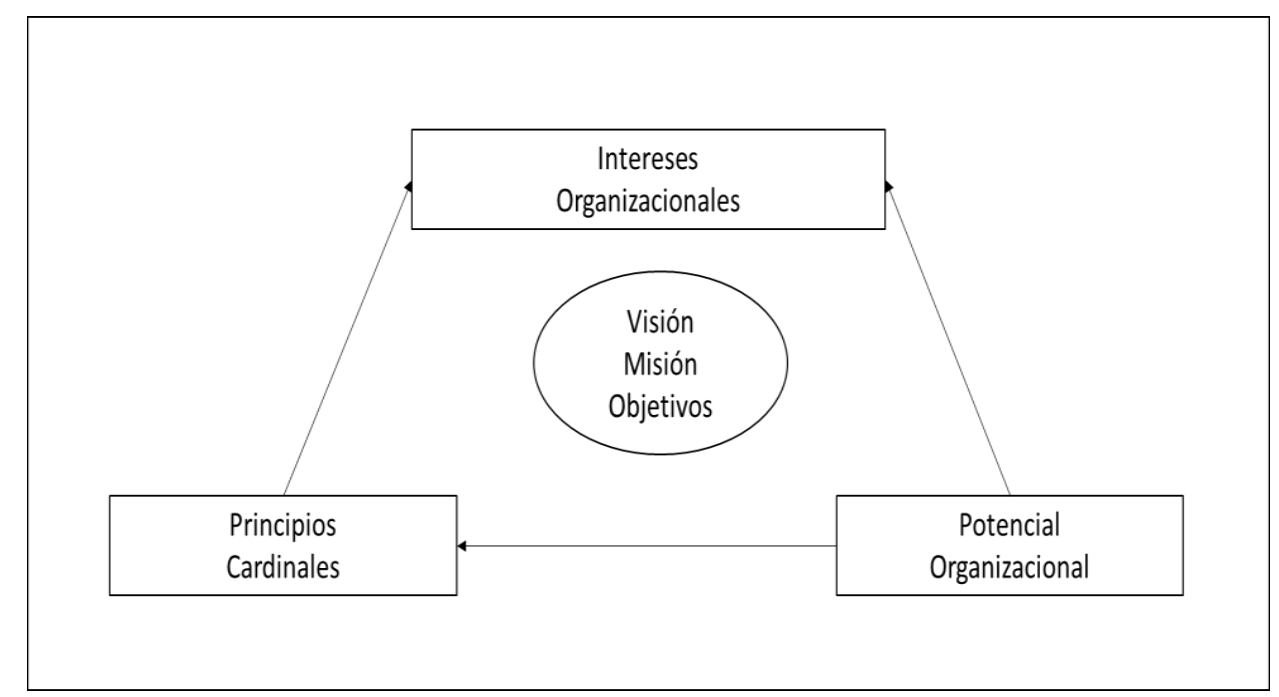

Figura 54. Teoría tridimensional de la relación entre organizaciones. Adaptado de "The relations of nations" (p. 154), D’Alessio, 2015, por F. H. Hartmann, 1957/1983. 6th ed., New York, NY: Macmillan.

Estos Principios Cardinales Organizacionales, permiten reconocer las oportunidades y amenazas del entorno y determinar cuáles son las estrategias más adecuadas para la organización. Este análisis facilitará la priorización de los intereses de la empresa.

\subsubsection{Comparación de la estrategia con los criterios}

En la siguiente tabla se muestra la Matriz de Intereses Organizacionales y su relación con las estrategias seleccionadas, donde se determinan que estrategias son vitales, importantes y periféricas. 
Tabla 79

Matriz de Intereses Organizacionales: Estrategias Seleccionadas

\begin{tabular}{|c|c|c|c|}
\hline \multirow{2}{*}{ Interés organizacional: Estrategias Seleccionadas } & \multicolumn{3}{|c|}{ Intensidad del Interés } \\
\hline & Vital & Importante & Periférico \\
\hline Captación de materia prima de mercados de provincia de zona norte & $\mathrm{X}$ & & \\
\hline Desarrollo de nuevos productos especializados y alto valor agregado & $\mathrm{X}$ & & \\
\hline Generar alianzas con proveedores de materias primas para incrementar el servicio de maquila & $\mathrm{X}$ & & \\
\hline Integración vertical con proveedores que acopien materia prima & & $\mathrm{X}$ & \\
\hline Implementar gestión comercial y de marketing a través de medios digitales & & $\mathrm{X}$ & \\
\hline Reestructuración organizacional en toda la compañía & $\mathrm{X}$ & & \\
\hline Establecimiento de estrategias y objetivos para proyección de crecimiento a MP y LP & $\mathrm{X}$ & & \\
\hline Búsqueda de clientes en empresas medianas & & $\mathrm{X}$ & \\
\hline Certificar sistema de gestión de calidad y de inocuidad & & $\mathrm{X}$ & \\
\hline Alineamiento de los procesos de acuerdo a normativa legal vigente & & $\mathrm{X}$ & \\
\hline Desarrollar rendering para el rubro pecuario, acuícola y alimento para mascotas. & & & $\mathrm{X}$ \\
\hline Incrementar participación de mercado a través de política de precios & & $\mathrm{X}$ & \\
\hline
\end{tabular}

Gerencia, p. 217 


\subsection{Evaluación Financiera de la Estrategia}

Por medio de la evaluación de los estados financieros, es posible analizar: (a) el desempeño de años anteriores, (b) la condición actual del negocio, (c) predecir el potencial futuro de la empresa y (d) proporcionar indicios sobre la forma en la que la empresa responderá a los desafíos económicos que se le presenten.

El proceso de los análisis de los estados financieros contempla:

1. Conocer a la empresa: Es básico el conocimiento de la empresa en los aspectos organizacionales, económicos, financieros, de marketing, de producción y de capital humano.

2. Comprender los estados financieros: Cada empresa tiene particularidades en sus estados financieros que corresponden a la industria en que se desarrolla, como son las normativas, partidas contables, y la valorización de los activos.

3. Análisis del Balance General y Estado de Resultados: Basado en las técnicas del análisis horizontal y vertical, así como el análisis de los ratios financieros.

4. Análisis del Estado de Flujo de Efectivo: Análisis de la toma de decisiones financieras que realiza la empresa sobre su efectivo, siendo su función principal predecir el potencial flujo de efectivos futuros. (Stickney, Weil, Schipper, Francis y Avolio, 2013) 


\subsubsection{Proyección de los estados financieros (situación actual y con la nueva} estrategia)

Para proyectar los estados financieros tanto en la situación actual como con la implementación de las nuevas estrategias, se toma como base la tendencia histórica del crecimiento de las ventas de Los Ferroles, en un escenario donde se mantienen las mismas condiciones de operación.

\section{Proyección de los estados financieros - Situación actual}

Los Ferroles ha mostrado históricamente un crecimiento acelerado entre los años 2012 y 2014, periodo en el que ingresa a su cartera de clientes la empresa San Fernando, bajo el modelo de maquila. En el año 2014, entra en funcionamiento su segunda planta de procesamiento de harina de plumas, con la que maximiza la producción.

A partir del año 2015, el crecimiento de la venta registra una marcada desaceleración mostrando incrementos de aproximadamente $7 \%$ en comparación con años previos. Dada la coyuntura económica actual, para la proyección de la venta del período 2018 - 2020, se ha considerado el porcentaje de crecimiento del año 2017 que fue de $6 \%$.

En la tabla 80 se muestra el crecimiento histórico y las proyecciones de volúmenes, precios y venta total para el período 2015 - 2020; y en la tabla 81 los supuestos considerados para las proyecciones financieras bajo la situación actual. 
Tabla $\mathrm{N}^{\circ} 80$

Proyección de volumen y precio - Situación actual

\begin{tabular}{lrrrrrr}
\hline & \multicolumn{1}{c}{2015} & \multicolumn{1}{c}{2016} & \multicolumn{1}{c}{2017} & \multicolumn{1}{c}{2018} & \multicolumn{1}{c}{2019} & \multicolumn{1}{c}{2020} \\
\hline Volumen (TM) & $15,504.00$ & $16,507.34$ & $17,080.39$ & $17,673.33$ & $18,286.90$ & $18,921.74$ \\
Precio S/ & $1,551.39$ & $1,559.09$ & $1,597.19$ & $1,636.22$ & $1,676.20$ & $1,717.16$ \\
Total Venta S/ & $24,052,743$ & $25,736,435$ & $27,280,621$ & $28,917,458$ & $30,652,506$ & $32,491,656$ \\
Incr Venta Aa (\%) & & $7.0 \%$ & $6.0 \%$ & $6.0 \%$ & $6.0 \%$ & $6.0 \%$ \\
\hline
\end{tabular}

Nota. $A a=$ respecto al año anterior

Tabla 81

Supuestos para la proyección de Estados financieros - Situación actual

\begin{tabular}{lc}
\hline \multicolumn{1}{c}{ SUPUESTOS } & $\%$ \\
\hline Tasa de crecimiento anual de las ventas & $6.0 \%$ \\
Costo de Ventas & $87.2 \%$ \\
Gastos de Ventas & $1.5 \%$ \\
Gastos Administrativos & $3.9 \%$ \\
Otros ingresos de gestión & $0.1 \%$ \\
Gastos financieros & $2.7 \%$ \\
Tasa de interés financiamiento a Largo Plazo & $8.9 \%$ \\
Impuesto a la Renta & $29.5 \%$ \\
\hline
\end{tabular}

\section{Proyección de los estados financieros - Con estrategia}

Para la proyección de la venta del período 2018 - 2020, considerando la implementación de las estrategias propuestas, se ha definido un porcentaje de crecimiento gradual de la venta de $7 \%, 8.5 \%$ y $10 \%$ respectivamente.

En la tabla 82 se muestra el crecimiento histórico y las proyecciones de costo de ventas y venta total para el período 2015 - 2020; y en la tabla 83 los 
supuestos considerados para las proyecciones financieras con la estrategia propuesta.

Tabla 82

Proyección de volumen y precio - con la nueva estrategia.

\begin{tabular}{lrrrrrr}
\hline & \multicolumn{1}{c}{2015} & \multicolumn{1}{c}{2016} & \multicolumn{1}{c}{2017} & \multicolumn{1}{c}{2018} & \multicolumn{1}{c}{2019} & \multicolumn{1}{c}{2020} \\
\hline Volumen (TM) & $15,504.00$ & $16,507.34$ & $17,080.39$ & $19,885.23$ & $22,271.45$ & $24,944.03$ \\
Precio S/ & $1,551.39$ & $1,559.09$ & $1,597.19$ & $1,636.27$ & $1,676.30$ & $1,717.31$ \\
Total Venta S/ & $24,052,743$ & $25,736,435$ & $27,280,621$ & $29,190,265$ & $31,671,437$ & $34,838,581$ \\
Incr. Venta (\%) & & $7.0 \%$ & $6.0 \%$ & $7.0 \%$ & $8.5 \%$ & $10.0 \%$ \\
\hline
\end{tabular}

Tabla 83

Supuestos para la proyección de Estados financieros, con la nueva estrategia.

\begin{tabular}{|c|c|c|c|c|}
\hline & & 2018 & 2019 & 2020 \\
\hline Tasa de crecimiento anual de las ventas & & $7.00 \%$ & $8.50 \%$ & $10.00 \%$ \\
\hline Costo de ventas & & $-86.70 \%$ & $-86.00 \%$ & $-85.00 \%$ \\
\hline Gastos de ventas & $1.8 \%$ & & & \\
\hline Gastos administrativos & $4.0 \%$ & & & \\
\hline Otros ingresos de gestión & $0.1 \%$ & & & \\
\hline Tasa de interés financiamiento a & & & & \\
\hline largo plazo & $8.9 \%$ & & & \\
\hline Impuesto a la renta & $29.5 \%$ & & & \\
\hline
\end{tabular}

10.2.2 Estado de resultados (situación actual y con la nueva estrategia)

Situación actual.

Para proyectar los Estados de Resultados sin estrategias, se toma como base la tendencia histórica del crecimiento de ventas de los Ferroles, manteniendo los porcentajes actuales de costo de venta, gastos administrativos y gastos de venta. Respecto a la proyección de las obligaciones financieras 
2018- 2020, se ha considerado una TEA del $8.9 \%$ sobre el monto de la deuda a largo plazo. En la siguiente tabla 84 se proyectan los Estados de Resultados para los próximos tres años.

Tabla 84

Proyección de los Estados de Resultados, sin estrategia

ESTADO DE RESULTADOS SIN ESTRATEGIA

\begin{tabular}{lrrrr}
\hline ESTADO DE RESULTADOS (En soles) & ANO DADL & & PROYECTADO & \\
& $\mathbf{2 0 1 7}$ & $\mathbf{2 0 1 8}$ & \multicolumn{1}{c}{$\mathbf{2 0 1 9}$} & \multicolumn{1}{c}{$\mathbf{2 0 2 0}$} \\
\hline Ventas netas & $\mathbf{2 7 , 2 8 0 , 6 2 2}$ & $\mathbf{2 8 , 9 1 7 , 4 5 9}$ & $\mathbf{3 0 , 6 5 2 , 5 0 6}$ & $\mathbf{3 2 , 4 9 1 , 6 5 7}$ \\
Costo de ventas & $(23,778,953)$ & $(25,205,691)$ & $(26,718,032)$ & $(28,321,114)$ \\
Utilidad Bruta & $\mathbf{3 , 5 0 1 , 6 6 8}$ & $\mathbf{3 , 7 1 1 , 7 6 8}$ & $\mathbf{3 , 9 3 4 , 4 7 4}$ & $\mathbf{4 , 1 7 0 , 5 4 3}$ \\
Gastos de ventas & $(407,037)$ & $(431,459)$ & $(457,347)$ & $(484,787)$ \\
Gastos de administración & $(1,051,702)$ & $(1,114,805)$ & $(1,181,693)$ & $(1,252,594)$ \\
Ganancia (Pérdida) por actividades de & $\mathbf{2 , 0 4 2 , 9 2 9}$ & $\mathbf{2 , 1 6 5 , 5 0 5}$ & $\mathbf{2 , 2 9 5 , 4 3 5}$ & $\mathbf{2 , 4 3 3 , 1 6 1}$ \\
operación & & & & $(815,096)$ \\
Gastos financieros & $(725,432)$ & $(768,958)$ & $(864,002)$ \\
Otros Ingresos de Gestion & 31,859 & 33,771 & 35,797 & 37,945 \\
Resultado antes de Impuesto a las & $\mathbf{1 , 3 4 9 , 3 5 6}$ & $\mathbf{1 , 4 3 0 , 3 1 7}$ & $\mathbf{1 , 5 1 6 , 1 3 6}$ & $\mathbf{1 , 6 0 7 , 1 0 4}$ \\
Ganancias & $(398,060)$ & $(421,943)$ & $(447,260)$ & $(474,096)$ \\
Impuesto a la Renta & $\mathbf{9 5 1 , 2 9 6}$ & $\mathbf{1 , 0 0 8 , 3 7 3}$ & $\mathbf{1 , 0 6 8 , 8 7 6}$ & $\mathbf{1 , 1 3 3 , 0 0 8}$ \\
\hline Ganancia (Pérdida) Neta del Ejercicio/ & & & & \\
\hline
\end{tabular}

\section{Situación con la nueva estrategia}

En este escenario se proyectan los Estados de Resultados considerando las iniciativas propuestas, las mismas que significan realizar inversiones en intangibles y activos fijos, así como la reducción en el costo de producción; con la finalidad de generar un impacto positivo en los ingresos y la rentabilidad de la empresa. 
En la siguiente tabla 85 se describen las inversiones requeridas para activos fijos e intangibles, así mismo se detalla su valorización, vida útil, depreciación y valor en libros al tercer año de la ejecución del proyecto. 


\section{Tabla 85}

Costos de operación y de inversión con la nueva estrategia.

\begin{tabular}{|c|c|c|c|c|c|c|}
\hline $\begin{array}{c}\text { Tipo de } \\
\text { Activo }\end{array}$ & Descripción de la Inversión & $\begin{array}{c}\text { Total } \\
\text { Valor }(S / .)\end{array}$ & $\begin{array}{l}\text { Vida útil contable } \\
\text { (años) }\end{array}$ & $\begin{array}{c}\text { Depreciación } \\
\text { anual }\end{array}$ & $\begin{array}{c}\text { Depreciación } \\
\text { (3 años) }\end{array}$ & $\begin{array}{c}\text { Valor en } \\
\text { (3er año) }\end{array}$ \\
\hline \multirow{3}{*}{ Intangibles } & Adquisición de software para mantenimiento preventivo & 10,000 & 4 & 2,500 & 7,500 & 2,500 \\
\hline & Adquisición de software para control estadístico de procesos & 10,000 & 4 & 2,500 & 7,500 & 2,500 \\
\hline & Total & 20,000 & & 5,000 & 15,000 & 5,000 \\
\hline \multirow{4}{*}{$\begin{array}{l}\text { Activos } \\
\text { Fijos }\end{array}$} & Adquisición de camiones para acopio de materia prima & 400,000 & 5 & 80,000 & 240,000 & 160,000 \\
\hline & $\begin{array}{l}\text { Instalación de sistema para pre secado de plumas y reducción de } \\
\text { humedad }\end{array}$ & 150,000 & 10 & 15,000 & 45,000 & 105,000 \\
\hline & $\begin{array}{l}\text { Instalación de sistema para pre secado de plumas y reducción de } \\
\text { humedad }\end{array}$ & 75,000 & 10 & 7,500 & 15,000 & 60,000 \\
\hline & Total & 625,000 & & 102,500 & 300,000 & 325,000 \\
\hline
\end{tabular}


En la siguiente tabla 86 se proyectan los Estados de Resultados para los próximos tres años considerando la estrategia propuesta.

Tabla 86

Proyección de los Estados de Resultados, con la nueva estrategia.

\begin{tabular}{lrrrr}
\hline ESTADO DE RESULTADOS (En soles) & \multicolumn{1}{c}{ AÑO BASE } & \multicolumn{3}{c}{ PROYECTADO } \\
& \multicolumn{1}{c}{$\mathbf{2 0 1 7}$} & \multicolumn{1}{c}{$\mathbf{2 0 1 8}$} & \multicolumn{1}{c}{$\mathbf{2 0 1 9}$} & \multicolumn{1}{c}{$\mathbf{2 0 2 0}$} \\
\hline Ventas netas & $\mathbf{2 7 , 2 8 0 , 6 2 2}$ & $\mathbf{2 9 , 1 9 0 , 2 6 5}$ & $\mathbf{3 1 , 6 7 1 , 4 3 8}$ & $\mathbf{3 4 , 8 3 8 , 5 8 1}$ \\
Costo de ventas & $(23,778,953)$ & $(25,307,960)$ & $(27,237,436)$ & $(29,612,794)$ \\
Utilidad Bruta & $\mathbf{3 , 5 0 1 , 6 6 8}$ & $\mathbf{3 , 8 8 2 , 3 0 5}$ & $\mathbf{4 , 4 3 4 , 0 0 1}$ & $\mathbf{5 , 2 2 5 , 7 8 7}$ \\
Gastos de ventas & $(407,037)$ & $(525,425)$ & $(570,086)$ & $(627,094)$ \\
Gastos de administración & $(1,051,702)$ & $(1,167,611)$ & $(1,266,858)$ & $(1,393,543)$ \\
Ganancia (Pérdida) por actividades de & $\mathbf{2 , 0 4 2 , 9 2 9}$ & $\mathbf{2 , 1 8 9 , 2 7 0}$ & $\mathbf{2 , 5 9 7 , 0 5 8}$ & $\mathbf{3 , 2 0 5 , 1 4 9}$ \\
operación & $(725,432)$ & $(760,355)$ & $(782,417)$ & $(790,468)$ \\
Gastos financieros & 31,859 & 29,190 & 31,671 & 34,839 \\
Otros Ingresos de Gestión & $\mathbf{1 , 3 4 9 , 3 5 6}$ & $\mathbf{1 , 4 5 8 , 1 0 5}$ & $\mathbf{1 , 8 4 6 , 3 1 2}$ & $\mathbf{2 , 4 4 9 , 5 2 0}$ \\
Resultado antes de Impuesto a las & $\mathbf{3 9 8 , 0 6 0 9}$ & $(430,141)$ & $(544,662)$ & $(722,608)$ \\
Ganancias & $\mathbf{9 5 1 , 2 9 6}$ & $\mathbf{1 , 0 2 7 , 9 6 4}$ & $\mathbf{1 , 3 0 1 , 6 5 0}$ & $\mathbf{1 , 7 2 6 , 9 1 2}$ \\
\hline Impuesto a la Renta & & &
\end{tabular}

Como se muestra en la tabla 86, la aplicación de la estrategia busca incrementar las ventas, así como reducir los costos de operación, lo que genera un impacto positivo en la utilidad neta presentando un margen de crecimiento promedio anual del $22.45 \%$, en la tabla 87 se ilustran los valores obtenidos. 
Tabla 87

Crecimiento de la utilidad neta, con la nueva estrategia

\begin{tabular}{lcccc}
\hline $\begin{array}{l}\text { CRECIMIENTO } \\
\text { UTILIDAD } \\
\text { NETA }\end{array}$ & Año Base & Año 2018 & Año 2019 & Año 2020 \\
\hline Utilidad Neta & 951,296 & $1,027,964$ & $1,301,650$ & $1,726,912$ \\
Variación Relativa & & $8.06 \%$ & $26.62 \%$ & $32.67 \%$ \\
Promedio & & & $\mathbf{2 2 . 4 5 \%}$ & \\
\hline
\end{tabular}

\subsubsection{Balance general (sin estrategia y con la nueva estrategia)}

\section{Situación actual}

Para proyectar el Balance General en la situación actual, se toma como base la tendencia actual del crecimiento de ventas de Los Ferroles (6\%), para los activos corrientes y no corriente y para los pasivos corrientes. En el caso del pasivo no corriente (obligaciones financieras a largo plazo), se proyectó que éstas disminuirían conforme al cumplimiento del cronograma de pagos.

En la tabla 88 se muestra la proyección del Balance General para los próximos tres años, sin considerar la estrategia propuesta. 
Tabla 88

Proyección del Balance General, sin la estrategia

\begin{tabular}{|c|c|c|c|c|}
\hline & 2017 & 2018 & 2019 & 2020 \\
\hline \multicolumn{5}{|l|}{ Activos/ } \\
\hline \multicolumn{5}{|l|}{ Activos Corrientes/ } \\
\hline Caja y Bancos & 273,740 & 290,164 & 307,574 & 326,029 \\
\hline Cuentas por cobrar comerciales & $1,020,158$ & $1,081,367$ & $1,146,250$ & $1,215,025$ \\
\hline Cuentas por cobrar diversas & $1,067,518$ & $1,131,569$ & $1,199,463$ & $1,271,431$ \\
\hline Servicios otros contratados por anticipado & 579,810 & 614,599 & 651,475 & 690,563 \\
\hline Existencias & $5,481,208$ & $5,810,080$ & $6,158,685$ & $6,528,206$ \\
\hline Total Activos Corrientes/ & $8,422,434$ & $8,927,780$ & $9,463,447$ & $10,031,254$ \\
\hline \multicolumn{5}{|l|}{ Activos No Corrientes/ } \\
\hline Activos Adquir Arrend Financiero & $11,783,780$ & $12,490,807$ & $11,783,780$ & $11,783,780$ \\
\hline Inmueble, maquinaria y equipo neto & $17,593,480$ & $18,649,089$ & $19,768,034$ & $20,954,116$ \\
\hline Depreciación y Amortización acumulada & $-7,579,423$ & $-8,034,188$ & $-8,516,240$ & $-9,027,214$ \\
\hline Intangibles & 23,210 & 24,603 & 26,079 & 27,643 \\
\hline Total Activos No Corrientes/ & $21,821,047$ & $23,130,310$ & $23,061,653$ & $23,738,326$ \\
\hline TOTAL DE ACTIVOS/ & $30,243,481$ & $32,058,090$ & 32,525,100 & 33,769,579 \\
\hline \multicolumn{5}{|l|}{ Pasivos y Patrimonio/ } \\
\hline \multicolumn{5}{|l|}{ Pasivos Corrientes/ } \\
\hline Tributo por Pagar & 33,461 & 35,469 & 37,597 & 39,853 \\
\hline Remuneraciones por Pagar & 68,254 & 72,349 & 76,690 & 81,292 \\
\hline Cuentas por Pagar Comerciales & $4,154,501$ & $4,403,771$ & $4,667,997$ & $4,948,077$ \\
\hline Obligaciones Financieras C.P. & $2,930,407$ & $3,106,231$ & $3,292,605$ & $3,490,162$ \\
\hline Cuentas por Pagar Accionistas & 0 & 0 & 0 & 0 \\
\hline Cuentas por Pagar Diversas & 740,376 & 784,799 & 831,886 & 881,800 \\
\hline Total Pasivos Corrientes/ & 7,926,999 & $8,402,619$ & $8,906,776$ & $9,441,183$ \\
\hline \multicolumn{5}{|l|}{ Pasivos No Corrientes/ } \\
\hline Obligaciones financieras & $13,513,552$ & $13,000,281$ & $10,999,738$ & $9,628,611$ \\
\hline Total Pasivos No Corrientes/ & $13,513,552$ & $13,000,281$ & $10,999,738$ & $9,628,611$ \\
\hline TOTAL PASIVOS/ & $21,440,551$ & $21,402,900$ & $19,906,514$ & $19,069,793$ \\
\hline \multicolumn{5}{|l|}{ Patrimonio/ } \\
\hline Capital & $3,180,000$ & $3,180,000$ & $3,180,000$ & $3,180,000$ \\
\hline Excedente de Revaluación & $1,394,453$ & $1,394,453$ & $1,394,453$ & $1,394,453$ \\
\hline Resultados Acumulados & $3,277,181$ & $4,228,477$ & $5,236,851$ & $6,305,726$ \\
\hline Resultado del ejercicio & 951,296 & $1,008,373$ & $1,068,876$ & $1,133,008$ \\
\hline Total Patrimonio/ & $8,802,930$ & $9,811,303$ & $10,880,179$ & $12,013,187$ \\
\hline TOTAL PASIVO Y PATRIMONIO/ & $30,243,481$ & $31,214,203$ & $30,786,693$ & $31,082,981$ \\
\hline
\end{tabular}




\section{Situación con la nueva estrategia}

En la tabla 89 se muestra la proyección del Balance General para los próximos tres años, considerando la nueva estrategia.

Tabla 89

Proyección del Balance General, con la nueva estrategia

\begin{tabular}{|c|c|c|c|c|}
\hline BALANCE GENERAL & 2017 & 2018 & 2019 & 2020 \\
\hline \multicolumn{5}{|l|}{ Activos/ } \\
\hline \multicolumn{5}{|l|}{ Activos Corrientes/ } \\
\hline Caja y Bancos & 273,740 & 292,902 & 317,798 & 349,578 \\
\hline Cuentas por cobrar comerciales & $1,020,158$ & $1,091,569$ & $1,184,352$ & $1,302,788$ \\
\hline Cuentas por cobrar diversas & $1,067,518$ & $1,142,244$ & $1,239,335$ & $1,363,269$ \\
\hline $\begin{array}{l}\text { Servicios otros contratados por } \\
\text { anticipado }\end{array}$ & 579,810 & 620,397 & 673,130 & 740,443 \\
\hline Existencias & $5,481,208$ & $5,864,893$ & $6,363,408$ & $6,999,749$ \\
\hline Total Activos Corrientes/ & $8,422,434$ & $9,012,004$ & $9,778,025$ & $10,755,827$ \\
\hline \multicolumn{5}{|l|}{ Activos No Corrientes/ } \\
\hline Activos Adquir Arrend Financiero & $11,783,780$ & $13,094,723$ & $14,899,748$ & $16,532,139$ \\
\hline Inmueble, maquinaria y equipo neto & $17,593,480$ & $19,375,024$ & $20,537,525$ & $22,591,277$ \\
\hline Depreciación y Amortización acumulada & $-7,579,423$ & $-8,008,316$ & $-8,681,523$ & $-9,549,675$ \\
\hline Intangibles & 23,210 & 24,835 & 26,573 & 29,230 \\
\hline Total Activos No Corrientes/ & 21,821,047 & $24,486,265$ & $26,782,323$ & $29,602,972$ \\
\hline TOTAL DE ACTIVOS/ & $30,243,481$ & $33,498,269$ & $36,560,348$ & $40,358,799$ \\
\hline \multicolumn{5}{|l|}{ Pasivos y Patrimonio/ } \\
\hline \multicolumn{5}{|l|}{ Pasivos Corrientes/ } \\
\hline Tributo por Pagar & 33,461 & 35,803 & 38,847 & 42,731 \\
\hline Remuneraciones por Pagar & 68,254 & 73,032 & 79,239 & 87,163 \\
\hline Cuentas por Pagar Comerciales & $4,154,501$ & $4,445,316$ & $4,823,168$ & $5,305,485$ \\
\hline Obligaciones Financieras C.P. & $2,930,407$ & $3,135,535$ & $3,402,056$ & $3,742,262$ \\
\hline Cuentas por Pagar Accionistas & 0 & 0 & 0 & 0 \\
\hline Cuentas por Pagar Diversas & 740,376 & 792,202 & 859,540 & 945,493 \\
\hline Total Pasivos Corrientes/ & 7,926,999 & $8,481,889$ & $9,202,849$ & $10,123,134$ \\
\hline \multicolumn{5}{|l|}{ Pasivos No Corrientes/ } \\
\hline Obligaciones financieras & $13,513,552$ & 13,984,992 & $13,841,090$ & $13,684,326$ \\
\hline Total Pasivos No Corrientes/ & $\mathbf{1 3 , 5 1 3 , 5 5 2}$ & $13,984,992$ & $13,841,090$ & $13,684,326$ \\
\hline TOTAL PASIVOS/ & $21,440,551$ & $22,466,881$ & $23,043,939$ & $23,807,461$ \\
\hline \multicolumn{5}{|l|}{ Patrimonio/ } \\
\hline Capital & $3,180,000$ & $3,180,000$ & $3,180,000$ & $3,180,000$ \\
\hline Excedente de Revaluación & $1,394,453$ & $1,394,453$ & $1,394,453$ & $1,394,453$ \\
\hline Resultados Acumulados & $3,277,181$ & $4,228,477$ & $5,256,441$ & $6,558,091$ \\
\hline Resultado del ejercicio & 951,296 & $1,027,964$ & $1,301,650$ & $1,726,912$ \\
\hline Total Patrimonio/ & $8,802,930$ & $\mathbf{9 , 8 3 0 , 8 9 4}$ & $11,132,544$ & $12,859,455$ \\
\hline TOTAL PASIVO Y PATRIMONIO/ & $30,243,481$ & $32,297,775$ & $34,176,483$ & $36,666,916$ \\
\hline
\end{tabular}


Para proyectar el Balance General con la nueva estrategia, se consideró el crecimiento de las ventas en $7 \%, 8.5 \%$ y $10 \%$ respectivamente, para la proyección del activo corriente y pasivo corriente. Respecto al activo no corriente se incluyen las inversiones de las estrategias propuestas. En el caso del pasivo no corriente (obligaciones financieras a largo plazo), se proyectó en base a la estructura de financiamiento del préstamo, cuya TEA es de $8.9 \%$.

Para el proyecto planteado se ha considerado que las inversiones de los bienes tangibles e intangibles, sean financiadas con capital propio (60\%) y con préstamo bancario (40\%). A continuación, se indican las condiciones del préstamo:

Tabla 90

Condiciones de Financiamiento Bancario

\begin{tabular}{lc}
\hline Préstamo & S/ 471,440 \\
\hline TEA & $8.9 \%$ \\
TEM & $0.72 \%$ \\
Años & 3 \\
\hline
\end{tabular}

Tabla 91

Resumen de Financiamiento Bancario

\begin{tabular}{lcccc}
\hline & Deuda & Interés & Amortización & Cuota \\
\hline Año 1 & $471,440.00$ & $34,922.98$ & $143,902.20$ & $178,825.18$ \\
Año 2 & $327,537.80$ & $22,061.67$ & $156,763.51$ & $178,825.18$ \\
Año 3 & $170,774.30$ & $8,050.88$ & $170,774.30$ & $178,825.18$ \\
\hline TOTAL & & $\mathbf{6 5 , 0 3 5 . 5 3}$ & $\mathbf{4 7 1 , 4 4 0 . 0 0}$ & $\mathbf{5 3 6 , 4 7 5 . 5 3}$ \\
\hline
\end{tabular}


Tabla 92

Cronograma de Financiamiento Bancario

\begin{tabular}{|c|c|c|c|c|}
\hline Periodo & Deuda & Interés & Amortización & Cuota \\
\hline 1 & $471,440.00$ & $3,375.14$ & $11,526.96$ & $14,902.10$ \\
\hline 2 & $459,913.04$ & $3,292.61$ & $11,609.48$ & $14,902.10$ \\
\hline 3 & $448,303.56$ & $3,209.50$ & $11,692.60$ & $14,902.10$ \\
\hline 4 & $436,610.96$ & $3,125.79$ & $11,776.31$ & $14,902.10$ \\
\hline 5 & $424,834.65$ & $3,041.48$ & $11,860.62$ & $14,902.10$ \\
\hline 6 & $412,974.03$ & $2,956.57$ & $11,945.53$ & $14,902.10$ \\
\hline 7 & $401,028.50$ & $2,871.05$ & $12,031.05$ & $14,902.10$ \\
\hline 8 & $388,997.45$ & $2,784.91$ & $12,117.18$ & $14,902.10$ \\
\hline 9 & $376,880.27$ & $2,698.16$ & $12,203.93$ & $14,902.10$ \\
\hline 10 & $364,676.33$ & $2,610.79$ & $12,291.30$ & $14,902.10$ \\
\hline 11 & $352,385.03$ & $2,522.80$ & $12,379.30$ & $14,902.10$ \\
\hline 12 & $340,005.73$ & $2,434.17$ & $12,467.93$ & $14,902.10$ \\
\hline 13 & $327,537.80$ & $2,344.91$ & $12,557.19$ & $14,902.10$ \\
\hline 14 & $314,980.62$ & $2,255.01$ & $12,647.09$ & $14,902.10$ \\
\hline 15 & $302,333.53$ & $2,164.47$ & $12,737.63$ & $14,902.10$ \\
\hline 16 & $289,595.90$ & $2,073.28$ & $12,828.82$ & $14,902.10$ \\
\hline 17 & $276,767.08$ & $1,981.43$ & $12,920.66$ & $14,902.10$ \\
\hline 18 & $263,846.42$ & $1,888.93$ & $13,013.17$ & $14,902.10$ \\
\hline 19 & $250,833.25$ & $1,795.77$ & $13,106.33$ & $14,902.10$ \\
\hline 20 & $237,726.92$ & $1,701.94$ & $13,200.16$ & $14,902.10$ \\
\hline 21 & $224,526.76$ & $1,607.43$ & $13,294.66$ & $14,902.10$ \\
\hline 22 & $211,232.10$ & $1,512.25$ & $13,389.84$ & $14,902.10$ \\
\hline 23 & $197,842.25$ & $1,416.39$ & $13,485.70$ & $14,902.10$ \\
\hline 24 & $184,356.55$ & $1,319.85$ & $13,582.25$ & $14,902.10$ \\
\hline 25 & $170,774.30$ & $1,222.61$ & $13,679.49$ & $14,902.10$ \\
\hline 26 & $157,094.81$ & $1,124.67$ & $13,777.42$ & $14,902.10$ \\
\hline 27 & $143,317.38$ & $1,026.04$ & $13,876.06$ & $14,902.10$ \\
\hline 28 & $129,441.33$ & 926.70 & $13,975.40$ & $14,902.10$ \\
\hline 29 & $115,465.93$ & 826.64 & $14,075.45$ & $14,902.10$ \\
\hline 30 & $101,390.47$ & 725.88 & $14,176.22$ & $14,902.10$ \\
\hline 31 & $87,214.25$ & 624.39 & $14,277.71$ & $14,902.10$ \\
\hline 32 & $72,936.54$ & 522.17 & $14,379.93$ & $14,902.10$ \\
\hline 33 & $58,556.61$ & 419.22 & $14,482.88$ & $14,902.10$ \\
\hline 34 & $44,073.73$ & 315.53 & $14,586.57$ & $14,902.10$ \\
\hline 35 & $29,487.16$ & 211.10 & $14,690.99$ & $14,902.10$ \\
\hline 36 & $14,796.17$ & 105.93 & $14,796.17$ & $14,902.10$ \\
\hline TOTAL & & $65,035.53$ & $471,440.00$ & $\mathbf{5 3 6 , 4 7 5 . 5 3}$ \\
\hline
\end{tabular}


10.2.4 Flujo de efectivo (situación actual y con la nueva estrategia)

\section{Situación actual}

En la tabla 93 se muestra el flujo de efectivo para el periodo 2018 2020 de la situación actual de la empresa. Para la proyección se ha considerado una tasa de crecimiento de las ventas de $6 \%$ y un costo de ventas de $87.2 \%$. Respecto al gasto de venta y de administración se define un porcentaje sobre las ventas de $1.5 \%$ y $3.9 \%$ respectivamente.

Tabla 93

Proyección del Flujo de Efectivo, sin la estrategia

\begin{tabular}{lrrr}
\hline \multicolumn{1}{c}{ FLUJO DE EFECTIVO } & \multicolumn{3}{c}{ SIN ESTRATEGIA } \\
& Año 2018 & Año 2019 & Año 2020 \\
\hline Ingresos por ventas & $28,917,459$ & $30,652,506$ & $32,491,657$ \\
Costo de ventas & $(25,205,691)$ & $(26,718,032)$ & $(28,321,114)$ \\
Gastos de Ventas & $(431,459)$ & $(457,347)$ & $(484,787)$ \\
Gastos de Administración & $(1,114,805)$ & $(1,181,693)$ & $(1,252,594)$ \\
Intereses & $(768,958)$ & $(815,096)$ & $(864,002)$ \\
Depreciación y amortización & & & \\
acumulada & $(886,903)$ & $(886,903)$ & $(886,903)$ \\
Utilidad & $\mathbf{5 0 9 , 6 4 3}$ & $\mathbf{5 9 3 , 4 3 6}$ & $\mathbf{6 8 2 , 2 5 6}$ \\
Impuesto Renta & $(150,345)$ & $(175,064)$ & $(201,266)$ \\
Utilidad Neta & $\mathbf{3 5 9 , 2 9 9}$ & $\mathbf{4 1 8 , 3 7 2}$ & $\mathbf{4 8 0 , 9 9 1}$ \\
Depreciación y amortización & & & \\
acumulada & 886,903 & 886,903 & 886,903 \\
Fondos Generados en Operación & & & \\
(FGO) & $\mathbf{1 , 2 4 6 , 2 0 2}$ & $\mathbf{1 , 3 0 5 , 2 7 5}$ & $\mathbf{1 , 3 6 7 , 8 9 4}$ \\
Variación de Capital de Trabajo & $(29,726)$ & $(31,510)$ & $(33,400)$ \\
\hline FLUJO CAJA DE OPERATIVO & $\mathbf{1 , 2 1 6 , 4 7 5}$ & $\mathbf{1 , 2 7 3 , 7 6 6}$ & $\mathbf{1 , 3 3 4 , 4 9 4}$ \\
\hline
\end{tabular}

\section{Situación con la nueva estrategia}

En la tabla 94 se muestra el flujo de efectivo para el periodo 2018 2020 con la estrategia propuesta. Para las proyecciones se ha considerado un crecimiento de las ventas de $7 \%, 8.5 \%$ y $10 \%$, y un costo de ventas de $86.7 \%$, 
$86 \%$ y $85 \%$ para los años 2018, 2019 y 2020 respectivamente. En cuanto al gasto de venta se ha estimado en $1.8 \%$ y el gasto de administración en $4 \%$ (para los tres años), respecto a los ingresos por ventas. 
Tabla 94

Proyección del Flujo de Efectivo, con la nueva estrategia

\begin{tabular}{|c|c|c|c|c|}
\hline \multirow{2}{*}{ FLUJO DE EFECTIVO } & \multicolumn{4}{|c|}{ CON ESTRATEGIA } \\
\hline & Año Base & Año 2018 & Año 2019 & Año 2020 \\
\hline Ingresos por ventas & & $29,190,265$ & $31,671,438$ & $\mathbf{3 4 , 8 3 8 , 5 8 1}$ \\
\hline Costo de ventas & & $(25,307,960)$ & $(27,237,436)$ & $(29,612,794)$ \\
\hline Gastos de Ventas & & $(525,425)$ & $(570,086)$ & $(627,094)$ \\
\hline Gastos de Administración & & $(1,167,611)$ & $(1,266,858)$ & $(1,393,543)$ \\
\hline Intereses & & $(768,958)$ & $(815,096)$ & $(864,002)$ \\
\hline Intereses (con estrategia) & & $(34,923)$ & $(22,062)$ & $(8,051)$ \\
\hline $\begin{array}{l}\text { Depreciación y amortización (sin } \\
\text { estrategia) }\end{array}$ & & $(886,903)$ & $(886,903)$ & $(886,903)$ \\
\hline $\begin{array}{l}\text { Depreciación y amortización (con } \\
\text { estrategia) }\end{array}$ & & $(101,667)$ & $(109,167)$ & $(109,167)$ \\
\hline Utilidad & & 396,819 & 763,831 & $\mathbf{1 , 3 3 7 , 0 2 7}$ \\
\hline Impuesto Renta & & $(117,062)$ & $(225,330)$ & $(394,423)$ \\
\hline Utilidad Neta & & 279,757 & 538,501 & 942,604 \\
\hline $\begin{array}{l}\text { Depreciación y amortización (sin } \\
\text { estrategia) }\end{array}$ & & 886,903 & 886,903 & 886,903 \\
\hline $\begin{array}{l}\text { Depreciación y amortización (con } \\
\text { estrategia) }\end{array}$ & & 101,667 & 109,167 & 109,167 \\
\hline Fondos Generados en Operación (FGO) & & $1,268,327$ & $\mathbf{1 , 5 3 4 , 5 7 0}$ & $1,938,674$ \\
\hline Variación de Capital de Trabajo & $(34,680)$ & $(45,060)$ & $(57,518)$ & \\
\hline FLUJO CAJA DE OPERATIVO & $(34,680)$ & $1,223,267$ & $1,477,053$ & $1,938,674$ \\
\hline \multicolumn{5}{|l|}{ Inversiones } \\
\hline Inversión Activos & $(550,000)$ & $(75,000)$ & & \\
\hline Inversión Intangibles & $(20,000)$ & & & \\
\hline FLUJO CAJA INVERSIONISTA & $(\mathbf{5 7 0 , 0 0 0 )}$ & $(\mathbf{7 5 , 0 0 0 )}$ & $\mathbf{0}$ & $\mathbf{0}$ \\
\hline Préstamo & 471,440 & & & \\
\hline Amortización préstamo & & $(143,902)$ & $(156,764)$ & $(170,774)$ \\
\hline FLUJO CAJA DEUDA & $\mathbf{4 7 1 , 4 4 0}$ & $(143,902)$ & $(156,764)$ & $(\mathbf{1 7 0 , 7 7 4 )}$ \\
\hline FLUJO CAJA FINANCIERO & $(133,240)$ & $1,004,365$ & $1,320,289$ & $1,767,900$ \\
\hline
\end{tabular}

10.2.5 Proyección de flujos (incremental)

En la siguiente tabla 95 se muestra el flujo de efectivo incremental del proyecto para el periodo 2018-2020, cabe señalar que el resultado proviene de la diferencia del flujo de efectivo de la situación actual y con la nueva estrategia. 
Tabla 95

Proyección del Flujo Incremental

\begin{tabular}{|c|c|c|c|c|}
\hline \multirow{2}{*}{$\begin{array}{l}\text { FLUJO CAJA DE } \\
\text { INCREMENTAL }\end{array}$} & \multicolumn{4}{|c|}{ INCREMENTAL } \\
\hline & Año Base & Año 2018 & Año 2019 & Año 2020 \\
\hline Ingresos por ventas & & 272,806 & $1,018,931$ & $2,346,925$ \\
\hline Costo de ventas & & $(102,269)$ & $(519,404)$ & $(1,291,680)$ \\
\hline Gastos de Ventas & & $(93,966)$ & $(112,739)$ & $(142,307)$ \\
\hline Gastos de Administración & & $(52,806)$ & $(85,165)$ & $(140,949)$ \\
\hline Intereses & & $(34,923)$ & $(22,062)$ & $(8,051)$ \\
\hline $\begin{array}{l}\text { Depreciación y amortización (con } \\
\text { estrategia) }\end{array}$ & & $(101,667)$ & $(109,167)$ & $(109,167)$ \\
\hline Utilidad & & $(\mathbf{1 1 2 , 8 2 5 )}$ & 170,394 & 654,771 \\
\hline Impuesto Renta & & $(33,283)$ & 50,266 & 193,157 \\
\hline Utilidad Neta & & $(146,108)$ & 220,661 & 847,928 \\
\hline Depreciación activos & & 101,667 & 109,167 & 109,167 \\
\hline $\begin{array}{l}\text { Fondos Generados en Operación } \\
\text { (FGO) }\end{array}$ & & $(44,441)$ & 329,828 & 957,095 \\
\hline Variación de Capital de Trabajo & $(34,680)$ & $(45,060)$ & $(57,518)$ & \\
\hline FLUJO CAJA DE OPERATIVO & $(34,680)$ & $(89,501)$ & 272,310 & 957,095 \\
\hline \multicolumn{5}{|l|}{ Inversiones } \\
\hline Inversión Activos & $(550,000)$ & $(75,000)$ & & \\
\hline Inversión Intangibles & $(20,000)$ & & & \\
\hline FLUJO CAJA INVERSIONISTA & $(570,000)$ & $(75,000)$ & $\mathbf{0}$ & $\mathbf{0}$ \\
\hline Préstamo & 471,440 & & & \\
\hline Amortización préstamo & & $(143,902)$ & $(156,764)$ & $(170,774)$ \\
\hline FLUJO CAJA DEUDA & $\mathbf{4 7 1 , 4 4 0}$ & $(143,902)$ & $(156,764)$ & $(170,774)$ \\
\hline FLUJO CAJA FINANCIERO & $(133,240)$ & $(308,403)$ & 115,546 & 786,321 \\
\hline
\end{tabular}




\subsubsection{Evaluación financiera (VAN, TIR, ratios financieros)}

Las razones financieras son coeficientes que vinculan diferentes partes de los Estados Financieros con la finalidad de encontrar aspectos particulares del negocio. (Stickney, Weil, Schipper, Francis y Avolio, 2013)

Por lo general, se evalúan cuatro áreas específicas, como son:

1. La liquidez a corto plazo, mide la capacidad de la empresa en hacer frente a sus obligaciones que se derivan del ciclo operativo.

2. La solvencia a largo plazo, permite evaluar la capacidad de endeudamiento de la empresa y el respaldo patrimonial que tienen para hacer frente a sus deudas de corto y largo plazo, satisfaciendo los pagos de intereses y dividendos.

3. La gestión o eficiencia, permite evaluar los efectos de las políticas y decisiones de la empresa en la utilización de sus recursos respecto a cobros, pagos, inventarios y activos.

4. La rentabilidad, evalúan los resultados de la gestión empresarial, es decir el poder de generar utilidades y obtener un rendimiento sobre los recursos invertidos. (Stickney, Weil, Schipper, Francis y Avolio, 2013)

En las tablas 96 y 97 se muestran la proyección de los ratios financieros para los próximos tres años, sin considerar la estrategia propuesta y con la nueva estrategia. 
Tabla 96

Proyección de los Ratios Financieros sin estrategia

\begin{tabular}{|c|c|c|c|c|c|}
\hline RATIOS FINANCIEROS & FÓRMULA & 2017 & 2018 & 2019 & 2020 \\
\hline \multicolumn{6}{|l|}{ RATIOS DE LÍQUIDEZ } \\
\hline $\begin{array}{l}\text { RATIO CIRCULANTE O } \\
\text { RAZÓN CORRIENTE }\end{array}$ & $\frac{\text { ACTIVO CORRIENTE }}{\text { PASIVO CORRIENTE }}$ & 1.06 & 1.06 & 1.06 & 1.06 \\
\hline PRUEBA ÁCIDA & $\begin{array}{l}\frac{\text { ACTIVO CORRIENTE - }}{\underline{\text { INVENTARIOS }}} \\
\text { PASIVO CORRIENTE }\end{array}$ & 0.33 & 0.37 & 0.37 & 0.37 \\
\hline \multicolumn{6}{|l|}{$\begin{array}{l}\text { RATIOS DE GESTIÓN O } \\
\text { EFICIENCIA }\end{array}$} \\
\hline $\begin{array}{l}\text { ROTACIÓN DE CUENTAS POR } \\
\text { COBRAR } \\
\text { (Días) }\end{array}$ & $\frac{\text { CUENTAS POR COBRAR }}{\underline{\text { COMERCIALES X } 360}}$ & 13 & 13 & 13 & 13 \\
\hline $\begin{array}{l}\text { ROTACIÓN DE CUENTAS POR } \\
\text { PAGAR } \\
\text { (Días) }\end{array}$ & $\begin{array}{l}\text { VENTAS NETAS } \\
\frac{\text { CUENTAS POR PAGAR }}{\text { COMERCIALES x } 360} \\
\text { COSTO DE VENTAS }\end{array}$ & 63 & 63 & 63 & 63 \\
\hline $\begin{array}{l}\text { ROTACIÓN DE CUENTAS } \\
\text { INVENTARIOS } \\
\text { (Días) }\end{array}$ & $\frac{\text { EXISTENCIAS x } 360}{\text { COSTO DE VENTAS }}$ & 83 & 75 & 83 & 83 \\
\hline ROTACION DE ACTIVOS & $\frac{\text { VENTAS NETAS }}{\text { ACTIVOS }}$ & 0.90 & 0.90 & 0.94 & 0.96 \\
\hline \multicolumn{6}{|l|}{ RATIOS DE SOLVENCIA } \\
\hline APALANCAMIENTO & $\begin{array}{l}\text { PASIVO } \\
\text { PATRIMONIO }\end{array}$ & 2.4 & 2.2 & 1.8 & 1.6 \\
\hline GRADO DE PROPIEDAD (\%) & PATRLAONIO & $29 \%$ & $31 \%$ & $33 \%$ & $36 \%$ \\
\hline \multicolumn{6}{|l|}{ RATIOS DE RENTABILIDAD } \\
\hline MARGEN NETO (\%) & $\frac{\text { UTILIDAD NETA }}{\text { VENTAS NETAS }}$ & $3.5 \%$ & $3.5 \%$ & $3.5 \%$ & $3.5 \%$ \\
\hline $\begin{array}{l}\text { RENTABILIDAD DE LOS } \\
\text { ACTIVOS - ROA }(\%)\end{array}$ & $\frac{\text { UTILIDAD NETA }}{\text { ACTIVO }}$ & $3.1 \%$ & $3.1 \%$ & $3.3 \%$ & $3.4 \%$ \\
\hline $\begin{array}{l}\text { RENTABILIDAD DEL } \\
\text { PATRIMONIO - ROE }(\%)\end{array}$ & $\frac{\text { UTILIDAD NETA }}{\text { PATRIMONIO }}$ & $11 \%$ & $10 \%$ & $10 \%$ & $9 \%$ \\
\hline
\end{tabular}


Tabla 97

Proyección de los Ratios Financieros con la estrategia

\begin{tabular}{|c|c|c|c|c|c|}
\hline RATIOS FINANCIEROS & FÓRMULA & 2017 & 2018 & 2019 & 2020 \\
\hline \multicolumn{6}{|l|}{ RATIOS DE LÍQUIDEZ } \\
\hline $\begin{array}{l}\text { RATIO CIRCULANTE O } \\
\text { RAZÓN CORRIENTE }\end{array}$ & $\frac{\text { ACTIVO CORRIENTE }}{\text { PASIVO CORRIENTE }}$ & 1.06 & 1.06 & 1.06 & 1.06 \\
\hline PRUEBA ÁCIDA & $\begin{array}{l}\frac{\text { ACTIVO CORRIENTE - }}{\text { INVENTARIOS }} \\
\text { PASIVO CORRIENTE }\end{array}$ & 0.33 & 0.37 & 0.37 & 0.37 \\
\hline \multicolumn{6}{|l|}{$\begin{array}{l}\text { RATIOS DE GESTIÓN O } \\
\text { EFICIENCIA }\end{array}$} \\
\hline $\begin{array}{l}\text { ROTACIÓN DE CUENTAS POR } \\
\text { COBRAR } \\
\text { (Días) }\end{array}$ & $\frac{\text { CUENTAS POR COBRAR }}{\underline{\text { COMERCIALES X } 360}}$ & 13 & 13 & 13 & 13 \\
\hline $\begin{array}{l}\text { ROTACIÓN DE CUENTAS POR } \\
\text { PAGAR } \\
\text { (Días) }\end{array}$ & $\begin{array}{l}\text { VENTAS NETAS } \\
\frac{\text { CUENTAS POR PAGAR }}{\text { COMERCIALES x } 360} \\
\text { COSTO DE VENTAS }\end{array}$ & 63 & 63 & 64 & 64 \\
\hline $\begin{array}{l}\text { ROTACIÓN DE CUENTAS } \\
\text { INVENTARIOS } \\
\text { (Días) }\end{array}$ & $\frac{\text { EXISTENCIAS x } 360}{\text { COSTO DE VENTAS }}$ & 83 & 83 & 84 & 85 \\
\hline ROTACION DE ACTIVOS & $\frac{\text { VENTAS NETAS }}{\text { ACTIVOS }}$ & 0.90 & 0.87 & 0.87 & 0.86 \\
\hline \multicolumn{6}{|l|}{ RATIOS DE SOLVENCIA } \\
\hline APALANCAMIENTO & $\frac{\text { PASIVO }}{\text { PATRIMONIO }}$ & 2.4 & 2.3 & 2.1 & 1.9 \\
\hline GRADO DE PROPIEDAD (\%) & PATRIMONIO & $29 \%$ & $29 \%$ & $30 \%$ & $32 \%$ \\
\hline \multicolumn{6}{|l|}{ RATIOS DE RENTABILIDAD } \\
\hline MARGEN NETO (\%) & $\frac{\text { UTILIDAD NETA }}{\text { VENTAS NETAS }}$ & $3.5 \%$ & $3.5 \%$ & $4.1 \%$ & $5.0 \%$ \\
\hline $\begin{array}{l}\text { RENTABILIDAD DE LOS } \\
\text { ACTIVOS - ROA }(\%)\end{array}$ & $\frac{\text { UTILIDAD NETA }}{\text { ACTIVO }}$ & $3.1 \%$ & $3.4 \%$ & $3.6 \%$ & $4.3 \%$ \\
\hline $\begin{array}{l}\text { RENTABILIDAD DEL } \\
\text { PATRIMONIO - ROE }(\%)\end{array}$ & $\frac{\text { UTILIDAD NETA }}{\text { PATRIMONIO }}$ & $11 \%$ & $10.5 \%$ & $11.7 \%$ & $13.4 \%$ \\
\hline
\end{tabular}


De acuerdo al resultado de la proyección de los ratios financieros con la nueva estrategia, podemos mencionar que:

- La empresa tendrá liquidez y podría afrontar sus obligaciones en el corto plazo, el porcentaje obtenido de 1.06 nos hace referencia que parte de los activos corrientes están siendo financiados con pasivos a largo plazo.

- En cuanto a los ratios de gestión, la empresa convertiría rápidamente las cuentas por cobrar en efectivo (13 días), en diferencia con las cuentas por pagar (64 días) que se pagan en un plazo más largo.

- La implementación de las iniciativas le permitiría generar eficiencia operativa (margen neto), eficiencia en la inversión (rotación de activos) y eficiencia financiera (grado de endeudamiento), dando como resultado una mayor rentabilidad tanto en los activos como el patrimonio.

\section{VAN y TIR.}

Para hallar la tasa de descuento que se aplicará a los flujos de efectivo futuros, utilizaremos el modelo CAPM (Capital Asset Pricing Model), concepto que luego utilizamos para calcular el WACC (Weighted Average Cost of Capital) o Costo promedio ponderado de las Fuentes de financiamiento, en español.

En la tabla 98, se muestran los cálculos para hallar el costo de oportunidad se tomaron los siguientes puntos:

- Para determinar la prima de mercado (Rm) se ha considerado la fuente pública Aswath Damodaran (S\&p 500 2007-2016), dando como resultado un valor de $11.42 \%$. 
- Para determinar la tasa libre de riesgo (Rf) se ha considerado los rendimientos del tesoro americano a diez años, con un valor de $5.18 \%$

- Para determinar el Beta desapalancado se ha considerado como referencia la fuente pública Aswath Damodaran para el sector de alimentos procesados, dando como resultado un valor de 0.61 .

- Para determinar el Riesgo País se tomó como referencia la fuente pública JP Morgan, dando como resultado un valor de 3.04\%.

Tabla 98

Cálculos para el Modelo CAPM y WACC

\begin{tabular}{lc}
\hline $\begin{array}{c}\text { Costo de oportunidad del capital } \\
\text { (COK) }\end{array}$ & Modelo CAPM \\
\hline Rendimiento de mercado (Rm) & $11.42 \%$ \\
Tasa de libre riesgo (Rrf) & $5.18 \%$ \\
Tirenta Perú & $29.5 \%$ \\
Tirenta EEUU & $35.0 \%$ \\
Inflación EEUU & $2.23 \%$ \\
Inflación Perú & $3.17 \%$ \\
Beta desapalancada EEUU * & 0.61 \\
\%D & $40.0 \%$ \\
\%C & $60.0 \%$ \\
D/C & $66.7 \%$ \\
TEA & $8.9 \%$ \\
Riesgo país Perú** & $3.04 \%$ \\
Beta Apalancado EEUU*** & 0.87 \\
Beta Apalancada Empresa & 1.29 \\
\hline COK EEUU Nominal & $\mathbf{1 3 . 2 0 \%}$ \\
\hline COK EEUU Real & $\mathbf{1 0 . 7 3 \%}$ \\
\hline COK Perú Nominal & $\mathbf{1 7 . 3 8 \%}$ \\
\hline COK PERU Real & $\mathbf{1 3 . 7 7 \%}$ \\
\hline * Damodaran Unlevered Beta (Food & \\
Processing) & \\
** JP Morgan & \\
*** www.global-rates.com - Estadísticas Económicas
\end{tabular}


Tabla 99

Estructura de Fuente de Financiamiento

\begin{tabular}{lcccc}
\hline \multicolumn{1}{c}{ WACC } & $\begin{array}{c}\text { \% de } \\
\text { proporción }\end{array}$ & $\begin{array}{c}\text { Costo Deuda / } \\
\text { Costo Capital }\end{array}$ & IR & WACC \\
\hline Deuda ( D) & $40 \%$ & $8.94 \%$ & $29.50 \%$ & \\
Capital propio ( E) & $60 \%$ & $17.38 \%$ & & \\
\hline \multicolumn{5}{c}{} \\
\hline
\end{tabular}

Tabla 100

Cálculos del VAN Y TIR para los flujos de efectivo incremental

\begin{tabular}{lcccc}
\hline \multicolumn{1}{c}{ DATOS } & \multicolumn{5}{c}{ PROYECTADO } \\
& Año Base & $\begin{array}{r}\text { Año } \\
\mathbf{2 0 1 8}\end{array}$ & $\begin{array}{r}\text { Año } \\
\mathbf{2 0 1 9}\end{array}$ & $\begin{array}{c}\text { Año } \\
\mathbf{2 0 2 0}\end{array}$ \\
\hline $\begin{array}{l}\text { FLUJO DE CAJA } \\
\text { (INCREMENTAL) }\end{array}$ & & & & \\
\hline Flujos caja & & - & & \\
financiero & $-133,240$ & 308,403 & 115,546 & 786,321 \\
\hline VANF & 203,647 & & & \\
TIRF & $39 \%$ & & & \\
WACC $=$ & $12.95 \%$ & & & \\
\hline
\end{tabular}

De acuerdo con la tabla 100 y tomando como base los cálculos del flujo de caja incremental, podemos concluir que la aplicación de las estrategias generan un VAN financiero de S/ 203,647 y una TIR financiera de 39\%. Estos resultados muestran que la tasa de descuento supera los costos de su financiación, resultando un WACC de $12.95 \%$ y un COK de $13.77 \%$, siendo viable financieramente las implementación de las estrategias propuestas, lo que finalmente generará incrementar la rentabilidad de la empresa. 


\section{Conclusiones y Recomendaciones}

\section{Conclusiones}

El sector rendering se encuentra en etapa de crecimiento, dado que las empresas que lo conforman son muy pocas y carecen en su mayoría de profesionalización y tecnificación en sus procesos; a excepción de Los Ferroles quienes cuentan con tecnología moderna.

Los Ferroles es una empresa que lleva en el mercado más de 12 años, lo cual le ha permitido posicionarse como una de las mejores empresas de rendering en el Perú. La empresa desea mantener su liderazgo en el mercado, y para ello es consiente que debe desarrollar un plan estratégico que le permita alcanzar sus objetivos a corto y largo plazo que asegure su rentabilidad y sostenibilidad en el tiempo.

En cuanto al aspecto económico, Los Ferroles tuvo un despegue y crecimiento acelerado entre los años 2010 y 2013 logrando duplicar maximizando sus volúmenes de producción y captar una alta participación de mercado. Del 2014 a la actualidad, su crecimiento ha sido influenciado por la alianza estratégica con San Fernando, quienes han incorporado las harinas proteicas del rendering como un insumo clave en la alimentación de las aves. El actual volumen de producción supera las 16,000 toneladas anuales.

Con respecto al aspecto legal, no existe reglamentación técnica que norme los procesos productivos ni sanitarios, sólo se ven regulados a través de normativa ambiental, laboral y tributaria. Esta falta de normatividad brinda a la empresa mayor flexibilidad en sus operaciones, lo cual les genera una ventaja con respecto a otros sectores. 
Los Ferroles presentan como ventajas competitivas tecnología de punta y especialización en el mercado avícola. Ambos factores diferencian a la empresa de sus competidores y forman parte de la propuesta de valor para sus clientes.

Entre los aspectos por mejorar, se identifican los siguientes puntos:

- En cuanto a estructura organizacional, poseen una débil organización interna con bajo nivel de profesionalización sin plan de sucesión que asegure la continuidad del negocio. Tampoco cuentan con área de Recursos Humanos que dirija la gestión humana, siendo ésta una de sus principales debilidades.

- En el aspecto comercial, carecen de estrategias de marketing que marquen la dirección y acciones necesarias para desarrollar la marca en el mercado; asimismo, no cuentan con procesos de investigación y desarrollo que permitan diversificar sus productos, lo cual resulta una desventaja con respecto a sus competidores, quienes ofrecen al mercado una mayor variedad de líneas de harinas.

- No han implementado sistemas de gestión de la calidad ni inocuidad, tales como ISO 9001 y HACCP, que garanticen procesos estandarizados, inocuos, eficaces, eficientes y enfocados en el cliente.

El Plan Estratégico presentado plantea un total de 37 iniciativas enfocadas en incrementar ingresos, reducir costos y gastos, y fortalecimiento institucional. La implementación de estas iniciativas busca alcanzar el logro de los objetivos estratégicos de la empresa. El resultado del VANF de S/ 203,647 y la TIRF de 39\% confirman una rentabilidad ROE de 13.4\% para finales del año 2020. 


\section{Recomendaciones}

Reestructurar la organización interna, profesionalizando y fortaleciendo las áreas que generan mayor valor para la empresa, así mismo se propone la creación de las áreas de Recursos Humanos y Comercial.

Expandir su participación de mercado a través de búsqueda de clientes, lo cual permitirá maximizar los volúmenes de producción, reducir costos, incrementar los ingresos por venta y sobre todo generar presencia de la marca en el exterior.

En el aspecto financiero, se recomienda la capitalización de los resultados acumulados con la finalidad de que el capital social aumente y le permita contar con mayor fortaleza empresarial y de financiamiento ante entidades de crédito. También se recomienda que pueda reducir los altos gastos financieros, mejorando los tiempos de pago de las cuentas por pagar.

Cumplir con el cronograma establecido para la implementación de las iniciativas, a fin de asegurar que no se desfasen en el tiempo. Asimismo, realizar un seguimiento y control periódico, trimestral y anual a través de los indicadores de gestión propuestos, para medir el desempeño de la implementación y tomar las acciones necesarias para asegurar el cumplimiento del Plan Estratégico 2018-2020. 


\section{Anexos}

\section{Anexo 1: Compendio Brasileño de Alimentación Animal (2004)}

\section{Ingredientes de Origen Animal}

Todos los ingredientes presentados deben ser exentos de materiales extraños en su composición y microorganismos patógenos.

La Prueba de Éber es un indicativo, necesitándose de otras determinaciones conclusivas.

Los parámetros de los ingredientes aquí presentados son basados en referencias observadas en el mercado, en la comunidad técnica y en publicaciones públicas y privadas. De esta forma, se trata de una guía orientativa, no presentando carácter oficial.

\section{Aves}

1. Harina de Pluma y vísceras:

Es el producto resultante de las plumas limpias y no descompuestas, hidrolizadas bajo presión y mezcladas con residuos del faenado de aves cosidos y prensados para extracción del óleo (vísceras, cuello, pies), siendo permitida la participación de cadáveres y sangre desde que su inclusión no altere significativamente la composición estipulada.

2. Harina de pluma hidrolizada:

Es el producto resultante de la cocción bajo presión de plumas limpias y no descompuestas, obtenidas en el faenado de aves, siendo permitida la participación de sangre mientras que su inclusión no altere significativamente su composición media. 
3. Harina de vísceras:

Es el producto resultante de la cocción, secado y molienda de vísceras de aves, siendo permitida la inclusión de cabezas y pies. No debe contener plumas, excepto aquellas que pueden ocurrir no intencionalmente, y ni residuos de incubatorio y de otras materias extrañas a su composición. No debe presentar contaminación con cáscara de huevo.

4. Harina de residuos de incubación:

Es el producto resultante de la cocción, secado y molienda de la mezcla de cáscaras de huevos, huevos infértiles y no eclocionados, pintos no viables y los descartados, removida la grasa.

5. Harina de vísceras con huesos:

Es el producto semejante la harina de vísceras con la inclusión de huesos y cartílagos obtenidos como residuos de la carne mecánicamente separada (CMS).

6. Harina de vísceras con huesos y residuos de incubación:

Es el producto semejante a la harina de vísceras con la inclusión de huesos y cartílagos obtenidos como residuos de la carne mecánicamente separada (CMS) y residuos de incubación (cáscaras de huevos, huevos infértiles y no eclosionados, pollos no nacidos y los descartados). 


\begin{tabular}{|c|c|c|c|c|c|c|c|}
\hline PARÂMETROS & UNIDAD & $\begin{array}{c}\text { H. Pluma y } \\
\text { víscera }\end{array}$ & $\begin{array}{l}\text { H.Pluma } \\
\text { hidrolis. }\end{array}$ & H. Vísceras & $\begin{array}{l}\text { H. Resid } \\
\text { incuba. }\end{array}$ & $\begin{array}{l}\text { H.Víscera } \\
\text { c/huesos }\end{array}$ & $\begin{array}{c}\text { H. Víscera } \\
\text { c/huesos y resid. } \\
\text { incuba. }\end{array}$ \\
\hline Unidad (máximo) & $\%$ & 8,00 & 10.00 & 8,00 & 8,00 & 8,00 & 8,00 \\
\hline Proteína Bruta (mínimo) & $\%$ & 62,00 & 80.00 & 55,00 & 25,00 & 52,00 & 54,00 \\
\hline Extracto Etéreo (mínimo) & $\%$ & 7,00 & 2,00 & 10.00 & 10.00 & 10.00 & 11,00 \\
\hline Materia Mineral (máximo) & $\%$ & 17,00 & 4,00 & 15,00 & 60.00 & 22,00 & 25,00 \\
\hline Calcio (máximo) & $\%$ & 6,00 & - & 5,00 & 20.00 & 8,50 & 9,00 \\
\hline Fósforo (mínimo) & $\%$ & 1,10 & - & 1,50 & 0.50 & 2,50 & 2,00 \\
\hline $\begin{array}{c}\text { Digestibilidad en } \\
\text { Pepsina 1:10.000 a 0.02\% } \\
\text { en } \mathrm{HCl} 0.075 \text { N (mínimo) }\end{array}$ & $\%$ & 45,00 & 40.00 & 60.00 & - & 60.00 & 60.00 \\
\hline Acidez (máximo) & $\mathrm{mg} \mathrm{NaOH} / \mathrm{g}$ & 3,00 & 2,00 & 3,00 & 3,00 & 3,00 & 3,00 \\
\hline Índice de Peróxido (máximo) & meq/1000g & 10.00 & 10.00 & 10.00 & 10.00 & 10.00 & 10.00 \\
\hline Salmonela & & \multicolumn{6}{|c|}{ ausencia en $25 \mathrm{~g}$} \\
\hline $\begin{array}{c}\text { Retención de } \\
\text { tamiz 3,4mm (máximo) }\end{array}$ & $\%$ & 0.00 & 0.00 & 0.00 & 0.00 & 0.00 & 0.00 \\
\hline $\begin{array}{c}\text { Retención de } \\
\text { tamiz 2mm (máximo) }\end{array}$ & $\%$ & 5,00 & 5,00 & 5,00 & 5,00 & 5,00 & 5,00 \\
\hline $\begin{array}{c}\text { Retención de } \\
\text { tamiz 1,68mm (máximo) }\end{array}$ & $\%$ & 10.00 & 10.00 & 10.00 & 10.00 & 10.00 & 10.00 \\
\hline
\end{tabular}




\section{Anexo 2: Entrevista a Clientes}

\section{CLIENTE SAN FERNANDO \\ Ficha Técnica - Estudio Exploratorio- Entrevista a Profundidad}

\section{Objetivos de la investigación}

Recopilar información relevante sobre la relación comercial que mantienen las empresas San Fernando y Los Ferroles, identificar el nivel de satisfacción de San Fernando como cliente, expectativas, principales aspectos que valoran, entre otros.

\section{Contenido}

Técnica: $\quad$ Entrevista de escalonamiento (Malhotra, 2008, p. 158).

Instrumento: Las preguntas se desarrollaron en base a la guía de pautas sobre la información interna de la empresa, sus características principales y en el entorno en el que se desarrolla.

Fecha de campo: $\quad$ El 22 de septiembre de 2016

Lugar: $\quad$ En las oficinas de San Fernando (San Isidro)

Responsable: $\quad$ Yiesmin Zaad Oporto, estudiante de Maestría del Programa de

Ciencias Empresariales de la Escuela de Postgrado de la

Universidad San Ignacio de Loyola.

\section{Perfil del Participante}

Nombre: $\quad$ Elizabeth Rischmoller

Edad: $\quad 45$

Nacionalidad: Peruana 
Formación: $\quad$ Ingeniera zootecnista

Puesto: $\quad$ Jefe de Nutrición

\section{Cuestionario}

\section{Guía de pautas}

\section{a) Frase de presentación}

Buenos días/tardes. Mi nombre es Yiesmin Zaad Oporto, estudiante de Maestría de la Escuela de Post Grado de la Universidad San Ignacio de Loyola. Como parte del trabajo de tesis final, estamos trabajando en la elaboración de un plan estratégico para la empresa Los Ferroles; en tal sentido, deseamos realizarle una entrevista para poder conocer un poco más a detalle la relación comercial que mantiene San Fernando con Los Ferroles y cuál es la percepción que tienen sobre sus productos y el nivel de servicio; cabe señalar que toda la información recopilada tendrá fines académicos exclusivamente.

\section{b) Permiso para grabar}

Para agilizar la toma de la información, resulta de mucha utilidad grabar la conversación. Tomar notas a mano demora mucho tiempo y se pueden perder detalles importantes de las respuestas. ¿Existe algún inconveniente en que grabemos la conversación?

\section{c) Listado de preguntas}

\section{Bloque 1- Antecedentes y primer contacto con Los Ferroles}

1. ¿Cómo y hace cuánto fue el primer contacto con Los Ferroles? 
2. ¿Cómo surge la necesidad del uso de harinas proteicas por parte de San Fernando?

3. ¿Tuvieron contacto con otras empresas proveedoras de las mismas harinas?

4. ¿Evaluaron sus productos?

5. ¿Cuál fue el motivo principal por el cual escogieron a Los Ferroles como proveedor?

\section{Bloque 2- El valor del producto}

1. ¿Cuál es la característica que más valora de los productos de la empresa Los Ferroles?, ¿Y lo que menos valora?

2. ¿Qué cambiaría en el producto o servicio?

3. En general, ¿cómo ha sido su experiencia usando el producto?

4. ¿Cuán satisfecho se siente con el servicio post venta que ofrece Los Ferroles?

5. ¿Cuán satisfecho se siente con el servicio de maquila que ofrece Los Ferroles?

6. ¿Cuán satisfecho se siente con el servicio de entrega que ofrece Los Ferroles?

7. ¿Existen en el mercado otros proveedores que puedan suplir el producto de Los Ferroles?, ¿Cuáles?

8. ¿Considera que hay productos sustitutos para el de Los Ferroles?

9. ¿Sabe si además de San Fernando existen otras empresas de la competencia que también usan este tipo de harinas?

\section{Bloque 3 - La relación con Los Ferroles}

1. ¿Qué fortalezas ha identificado en Los Ferroles como empresa?

2. ¿Qué oportunidades de mejora ha identificado? 
3. ¿Cómo es la comunicación que mantiene con Los Ferroles?, ¿Por qué medios lo hace?

4. ¿Considera a Los Ferroles como un proveedor de confianza?

5. ¿Considera que Los Ferroles es un socio estratégico para San Fernando?, ¿Por qué?

6. ¿Tiene alguna propuesta de mejora para el producto y/o servicio que brinda Los Ferroles? 


\section{REPORTE DE ENTREVISTA A CLIENTE SAN FERNANDO}

\section{Aspectos Generales}

a. La entrevista se realizó el día martes 4 de octubre del 2016 en las oficinas de San Fernando, ubicadas en San Isidro.

b. La persona entrevistada fue la señora Elizabeth Rischmoller, quien ocupa el puesto de Jefe de nutrición, y tiene a cargo el departamento de Nutrición de la empresa.

c. La entrevista inició a las 7:00 pm y concluyó a las 9:45pm; fue realizada de manera fluida y con mucha apertura por parte del entrevistado.

\section{Desarrollo}

\section{Antecedentes}

Se inició la entrevista consultándole cómo surgió la necesidad del uso de las harinas proteicas provenientes del rendering. Nos comentó que a través del rendering se da solución a dos problemáticas provenientes del negocio avícola: (a) escasez, precio alto y calidad no estandarizada de la torta de soya (fuente de proteína del alimento balanceado para ave) y (b) tratamiento y destino de desechos generados de la planta de faenado. Asimismo, comentó que los diversos asesores que visitaron la empresa así como en los congresos en que participó, se recomendaba el uso de este tipo de harinas dado que en países de la región como Brasil se venía utilizando exitosamente. 
Sobre las pruebas iniciales, la entrevistada señaló que adicionalmente a Los Ferroles se contactaron con la empresa Technofeed y realizaron pruebas con los productos de ambas empresas, con la finalidad de validar la calidad. Como resultado de ello, se obtuvo que el producto de Los Ferroles presentó menor variación en su composición nutricional. Asimismo, otros de los factores que determinó trabajar con los Ferroles fue la apertura y acceso al control de sus procesos, el cual era un requisito básico para asegurar la calidad del producto terminado.

\section{Relación comercial con Los Ferroles}

La entrevistada inició describiéndonos su primer acercamiento con Los Ferroles, el cual fue en el año 2005, y duró sólo unos meses. Comentó que en ese entonces no realizaron pruebas de calidad ni validaciones, la compra fue más que nada por referencia de empresas y asesores del sector. Luego de algunos años, a inicio del 2012, se restablece el contacto con Los Ferroles a través de su Director Rogelio Romero, retomándose la relación comercial. San Fernando venía buscando insumos alternativos que pueda reemplazar el valor nutricional de la torta de soya a un menor costo y con el mismo nivel proteico. Durante esta etapa, se realizaron pruebas experimentales y validaciones del producto y proceso para asegurar la calidad de la harina, y sobre todo garantizar que se cumplía con los estándares de inocuidad requeridos por San Fernando. Con los resultados conformes de las validaciones, en mayo de ese mismo año se aprueba el contrato para maquilar los subproductos de las plantas de beneficio, inician con la planta de Huaral, y meses después se adiciona la de Chincha. El contrato de maquila que se establece con Los Ferroles, involucraba la supervisión del proceso, tal es así que se asigna un supervisor de producción y otro de calidad para el monitoreo del proceso productivo. Durante este primer año de 
maquila, ambas empresas trabajaron en la mejora del proceso, se implementaron controles, se estandarizaron procesos y se establecieron normas de calidad e inocuidad. En noviembre del 2013 se inaugura la planta de procesamiento de plumas con maquinaria automatizada y con tecnología de punta con lo cual se garantiza la calidad de la harina.

Actualmente los volúmenes que se comercializan son los siguientes:

(a) Maquila: 250 toneladas de harina de pluma y 200 toneladas de harina de vísceras mensuales.

(b) Compra: 300 toneladas de harina de pluma y 120 toneladas de harina de vísceras mensuales.

\section{Perspectiva Cliente}

Al consultarle sobre lo que más valora del producto y servicio brindado por Los Ferroles indicó lo siguientes aspectos:

(a) Apertura a la supervisión del proceso productivo.

(b) Alto grado de inversión en tecnología.

(c) Alta calidad del producto.

Respecto a las oportunidades de mejora mencionó los siguientes aspectos:

(a) Alta rotación el personal clave que coordina con San Fernando (jefe de calidad) lo cual genera que no exista continuidad en el trabajo.

(b) Falta de control del proceso. Orden y limpieza de la planta.

(c) Mejorar administración de almacén, asegurando la adecuada rotación del producto. 
Sobre la comunicación indicó que es fluida y que tienen acceso a la supervisión del proceso productivo, asimismo, se mantiene reuniones mensuales con el equipo técnico de ambas empresas. Finalmente la entrevistada comentó que si bien Los Ferroles es un socio estratégico el factor confianza aún se está trabajando.

Dentro de las alternativas de proveedores que pueden ofrecerle el mismo producto mencionó a las empresas Technofeed y Chimú Agropecuaria; respecto a los productos sustitutos comentó que existen en el mercado varias alternativas como la harina de girasol, canola, corngluten y DDGS (granos secos de destilería con solubles). 


\section{CLIENTE - PROVEEDOR SAN FERNANDO}

\section{Ficha Técnica - Estudio Exploratorio- Entrevista a Profundidad}

\section{Objetivos de la investigación}

Recopilar información relevante sobre el aspecto técnico del tratamiento de los subproductos (vísceras y plumas) en la planta de producción de San Fernando, así como la principal problemática y oportunidades de mejora con respecto a este tema.

\section{Contenido}

Técnica: $\quad$ Entrevista de escalonamiento (Malhotra, 2008, p. 158).

Instrumento: Las preguntas se desarrollaron en base a la guía de pautas sobre la información interna de la empresa, sus características principales y en el entorno en el que se desarrolla.

Fecha de campo: $\quad$ El 05 de mayo de 2017

Lugar: $\quad$ En la planta de beneficio de aves de San Fernando - Chincha.

Responsable: $\quad$ Yiesmin Zaad Oporto, estudiante de Maestría del Programa de Ciencias Empresariales de la Escuela de Postgrado de la Universidad San Ignacio de Loyola.

\section{Perfil del Participante}

Nombre: $\quad$ Ever Cantoral

Edad: $\quad 49$

Nacionalidad: Peruana

Formación: $\quad$ Ingeniero pesquero

Puesto: Jefe de planta 


\section{Cuestionario}

\section{Guía de pautas}

\section{a) Frase de presentación}

Buenos días/tardes. Mi nombre es Yiesmin Zaad Oporto, estudiante de Maestría de la Escuela de Post Grado de la Universidad San Ignacio de Loyola. Como parte del trabajo de tesis final, estamos trabajando en la elaboración de un plan estratégico para la empresa Los Ferroles; en tal sentido, deseamos realizarle una entrevista para poder conocer un poco más a detalle el aspecto técnico del manejo de los subproductos (pluma y vísceras) en la planta y la forma en que se despacha a Los Ferroles; cabe señalar que toda la información recopilada tendrá fines académicos exclusivamente.

\section{b) Permiso para grabar}

Para agilizar la toma de la información, resulta de mucha utilidad grabar la conversación. Tomar notas a mano demora mucho tiempo y se pueden perder detalles importantes de las respuestas. ¿Existe algún inconveniente en que grabemos la conversación?

\section{c) Listado de preguntas}

\section{Bloque 1- Entendimiento del proceso productivo}

1. ¿Cuáles son las etapas del proceso de beneficio de las aves?

2. ¿Qué tipo de maquinaria se emplea?

3. ¿Cuáles son las etapas más críticas del proceso?

4. ¿En qué etapa se separan las plumas y vísceras del ave? 
5. ¿Qué porcentaje del peso del pollo representan las plumas y las vísceras?

6. ¿Se emplea alguna tecnología especial para estos procesos?

7. ¿Por cuánto tiempo y donde almacenan los subproductos generados del procesamiento? ¿Qué tiempo de vida tienen estos subproductos?

8. Para complementar la explicación, ¿Podríamos hacer un recorrido por planta para observar los procesos?

\section{Bloque 2- El tratamiento y despacho de los subproductos}

1. ¿Cuáles son las etapas del proceso de segregación y despacho de los subproductos?

2. ¿Qué aspectos son los más críticos en este proceso?

3. ¿Cómo evitan o controlan la contaminación?

4. ¿Cuánto personal interviene en estas operaciones?

5. ¿Cuánto dura el proceso de despacho de los subproductos? ¿A qué hora Los Ferroles recoge los subproductos?

6. ¿Qué tipo de vehículos emplea? ¿Requieren de algunas condiciones o permisos especiales?

7. ¿Cómo se controla la carga en el camión? ¿Se generan memas durante el transporte hasta la planta de Los Ferroles en el Callao?

8. ¿Qué pasa si no se recogen los subproductos de un día de producción?

9. Si no hicieran harinas con los subproductos, ¿qué otro uso se les darían?

10. ¿Alguna vez procesó San Fernando sus subproductos para hacer harinas?

11. ¿Cuáles son los aspectos que se podrían mejorar para hacer más eficientes las operaciones tanto por el lado de San Fernando como por Los Ferroles? 


\section{Bloque 3 - La relación con Los Ferroles}

1. ¿Qué fortalezas ha identificado en Los Ferroles como empresa?

2. ¿Qué oportunidades de mejora ha identificado?

3. ¿Cómo es la comunicación que mantiene con Los Ferroles?, ¿Por qué medios lo hace?

4. ¿Desde cuándo inició el abastecimiento de plumas para Los Ferroles?

5. ¿Se realizaron pruebas previas? ¿Cómo fueron las coordinaciones?

6. ¿Considera a Los Ferroles como un proveedor de confianza?

7. ¿Considera que Los Ferroles es un socio estratégico para San Fernando?, ¿Por qué?

8. ¿Tiene alguna propuesta de mejora para el producto y/o servicio que brinda Los Ferroles? 


\section{REPORTE DE ENTREVISTA A CLIENTE - PROVEEDOR SAN FERNANDO}

\section{Aspectos Generales}

a. La entrevista se realizó el día viernes 5 de mayo de 2017 en la planta de beneficio de pavos de San Fernando, ubicada en Chincha Baja, Ica.

b. La persona entrevistada fue el ingeniero Ever Cantoral, quien ocupa el puesto de Jefe de planta, y tiene a cargo todos los procesos internos dentro de la planta.

c. La entrevista inició a las 10:00 am y concluyó a las 3:00pm; fue realizada de manera fluida y con mucha apertura por parte del entrevistado, y su equipo técnico

\section{Desarrollo}

\section{Sobre el proceso productivo}

La entrevista inició consultándole sobre las etapas y características del proceso de beneficio de las aves, a lo cual nos describió a detalle las etapas y principales controles del proceso, las cuales se indican:

a. Recepción de las aves: las aves llegan a granel, sin jabas, en camiones cerrados enmallados para la mejor ventilación de las aves.

b. Colgado: se colocan en los ganchos de la cadena transportadora colgados de las patas.

c. Aturdimiento: una vez colgadas las aves, pasan sus cabezas a través de una tina con agua donde reciben una descarga eléctrica que las desmaya.

d. Deguello y desangrado: una vez inmóviles, se les corta la yugular de forma manual para la expulsión de la mayor cantidad de sangre. Es importante que el ave no esté muerta para que el corazón siga bombeando y ayude a la salida de la sangre. 
e. Escaldado: las aves son sumergidas en un tanque de agua, cuya temperatura oscila alrededor de $\operatorname{los} 60^{\circ} \mathrm{C}$; esto ayuda a que se abran los poros y facilite el posterior pelado.

f. Pelado: las aves pasan a través de dos máquinas peladoras en línea, las cuales desprenden las plumas con ayuda de dedos de jebe giratorios.

g. Eviscerado: en esta etapa, se realiza el corte abdominal y se retira el paquete intestinal del ave (intestinos, molleja, hígado y corazón). Cada órgano se almacena por separado para su posterior tratamiento.

h. Enfriado y desinfección: la carcasa ingresa a grandes tanques de agua helada para reducir su temperatura a menos de $5^{\circ} \mathrm{C}$. Tiene un tiempo de permanencia de alrededor de 60 minutos.

i. Trozado: las carcasas enteras son trozadas manual y/o automáticamente, según los cortes que se deseen obtener.

j. Empaque: las piezas trozadas o carcasas enteras son embolsadas.

k. Refrigeración o Congelamiento: según el requerimiento, los productos son congelados, o almacenados en refrigeración para su posterior despacho.

Sobre el tipo de maquinaria empleada, comentó que cuentan con tecnología moderna para la mayoría de los procesos ulteriores, como el trozado, fileteo y molienda; el resto de la maquinaria es antigua o de fabricación nacional. Indicó también, que la planta cuenta con certificación ISO 9001, ISO 14001 y HACCP, lo cual asegura la calidad de la producción y que los procesos están orientados a prevenir la contaminación ambiental. Cuentan con una moderna planta de tratamiento de aguas residuales. 


\section{Sobre los subproductos para el rendering}

En cuanto a los subproductos generados (plumas y vísceras), el ingeniero indicó que la pluma húmeda representa aprox. el 12\% del peso del ave, y las vísceras el 6\%. Ambos subproductos son separados durante el proceso productivo y almacenados en contenedores adecuados para su posterior tratamiento. Se emplea sólo una persona para el control de estas operaciones:

a. Las plumas: son conducidas a través de las canaletas de agua desde la sala de procesos hasta la zona exterior de la planta, donde ingresan a un tambor rotatorio para una primera separación y limpieza. Luego son elevadas a través de transportadores mecánicos a la tolva de descarga para su despacho a los camiones de Los Ferroles.

b. Las vísceras y sangre: son almacenadas en contenedores independientes hasta el momento del despacho a los camiones. A la sangre se le realiza una pre cocción para reducir el porcentaje de humedad, y reducir el volumen a ser transportado. Las vísceras se despachan en cilindros plásticos, y la sangre cocida es ensacada.

Nos indicaron que si bien la planta actualmente no cuenta con equipos apropiados para producir harinas, anteriormente cuando pertenecía a otro dueño, antes que la planta fuera comprada por San Fernando, sí se fabricaban harinas de plumas y de vísceras. Actualmente, dado el bajo volumen generado de estos subproductos por la estacionalidad de la venta del pavo, no es rentable la producción. El contar con Los Ferroles como acopiador y procesador de estas harinas es de gran valor para la empresa, pues adicional a la producción de las harinas, ayuda a reutilizar el desecho propio de la producción, contribuyendo a disminuir la contaminación. 
Sobre el proceso de recojo de los subproductos de la planta, el entrevistado señaló que Los Ferroles envía camiones cerrados herméticos para evitar la contaminación durante el traslado; estos camiones pertenecen a una EPS-RS, y cuentan con los permisos necesarios indicados por el ministerio de salud. Los camiones son pesados a la salida de la planta, pero a la llegada a la planta de Los Ferroles registran un peso menor debido a la merma (agua). Es por ello, que la principal mejora sobre la cual se requiere trabajar, es la reducción del porcentaje de humedad de la pluma. Con respecto a este tema, la planta conjuntamente con Los Ferroles, viene desarrollando un proyecto de mejora para prensar la pluma previa a su despacho, a fin de reducir al máximo la humedad, y evitar falsos fletes por agua.

A continuación se muestra el perfil de proyecto de mejora a desarrollar para reducir la humedad de las plumas, y hacer más eficiente el transporte desde Chincha hasta la planta del Callao. La información fue brindada por el entrevistado y su equipo técnico:

\section{PROYECTO DE MEJORA PARA PRENSADO DE PLUMA}

\section{Antecedentes}

Actualmente la recolección y transporte de las plumas representa para Los Ferroles uno de los principales costos, dado que son aproximadamente $500 \mathrm{Km}$ de recorrido diario entre Chincha y el Callao.

A continuación se detalla el proceso de recolección de plumas en la planta de beneficio de pavos de San Fernando:

- Canalización de las plumas en la canaleta, luego del pelado de las aves

- Separación de las plumas e impurezas en tambor rotatorio

- Descarga a camión. 


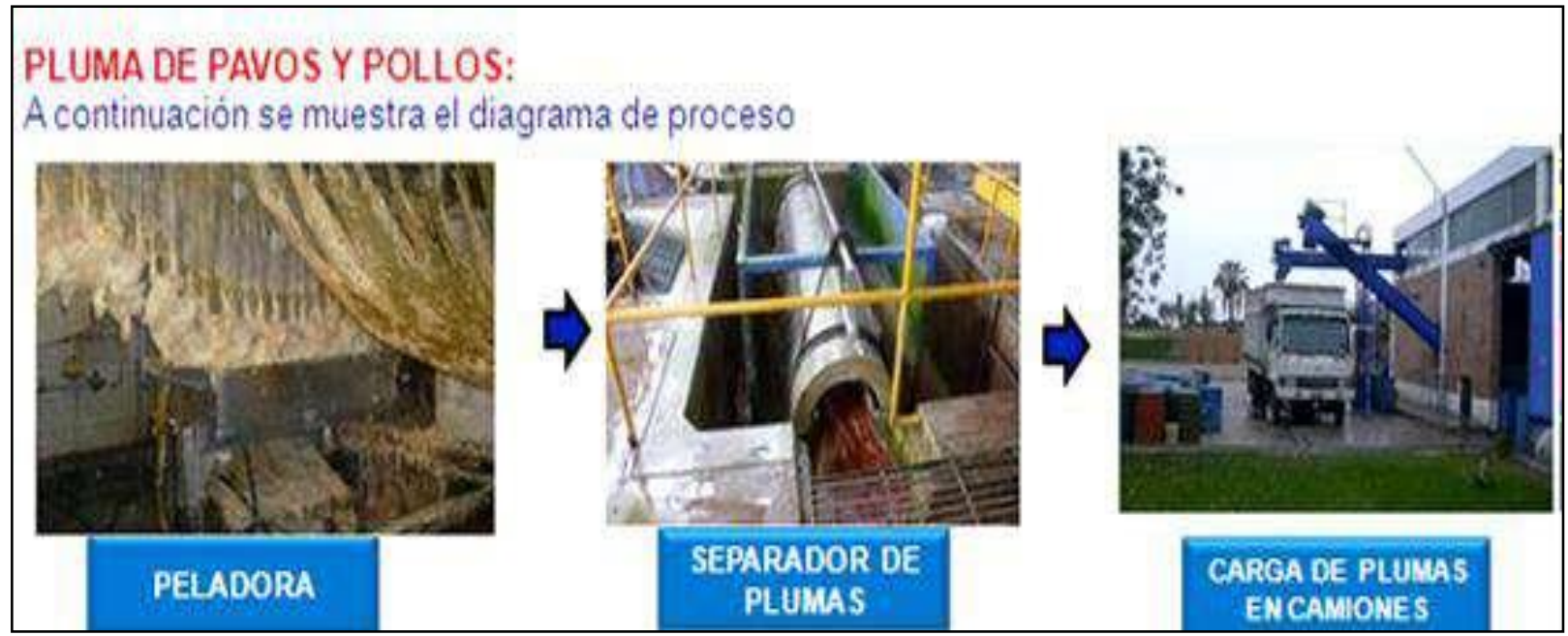

\section{Problema}

El sistema de segregación, limpieza y despacho de las plumas, no contempla en ninguna de las etapas la eliminación de la humedad, por lo que la pluma es despachada acompañada de un alto porcentaje de agua, generando un mayor volumen.

\section{Propuesta}

Instalación de un sistema de prensado de plumas para reducir el porcentaje de humedad, y por tanto reducir el volumen a ser transportado.

\section{Beneficios}

- Mejor calidad de las plumas a la llegada a la planta del Callao, puesto que a menor nivel de humedad, menor desarrollo de microorganismos.

- Reducción de la contaminación durante el transporte, reducción de olores y derrame de líquidos.

- Reducción de la merma de transporte 
- Incremento de la capacidad de transporte de plumas, puesto que se transporta sólo pluma y no agua.

- Reducción del costo unitario del transporte, por mayor capacidad.

- Reducción del tiempo de despacho.

\section{Inversión/Costos}

Los costos de implementación del sistema prensa pluma, fueron estimados por el equipo técnico de mantenimiento de la planta de San Fernando:

Inversión:

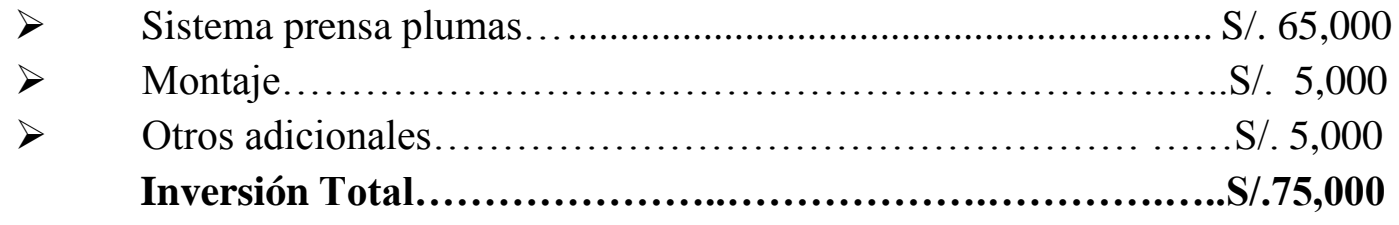

Se estima que esta inversión, generará un ahorro de aproximadamente $10 \%$ en el costo de transporte.

\section{Relación comercial con Los Ferroles}

El entrevistado señaló que mantiene una buena relación con los señores Romero, sobre todo en el aspecto técnico, muestran mucha apertura a nuevas ideas y cambios requeridos. La comunicación es fluida a través de diferentes medios, y los mantienen informados de los cambios o pruebas que realizan. 
Anexo 3: Entrevista a la Competencia

\section{COMPETENCIA - EMPRESA ALIMENCORP}

Ficha Técnica - Estudio Exploratorio- Entrevista a Profundidad

\section{Objetivos de la investigación}

Recopilar información relevante sobre los principales competidores de Los Ferroles, dentro de la industria del rendering.

\section{Contenido}

Técnica: $\quad$ Entrevista de escalonamiento (Malhotra, 2008, p. 158).

Instrumento: Las preguntas se desarrollaron en base a la guía de pautas sobre la información interna de la empresa, sus características principales y en el entorno en el que se desarrolla.

Fecha de campo: $\quad$ El 12 de noviembre de 2016

Lugar: $\quad$ Av. Petit Thouars 3085, San Isidro.

Responsable: Debbie Soto, estudiante de Maestría del Programa de Ciencias Empresariales de la Escuela de Postgrado de la Universidad San Ignacio de Loyola.

\section{Perfil del Participante}

Nombre: Henry Burga Toledo

Edad: 35 años

Nacionalidad: Peruana

Formación: Administrador de Empresas

Puesto: Gerente General 


\section{Cuestionario}

\section{Guía de pautas}

\section{a) Frase de presentación}

Buenos días. Mi nombre es DEBBIE SOTO, estudiante de Maestría de la Escuela de Post Grado de la Universidad San Ignacio de Loyola. Como parte del trabajo de tesis final, estamos realizando una investigación sobre la industria del rendering; en tal sentido, deseamos realizarle una entrevista para poder conocer su opinión sobre el uso de harinas proteicas provenientes de esta industria; cabe señalar que toda la información recopilada tendrá fines académicos exclusivamente.

\section{b) Permiso para grabar}

Para agilizar la toma de la información, resulta de mucha utilidad grabar la conversación. Tomar notas a mano demora mucho tiempo y se pueden perder detalles importantes de las respuestas. ¿Existe algún inconveniente en que grabemos la conversación?

\section{c) Listado de preguntas}

\section{Bloque 1-Antecedentes}

1. ¿Cómo se inician en la industria del rendering?

2. ¿Quiénes son los fundadores?

3. ¿Cuáles fueron los primeros productos con los que iniciaron las producciones?

\section{Bloque 2 - Industria Rendering}

1. ¿Cómo ve a la industria del rendering en el Perú actualmente? 
2. ¿Y cómo ve a la industria del rendering de aquí a 5 años?

3. ¿Cómo se encuentra la industria en relación a los países de la región?

4. ¿Cuál es el posicionamiento de Alimencorp en el mercado peruano?

5. ¿Quiénes considera que son los líderes del mercado?

6 ¿Existen barreras para el ingreso a la industria del rendering? ¿Son altas?

7. ¿Qué productos sustitutos a las harinas proteicas del rendering existen en el mercado? ¿Qué proveedores las ofrecen?

8. ¿Qué tipo de proveedores les abastecen de las materias primas?

9. ¿Quiénes son los principales proveedores que existen en el mercado?

10. ¿Cuentan con alguna certificación de Sistemas de Calidad?

\section{Bloque 3 - Gestión Comercial}

1. ¿Qué productos ofrecen al mercado?

2. ¿A qué tipo de industria se dirigen?

3. ¿En la industria del rendering, la producción se trabaja sobre pedido del cliente?, ¿o se generan stocks para la venta al mercado?

4. ¿Qué herramientas de marketing utilizan?

5. ¿Cómo fidelizan a sus clientes?

6. ¿Cuáles consideran que son sus ventajas competitivas?

7. ¿En esta industria, se brinda servicio post venta a los clientes? ¿Qué tipo de servicio?

\section{Bloque 4 - Proceso productivo}

1. ¿Cómo es el proceso del rendering? 
2. ¿Cuál es el nivel de tecnología requerida en esta industria?

3. ¿Se puede producir en la misma línea de producción diferentes tipos de productos (avícolas, pecuario, mascotas) ¿O cada tipo de producto requiere una línea diferente?

4. ¿Cómo evalúan la calidad de su producto?

5. ¿Trabajan al máximo de su capacidad?

6. ¿Cuántos turnos de trabajo tienen?

7. ¿Cuánto personal trabaja en planta?

8. ¿Cuáles son los beneficios del uso de estas harinas para el cliente?

9. ¿Cuáles son las desventajas del uso de estas harinas para el cliente?

10. ¿Cuál es el impacto ambiental que genera el proceso productivo en esta industria? 


\section{REPORTE DE ENTREVISTA A LA COMPETENCIA \\ EMPRESA ALIMENCORP SAC}

\section{Aspectos Generales}

a. La entrevista se realizó el día 12 de noviembre de 2016, en las oficinas de Alimencorp Av. Petit Thouars 3085, San Isidro.

b. La persona entrevistada fue el ingeniero Henry Burga, quien actualmente ocupa el cargo de gerente general de Alimencorp.

c. La entrevista inició a las 11 am y concluyó a las 1:30pm, fue realizada de manera fluida y con mucha apertura de información por parte del entrevistado.

\section{Desarrollo}

\section{Antecedentes}

Al consultar al entrevistado sobre los orígenes de la empresa, comentó que datan de 15 años atrás, con la fundación de la empresa COINSA SAC (Complejo Industrial Santa Arminda), quienes inician la producción de harinas de rendering con subproductos de la industria pecuaria. Años más tarde, en el 2006, la empresa cambia de razón social a North Pacific SAC. En el año 2013, el Ing. Amadeo Burga compra la empresa North Pacific SAC y crea la empresa Alimencorp SAC, iniciando así sus operaciones en el rubro. Desde entonces hasta la fecha, la empresa ha implementado una serie de mejoras en los procesos productivos y administrativos que ha permitido ubicarlos como líderes en el sector rendering (pecuario).

Asimismo, hasta el año 2013 la empresa se dedicó al procesamiento de subproductos cárnicos (harina de carne y hueso) a través de la exportación teniendo como cliente 
clave el mercado Ecuatoriano. El entrevistado comentó que en esa etapa, el mercado ecuatoriano era poco técnico, solo se encontraba enfocado en la proteína propiamente como factor de demanda del subproducto, por lo tanto no era de tan buena calidad como el que actualmente procesan. Debido a problemas políticos gubernamentales, asimismo, las altas barreras arancelarias que se presentaron se vieron obligados a parar las negociaciones y venta de las harinas en ese país.

Después de seis meses de lo ocurrido en Ecuador ingresaron al mercado nacional habiendo realizado un estudio previo de los escenarios externos del sector, donde analizaron desventajas y beneficios para aplicar su estrategia empresarial en mercado peruano.

\section{Inicios de Alimencorp}

\section{Estrategia inicial}

Cuando la dirección de la gerencia general fue adquirida por Henry Burga Toledo, hijo del dueño de la compañía, como estrategia inicial desarrolló una reingeniería integral en toda la organización, enfocado en el principio de innovación de valor del modelo de ocèano azul, donde buscó dejar a un lado la competencia entre las empresas ampliando el mercado a través de la innovación, ofreciendo una diversidad de harinas proteicas para sus clientes.

\section{Proceso de reingeniería organizacional}

Dentro del proceso de reingeniería organizacional desarrollado, el entrevistado mencionó que unos de sus objetivos fue apostar por el talento humano, dado que el enfoque en los valores es altamente rentable. Para ello, desarrollan capacitaciones 
continuas para sus colaboradores, dándole prioridad a sus operarios, quienes son considerados altamente importantes dentro del proceso productivo, asimismo; a través del diálogo fluido entre los colaboradores se realiza mejoras continuas en el proceso de producción. Una de las buenas prácticas orientadas al enfoque del capital humano, es la formación de equipos multidisciplinarios donde se realizan feedback continuos en cada área para proponer, mejorar o corregir procedimientos en toda la cadena del proceso, lo que genera compromiso en los colaboradores.

\section{Industria Rendering}

El entrevistado comentò que hace trece años la industria del rendering era totalmente incipiente, con alto grado de informalidad, con procesos artesanales y sin profesionalización. Actualmente la industria del rendering se encuentra en crecimiento y aún tiene un largo camino por recorrer, más aún si es comparada con el desarrollo del rendering en países como Brasil y España, dado que las normas regulatorias son estrictas; sin embargo en el Perú no se cuenta con normas que regulen la actividad de la industria.

Sobre las empresas que integran la industria, mencionó que se divide en dos agentes, los formales y los informales. Los informales operan en un escenario no regulado, sin tecnología, sin normas, en contaminación, estas empresas se ubican básicamente en el norte y sur de Lima. Dentro de los agentes formales se encuentran tres empresas competidoras: Technofeed, Los Ferroles y Alimencorp. Asimismo, existen empresas del sector avícola que realizan su propio tipo rendering tales como: San Fernando, Avinka, Rico Pollo. 


\section{Barreras de ingreso al sector}

Respecto a las barreras que existen en el mercado peruano para el ingreso de nuevos competidores en la industria, el entrevistado mencionó que actualmente las barreras de la industria son altas en comparación con el escenario de hace algunos años, dado que si bien el gobierno no tiene una regulación específica, actualmente existen normas de salubridad e inocuidad que de alguna forma controlan el proceso productivo. Otra barrera en nuestro país es el acceso a la materia prima pues ésta es escasa.

\section{Liderazgo}

Sobre el liderazgo de las empresas competidoras que integran la industria, enfocado al volumen de producción mensual, el entrevistado mencionó que Alimencorp se encuentra liderando el mercado en ese factor, con una producción mensual de 1,600 toneladas, seguidos por Los Ferroles con 1,300 toneladas y Technofeed 1,000 toneladas aproximadamente.

\section{Proveedores}

Respecto a los proveedores que participan en la cadena de proceso de producción, se encuentran los centros de beneficio, los centros de acopiadores, indicó que se caracterizaban hasta hace algunos años por trabajar de forma monopólica muy concentrados, siendo alto el poder de negociación con ellos, por lo que la empresa ha venido trabajando arduamente para integrar a sus proveedores en sus procesos formales, habiendo logrado captar el $15 \%$ de proveedores formales en el sector estableciendo alianzas estratégicas. 


\section{Productos Sustitutos}

Sobre los productos sustitutos existentes en el mercado, comentó que se tiene a la harina de pescado, esta harina contiene un alto valor proteico sin embargo su precio es mayor al de las harinas de subproductos avícolas. Otro sustituto, es la torta de soya siendo de origen vegetal, explicó que la torta soya podría competir en precio con la harina de pluma y víscera pero que no es altamente digestible por lo que el ave no aproveche todo el producto dado que genera alta cantidad de excreta.

\section{Gestión Comercial}

Cuando Henry Burga, asume la gerencia general de Alimencorp también asume la responsabilidad de la Gestión Comercial. Para el desarrollo de las estrategias en la gestión comercial de la compañía, integra a su staff de especialistas a un experto en marketing. Así como para el desarrollo de productos trabaja en conjunto con zootecnistas, nutricionistas, ingenieros de industrias alimentarias y veterinarios para la creación y adaptación de fórmulas que se adecuen a las necesidades del cliente. Luego de haber analizado la industria y los factores externos presentados, su estrategia fue la de liderazgo de categoría en la industria,

\section{Productos}

Dentro de su cartera de productos, ésta se encuentra diversificada en los siguientes productos: (a) Harina de subproductos de origen animal, se oferta al mercado con la marca PROTEIKA. (b) Harina de carne y hueso (de alto valor nutricional) se oferta al mercado con la marca HARICAR. (c) Concentrado nutricional plus (alto contenido de harina de pescado), (de) Harina de plumas hidrolizada, (e) Proteika Plus (harina de subproducto de origen animal premium). 
Alimencorp a diferencia de la competencia no solo abarca el sector pecuario, la empresa ha diversificado su oferta de productos al mercado de mascotas, quien actualmente se encuentra en crecimiento. Asimismo, cada producto ofertado es complementario para el desarrollo de la fórmula del alimento balanceado, Respecto a los productos que ofrece la competencia menciona que la empresa Los Ferroles solo produce harina de plumas y la empresa Technofeed solo produce harina mixta por lo que su oferta al mercado es limitada.

\section{Ventaja competitiva}

El entrevistado indica que sus ventajas competitivas se enfocan en:

(a) Cuenta con certificación internacional de inocuidad (HACCP).

(b) Ofrecen diferentes líneas de productos tanto para el sector pecuario, mercado de mascotas.

(b) Cuenta con un área de investigación de desarrollo.

(c) Su servicio es personalizado y enfocado a las necesidades del cliente.

(d) Desarrollan servicio de post venta.

(e) Marca que garantiza calidad.

\section{Clientes}

Respecto a sus clientes señala que posee tres tipos de clientes, claramente definidos: (a)Los Consultivos, con quienes desarrolla productos de acuerdo a sus necesidades, realizando pruebas de investigación, el servicio es personalizado, (b) los transaccionales, que son cazadores de precios (c ) los potenciales, quienes trabajan con otras empresas fabricantes de harinas proteicas y/o harinas de origen vegetal es 
por ello que realizan investigaciones continuas con el apoyo de sus socios estratégicos.

Actualmente la empresa atiende al mercado de petfood teniendo como clientes a las empresas Purina y Molitalia, así como también a empresas del sector pecuario.

\section{Marketing Digital}

Para el diseño e implementación de estrategias de marketing, se cuenta con una jefa del área, de gran experiencia y con quien viene trabajando el liderazgo de categoría en la industria. Asimismo, Alimencorp utiliza medios digitales para el desarrollo de promoción de la empresa y de los beneficios de sus productos. Tiene presencia en redes sociales (Facebook) y una página web recientemente creada.

\section{Proceso productivo}

El proceso productivo de la empresa comienza con el recojo de materia prima de los centros de faenado de aves y de ganado, para posteriormente ser llevados a la planta procesadora ubicada en Chilca para la elaboración del producto.

Sus líneas de productos son elaboradas con una misma maquinaria, dependiendo del requerimiento de los clientes. Asimismo, cada lote producido pasa bajo una estricta prueba de calidad, de ésta manera se asegura que se cumpla con los estándares solicitados por los clientes.

Sobre las certificaciones nos comentó que, actualmente la empresa cuenta con la certificación de HACCP (Análisis de Peligros y Puntos Críticos de Control, APPCC en sus siglas en español) que le permite demostrar el compromiso de Alimencorp con la inocuidad de sus procesos, lo cual genera una ventaja competitiva frente a la competencia. 


\section{Responsabilidad Social}

Uno de los valores de la empresa Alimencorp es su preocupación por la comunidad y su compromiso para reducir el impacto ambiental. Actualmente la empresa mantiene planes de labor social y apoyo a la comunidad de Chilca, donde se encuentra ubicada la planta. Asimismo para reducir el impacto ambiental, cuentan con un sistema de gestión de olores el cual hace tres años se redujo al 90\%. Para ello trabajan con un equipo de expertos para la implementación de mejoras en los procesos de tal forma minimizar posibles impactos medioambientales.

\section{Proyección empresarial}

El entrevistado mencionó que dentro de su visión empresarial se encuentra fortalecer su posicionamiento en la industria a través de la consolidación de sus marcas, fortalecer la interdependencia con sus socios estratégicos, volver a la internacionalización mediante la exportación.

Mencionó también que para que lograr que la industria del rendering en el Perú mejore el gobierno necesita establecer una reforma en la normas para llevar un correcto control en los procesos. 
COMPETENCIA - EMPRESA TECHNOFEED

\section{Ficha Técnica - Estudio Exploratorio- Entrevista a Profundidad}

\section{Objetivos de la investigación}

Recopilar información relevante sobre los principales competidores de Los Ferroles, dentro de la industria del rendering.

\section{Contenido}

Técnica: $\quad$ Entrevista de escalonamiento (Malhotra, 2008, p. 158).

Instrumento: Las preguntas se desarrollaron en base a la guía de pautas sobre la información interna de la empresa, sus características principales y en el entorno en el que se desarrolla.

Fecha de campo: $\quad$ El 22 de noviembre de 2016

Lugar: $\quad$ Pasaje Don Oscar 155, zona industrial Acapulco, Callao.

Responsable: Debbie Soto, estudiante de Maestría del Programa de Ciencias Empresariales de la Escuela de Postgrado de la Universidad San Ignacio de Loyola.

\section{Perfil del Participante}

Nombre: Apolinario Blacido Alva

Edad: 60 años

Nacionalidad: Peruana

Formación: Especialista en rendering

Puesto: Administrador General 


\section{Cuestionario}

\section{Guía de pautas}

\section{a) Frase de presentación}

Buenos días. Mi nombre es Debbie Soto, estudiante de Maestría de la Escuela de Post Grado de la Universidad San Ignacio de Loyola. Como parte del trabajo de tesis final, estamos realizando una investigación sobre la industria del rendering; en tal sentido, deseamos realizarle una entrevista para poder conocer su opinión sobre el uso de harinas proteicas provenientes de esta industria; cabe señalar que toda la información recopilada tendrá fines académicos exclusivamente.

\section{b) Permiso para grabar}

Para agilizar la toma de la información, resulta de mucha utilidad grabar la conversación. Tomar notas a mano demora mucho tiempo y se pueden perder detalles importantes de las respuestas. ¿Existe algún inconveniente en que grabemos la conversación?

\section{c) Listado de preguntas}

\section{Bloque 1-Antecedentes}

1. ¿Cómo se inician en la industria del rendering?

2. ¿Quiénes son los fundadores?

3. ¿Cuáles fueron los primeros productos con los que iniciaron las producciones?

\section{Bloque 2 - Industria Rendering}

1. ¿Cómo ve a la industria del rendering en el Perú actualmente?

2. ¿Y cómo ve a la industria del rendering de aquí a 5 años?

3. ¿Cómo se encuentra la industria en relación a los países de la región? 
4. ¿Cuál es el posicionamiento de Technofeed en el mercado peruano?

5. ¿Quiénes considera que son los líderes del mercado?

6 ¿Existen barreras para el ingreso a la industria del rendering? ¿Son altas?

7. ¿Qué productos sustitutos a las harinas proteicas del rendering existen en el mercado? ¿Qué proveedores las ofrecen?

8. ¿Qué tipo de proveedores les abastecen de las materias primas?

9. ¿Quiénes son los principales proveedores que existen en el mercado?

10. ¿Cuentan con alguna certificación de Sistemas de Calidad?

\section{Bloque 3 - Gestión Comercial}

5. ¿Qué productos ofrecen al mercado?

6. ¿A qué tipo de industria se dirigen?

7. ¿En la industria del rendering, la producción se trabaja sobre pedido del cliente?, ¿o se generan stocks para la venta al mercado?

8. ¿Qué herramientas de marketing utilizan?

5. ¿Cómo fidelizan a sus clientes?

6. ¿Cuáles consideran que son sus ventajas competitivas?

7. ¿En esta industria, se brinda servicio post venta a los clientes? ¿Qué tipo de servicio?

\section{Bloque 4 - Proceso productivo}

1. ¿Cómo es el proceso del rendering? 
3. ¿Se puede producir en la misma línea de producción diferentes tipos de productos (avícolas, pecuario, mascotas) ¿O cada tipo de producto requiere una línea diferente?

4. ¿Cómo evalúan la calidad de su producto?

5. ¿Trabajan al máximo de su capacidad?

6. ¿Cuántos turnos de trabajo tienen?

7. ¿Cuánto personal trabaja en planta?

8. ¿Cuáles son los beneficios del uso de estas harinas para el cliente?

9. ¿Cuáles son las desventajas del uso de estas harinas para el cliente?

10. ¿Cuál es el impacto ambiental que genera el proceso productivo en esta industria? 


\section{REPORTE DE LA ENTREVISTA A LA COMPETENCIA EMPRESA TECHNOFEED SAC}

\section{Aspectos Generales}

a. La entrevista se realizó el día 22 de noviembre de 2016, en la planta de Technofeed Pasaje Don Oscar 155, Zona Industrial Acapulco, Callao.

b. La persona entrevistada fue el señor Apolinario Blácido, quien actualmente ocupa el cargo de administrador de la empresa Technofeed.

c. La entrevista se inició a las 9:30 am y concluyó a las 11:00 am, fue realizada de manera fluida y con mucha apertura de información por parte del entrevistado.

\section{Desarrollo}

\section{Antecedentes}

La empresa Technofeed proviene de una empresa familiar, cuyos inicios datan del año 1987, iniciando sus operaciones en la industria pesquera mediante la producción y comercialización de conservas, harinas y aceite de pescado.

Entre los años 1998 y 1999 debido a la aparición del fenómeno del niño, el cual afectó la costa peruana, produjo la escasez de recursos hidrobiológicos como la anchoveta y la sardina afectando directamente al sector pesquero. Ante este escenario, en el año 2000, la empresa busca invertir en otros sectores. Es en este periodo cuando la empresa ingresa a la industria del rendering. En aquel tiempo, la industria aún era incipiente, se utilizan procesos artesanales para la producción de harinas proteicas. 
A partir del año 2001, Technofeed ve la necesidad de tecnificarse para poder abastecer la demanda de los clientes, asimismo, mejorar en el proceso productivo por ende en la calidad de sus productos. Technofeed inicia con "autoclaves" (recipiente de presión metálico de paredes gruesas con un cierre hermético que permite trabajar a alta presión para la cocción y esterilización industrial con vapor de agua), esta maquinaria aún era básica, sin embargo, les permitía una producción mayor. Posteriormente, la empresa continúa mejorando en tecnología, adquiriendo “digestores" (contenedor metálico utilizado para esterilizar, hidrolizar y secar el producto), este tipo de maquinaría les permitiría trabajar con una mayor resistencia en grados de presión y temperatura, generando que el producto terminado resulte de mayor calidad. Actualmente, el proceso productivo lo realizan a través de "batch" (producción por bloque) para la elaboración de las líneas de productos. El entrevistado mencionó que este proceso es laborioso pero que les asegura una mejor calidad del producto terminado a diferencia de una maquinaria de proceso continuo que se centra en el volumen de producción.

\section{Rendering en el Perú}

El entrevistado comentó que en los años 80’s hubo una superproducción de pollos en el Perú, por lo que se incrementó la distribución del ave viva en los mercados de lima. Una vez distribuidas las aves en los mercados, luego del proceso de faenado, quedaba gran cantidad de residuos propios del beneficio de aves. Los vendedores de aves, pagaban por el recojo de estos residuos a los recicladores de la zona. Años después, se formaron los centros de acopio, la cual facilitan a las empresas de la industria del rendering en el proceso logístico para la obtención de la materia prima como centro de 
recojo de los subproductos. Aún a estos centros les falta formalizarse, ello es un trabajo en conjunto con el municipio y el gobierno para que se establezcan normas que regulen el correcto funcionamiento de los mismos.

Asimismo, si se compara con los países de la región, por ejemplo, Bolivia se encuentra más tecnificado en ese aspecto, los camales y centros de beneficio de aves se encuentran en su mayoría formalizados. Lo cual permite una mejor logística de recolección de materia prima y un menor grado de contaminación por lo residuos.

\section{Gestión Comercial}

\section{Propuesta de valor}

Technofeed se centra en la transformación de residuos sólidos orgánicos, a través de la elaboración de alimentos balanceados con alto contenido proteico para el sector pecuario, acuicultura y pet food (alimentos para mascotas) contribuyendo con la reducción del impacto ambiental.

\section{Ventaja Competitiva}

El entrevistado indica que sus ventajas competitivas se enfocan en:

- Es la única empresa de la industria del rendering que cuenta con certificación Iso 9001- 2008, actualmente se encuentra en proceso para la obtención de la versión 2015.

- Las líneas de productos ofertados son de alta calidad.

- Tienen experiencia y know how en el mercado, asimismo, cuentan con equipo multidisciplinario de especialistas.

- Tienen como clientes claves a empresas reconocidas en el mercado peruano. 


\section{Productos}

Al consultarle sobre los productos que ofrece Technofeed al mercado, el entrevistado listó: (a) Harina de plumas; (b) Harina de pollo (menudencia y vísceras); (c) Aceite de pollo; (d) Harina de carne (equino, vacuno, porcino, ovino) y (e) Harina de hueso.

Asimismo, el entrevistado refirió que los productos ofertados son de alta calidad, dado que pasan por estrictos controles de calidad, muchas veces los parámetros son definidos por sus clientes; siendo la calidad una fortaleza relevante que diferencia a Technofeed con el resto de sus competidores.

\section{Clientes}

Dentro de sus principales clientes mencionó:

(a) Alicorp (nicho acuicultura)

(b) Purina (nicho pet food)

(c) Vitapro (nicho avicultura)

(d) Naltech (nicho acuicultura)

(e) Molitalia (nicho pet food)

(f) Ganadera Santa Elena (nicho avicultura),

(g) Caisa aromas (nicho pet food)

Asimismo; indicó que realiza pruebas continuas de calidad, de ésta manera cumple con estándares exigidos por los clientes.

\section{Competencia}

El entrevistado indicó que las empresas que compiten en la industria del rendering son Alimencorp y Negocios Agroindustriales Los Ferroles. Es con la empresa Alimencorp 
con quien compite directamente dado tanto como Alimencorp y Technofeed han diversificado su oferta de líneas de productos en diferentes nichos de mercado.

\section{Sustitutos}

Al consultarle sobre los principales sustitutos mencionó a los productos en base a proteína vegetal como la torta de soya y maíz. El entrevistado mencionó que unos de los factores que influyen tanto en la demanda de la torta de soya y maíz como las harinas proteicas de origen animal es el factor precio, otro factor es la disponibilidad de soya y maíz debido a las condiciones climáticas que encarecen el producto.

\section{Proveedores}

Tecnofeed cuenta con sus propios acopiadores tanto para la obtención de los residuos provenientes del sector avícola, sector pecuario y equino, estos últimos se negocian directamente en camales de beneficio quienes le proporciona la materia prima en forma de carcasa (un conjunto de piezas duras y resistentes, que dan soporte interno y externo a los animales como por ejemplo los huesos) para la elaboración de las harinas proteicas. Asimismo, otros proveedores son las empresas prestadoras de servicio de residuos sólidos - EPS-RS controladas por DIGESA quien traslada los residuos sólidos tanto del sector avícola y pecuario hacia la planta de Technofeed.

\section{Tecnología}

El entrevistado refirió que Tecnofeed se ha ido tecnificando con el transcurrir de los años, asimismo la tecnología ha sido un factor indispensable para el crecimiento de la empresa, debido a las exigencias de calidad de los clientes quienes se encuentran fidelizados por este valor. Iniciaron con autoclaves, luego pasaron a digestores y 
actualmente utilizan tecnología por batch, dicha maquinaria fue importada de los Estados Unidos.

\section{Proyección Empresa / Industria}

\section{Empresa}

El entrevistado mencionó que tienen proyectado en un mediano plazo, implementar nueva maquinaria acorde a el desarrollo tecnológico de la industria. Asimismo, se encuentran trabajando la implementación de la certificación HACCP (Análisis de Peligros y Puntos Críticos de Control) y BPM (Buenas prácticas de manipulación).

\section{Industria}

El entrevistado manifestó que para que industria del rendering siga creciendo es necesario que el gobierno establezca mayor regulación al sector para que opere de forma ordenada, pone énfasis en la formalización de centros de acopio por zonas, ello es un trabajo en conjunto con las municipalidades, la empresa y comunidad.

De esa forma se evitará la contaminación cruzada, se reducirán los costos logísticos de acopio de materia prima, contribuyendo así con la reducción del impacto ambiental en beneficio de la comunidad. 


\section{Anexo 4: Entrevista a Directivos de la Empresa Los Ferroles}

\section{GERENTE GENERAL}

Ficha Técnica - Estudio Exploratorio- Entrevista a Profundidad

\section{Objetivos de la investigación}

Recopilar información relevante sobre la situación actual de la empresa, su organización y funcionamiento administrativo, comercial y operacional, planes de crecimiento, así como identificar y comprender la problemática y fortalezas de la empresa y del rubro.

\section{Contenido}

Técnica: $\quad$ Entrevista de escalonamiento (Malhotra, 2008, p. 158).

Instrumento: Las preguntas se desarrollaron en base a la guía de pautas sobre la información interna de la empresa, sus características principales y en el entorno en el que se desarrolla.

Fecha de campo: $\quad$ El 23 de septiembre de 2016

Lugar: $\quad$ En las oficinas de Los Ferroles (Callao)

Responsable: $\quad$ Yiesmin Zaad Oporto, estudiante del Programa de Maestría en

Ciencias Empresariales de la Escuela de Postgrado de la Universidad San Ignacio de Loyola.

\section{Perfil del Participante}

Nombre: $\quad$ Rogelio Romero

Edad: $\quad 60$ años

Nacionalidad: Peruana 
Formación: $\quad$ Experto en industria del rendering

\section{Cuestionario}

\section{Guía de pautas}

\section{a) Frase de presentación}

Buenos días/tardes. Mi nombre es Yiesmin Zaad Oporto, estudiante de Maestría de la Escuela de Post Grado de la Universidad San Ignacio de Loyola. Como parte de las actividades de levantamiento de información para la elaboración de la propuesta de Plan Estratégico, consideramos importante realizarle una entrevista para poder conocer más a profundidad la empresa, la cultura organizacional, lo que representa hoy en día y a lo que apunta a futuro; asimismo, identificar fortalezas, debilidades, oportunidades y amenazas; que nos ayuden en la formulación de estrategias para el futuro plan; cabe señalar que toda la información recopilada tendrá fines académicos exclusivamente.

\section{b) Permiso para grabar}

Para agilizar la toma de la información, resulta de mucha utilidad grabar la conversación. Tomar notas a mano demora mucho tiempo y se pueden perder detalles importantes de las respuestas. ¿Existe algún inconveniente en que grabemos la conversación?

\section{c) Listado de preguntas}

\section{Bloque 1 - Antecedentes de la empresa}

1. ¿Nos podría comentar cuál es la historia de la empresa?, ¿Cómo usted incursionó en la industria del rendering? 


\section{Bloque 2- Declaración de la Misión, Visión, Valores}

1. ¿Cuál considera usted que es la misión de la empresa?

2. ¿Cuál considera usted que es la visión de la empresa?

3. ¿Cuáles son las creencias, valores y aspiraciones de la empresa?

4. ¿Esta misión, visión y valores están formalmente desarrolladas en la empresa?

5. ¿Cómo lo difunden al personal de la empresa?

6. Si la respuesta es afirmativa, ¿Se comunica al personal durante su etapa de inducción en la empresa?

7. ¿Cómo visualiza a su empresa en los próximos tres años?, ¿A dónde quisiera llegar?

8. ¿Cómo definiría la cultura organizacional de su empresa?, ¿Cómo quisiera que se caracterice?

9. ¿De qué manera su empresa contribuye con los temas sociales y medioambientales?

\section{Bloque 3 - Enfoque Externo}

1. ¿Cuál es su percepción de la situación actual del sector?

2. ¿Cuáles son las tendencias que avizora para los próximos tres años para el sector?

3. ¿Cuáles considera que son las principales amenazas que podría enfrentar en los próximos años?

4. ¿Qué oportunidades podría aprovechar?

\section{Bloque 4 - Organización Interna}

1. ¿Cómo es la estructura organizacional de la empresa?

2. ¿Considera usted que este organigrama hoy en día está vigente?

3. ¿Cómo es la toma de decisiones en la empresa? 
4. ¿Cuáles considera que son las principales fortalezas y debilidades de la empresa?

5. ¿Cuáles son sus políticas de gestión con respecto al recurso humano?

6. ¿Enfrenta alta rotación de personal?

7. Como Director, ¿En qué aspectos se focaliza?

8. ¿Han considerado la incorporación de otros socios para la empresa?

9. ¿Cuál es el concepto de gestión de tiempo en eficiencia y eficacia que aplica en la institución?

10. ¿Cuentan con alguna plataforma tecnológica o ERP para la gestión interna de la empresa?

\section{Bloque 5 - Competencia}

1. ¿En dónde compite la empresa? (Geográfico)

2. ¿Quiénes son sus principales competidores?

3. ¿Cuánto los conoce o conoce de sus estrategias?

4. ¿Cuáles son los productos sustitutos?

5. ¿Cuál considera que es su participación de mercado?

\section{Bloque 6 - Modelo de Negocio}

\section{Propuesta de valor}

1. ¿Qué vende Los Ferroles? ¿Qué ofrece al mercado?

2. ¿Qué marca la diferencia?

3. ¿Qué le soluciona Los Ferroles a sus clientes?

4. ¿Cuál es su propuesta de valor en el mercado?

5. ¿Cuál considera que es su ventaja competitiva?

6. ¿Considera que su ventaja competitiva es fácil de igualar por sus competidores? 


\section{Alianzas Claves}

1. El negocio ¿Cuenta con aliados o alianzas claves? ¿Quiénes son?

2. ¿Cuáles son los principales beneficios que obtiene?

\section{Recursos Claves}

1. ¿Cuáles considera que son los recursos claves para el éxito del negocio?

2. ¿Cree usted que cuenta con el personal apropiado para ser suficientemente competente?

3. ¿Cree usted que cuenta con la maquinaria y tecnología adecuada para diferenciarse en el mercado?

\section{Actividades Clave}

1. ¿Cuáles son las actividades claves del negocio?

\section{Relación con clientes:}

1. ¿Qué tipo de clientes tiene la empresa?

2. ¿Cuáles son los principales?, ¿Cuántos son?

3. ¿Cómo les impacta la variación de precios de los productos sustitutos del mercado?

4. ¿Cómo gestiona la comunicación con sus clientes?

\section{Canales:}

1. ¿Cuál es el sistema de distribución que emplean?

2. ¿Cuáles son las formas de comunicación que mantiene con sus clientes?, ¿Cómo las gestiona?

\section{Enfoque financiero}

1. ¿Qué expectativas tiene de crecimiento para la empresa?, ¿Se ha trazado alguna meta? 
2. ¿Cuán factible es conseguir financiamiento para la empresa hoy en día?

3. ¿De qué forma gestionan su capacidad de apalancamiento, ingresos directos o indirectos?

4. ¿De qué forma optimizan los costos y gastos en la empresa?

5. ¿Trabajan con un presupuesto anual por áreas y como compañía?

6. ¿La rentabilidad que obtienen es la esperada?, ¿Es sostenible en el tiempo? 


\section{REPORTE DE ENTREVISTA A DIRECTIVO \\ GERENTE GENERAL \\ LOS FERROLES}

\section{Aspectos Generales}

a. La entrevista se realizó el día jueves 29 de setiembre del 2016 en el distrito de San Miguel.

b. La persona entrevistada fue el Sr. Rogelio Romero, quien tiene a su cargo la dirección general de la empresa Negocios Agroindustriales los Ferroles.

c. La entrevista inició a las 06:45 pm y concluyó a las 08:00 pm; fue realizada de manera fluida y con mucha apertura de información por parte del entrevistado.

\section{Antecedentes de la empresa}

La entrevista inició solicitando al Sr. Romero comente como fueron los inicios de la empresa; él indicó que en el año 2004 se asoció con un amigo, el Sr. Gomero, quien en ese entonces era dueño de la Avícola Santa Clara. Ambos decidieron unir capitales para fundar la empresa Los Ferroles, con la finalidad de aprovechar los residuos cárnicos del procesamiento de las aves y darle valor a esa materia prima. Pocos años después en el año 2007, decide comprarle las acciones, por lo que hoy en día la familia Romero son los accionistas totales de la empresa Negocios Agroindustriales Los Ferroles.

Sobre el desarrollo de la empresa a través de los años, el entrevistado comentó que en el año 2004, iniciaron en el local de Santa Clara, con una tecnología muy antigua de autoclaves y secadores directos; en el año 2006, debido a la presión 
del crecimiento urbano de la zona, se trasladaron al local del Callao, el cual fue comprado con capital propio y exclusivamente para este fin. Entre los años 2007 y 2009 compran el primer digestor discontinuo importado de Chile y secadores de aire caliente. Por esos años, los principales clientes eran los criadores pequeños de pollos, es decir atendían el mercado informal. En el año 2011, cuando se sintieron listos para dar un salto en tecnología, incrementaron su capacidad instalada y modernizaron la maquinaria de la planta, adquiriendo equipos de la marca Haarslev (de procedencia danesa) que es una de las marcas líderes en el mercado en la industria del rendering. Al inicio compraron piezas y maquinaria pequeña para ir probando el desempeño de la marca; pocos años después en el 2013, montaron la nueva planta de Oquendo (también ubicada en el Callao) con una línea continua completa totalmente automatizada para harina de plumas.

Actualmente la empresa cuenta con dos plantas productoras, la planta Los Ferroles, donde procesan la harina de vísceras, y la planta Oquendo, donde procesa la harina de plumas.

\section{Visión, Misión y Valores}

El entrevistado indicó que aproximadamente por el año 2007 decidieron elaborar una folletería propia (brochure) para uso externo e interno que abarcaba los productos que la empresa ofrece y también las declaraciones de misión y visión.

La actual Misión y Visión de la empresa es la siguiente: 
Misión: "Brindar servicios y productos con alto contenido proteínico al sector Agropecuario, con filosofía de calidad total.”

Visión: "Consolidarse como una empresa ecoeficiente en el rubro agroindustrial y proyectarse a un mercado globalizado, empleando la tecnología de última generación.”

Actualmente las declaraciones de misión y visión siguen vigentes en la organización, pero no se han difundido al personal, por lo que es probable que ellos no tengan conocimiento de estas.

\section{Enfoque Externo}

Identificó como oportunidad que hoy en día la exigencia normativa no es tan fuerte pero es una tendencia. A la empresa Los Ferroles los controla Senasa y el Ministerio de Producción, quienes tienen una cierta estructura, manuales pero muy básicos porque ellos están en sistemas digestores, en este sentido es que la empresa Los Ferroles están más adelantado en tecnología y utilizan las normativas que se aplican en países más desarrollados y las replican en su tecnología de punta y por ende en sus procesos productivos.

Mencionó que en cuanto a los temas medioambientales se consideran una empresa ecoeficiente, no sólo porque reutilizan los desechos cárnicos de las aves, sino que el término ecoeficiente es su filosofía de trabajo para reducir los costos, con la máxima productividad, con mínimas fallas y como resultado productos de alto rendimiento. 


\section{Organización interna}

Actualmente es una empresa familiar que es dirigida por el padre y los dos hijos, con funciones gerenciales definidas en el organigrama de la empresa. Debido al crecimiento de la empresa están en proceso de un nuevo diseño de organigrama para definir las funciones y roles.

Como se mencionó anteriormente, ellos invierten en tecnología para ser más eficientes en sus procesos productivos y ofrecer productos de calidad. En cuanto a la utilización de la tecnología para la gestión administrativa cuentan con un sistema llamado Horizont.

\section{La Competencia}

La empresa se desarrolla y compite en la ciudad de Lima, sus plantas productivas y oficinas administrativas se encuentran en Gambeta - Callao. En cuanto a sus principales competidores nos mencionó a las empresas Alimencorp y Technofeed, pero ninguna de esas empresas cuentan con la tecnología de punta que tiene la empresa Los Ferroles.

Asimismo, mencionó que las empresas Alimencorp y Technofeed tienen un $35 \%$ de la participación del mercado, y que ellos el $65 \%$ restante; por lo que son líderes en el sector avícola.

\section{El Modelo de Negocio}

La empresa Los Ferroles ofrece al mercado avícola dos tipos de harinas proteicas: la harina de plumas y la de vísceras. 
El entrevistado mencionó que su principal ventaja competitiva es la tecnología de punta que utiliza en sus procesos productivos. En los 12 años que tiene la empresa, ha cambiado cuatro veces de tecnología, empezó con autoclaves, luego cambiaron a digestores, después a hidrolizadores y actualmente tienen una nueva planta compacta de tecnología Danesa.

Asimismo señaló que la empresa se enfoca en brindar el mayor valor agregado a sus clientes, en el sentido del adecuado manejo y utilización de sus residuos. Contribuye al alineamiento de la norma ISO 14000 de alguno de sus clientes como San Fernando, pues facilita el manejo y disposición final de los subproductos de manera controlada y de acuerdo a la normativa legal medioambiental. 


\section{GERENTE DE ADMINISTRACION Y FINANZAS}

\section{Ficha Técnica - Estudio Exploratorio- Entrevista a Profundidad}

\section{Objetivos de la investigación}

\section{Recopilar información sobre:}

- Las operaciones, el proceso productivo, programación, compras, transporte, proveedores, tecnología, calidad del producto, la mano de obra y nivel de competitividad.

- $\quad$ El proceso comercial, tipo de clientes, la relación con ellos, el servicio, los modelos de negocio que aplica, el mercado y la competencia.

\section{Contenido}

Técnica: $\quad$ Entrevista de escalonamiento (Malhotra, 2008, p. 158).

Instrumento: Las preguntas se desarrollaron en base a la guía de pautas que tienen la información interna de la empresa, sus características principales y en el entorno en el que se desarrolla.

Fecha de campo: El 23 de septiembre de 2016

Lugar: $\quad$ En las oficinas de Los Ferroles (Callao)

Responsable: Carmen Jiménez Paredes, estudiante del Programa de Maestría en Ciencias Empresariales de la Escuela de Postgrado de la Universidad San Ignacio de Loyola.

\section{Perfil del Participante}

Nombre: $\quad$ Franco Romero 
Edad: $\quad 35$

Nacionalidad: $\quad$ Peruana

Formación: $\quad$ Ingeniero Industrial

\section{Cuestionario}

\section{Guía de pautas}

\section{a) Frase de presentación}

Buenos días/tardes. Mi nombre es Carmen Jimenez Paredes, estudiante de Maestría de la Escuela de Post Grado de la Universidad San Ignacio de Loyola. Como parte de las actividades de levantamiento de información para la elaboración de la propuesta de Plan Estratégico, consideramos importante realizarle una entrevista para poder conocer un poco más a detalle el desarrollo de las operaciones productivas y el aspecto comercial, sobre todo las relaciones que mantienen con sus clientes. Esta información nos permitirá entender de mejor manera el contexto actual y formular estrategias para el futuro plan; cabe señalar que toda la información recopilada tendrá fines académicos exclusivamente.

\section{b) Permiso para grabar}

Para agilizar la toma de la información, resulta de mucha utilidad grabar la conversación. Tomar notas a mano demora mucho tiempo y se pueden perder detalles importantes de las respuestas. ¿Existe algún inconveniente en que grabemos la conversación?

\section{c) Listado de preguntas.}

\section{Gestión de Operaciones}




\section{Bloque 1 - Organización y Funciones}

1. ¿Cuáles son sus funciones principales en la empresa?

2. ¿Cómo administra su tiempo para gestionar todos estos aspectos?

Bloque 2- Declaración de la Misión, Visión, Valores

1. ¿Cuál considera que es o debería ser la misión de la empresa?

2. ¿Cuál considera que es o debería ser la visión de la empresa?

3. ¿Cómo definiría las creencias, valores y aspiraciones de la empresa?

\section{Bloque 3- Gestión de Operaciones}

\section{Producción}

1. ¿Nos podría describir las fases del proceso productivo?, ¿Cuáles son las etapas claves dentro del proceso?

2. En cuanto a la capacidad instalada, ¿Tienen planes de ampliación o crecimiento?

3. ¿Por qué decidieron ubicar sus plantas productivas en el Callao?

4. ¿Qué tipo de tecnología utiliza en su planta?, ¿Considera que están encima, igual o por debajo del promedio de la industria?

5. ¿Quiénes son sus principales proveedores?

6. ¿Cuentan con políticas de mantenimiento preventivo sus equipos?, ¿Lo realiza personal de la empresa o es servicios de terceros?

7. ¿Cómo organizan al personal operario de planta?

8. ¿Cuáles considera que son las ventajas y desventajas competitivas de su producto?

9. ¿Qué cantidad producen semanal o mensualmente?

10. ¿Cuál es el grado de cumplimiento que dan a la ley de seguridad y salud en el trabajo? 


\section{Calidad}

1. ¿Ha implementado algún sistema de gestión de calidad?

2. ¿En qué piensa que podría beneficiarlo?

3. ¿Cuán estandarizadas están las actividades claves de la empresa?

4. ¿Cómo es el control de calidad que realiza a la producción?

5. ¿Qué exigencias tiene de sus clientes con respecto a la calidad de los productos?

\section{Logística}

1. ¿Cómo se abastecen de la materia prima?

2. ¿La distribución la realizan con flota propia o tercerizada?

3. ¿Existe algún cuello de botella en estas actividades?

4. ¿Quién toma las decisiones de compra en cuanto calidad, cantidad, precio?

5. ¿Cómo eligen a sus proveedores, los evalúan?

\section{Bloque 4- Gestión Comercial}

1. ¿Qué productos comercializa?

2. ¿Cuál es la ventaja competitiva de sus productos?

3. ¿Cómo se reparte la facturación en la cartera de clientes que manejan?, ¿Cuál es el porcentaje por cliente?, ¿Manejan datos estadísticos?

4. ¿Cómo son las relaciones que tienen con sus clientes?, ¿Cómo los captan y cómo los fidelizan?

5. ¿Qué modelo de comercialización mantienen con sus clientes?

6. ¿Mantienen contratos con sus clientes?

7. De los productos que comercializa, ¿Cuál es el que más se vende?, ¿Cuál es el más rentable? 
8. En cuanto al precio, ¿Quién negocia y toma las decisiones de precio?, ¿Otorgan crédito?

9. ¿Qué volumen de venta representan las empresas formales?, ¿Qué volumen los clientes menores?

10. ¿Han pensado en retomar la exportación?

11. ¿Qué tan competitivo es el negocio del rendering?, ¿Conoce qué participación del mercado tienen?

12. ¿Cuáles son sus principales competidores?

13. ¿Conoce la participación del mercado que tienen sus competidores?

14. ¿Cuáles considera que son los principales factores diferenciadores con la competencia?

15. ¿Qué herramientas de marketing emplean? 


\section{REPORTE DE ENTREVISTA A DIRECTIVO \\ GERENTE DE ADMINISTRACION Y FINANZAS \\ LOS FERROLES}

\section{Aspectos Generales}

a. La entrevista se realizó el día viernes 30 de setiembre del 2016, en el distrito de Lince.

b. La persona entrevistada fue el ingeniero industrial Franco Romero, quien es uno de los dueños y ocupa el puesto de gerente de administración y finanzas de la empresa.

c. La entrevista inició a las 12:45 am y concluyó a las 2:00pm; fue realizada de manera fluida y con mucha apertura de información por parte del entrevistado.

\section{Misión y Visión}

Al consultarle sobre la misión y visión, el entrevistado indicó que en el año 2007 se definieron ciertos conceptos de misión y visión, dado que la empresa estaba en proceso de profesionalización y formalizando su estructura organizacional. Comentó que se creó un brochure describiendo los productos que se ofrecían y las declaraciones de misión y visión; el brochure fue creado para ser difundido tanto a los clientes internos como externos. Asimismo, indicó que en la actualidad los conceptos de misión y visión se mantienen, sin embargo considera necesario realizar un proceso de revisión completo para revalidarlos; también comentó que es probable que el personal no tenga interiorizado estos conceptos porque no ha habido difusión desde hace varios años.

\section{Gerencia de Administración y Finanzas}


$\mathrm{Al}$ consultarle sobre sus funciones, el entrevistado señaló que tiene a cargo la Gerencia de Administración y Finanzas de la empresa, la cual abarca la gestión financiera, contabilidad y logística. Como parte de sus actividades sostiene reuniones de coordinación semanales con el jefe de Producción y Supervisor de Aseguramiento de Calidad con el objetivo de coordinar las operaciones de producción; asimismo, señaló que también sostiene reuniones semanales de coordinación con sus reportes directos para tratar temas de administración y finanzas propiamente.

Al consultarle sobre los colaboradores que conforman la empresa, comentó que son 90 personas entre personal propio y personal tercero, distribuidos en:

- Planta: 40 personas (entre las dos plantas)

- Administrativos: 40 personas

- Terceros: 10 personas (personal técnico de mantenimiento de planta)

Detalló a manera general los principales puestos y funciones de la empresa:

- Jefe de administración: manejan la emisión y recepción de facturas y documentación del día a día.

- Subcontadora: se encarga de temas contables financieros, y análisis de indicadores.

- Jefe de ventas: maneja órdenes de compra, programaciones de compra, cronograma de entrega de documentos, tiene contacto directo con los clientes.

- Jefe de Logística: se encarga de las gestiones de compra de productos y servicios diversos, a excepción de las compras de materia prima, que lo administra directamente el gerente. 
También comentó que actualmente están trabajando la implementación de políticas de seguridad y salud en el trabajo, y en la estandarización de sus procesos.

Sobre las herramientas tecnológicas empleadas para la gestión interna, señaló que cuentan con un ERP (Horizont ERP) que adquirieron hace algunos años, el cual integra procesos de administrativos, logísticos y financieros. Si bien ha sido implementado casi a totalidad, aún existen algunos procesos pendientes y por mejorar, como el control de ingreso de materia prima y volúmenes de producción. Señaló que es el área de Logística quien tiene a cargo esta implementación.

\section{Sobre el aspecto comercial.}

Al consultarle sobre el tipo de marketing que emplean en la empresa, comentó que es a través del contacto directo con los clientes (tanto él como gerente, como el jefe de ventas), y que para conocer sus necesidades y asegurar su fidelización mantienen comunicación frecuente y realizan reuniones periódicas. El feedback obtenido les permite actualizarse permanentemente respecto a las necesidades del mercado.

Comentó también que aún no tienen presencia en medios digitales, pues no cuentan con página web ni presencia en redes, pero que lo considera un punto importante a desarrollar y lo trabajarán próximamente.

Mencionó que la ventaja competitiva que los distingue se centra en dos factores, uno es la especialización de sus productos para la industria avícola que se especializan solo en la elaboración de harina de plumas y vísceras para evitar contaminación cruzada; y el otro factor es el nivel de tecnología, dado que son la 
única empresa en el Perú que cuentan con tecnología moderna europea, ningún competidor cuenta con tan alta tecnología.

Respecto a la participación de mercado, mencionó que Negocios Agroindustriales Los Ferroles abarca el 62\%, mientras que el otro 35\% se divide en las empresas Alimencorp y Technofeed. La producción semanal que manejan es de 180 toneladas de harina de plumas y 90 toneladas de vísceras al mes.

Sobre sus proveedores de materia prima indicó que son las empresas acopiadoras de subproductos que recolectan en mercados y centros de acopio; dentro de ellos se encuentra la empresa Pachincho que es una de las más grandes. Estos proveedores realizan el proceso de recojo y lo llevan los subproductos hasta las mismas plantas. Con ellos se negocia el precio y el plazo según los escenarios actuales del mercado.

Actualmente no trabajan con ninguna empresa bajo la modalidad de contrato, todo es con órdenes de compra puntuales.

Al consultarle sobre la distribución de la facturación que realiza, señaló que las empresas grandes como San Fernando y Santa Elena representan $75 \%$ de sus ventas y el $25 \%$ restante lo comprenden empresas cuyos volúmenes y frecuencias de compra son variables como Redondos y otros menores. El aspecto que más exigen los clientes es la calidad del producto terminado. En tal sentido, todos los clientes realizan inspecciones y auditorías al proceso productivo; siendo San Fernando quien con más frecuencia audita los procesos. 
Sobre el producto más vendido y de mayor rentabilidad, indicó que es la harina de plumas; motivo por el cual invirtieron en tecnología.

Respecto a temas de exportación, señaló que por el momento quieren enfocarse en sus clientes locales dado que su limitante es la materia prima, debilidad propia de la industria; asimismo indicó que tienen planes de crecimiento vertical, siendo una alternativa el expandirse a la provincia de Trujillo. 
Anexo 5: Entrevista a Jefes de Área de la Empresa Los Ferroles

\section{JEFE DE PRODUCCION}

Ficha Técnica - Estudio Exploratorio- Entrevista a Profundidad

\section{Objetivos de la investigación}

Recopilar información relevante sobre el proceso productivo, abarcando los aspectos relacionados a controles, flujos, indicadores, tecnología y gestión de personal.

\section{Contenido}

Técnica: $\quad$ Entrevista de escalonamiento (Malhotra, 2008, p. 158).

Instrumento: Las preguntas se desarrollaron en base a la guía de pautas sobre la información interna de la empresa, sus características principales y en el entorno en el que se desarrolla.

Fecha de campo: $\quad$ El 10 de octubre de 2016

Lugar: $\quad$ Planta de producción de harina de vísceras (Callao)

Responsable: Yiesmin Zaad Oporto, estudiante de Maestría del Programa de Ciencias Empresariales de la Escuela de Postgrado de la Universidad San Ignacio de Loyola.

\section{Perfil del Participante}

Nombre: Janio Haro

Edad: $\quad 50$

Nacionalidad: Peruana

Formación: $\quad$ Ingeniero pesquero 


\section{Cuestionario}

\section{Guía de pautas}

\section{a) Frase de presentación}

Buenos días/tardes. Mi nombre es Yiesmin Zaad Oporto, estudiante de Maestría de la Escuela de Post Grado de la Universidad San Ignacio de Loyola, deseamos realizarle una entrevista para poder conocer un poco más a detalle los procesos productivos de la empresa, el manejo de las relaciones, la cultura existente, así como la principal problemática que afrontan y los planes que tienen por implementar. Toda esta información nos permitirá formular estrategias que plasmaremos en la elaboración de un plan estratégico para la empresa; cabe señalar que toda la información recopilada tendrá fines académicos exclusivamente.

\section{b) Permiso para grabar}

Para agilizar la toma de la información, resulta de mucha utilidad grabar la conversación. Tomar notas a mano demora mucho tiempo y se pueden perder detalles importantes de las respuestas. ¿Existe algún inconveniente en que grabemos la conversación?

\section{c) Listado de preguntas}

\section{Bloque 1 - Organización y Funciones}

1. ¿Cuánto tiempo viene laborando en la empresa?

2. Como jefe de planta, ¿Cuáles son sus principales actividades?

3. ¿Cómo está estructurada el área?

4. ¿Cuál es el perfil del colaborador que labora en el área? 
5. ¿El personal conoce sus funciones?, ¿Están documentadas?

6. ¿Considera que tiene el personal en la cantidad y con las competencias necesarias?

7. ¿Cuántos turnos de trabajo tienen?

8. ¿Cuántas personas laboran en planta?

9. ¿Tienen definidos objetivos de trabajo?, ¿El personal lo conoce?

10. ¿Qué indicadores de gestión manejan?

Bloque 2 - Declaración de la Misión y Visión

1. ¿Conoce la misión y visión de la empresa?

2. ¿El personal de planta conoce la misión y visión de la empresa?

3. ¿De qué forma han realizado la difusión?

4. ¿Cómo ve a la empresa de acá a tres años?

5. ¿Cómo se ve en la empresa de acá a tres años?

\section{Bloque 3 - Gestión del recurso humano}

1. ¿Cómo se capacita al personal?, ¿En qué temas se enfocan?

2. ¿Cómo es la rotación y el ausentismo del personal?

3. ¿Cómo evalúa el desempeño de los colaboradores?

4. ¿Tienen un sistema de reconocimiento y/o motivación para el personal?

5. ¿Cuentan con un sistema de seguridad y salud en el trabajo?

\section{Bloque 4 - Comunicación Interna}

1. ¿La comunicación es fluida en el área?, ¿Y con el resto de áreas cómo es?

2. ¿Cómo se encuentra actualmente el clima laboral en el área?, ¿Lo miden?

\section{Bloque 5 - Maquinaria y Tecnología}

1. ¿Qué tipo de tecnología utilizan en la planta?

2. ¿Cuál es la capacidad instalada? 
3. ¿Qué porcentaje de la capacidad han cubierto?

4. ¿Cuál es la velocidad de producción?

5. ¿Existe algún proceso o equipo que sea cuello de botella?

6. ¿Cómo realizan el mantenimiento preventivo / correctivo de los equipos?

7. ¿Cómo ve a la empresa con relación a la competencia en este aspecto de maquinaria y tecnología?

\section{Bloque 6 - Análisis Interno}

1. ¿Qué aspectos mejoraría en su proceso?

2. ¿Cuáles son las fortalezas del proceso productivo?

3. ¿Desarrollan la función de control y planeamiento de la producción?

4. ¿Desarrollan control de calidad del producto final?

\section{Bloque 7 - Proceso Productivo}

1. ¿Cuáles son los procesos críticos en la producción?

2. ¿Han definido los puntos críticos de control (PCC)?

3. ¿Cuáles son los parámetros críticos de control?

4. ¿Existe alguna entidad regulatoria gubernamental que los supervise?

5. ¿Cuál es la política de seguridad y salud que tienen establecido para los empleados?, ¿Cómo controlan estos aspectos?

6. ¿Han pasado alguna auditoría externa por parte del estado o por algún tercero?

7. ¿Considera que están dando cabal cumplimiento a la ley de seguridad y salud en el trabajo?

8. Recorrido por planta para observación de procesos. 


\section{REPORTE DE ENTREVISTA A JEFE DE AREA \\ JEFE DE PRODUCCION Y MANTENIMIENTO \\ LOS FERROLES}

\section{Aspectos Generales}

a. La entrevista se realizó el día lunes 17 de Octubre del 2016, en la planta de procesamiento de harina de vísceras (Gambeta - Callao).

b. La persona entrevistada fue el ingeniero Janio Haro, quien actualmente labora como Jefe de producción y mantenimiento en la empresa.

c. La entrevista inició a las 10:00 am y concluyó a las 12:00 m; fue realizada de manera fluida y con mucha apertura de información por parte del entrevistado.

\section{Desarrollo}

\section{Organización y Funciones}

El entrevistado indicó que viene laborando desde enero del presente año en la empresa; y que se ha adaptado bien para trabajar con la gerencia general. Comentó que tiene mucha experiencia del sector del rendering, ya que laboró en una planta similar en España durante 6 años. Señaló que le gusta que le den libertar para tomar decisiones en su gestión, y que la gerencia general le brinda esa flexibilidad, lo que le genera es sentirse cómodo con su gestión. Asimismo comentó de varias mejoras a los procesos que viene trabajando, y otras que tiene en mente; actualmente está redefiniendo el proceso de obtención de aceites, el cual considera que es un insumo de gran valor, pero que por el problema de la oxidación que actualmente tienen, no logran explotar al máximo. También mencionó que está trabajando en el mantenimiento preventivo de la maquinaria, de manera de lograr un mejor performance de los equipos y así evitar paradas de planta. 
Señaló que poco a poco está tratando de introducir estos cambios con los dueños, y que tiene que evidenciar el retorno de la inversión para que estos proyectos fluyan.

Sobre la estructura organizacional, señaló que él dirige la producción de las dos plantas, para ello cuenta con un equipo de trabajo en cada planta, un asistente de producción y dos jefes de turno, adicional al personal operario y de mantenimiento de equipos, en total son aproximadamente 40 personas en el equipo. Indicó también que parte del personal de mantenimiento es tercero, los cuales son llamados de manera puntual cada vez que se requiere de sus servicios.

Comentó que están en proceso de implementación del sistema ISO 9001, así como el sistema de seguridad y salud en el trabajo; se ha trabajado arduo en ambos sistemas y el personal está en proceso de adaptación.

\section{Comunicación Interna}

En cuanto a su comunicación con los gerentes, indicó que mantienen una reunión semanal (los días martes) donde se presentan los resultados productivos a través de indicadores como: toneladas producidas, rendimiento, consumo combustible, entre otros. En estas reuniones se discuten y toman decisiones sobre la gestión.

Sobre el ambiente laboral, señaló que la adaptación a los procesos productivos es bastante duro para el personal, pero a pesar de ello la rotación no era tan alta. Indicó que los puestos que más rotan son los de limpieza, pero que los operadores de máquina son más estables. En cuanto al clima laboral, indicó que se encuentra en proceso de gestión del capital humano, es flexible en cuanto a dar permisos, o gestionar algún prestamos con la gerencia; también señaló que se organizan campeonatos de futbol los cuales son muy del agrado del personal.

\section{Proceso Productivo}


Sobre el proceso señaló que la capacidad real de producción está aproximadamente al 90\%, ya que trabajan a doble turno en ambas plantas. Los días lunes se han establecido como días de parada para mantenimiento y limpieza, lo cual ayuda para asegurar la continuidad de la operación. Si bien no cuentan con un sistema HACCP (Análisis de peligros y control de puntos críticos), están implementando algunos controles a través del sistema ISO 9001.

Sobre la capacitación al personal, indicó que él mismo da charlas de vez en cuando sobre aspectos de la producción, adicional de las reuniones de trabajo donde remarca temas importantes. Adicional, señaló que el área de Calidad también imparte charlas al personal orientadas a las Buenas Prácticas de Manufactura.

Al preguntarle sobre el control de entidades gubernamentales, señaló que realizan análisis medioambientales a través de un laboratorio tercero, y los resultados los reportan al ministerio. Por el momento ninguna entidad los audita.

Sobre la misión y visión indicó que no se ha realizado ningún despliegue al personal; por el momento están en proceso de implementación del ISO 9001. 


\section{SUB CONTADORA}

\section{Ficha Técnica - Estudio Exploratorio- Entrevista a Profundidad}

\section{Objetivos de la investigación}

Recopilar información relevante sobre el proceso contable y de administración de personal.

\section{Contenido}

Técnica: $\quad$ Entrevista de escalonamiento (Malhotra, 2008, p. 158).

Instrumento: Las preguntas se desarrollaron en base a la guía de pautas sobre la información interna de la empresa, sus características principales y en el entorno en el que se desarrolla.

Fecha de campo: $\quad$ El 10 de octubre de 2016

Lugar: $\quad$ Planta de producción de harina de vísceras (Callao)

Responsable: Carmen Jimenez Paredes, estudiante de Maestría del Programa de Ciencias Empresariales de la Escuela de Postgrado de la Universidad San Ignacio de Loyola.

\section{Perfil del Participante}

Nombre: Rosa Romero

Edad: $\quad 48$

Nacionalidad: Peruana

Formación: $\quad$ Contadora

\section{Cuestionario}




\section{Guía de pautas}

\section{a) Frase de presentación}

Buenos días/tardes. Mi nombre es Carmen Jimenez Paredes, estudiante de Maestría de la Escuela de Post Grado de la Universidad San Ignacio de Loyola, deseamos realizarle una entrevista para poder conocer un poco más a detalle los procesos contables y de administración de personal, el manejo de las relaciones, la cultura existente, así como la principal problemática que afrontan y los planes que tienen por implementar. Toda esta información nos permitirá formular estrategias que plasmaremos en la elaboración de un plan estratégico para la empresa; cabe señalar que toda la información recopilada tendrá fines académicos exclusivamente.

\section{b) Permiso para grabar}

Para agilizar la toma de la información, resulta de mucha utilidad grabar la conversación. Tomar notas a mano demora mucho tiempo y se pueden perder detalles importantes de las respuestas. ¿Existe algún inconveniente en que grabemos la conversación?

\section{c) Listado de preguntas}

\section{Bloque 1 - Organización y Funciones}

1. ¿Cuánto tiempo viene laborando en la empresa?

2. ¿Ha laborado en otras áreas?

3. ¿Cuáles son sus principales actividades?

4. ¿Cómo canaliza la comunicación con la contadora externa de la empresa?

5. ¿Cómo está estructurada internamente el área?

6. ¿Cuál es el perfil del colaborador que labora en el área?

7. ¿El personal conoce sus funciones?, ¿Están documentadas? 
8. ¿Tienen definidos objetivos de trabajo?, ¿El personal los conoce?

9. ¿Qué indicadores de gestión manejan?

\section{Bloque 2 - Declaración de la Misión y Visión}

1. ¿Conoce la misión y visión de la empresa?

2. ¿El personal del área conoce la misión y visión?

3. ¿Cómo ve a la empresa de acá a tres años?

4. ¿Cómo se ve en la empresa de acá a tres años?

\section{Bloque 3 - Comunicación Interna}

1. ¿La comunicación es fluida en el área?, ¿Y con el resto de áreas cómo es?

2. ¿Cómo se encuentra actualmente el clima laboral en el área?, ¿Lo miden?

\section{Bloque 4 - Análisis Interno}

1. ¿Qué aspectos mejoraría en su proceso?

2. ¿Cuáles son las fortalezas de su proceso?

3. ¿Emplean algún sistema de información para el proceso contable?

4. ¿Cómo es el proceso de cierre contable?, ¿Tienen un cronograma establecido con la gerencia?

5. ¿Qué EEFF presentan a la gerencia y con qué periodicidad?

6. ¿Presentan problemas o deficiencias en el proceso contable?

\section{Bloque 5 - Gestión Humana}

\section{Reclutamiento y selección}

1. ¿Cuál es la política de reclutamiento y contratación que mantienen?

2. ¿Cuál es el modo de contratación que aplican?, ¿Plazo fijo, indeterminado?

3. ¿Tienen escritos los manuales de perfiles de puestos?, ¿Las descripciones y especificaciones de los puestos son claras?, ¿Emplean estos perfiles para el proceso de contratación del personal? 
4. ¿La rotación de personal y el ausentismo se mantienen en un nivel bajo?

\section{Documentación y Organización interna}

1. ¿Tienen un manual de organización y funciones?, ¿Se encuentra implementado?

2. ¿Existe un organigrama con puestos definidos y documentados?, ¿Es de conocimiento del personal?

3. ¿Se ha definido el nivel de competencias necesarias en el perfil de puestos?

\section{Compensación salarial}

1. ¿Cuál es la política de sueldos y salarios que tienen establecido?

2. ¿Mantienen escalas salariales según puestos?

3. ¿Manejan alguna política de incentivos para el personal?

\section{Capacitación y Desarrollo}

1. ¿Tienen implementado planes de capacitación y desarrollo para el personal administrativo y operario?

2. ¿El personal conoce su línea de carrera?

3. ¿Trabajan con objetivos medibles?

4. ¿Desarrollan evaluaciones de desempeño tanto para el personal administrativo como operario?

5. ¿Existen mecanismos de recompensas y de control en base al logro de objetivos?

\section{Bienestar Social}

1. ¿Cuentan con asistenta social dentro de la compañía?

2. ¿Qué actividades relacionadas al bienestar social realizan? 


\section{REPORTE DE ENTREVISTA A JEFE DE AREA \\ SUB CONTADORA \\ LOS FERROLES}

\section{Aspectos Generales}

a. La entrevista se realizó el día lunes 17 de Octubre del 2016, en la planta de procesamiento de harina de vísceras (Gambeta - Callao).

b. La persona entrevistada fue la señora Rosa Romero, quien actualmente labora como sub contadora de la empresa.

c. La entrevista inició a las 11:30 am y concluyó a las 1:00pm; fue realizada de manera fluida y con mucha apertura de información por parte del entrevistado.

\section{Desarrollo}

\section{Organización y Funciones}

Nos comentó que viene trabajando desde el año 2014, en la misma posición en la que se desempeña actualmente. Dentro de sus principales funciones está la de alimentar al ERP Horizont (Enterprise Resource Planning) sobre las operaciones que realiza la empresa para la generación de asientos contables, que luego pasan al asesor contable para la elaboración de los estados financieros. Así mismo es responsable de la presentación mensual de impuestos a la SUNAT (Superintendencia Nacional de Administración Tributaria).

En su posición, adicionalmente viene desarrollando un rol de encargada de recursos humanos, que no es propio del perfil de la posición de sub contadora. En tal sentido, se encarga de la emisión de planillas, liquidaciones de beneficios, contratos del nuevo personal, renovación de contratos y entrega de documentos a los trabajadores que estas 
gestiones impliquen. Así mismo es responsable de las negociaciones de pago con el personal que renuncia o que es desvinculado de la empresa. Dada estas responsabilidades adicionales a su perfil tiene a su cargo un asistente contable que la apoya con las gestiones a realizar.

Nos comentó que de momento no se manejan indicadores en el área, pero que conjuntamente con la implementación del ISO 9001, se viene trabajando en ello.

\section{Declaración de Misión y Visión}

En cuanto a las declaraciones de la misión y visión, la entrevistada indicó que si bien dichos conceptos se encuentran definidos en el brochure institucional de la empresa, no son de conocimiento del personal. Si considera necesario su revisión y comunicación a todos los colaboradores, para que sean interiorizados.

\section{Comunicación Interna}

En la comunicación dentro del área, indicó que es fluida. No ha tenido inconvenientes hasta el momento. Consultándole sobre el clima laboral, nos comentó que, no es una variable que actualmente se mida en la empresa.

\section{Gestión Humana}

Nos explicó, que las políticas de reclutamiento las maneja cada área, y que su posición se encarga de la contratación propiamente dicha. Así mismo, en cuanto a la modalidad de contratación, todo colaborar tiene un periodo de prueba de tres meses. Los contratos son de carácter temporal, que se van renovando de acuerdo al performance del trabajador. Sólo los colaboradores antiguos, que comenzaron básicamente con la empresa tienen contrato de carácter indefinido y son colaboradores de confianza de los dueños. 
La rotación de personal reconoce que es alta en el área de operaciones (operarios de planta), a comparación del personal administrativo. Asume que se debe al tipo de trabajo que realizan los operarios.

En cuanto a la política de remuneraciones, estas son abonadas semanalmente tanto al personal administrativo como de planta. Las escalas salariales para obreros son de S/. 980 nuevos soles para el nuevo colaborador y hasta S/. 1,200 nuevos soles luego de pasar los 3 meses de prueba. Para el personal administrativo la escala salarial fluctúa de S/.1, 500 a S/.6,000 nuevos soles. De momento no cuentan con una política de incentivos para el personal.

No cuentan con un asistente social ni área de bienestar social dentro de la empresa, toda actividad o coordinación sobre el personal se realiza a través del jefe del área. 


\section{JEFA DE ADMINISTRACION}

\section{Ficha Técnica - Estudio Exploratorio- Entrevista a Profundidad}

\section{Objetivos de la investigación}

Recopilar información relevante sobre la organización y el proceso administrativo documentario.

\section{Contenido}

Técnica: $\quad$ Entrevista de escalonamiento (Malhotra, 2008, p. 158).

Instrumento: Las preguntas se desarrollaron en base a la guía de pautas sobre la información interna de la empresa, sus características principales y en el entorno en el que se desarrolla.

Fecha de campo: $\quad$ El 10 de octubre de 2016

Lugar: $\quad$ Planta de producción de harina de vísceras (Callao)

Responsable: Yovana Rios Cardenas, estudiante de Maestría del Programa de Ciencias Empresariales de la Escuela de Postgrado de la Universidad San Ignacio de Loyola.

\section{Perfil del Participante}

Nombre: $\quad$ Elizabeth Ibarra

Edad: $\quad 38$

Nacionalidad: Peruana

Formación: $\quad$ Administradora 


\section{Cuestionario}

\section{Guía de pautas}

\section{a) Frase de presentación}

Buenos días/tardes. Mi nombre es Yovana Rios Cardenas, estudiante de Maestría de la Escuela de Post Grado de la Universidad San Ignacio de Loyola, deseamos realizarle una entrevista para poder conocer un poco más a detalle los procesos contables y de administración de personal, el manejo de las relaciones, la cultura existente, así como la principal problemática que afrontan y los planes que tienen por implementar. Toda esta información nos permitirá formular estrategias que plasmaremos en la elaboración de un plan estratégico para la empresa; cabe señalar que toda la información recopilada tendrá fines académicos exclusivamente.

\section{b) Permiso para grabar}

Para agilizar la toma de la información, resulta de mucha utilidad grabar la conversación. Tomar notas a mano demora mucho tiempo y se pueden perder detalles importantes de las respuestas. ¿Existe algún inconveniente en que grabemos la conversación?

\section{c) Listado de preguntas}

\section{Bloque 1 - Organización y Funciones}

1. ¿Cuánto tiempo viene laborando en la empresa?

2. ¿Ha pasado por otras áreas?

3. ¿Cuáles son sus principales actividades?

4. ¿Cómo está estructurada el área? 
5. ¿Cuál es el perfil del colaborador que labora en el área?

6. ¿Quiénes son sus clientes internos?

7. ¿Tienen definidos objetivos de trabajo?, ¿El personal lo conoce?

8. ¿Qué indicadores de gestión manejan?

\section{Bloque 2 - Declaración de la Misión y Visión}

1. ¿Conoce la misión y visión de la empresa?

2. ¿El personal del área conoce la misión y visión de la empresa?

3. ¿Cómo ve a la empresa de acá a tres años?

4. ¿Cómo se ve en la empresa de acá a tres años?

\section{Bloque 3 - Comunicación Interna}

1. ¿La comunicación es fluida en el área y con el resto de áreas?

2. ¿Cómo se encuentra actualmente el clima laboral en el área?, ¿Lo miden?

\section{Bloque 4 - Análisis Interno}

1. ¿En qué consiste el proceso administrativo que tiene a cargo?

2. ¿Emplean algún sistema de información integral en la organización (ERP)?

3. ¿Qué tipo de controles tienen establecidos en el proceso?

4. ¿Cuáles son las fortalezas dentro del área?

5. ¿Qué aspectos mejoraría en su proceso? 


\section{REPORTE DE ENTREVISTA A JEFE DE ÁREA \\ JEFA DE ADMINISTRACIÓN \\ LOS FERROLES}

\section{Aspectos Generales}

a. La entrevista se realizó el día lunes 17 de Octubre de 2016 en las oficinas de Los Ferroles, ubicadas dentro de la planta de producción de harina de vísceras en el Callao.

b. La persona entrevistada fue la señora Elizabeth Ibarra, quien ocupa el puesto de Jefe de Administración, y tiene a cargo el departamento de Administración de la empresa.

c. La entrevista inició a las 10:00 am y concluyó a las 11:30 am; fue realizada de manera fluida y con mucha apertura por parte de la entrevistada.

\section{Desarrollo}

\section{Organización y Funciones}

Se inició la entrevista consultándole el tiempo que viene trabajando en la empresa y nos mencionó que tiene más de diez años laborando en Los Ferroles, asimismo nos contó un poco sobre su trayectoria en la empresa, la entrevistada inició sus labores como secretaria del Gerente General, en ese momento adicional a sus funciones secretariales también apoyaba en tareas de gestión de calidad, almacén y compras; con el crecimiento de la empresa surgió la necesidad de crear las áreas de Calidad, Compras y Almacén. 
Actualmente sus principales funciones son elaborar el presupuesto de ingresos y gastos que presenta de manera semanal al Gerente General para que de aprobación de los pagos a realizar en la semana, así como tramitar los financiamientos de las facturas con el Banco BCP y Santander, por ello realiza mucho seguimiento al área de ventas (para la empresa, el área de ventas es facturación y cobranza).

Se pudo apreciar que no tienen clara su estructura organizacional y del área, en cuanto al perfil de los asistentes son personal con conocimientos básicos y poca experiencia para el puesto, mencionó como clientes internos a los departamentos de Ventas, Tesorería y Finanzas, Contabilidad y Almacén. Asimismo, todavía no tienen definido objetivos de trabajo, ni indicadores pero están en proceso de definirlos con la implementación del ISO 9001.

\section{Declaración de Misión, Visión y Valores}

En cuanto a las declaraciones de la misión y visión, la entrevistada indicó que están definidos por la empresa, pero no son de conocimiento general de los trabajadores, mencionó como principales valores la colaboración y la responsabilidad.

La entrevistada se muestra muy identificada con la empresa y opina que la organización tiene un crecimiento adecuado y espera seguir laborando más tiempo y ocupando cargos de confianza y de mayor responsabilidad.

\section{Análisis interno}

La entrevistada mencionó que la comunicación con las áreas es vía telefónica, email y desde su punto de vista considera que hay buen clima laboral en la empresa, pero que nunca se ha realizado una evaluación. 
Actualmente para la elaboración del presupuesto semanal lo realizan en Excel, pero utilizan el ERP Horizont para los otros procesos de ventas, almacén, producción, contabilidad, el cual también es alimentado con información que ingresa la entrevistada según sus funciones.

Sobre los aspectos a mejorar indicó que las áreas de producción, calidad y almacén deberían programarse mejor en cuanto a sus requerimientos y pedidos, para evitar las urgencias y disponibilidad de caja efectivo. 


\section{JEFE DE LOGISTICA}

\section{Ficha Técnica - Estudio Exploratorio- Entrevista a Profundidad}

\section{Objetivos de la investigación}

Recopilar información relevante sobre la gestión logística, abarcando las compras de productos y servicios, relación con proveedores e indicadores de gestión.

\section{Contenido}

Técnica: $\quad$ Entrevista de escalonamiento (Malhotra, 2008, p. 158).

Instrumento: Las preguntas se desarrollaron en base a la guía de pautas sobre la información interna de la empresa, sus características principales y en el entorno en el que se desarrolla.

Fecha de campo: $\quad$ El 10 de octubre de 2016

Lugar: $\quad$ En la planta de producción de harina de vísceras (Callao)

Responsable: Debbie Soto Salazar, estudiante de Maestría del Programa de Ciencias Empresariales de la Escuela de Postgrado de la Universidad San Ignacio de Loyola.

3. Perfil del Participante

Nombre: $\quad$ Miguel Tiravantti

Edad: $\quad 30$

Nacionalidad: Peruana

Formación: $\quad$ Ingeniero Industrial

\section{Cuestionario}




\section{Guía de pautas}

\section{a) Frase de presentación}

Buenos días/tardes. Mi nombre es Debbie Soto Salazar, estudiante de Maestría de la Escuela de Post Grado de la Universidad San Ignacio de Loyola, deseamos realizarle una entrevista para poder conocer un poco más a detalle los procesos logísticos y de administración de información, el manejo de las relaciones, la cultura existente, así como la principal problemática que afrontan y los planes que tienen por implementar. Toda esta información nos permitirá formular estrategias que plasmaremos en la elaboración de un plan estratégico para la empresa; cabe señalar que toda la información recopilada tendrá fines académicos exclusivamente.

\section{b) Permiso para grabar}

Para agilizar la toma de la información, resulta de mucha utilidad grabar la conversación. Tomar notas a mano demora mucho tiempo y se pueden perder detalles importantes de las respuestas. ¿Existe algún inconveniente en que grabemos la conversación?

\section{c) Listado de preguntas}

\section{Bloque 1 - Organización y Funciones}

1. ¿Cuánto tiempo viene laborando en la empresa?

2. ¿Ha laborado en otras áreas?

3. ¿Cuáles son sus principales actividades?

4. ¿Cómo está estructurada el área?

5. ¿Cuál es el perfil del colaborador que labora en el área? 
6. ¿Tienen definidos objetivos de trabajo?, ¿El personal lo conoce?

7. ¿Qué indicadores de gestión manejan?

\section{Bloque 2 - Declaración de la Misión y Visión}

1. ¿Conoce la misión y visión de la empresa?

2. ¿El personal del área conoce la misión y visión de la empresa?

3. ¿Cómo ve a la empresa de acá a tres años?

4. ¿Cómo se ve en la empresa de acá a tres años?

\section{Bloque 3 - Comunicación Interna}

1. ¿La comunicación es fluida en el área y con el resto de áreas?

2. ¿Cómo se encuentra actualmente el clima laboral en el área?, ¿Lo miden?

\section{Bloque 4 - Análisis Interno}

1. ¿Qué procesos abarca la gestión logística que tiene a cargo?

2. ¿Cuentan con un área de servicios generales o internos?

3. ¿Emplean algún sistema de información integral (ERP) en el área?

4. ¿El personal está capacitado en el manejo de este sistema?

5. Respecto a las compras, ¿Ustedes gestionan todo tipo de compras?

6. ¿Cómo es la relación con los proveedores?

7. ¿Qué criterios emplea para evaluar a sus proveedores?

8. ¿Cómo es la política de pago a proveedores?

9. ¿Qué aspectos mejoraría en su proceso?

10. ¿Cuáles son las fortalezas dentro del área de trabajo?

11. ¿Brindan planes de capacitación al personal del área?, ¿Qué tipo de capacitación realizan?

12. ¿Cómo miden el desempeño de los colaboradores del área? 
13. ¿De qué forma se motiva al personal para el cumplimiento de las metas del área?

14. ¿De qué forma se les reconoce el cumplimiento de metas? 


\section{REPORTE DE ENTREVISTA A JEFE DE AREA \\ JEFE DE LOGISTICA \\ LOS FERROLES}

\section{Aspectos Generales}

a. La entrevista se realizó el día lunes 17 de Octubre del 2016, en la planta de procesamiento de harina de vísceras (Gambeta - Callao).

b. La persona entrevistada fue el señor Miguel Tiravantti, quien actualmente labora como Jefe de logística de la empresa.

c. La entrevista inició a las 12:30 am y concluyó a las 1:45pm; fue realizada de manera fluida y con mucha apertura de información por parte del entrevistado.

\section{Desarrollo}

El entrevistado comentó que viene trabajando desde hace tres años en Los Ferroles ocupando el cargo de Jefe de Logística. Dentro de sus principales funciones está la gestión de compras, atendiendo requerimientos tanto de las áreas administrativas como de planta, así como el monitoreo y control de los almacenes de productos terminados y de suministros varios.

En cuanto a la gestión de compras, utiliza el ERP Horizont (Enterprise Resource Planning) para la generación de órdenes de compra. Nos comentó que, en caso sean requerimientos por montos mayores a S/300.00 nuevos soles, necesitan la aprobación del Director de la empresa, previa coordinación con la jefatura de administración.

Actualmente tiene a su cargo tres asistentes de almacén, dos de ellos durante el día (horario de oficina) y uno para el turno de la noche. Al consultarle si los asistentes 
utilizan alguna herramienta o software, nos comentó que aún les falta capacitación en el ERP.

Durante la entrevista nos comentó que dentro de las oportunidades de mejora del área están la generación de indicadores de medición de la gestión. El entrevistado también señaló que los requerimientos solicitados los programa y compra con una frecuencia semanal, y lo que es de emergencia, en un plazo de 3 días o menos. Los requerimientos de emergencia constituyen aproximadamente la mitad del total de los requerimientos, por lo que le es muy necesario que este tipo de solicitudes se trabajen con más anticipación, de manera que le permita realizar una mejor gestión, cotizando y seleccionando el proveedor más conveniente.

Sobre la gestión con proveedores, señaló que no cuentan con un proceso de evaluación y selección de proveedores, tampoco realizan auditorías a la gestión de los proveedores. Estos procesos se irán implementando en los próximos meses, en la medida que vayan implementando el ISO 9001 en la organización.

Nos explicó adicionalmente, que la planificación de compras se maneja en Microsoft Excel, la cual es de periodicidad semanal. A la fecha se encuentra pendiente la actualización del Kardex (herramienta de registro de almacén) en el ERP que maneja la empresa, lo cual les viene generando inconvenientes en el control del almacén.

\section{Declaración de Misión y Visión}

Al consultarle sobre las declaraciones de la misión y visión, nos señaló que no son de conocimiento del personal.

\section{Comunicación Interna}


Sobre la comunicación dentro del área, indicó que esta es fluida con su equipo de trabajo y con la mayoría de áreas; sólo recomienda trabajar más en las coordinaciones de requerimientos del personal de planta, dado que las solicitudes no se ingresan con anticipación. Es decir, no existe de momento una planificación de compras de suministros de planta. Por lo que debe atender requerimientos en un máximo de tres días, lo cual dificulta la negociación de precios y/o búsqueda de nuevos proveedores. 


\section{Anexo 6: Entrevista a Expertos del Sector}

\section{ASESOR EXTERNO EN NUTRICIÓN ANIMAL \\ Ficha Técnica - Estudio Exploratorio- Entrevista a Profundidad}

\section{Objetivos de la investigación}

Recopilar información relevante sobre la industria del rendering, las principales empresas que conforman este sector, y la calidad en productos y servicios que ofrecen.

\section{Contenido}

Técnica: $\quad$ Entrevista de escalonamiento (Malhotra, 2008, p. 158).

Instrumento: Las preguntas se desarrollaron en base a la guía de pautas sobre la información interna de la empresa, sus características principales y en el entorno en el que se desarrolla.

Fecha de campo: $\quad$ El 7 y 8 de noviembre de 2016

Lugar: $\quad$ En el distrito de Surco.

Responsable: $\quad$ Yovana Ríos, Carmen Jimenez, Debbie Soto y Yiesmin Zaad, estudiantes de Maestría del Programa de Ciencias Empresariales de la Escuela de Postgrado de la Universidad San Ignacio de Loyola.

\section{Perfil del Participante}

Nombre: $\quad$ Wilfredo Ochoa

Edad: $\quad 42$

Nacionalidad: peruana 
Formación: $\quad$ Ingeniería Zootecnista

Puesto: $\quad$ Asesor externo en nutrición animal

\section{Cuestionario}

Guía de pautas

\section{a) Frase de presentación}

Buenos días/tardes. Somos Yovana Rios, Carmen Jimenez, Debbie Soto y Yiesmin Zaad, estudiantes de Maestría de la Escuela de Post Grado de la Universidad San Ignacio de Loyola. Como parte del trabajo de tesis final, estamos trabajando en la elaboración de un plan estratégico para la empresa Los Ferroles; en tal sentido, deseamos realizarle una entrevista para poder conocer un poco más sobre la industria del rendering y las empresas que la conforman; cabe señalar que toda la información recopilada tendrá fines académicos exclusivamente.

\section{b) Permiso para grabar}

Para agilizar la toma de la información, resulta de mucha utilidad grabar la conversación. Tomar notas a mano demora mucho tiempo y se pueden perder detalles importantes de las respuestas. ¿Existe algún inconveniente en que grabemos la conversación? 


\section{c) Listado de preguntas}

\section{Bloque 1- Historia del rendering en el Perú}

1. ¿Cómo se introduce el concepto del rendering al sector avícola?

2. ¿Cuán desarrollada se encuentra la industria con respecto a otros países en la región?

3. ¿Qué factores han influenciado en la evolución del rendering en el Perú, tanto positiva como negativamente?

4. ¿Qué rol juega el gobierno en el desarrollo de esta industria?

5. ¿Qué sectores consumen rendering en el Perú? ¿Cuáles son los más rentables?

6. ¿Cómo ves la industria dentro de cinco años?

7. ¿Qué rol juega el rendering en el contexto actual de dar más énfasis al cuidado medio ambiental?

\section{Bloque 2- Rendering en la actualidad}

1. ¿Cuáles son las principales empresas que conforman la industria del rendering en el Perú?

2. ¿Qué barreras existen para ingresar al sector rendering? ¿Son altas?

3. ¿Cuáles son las empresas que abastecen de harinas de rendering al sector avícola?

4. ¿Qué factores influyen en la calidad de las harinas que se producen?

5. ¿Qué tipo de tecnología emplean las empresas de rendering?

6. ¿Cuáles son los principales sustitutos de las harinas del rendering?

7. ¿Por qué es importante el uso de las harinas de rendering en el sector avícola?

8. ¿Qué efectos a nivel productor, cliente y consumidor trae consigo el uso de harinas del rendering? ¿El consumidor final percibe el uso de estas harinas en el pollo? 
9. ¿Existen empresas avícolas que produzcan su propio rendering? ¿Existen diferencias con el rendering de las empresas especializadas?

10.¿Cuán normado está el sector del rendering? ¿Existe control gubernamental que los regule o límite?

11. ¿Cuáles son los factores que limitan el crecimiento del rendering en el Perú?

12. ¿Se realiza investigación a nivel nacional sobre esta industria?

13. ¿Qué fortalezas y oportunidades de mejora ha identificado en esta industria?

14. ¿Considera que el rendering es un sector atractivo?

15.¿Cuán beneficiosas son las alianzas estratégicas con la industria avícola; por ejemplo la alianza de Los Ferroles con San Fernando?

16. ¿Considera que existe rivalidad entre las actuales empresas del sector? 


\section{REPORTE DE ENTREVISTA A EXPERTO DEL SECTOR \\ ASESOR EXTERNO EN NUTRICIÓN ANIMAL}

\section{Aspectos Generales}

a. La entrevista se realizó durante dos días consecutivos: el lunes 7 y martes 8 de noviembre de 2016, en Santiago de Surco

b. La persona entrevistada fue el ingeniero Wilfredo Ochoa, quien actualmente labora como asesor externo en nutrición y rendering en diversas empresas avícolas.

c. Las entrevistas iniciaron a las 8:00 pm y concluyeron a las 10:00 pm ambos días; fue realizada de manera fluida y con mucha apertura de información por parte del entrevistado.

\section{Desarrollo}

El entrevistado comentó que viene laborando en el sector desde hace más de 15 años, tiempo en el que ha tenido la oportunidad de ganar experiencia de campo en diferentes empresas. Indicó que el rendering, surge como una solución para el manejo de residuos sólidos de las empresas agropecuarias, ahorrando así el costo de la eliminación de los mismos y generando su aprovechamiento mediante la elaboración de harinas proteicas. Es por ello que el concepto de rendering se encuentra relacionado con el reciclaje y por tanto con el cuidado medioambiental. El rendering lo enfoca como un proceso de reutilización de la proteína animal, el cual es un negocio de alto rendimiento.

Sobre Los Ferroles, indicó que es una de las pocas empresas que cumple con normas sanitarias durante la producción, pero que tiene procesos por mejorar como la 
producción de aceite de pollo, el cual es un insumo de alto valor nutricional, pero cuya acidez en muy alta debido a la calidad de proceso que manejan.

Sobre la proteína, indicó que las harinas del rendering son una importante fuente proteica, de alta digestibilidad. El pollo necesita proteína animal y mejor si proviene de él mismo, ya que contiene los aminoácidos necesarios (la proteína ideal). Al consultarle sobre las diferencias o el factor de decisión para la compra de harinas proteicas, nos mencionó que la elección dependerá del grado de proteína que se desee suministrar al ave y el porcentaje de digestibilidad que presente el producto. Por ejemplo, la pluma requiere ser hidrolizada (proceso térmico) para ser digerible, y presenta un $80 \%$ de proteína y $60 \%$ de digestibilidad; mientras que la víscera presenta $60 \%$ de proteínas y $90 \%$ digestibilidad.

\section{Historia del Rendering}

El entrevistado indicó que el rendering en el Perú hace pocos años que viene potenciando su desarrollo, por el contexto socioeconómico de las décadas pasadas, no hubo necesidad de incentivar el uso de este tipo de subproductos en la crianza animal. Hoy en día, la globalización ha ejercido fuerte influencia y el entorno de las empresas avícolas ha cambiado por lo que el rendering ha empezado a introducirse en la alimentación animal como una fuente proteica importante.

Asimismo, mencionó que entre los principales factores que influenciaron en la evolución del rendering en el Perú se tienen: 
- $\quad$ Harina de pescado: Su alta disponibilidad y precio bajo debido al boom de la pesca en el Perú en las décadas de los sesenta y setenta, la convirtió en una de las principales fuentes proteicas para la alimentación animal. A partir de los ochentas se hizo más escasa, por lo que se buscó otra harina que pueda reemplazar su valor proteico. Es así que aparece la torta de soya como sustituto.

- $\quad$ Harina de torta de soya (importada): su alta disponibilidad y precio bajo, hizo que se le considerara como la principal fuente de proteína desde hace varias décadas. Entre el 2000 y 2005 se da un boom internacional de este insumo, incrementándose aún más su oferta y disminuyendo el precio. Hoy en día, las cosechas de soya no son tan eficientes como antes, y se ven afectadas por diversos factores (climáticos, económicos, etc), por lo que su disponibilidad en el mercado ha disminuido.

- Idiosincrasia de los profesionales del sector avícola en las décadas pasadas, quienes mayormente eran del tipo conservador y no se arriesgaban a probar harinas proteicas procedentes del rendering por considerarlas de alto riesgo sanitario. En este aspecto la avicultura está cambiando, y los nutricionista de hoy muestran mayor apertura al rendering.

- $\quad$ Falta de exigencias normativas gubernamentales para el tratamiento y disposición de los subproductos cárnicos; por lo que las empresas avícolas y cárnicas no priorizaban la gestión de los subproductos, ni les generaba una problemática relevante. Otros países (como Brasil y USA), donde las normas referidas a estos temas son más exigentes, si vieron la necesidad de desarrollar la industria del rendering como una solución integral al manejo de los residuos cárnicos. 
- Costumbre arraigada de utilizar de subproductos avícolas (menudencias, apéndices, sangre) dentro de la cocina peruana.

\section{Desarrollo del rendering}

El entrevistado señaló que en el año 2002, se encontró un nicho de mercado muy rentable para el rendering: la acuicultura, y así comienza a incrementar la demanda.

Asimismo indicó que en los últimos años, se han realizado diversas investigaciones a nivel internacional orientadas a la nutrición animal, buscando optimizar los costos y mejorar los rendimientos. En tal sentido, en estas investigaciones se determina que las harinas procedentes del rendering tienen mejor digestibilidad que la torta de soya (mayor desarrollo en el animal y menor cantidad de excretas).

Sobre las actuales necesidades del mercado, el entrevistado indicó que se requiere un pollo que no presente los intestinos cargados. La fibra procedente de la torta de soya genera esta problemática, dado que el $47 \%$ de este insumo es proteína, y el resto es mayormente fibra. En los mercados, el principal indicador de la calidad del pollo es el peso de los intestinos, puesto que es merma para el cliente, por lo que cuanto menos cargados estén, mayor será la percepción de calidad para el cliente. Desde este punto de vista, la alimentación de las aves puramente de soya no es atractiva. 


\section{Sobre la calidad de rendering que se procesa en el Perú}

El entrevistado señaló que son varias las empresas avícolas que desarrollan su propio rendering (harinas de plumas y harinas mixtas), pero ninguna cuenta con tecnología moderna por lo que la calidad no es la adecuada. Cuando la materia prima no es acondicionada (prensada) previamente, el tratamiento térmico requerido es demasiado intenso, y esto genera pérdida de calidad (pérdida de digestibilidad). Para estas empresas el rendering es principalmente una manera de tratar sus subproductos. $\mathrm{Al}$ consultar sobre las principales empresas que compiten en la industria del rendering, el entrevistado comentó que básicamente el mercado es atendido por tres empresas: Technofeed SAC, Los Ferroles SAC y Alimencorp SAC; de las cuales Los Ferroles posee la tecnología más moderna para el procesamiento, puesto que cuenta con una línea continua; el nivel tecnológico de las otras dos no permite obtener una óptima calidad.

Sobre el acopio de la materia prima, indicó que entre las tres empresas captan la mayor cantidad de subproductos a nivel nacional, y trabajan con las principales empresas (EPS-RS) acopiadoras de subproductos. Alimencorp, ha implementado una gestión de acopio muy eficiente a nivel nacional, mientras que Technofeed y Los Ferroles lo hacen a nivel de Lima y Callao.

Si bien Los Ferroles se ha especializado en la producción de harinas para el sector avícola, uno de los nichos de mercado más rentables en rendering es alimento para mascotas (Pet Food); dada la disposición del precio de parte del comprador final. El Perú no tiene este sector tan desarrollado, pero otros países como México y Colombia son mercados atractivos. 


\section{Sobre la principal problemática del rendering en el Perú}

Indicó que el principal problema es la restricción de materia prima, y la alta dependencia del "dueño" del pollo vivo. En el Perú no existe una normativa específica para la regulación del rendering, es por ello que los centros de faenado de aves en su mayoría se encuentran dispersos, lo que hace que el costo del acopio sea mayor. En tal sentido, uno de los factores claves es la logística de acopio. Las distancias y sistemas de transporte de las materias primas desde los centros de faenado hasta las plantas de rendering, son determinantes en la rentabilidad del producto final. Alianzas estratégicas como la de San Fernando y Los Ferroles, son altamente convenientes.

\section{Sobre el ingreso de nuevos competidores al mercado}

El entrevistado señaló que existen empresas internacionales interesadas en establecer alianzas estratégicas con las empresas avícolas que no generan su propio rendering; por ejemplo la empresa americana Thor estuvo interesada hace algunos años en trabajar con una de las empresas líderes del sector para montar una planta de rendering, pero por temas internos la alianza no se concretó. Indicó también que son pocas las plantas faenadoras a nivel nacional: San Fernando (dos), Redondos (una), Avinka (una), Ricopollo (una en Arequipa), Rinconada del Sur (una en Arequipa), Chimú Agropecuaria (una en La Libertad); asimismo, comentó que existen algunas empresas informales (en su mayoría) que hacen rendering para ganado, principalmente porcino, pero a nivel artesanal. 


\section{Anexo 7: Entrevista a No Clientes}

\section{EMPRESA CORPORACION EL MARQUEZ}

\section{Ficha Técnica - Estudio Exploratorio- Entrevista a Profundidad}

\section{Objetivos de la investigación}

Recopilar información relevante sobre las ventajas y desventajas del uso de harinas proteicas de origen animal provenientes de la industria del rendering, como insumo para la elaboración del alimento balanceado de las aves.

\section{Contenido}

Técnica: $\quad$ Entrevista de escalonamiento (Malhotra, 2008, p. 158).

Instrumento: Las preguntas se desarrollaron en base a la guía de pautas sobre la información interna de la empresa, sus características principales y en el entorno en el que se desarrolla.

Fecha de campo: $\quad$ El 30 de septiembre de 2016

Lugar: $\quad$ En las oficinas de la empresa El Marquéz

Responsable: $\quad$ Yiesmin Zaad Oporto, estudiante de Maestría del Programa de

Ciencias Empresariales de la Escuela de Postgrado de la

Universidad San Ignacio de Loyola.

\section{Perfil del Participante}

Nombre: $\quad$ Wilfredo Castañeda

Edad: $\quad 33$

Nacionalidad: Peruana

Formación: Ingeniero zootecnista 
Puesto: $\quad$ Nutricionista de la empresa

\section{Cuestionario}

\section{Guía de pautas}

\section{a) Frase de presentación}

Buenos días. Mi nombre es Yiesmin Zaad Oporto, estudiante de Maestría de la Escuela de Post Grado de la Universidad San Ignacio de Loyola. Como parte del trabajo de tesis final, estamos realizando una investigación sobre la industria del rendering; en tal sentido, deseamos realizarle una entrevista para poder conocer su opinión sobre el uso de harinas proteicas provenientes de esta industria; cabe señalar que toda la información recopilada tendrá fines académicos exclusivamente.

\section{b) Permiso para grabar}

Para agilizar la toma de la información, resulta de mucha utilidad grabar la conversación. Tomar notas a mano demora mucho tiempo y se pueden perder detalles importantes de las respuestas. ¿Existe algún inconveniente en que grabemos la conversación?

\section{c) Listado de preguntas}

\section{Bloque 1- Antecedentes}

1. ¿Cómo surge la necesidad del uso de harinas proteicas por parte de la empresa?

2. ¿Cuáles son los beneficios del uso de estas harinas?

3. ¿Realizaron pruebas de campo para validar estos beneficios? 
4. ¿Cuáles son las desventajas del uso de estas harinas?

5. ¿Qué tipo de harinas proteicas fueron las que inicialmente incorporaron a la dieta?

\section{Bloque 2- Experiencia con el producto}

1. ¿Cómo ha sido su experiencia usando las harinas proteicas?

2. ¿A qué empresas le ha comprado estas harinas?

3. ¿Qué factores se deben considerar al elegir un proveedor de este producto?

4. ¿Encontró diferencias en cuanto a calidad y/o precio entre los distintos proveedores?

5. ¿Cómo era la relación comercial que mantenía con las empresas proveedoras?

6. ¿Cómo era el nivel de servicio recibido de las empresas proveedoras?

7. ¿Actualmente a qué proveedor le compra?

8. ¿Se siente satisfecho con el servicio brindado por el actual proveedor?

9. ¿Qué volúmenes de compra realiza?

10. ¿Existe en el mercado productos sustitutos que reemplacen los beneficios de estas harinas?

11. ¿Qué proveedores los ofrecen?

12. ¿Sus precios son más competitivos?

13. ¿Ha evidenciado si la falta de uso de harinas proteicas ha impactado en el rendimiento de la producción? 


\section{REPORTE DE ENTREVISTA A NO CLIENTE \\ EMPRESA CORPORACION EL MARQUEZ}

\section{Aspectos Generales}

a. La entrevista se realizó el día jueves 29 de setiembre de 2016 en las oficinas de la empresa, ubicadas dentro de las instalaciones de la planta de producción de alimentos balanceados, en el distrito de Lurín.

b. La persona entrevistada fue el ingeniero zootecnista Willy Castañeda, quien ocupa el puesto de nutricionista y tiene a cargo el departamento de Nutrición de la empresa. c. La entrevista inició a las 8:40 am y concluyó a las 9:45 am; fue realizada de manera fluida y con mucha apertura por parte del entrevistado.

\section{Desarrollo}

Sobre el uso de harinas proteicas de origen vegetales:

El entrevistado inició describiéndonos los principios básicos que considera para realizar la formulación del alimento. Indicó que los animales requieren una determinada dosis de energía y proteína para su alimentación, siendo el maíz la principal fuente de energía (carbohidratos) y la torta de soya la principal fuente de proteína. Asimismo indicó que en una formulación de alimento, aproximadamente el $60 \%$ está compuesta de maíz, el $20 \%$ de torta de soya, y el resto de otros insumos como carbonatos y grasas. Sobre la procedencia de la soya, señaló que es importada, y que dentro de los países desde donde se importa se encuentran Paraguay, Bolivia, y Estados Unidos, cada uno ofrece diferentes niveles de proteína, siendo la paraguaya una de las mejores. Asimismo comentó que entre las principales limitaciones que presenta la torta de soya como fuente proteica, es la limitada disponibilidad del 
aminoácido, la cual es como máximo 70\%, siendo necesaria la adición de fitasas a la formulación si se desea incrementar esta disponibilidad, lo cual encarece la fórmula; señaló que el precio de la fitasa en el mercado es de aproximadamente \$19/Kg. Por otro lado, la torta de soya no siempre se encuentra disponible en el mercado, según la temporada del año puede escasear, y esto genera incremento del precio.

\section{Sobre el uso de harinas proteicas de origen animal y su experiencia}

El entrevistado indicó que las harinas proteicas de origen animal como la harina de víscera, la harina de pluma y el concentrado proteico (harina de pollo), son un sustituto al uso de harina de soya debido a los elevados niveles de proteína, que presentan y a la buena disponibilidad del aminoácido para la absorción (a diferencia de harina de soya). Asimismo, detalló los porcentajes proteicos de la siguiente manera:

Harina de plumas: $\quad 81 \%$

Harina de vísceras: $\quad 60.1 \%$

Harina de soya (torta): $\quad 47 \%$

Por otro lado, indicó que la principal limitante en el uso de este tipo de harinas en el alimento es el aspecto sanitario, ya que las materias primas de fuente animal suelen ser portadoras de bacterias como el clostridium perfringens y la salmonela spp, las cuales son bacterias patógenas de alto riesgo. Sobre los precios, señaló que éstos varían según el nivel de proteína que ofrecen, por lo que la harina de soya es la de menor cuantía. Asimismo, indicó que los precios del mercado son bastante estables y parejos, y son aproximadamente los siguientes:

Harina de plumas: $\quad \$ 585$ / tonelada

Harina de vísceras: $\quad \$ 580$ / tonelada 
Harina de soya (torta): $\quad \$ 480 /$ tonelada

Al consultarle sobre su experiencia con el uso de harinas proteicas de origen animal, el nutricionista indicó que la harina de pescado la vienen usando desde hace varios años atrás, pero las harinas proteicas de pluma y víscera recién desde el año 2014 aproximadamente; asimismo, indicó que iniciaron comprando a la empresa Yachi, la cual es una pequeña empresa que recién tiene en el mercado 3 años. Posteriormente, desde enero del 2016 hasta marzo del mismo año, por indicación del dueño, cambiaron de proveedor y pasaron a trabajar con Los Ferroles, pero por problemas enfocados en calidad del producto suspendieron la compra. El principal problema identificado fue la alta variación de los niveles nutricionales de proteína y calcio, lo cual evidenciaba una falta de estandarización en el mix de materias primas empleadas en la fabricación (proporción entre hueso, grasa y vísceras). Sobre el nivel de servicio que ofrecía Los Ferroles indicó que fue bueno, cumplidos con los despachos y los horarios de entrega. Finalmente señaló que actualmente le compran a la empresa Alimencorp, a la cual la describió como una empresa seria y que ofrece una buena calidad de producto y nivel de servicio. Comentó que ha visitado la planta (ubicada en San Bartolo), para poder conocer su proceso productivo y observó que es bastante controlado; asimismo señaló que ellos producen un concentrado proteico equivalente a la harina de víscera (de pollo), pero que está compuesta de subproductos de ganado equino, porcino y vacuno. Sobre la calidad nutricional de estos productos indicó que los análisis nutricionales que realiza le arrojan mínima variación, así como ausencia de patógenos en el aspecto microbiológico, lo cual le genera confianza y garantía de calidad. Sobre los volúmenes comprados actualmente, señaló que son de 30 toneladas por semana de harina de pluma y 60 toneladas diarias de concentrado proteico, y el porcentaje de participación en la fórmula es de máximo 2.5\% para la harina de pluma 
y de $7 \%$ para el concentrado proteico. Estos valores los ha obtenido como resultado de pruebas de campo en la granja experimental de la empresa, donde probaron distintos tratamientos con diferentes porcentajes de harinas proteicas en los alimentos, logrando la maximización del rendimiento cárnico del ave con los valores anteriormente indicados. Uno de los aspectos que la empresa más valora del servicio que ofrece Alimencorp, es la capacitación y soporte técnico que brinda la empresa, dado que no sólo se limita a entregar una ficha técnica con las especificaciones de los productos, sino que brinda asistencia técnica personalizada al personal de planta. El buen servicio que ofrecen hace que se sientan satisfechos con la empresa por lo que tienen en sus planes continuar comprando a Alimencorp ya que lo consideran un socio estratégico.

Como tema final, al consultarle sobre otros productos sustitutos que existen en el mercado, el nutricionista señaló al germen de trigo como otra buena alternativa, el cual posee $51 \%$ de proteína aproximadamente y una buena disponibilidad de aminoácidos. 
Anexo 8 - Negocios Agroindustriales Los Ferroles SAC

VISITA PLANTA PROCESAMIENTO DE PLUMAS EN CALLAO - GAMBETA
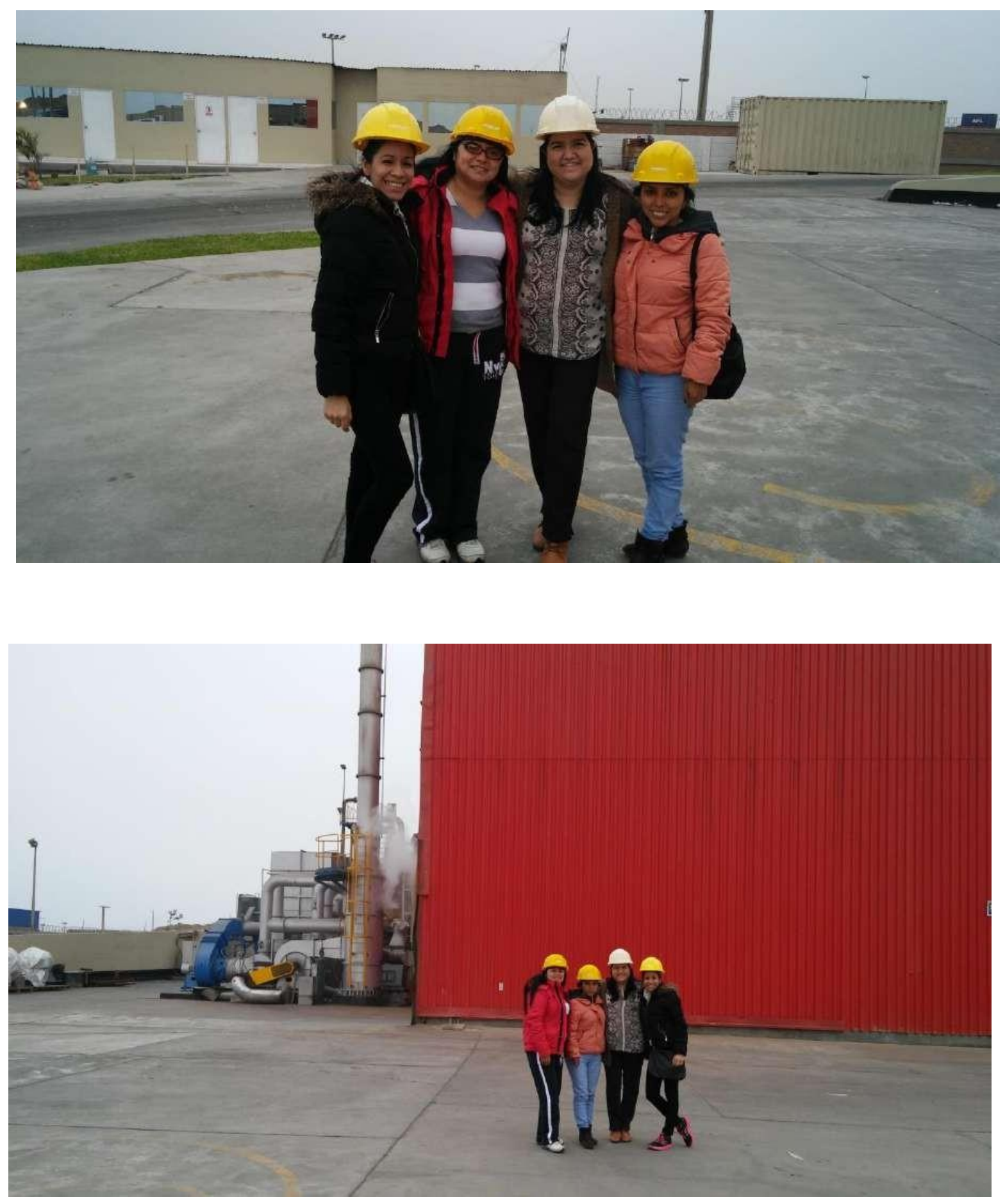
La harina de plumas de produce a partir de plumas de aves hidrolizándolas a temperatura y presión elevadas
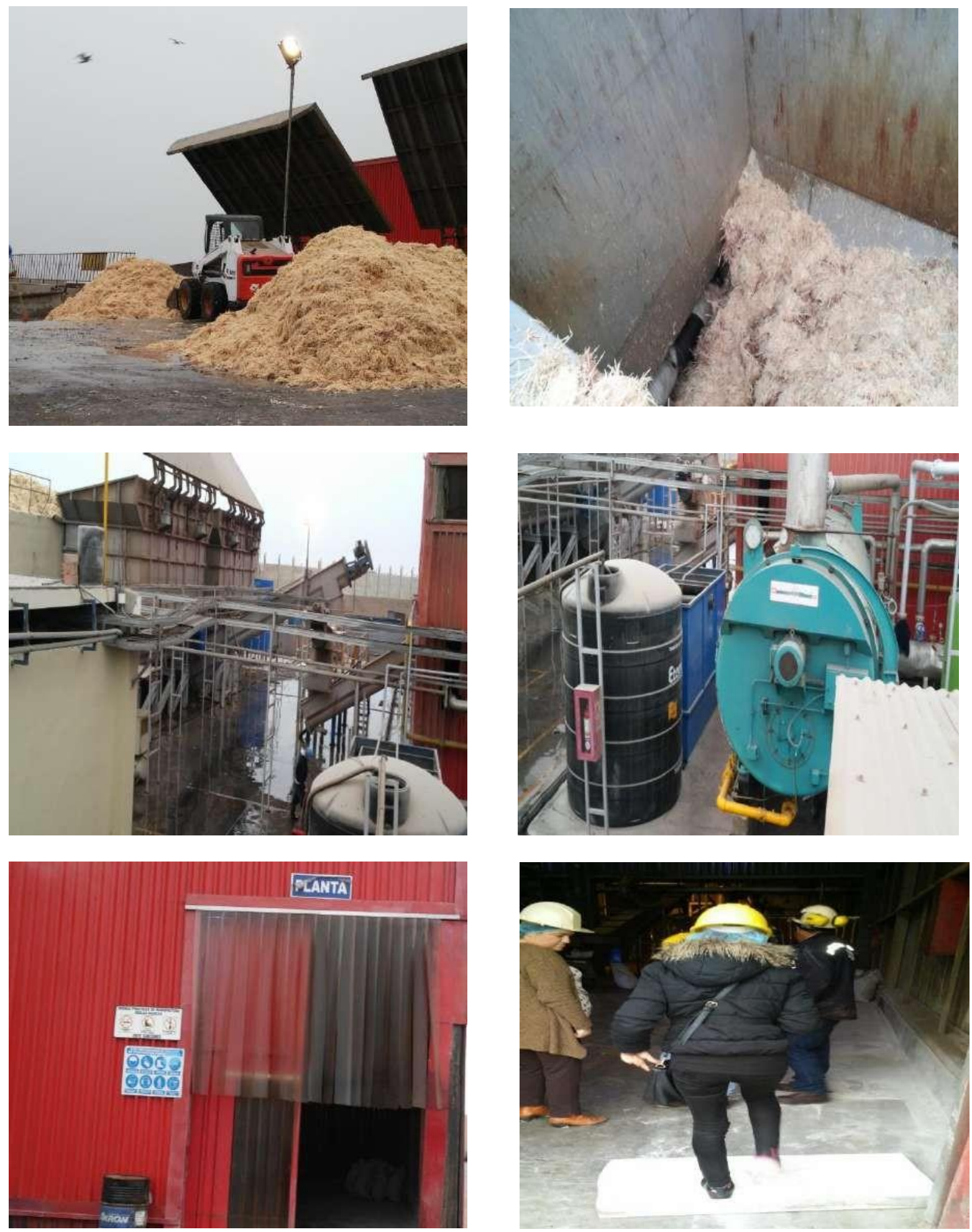
La hidrolización de las plumas previa al secado rompe las uniones de las proteínas en la materia prima y transforma la harina de plumas en altamente digestible
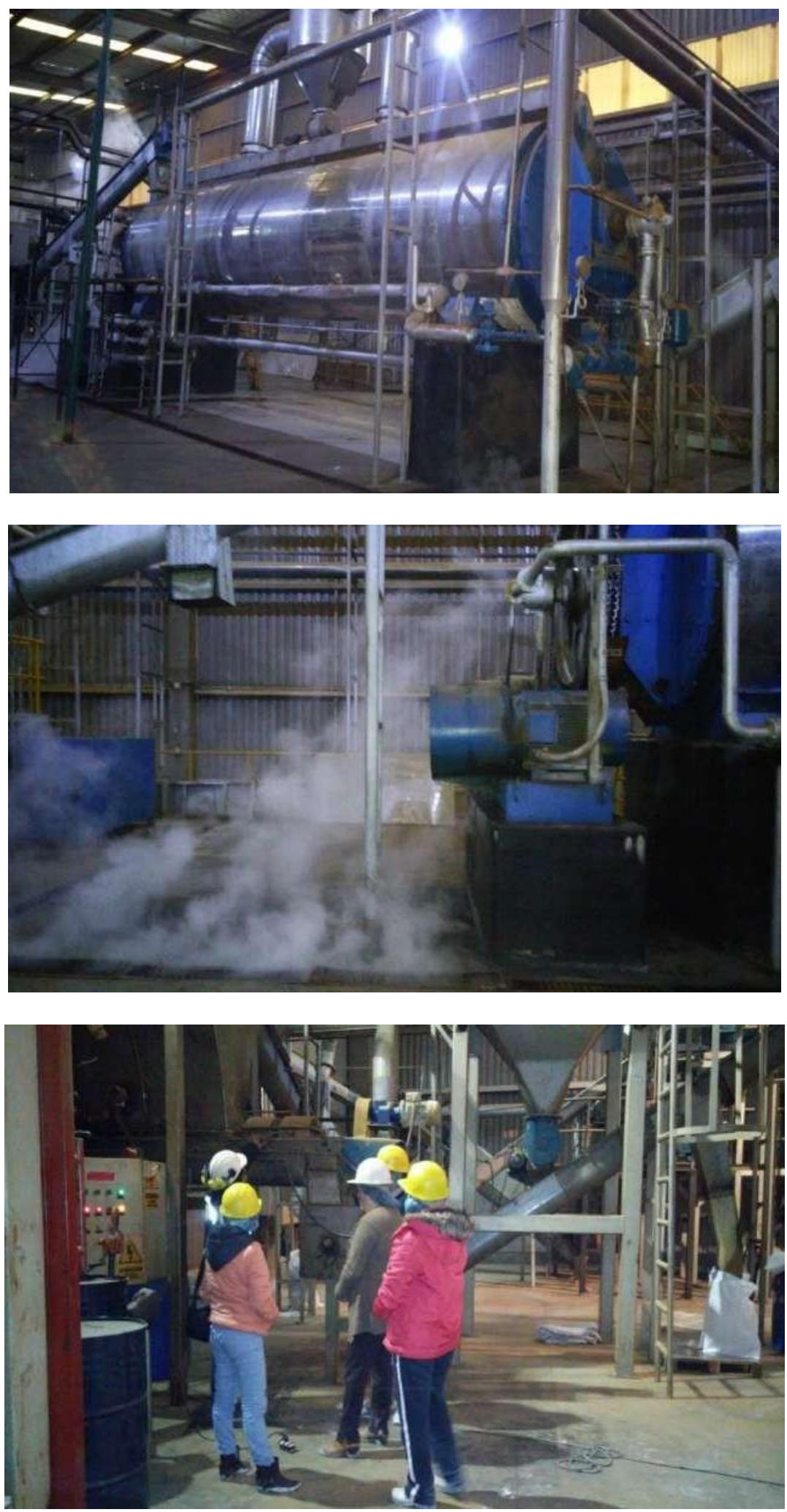
La harina de plumas hidrolizada es una buena fuente de proteína natural para la mayoría de las dietas animales
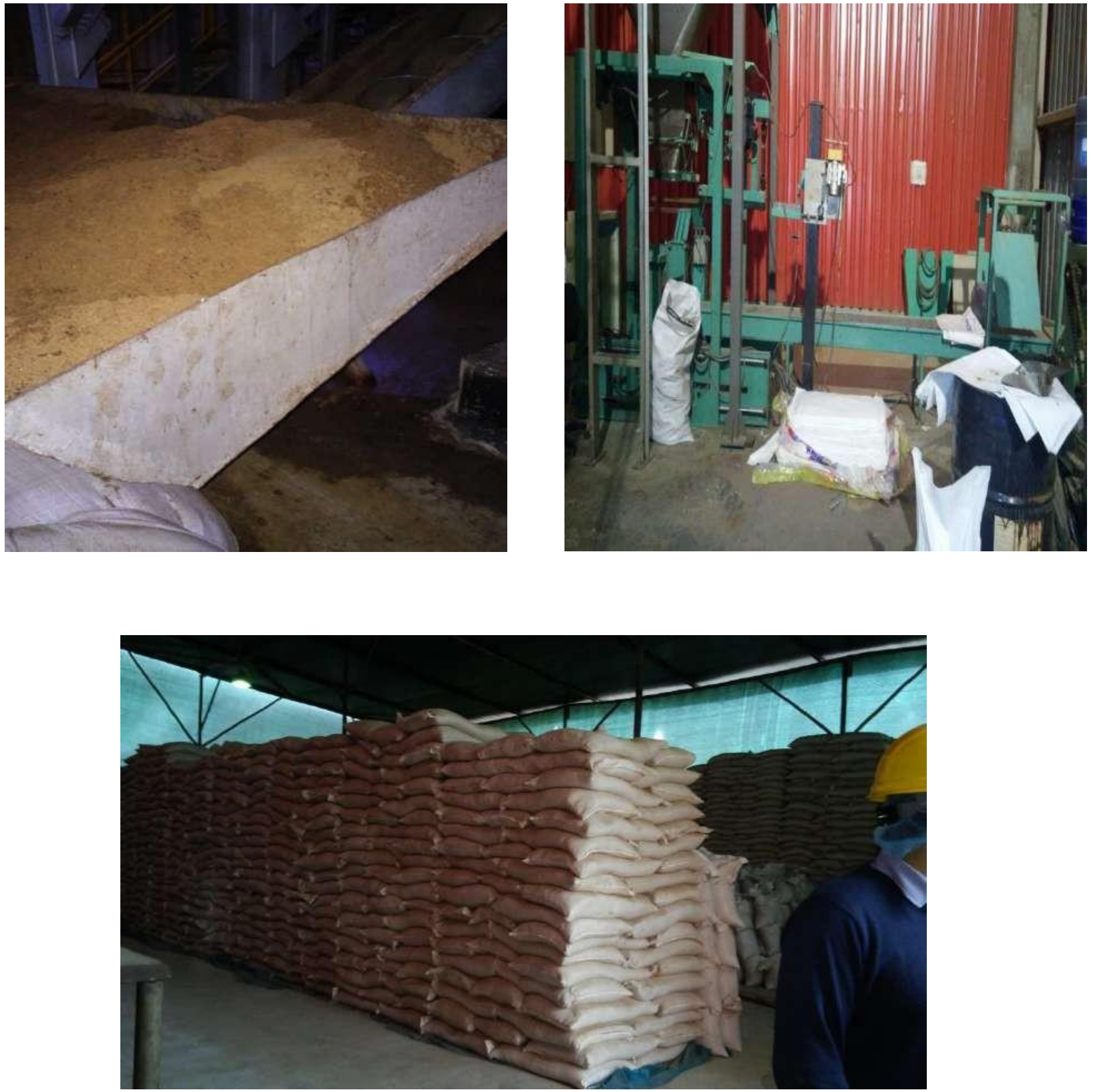


\section{Bibliografía}

Armstrong, G y Kotler, P. (2012). Marketing (14 ava ed.). México: Pearson Educación.

Chiavenato, I (2009). Comportamiento Organizacional, La dinámica del éxito en las organizaciones (2da ed.). México DF, México: McGraw-Hill / Interamericana Editores, S.A. de C.V.

Clyde P. Stickney, Roman L. Weil, Katherine Schipper, Jennifer Francis, (2013). Contabilidad Financiera. Una introducción a conceptos, métodos y usos. Buenos Aires, Argentina: Cengage Learning.

D’alessio, F. (2015). El Proceso Estratégico, Un enfoque de gerencia. (3era ed.). Lima, Perú: Pearson.

David, F. (2013). Concepto de Administración Estratégica. (14ava ed.). México: Pearson Educación.

Kotler, P. y Keller, K. (2012). Dirección del Marketing (14ava ed.). México: Pearson Educación.

Nassir Sapag Chain (2011). Proyectos de inversión. formuación y evaluación de proyectos (2da ed.) Chile: Pearson Educación. 
Thompson, A., \& Strickland, A. (2004). Administración Estratégica. (13a ed.). México:

Editorial Mc Graw Hill. 


\section{Referencias Electrónicas}

Aceite de Semillas, 2016. Definición de la torta de girasol. Recuperado de http://www.aceitesdesemillas.com/es/tortas-harinas.php

Administración y Gerencia de Marketing 2015. Las cinco estrategias competitivas genéricas. Recuperado de http://admymercadeo.blogspot.pe/2015/03/las-cinco-estrategias-competitivasgenericas.html

Agrocolanda, 2016. Portafolio de productos, materias primas. Recuperado de http://www.agrocolanta.com/productos/materias-primas/torta-de-soya/

Alimencorp SAC (2015). Página Facebook. Recuperado de https://es-la.facebook.com/alimencorpsac.pe/

América Económica (2016). Notas sobre la estabilidad política y económica del Perú. Recuperado de http://aempresarial.com/web/informativo.php?id=18465

América Económica (2016). Notas sobre la estabilidad política y económica del Perú. Recuperado de_http://www.americaeconomia.com/economia$\underline{\text { mercados/comercio/estabilidad-politica-y-economica-en-peru }}$

AviNews (2016). Dietas Avícolas Groseras // Salud intestinal en pollos y eficiencia. Recuperado de http://avicultura.info/dietas-avicolas-groseras-efectos-sobre-laeficiencia-del-nitrogeno-y-la-salud-intestinal-en-pollos/ 
BCRP (2016). Nota Estudios 2016. Recuperado de

http://www.bcrp.gob.pe/docs/Publicaciones/Notas-Estudios/2016/nota-de-estudios-

70-2016.pdf

BCRP (2016). Nota Semanal 2016, Resumen informativo. Recuperado de

http://www.bcrp.gob.pe/docs/Publicaciones/Nota-Semanal/2016/resumen-

informativo-38-2016.pdf

BCRP (2016). Reporte de Estabilidad Financiera, Mayo 2016. Recuperado de

http://www.bcrp.gob.pe/docs/Publicaciones/Reporte-Estabilidad-Financiera/ref-mayo-

2016.pdf

BCRP (2016). Reporte de inflación 2016. Recuperado de

http://www.bcrp.gob.pe/docs/Publicaciones/Reporte-

Inflacion/2016/setiembre/reporte-de-inflacion-setiembre-2016.pdf

Blog de Luis Manuel Manene (2011), “Benchmarking, definiciones, aplicaciones, tipos y fases de proceso”. Recuperado de

https://luismiguelmanene.wordpress.com/2011/04/15/benchmarkingdefinicionesaplicaciones-tipos-y-fases-del-proceso/

David Polo (2015), Ciclo de vida de un producto. Recuperado de http://www.emprenderfacil.com/es/ciclo-de-vida-de-un-producto-y-sus-etapas/ 
Diario Correo (2016). Jose Vera: "Pollo es de lejos la carne más cómoda y Accesible".

Recuperado de_http://diariocorreo.pe/miscelanea/jose-vera-el-pollo-es-de-lejos-lacarne-mas-comoda-y-accesible-698153/

Diario El Comercio (2015). Crecimiento en más de una década. Recuperado de http://elcomercio.pe/economia/peru/pbi-asi-fue-su-crecimiento-mas-decadainteractivo-noticia-1798719

Diario El Peruano (2016). Perú tiene el mayor índice de confianza del consumidor. Recuperado de http://www.elperuano.pe/noticia-peru-tiene-mayor-indice-confianzadel-consumidor-45124.aspx

Diario Gestión (2016). Avinka y Ganadera Santa Elena se fusionan y están detrás de San Fernando. Recuperado de http://gestion.pe/empresas/avinka-y-ganadera-santa-elena$\underline{\text { se-fusionan-y-estan-detras-san-fernando-2176246 }}$

Diario Gestión (2016). Gestión Empresarial mejora en primer mes del Gobierno de PPK. Recuperado de http://gestion.pe/economia/confianza-empresarial-mejora-primer-mesgobierno-ppk-2169358

Diario Gestión (2016). Nota Alonso Segura sobre la política Fiscal. Recuperado de http://gestion.pe/economia/alonso-segura-20016-habra-politica-fiscal$\underline{\text { moderadamente-expansiva-que-soporte-crecimiento-2141430 }}$ 
DIGESA (2016). Institucional. Recuperado de http://www.digesa.sld.pe/

El Sitio Avícola (2016). La tasa de crecimiento de la industria avícola peruana se modelará el 2016. Recuperado

de http://www.elsitioavicola.com/poultrynews/31553/la-tasa-de-crecimiento-de-laindustria-avacola-peruana-se-moderara-el-2016/

Eder Davila (2014). Análisis y Elección de Estrategias. Recuperado de http://uatlanticogestionestrategica.blogspot.pe/2014/11/matriz-peyea-matriz-de-laposicion.html

Empresariados (2014). ¿Qué es la competencia de orientación al servicio? Recuperado de http://empresariados.com/que-es-la-competencia-de-orientacion-al-servicio/

Entrepeneur (2016). Establece metas en tu empresa. Recurado de https://www.entrepreneur.com/article/264927

Estadísticas. Banco Central de Reserva del Perú. PBI por sectores. Recuperado de: https://estadisticas.bcrp.gob.pe/estadisticas/series/mensuales/pbi-por-sectores

Estadísticas. Banco Central de Reserva del Perú. Resumen informativo semanal. Recuperado de: http://www.bcrp.gob.pe/publicaciones/nota-semanal/resumeninformativo.html

Excellence Management (2016). Calidad Total (TQM) \& Mejora Continua. Recuperado de https://excelencemanagement.wordpress.com/calidad/ 
Fis-net, 2016. Harina de Pescado. Recuperado de http://www.fis-net.com/snp/harina.htm Gestiopolis. Lara Martinez Octavio Rolando. (2011). ERP: Planificación de recursos empresariales. Recuperado de http://www.gestiopolis.com/erp-planificacion-derecursos-empresariales/ 
Fundación Ellen MacArthur (2014). Resumen Ejecutivo Hacia una Economía Circular.

Recuperado de

https://www.ellenmacarthurfoundation.org/assets/downloads/languages/EMF_Spanish _exec_pages-Revise.pdf

Grupo Agronegocios (2015). Invetsa en el IPPE 2015. Recuperado de http://www.agronegocios.pe/tecnologia/item/5599-la-avicultura-peruana-sedesarrolla-gracias-a-la-tecnologia

HAARSLEV (2014). Brochure Rendering. Recuperado de http://www.alapre.org/Downloads/Congresos/Primer_Congreso/Haarslev_Josep_Clos a.pdf

INEI (2016). Informe técnico PBI trimestral. Recuperado de https://www.inei.gob.pe/media/MenuRecursivo/boletines/informe-tecnico-n02_pbitrimestral_2016i.pdf

INEI (2016). Informe técnico de las exportaciones e importaciones. Recuperado de https://www.inei.gob.pe/media/MenuRecursivo/boletines/informe-tecnicon09_exportaciones-e-importaciones-jul2016.pdf

Isotools (2015). Cómo elegir los mejores indicadores de un Balanced Scorecard. Recuperado de https://www.isotools.org/2015/05/27/como-elegir-los-mejoresindicadores-de-un-balanced-scorecard/ 
Isotools (2015). Iniciativas en Balanced Scorecard: La importancia de racionalizarlas

https://www.isotools.org/2016/12/12/balanced-scorecard-iniciativas-estrategicas/ 
Lara Martinez Octavio Rolando. (2011). ERP: Planificación de recursos empresariales.

Recuperado de http://www.gestiopolis.com/erp-planificacion-de-recursosempresariales/

Las 5 Fuerzas de Porter (2015). Matia Riquelme. "Las 5 Fuerzas de Porter-Clave para el Éxito de la Empresa”. Recuperado de http://www.5fuerzasdeporter.com/.

Luis Castellano (2015), Estrategia y Planificación Estratégica". Recuperado de https://lcestrategia.wordpress.com/2015/01/25/05-1-matriz-interna-externa-ie/

Marketing y Finanzas (2016). Cómo hacer una buena estrategia de producto en el mix de marketing. Recuperado de http://www.marketingyfinanzas.net/2015/02/como-hacer-una-buena-estrategia-deproducto-en-el-mix-de-marketing/

Meeker, D. (2009). Essential Rendering Book. Virginia, Estados Unidos: Kirby Lithographic Company, Inc. Recuperado de $\underline{\text { http://assets.nationalrenderers.org/essential_rendering_book.pdf }}$

MEF (2016). Marco macroeconómico 2017-2019. Recuperado de https://www.mef.gob.pe/contenidos/pol_econ/marco_macro/MMM_2017_2019_Revi $\underline{\text { sado.pdf }}$ 
MINAGRI (2016). Boletín Estadístico Mensual del Sector Avícola 2016. Recuperado de http://www.minagri.gob.pe/portal/boletin-estadistico-mensual-de-la-produccion-y$\underline{\text { comercializacion-avicola/sector-avicola-2016 }}$

Ministerio de Salud (2016). Influenza aviar. Recuperado de http://www.minsa.gob.pe/portada/Especiales/2007/aviar/default.asp

Naciones Unidas (2016). Definición de Gripe aviar. Recuperado de http://www.un.org/es/influenza/topics/avian_influenza.shtml

OEFA (2016). Transferencia de funciones Produce. Recuperado de http://www.oefa.gob.pe/transferencia-de-funciones-produce-oefa

Organización Mundial de Sanidad Animal (2016). Gripe Aviar. Recuperado de http://www.oie.int/doc/ged/D13948.PDF

PRODUCE (2010). Resolución Ministerial. Recuperado de http://www2.produce.gob.pe/dispositivos/publicaciones/2010/diciembre/rm326-2010produce.pdf

Retos Directivos (2016). 7 valores empresariales claves para cualquier compañía. Recuperado de http://retos-directivos.eae.es/7-valores-empresariales-claves-paracualquier-compania/

Semana Sostenible (2010). Negocios Verdes. Recuperado de http://sostenibilidad.semana.com/negocios-verdes/articulo/10-egresados-stanfordhablan-negocios/29615 
SENASA (2014). Reglamento Sanitario de Faenado. Recuperado de http://www.senasa.gob.pe/senasa/wp-content/uploads/2014/10/Reglamento-Sanitariodel-Faenado.pdf

SENASA (2016). Institucional. Recuperado de_http://www.senasa.gob.pe/senasa/

SUNAFIL (2016). Institucional. Recuperado de http://www.sunafil.gob.pe/portal/sunafil

SUNAT (2016). Institucional. Recuperado de http://www.sunat.gob.pe/institucional/quienessomos/index.html

Technofeed (2013). Página Web Corporativa. Recuperado de http://www.technofeed.com.pe/

Todoagro, 2016. Harina de Gluten de Maíz. Recuperado de http://www.todoagro.com.ar/noticias/nota.asp?nid=10751

Trissa Strategy Consulting, (2016). Mapas Estratégicos: Una pieza clave. Recuperado de http://www.trissa.com.mx/articulos/mapas-estrategicos-una-pieza-clave

Universidad Nacional del Callao (2012). Informe de Obtención de Aceite y Harina Proteica de Alta Calidad a partir de Pollos de Descarte y Vísceras. Recuperado de s/organizacion/vri/cdcitra/Informes_Finales_Investigacion/IF_DICIEMBRE_2012/IF _AVALOS\%20JACOBO_FIQ.pdf 
Web y empresas, 2016. Como redactar un objetivo SMART. Recuperado de http://www.webyempresas.com/como-redactar-un-objetivo-smart/ 